\title{
The glacial history of Tongariro and Ruapehu volcanoes, New Zealand.
}

by

Shaun Robert Eaves

\author{
A thesis \\ submitted to the Victoria University of Wellington \\ in fulfilment of the \\ requirements for the degree of \\ Doctor of Philosophy \\ in Geology.
}

Victoria University of Wellington 



\begin{abstract}
Understanding the drivers and mechanisms of past, natural changes in Earth's climate is a fundamental goal of palaeoclimate science. Recent advances in cosmogenic surface exposure dating and numerical glacier modelling have greatly improved the utility of geological glacial records for palaeoclimatic reconstruction. Here, I apply these techniques to investigate the timing and magnitude of late Quaternary mountain glacier fluctuations on Tongariro massif and Mt. Ruapehu volcanoes in central North Island, New Zealand $\left(39^{\circ} \mathrm{S}\right)$.
\end{abstract}

First, I constrain the local cosmogenic ${ }^{3} \mathrm{He}$ production rate, in order to compare my subsequent ${ }^{3} \mathrm{He}$ moraine chronologies with other well-dated palaeoclimate records. I present a new radiocarbon age for a large debris avalanche event on the northwest slopes of Mt. Ruapehu that occurred at 10.4-10.6 cal. ka BP. Cosmogenic ${ }^{3} \mathrm{He}$ concentrations in surficial boulders deposited during this event are consistent with that predicted by a global compilation of similar production rate calibrations. Thus, I conclude that this globally compiled production rate is suitable for cosmogenic ${ }^{3} \mathrm{He}$ exposure age calculations in New Zealand.

Exposure ages from moraine boulders on both volcanoes constrain the timing of two periods of glaciation during the last glacial cycle, when the termini of valley glaciers reached c. $1200 \mathrm{~m}$ asl. The most recent of these events occurred between c. 31-17 ka, which corresponds with the global Last Glacial Maximum. During this period, the local equilibrium line altitude was depressed by c. 800-1100 m. Numerical model simulations of the glaciers, using a coupled energy balance/ice flow model, suggest that local atmospheric temperature was $4-7^{\circ} \mathrm{C}$ colder than present. This palaeotemperature estimate is not greatly impacted by post-glacial topographic change on these active volcanoes. Surface exposure ages from a degraded lateral moraine on Tongariro massif indicate that an earlier period of glaciation, of similar extent to that at the LGM, culminated during Marine Isotope Stage 4.

During the last glacial-interglacial transition (c. 18-11 ka), glacial retreat on Mt. Ruapehu was interrupted by a re-advance during the late-glacial (c. 15-11 ka). Exposure ages for this event exhibit some scatter, likely due to surface processes. Accounting for these processes with a topographic diffusion model yields a best-estimate age of 
14-13 ka, corresponding to the Lateglacial reversal in New Zealand. Glacier model experiments indicate this re-advance resulted from a temperature lowering of 2.5-3.4 ${ }^{\circ} \mathrm{C}$ relative to present. Comparison with other proxy records suggests that this cooling was most pronounced during summer. Due to its lower elevation, it is unlikely that glaciers were present on Tongariro massif at this time.

The results of this research provide the first direct age constraint and quantitative palaeoclimate reconstructions for late Quaternary glacier fluctuations in central North Island, New Zealand. The timing and magnitude of these changes are in good agreement with glacial records from the Southern Alps and South America. This suggests that glaciers in the southern mid-latitudes were responding to common climatic forcings at orbital- and millennial-timescales, during the last glacial cycle. 


\section{Acknowledgments}

Many people have helped make this research feasible. Firstly, I would like to thank my supervisor, Andrew Mackintosh, for supporting me in pursuit of my research interests. The work presented here would not have been possible without his expert guidance and unwavering enthusiasm for this project. I am also indebted to Andrew for my development as a scientist over the last 3.5 years. He has challenged me to think about the methods of scientific enquiry, included me in the development of research proposals and peer reviews, and shared with me his wide network of collaborators. For all of this, I am extremely grateful.

I thank Brian Anderson for introducing me to glacier modelling and providing advice in the manipulation and application of his model code. Dougal Townsend and Graham Leonard have provided excellent maps, new insights into the geological evolution of the central North Island volcanoes, and continual logistical support for fieldwork. All supervisors have provided valuable, constructive feedback on thesis chapters and manuscripts.

I thank all of the other brilliant scientists with whom I have had the opportunity to collaborate. Gisela Winckler and Joerg Schaefer generously hosted me at LamontDoherty Earth Observatory in 2013 and granted me the freedom to run samples until the early hours! Sascha Serno, Linda Baker and Roseanne Schwartz also provided expert guidance on sample preparation and noble gas mass spectrometry, as well as a friendly working atmosphere. Brent Alloway has provided invaluable insight to volcanic sedimentology and tephrostratigraphy, as well as elegant stratigraphic logs. Marcus Vandergoes introduced me to the intricacies of radiocarbon sample selection and provided radiocarbon measurements. Diane Seward kindly taught me techniques in mineral separation. Kevin Norton inspired me to take a quantitative approach to geomorphological problems and provided great company and coffee on various field trips. Regine Hock kindly hosted me in Fairbanks and constructed the superb International Glaciology Summer School, in which I was fortunate to participate.

The staff of the Antarctic Research Centre and the School of Geography, Environment 
and Earth Sciences have created a friendly and productive academic environment. Michelle Dow, Robyn Mcfarlane and Kate King have ensured smooth negotiation of various grant systems, building works and other administrative tasks.

It has been a privilege to share the doctoral research experience with other postgraduate students in the ARC and SGEES. I thank Chris Conway for being a great field companion and for helpful discussions about lava-ice interactions. Alice Doughty provided invaluable support for exposure dating sample selection and glacier modelling, as well as shared a general fascination with mountain glaciers and Quaternary palaeoclimate. I thank fellow 'Beer Pom', Richard Jones for useful scientific discussions and field assistance. Bella Duncan has been an ever-present officemate, part-time flatmate and full-time friend. Thanks for all the cups of tea and delicious roast dinners! Thanks to Matt Ryan and Ignacio Jara for discussions about Southern Hemisphere palaeoclimate. Emily, Loretta, Juliet, Molly, Prisco, Ari, Julene and many others have also helped make office, lab and general life enjoyable. I thank Max Watt for teaching me how to fish the local waters without ever having to worry about catching anything!

I thank my Mum and Dad for their unconditional love and support from the other side of the world.

Jenni, thank you for always knowing what is best. And for supplying beautiful artwork (opposite). I can't wait for our next adventure.

I am grateful for support from Victoria University of Wellington Doctoral and Submission Scholarships. I also acknowledge generous financial support from the Antarctic Research Centre Endowed Development Fund, VUW Strategic Research Grants, the ST Lee Travel Award, and the Project Tongariro Memorial Award.

Finally, thank you to Rewi Newnham (VUW), David Barrell (GNS Science) and Bethan Davies (RHUL, UK) for each taking the time to provide detailed feedback on the content and structure of this thesis, and for providing a stimulating discussion at the oral exam. 


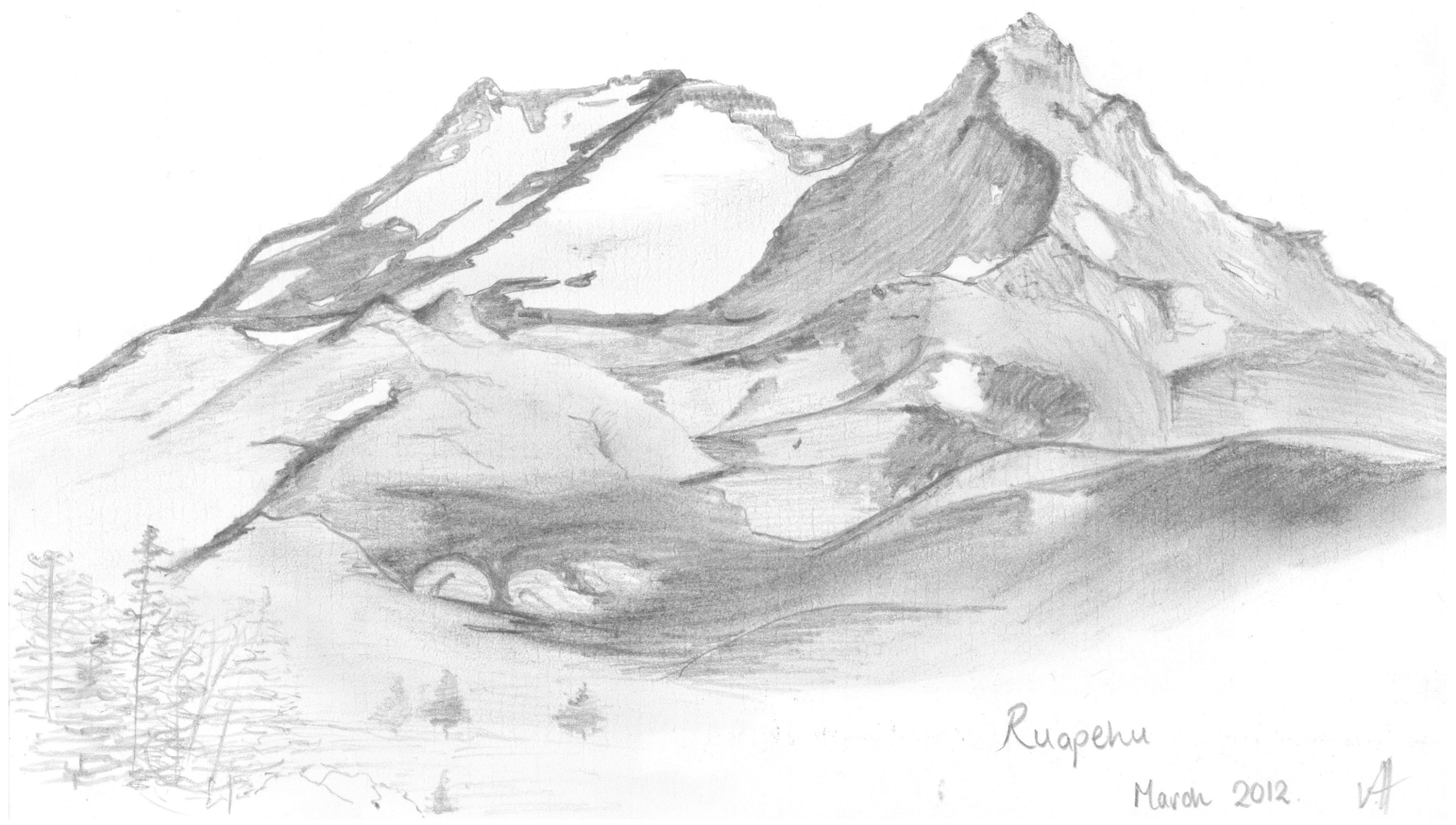




\section{Contents}

1 Introduction 1

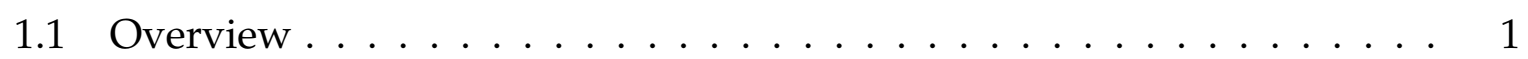

1.2 Organisation of this thesis ................... 5

1.3 Statement on the contributions made to this thesis by the author, supervisors and collaborators . . . . . . . . . . . . . . 5

2 Background $\quad 7$

2.1 Glaciers as a palaeoclimate proxy . . . . . . . . . . . . . 8

2.2 Quaternary palaeoclimate: a brief history of the orbital revolution . . . . 9

2.2.1 Outstanding questions in orbital theory - southern connections . 13

2.3 Millennial-scale oscillations . . . . . . . . . . . . . . 17

2.4 The late Quaternary glacial history of New Zealand (c. 125 - $10 \mathrm{ka}$ ) . . . 19

2.4.1 Pre-Last Glacial Maximum (c. 125 - 35 ka) . . . . . . . . . . . . . . 20

2.4.2 Last Glacial Maximum (c. 35 - 18ka) . . . . . . . . . . . . . . . . 21

2.4 .3 Late-Glacial $(15-11.5 \mathrm{ka}) \quad \ldots \ldots \ldots 24$

2.5 Study site and previous work . . . . . . . . . . . . . . . . . 29

2.5.1 Geological setting . . . . . . . . . . . . . . . . . . . . 29

2.5.2 Present day climatic situation . . . . . . . . . . . . 31

2.5.3 Contemporary glacierisation ............... 35

2.5.4 Previous work: palaeo-glaciation in Tongariro National Park . . . 43

2.6 Research questions . . . . . . . . . . . . . . . . . . . 45

3 Methodology 47

3.1 Geomorphological mapping . . . . . . . . . . . . . . . . . 47

3.2 Cosmogenic surface exposure dating . . . . . . . . . . . . 50

3.2.1 Cosmic radiation and nuclide production . . . . . . . . . . 51

3.2.2 Application to palaeoglaciology . . . . . . . . . . . . 53

3.2.3 Approach used in this thesis . . . . . . . . . . . . 55

3.3 Palaeoclimate reconstruction using glaciers . . . . . . . . . . . . 61

3.3.1 Equilibrium line altitude (ELA) reconstruction . . . . . . . . . . . 61

3.3.2 Numerical glacier modelling . . . . . . . . . . . . . . 62 
3.3.3 Application of these methods in this thesis . . . . . . . . 76

4 A test of the cosmogenic ${ }^{3} \mathrm{He}$ production rate in the southwest Pacific $\left(39^{\circ} \mathrm{S}\right) \quad 79$

4.1 Abstract ......................... 79

4.2 Introduction . . . . . . . . . . . . . . . . . . . . 79

4.3 Facies architecture and stratigraphy of the Murimotu Formation debris avalanche deposit . . . . . . . . . . . . . . . . . 81

4.4 Methods . . . . . . . . . . . . . . . . . . . . . 87

4.4 .1 Radiocarbon dating . . . . . . . . . . . . . 87

4.4.2 ${ }^{3} \mathrm{He}_{\cos }$ sample collection, preparation and measurement . . . . 87

4.4 .3 Production rate calculations . . . . . . . . . . . . . . 88

4.5 Results and discussion . . . . . . . . . . . . . . . . . . . . 90

4.5.1 Radiocarbon dating of the Murimotu debris avalanche . . . . . . 90

4.5.2 ${ }^{3} \mathrm{He}_{\text {cos }}$ measurements and production rate calibration . . . . . . . 91

4.6 Conclusion . . . . . . . . . . . . . . . . . . . . 98

5 A cosmogenic ${ }^{3} \mathrm{He}$ chronology of mountain glacier fluctuations in North Island, New Zealand (39 $\left.{ }^{\circ}\right)$ during the last glacial cycle. 99

5.1 Abstract . . . . . . . . . . . . . . . . . . . . 99

5.2 Introduction . . . . . . . . . . . . . . . . . . . 100

5.3 Setting . . . . . . . . . . . . . . . . . . 101

5.3.1 Regional climatic situation . . . . . . . . . . . . . . 101

5.3.2 Study site and previous work . . . . . . . . . . . . . . . 102

5.4 Methods . . . . . . . . . . . . . . . . . . . . 108

5.4.1 Cosmogenic surface exposure dating . . . . . . . . . . . 108

5.4 .2 Tephrochronology . . . . . . . . . . . . . . . . 111

5.4.3 Equilibrium line altitude reconstruction . . . . . . . . . . . . . . 112

5.5 Results . . . . . . . . . . . . . . . . . . . . . . . . 114

5.5.1 Cosmogenic ${ }^{3}$ He results and moraine age interpretation . . . . . 114

5.5.2 Coverbed stratigraphy and tephra major element geochemistry . 121

5.5.3 Equilibrium line altitude reconstruction . . . . . . . . . . . . 126

5.6 Discussion . . . . . . . . . . . . . . . . . . . . . . 127

5.6.1 The Last Glacial Cold Period in central North Island . . . . . . . 127

5.6 .2 Pre-LGCP glaciation . . . . . . . . . . . . . . . . . . . 129

5.7 Conclusions . . . . . . . . . . . . . . . . . . . . 131

6 Uniform summertime cooling across New Zealand drove glacial readvance during the late-glacial (15-11 ka) 133

6.1 Abstract . . . . . . . . . . . . . . . . . . . 133

6.2 Introduction . . . . . . . . . . . . . . . . . . . . 134 
6.3 Study site and previous work . . . . . . . . . . . . . . . 135

6.4 Methods . . . . . . . . . . . . . . . . . . . . . 138

6.4.1 Geomorphological mapping . . . . . . . . . . . . . . . . 138

6.4.2 Cosmogenic ${ }^{3}$ He surface exposure dating . . . . . . . . . . . . 138

6.4 .3 Glacier modelling . . . . . . . . . . . . . . . . . . 140

6.5 Results . . . . . . . . . . . . . . . . . . . 145

6.5.1 Glacial geomorphology and chronology . . . . . . . . . . . . . 145

6.5 .2 Glacier modelling . . . . . . . . . . . . . . . 151

6.6 Discussion . . . . . . . . . . . . . . . . . . . 155

6.6.1 Glacial chronology . . . . . . . . . . . . . . . . . . . 155

6.6.2 Palaeoclimatic reconstruction . . . . . . . . . . . . . . 162

6.7 Conclusion . . . . . . . . . . . . . . . . . . . . . . 170

7 Temperature change during the Last Glacial Cold Period in central North Island, New Zealand $\left(39^{\circ} \mathrm{S}\right)$, inferred from 2D glacier modelling 171

7.1 Abstract . . . . . . . . . . . . . . . . . 171

7.2 Introduction . . . . . . . . . . . . . . . . . 172

7.2 .1 Setting . . . . . . . . . . . . . . . 174

7.3 Methodology . . . . . . . . . . . . . . . 176

7.3.1 Cosmogenic ${ }^{3}$ He surface exposure dating . . . . . . . . . . . . 176

7.3.2 Model input data . . . . . . . . . . . . . . . . 178

7.3.3 Model description . . . . . . . . . . . . . . . . . . 179

7.3.4 Sensitivity tests . . . . . . . . . . . . . . . . 181

7.3.5 Approach . . . . . . . . . . . . . . . . 182

7.4 Geomorphological characterisation . . . . . . . . . . . . . . . . . 190

7.4.1 Whakapapaiti valley $\left({ }^{\prime} \mathrm{WHA}^{\prime}\right)$. . . . . . . . . . . . . 190

7.4.2 Mangaturuturu valley ('MTU') . . . . . . . . . . . . . . . . 192

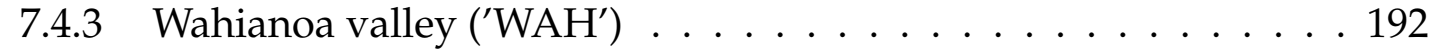

7.4.4 Mangatoetoenui valley $\left({ }^{\prime} \mathrm{MTO}^{\prime}\right)$. . . . . . . . . . . . . . . . . . . 194

7.4 .5 Mangatepopo Valley $\left({ }^{\prime} \mathrm{MPO}^{\prime}\right)$. . . . . . . . . . . . . . . . . 198

7.4 .6 Eastern Tongariro massif . . . . . . . . . . . . . . . . . . 198

7.5 Results . . . . . . . . . . . . . . . . . . . 201

7.5.1 Cosmogenic surface exposure dating . . . . . . . . . . . 201

7.5 .2 Glacier modelling . . . . . . . . . . . . . . . 202

7.6 Discussion . . . . . . . . . . . . . . . . . . 205

7.6.1 Topographic uncertainty . . . . . . . . . . . . . . . 205

7.6.2 Glacier model uncertainty . . . . . . . . . . . . . . . . . 207

7.6.3 LGCP climate in New Zealand . . . . . . . . . . . . . . . . . . . 209

7.7 Conclusion . . . . . . . . . . . . . . . . . . . . . . 211 
8.1 Introduction . . . . . . . . . . . . . . . . . . 213

8.2 Original scientific contributions made by this research . . . . . . . . 213

8.3 Research Questions . . . . . . . . . . . . . . . . . . . . . . . 215

8.3.1 Can cosmogenic isotopes be used to constrain past glacial activity on the North Island volcanoes? . . . . . . . . . . . . . . . . 215

8.3.2 When did glaciers in central North Island reach their maximum extent during the last glacial cycle? . . . . . . . . . . . . . . . 218

8.3.3 How cold was was the Last Glacial Cold Period in central North Island? . . . . . . . . . . . . . . . . . . . . . . 220

8.3.4 Did glaciers in central North Island respond to the late-glacial climate reversal in New Zealand? . . . . . . . . . . . . . . . . 223

8.4 Further research . . . . . . . . . . . . . . . . . . . . . . . . . 225

8.4.1 Refined estimates of local cosmogenic ${ }^{3} \mathrm{He}$ production . . . . . 225

8.4.2 Development of other cosmogenic nuclides for use in the south west Pacific . . . . . . . . . . . . . . . . . . . 226

8.4.3 What caused the Antarctic Cold Reversal? . . . . . . . . . . 227

8.4.4 Holocene glacier fluctuations in the Southern Hemisphere . . . 228 


\section{List of Figures}

2.1 Milankovitch cycles: eccentricity, obliquity and axial precession . . . . . 11

2.2 Covariance of austral $\left(77^{\circ} \mathrm{S}\right)$ summer duration and boreal $\left(65^{\circ} \mathrm{N}\right)$ summer insolation intensity . . . . . . . . . . . . . . . . 15

2.3 Millennial-scale climate variability in ice cores $(10-90 \mathrm{ka})$. . . . . . . . 18

2.4 Recalculation of cosmogenic exposure ages from Cobb valley . . . . . 25

2.5 Geological setting of Tongariro and Ruapehu volcanoes . . . . . . . . . . 32

2.6 Existing radiometric ages of lava flows on Tongariro massif and Mt. Ruapehu . . . . . . . . . . . . . . . . . . . 33

2.7 New Zealand climatic situation . . . . . . . . . . . . . . . . . . . 34

2.8 Climate at Whakapapa Village (1097 m asl), Mt. Ruapehu . . . . . . . . . 36

2.9 Contemporary glaciers on Mt. Ruapehu . . . . . . . . . . . . . . . . . 37

2.10 Photograph of Mangaehuehu Glacier, Mt. Ruapehu . . . . . . . . . . . 39

2.11 Photograph of Summit Plateau, Mt. Ruapehu . . . . . . . . . . . . . . . . 40

2.12 Photograph of Mangatoetoenui Glacier, Mt. Ruapehu . . . . . . . . . . . 41

2.13 Photograph of Crater Lake, Mt. Ruapehu . . . . . . . . . . . . . . . . 42

2.14 Photograph of lacustrine sediments in Mangaetoetoenui valley, $\mathrm{Mt}$. Ruapehu .......................... 44

3.1 Attenuation of cosmogenic nuclide production due to shielding . . . . 58

3.2 Ice melt from geothermal heating on active volcanoes . . . . . . . . . 71

3.3 Modelled present day ice distribution on Mt. Ruapehu . . . . . . . . . 75

4.1 Map of existing cosmogenic ${ }^{3} \mathrm{He}$ geological calibration sites . . . . . . 81

4.2 Map of Murimotu Formation debris avalanche deposit and sample sites 84

4.3 Stratigraphic logs of Murimotu Formation debris avalanche . . . . . . . 85

4.4 Field and laboratory photographs of radiocarbon samples at Murimotu

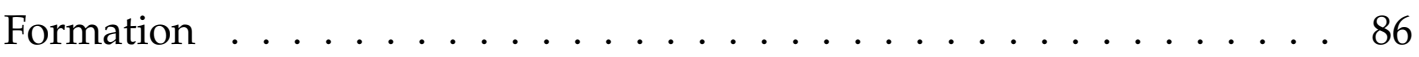

4.5 Cosmogenic ${ }^{3}$ He samples from Murimotu Formation . . . . . . . . . . . 89

4.6 Radiocarbon results from Murimotu Formation . . . . . . . . . . . . . . 92

4.7 Calibrated cosmogenic ${ }^{3}$ He production rates from Murimotu Formation 94 
5.1 Maps showing climatic and topographic setting of Mangatepopo valley 102

5.2 The glacial geology of Mangatepopo valley . . . . . . . . . . . . . 105

5.3 Selected photos of glacial landforms on western Tongariro massif . . . . 106

5.4 Photographs of boulders sampled for cosmogenic ${ }^{3} \mathrm{He}$ surface exposure dating in Mangatepopo valley . . . . . . . . . . . . . . . . . . . . . . . 110

5.5 The impact of hypothetical soil/ash burial scenarios on exposure ages in Mangatepopo valley . . . . . . . . . . . . . . . . . 117

5.6 Stratigraphic log and photos of moraine coverbed in Mangatepopo valley122

5.7 Major element tephra chemistry from rhyolite horizons in Mangatepopo valley . . . . . . . . . . . . . . . . . . . . . 125

5.8 ELA and palaeotemperature reconstruction of the former Mangatepopo glacier . . . . . . . . . . . . . . . . . . 127

6.1 Overview of study region on southern Mt. Ruapehu . . . . . . . . . . . 136

6.2 Examples of boulders from late-glacial moraines sampled for cosmogenic ${ }^{3}$ He exposure dating . . . . . . . . . . . . . . . . . . . . . . 141

6.3 The glacial geology of Mangaehuehu catchment, Mt. Ruapehu . . . . . . 147

6.4 Photographs of sediment underlying moraine LG1 . . . . . . . . . . . . 148

6.5 The glacial geology of Te Unuunuakapuateariki catchment, Mt. Ruapehu 149

6.6 The glacial geology of Wahianoa catchment, Mt. Ruapehu . . . . . . . 150

6.7 Late-glacial palaeotemperature-precipitation results from numerical glacier modelling . . . . . . . . . . . . . . . . 154

6.8 Seasonal sensitivity analyses of glacier length on Mt. Ruapehu . . . . . . 155

6.9 The impact of hypothetical soil/ash burial scenarios on the LG1 moraine exposure ages . . . . . . . . . . . . . . . . . . . 158

6.10 Cosmogenic surface exposure age distribution from Mangaehuehu catchment . . . . . . . . . . . . . . . . . 165

6.11 Histograms of good-fit moraine degradation model results, applied to LG1 moraine . . . . . . . . . . . . . . . . . . . . . . . . 166

7.1 Digital elevation model and Last Glacial Cold Period ice limits of Mt. Ruapehu . . . . . . . . . . . . . . . . . . . . 175

7.2 Topographic reconstruction of Tongariro Volcanic Centre (>15 ka) . . . 185

7.3 Modelled ice thickness on both volcanoes from step-cooling experiments 186

7.4 Palaeotemperature estimates from glacier modelling - present day topog-

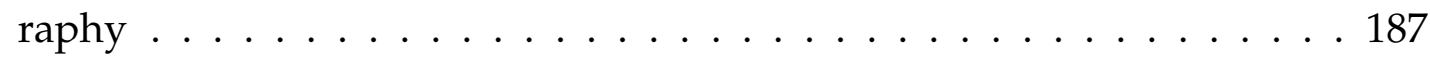

7.5 Modelled ice thickness and distribution from select Experiment 2 experiments . . . . . . . . . . . . . . . . . . . . . . 188

7.6 Palaeotemperature estimates from glacier modelling - pre-15 ka topogra-

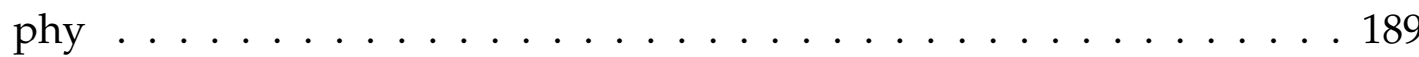


7.7 The glacial geology of Whakapapaiti valley . . . . . . . . . . . . . 191

7.8 The glacial geology of Mangaturuturu valley . . . . . . . . . . . . . 193

7.9 The glacial geology of Wahianoa valley . . . . . . . . . . . . . . 195

7.10 Ice-scoured, striated bedrock in Wahianoa valley . . . . . . . . . . . . 196

7.11 The glacial geology of Mangatoetoenui valley . . . . . . . . . . . . . . 197

7.12 The glacial geology of eastern Tongariro massif. . . . . . . . . . . . . . 199

8.1 Photograph of ice needles lifting sediment . . . . . . . . . . . . . 218 


\section{List of Tables}

3.1 Geomorphological mapping workflow for this study . . . . . . . . . . 49

3.2 Empirically derived, seasonal air temperature lapse rates for upland ( $>$ $300 \mathrm{~m}$ asl) New Zealand . . . . . . . . . . . . . . . . . . . 65

3.3 Optimal energy balance and ice flow model parameter settings. . . . . . 72

4.1 Radiocarbon data from organic material entrained within/buried by the Murimotu Formation debris avalanche. . . . . . . . . . . . . . . . 90

4.2 Elemental composition of pyroxene samples . . . . . . . . . . . . . 95

4.3 Murimotu Formation cosmogenic ${ }^{3} \mathrm{He}$ sample locations, geometrical corrections and noble gas mass spectrometry data . . . . . . . . . . . 95

4.4 Calibrated SLHL ${ }^{3} \mathrm{He}$ production rates from the Murimotu Formation . 96

4.5 Cosmogenic ${ }^{3} \mathrm{He} /{ }^{10} \mathrm{Be}$ and ${ }^{3} \mathrm{He} /{ }^{14} \mathrm{C}$ production ratios for New Zealand 96

5.1 Location and geometry of cosmogenic ${ }^{3} \mathrm{He}$ samples from Mangatepopo valley . . . . . . . . . . . . . . . . . . . . . . 109

5.2 Helium isotope data of all samples from Mangatepopo valley . . . . . 120

5.3 Cosmogenic ${ }^{3} \mathrm{He}$ surface exposure ages for all samples from Mangatepopo valley . . . . . . . . . . . . . . . . . . . . . . 121

5.4 Glass shard major element compositions of rhyolitic tephras from the Taurewa and Mangatepopo sections, compared with potential correlatives from the Okataina Volcanic Centre (OVC). . . . . . . . . . . . . . . . 124

6.1 Moraine boulder cosmogenic ${ }^{3} \mathrm{He}$ sample details (Mangaehuehu and Te Unuunuakapuateariki catchments). . . . . . . . . . . . . . . . 139

6.2 Helium mass spectrometry data (Mangaehuehu and Te Unuunuakapuateariki catchments) . . . . . . . . . . . . . . . . . . . . . . 152

6.3 Exposure ages (ka) for all samples in the Mangaehuehu and Te Unuunuakapuateariki catchments . . . . . . . . . . . . . . . 153

6.4 Moraine degradation model parameters space and best fit result . . . . . 161

6.5 Best-fit moraine degradation model parameter combinations when individual variables are prescribed using literature-based values. . . . . . . . 161 
6.6 A compilation of chronologies and quantitative palaeoclimate reconstructions for the late-glacial climate reversal in New Zealand. . . . . . . 167

7.1 Cosmogenic ${ }^{3} \mathrm{He}$ surface exposure dating sample details, helium content and exposure ages for Wahianoa valley . . . . . . . . . . . . . . . . . 201

7.2 Model-derived LGCP equilibrium line altitudes for glacial catchments in Tongariro National Park . . . . . . . . . . . . . . . . . . . 203 


\section{Chapter 1}

\section{Introduction}

\subsection{Overview}

The last c. 1 million years of Earth's history have been characterised by natural, cyclical changes between glacial and interglacial climate, which occurred over periods of $c$. 80-120 $\mathrm{kyr}^{1}$. These cycles are paced by astronomically induced changes in the seasonal distribution of insolation (Croll, 1864; Milankovitch, 1941; Hays et al., 1976). However, the response of global climate to orbital forcing exhibits several non-linearities that have thus far defied explanation. At first order, a single glacial cycle comprises a long (c. 80-90 kyr) gradual cooling, during which, global mean temperatures decline by 3-4 ${ }^{\circ} \mathrm{C}$ (Schneider von Deimling et al., 2006), ice sheets advance over northern Europe and North America (Clark et al., 2009), global mean sea level falls by c. 120-140 m (Fleming et al., 1998; Lambeck et al., 2014) and atmospheric $\mathrm{CO}_{2}$ is reduced by c. 100 ppmv (Monnin et al., 2001). Then, over the course of c. $10 \mathrm{kyr}$ all of this is reversed and an interglacial climate emerges (Denton et al., 2010), before the cycle is repeated. Within these cycles, many high-amplitude oscillations occur over sub-orbital, millennial timescales and appear to be antiphased between the hemispheres (Blunier and Brook, 2001; EPICA Community Members, 2006). Resolving the drivers and mechanisms of these changes remains an outstanding goal of palaeoclimate science.

Few opportunities exist to examine the imprint of past ice age climate in the Southern Hemisphere. Where available, climate proxy records from austral mid- to high-latitudes offer insight to past changes of components of the atmospheric and oceanic systems, which are considered to play important roles in driving global climatic change over orbital- to millennial timescales (Anderson et al., 2009; Barker et al., 2009; Denton et al., 2010; Putnam et al., 2010a; Whittaker et al., 2011; De Deckker et al., 2012). The New Zealand landmass is situated at a climatic boundary between sub-tropical and

\footnotetext{
${ }^{1}$ Following Aubry et al. (2009), I use 'annus' ('a') to denote absolute time and 'year' ('yr') for durations.
} 
sub-polar air and water masses. High relief topography, spanning $>10^{\circ}$ of latitude $\left(34-47^{\circ} \mathrm{S}\right)$, interacts with prevailing westerly circulation creating steep environmental gradients that are susceptible to small changes in atmospheric and oceanic conditions (Alloway et al., 2007). Thus, palaeoclimate reconstructions from New Zealand can provide unique insight to past changes in the global climate system.

The distinctive landscapes created through the erosion, entrainment and deposition of rocks by glaciers provided the first clues for Quaternary glacial cycles (Agassiz, 1840). Mountain glaciers are highly sensitive to changes in climate, in particular temperature and precipitation (Oerlemans, 2001). Changes in mean annual temperature alter the mass balance of glaciers by increasing/decreasing surface melt and changing the ratio of solid to liquid precipitation. Changes in total precipitation alter the amount of precipitation that can fall as snow. New Zealand glaciers are most sensitive to temperature changes, with c. $30-80 \%$ increases in precipitation required to balance a $1{ }^{\circ} \mathrm{C}$ increase in temperature (Oerlemans, 1997; Anderson and Mackintosh, 2006; Anderson et al., 2010; Anderson and Mackintosh, 2012). Positive glacier mass balance increases glacier volume and, if sustained (over timescales of years-to decades), this mass gain typically results in advance of the terminus. Meanwhile glacier retreat occurs following sustained negative mass balance. Thus, geological records of past glacier fluctuations afford insight into past, natural climate variations.

Two recent developments have improved the utility of glacial geology for palaeoclimate reconstruction. First, improved understanding of the production (e.g. Goehring et al., 2010; Putnam et al., 2010b; Blard et al., 2013b), extraction and measurement (Schaefer et al., 2009) of terrestrial cosmogenic nuclides has provided a means to directly date glacial landforms (Balco, 2011). Second, increased understanding of ice-climate relationships (e.g. Oerlemans, 2001), coupled with advances in computing power and the increasing availability of digital datasets, means that numerical glacier models of varying complexity can now be used to investigate the climatic significance of past glacier fluctuations (Plummer and Phillips, 2003; Oerlemans, 2005; Kessler et al., 2006). Application of these methods in recent years has resulted in a step-increase in understanding of the timing and climatic significance of palaeo- glacier fluctuations worldwide, including in the Southern Alps of New Zealand (e.g. Ivy Ochs et al., 1999; Shulmeister et al., 2005; Anderson and Mackintosh, 2006; Schaefer et al., 2006; Barrows et al., 2007b; Schaefer et al., 2009; McCarthy et al., 2008; Kaplan et al., 2010, 2013; Putnam et al., 2010a, 2012, 2013a,b; Golledge et al., 2012; Barrows et al., 2013; Doughty et al., 2013; Rowan et al., 2013; Rother et al., 2014).

Despite this progress, well dated, quantitative palaeoclimatic reconstructions in New 
Zealand remains relatively restricted. Much work has focused on the central Southern Alps, which afford well-preserved suites of glacial landforms (Barrell, 2011, 2014), as well as pristine, sedimentary archives that contain fossil pollen assemblages and other palaeo-environmental proxies (Vandergoes et al., 2005, 2008). Expanding the spatial range of palaeoclimate records allows consideration of past climatic gradients, which may be indicative of past climate drivers (Carter et al., 2008; Lorrey et al., 2012b; Newnham et al., 2012).

In North Island, late Quaternary palaeoclimate records predominantly consist of lowaltitude sedimentary archives that preserve fossil pollen and diatom assemblages (Newnham and Lowe, 2000; Newnham et al., 2007, 2012; Stephens et al., 2012a,b; Sikes et al., 2013). In conjunction with a well-constrained local tephrostratigraphy (Lowe et al., 2008, 2013), these archives have provided important insight to the timing of palaeoenvironmental change in North Island (Newnham and Lowe, 2000; Hajdas et al., 2006). However, quantitative palaeoclimate reconstruction using such proxies is subject to relatively high uncertainties (Wilmshurst et al., 2007; Newnham et al., 2013). Addition of alternative quantitative palaeoclimate reconstructions from North Island will allow robust assessment of past climatic gradients across the latitudinal length of New Zealand.

The volcanic peaks of Tongariro massif and Mt. Ruapehu, in central North Island, formed over the last $250 \mathrm{ka}$ (Gamble et al., 2003), thus were present through at least one full glacial cycle. Mt. Ruapehu is the highest peak in North Island and the only one to intercept the current permanent snowline, with several small cirque glaciers present on its upper slopes (Keys, 1988; Brook et al., 2011). Thus, there is potential to investigate past climate change in this region using glaciers. Indeed, geomorphological evidence for past, more extensive glaciation of the central North Island volcanoes has long been recognised (Taylor, 1927; Mathews, 1967; Topping, 1974; McArthur and Shepherd, 1990; Barrell, 2011). However, the absence of geochronological tools has thus far limited the utility of these glacial records for palaeoclimatic research.

Taking advantage of recent developments in surface exposure dating and numerical glacier modelling, my primary aim in this thesis is to constrain the timing and magnitude of glacier fluctuations in central North Island over the late Quaternary, in order to improve understanding of orbital- and millennial-scale climatic drivers.

To achieve this aim, I complete the following objectives:

1. Delineate the spatial extent of past mountain glacier fluctuations on the central North Island volcanoes, through remote- and field-based geomorphological 
mapping of glacial landforms.

- Field investigations serve to 'ground-truth' initial, desk-based interpretations, as well as identify sites and collect samples for objective 2 (below).

2. Develop and apply tools to constrain the timing of past glacial activity in central North Island, New Zealand.

- Comparison of glacial chronologies with other, well-dated palaeoclimate proxy records provides insight to the relative timing of past changes in climate, at various spatial scales (i.e. regional, hemispheric, inter-hemispheric). Identification of leads-lags helps to inform the possible drivers of climatic change.

3. Provide quantitative estimates of past temperature change in central North Island, using a physically-based, numerical model to simulate former glacier extents.

- Quantifying palaeoclimatic change using proxy evidence helps to understand the drivers and mechanisms causing the observed changes, in two main ways: (i) constraining spatial gradients of change with that predicted by specific hypotheses; and (ii) comparison with outputs from global climate model experiments.

In completing these objectives, I make the following original contributions:

- geological constraint of cosmogenic ${ }^{3} \mathrm{He}$ production in the south west Pacific since c. $11 \mathrm{ka}$

- maps of the glacial landform/sediment distribution in central North Island

- direct age constraint of glacier fluctuations on both volcanoes over the last glacial cycle

- quantitative palaeotemperature estimates for the Last Glacial Maximum and the late-glacial climate reversal

- a hypothesis concerning the inter-proxy comparisons and seasonal climate change during the late-glacial

- an investigation into the effects of changing topographic boundary conditions for palaeoclimate estimates using glacier models in dynamic landscapes 


\subsection{Organisation of this thesis}

In Chapters 4 - 7, I present original research, designed and carried out by myself (see below for supervisor/collaborator contributions). In each of these chapters, I address a primary research question identified in Section 2.6. These chapters are formatted in the traditional style of a full scientific journal article. Some have already been submitted for publication in international journals. At the front end of the thesis, I present a literature review and introduction to the study region, before identifying several research questions to be addressed (Chapter 2). In Chapter 3, I provide descriptions and justifications for use of the methodologies adopted in this thesis. After the primary data are presented (Chapters 4-7), I readdress the original research questions in light of the results (Chapter 8).

\subsection{Statement on the contributions made to this thesis by the author, supervisors and collaborators}

Research design, data collection, interpretation and presentation, and write up represent my own efforts. This project was supervised by A. Mackintosh (ARC/SGEES), B. Anderson (ARC) and D. Townsend (GNS Science). Supervisor contributions to this thesis primarily include: (i) discussion and contribution of scientific ideas and concepts; (ii) editorial advice on write up of results; (iii) digital datasets; and (iv) research funds for fieldwork and sample costs, as well as overseas travel. Primary supervisor A.Mackintosh is co-author on all manuscripts. The ice-flow and energy-balance models were originally coded by secondary supervisor B. Anderson (Victoria University of Wellington). Anderson is co-author on manuscripts where I have utilised his glacier model code. The research in this thesis also contributes towards a new geological map of Tongariro National Park, with accompanying written descriptions (GNS Science contract DM-593774). This project is led by external supervisor D. Townsend, who has provided digital datasets and initial geomorphological interpretations. Townsend is co-author on all manuscripts.

Below, I have detailed the research manuscripts that comprise this thesis, the co-authors and any publication information. Brief statements describing collaborator contributions are also included.

Chapter 4: Eaves, S.R., Winckler, G., Schaefer, J.M., Vandergoes, M., Alloway, B.V., Mackintosh, A., Townsend, D.B., Ryan, M.T., Li, X. A test of the cosmogenic ${ }^{3}$ He produc- 
tion rate in the south west Pacific $\left(39^{\circ} \mathrm{S}\right)$. Accepted for publication in Journal of Quaternary Science.

Winckler, Schaefer and I provided cosmogenic ${ }^{3}$ He measurements. Alloway, Mackintosh, Ryan, Vandergoes and I undertook stratigraphic field investigations and collected radiocarbon samples. Vandergoes and Li provided radiocarbon measurements.

Chapter 5: Eaves, S.R., Mackintosh, A., Winckler, G., Schaefer, J.M., Alloway, B.V., Townsend, D.B. Orbital scale glacier fluctuations in North Island, New Zealand $\left(39^{\circ} \mathrm{S}\right)$ during the last glacial cycle. in prep.

Mackintosh and I identified the sites and undertook palaeoglaciological reconstructions. Winckler, Schaefer and I provided cosmogenic ${ }^{3} \mathrm{He}$ measurements. Alloway and I provided stratigraphic field investigations and electron microprobe analysis of tephra. Townsend and I provided geomorphological maps.

Chapter 6: Eaves, S.R., Mackintosh, A., Winckler, G., Schaefer, J.M., Anderson, B.M., Doughty, A.M., Townsend, D.B. Uniform summer cooling across New Zealand drove glacier readvance during the late-glacial (15-11 ka). in prep.

Mackintosh, Doughty and I carried out fieldwork. Winckler, Schaefer and I provided out cosmogenic ${ }^{3} \mathrm{He}$ measurements. Anderson and Doughty provided guidance on model initialisation. Townsend and I provided geomorphological maps.

Chapter 7: Eaves, S.R., Anderson, B.M., Mackintosh, A., Winckler, G., Schaefer, J.M., Townsend, D.B., Leonard, G., Conway, C. Temperature change during the Last Glacial Cold Period in central North Island, New Zealand (39 ${ }^{\circ}$ ), inferred from $2 \mathrm{D}$ glacier modelling. in prep.

Winckler, Schaefer and I carried out cosmogenic ${ }^{3} \mathrm{He}$ measurements. Townsend and I provided geomorphological maps. Townsend, Conway and Leonard provided geological reconstructions of LGM topographies based on field mapping and radiometric dating. 


\section{Chapter 2}

\section{Background}

'What's past is prologue.'

William Shakespeare (1611)

Palaeoclimate (palaeo- from Greek palaios, meaning 'ancient') research has two fundamental aims: (i) to reconstruct, both qualitatively and quantitatively, the magnitude and timing of pre-historic changes in climatic variables; and (2) to understand the drivers and mechanisms of these changes. The former is achieved using preserved components of natural environmental systems that are strongly dependent on climate - known as climate proxies (e.g. see Alloway et al., 2007 for a review of key late-Quaternary climate proxy records in New Zealand). The latter increasingly uses numerical models that represent the systems of interest in sets of equations bound by physical and material laws. Combination of climate proxy reconstructions with physically-based models provides a powerful method to understand the workings, interactions and feedbacks of the Earth system and provide context for the rates and magnitudes of contemporary climate change (e.g. Masson Delmotte et al., 2013). Furthermore, quantitative palaeoclimate reconstructions from climatic states much different from today provide critical benchmarks for global climate models that are used to predict future change (e.g. Braconnot et al., 2012). Thus, whilst the present may be key to the past, the past can help illuminate the future.

In this chapter, I first present a short argument for the use of mountain glaciers as a palaeoclimate proxy. Following this, I review the present understanding of late Quaternary glacier fluctuations in New Zealand. I then provide an overview of the climatic, glaciological and geological setting of Ruapehu and Tongariro volcanoes, including a review of existing knowledge of the local glacial history. From this review, I identify 
several research questions that are addressed in this thesis.

\subsection{Glaciers as a palaeoclimate proxy}

Glaciers are perennial masses of frozen water that flow under their own weight and form in specific topoclimatic situations where solid precipitation remains on the ground throughout the year. Thus, they are intimately connected to climate through the strong dependence of glacier mass balance on climatic variables - in particular temperature and precipitation (Oerlemans and Fortuin, 1992; Oerlemans, 2001, 2005). Mass accumulation on the glacier surface is predominantly sourced from solid precipitation, which occurs when near surface air temperature is beneath a critical threshold (typically $<2$ $\left.{ }^{\circ} \mathrm{C}\right)$. Site-specific topoclimatic factors can also contribute to snow accumulation, such as avalanching from steep slopes and wind-drifting. Ablation of mountain glacier snow and ice occurs as surface melt, sublimation, erosion by wind, avalanching and lake-calving. Surficial melt of snow and ice is the dominant process causing ablation on land-terminating glaciers in the temperate mid-latitudes (Cuffey and Paterson, 2010). Melt occurs when there is a net flux of energy to the glacier surface and the temperature of the surface is at $0{ }^{\circ} \mathrm{C}(273.15 \mathrm{~K})$. Most of the energy that contributes to melt comes from solar radiation and atmospheric heat content (Cuffey and Paterson, 2010; also see Chapter 3 for a detailed description of surface energy balance components). Energy exchanges at glacier surfaces can be represented by relatively simple, physical models (Hock, 1999). In New Zealand, development and application of energy and mass balance models has shown that net radiation and turbulent heat exchanges provide roughly equal contributions to glacier melt, and that local glacier mass balance is most sensitive to temperature change (Anderson et al., 2010; Anderson and Mackintosh, 2012). Coupling mass balance models to ice-flow models provides a means to quantify the palaeoclimatic information represented in historic and geological glacier length change records (e.g. Oerlemans, 2005; Anderson and Mackintosh, 2006; Doughty et al., 2013).

The flow of ice under gravity results in erosion and entrainment of sediment, which is transported down-valley and to the ice margins via a combination of supraglacial, englacial and/or subglacial pathways (Kirkbride, 1995). Erosion, modification and deposition of sediment by glaciers creates distinctive sediment facies, landforms and landform assemblages, which can be preserved long after glacial retreat (Benn and Evans, 2010). Empirical observations of geomorphological process-form relationships in

glacierised environments have classified common assemblages of glacial sediments and landforms at a variety of different glaciological settings (e.g. Evans, 2003). Identification of preserved glacial landform assemblages, following glacier retreat, can therefore be 
used to reconstruct past styles and extents of glaciation.

Almost all reconstructions of palaeoglacier geometries utilise moraines. 'Moraine' is a general term that is used in glaciological and palaeoclimatic literature to describe both landforms and sediment facies transported and deposited by glaciers. In this thesis, I use moraine to describe discrete landforms composed of glacially transported sediment deposited at a former ice margin. Transport of sediment from glacier ice to outside of the glacier margins, to form moraines, occurs downstream of the equilibrium line (Benn and Evans, 2010). Where the geometry and mass balance of a particular glacier is in equilibrium with local climate, the continuation of moraine-building processes can build large (several 10-100s of metres high), linear moraines that delimit the ice margin. Sediment deposited by retreating glaciers forms less distinct and less readily preserved landforms due to the dynamic ice margin. Meanwhile advancing glaciers may override and destroy moraines. Thus, unlike continuous sedimentary archives (e.g. ice cores, tree rings, lacustrine/marine sediments), moraines preserved in the landscape represent a snapshot in time of a former glacial extent. Moraines depicting former ice margins are found on all continents of Earth (e.g. Ehlers et al., 2011), often at high altitude, in areas with few other opportunities for palaeoclimate reconstruction. Substantial progress in the field of cosmogenic nuclides over the last two decades has resulted in a range of tools that are now widely accessible and widely applied to constrain the age of glacial landforms (Balco, 2011). Thus, well-dated moraine sequences provide ideal targets for quantitative palaeoclimatic reconstruction.

\subsection{Quaternary palaeoclimate: a brief history of the or- bital revolution)}

The Quaternary is the most recent geological period (2.58 Ma - present; Cohen et al., 2013) and is characterised by cyclical shifts in the Earth's climate between cold glacialand warm interglacial-conditions. Glacial geomorphology provided some of the first evidence for major climatic cooling in the recent geological past. In the early-mid 19th century, a group of European naturalists (Evans (1887) and Imbrie and Imbrie (1986) review the relative individual contributions) formulated the theory that expanded glaciation was responsible for the distribution of erratic boulders and polished, striated bedrock surfaces observed several kilometres down-valley of contemporary glaciers in the European Alps. This 'Ice Age Theory' was formalised and widely promoted by Agassiz (1840), who discovered further evidence for former existence and greater extent of ice across parts of the Northern Hemisphere. Whilst this idea had been postu- 
lated in various forms by geologists and naturalists for several decades, it remained controversial for two main reasons: (i) it challenged the prevailing 'flood hypothesis' of the time; and (ii) it lacked any accompanying theory or evidence that could explain the drivers and mechanisms of glacier advance (Imbrie and Imbrie, 1986).

Orbital theory of the ice ages attributes past waxing and waning of continental ice sheets to cyclical variations in solar insolation caused by changing orbital geometries. Three main mechanisms are responsible for orbital forcing of the spatial and temporal patterns of insolation.

Eccentricity (e; Equation 2.1) describes the deviation of Earth's solar orbit from a perfect circle (defined as $e=0$ ). Currently, the Earth-Sun distance at aphelion and perihelion is similar and Earth's orbit is close to circular $(e=0.0167)$. Variations in the gravitational forces imparted by other planets (mainly Jupiter and Saturn) cause Earth's eccentricity to vary between a maximum of 0.058 and a minimum of 0.0034 (Figure 2.1A). This has periods of $100 \mathrm{kyr}$ and $400 \mathrm{kyr}$ and has the effect of lengthening summer (winter) in one hemisphere at the expense of summer (winter) in the opposite hemisphere. This oscillation also alters the total annual insolation, although only on the order of $<0.2 \%$. More importantly, Earth's eccentricity cycle modulates the amplitude of the precessional cycle (see below).

$$
e=\frac{a-p}{a+p}
$$

where $a$ is the Earth-Sun distance at aphelion (currently c. $152 \times 10^{6} \mathrm{~km}$ ) and $p$ is the Earth-Sun distance at perihelion (currently c. $147 \times 10^{6} \mathrm{~km}$ ).

Obliquity describes Earth's axial tilt relative to its orbital plane (currently $23.4^{\circ}$ ), which varies by up to $2.4^{\circ}$ over a $41 \mathrm{kyr}$ cycle (Figure 2.1B). This tilt causes the seasons and opposing insolation intensity between the hemispheres. Changes in tilt angle influence the spatial variation of insolation. Higher tilt results in higher solar radiation receipts at high latitudes.

Precession is the change in orientation, or 'wobble', of Earth's rotational axis resulting from the gravitational forces exerted on Earth by the Sun and moon. This cycle has dominant periodicities of $23 \mathrm{kyr}$ and $19 \mathrm{kyr}$ and has the effect of changing the occurrence of the equinoxes and solstices, relative to Earth's position in its solar orbit. Thus, precession alters the timing of the seasons, relative to perihelion/aphelion. The amplitude of precessional forcing is dictated by the eccentricity cycle (above; Figure 

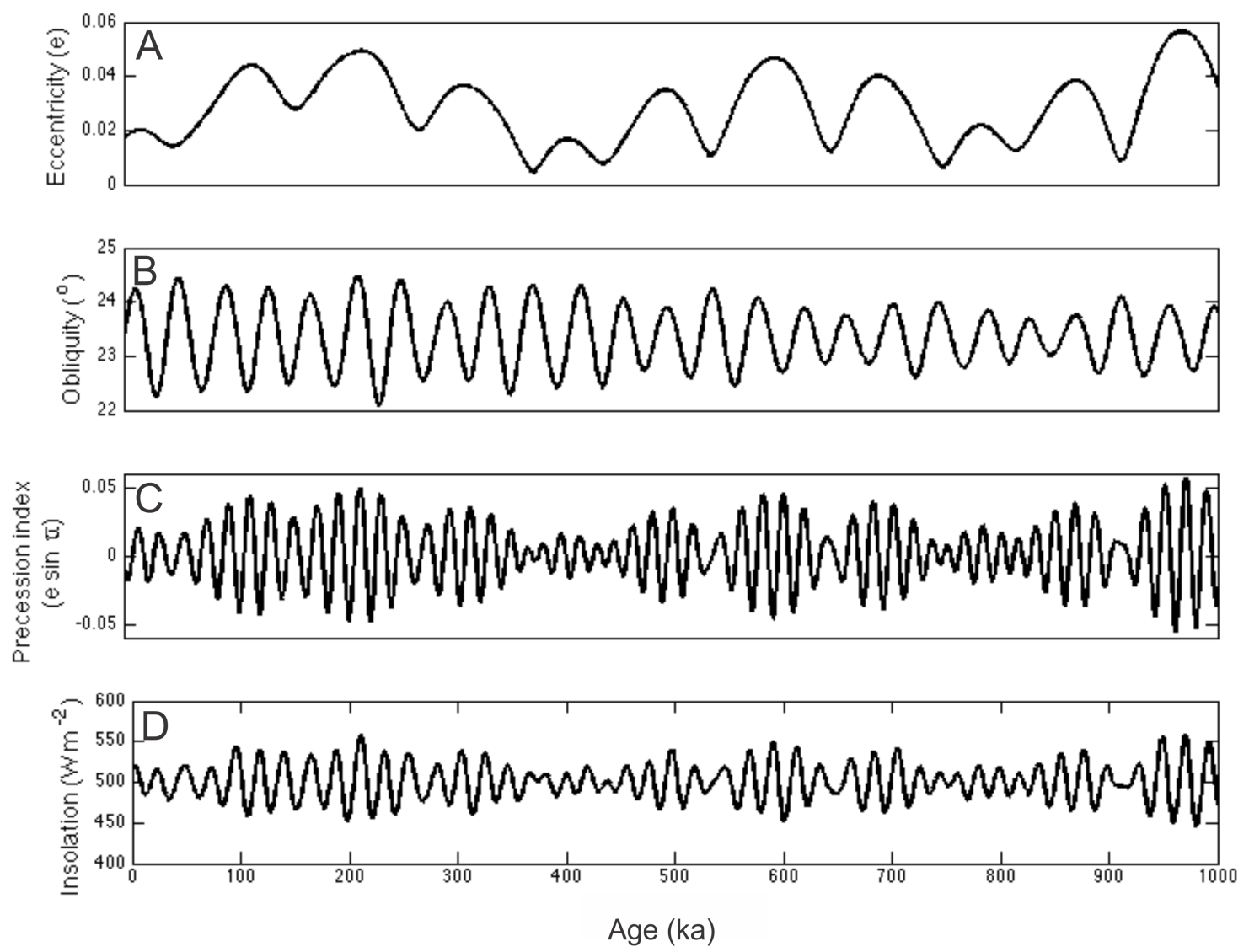

Figure 2.1: (A) Axial eccentricity; (B) obliquity; (C) precessional index (esin $\varpi)$; and (D) mid-summer (Dec. 21) insolation intensity at $39^{\circ} S$ (lower panel). Values calculated using the code of Huybers and Eisenman (2006).

2.1A). This effect, together with changing obliquity, dictates changes in the frequency and amplitude of insolation, in time (e.g. see Figure 2.1C, lower panel) and space.

Adhemar (1842) was the first to call on orbital variations as the driver of past ice ages. He suggested that Agassiz's glaciation was induced by lengthened boreal winters, caused by the precessionally-forced coincidence of Northern Hemisphere winter solstice with aphelion. This theory predicts anti-phased glacial cycles between the hemispheres and Adhemar used the present-day Antarctic ice sheets as evidence to support his idea. Adhemar's theory was dismissed by Von Humboldt (1852) who stated that the reduced radiation receipts of winter are made up for by increases during summer as a result of the alignment with perihelion.

Scottish geologist James Croll took up the orbital theory, building on the discovery that the eccentricity of Earth's orbit changes with time (Leverrier, 1843). Extending the 
eccentricity reconstruction to $3 \mathrm{Ma}$, Croll (1864) found evidence for a $400 \mathrm{kyr}$ periodicity, which modulates the amplitude of the 100 kyr cycle. Combining his eccentricity calculations with precession, Croll (1864) hypothesised that glacial-interglacial cycles followed the 400 kyr cycle, which dictated when aphelion was far enough away to sufficiently reduce winter radiation receipts. During these 'glacial periods', Croll believed precession then prescribed which hemisphere experienced glaciation, through its control on the position of the solstices relative to the orbital plane. Unlike Adhemar (1842), this theory was based on the premise that the reduction in winter insolation intensity, rather than winter duration, is key for glacial inception. Croll (1864) further advanced this hypothesis by considering the feedbacks of continental glaciation on the Earth system. He suggested that increased snowfall would amplify the orbital impacts by increasing the surface albedo and that growing ice masses would disrupt atmospheric and oceanic circulation. Despite some mismatches between his theory and observations (see Sugden, 2014), the majority of Croll's thinking was almost a century ahead of its time. However, the geochronological methods required to test his ideas about orbital forcing of glacial climates were not developed until the mid-20th century. Thus, despite support from eminent scientists of the time, including Charles Lyell and William Buckland, Croll's theory could not be tested.

In the early-mid 20th century, Serbian mathematician, Milutan Milankovitch, corrected and further refined the calculations of his predecessors, adding in the effects of orbital obliquity (see above) and computing the energy balance to estimate the magnitude of past radiation change (Milankovitch, 1920, 1941). In contrast to Adhemar and Croll, Milankovitch considered changes in summer radiation receipts at high latitude as the main limiting factor for glacial development, due to the strong correlation with summer insolation and the snowline (Milankovitch, 1920; Köppen and Wegener, 1924). Milankovitch calculated that summer insolation at $65^{\circ} \mathrm{N}$ can vary by $20 \%$ when maximum obliquity and eccentricity coincide (e.g. see Figure 2.1, c. 200 ka). Like his predecessors, Milankovitch suffered from a lack of geochronological methods to test his hypothesis. Furthermore, geologists remained sceptical as orbital theory predicted many more ice ages than the four that were chiefly preserved in terrestrial glacial and fluvial sequences (e.g. Penck and Brückner, 1909).

The development of radiometric geochronological methods (chiefly radiocarbon, and U-Th dating) and the extraction of deep-sea sediment cores provided chronologicallyconstrained, continuous records of palaeoenvironmental change of sufficient length to overcome the preservation issues of terrestrial glacial and fluvial records. Stable oxygen isotope ratios of marine foraminifera preserved in these cores predominantly reflect changes in global ice volume (Shackleton, 1967). Emiliani (1955) presented the first such 
record from a core covering approximately the last $280 \mathrm{kyr}$, although he interpreted the $\delta^{18} \mathrm{O}$ signal to reflect changes in surface ocean temperatures, rather than ice volume. Nevertheless, this work agreed well with Milankovitch's prediction of the last glacial maximum occurring c. $20 \mathrm{ka}$ and the last interglacial at c. $100 \mathrm{ka}$. Further addition of marine cores that largely replicated the results of Emiliani (1955), as well as U-Th dating of coral reefs (Broecker, 1966; Broecker et al., 1968), and terrestrial proxy records such as loess accumulations (e.g. Kukla, 1970), added to the growing support for orbital theory as proposed by Milankovitch. The seminal work of Hays et al. (1976), using spectral analysis, showed the prominence of the precessional, obliquital and eccentrical periodicities in time series of foraminiferal $\delta^{18} \mathrm{O}$ spanning c. 0-300 ka. This provided conclusive evidence that orbitally-driven changes in insolation played a key role in late Pleistocene global ice volume changes.

Extraction of ice cores from Greenland corroborated the broad pattern of cooling, at orbital timescales over the last glacial cycle (Dansgaard et al., 1969, 1982). Comparison with early ice core records from Camp Vostok in Antarctica showed that the polar ice sheets in each hemisphere exhibit broad covariance in cooling and warming patterns over orbital timescales, which indicated glacial-interglacial cycles were global in extent (Epstein et al., 1970; Lorius et al., 1985; Jouzel et al., 1987). Later, more detailed work would show important differences between the hemispheres at shorter timescales (see Section 2.3). The location of Antarctic ice cores, situated distal to terrestrial $\mathrm{CaCO}_{3}$ dust fluxes, also permitted measurement of atmospheric composition. These measurements showed covariance of Antarctic temperature and atmospheric $\mathrm{CO}_{2}$ (Barnola et al., 1987), which indicated that insolation effects may have been amplified by radiative forcing from atmospheric changes. This lead to the suggestion that changes in atmospheric greenhouse gases may explain the globally synchronous climatic changes between the hemispheres, despite out of phase insolation (Jouzel et al., 1987; see Section 2.2.1 below).

\subsubsection{Outstanding questions in orbital theory - southern connections}

Discovery of orbital frequencies in palaeoenvironmental proxies by Hays et al. (1976) raised several important questions, and the precise role of insolation changes in driving global climate change over the Pleistocene remains uncertain (see Pierrehumbert, 2010). For example, why does the 100 kyr cycle dominate oxygen isotope spectra during the late Pleistocene, especially given the negligible impact of the $100 \mathrm{kyr}$ eccentricity cycle on insolation (Imbrie et al., 1993)? Why are glacial cycles 'saw-tooth' in shape (Broecker and Donk, 1970), with long (c. 70-90 kyr) periods of gradual cooling and abrupt returns to interglacial periods, dubbed 'terminations', over c. $10 \mathrm{kyr}$ ? What caused the shift 
from $40 \mathrm{kyr}$ to $100 \mathrm{kyr}$ glacial cycles that occurred at c. $1 \mathrm{Ma}$ ? Why has ice volume in both hemispheres varied in broad synchrony, despite anti-phased changes in summer insolation (Broecker, 1978; Mercer, 1984; Lorius et al., 1985)? The latter question is pertinent to the research presented in this thesis and I review the topic in more detail below.

Over orbital timescales, changes in seasonal insolation intensity are anti-phased between the hemispheres, due to the dominance of the precessional component. As a consequence, both Adhemar and Croll explicitly predicted asynchronous glacial advance-retreat cycles between the hemispheres (see above). However, it has been shown convincingly, using a multitude of climatic proxy reconstructions, that Southern Hemisphere climate varied in-phase with the north, over orbital timescales, during the late Pleistocene (Hays et al., 1976; Mercer, 1984; Denton et al., 1999; Petit et al., 1999; Vandergoes et al., 2005; Schaefer et al., 2006; Barrows et al., 2007a; Kawamura et al., 2007; Clark et al., 2009; Putnam et al., 2013b). What drives Southern Hemisphere glacial cycles, if not local summer insolation intensity? This conundrum has been termed a 'fly in the insolation ointment' (Broecker (1978), cited in Mercer, 1984). Resolving the mechanisms that synchronised the hemispheres over orbital timescales remains a major outstanding question in palaeoclimatic research, and a number of theories have been put forward.

Several researchers have assumed that the close resemblance of southern climate proxy records to boreal insolation change implies a northern driver-southern response relationship. As such, an interhemispheric pathway, to synchronise the hemispheres, has been sought in the global atmospheric-oceanic system. For example, Imbrie et al. (1992) and Gildor and Tziperman (2001) suggest cooling of North Atlantic Deepwater (NADW), due to growth of the northern ice sheets, is translated to the Southern Ocean via the thermohaline circulation, leading to increased stratification and sea ice development. A major issue with these theories is that changes in southern proxy records are in phase with, or even lead, northern changes (e.g. Hays et al., 1976; Wolff et al., 2009), whilst translation of northern forcing through the oceans is thought to be subject to a significant time lag.

A separate agent, with strong potential for closely coupling the hemispheres, is atmospheric carbon dioxide. Carbon dioxide is well mixed in the global atmosphere (Pierrehumbert, 2010), thus changes are felt instantaneously around the globe. Variations in the atmospheric partial pressure of carbon dioxide $\left(p \mathrm{CO}_{2}\right)$, as recorded in Antarctic ice cores, closely tracked Antarctic temperature change over the last 800,000 years (Petit et al., 1999; Siegenthaler et al., 2005; Lüthi et al., 2008), reaching lows of c. 180 ppm $v$ during peak glacial times and highs of c. 280 ppm $v$ during interglacials. 


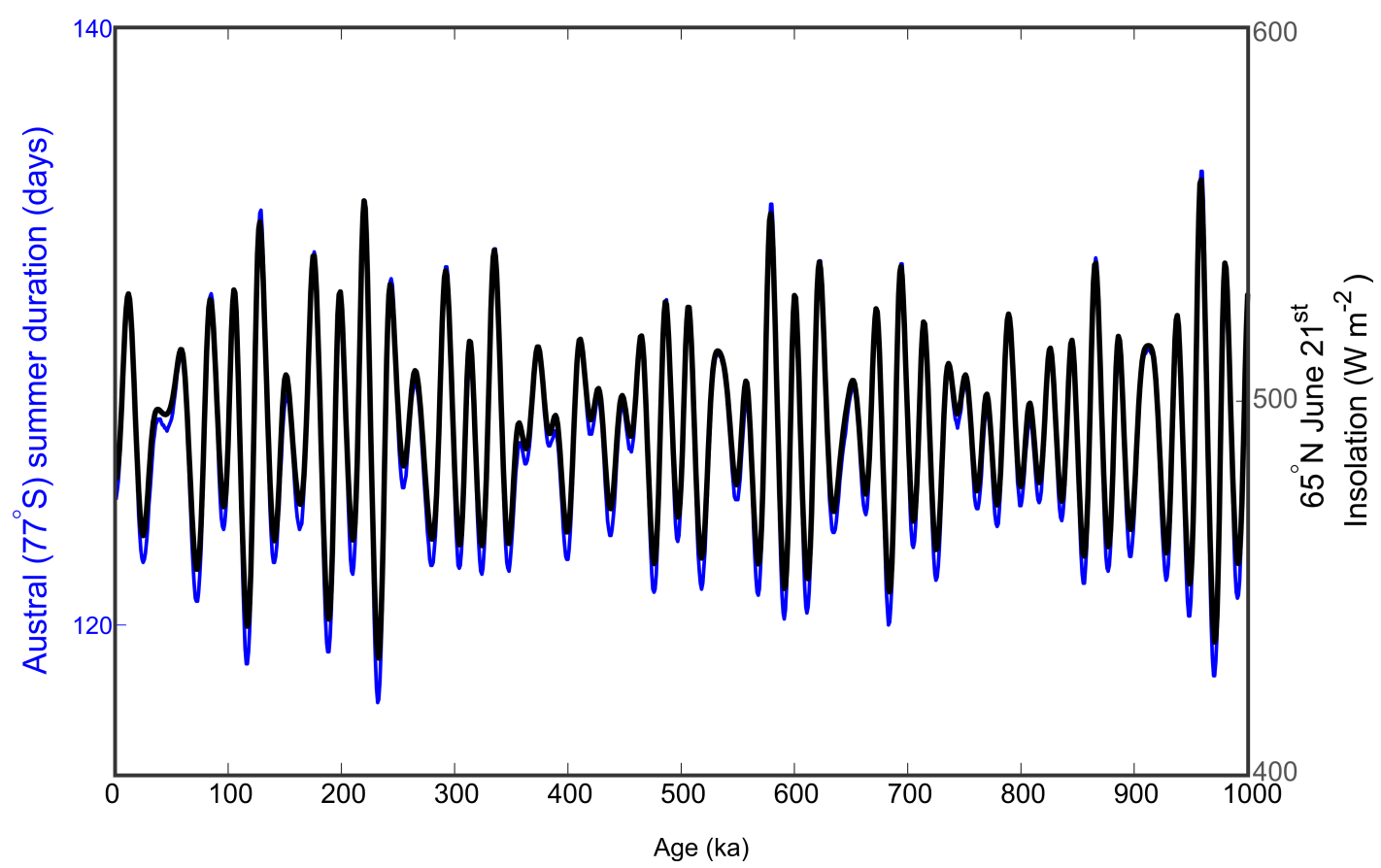

Figure 2.2: Austral spring insolation intensity (blue), austral summer duration (defined as days with average insolation $>250 \mathrm{~W} \mathrm{~m}^{-2}$ ) at $77^{\circ} \mathrm{S}$ (blue) and boreal summer solstice intensity at $65^{\circ} \mathrm{N}$ (black) for the last $1 \mathrm{Ma}$, calculated using the code of Huybers (2006).

An estimated $30-70 \%$ of temperature decline in the Southern Hemisphere at the LGM can be attributed to the radiative effects of atmospheric $p \mathrm{CO}_{2}$ reduction (Broccoli and Manabe, 1987; Lorius et al., 1990; Schneider von Deimling et al., 2006). It is likely that the ocean acted as the main sink for atmospheric $p \mathrm{CO}_{2}$ during glacial times, due to its large storage capacity (Sigman and Boyle, 2000). The prevailing view is that this oceanic drawdown occurred through increased utilisation of nutrients, phosphate and nitrate, by plants in the surface of the Southern Ocean (i.e. a more efficient biological pump; e.g. Broecker, 1982). However, the driver of this change remains uncertain. One possibility is that increased fertilisation of the surface ocean by iron input from raised dust flux during peak glacial times facilitated this drawdown (Martin, 1990). However, this scenario is predicated on cooling having already occurred, which would facilitate greater meridional temperature gradients and increased windiness required to increase the land-ocean dust flux (Broecker, 2013). More recently, Broecker (2013) proposed that drawdown of atmospheric $p \mathrm{CO}_{2}$ was the cause of glacial, rather than a consequence. Broecker outlines how density changes in high latitude water masses may result from orbital forcing, which would lead to increased ocean stratification and utilisation of phosphate. Precisely resolving the leads-lags between $p \mathrm{CO}_{2}$ and temperature change (e.g. Shakun et al., 2012) for periods before the last termination will provide critical tests for determining the role of $p \mathrm{CO}_{2}$ in glacial cycles. 
Alternative theories invoke components of local insolation as drivers of austral glacial cycles. Huybers (2006) argued that insolation integrated over a given intensity threshold (related to the sign of surface temperature) is a more relevant index for glacier mass balance, due to the strong relationship between positive degree days and glacier melt (e.g. Ohmura, 2001). Using radiative equilibrium theory, Huybers and Denton (2008) show that radiative equilibrium temperature is more sensitive at lower atmospheric temperatures. Thus, higher temperatures result from weaker, but longer duration summers, as occurs when summer solstice aligns with aphelion. They argue that this is the dominant driver of temperature change in Antarctica at orbital timescales, as feedbacks (e.g. albedo, surface elevation) associated with ice sheet growth and decay are less relevant at the polar-centric Antarctic ice sheets. In contrast, summer insolation intensity is key in the north where ice sheets reached lower latitudes and radiation contributes directly to surface melt and the feedbacks associated with ice sheet growth/decay strongly dictate local temperature. Austral summer duration covaries with northern summer intensity (e.g. Figure 2.2), therefore providing a means of synchronising climate between the hemispheres at orbital timescales (Huybers and Denton, 2008).

At the culmination of the LGM, surface temperatures in West Antarctica began rising several millennia prior to those in East Antarctica (Blunier and Brook, 2001; Fudge et al., 2013). This occurrence is interpreted to represent a response to the early break up of sea ice (e.g. Allen et al., 2011; Collins et al., 2012) due to increasing summer duration, which facilitated advection of warmer air masses into the lower elevation ice surfaces in West Antarctica (Fudge et al., 2013). The onset of warming at in West Antarctica also coincides with increasing austral $\left(63^{\circ} \mathrm{S}\right)$ spring insolation. Timmermann et al. (2009) argue that this is an important pacemaker for southern glacial cycles through two mechanisms: (i) controlling the availability of heat for advection to the Antarctic continent; and more importantly, (ii) controlling ventilation of $\mathrm{CO}_{2}$ from the Southern Ocean. Thus, although there are plausible local drivers of southern climate over glacial cycles, it is difficult to discriminate between different theories when they share essentially the same pattern of change (Huybers, 2009; Figure 2.2).

Palaeoclimatic research can inform this debate in two main ways: (i) providing increased number of spatially distributed, well-dated quantitative palaeoclimate reconstructions, particularly prior to the LGM, in order to assess the timing and magnitude of change; and (ii) using this information to evaluate global climate model experiments that test specific hypotheses about possible drivers and mechanisms of past climate change (e.g. Braconnot et al., 2007; He et al., 2013). 


\subsection{Millennial-scale oscillations}

Superimposed on orbital scale glacial cycles, are high amplitude, millennial-scale oscillations. These changes occur over timescales too short to have been driven by changes in orbital geometry, therefore they most likely represent internal feedbacks in the global atmospheric-oceanic system. First recognised in Greenland ice cores (Dansgaard et al., 1982, 1984), such millennial-scale oscillations are present in continuous palaeoclimatic proxy records globally (e.g. Arz et al., 1998; McManus et al., 1999; Blunier and Brook, 2001; Wang et al., 2001, 2004), although the shape and timing of these changes differs markedly between the hemispheres (Blunier and Brook, 2001). In Greenland ice cores, ${ }^{18} \mathrm{O} /{ }^{16} \mathrm{O}\left(\delta^{18} \mathrm{O}\right)$ ratios indicate abrupt warming events, $\left(>10^{\circ} \mathrm{C}\right.$ over $3-4$ decades $)$, which occurred quasi-periodically throughout the last glacial cycle (Dansgaard et al., 1993). Each warming event was followed by slow return to pre-warming conditions lasting c. 1-3 kyr and is known as a 'Dansgaard-Oeschger' (D-O) cycle (Figure 2.3). Synchronising Antarctic and Greenland ice core records, using methane concentrations in air bubbles, Blunier and Brook (2001) showed that temperatures in Antarctica tend to rise steadily during cold intervals in Greenland and decrease steadily during boreal warm intervals (Figure 2.3). This is best illustrated during the late-glacial chron (15-11 ka). At the onset of the Antarctic Cold Reversal (c. $14.6 \mathrm{ka}$ ), deglacial temperature rise in Antarctica reversed, which coincided with rapid warming in Greenland (D-O event 1; Figure 2.3). Warming then resumed in Antarctica when Younger Dryas cooling prevailed in Greenland some 1800 yr later (Figure 2.3).

It is widely believed that these millennial scale oscillations, of opposite sign between the hemispheres, represent the spatial redistribution of heat brought about by changes in ocean circulation, although the ultimate driver(s) remain unclear. The bi-polar seesaw hypothesis invokes variability in NADW formation as the mechanism that generates opposing changes in the south (Crowley, 1992; Broecker, 1998). Reduced Atlantic meridional overturning circulation (AMOC) decreases the northward flux of warm surface waters from low-latitudes causing regional cooling in boreal high-latitudes. At the same time, reduced heat export from the South Atlantic leads to local warming (Crowley, 1992). Barker et al. (2009) showed that millennial-scale variability in the South Atlantic exhibits similar timing and rates of opposing change to that of the North Atlantic, thus supporting the theory that the Atlantic basin served as the gateway for interhemispheric transmission of abrupt climate change during the last termination. The Southern Ocean is thought to be slower (on the order of centuries to millennia) to respond to such changes due to thermal inertia and the absence of landmasses to support wave propagation of density anomalies (Stocker and Johnsen, 2003). Stocker 


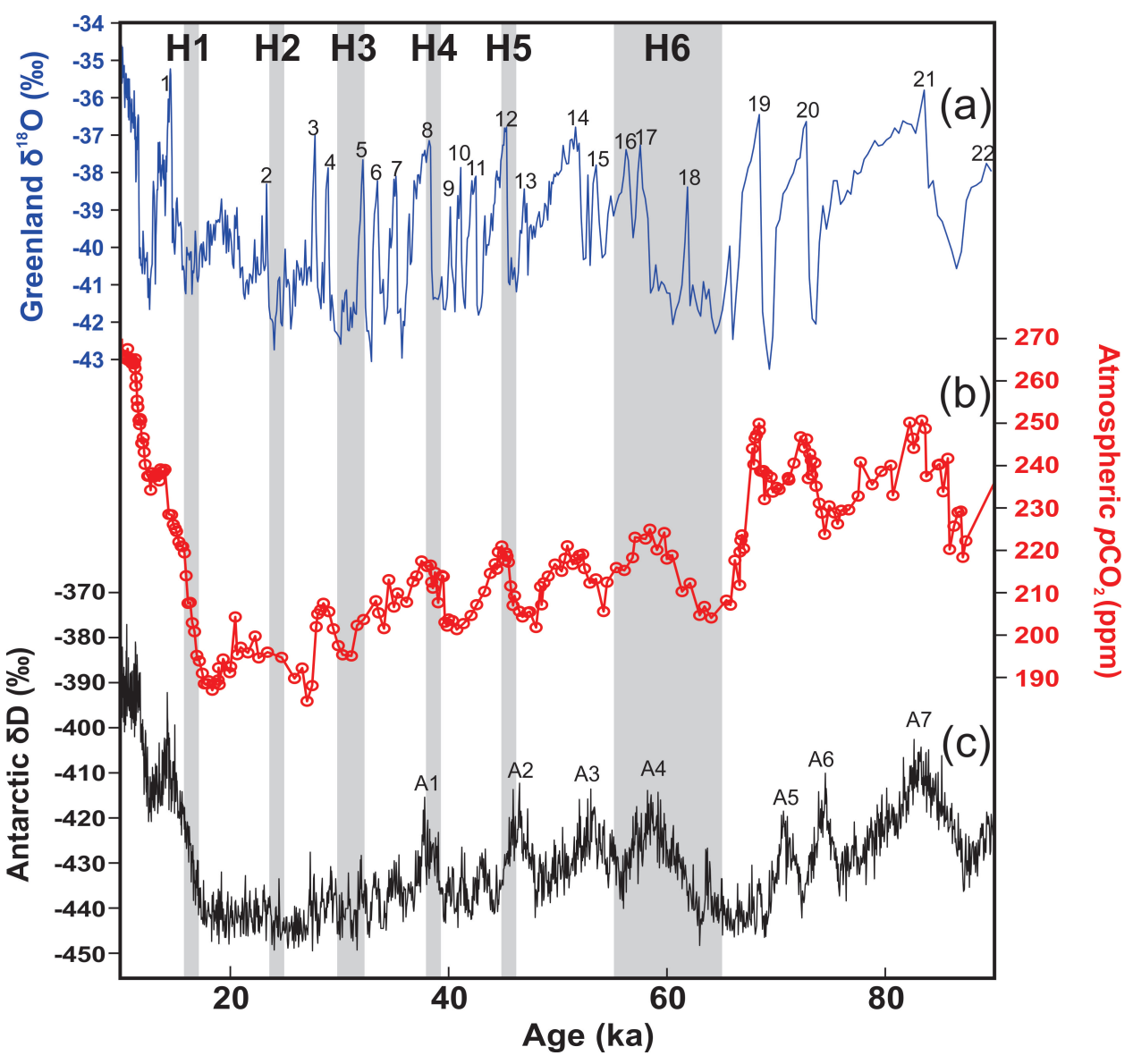

Figure 2.3: (a) GISP2 oxygen isotope record, showing D-O events (numbered); (b) Atmospheric $\mathrm{pCO}_{2}$ from Antarctica (Monnin et al., 2001; Ahn and Brook, 2008); (c) EPICA Dome C deuterium record (EPICA Community Members, 2004), with the Antarctic warming events originally identified by Blunier and Brook (2001). Vertical grey bars indicate Heinrich events (Heinrich, 1988) using the chronology of Hemming (2004).

and Johnsen (2003) suggest that this muted response of the Southern Ocean explains the different temporal characteristics of millennial-scale temperature changes in Antarctica, relative to Greenland (e.g. Figure 2.3).

Several studies have also highlighted the potential role of atmospheric changes for interhemispheric transmittance of abrupt climate changes (Wang et al., 2001; Anderson et al., 2009; Denton et al., 2010). Changes in equator-pole temperature gradients associated with the changes in winter sea ice extent (e.g. Denton et al., 2005; Anderson et al., 2009) result in latitudinal displacement of the thermal equator (Wang et al., 2001) and mid-latitude westerlies (Moreno et al., 1999; Toggweiler, 2009). Denton et al. (2010) suggest that southward movement of the southern westerlies during Greenland stadials would help facilitate austral warming via the break-up of sea ice, increased upwelling of warm deep water, and increased southward eddy-driven transport of heat. 
The Bølling-Allerød (Antarctic Cold Reversal) warming (cooling) event in the Northern (Southern) Hemisphere at c. $14.6 \mathrm{ka}$ is a well-studied example of one such millennial scale climate event. Cessation of freshwater forcing in the North Atlantic at the end of Heinrich stadial 1 represents one hypothesised trigger for the resumption of oceanic overturning this time (Liu et al., 2009). Far-field sea-level proxy records indicate a rise of c. 14-18 $\mathrm{m}$ in < 500 yrs (14.65-14.31 ka; Meltwater Pulse 1A - MWP1A), which indicates a significant freshwater flux to the global ocean coincided with resumed Atlantic overturning (Deschamps et al., 2012). Geological evidence and glaciological modelling suggests northern ice sheets contributed a substantial proportion of MWP1A (Carlson and Clark, 2012; Tarasov et al., 2012). However, a freshwater pulse to the North Atlantic is not consistent with concomitant abrupt intensification of AMOC, under the bipolar seesaw model. Weaver et al. (2003) show that freshwater forcing of equivalent magnitude to MWP1A applied to the Southern Ocean provides a viable trigger to restart Atlantic deep water formation and replicate the spatial pattern of northern warming (southern cooling) observed in proxy records at that time. Using an Earth system model, Menviel et al. (2011) show that a combination of southern freshwater forcing and North Atlantic overturning may be jointly responsible for this abrupt climatic transition. However, the proportion of MWP1A derived from Antarctica remains uncertain. Recent geological evidence shows evidence for increased Antarctic discharge at that time (Weber et al., 2014), although glaciological model simulations suggest this may have been a response to resumed AMOC (Golledge et al., 2014). Further addition of well-dated quantitative palaeoclimatic proxy reconstructions will help to constrain climate model simulations that seek to resolve the drivers and mechanisms of past abrupt climate change over the last glacial cycle.

\subsection{The late Quaternary glacial history of New Zealand (c. 125 - $10 \mathrm{ka}$ )}

The record of glaciation in New Zealand dates back to at least the early Pleistocene (Suggate, 1990). However, the active tectonic setting and high erosion rates mean that very little evidence of glacial fluctuations prior to the late Pleistocene is preserved in the modern landscape. Several reviews exist that draw together the fragmentary records of glacial geology and place these within local- to regional- stratigraphic and palaeoclimatic frameworks (Gage and Suggate, 1958; Gage, 1985; Suggate, 1990; Barrell, 2011). In this section, I review evidence for past glacier fluctuations in New Zealand over the last glacial cycle (c. $125 \mathrm{ka}$ to present) with a focus on geochronology and the debates surrounding the associated climatic drivers. 


\subsubsection{Pre-Last Glacial Maximum (c. 125 - 35 ka)}

Evidence for glaciation early in the last glacial cycle is limited and often restricted to exposures of glaciofluvial sedimentary sequences, usually found downstream of former ice limits. Using a variety of luminescence techniques to date glaciofluvial aggradation episodes in northern Westland, Preusser et al. (2005) constrain pre-LGM glacial advances to c. $111 \mathrm{ka}, \mathrm{c} .85 \mathrm{ka}$ and c. $64 \mathrm{ka}$. East of the Main Divide in Rakaia valley, Shulmeister et al. (2010b) document evidence for glacier fluctuations within a thick sedimentary sequence of glacial - glaciofluvial deposits. Using infrared stimulated luminescence dating they constrain the timing of glacier advances to $100-90 \mathrm{ka}, \mathrm{c} .80$ $\mathrm{ka}, \mathrm{c} .48 \mathrm{ka}$ and c. $40 \mathrm{ka}$. Luminescence ages from these two studies have uncertainties of $10-20 \%$.

Sutherland et al. (2007) present a cosmogenic ${ }^{10} \mathrm{Be}$ chronology for a series of moraines that document glacier extension of similar magnitude at 4 separate occasions in Cascade valley, southwest New Zealand. In the original paper Sutherland et al. (2007) suggest these moraines formed at 19-22 ka, $58 \pm 3 \mathrm{ka}, 79 \pm 4 \mathrm{ka}$ and $117 \pm 4 \mathrm{ka}$, which appears to correlate with minima in local mid-summer insolation intensity. Sutherland et al. (2007) interpret 4 outliers that cluster at c. $30 \mathrm{ka}$ as representing the onset of deteriorating climatic conditions leading into the LGM. Recalculating these ages with the revised, local cosmogenic ${ }^{10} \mathrm{Be}$ production rate of Putnam et al. (2010b) increases the exposure dates by an average of $17-18 \%$, which produces moraine ages of 22-25 ka (CA4/CA5), $68 \pm 4 \mathrm{ka}$ (CA3 younger), $93 \pm 2 \mathrm{ka}$ (CA3 older; wtd. mean, $n=5)$, and $138 \pm 6 \mathrm{ka}$ (CA2 younger). The outliers now cluster at c. $35 \mathrm{ka}$, instead of $30 \mathrm{ka}$.

There are few things to be noted about the revised Cascade valley moraine ages and their relationship to changing insolation patterns. Firstly, the work of Putnam et al. (2010b) represents a calibration of cosmogenic ${ }^{10} \mathrm{Be}$ production rate integrated over the last c. $10 \mathrm{ka}$, and they also demonstrate good agreement of this revised production rate with independent radiocarbon ages over the last $18 \mathrm{ka}$. Thus, whilst application of this new production rate to exposure ages from the LGM and younger is robust, application to older features becomes increasingly uncertain. Secondly, all of the recalculated ages of Sutherland et al. (2007) are presented assuming no erosion of the sampled surface, as was the protocol in the original paper. The study site experiences high total annual precipitation (c. 5-6 $\mathrm{m} \mathrm{yr}^{-1}$; Tait et al., 2006) and it is unlikely that the older samples in this dataset have remained pristine through successive stadial-interstadial cycles. Inclusion of conservative erosion rates impacts significantly on the exposure ages of the 
older moraines in this dataset and the possible correspondence with potential orbital drivers. For example, assuming erosion of $3 \mathrm{~mm} \mathrm{kyr}^{-1}$ (sensu Barrows et al., 2001) would place the CA3 older moraine in the peak glacial conditions of marine oxygen isotope stage (MIS) 6 (c. $130 \mathrm{ka}$ ).

There is increasing evidence for a major glacial maximum in New Zealand during late MIS 4. In the central Southern Alps, Schaefer et al. (2015) present 50 cosmogenic ${ }^{10} \mathrm{Be}$ surface exposure ages that show the former Pukaki glacier reached its most extensive position of the last glacial cycle at $65 \pm 3 \mathrm{ka}$. This coincides with the evidence presented by Preusser et al. (2005) (above), although recent cosmogenic surface exposure dating indicates that glacier advances in northern Westland were most extensive during MIS 2 (Barrows et al., 2013). In the Tasman mountains, northern South Island, McCarthy et al. (2008) report a basal OSL age of $65 \pm 10 \mathrm{ka}$ from glaciolacustrine sediment, which indicates glaciation in late MIS 4 that was slightly greater in extent than at the LGM. Glaciation in this region at this time is also supported when a single cosmogenic ${ }^{10} \mathrm{Be}$ exposure age of Thackray et al. (2009) is recalculated according to Putnam et al. (2010b). Thackray et al. (2009) report cosmogenic ${ }^{10}$ Be exposure ages of $53 \pm 6 \mathrm{ka}$ and $32 \pm 4$ ka from separate roche moutonee on Mt. Arthur tableland. The ages are increased by $11-13 \%$ by the recalculation, which suggests glacier retreat from these locations at $60 \pm$ $2 \mathrm{ka}$ and $36 \pm 2 \mathrm{ka}$, respectively.

There is very little evidence to constrain glacial extent early in MIS 3 (c. 45-60 ka), which suggests that glaciers were less extensive than MIS 2 and MIS 4 advances. In southern Westland, Almond et al. (2001) constrain the timing of glacial advance to between $45-50 \mathrm{ka}$. This agrees with the $48 \pm 3 \mathrm{ka}$ luminescence age obtained by Shulmeister et al. (2010b) for deposition of an ice-contact debris fan in Rakaia valley, which they interpret as relating to an advancing ice mass. However, ice geometries for these periods remain unconstrained. Recently, Kelley et al. (2014) have shown that the former Pukaki glacier extended into the Pukaki valley at c. $42 \pm 1$ ka. Few records exist from other catchments to indicate major glaciation at this time.

\subsubsection{Last Glacial Maximum (c. 35 - 18ka)}

There are three main outstanding questions concerning glacier advances in New Zealand during the Last Glacial Maximum:

1. When did glaciers first reach their maximum extent during this stadial?

2. What is the timing and magnitude of glacier fluctuations between $30-18 \mathrm{ka}$ ? 
3. When did deglaciation begin and how rapid was it?

The onset of cooling in New Zealand leading into the Last Glacial Cold Period (c. 28-18 ka; Alloway et al., 2007; Barrell et al., 2013; LGCP) remains relatively poorly constrained and glacial chronologies for this period are only available from a few sites. Putnam et al. (2013b) have shown that the former Ohau glacier, in central Southern Alps, reached a similar extent to that of the LGCP by $33 \pm 1 \mathrm{ka}$. This early onset of glaciation is further supported by the findings of Rowan et al. (2012), who present OSL and radiocarbon ages that constrain aggradation of glaciofluvial gravels on the Canterbury Plains to two periods, c. 37 - $31 \mathrm{ka}$ and c. 24 - 19 ka. Detailed stratigraphic investigation of moraine coverbeds in northern Westland, combined with radiocarbon dating, led Suggate and Almond (2005) to suggest the earliest advance (their la $\mathrm{a}_{1} / \mathrm{M}_{1}$ ) began at c. $34 \mathrm{ka}$. However, recent surface exposure dating by Barrows et al. (2013) found no evidence for glacier advance prior to $30 \mathrm{ka}$, or moraine formation prior to c. $27 \mathrm{ka}$.

The majority of glacial chronologies indicate that mountain glaciers in New Zealand attained their maximum extent of the last glacial cycle at c. 28 ka. For example, Kelley et al. (2014) show that the moraines immediately inboard of the 42 ka feature at Lake Pukaki date to $28 \pm 1 \mathrm{ka}$. In the Rangitata and Ashburton catchments, Rother et al. (2014) show that large outlet glaciers attained their maximum extent of the last glacial cycle at c. $28 \mathrm{ka}$, and subsequently fluctuated inboard of this dated limit. Shulmeister et al. (2010a) (recalculated after Putnam et al., 2010b, by Putnam et al., 2013a) find a similar age for outer LGM moraines in the Rakaia valley, which were deposited at c. 28-26 ka. In summary, there is evidence to suggest that glacier advance began prior to c. $33 \mathrm{ka}$, however moraines of this age are rare, which indicates that subsequent advances were most likely of equal or greater extent.

Subsequent to the $33 \mathrm{ka}$ moraine formation at Lake Ohau, Putnam et al. (2013b) show that discrete moraines were emplaced immediately inboard, at $27 \pm 1 \mathrm{ka}, 23 \pm 1 \mathrm{ka}$ and $18 \pm 1$ ka. Similarly, Kelley et al. (2014) and Schaefer et al. (2015) document moraine formation at $28 \mathrm{ka}, 21 \mathrm{ka}$ and $18 \mathrm{ka}$ at nearby Lake Pukaki. The youngest recalculated ages of Sutherland et al. (2007) indicate that former Cascade alley glacier was extended between c. 29 - 22 ka. In northern Westland, Barrows et al. (2013) show that glaciers deposited moraines on the coastal lowlands at c. $25 \pm 1 \mathrm{ka}, 21-20 \mathrm{ka}$ and 17 $\pm 1 \mathrm{ka}$. In the Rangitata and Ashburton catchments, east of the Main Divide, Rother et al. (2014) show that, between 19-16 ka, the former outlet glaciers were immediately inboard of the $28 \mathrm{ka}$ limits. In summary, it is clear that glaciers across the Southern Alps fluctuated about their extended positions between c. 28 and $18 \mathrm{ka}$. The recent cosmogenic surface exposure dating campaigns summarised above have served to affirm 
the general stratigraphic model of previous investigations (e.g. Suggate and Almond, 2005) that suggests glaciers advanced between 30-28 ka, and subsequently reached a similar extent between 23-18 ka. Whilst well-preserved moraine belts record the culmination of some advances during this period, it is unclear how much retreat occurred between moraine forming events. Furthermore, the chronological imprecision of surface exposure dating of moraines (mostly due to processes causing geological scatter), means that it is difficult to correlate minor fluctuations across catchments with certainty.

Modelling of the entire LGM Southern Alps ice field indicates that equilibrium line altitude (ELA) depressions were normally distributed (c. 500 to $1200 \mathrm{~m}$ ) about a mean of c. $840 \mathrm{~m}$ below present (Golledge et al., 2012). ELA depression was greatest in highprecipitation catchments, west of the Main Divide in central Southern Alps, and lower in drier, eastern regions. Manual ELA reconstructions from individual catchments generally fall within this range (e.g. Porter, 1975; McCarthy et al., 2008), although some reconstructions from small cirque glaciers indicate much greater lowering (e.g. Brook et al., 2008; Brook, 2009). Golledge et al. (2012) found a best fit to identified LGM limits when modern climate was $6-6.5{ }^{\circ} \mathrm{C}$ cooler and c. $25 \%$ drier than present. This is in good agreement with similar applications at individual catchment scale that typically indicate a cooling of 5-7 ${ }^{\circ} \mathrm{C}$ in central Southern Alps (McKinnon et al., 2012; Putnam et al., 2013b; Rowan et al., 2013).

Currently there are two main schools of thought concerning the onset and rate of deglaciation in New Zealand at the end of the LGCP. Moraine chronologies from large outlet glaciers in central and western Southern Alps indicate rapid withdrawal of ice beginning at c. 17-18 ka. For example, on the west coast, Barrows et al. (2013) show that the former Taramakau glacier withdrew rapidly from the Moana Formation moraines at $17.3 \pm 0.5 \mathrm{ka}$. The former Pukaki glacier retreated from the present-day, southern lake margin at c. $18 \mathrm{ka}$ (Putnam et al., 2010b; Kelley et al., 2014; Schaefer et al., 2015) and subsequently thinned by c. $400 \mathrm{~m}$ prior to $16.2 \pm 0.9$ cal. ka (Barrell and Read, 2014). Similarly, Putnam et al. (2013b) show that the terminus of the neighbouring Ohau glacier withdrew from the southern shoreline of present day lake shortly after $18 \mathrm{ka}$. Cosmogenic ${ }^{10} \mathrm{Be}$ surface exposure ages from a glacially abraded bedrock knob situated c. $24 \mathrm{~km}$ upstream of the southern lake margin, indicate that the Ohau glacier thinned vertically by c. $200 \mathrm{~m}$ within c. $300 \mathrm{yr}$ of the onset of retreat. Further to the east, abundant moraines and glacially abraded bedrock outcrops in Rakaia valley afford a more detailed investigation of glacial retreat. Putnam et al. (2013a) show that the glacier terminus withdrew from the innermost LGM moraines at c. $17.8 \pm 0.2 \mathrm{ka}$ and retreated c. $58 \mathrm{~km}$ up valley over the following c. $2 \mathrm{kyr}$. This directly contrasts with the earlier results of Shulmeister et al. (2010a), who had suggested the Rakaia glacier retained as 
much as 90\% of its LGM length until c. $15 \mathrm{ka}$. Adjusting for different production rates resolves some of the age discrepancies between these two studies, but Putnam et al. (2013a) draw on a far larger and more robust dataset in their rejection of delayed glacier retreat in the Rakaia catchment.

In contrast to the aforementioned findings, Rother et al. (2014) find that the former Rangitata glacier, situated c. $25 \mathrm{~km}$ south of Rakaia valley, retained up to $80 \%$ of its LGM length until c. $15.8 \pm 0.4 \mathrm{ka}$. Rother et al. (2014) argue that the retreat of former outlet glaciers at Pukaki, Ohau and Rakaia was significantly influenced by the formation of proglacial lakes, which may have decoupled glacier mass balance from atmospheric forcing and caused rapid retreat through calving. However, this theory does not explain why the Taramakau glacier retreated rapidly from the coastal lowland to the Main Divide at $17.3 \mathrm{ka}$ (Barrows et al., 2013). Nor does it provide an explanation for a deglacial chronology of former valley glacier in northwest South Island (Shulmeister et al., 2005) after recalculation using the updated local cosmogenic ${ }^{10}$ Be chronology of Putnam et al. (2010b). Shulmeister et al. (2005) present a ${ }^{10}$ Be chronology from moraine boulders and glacially-abraded bedrock exposures from Cobb valley. Twenty-one ages from 9 sites show good consistency (the authors identify 5 outliers, which fall outside of the arithmetic mean), indicating glacier retreat over a distance of c. $21 \mathrm{~km}$ was rapid at this location. Recalculating the ${ }^{10}$ Be ages according to Putnam et al. (2010b) raises the arithmetic mean of the dataset from $16.4 \pm 2.4 \mathrm{ka}$, to $19.5 \pm 3.1 \mathrm{ka}$ (or $19.7 \pm 1.5 \mathrm{ka}$, with the 5 outliers removed). In the original paper, Shulmeister et al. (2005) conclude that: (1) glacier retreat began no earlier than $20 \mathrm{ka}$; (2) thinning and retreat was well underway by $18 \mathrm{ka}$; and (3) that the glacier ceased to exist sometime between 14-15 ka. Following recalculation and outlier removal, the first two conclusions may still hold true, however there is little evidence to support the claim that the Cobb valley glacier existed post c. $18 \mathrm{ka}$. Recalculated exposure ages from moraine boulders and bedrock situated 4-15 km downstream from the valley head are indistinguishable suggesting rapid disappearance of this glacier between 18-19 ka. Thus, the glacial chronology from Cobb valley best fits the deglaciation scenario favoured by Putnam et al. (2013a) and Putnam et al. (2013b). The reservoir present in Cobb valley today is man made and Shulmeister et al. (2005) report no evidence for past, natural lake formation over the c. $20 \mathrm{~km}$ of valley floor mapped. Thus it would appear that the Rangitata record is somewhat anomalous amongst deglacial chronologies in New Zealand.

\subsubsection{Late-Glacial (15 - $11.5 \mathrm{ka})$}

The occurrence, precise timing and climatic significance of glacial advance in New Zealand during the late-glacial chron (c. 15 - $11.5 \mathrm{ka}$ ) has proved to be a controver- 


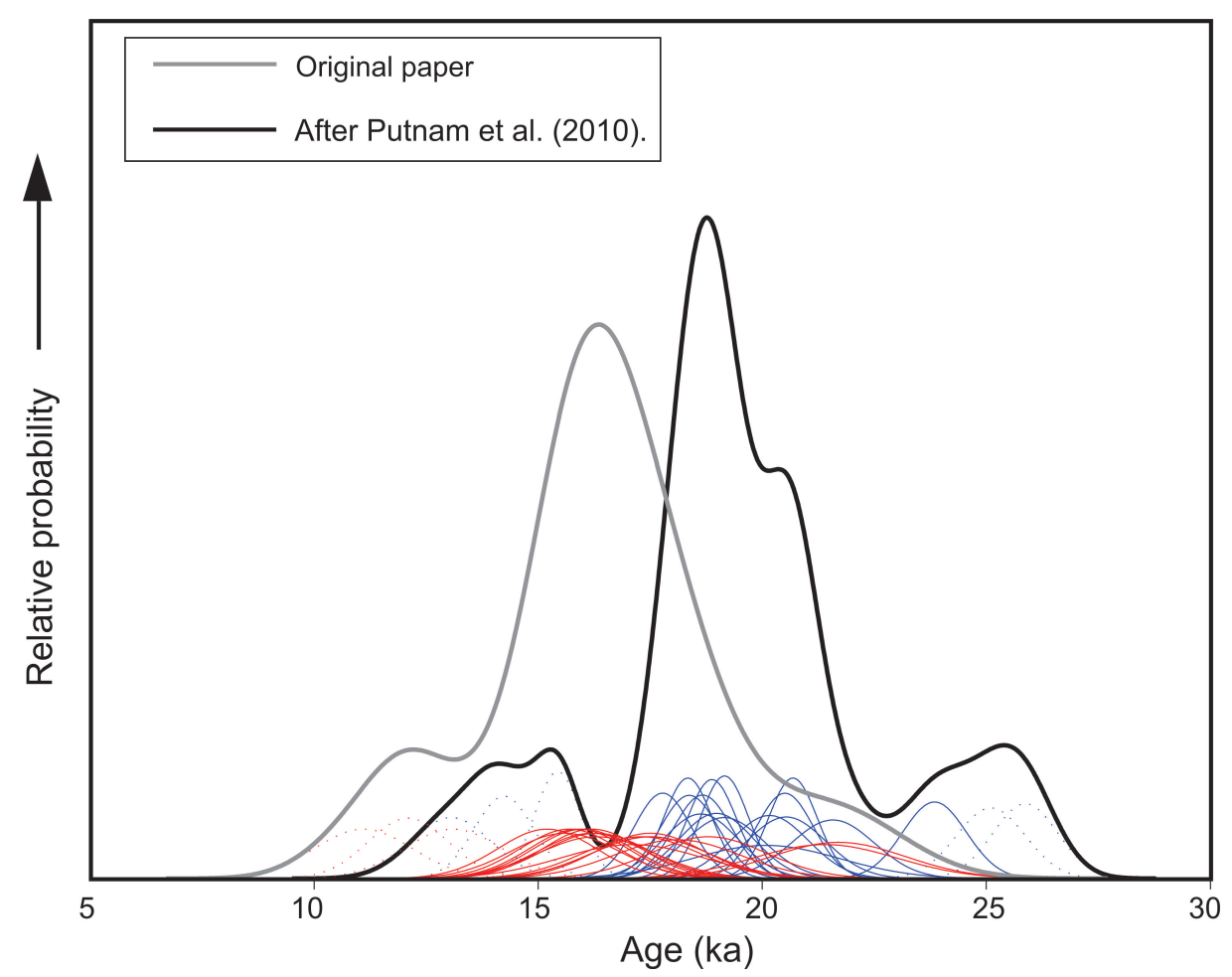

Figure 2.4: Probability density plots of cosmogenic ${ }^{10}$ Be exposure ages of Shulmeister et al. (2005) (red) recalculated according to Putnam et al. (2010b) (blue). Outliers identified by Shulmeister et al. (2005) shown as dashed lines.

sial topic. Fitzsimons (1997) reviewed the chronological understanding of late-glacial glacier advance in New Zealand and concluded that several instances of moraines situated between LGM and neoglacial limits had been identified, but precise chronological control was lacking. For example, glacial tills have been assigned late-glacial ages in Rakaia valley (11.9 - $10{ }^{14} \mathrm{C}$ ka BP - Burrows and Russell, 1975), Cropp River $\left(10.3{ }^{14} \mathrm{C}\right.$ ka BP - Basher and McSaveney, 1989) and the Wairau valley $\left(11.3-9.1{ }^{14} \mathrm{C}\right.$ ka BP McCalpin, 1992) based on bracketing radiocarbon dates, in combinations with clast weathering rind thicknesses.

On the west coast of South Island, the Waiho Loop moraine rises $>100 \mathrm{~m}$ above the Franz Josef Glacier foreland, c. $11 \mathrm{~km}$ from the modern glacier snout, and has long been identified as evidence for late-glacial glacier advance in New Zealand. However, despite many attempts at chronological constraint, the precise timing of moraine formation remains enigmatic. Early attempts at radiocarbon dating wood fragments within glacial till at Canavans Knob, a bedrock outcrop c. $2 \mathrm{~km}$ upstream of the Waiho Loop moraine, yielded a range of dates between $11.3-12.6{ }^{14} \mathrm{C}$ ka BP, which were interpreted to represent pre-Younger Dryas glacier advance (Wardle, 1978; Mercer, 1988). Comprehensive re-assessment by Denton and Hendy (1994) placed the timing of glacier advance at $11.1{ }^{14} \mathrm{C} \mathrm{ka} \mathrm{BP}$, leading to a conclusion of coeval glacier advance 
between New Zealand and Europe during the Younger Dryas. Turney et al. (2007) note the relatively wide range of dates $\left(11.5-10.7{ }^{14} \mathrm{C} \mathrm{ka} \mathrm{BP}\right)$ produced in the aforementioned studies from Canavans Knob, and use a $\chi^{2}$ test to demonstrate potential contamination of the sample population. New dates from a highly weathered Weinmannia racemosa fragment yield an error weighted mean of $11641 \pm 16{ }^{14} \mathrm{C}$ a BP, while a well preserved Metrosideros cf. umbellata dates to $11062 \pm 30{ }^{14} \mathrm{C}$ a BP (Turney et al., 2007). It was concluded that the older sample represents reworking of older wood fragments into the Canavan Knob sequence, likely causing the wide spread of ages seen in previous studies. Furthermore, the well-preserved Metrosideros sample was interpreted to represent tree-growth contemporaneous with late glacial advance of Franz Josef Glacier, therefore providing a maximum age. Calibration of this age (c. 13.1 cal. ka BP) places the time of Franz Josef Glacier advance before the onset of the Younger Dryas, therefore Turney et al. (2007) favour a scenario in which the till at Canavans Knob represents an advance of Franz Josef Glacier at the culmination of the ACR.

The glacial till at Canavans Knob cannot be stratigraphically connected to the Waiho Loop moraine, thus the two may not be contemporaneous. Barrows et al. (2007b) present a combination of $4{ }^{36} \mathrm{Cl}$ and $9^{10} \mathrm{Be}$ ages from boulders on the moraine surface, which yield an error weighted mean of $10.5 \pm 0.2 \mathrm{ka}$ suggesting early Holocene ice retreat from this location. They conclude that the Franz Josef Glacier: (i) was not responding to the same climatic forcing driving advance of European glaciers during the Younger Dryas; and (ii) may have remained extended down-valley for over two millennia after advancing over Canavans Knob, which potentially explains the large volume of the moraine. However, Applegate et al. (2008) challenge this age interpretation using a numerical model of moraine diffusion and cosmogenic nuclide production. They suggest that the samples analysed by Barrows et al. (2007a) do not have consistent exposure histories, with some boulders having been shielded from cosmogenic rays since deposition, therefore a weighted mean age provides a date that is younger than the true age of glacial retreat. Further analysis of this concept by Applegate et al. (2012), using the recalculated ages of Barrows et al. (2007a) after Putnam et al. (2010b), yields a best-fit age of $13.0 \mathrm{ka}$ for the Waiho Loop. Recent work by Barrows et al. (2013) has implied that previous cosmogenic ${ }^{36} \mathrm{Cl}$ production rates were too high. This would support an older age for the Waiho Loop than that presented in Barrows et al. (2007a).

Some studies have questioned whether the advance of Franz Josef Glacier to Waiho Loop was driven by climatic change, as suggested in a numerical modelling study by Anderson and Mackintosh (2006). Tovar et al. (2008) suggest the lithological composition of the moraine is restricted to angular low-grade metamorphosed sandstone, which only outcrops in a small portion of the catchment. They suggest a rock avalanche 
emplaced on the glacier surface may have decoupled glacier mass balance from local climate and induced glacier advance. However, subsequent glacier modelling analyses have questioned whether this scenario could produce a discrete moraine ridge such as the Waiho Loop (Vacco et al., 2010), or whether a rock avalanche is capable of producing terminus advance of the required magnitude (Alexander et al., 2014). Most recently (Alexander et al., 2014) suggest, based on seismic surveys and flowline modelling, that the Waiho Loop is the product of ice stagnation due to an overdeepened trough.

A non-climatic driver for late-glacial advance of Franz Josef Glacier is further weakened by the increasing evidence for synchronous, widespread glacier advance across the Southern Alps at this time. For example, Putnam et al. (2010a) present 24 cosmogenic ${ }^{10}$ Be exposure ages from the well-preserved Birch Hill moraines in the Pukaki valley, in central South Island. They find that the onset of rapid late-glacial glacier retreat was initiated at $13.0 \pm 0.3 \mathrm{ka}$, with $>150 \mathrm{~m}$ of glacier thinning in the following few centuries. Putnam et al. (2010a) also present $3{ }^{10}$ Be ages from the Macaulay catchment c. $50 \mathrm{~km}$ to the NE, indicating glacial retreat from $13.3 \pm 0.3 \mathrm{ka}$, which is synchronous, within error, with the Birch Hill data. Kaplan et al. (2010) report a similar situation of glacier retreat during the Younger Dryas in the Irishman Stream cirque, located $20 \mathrm{~km}$ SE of the Birch Hill moraine complex. Cosmogenic ${ }^{10}$ Be exposure ages from a series of recessional moraine ridges record the retreat of a small cirque glacier beginning at 13.0 $\pm 0.5 \mathrm{ka}$, with minor stillstands at $12 \mathrm{ka}$ and $11.5 \mathrm{ka}$. Recalibrating and combining the Canavans Knob till ages of Denton and Hendy (1994) and Turney et al. (2007), Putnam et al. (2010a) find good agreement with cosmogenic moraine chronologies and conclude that glaciers in four separate catchments advanced synchronously, in an event that culminated at c. 13 ka. More recently, Kaplan et al. (2013) find that a glacier in Whale Stream, in the Ben Ohau range, which is proximal to both the Birch Hill and Irishman Stream sites, was also extended during the late-glacial. Cosmogenic ${ }^{10} \mathrm{Be}$ exposure ages of moraines in this catchment show that the former glacier attained its greatest extent early (15-14 ka) in the Antarctic Cold Reversal, and subsequently underwent gradual retreat through the Younger Dryas and Holocene.

Further to the north, a series of stratigraphically-correlated late-glacial moraine ridges have been described lining the N-S trending head of the Bealey/Otira valley at the Main Divide of the Southern Alps, close to Arthurs Pass (Chinn, 1981). In the only study to address the chronology in this valley using absolute dating techniques thus far, Ivy Ochs et al. (1999) derive cosmogenic ${ }^{10}$ Be exposure ages from latero-frontal moraines situated inboard of Lake Misery. This complex is believed to have been deposited by an eastward flowing glacier sourced from the adjacent Otira valley. Four moraine boulder ages yield a weighted mean age of $11.7 \pm 0.3 \mathrm{ka}$, which led Ivy Ochs et al. (1999) to 
support Denton and Hendy's (1994) conclusion of Younger Dryas glacier response in New Zealand. More recently, Barrows et al. (2007b) recalculated these ages using the CRONUS cosmogenic ${ }^{10}$ Be production rate (Balco et al., 2008), which placed the retreat of late-glacial ice from Lake Misery at $13.4 \pm 0.6 \mathrm{ka}$, towards the latter stage of the Antarctic Cold Reversal and prior to the Younger Dryas. Barrows et al. (2013) further revise these ages based on Putnam et al. (2010b) and report a mean exposure age of $16.1 \pm 0.8 \mathrm{ka}$ (using Lifton et al., 2005 scaling, and NZ3 outlier removed), which places the formation of these moraines prior to the Antarctic Cold Reversal. Using the parameters reported by Ivy Ochs et al. (1999), the 'S555' beryllium standard (S.Ivy Ochs, pers. comm., 2014) and the ' $\mathrm{Li}$ ' model, I can not replicate this recalculated age. Instead, I derive a mean age of $14.8 \pm 1.6 \mathrm{ka}(n=5)$, and $15.4 \pm 0.8 \mathrm{ka}$ when sample NZ3 is removed. Using the ' $\mathrm{Lm}$ ' scheme, which has been shown to outperform the ' $\mathrm{Li}^{\prime}$ model (Lifton et al., 2014), yields arithmetic mean ages of $14.6 \pm 1.6 \mathrm{ka}(n=5)$ and $15.2 \pm 1.6$ $\mathrm{ka}$, respectively. It is therefore possible the Misery moraines correlate to the oldest ACR moraine found in Whale Stream by Kaplan et al. (2013), however the low number of samples and the relatively low precision of these early ${ }^{10} \mathrm{Be}$ measurements makes it difficult to discriminate between the latter scenario and the alternative suggested by Barrows et al. (2013). Revisiting this site with the aim of producing a greater number of exposure ages at the precision now afforded by accelerator mass spectrometry could reconcile this existing uncertainty.

In summary, recent developments in the field of cosmogenic surface exposure dating have been applied across several sites in the central Southern Alps, which have shown that glaciers advanced early in the late-glacial chron, coinciding with the Antarctic Cold Reversal. Numerical glacier modelling experiments at some of these sites have shown that this advance occurred when air temperatures were $2-4^{\circ} \mathrm{C}$ lower than present (Anderson and Mackintosh, 2006; Doughty et al., 2013; Kaplan et al., 2013). Slow retreat, punctuated by minor still stands, occurred through the Younger Dryas. Local improvements in other geochronological techniques, such as tephrochronology has shown that this temporal pattern of relative temperature change is also widely acknowledged in continuous climate proxy archives across New Zealand (Lowe et al., 2013), although outstanding questions remain over the magnitude and spatial pattern of cooling at this time (Newnham et al., 2012). 


\subsection{Study site and previous work}

\subsubsection{Geological setting}

Tongariro Volcanic Centre (TgVC) represents an area of predominantly andesitic volcanism, situated in an active graben at the south-western end of the Taupo Volcanic Centre (TVC), central North Island, New Zealand (Figure 2.5). TgVC consists of four Quaternary andesitic massifs, Kakaramea-Tihia, Pihanga, Tongariro, and Ruapehu, the latter two of which are the focus of this research and are described in more detail below.

Mount Ruapehu $\left(39^{\circ} 17^{\prime} \mathrm{S}, 175^{\circ} 34^{\prime} \mathrm{E}\right)$ is the highest peak (2797 $\mathrm{m}$ asl) in North Island, New Zealand. In its current configuration, Ruapehu consists of a c. $110 \mathrm{~km}^{3}$ volcanic cone, currently active through a single vent, Crater Lake (Hackett and Houghton, 1989). Previous geological mapping and petrological studies have identified four broad periods of geochemically-distinct cone-building activity at Mt. Ruapehu, which were assigned formation status (Hackett and Houghton, 1989; Price et al., 2012). In chronological order, these formations are termed, Te Herenga (250-180 ka); Wahianoa (160-115 ka); Mangawhero (55-15 ka); and Whakapapa (15-0 ka) (Gamble et al., 2003). A compilation of existing radiometric $\left({ }^{40} \mathrm{~K} /{ }^{40} \mathrm{Ar}\right.$ and $\left.{ }^{40} \mathrm{Ar} /{ }^{39} \mathrm{Ar}\right)$ ages from lava flows on both volcanoes is shown in Figure 2.6. This figure shows that the oldest lavas on Mt. Ruapehu (Te Herenga Fm) outcrop on the north western side of the volcano, whilst lavas pertaining to the Wahianoa Fm cone-building episode are concentrated on the south eastern side of the volcano. Several syn-glacial (c. 45-15 ka) lava flows have also been dated from several valleys on Mt. Ruapehu (Figure 2.6). These flows are typically positioned adjacent to the major glacial troughs and display a wide range of cooling fractures consistent with having chilled rapidly against the margins of former, more extensive mountain glaciers (Spörli and Rowland, 2006; Conway et al., 2015).

The present-day upper cone of Mt Ruapehu is broad (c. $2 \mathrm{~km}^{2}$ ) and elongate with a NNE-SSW orientation. The northern portion of this broad summit consists of an ice-filled depression (Otway et al., 1985), with thick surface debris cover, that forms a c. $1 \mathrm{~km}^{2}$ plateau, surrounded by a protruding rim, with several peaks exceeding $2600 \mathrm{~m}$ asl. The southern portion of the summit is dominated by the $0.5 \mathrm{~km}^{2}$ Crater Lake that fills the active, modern-day, volcanic vent. The acidic, warm lake water currently drains over a bedrock lip at its southern margin, into the deeply incised, eastward-draining Whangaehu river catchment.

Lying c. $15 \mathrm{~km}$ NNE of Ruapheu, the Tongariro massif $\left(39^{\circ} 08^{\prime} \mathrm{S}, 175^{\circ} 39^{\prime} \mathrm{E}\right)$ represents a coalescence of up to 17 effusive centres, totalling c. $60 \mathrm{~km}^{3}$ in volume (Hobden et al., 
1999). K-Ar dating of lava flows place the initiation of edifice growth at $275-250 \mathrm{ka}$, while further intensive periods of activity occurred 210-200 ka, 130-75 ka and 25-0 ka (Hobden et al., 1996). Figure 2.6 shows that all of radiometric ages collected from Tongariro massif predate the peak of the last glacial cycle (i.e. $>25 \mathrm{ka}$ ). Post-glacial eruptions on Tongariro massif have been sourced from several vents, but primarily from the Holocene-aged cone of Mt. Ngauruhoe (Hobden et al., 2002; Moebis et al., 2011), which today forms the highest peak of the massif. The oldest ages on the massif (c. $>260 \mathrm{ka}$ ) come from the southern flank, close to the saddle with Mt. Ruapehu. Proximal to this location, a cluster of ages show that cone-building occurred at c. 200 ka in the vicinity of the present-day Mt. Nguaruhoe. Lavas underlying previously identified moraines (e.g. Mathews, 1967; Topping, 1974) in several valleys such as Mangatepopo and Waihohonu, are in excess of the c. $90 \mathrm{ka}$. These ages provide maximum constraining ages for the overlying glacial landforms, which suggest they likely pertain to the last glacial cycle.

An additional record of volcanic activity for both volcanoes is preserved on their surrounding (and coalescent), 6 - $15 \mathrm{~km}$ wide ringplains (Donoghue et al., 1999). Thick accumulations of volcaniclastic material make up the ringplain, predominantly consisting of debris flow, debris avalanche, hyperconcentrated stream flow deposits, interbedded with a mixture of local andesitic and distal rhyolitic tephras (Donoghue and Neall, 2001). The latter are generally well-dated (e.g. Lowe et al., 2008, 2013; Vandergoes et al., 2013), therefore provide chronological constraint for the local tephrostratigraphic record. In particular, the Kawakawa/Oruanui Tephra (KOT; c. 25 ka), Waiohao Tephra (c. $14 \mathrm{ka}$ ) and the Taupo Ignimbrite (c. $1.8 \mathrm{ka}$ ) are the most widely distributed across TgVC Donoghue et al. (1995). Previous work has developed a detailed local tephrostratigraphic framework (Topping, 1974; Donoghue et al., 1995, 1997; Donoghue and Neall, 1996; Cronin and Neall, 1997), which allows correlation of volcaniclastic units and providing useful chronostratigraphic marker horizons, which help to constrain the timing of major geomorphic events such as moraine building.

In a comprehensive review of the local $\mathrm{TgVC}$ tephrostratigraphy, Donoghue et al. (1995) constrain the spatio-temporal patterns of local tephra dispersal and preservation. Isopach maps of locally-sourced tephras consistently show that volcanic products are preferentially transported and preserved to the east of $\mathrm{TgVC}$, which represents the influence of the prevailing westerly wind. For large eruptive events, thicknesses of individual members within tephra formations range from $<0.1 \mathrm{~m}$ to c. $1 \mathrm{~m}$ within c. $5 \mathrm{~km}$ downwind of the source vent. Thus, the most complete sedimentological sequence of local volcanic activity preserved on the ringplain is found to the east of $\mathrm{Mt}$ Ruapehu, whilst preservation of TgVC-sourced tephra elsewhere on the ringplain is 
comparatively low, particularly to the north, south and west of the main vents where palaeosol development is common between tephra horizons and the basal ages of cover bed sequences rarely exceeds c. 10 - 15 ka (Topping, 1973; Donoghue et al., 1995).

\subsubsection{Present day climatic situation}

Situated between $34-47^{\circ} \mathrm{S}$ in the south-west sector of the Pacific Ocean, New Zealand spans subtropical and subpolar climes (Figure 2.7), therefore is highly sensitive to regional climatic fluctuations (Newnham et al., 1999). Westerly atmospheric circulation dominates between $30-60^{\circ} \mathrm{S}$ and is responsible for the eastward migrating troughs and anticyclones that define weather variability in New Zealand (Sturman and Tapper, 1996). Southern Annular Mode (SAM) is an index of the atmospheric surface pressure gradient between high- and mid-latitudes in the Southern Hemisphere and represents an important control on weather variability in New Zealand at inter- to sub-annual timescales (Renwick and Thompson, 2006). During the positive phase of SAM the core of the westerlies move southwards away from New Zealand, resulting in reduced cyclonic activity and drier conditions. During the negative phase, the core of the westerlies is situated further north and wetter conditions prevail in New Zealand, particularly in western regions. At interannual timescales, El Niño Southern Oscillation (ENSO) is the dominant mode of climatic variability in the Pacific region (Salinger et al., 2001). El Niño conditions are associated with enhanced zonal circulation over New Zealand, which amplifies the west-east precipitation gradient and lowers average air temperatures (Salinger and Mullan, 1999). La Niña years are associated with enhanced north-easterly atmospheric flow, which generates a negative north-south precipitation gradient anomaly and generally higher air temperatures. At decadal timescales, ENSO activity is modulated by the Interdecadal Pacific Oscillation (IPO), which switched abruptly from a negative phase (favouring La Niña) to positive phase (favouring El Niño) in 1976/77 (Salinger et al., 2001).

Precipitation changes in New Zealand, associated with changes interannual to interdecadal regional circulation changes, are spatially variable, due to the interaction of airflow with local topography (Salinger, 1980a). Meanwhile, interannual-decadal air temperature anomalies in New Zealand are strongly influenced by upwind sea surface temperatures (Sutton et al., 2005) and are generally consistent across the country (Salinger, 1980b). Contemporary oceanic influences on North Island, New Zealand (34 $41^{\circ} \mathrm{S}$ ) are largely sub-tropical in nature, predominantly originating from an eastward flowing branch of the equatorial-sourced East Australian Current, known as the Tasman Front, which descends the northeast coast before continuing eastwards along the 


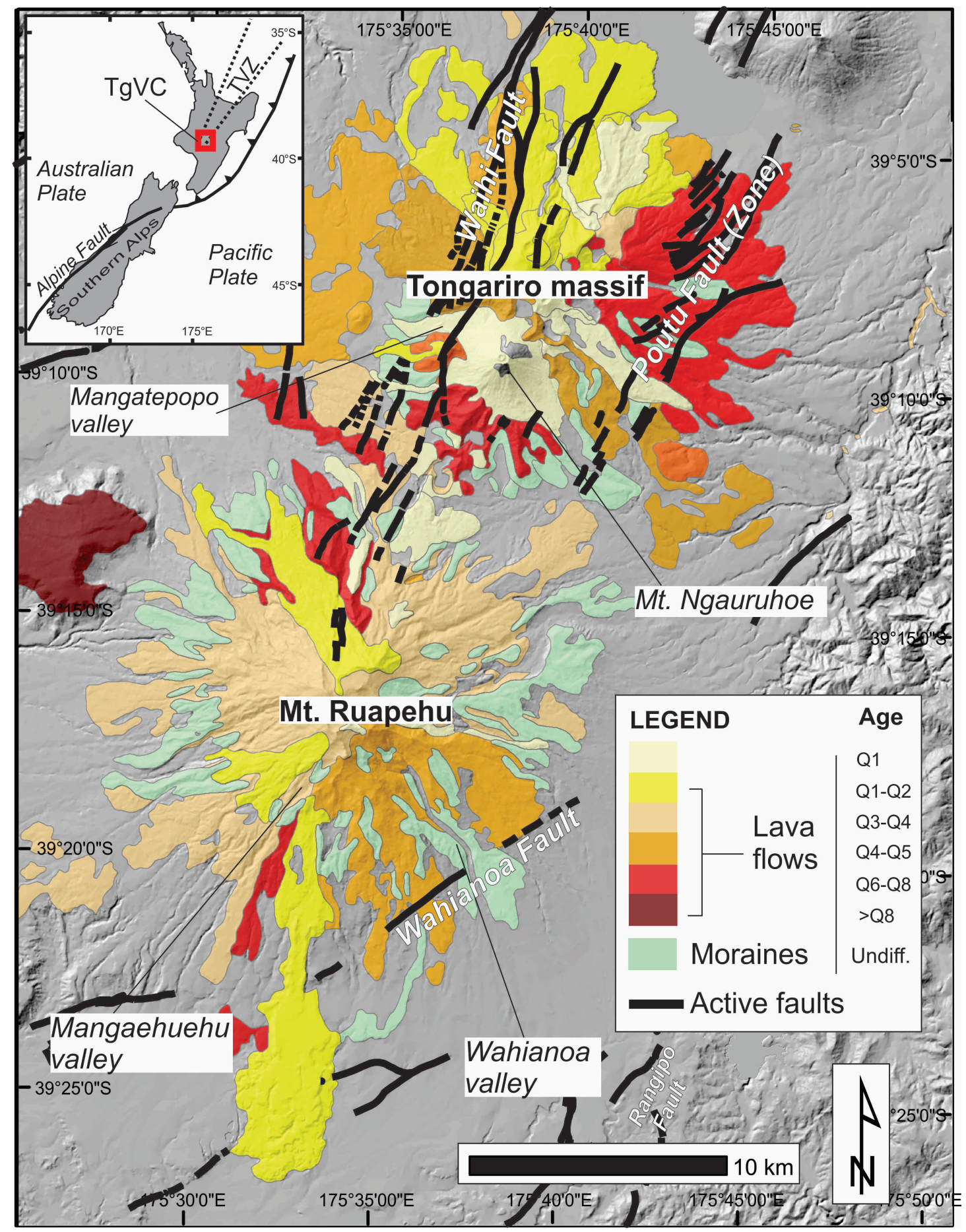

Figure 2.5: The geological and tectonic setting of Tongariro and Ruapehu volcanoes showing the distribution of lavas and their relative ages $(Q 1=0-12 \mathrm{ka} ; Q 2=24-12 \mathrm{ka} ; Q 3=59-24 \mathrm{ka}$; $Q 4=71-59 \mathrm{ka} ; Q 5=128-71 \mathrm{ka} ; Q 6=128-71 \mathrm{ka} ; Q 7=186-128 \mathrm{ka} ; Q 8=303-245 \mathrm{ka})$, moraines and major fault systems of the region. Geological data from the GNS Science QMAP series nos. 7 and 8 (Townsend et al., 2008; Lee et al., 2011) and tectonic data from the GNS Science Active Faults Database. Inset map shows the location of Tongariro Volcanic Centre at the southern end of Taupo Volcanic Zone (TVZ) in central North Island, New Zealand. 


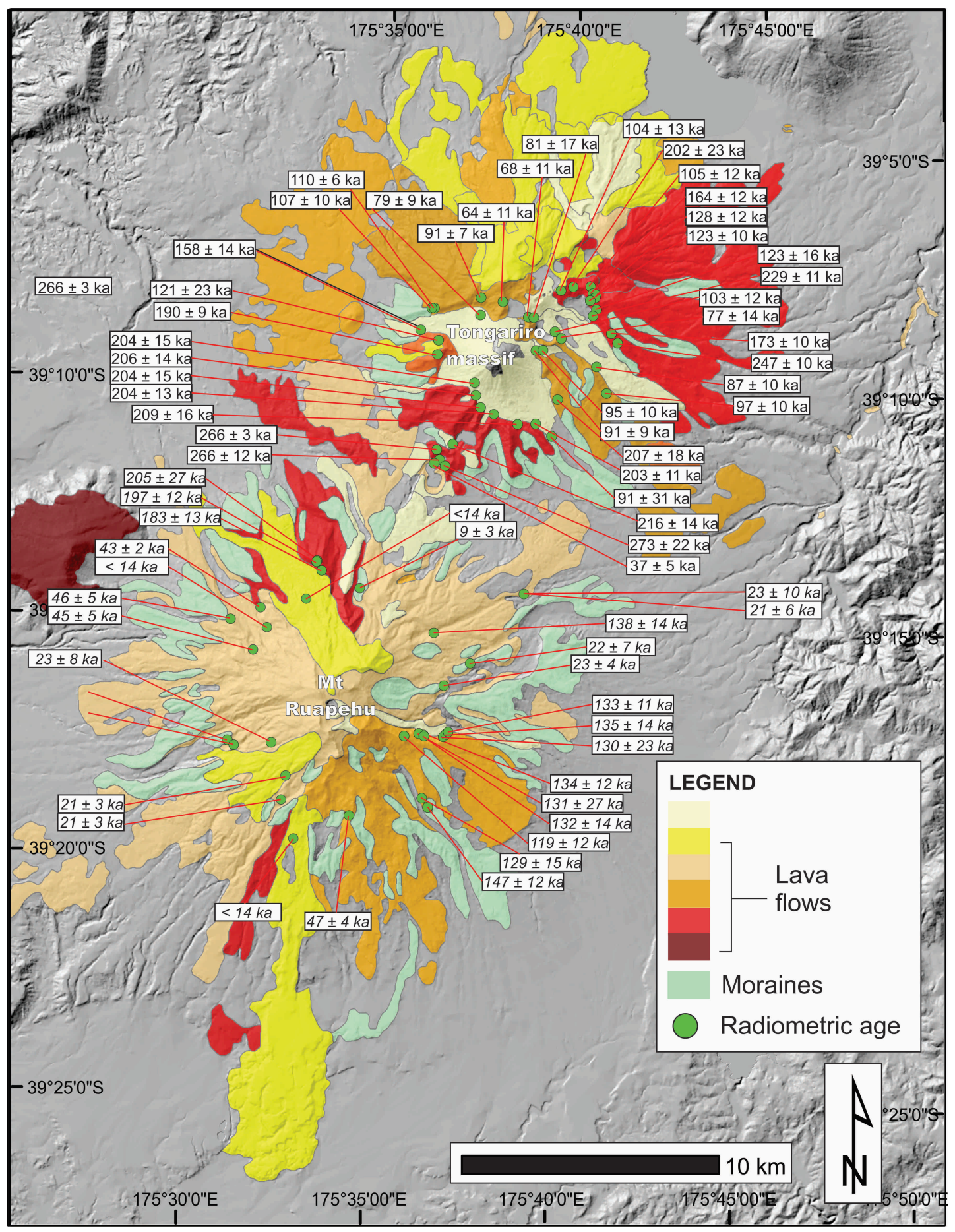

Figure 2.6: Existing radiometric ages of lava flows from Tongariro massif and Mt Ruapehu derived using ${ }^{40} \mathrm{~K} /{ }^{40} \mathrm{Ar}$ (Hobden et al., 1996) and ${ }^{40} \mathrm{Ar} /{ }^{39} \mathrm{Ar}$ (italics; Gamble et al., 2003; Conway et al., 2015) dating. Other data sources as for previous figure 
northern margin of the Chatham Rise (Figure 2.7). In contrast, South Island $\left(40-47^{\circ} \mathrm{S}\right)$ intersects the sub-tropical front (STF), where sub-tropical gyres and sub-antarctic water masses converge, representing a temperature, salinity and nutrient boundary, which defines the northern margin of the Southern Ocean (Sikes et al., 2009). Consequently, steep, zonal and meridional sea surface temperature (SST) gradients exist across New Zealand. For example, in the far north annual SSTs average c. $20{ }^{\circ} \mathrm{C}$ compared to c. 10 ${ }^{\circ} \mathrm{C}$ in the south (Uddstrom and Oien, 1999). This spatial variability in SSTs strongly influences terrestrial air temperature anomalies resulting from regional circulation changes.

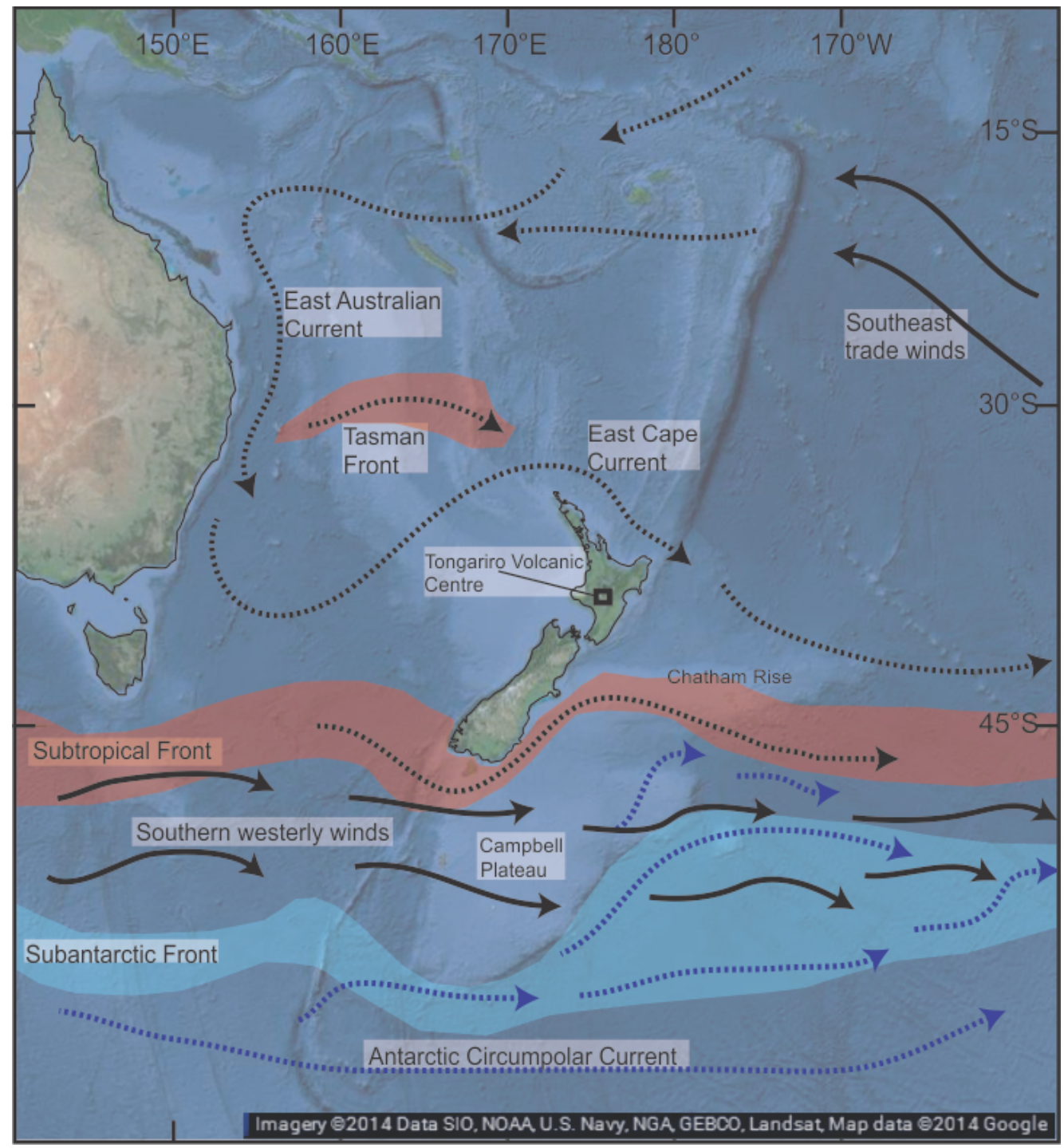

Figure 2.7: Contemporary atmospheric and oceanic circulation in the southwest Pacific (Background imagery from Google Maps - see figure for primary sources of imagery).

Mean annual temperature at Whakapapa Village, located at c. $1100 \mathrm{~m}$ asl on the NW flank of Ruapehu, is $7.5^{\circ} \mathrm{C}$ (Figure 2.8a). Mean monthly temperatures range from $3.1^{\circ} \mathrm{C}$ 
in July to $12.6^{\circ} \mathrm{C}$ in January. Precipitation at this location averages c. $2800 \mathrm{~mm}$ annually and is relatively evenly distributed throughout the year, with summer (DJF) totals slightly lower than those in winter (JJA; Figure 2.8a). At Ohakune township (607 m asl), situated to the south of Mt. Ruapehu, the monthly temperature and precipitation patterns broadly mirror those at Whakapapa village (Figure $2.8 \mathrm{~b}$ ), with differences in absolute values likely representing an different orographic influence on temperature and precipitation between the two sites.

Wind measurements at Whakapapa Village (Figure 2.8c) show that westerly wind conditions prevail, with typical ground wind speeds of $1-10 \mathrm{~m} \mathrm{~s}^{-1}$ and rarely exceeding $20 \mathrm{~m} \mathrm{~s}^{-1}$. This indicates that local airflow in the region is strongly influenced by regional atmospheric circulation. A significant ESE component is also present, with winds from this direction reaching speeds of $>15 \mathrm{~m} \mathrm{~s}^{-1}$. Figure $2.8 \mathrm{c}$ shows that while the westerly winds at Whakapapa are present year round, the ESE component is predominantly a winter (JJA) phenomenon. This suggests that katabatic winds, driven by lower winter air temperatures and seasonal snow cover, play an important role in boundary layer air movement on the mountain.

A transition from mountain beech and silver pine tree stands into sub-alpine shrub heath occurs at c. $1500 \mathrm{~m}$ asl on the western slopes, and c. $1100 \mathrm{~m}$ asl in the east (Wardle, 1991), perhaps reflecting spatial differences in moisture availability. This pattern may reflect an east-west precipitation gradient across Mt. Ruapehu. Prevailing westerly air masses are intercepted by the volcanic edifice, which produces orographic precipitation on the western slopes and possibly creating a rain-shadow effect on the eastern side. However, the precise magnitude of the climatic gradient is difficult to quantitatively constrain due to the paucity of proximal, empirical climate station data across this transect.

\subsubsection{Contemporary glacierisation}

At 2797 m asl, Mount Ruapehu represents the only peak in the North Island to currently intercept the permanent snowline. The most recent glacier survey on Ruapehu was conducted in 1988 in which, a total of 9 small glacial bodies were identified as containing $<0.2 \mathrm{~km}^{3}$ ice and covering an estimated $4 \mathrm{~km}^{2}$ (Keys, 1988).

Much less attention has been paid to contemporary North Island glaciers and their relationship with climate, in comparison to glaciers in the Southern Alps. Interpreting the climatic significance of past glacier fluctuations from geological records requires 


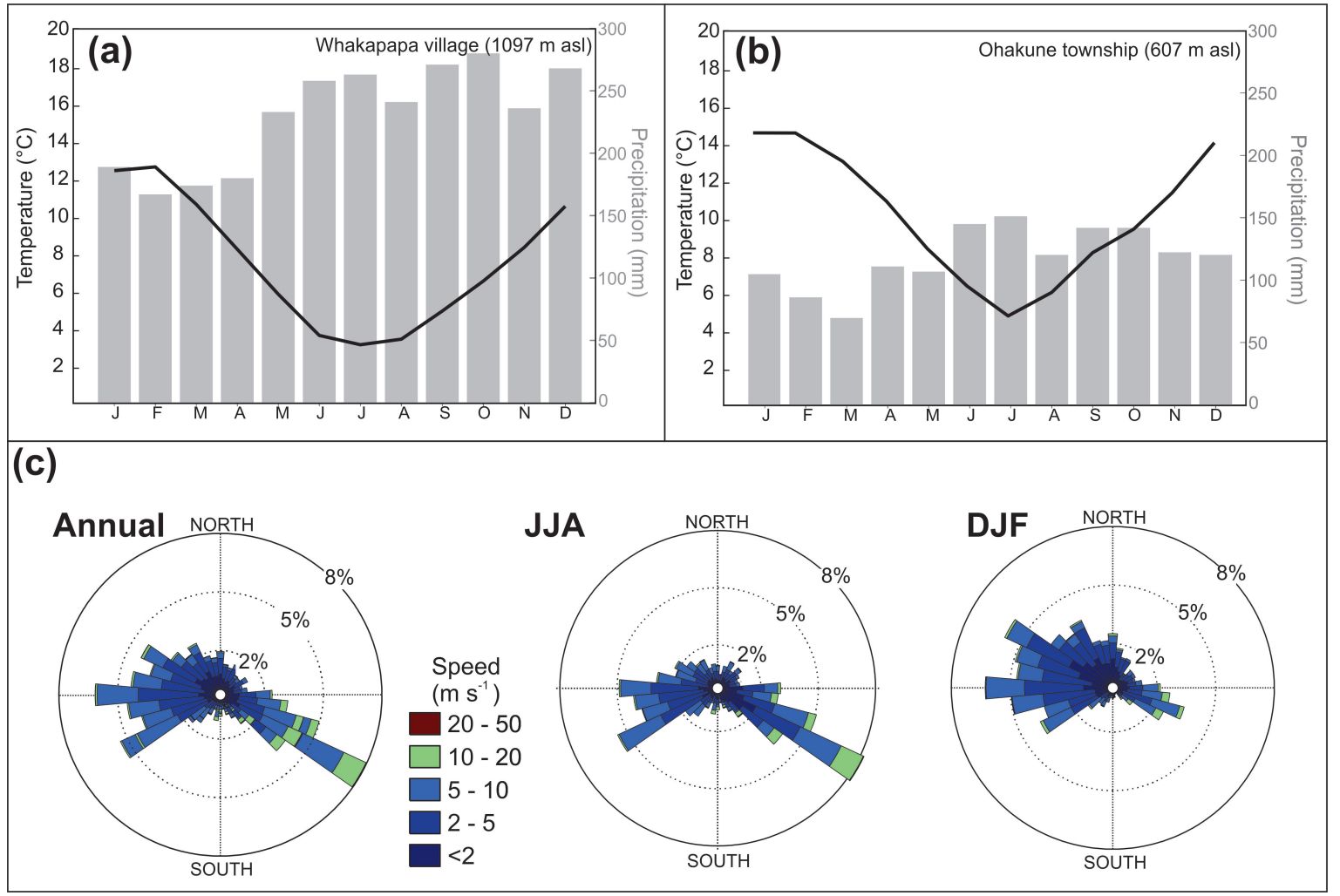

Figure 2.8: (a,b) 30 yr (1981-2010) mean monthly temperature and precipitation for Whakapapa Village and Ohakune climate stations, respectively (NIWA, 2014); (c) Wind roses derived using 10 yr (2001-2010) of hourly wind speed and direction measurements at Whakapapa Village (NIWA, 2014).

knowledge of present day glacier-climate relationship (e.g. mass balance controls, equilibrium line altitudes). In the following sections, I review the existing glaciological measurements and observations on Mt. Ruapehu, in order to assess the utility of these ice masses as a datum from which to infer past climate change using moraine records.

\subsubsection{Whakapapa glacier}

The former Whakapapa Glacier was the best studied ice mass on Mt Ruapehu, primarily due to its easy access via the Bruce Road and Whakapapa skifield. The first written account of this glacier estimated that the glacier terminus lay at approximately $7500 \mathrm{ft}$ (c. $2300 \mathrm{~m}$ ) above sea level (Taylor, 1927). Few direct glaciological observations/accounts were made in the subsequent three decades, although Krenek (1959) reported that the terminus remained 'more or less stationary' during the period 1930-1950.

The first comprehensive morphometric assessment of Whakapapa Glacier was carried out in 1953 by Odell (1955), who reported that the glacier length from the terminus 


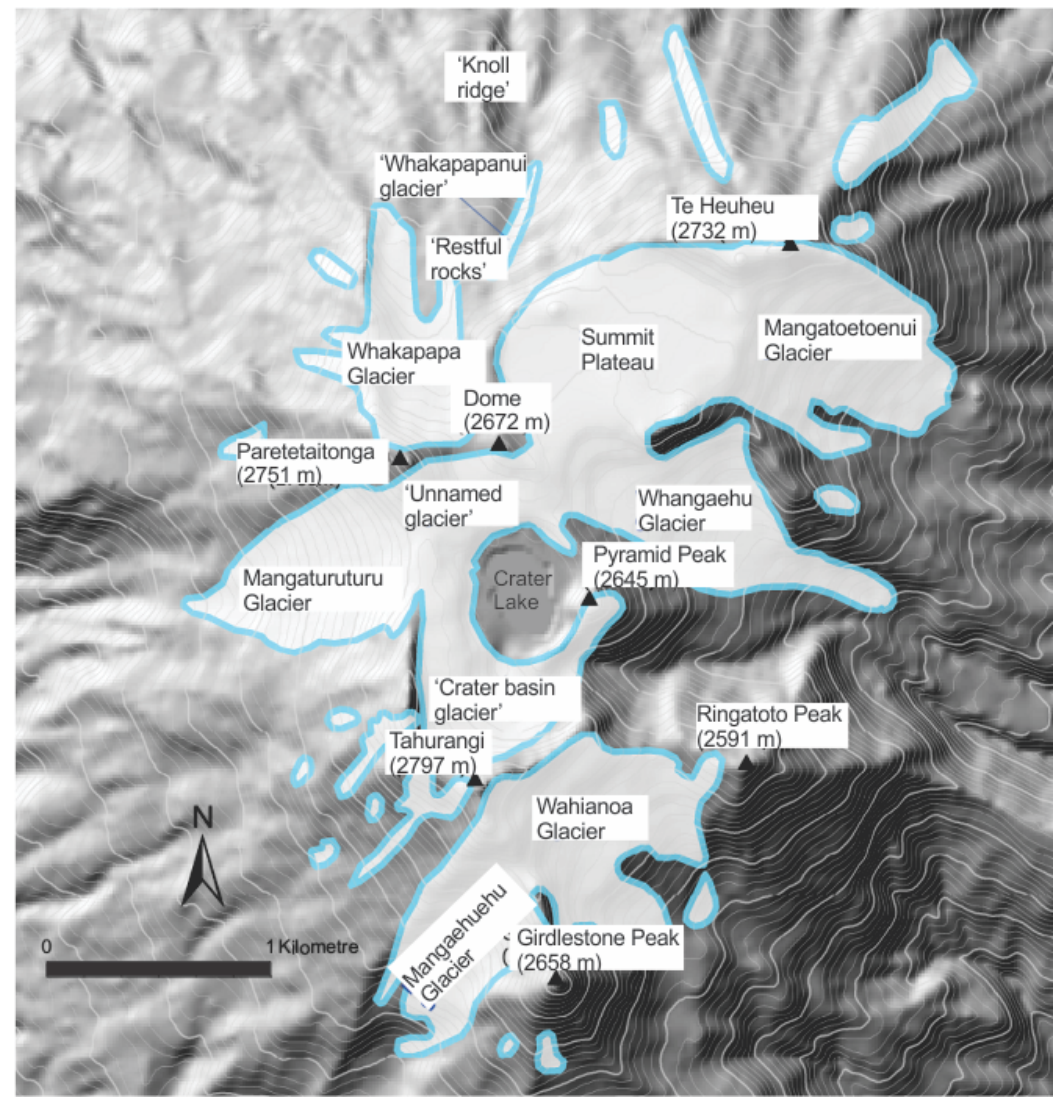

Figure 2.9: Ice and snow-patch distribution on Mt Ruapehu, as shown on LINZ Topo50 map and defined by Keys (1988). Selected peaks labeled in black, glaciers labeled in blue. Present-day (2014) ice coverage is reduced from that shown here.

position at $2130 \mathrm{~m}$ asl to Paretetaitonga col at $2621 \mathrm{~m}$ asl was slightly in excess of 1.5 km. In 1954, Krenek (1959) reported a minor (c. 2 m) advance of the glacier terminus and refined the estimate of glacier length to $1.7 \mathrm{~km}$. Detailed observations and repeat ground photography of the Whakapapa Glacier document the great changes that occurred in the mid-1950s. Krenek (1959) reported that the 1954 winter accumulation was entirely removed, midway through the following the ablation season (January 1955). By February 1955 the glacier terminus had retreated $68 \mathrm{~m}$, and by the end of the ablation season (April 1955) a total of $94 \mathrm{~m}$ retreat had occurred. In addition, surface lowering was measured as 6-8 $\mathrm{m}$ at the glacier margin, and 10-15 $\mathrm{m}$ on the glacier interior, causing the emergence of a distinct ash layer on the upper glacier, thought to have been deposited by the 1945 eruptions, as well as large areas of bedrock through the lower glacier. The emergence of bedrock enhanced the local melt potential as Krenek (1959) reported that large randklufts (gaps between glacier margin and bedrock) developed at the glacier margins. These effects were replicated during the 1956 ablation season causing a further $65 \mathrm{~m}$ of terminus retreat and the additional down-wasting resulted in the Whakapapanui lobe being completely isolated from the main Whakapapa Glacier 
by Restful Rocks ridge (Figure 2.9). After this severance, Whakapapa Glacier, became informally known as 'Whakapapaiti glacier' Keys (1988).

Recession continued in 1957, despite being reported as a positive balance year, although overall retreat was vastly reduced in comparison to the preceding two years, with just $6 \mathrm{~m}$ retreat measured (Krenek, 1959). Krenek (1959) also reported the existence of an 'inverted' end of summer snowline in 1957, with bare ice exposed on the upper glacier and net snow accumulation on the lower tongue. It was suggested that wind-driven re-distribution of winter snow likely played a significant role in this occurrence. The glacier terminus was recorded as stationary in the 1957-58 balance year (Krenek, 1959). The first direct mass balance measurements were carried out on the Whakapapa Glacier in spring 1958. Winter accumulation was measured in snow pits as $86 \mathrm{~cm}$ (1971 m asl); $125 \mathrm{~cm}$ (2344 m asl); and $145 \mathrm{~cm}$ (2454 m asl). Successive negative balance years from 1960-1962 resulted in further downwasting of both the Whakapapa and Whakapapanui glaciers, as recorded in repeat photo surveys (Heine, 1962, 1963). At the end of the 1961-62 balance year the Whakapapa Glacier length was measured as $0.6 \mathrm{~km}$, with the terminus at $2377 \mathrm{~m}$ asl; the Whakapapanui glacier was $0.3 \mathrm{~km}$ long and terminated at $2256 \mathrm{~m}$ asl (Heine, 1962). These measurements are consistent with the New Zealand Map Survey sheet for Ruapehu published in 1963. Field surveying and mass balance in 1968 (Thompson and Kells, 1973) estimated that the Whakapapanui glacier covered an area of $37000 \mathrm{~m}^{2}$, and terminated at $2273 \mathrm{~m}$ asl, indicating little change from the previous measurements in 1962. A comprehensive mass balance survey on the Whakapapanui glacier in the 1968-69 balance year measured a positive balance of c. $2 \mathrm{~m}$ snow water equivalent (swe). Thompson and Kells (1973) report that winter accumulation of 1968 was $45 \%$ above that of the 1957-68 average, whilst temperatures were c. 1.5 ${ }^{\circ} \mathrm{C}$ lower for the budget year. This positive balance was short-lived however, as the following ablation season removed the winter accumulation and $5.3 \mathrm{~m}$ of glacier ice, resulting in c. $150 \mathrm{~m}$ of terminus recession (Thompson and Kells, 1973). In 1988, the Whakapapa(iti) glacier terminus was recorded at $2400 \mathrm{~m}$, suggesting only minor (c. $100 \mathrm{~m}$ ) retreat from the measured position in 1962, in contrast to the Whakapapanui which receded c. $460 \mathrm{~m}$ and reduced in area by c. $0.017 \mathrm{~km}^{2}$ over the same time period (Keys, 1988). Today, no glacial ice remains in the vicinity of the Paratetaitonga and the Whakapapanui lobe persists as a snow patch.

\subsubsection{Mangaehuehu Glacier}

This southward draining cirque glacier occupies a topographic depression beneath Tahurangi, between Skyline Ridge to the north west, and Girdlestone Peak to the east 


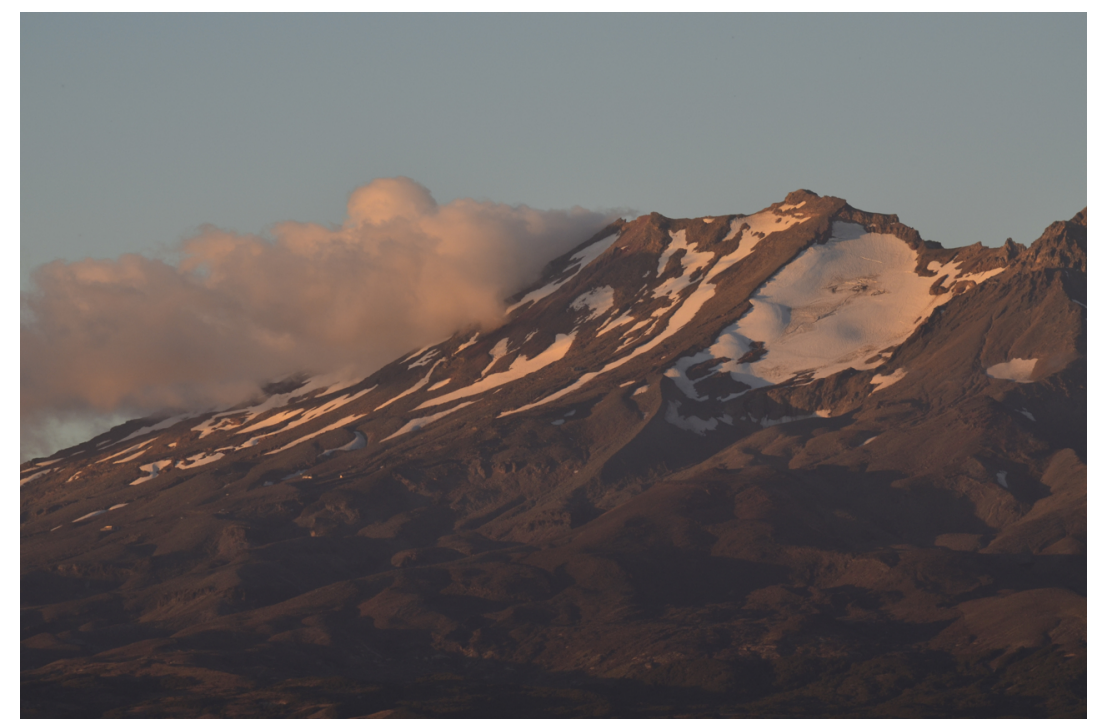

Figure 2.10: Mangaehuehu Glacier on the the southern slopes of Mt. Ruapehu. Note the sharp-crested lateral moraines immediately down valley of the current glacier terminus. Highest peak is Tahurangi (2797 $\mathrm{m}$ asl). (23 February 2013).

(Figure 2.9; and Figure 2.10). Heine (1963) reported the glacier terminus at $6800 \mathrm{ft}$ (c. $2050 \mathrm{~m}$ asl). Keys (1988) recorded c. $250 \mathrm{~m}$ terminus retreat, and c. $30 \mathrm{~m}$ surface lowering in the intervening period, with the glacier now terminating immediately above a steep rock cliff. Brook et al. (2011) analysed interannual changes in the surface area of Mangaehuehu Glacier between the years 1988 and 2007, using oblique aerial photographs. Correlation analysis between the observed glacier area changes and a series of meteorological data and climatic indices found that ablation season temperature is a key control on the interannual fluctuations of glacier size on Ruapehu, which in turn are connected to changes in atmospheric circulation, such as Southern Oscillation. This mirrors findings from the Southern Alps (Hooker and Fitzharris, 1999; Chinn et al., 2005), suggesting that modern glaciers across the latitudinal range of New Zealand respond to similar climatic forcing over interannual to interdecadal timescales.

\subsubsection{Summit Plateau}

Otway et al. (1985) conducted a radio-echo sounding survey on Summit Plateau (Figure $2.9)$, where it was estimated that $60-130 \mathrm{~m}$ of ice filled two crater-like depressions that cover c. $1 \mathrm{~km}^{2}$ of the northern portion of the mountain top. Keys (1988) estimated Summit Plateau ice volume at $0.05 \mathrm{~km}^{2}$, accounting for just under half of the total ice volume on the mountain. Otway et al. (1985) compare their results to an aerial survey conducted in the mid-1950s and derive mean ablation rates of $0.3-1.1 \mathrm{~m} \mathrm{yr}^{-1}$ (1955-1985), with higher values towards the southern end of the ice mass. Keys (1988) 


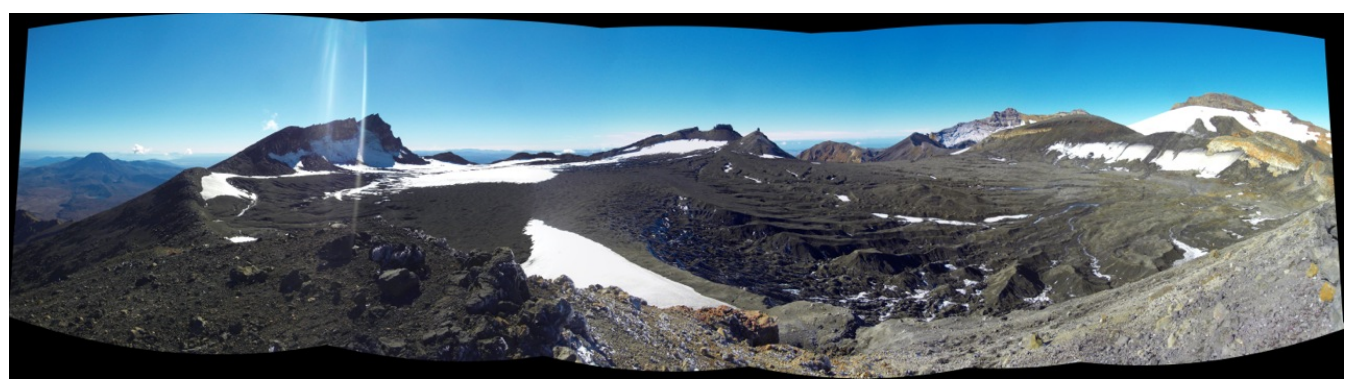

Figure 2.11: Panoramic photograph showing Summit Plateau after total melt of the winter snowpack. Photo taken from approx. Glacier Knob (2642 $\mathrm{m}$ asl). Tukino Peak at left and Paretetaitonga peak at far right. (25 February 2012).

reported that the downwasting of this ice over this period had lead to the emergence of the rock rim around the plateau, severing the connection and ice flow input to the Mangatoetoenui and former Whakapapa glaciers and reducing the input to the Whangaehu Glacier (see below). Despite this, several authors have noted that the plateau plays an important role in nourishing the surrounding outlet and cirque glaciers through wind-driven re-distribution of fresh snow (Krenek, 1959; Paulin, 2008).

In negative balance years, complete removal of the winter snowpack reveals a thick debris cover overlying the Summit Plateau ice mass, consisting largely of volcanic ash, lapilli and large boulders (Figure 2.11). Comparison of ice ablation beneath this debris cover against the measured ablation of clean ice showed that melt rates are highest where debris cover is c. $70 \mathrm{~mm}$ thick, whilst rates are reduced to below that of clean ice where debris cover exceeds $120 \mathrm{~mm}$ (Richardson and Brook, 2010). These findings are broadly consistent with other studies of the affect of debris cover on ice ablation, whereby small debris thicknesses (e.g. $<100 \mathrm{~mm}$ ) enhance ablation through reduced albedo and increased absorption of incoming shortwave radiation, whilst thicker debris cover ( $>100 \mathrm{~mm}$ ) has an insulating effect on the underlying ice, reducing the available radiative energy for melting (Brock et al., 2007).

\subsubsection{Whangaehu Glacier}

The Whangaehu Glacier is the largest glacier on the mountain, measured by Keys (1988) to cover $0.76 \mathrm{~km}^{2}$. This glacier is sourced from the southern end of Summit Plateau, close to Dome Ridge, and the debris-covered terminus is located at c. $2100 \mathrm{~m}$ asl (Figure 2.9). Keys (1988) reported that the Whangaehu Glacier was the only one to still be fed by ice flow from Summit Plateau, although it was observed that the continuing thinning of the plateau was reducing this input. Ice velocity measurements on the glacier by 


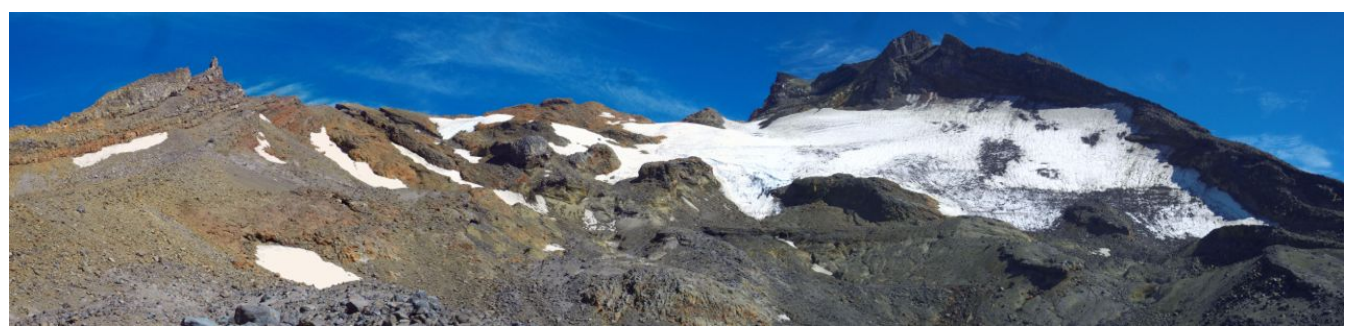

Figure 2.12: Panoramic photograph showing Mangatoetoenui Glacier beneath Te Heuheu peak (26 February 2012).

Paulin (2008) showed that the glacier was flowing at an average of $30 \mathrm{~m} \mathrm{yr}^{-1}$ and that ice contribution from Summit Plateau to the Whangaehu Glacier was negligible. Mass balance measurements and end-of-summer snowline (EOSS) observations on the Whangaehu Glacier showed complex and highly variable interannual patterns, likely driven by aeolian redistribution of snow and variations in ablation season temperatures (Paulin, 2008).

\subsubsection{Mangatoetoenui Glacier}

Mangatoetoenui Glacier is situated on the north-east flank Mt Ruapehu and bound by Te Heuheu peak to the north and Summit Plateau crater rim to the west (Figure 2.9). Heine (1963) reported that this south-eastward flowing glacier was partially fed by Summit Plateau ice and terminated at c.7000 ft (c. $2150 \mathrm{~m}$ asl). In 1988 this glacier had an area of $0.55 \mathrm{~km}^{2}$, an estimated volume of $0.013 \mathrm{~km}^{3}$ and an average velocity of $24 \pm 5 \mathrm{~m} \mathrm{yr}^{-1}$ (Keys, 1988). Keys (1988) also estimated that the surface lowered $20 \mathrm{~m}$ between 1961 and 1988, which resulted in severance from Summit Plateau ice field.

\subsubsection{Wahianoa Glacier}

Wahianoa Glacier is positioned on the south-eastern flank of the volcano and is bound by the Girdlestone-Tahurangi ridge to the west and Ringatoto Peak to the east (Figure 2.9). Heine (1963) reported that the head of this glacier was located at $8500 \mathrm{ft}$ (c. 2600 $\mathrm{m}$ asl) and terminated at $7120 \mathrm{ft}$ (c. $2150 \mathrm{~m}$ asl). Keys (1988) reported that this glacier retreated by c. $160 \mathrm{~m}$ between 1962-1988, and calculated a glacier area of $0.47 \mathrm{~km}^{2}$ and a volume of $0.0074 \mathrm{~km}^{3}$.

\subsubsection{Mangaturuturu Glacier}

Mangaturuturu Glacier is westward-draining and is located on the western slopes of Mt Ruapehu (Figure 2.9). Heine (1963) reported that Mangaturuturu Glacier existed between $8450 \mathrm{ft}$ (c. $2600 \mathrm{~m}$ asl) and $7200 \mathrm{ft}$ (c. $2200 \mathrm{~m}$ asl). Keys (1988) reported that 


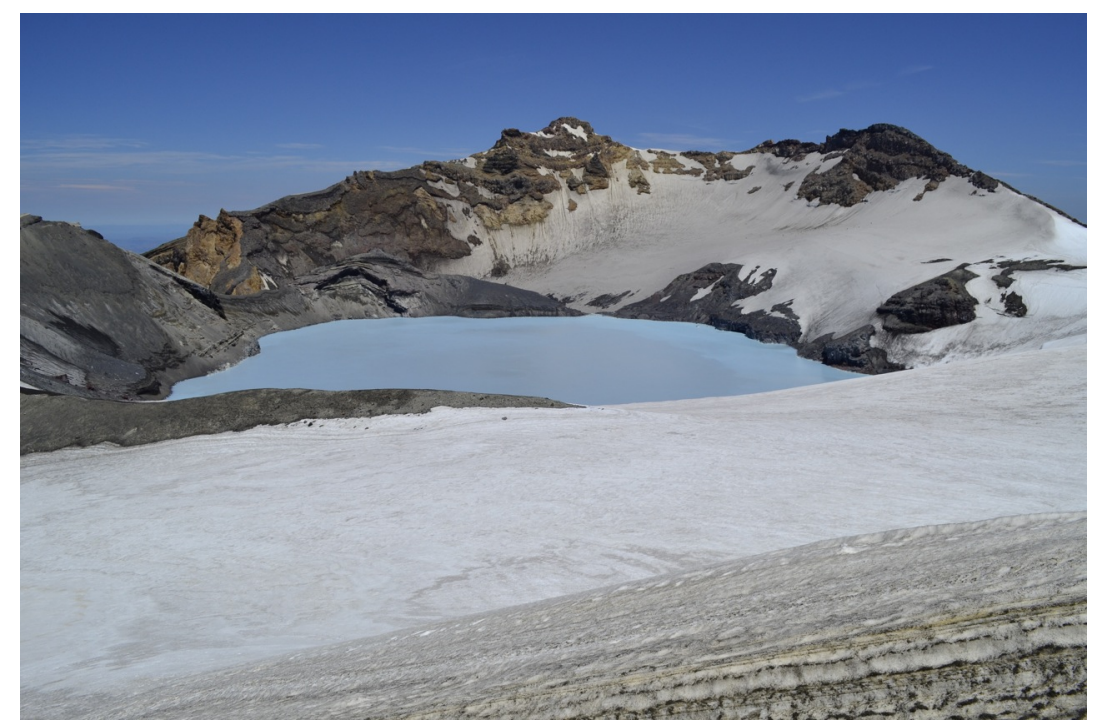

Figure 2.13: Photograph showing Crater Lake and Crater basin glacier beneath Tahurangi (19 January 2014).

this glacier retreated approximately 240 m since Heine's (1963) survey and measured the area of this glacier in 1988 to cover $0.42 \mathrm{~km}^{2}$ and contain c. $0.01 \mathrm{~km}^{3}$ of ice.

\subsubsection{Crater basin and 'unnamed' glaciers}

Keys (1988) defined the Crater basin glacier as that draining northwards from underneath Tahurangi peak, towards Crater Lake (Figure 2.9; Figure 2.13). This was differentiated from the connected, southward draining 'unnamed glacier' (see below) located beneath Paretetaitonga peak, on the grounds of significant differences in their response to the Crater Lake outburst of 1953. Following a rapid drop in the lake level by $>8 \mathrm{~m}$ in 1953, Keys (1988) reports that Crater basin glacier has thinned by up to $90 \mathrm{~m}$. Between 1961-1988, unnamed glacier was in a state of positive mass balance, resulting in a c. $30 \mathrm{~m}$ thickening of the glacier tongue, such that it now terminates in a $30 \mathrm{~m}$ ice cliff at the northern edge of Crater Lake. Keys (1988) attributes the positive mass balance to the topographic setting, situated on the leeward side of Paretetaitonga, where wind-blown snow accumulates and direct incoming shortwave radiation is reduced.

\subsubsection{Summary of present day glacier-climate relationship in North Island}

From the review presented above it is clear that most glaciers on Mt. Ruapehu have experienced net thinning and terminus retreat during the last century, probably in response to increasing ablation season temperatures. The finding that glacier surface area exhibits significant negative correlations with mean ablation season (Nov-Mar) air temperature (Brook et al., 2011), despite some evidence for topoclimatic controls on 
glacier mass balance (Krenek, 1959), provides confidence in the use of contemporary equilibrium line altitude observations (e.g. Keys, 1988) to relate geologically-inferred ELA changes to atmospheric temperature anomalies.

Furthermore, significant correlations with Southern Oscillation Index and end-ofsummer-snowline height in the Southern Alps suggests that glaciers in North Island and the Southern Alps respond similarly to changes in atmospheric circulation over interannual to interdecadal timescales (Hooker and Fitzharris, 1999; Brook et al., 2011). This inference is further supported by the detailed observations of length changes at Whakapapa Glacier during the late 1950s. The down-wasting and terminus retreat at Whakapapa Glacier during the 1955/1956 ablation season coincided with one of the strongest La Niña events of the 20th century (Lorrey et al., 2012a). On the west coast of South Island, Franz Josef and Fox glaciers, which exhibit reaction times of 0-5 years in response to a climatic perturbation, reduced in length by $10-15 \%$ between 1955 1965 (Purdie et al., 2014). La Niña events are characterised by positive mean annual temperature anomalies across New Zealand, but higher (lower) precipitation totals in North (South) Island (Sturman and Tapper, 1996). Similar changes of glaciers across both islands during this period, despite potential differences in precipitation anomalies, indicates a common sensitivity to atmospheric temperatures, although process-oriented studies using mass balance models and measurements are required to develop a more comprehensive understanding of these relationships. Comparison of the magnitudes of glacier fluctuations between these two regions over geological timescales may provide useful insight into past changes in regional temperature gradients.

\subsubsection{Previous work: palaeo-glaciation in Tongariro National Park}

In North Island, only Ruapehu is of sufficient altitude to support small modern glaciers; however both Mt. Ruapehu and Tongariro massif display characteristic glaciated valleys that radiate from the central peaks. Further evidence for former, more extensive glaciation in the TgVC includes: large lateral moraines; striae; cirques; and ice-contact lava flows (Taylor, 1927; Grange and Williamson, 1930; Hackett and Houghton, 1989; Spörli and Rowland, 2006; and references therein). However, such is the lack of understanding of the timing and former extent of these glaciations, that the two major reviews of New Zealand palaeo-glaciation (Suggate, 1990; Barrell, 2011) afford no more than one or two paragraphs to the matter. In the only significant publication thus far, McArthur and Shepherd (1990) reconstructed a c. $140 \mathrm{~km}^{2}$ ice mass on Ruapehu, based largely on geomorphological field mapping. Moraine ridges were identified flanking all of the major valleys draining Ruapehu, extending down to c. $1200 \mathrm{~m}$ asl. 


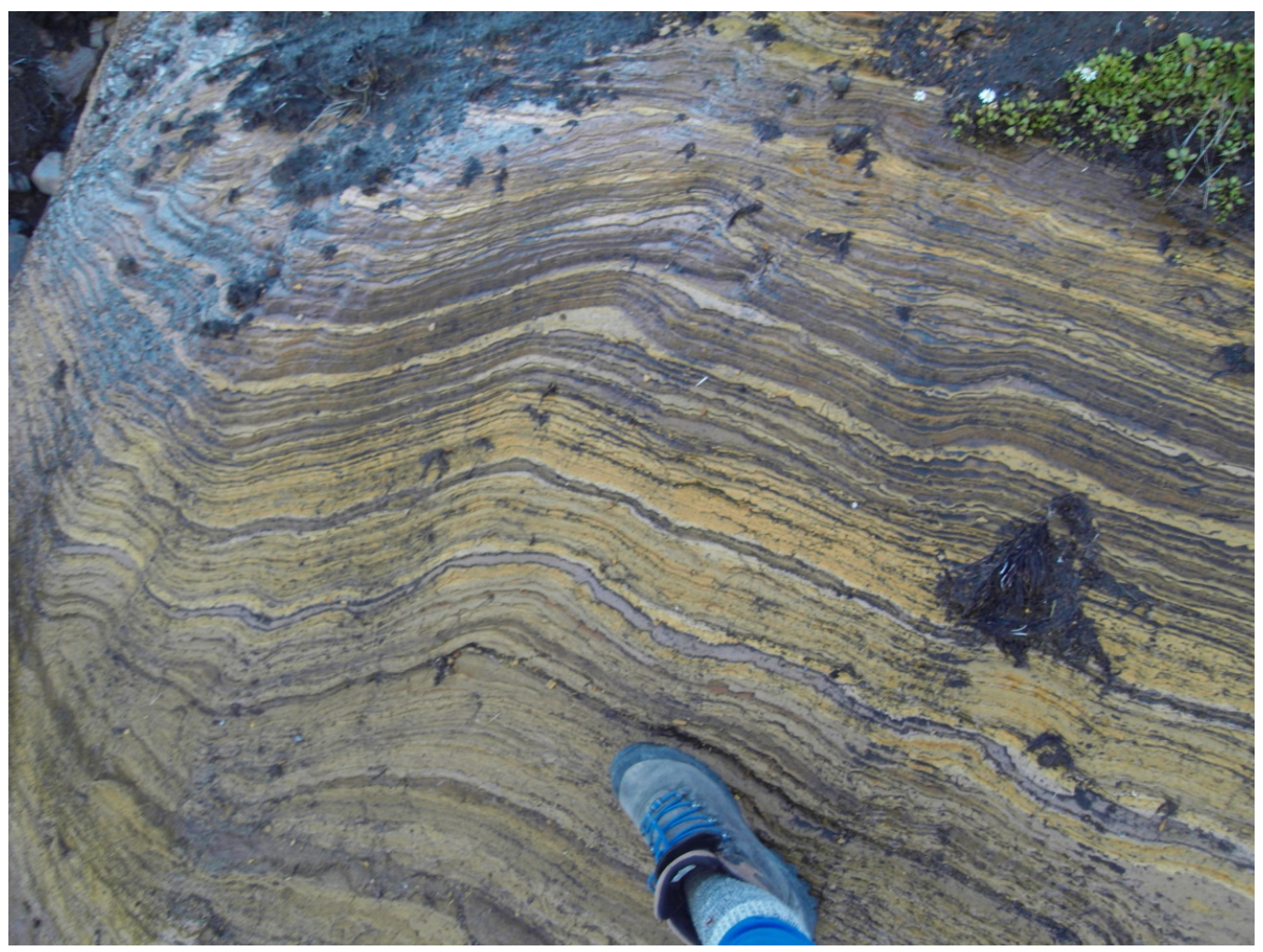

Figure 2.14: Photograph showing the horizontally-bedded lacustrine sediments in Mangatoetoenui valley, identified by Topping (1974) and described by McArthur and Shepherd (1990). (27 February 2012).

Additionally, deformed laminated silts and clays situated between inner and outer moraines in Mangatoetoenui valley (Figure 2.14) are thought to represent deposition and subsequent overriding of a proglacial lake, suggesting multiple glacial advances in this region.

The major contributions to the understanding of glaciation on Tongariro massif come from Mathews (1967) and Topping (1974), although the primary focus of these studies is volcanic. Mathews (1967) describes the conspicuous moraine ridges of the Mangatepopo and Waihohonu valleys and tentatively identifies morainic landforms in the Oturere valley. He also describes sediment sections of diamicton containing striated clasts, interpreted as glacial till, from Mangatepopo and Makahikatoa valleys on the western side of the massif. Topping (1974) builds on this work by identifying further diamictons inferred to be glacial till, as well as describing the relationships between moraine ridges and underlying lava flows. Despite this, no detailed ice mass reconstruction has yet been conducted for Tongariro massif.

The precise timing of glacial advance(s) on both volcanoes is unknown. Existing research utilises the approximate ages of volcanic products to provide chronostrati- 
graphic, minimum-maximum bracketing ages. Correlations with the better constrained timings of ice advance on the South Island have also been attempted. Using titanomagnetite analyses, Topping (1974) tentatively identified the Kawakawa/Oruanui Tephra (25.4 cal. ka BP) in a sequence of deformed lacustrine sediments interbedded with till (Figure 2.14). McArthur and Shepherd (1990) suggest these sediments were deposited by retreating ice correlated with the penultimate LGM advance of the South Island (equivalent to Kumara-2-2 in Suggate and Moar, 1970), and the deformation structures were therefore caused by ice advance correlated with the final (Kumara-3) event. McArthur and Shepherd (1990) highlight an alternative scenario in which the silts and tephra are deposited in front of the advancing Kumara-2-2 ice mass and are subsequently overrun and deformed during the same event. This therefore invokes earlier glacial advance on Ruapehu than that proposed by Topping (1974), where the outer moraines that impounded the proglacial lake could be much older (McArthur and Shepherd, 1990).

The thick (up to $5 \mathrm{~m}$ ) ash sequences overlying the lower sides of moraines on Tongariro massif provide useful chronostratigraphic markers (Mathews, 1967; Topping and Kohn, 1973; Topping, 1974). Assuming a constant Holocene sedimentation rate for overlying ash, Mathews (1967) calculated that the moraines ridges were formed before at least $4 \mathrm{ka}$, although he stated that they are more likely to correlate to late Pleistocene glaciations of the South Island. Using titano-magnetite assemblages, Topping and Kohn (1973) identified the Rerewhakaaitu ash mantling the large moraine ridge on the true right of Mangatepopo valley, which indicates a minimum moraine age of $17.5 \pm 0.5$ cal. ka BP (Lowe et al., 2013). The maximum ages of these moraines are constrained by underlying lava, which has been dated to > $100 \mathrm{ka}$ (Stipp, 1968; Hobden et al., 1996; Figure 2.6). Younger tephras are found mantling other moraines radiating from Tongariro, although these too provide a minimum age constraint due to the likelihood of older tephras having been stripped off during the harsher stadial climate (Topping, 1974).

\subsection{Research questions}

The idea that Earth has transitioned from glacial to interglacial climates was triggered by recognition of glacial landforms far outside of present day ice limits. Whilst many palaeoclimatic proxies now exist (often of high temporal resolution), records of past glacier fluctuations offer the opportunity to constrain past climate in alpine regions, using a relatively simple physical system. Recent advances in geochronological techniques such as cosmogenic surface exposure dating, and the development of numerical mod- 
els of glacial processes now afford the opportunity to obtain temporally-constrained, quantitative estimates of past cooling events.

New Zealand offers one of the few places to obtain terrestrial palaeoclimate records in the mid-latitudes of the Southern Hemisphere. Situated at the northern margin of the southern westerly circulation and straddling the modern oceanic subtropical front, local climate proxy records are ideally placed to record changes in these major climatic boundaries thought to be integral to major climatic shifts in recent Earth history. Widening the spatial scope of local glacial-climate reconstructions, which have thus far mainly focused on the Southern Alps, will allow quantitative constraint of past climatic gradients and spatiotemporal variability of past climatic change. With this in mind, I will answer the following research questions (each of which is addressed in one or more specific thesis chapters):

1. Can cosmogenic isotopes be used to constrain the timing of glaciation on the North Island volcanoes? (Chapter 4)

2. When did glaciers in central North Island advance during the last glacial cycle? (Chapters 5,7)

3. Did glaciers in central North Island respond to the late-glacial climate reversal? (Chapter 6)

4. What does the geological record of glaciation in central North Island tell us about the magnitude of past temperature changes? (Chapters 5,6,7) 


\section{Chapter 3}

\section{Methodology}

The concept of uniformitarianism dictates that past geological activity can all be explained by contemporary, measurable processes with invariant rates, which is embodied in the phrase: the present is key to the past. More recently, the importance of infrequent cataclysmic events punctuating the predominant gradual nature of geologic activity has been identified (e.g. Bretz, 1969), leading to a redefinition of uniformitarianism, also known as actualism. This $\mathrm{PhD}$ research is set within an actualistic framework, adopting largely uniformitarian principles by defining and interpreting the palaeoglaciology of $\mathrm{TgVC}$ in terms of empirically observed and analogous glacial processes, whilst accepting and questioning the likelihood of variance in process rates. An increasing body of empirically-derived, sedimentological and geomorphological process-response research in glacierised catchments is now available (e.g. Benn and Evans, 2010) for actualistic palaeoglaciological reconstructions using the geomorphological record. Furthermore, improved understanding of ice-flow and glacier-climate interactions (Oerlemans, 2001; Cuffey and Paterson, 2010) has facilitated development of numerical glacier models. The combination of well-dated, geomorphically-constrained glacier reconstructions and numerical glacier modelling provides a powerful tool in deriving quantified estimates of palaeoclimate (e.g. Anderson and Mackintosh, 2006; Putnam et al., 2013b; Doughty et al., 2013; Kaplan et al., 2013). Using this framework, the following section details the methods that will be employed for palaeoglaciological reconstruction in TgVC.

\subsection{Geomorphological mapping}

Geomorphological mapping is the process by which landforms are identified, their spatial location recorded and their genesis interpreted, based on the analysis of the land surface morphology and its constitutional geologic materials/structures (Hubbard and Glasser, 2005). The interpretative link to process-form geomorphic systems separates 
this activity from 'morphological mapping', which simply seeks to describe the form of a land surface (Knight et al., 2011). Table 3.1 outlines the methodological framework for the geomorphological mapping component of this research, based on the suggestions of Knight et al. (2011).

The aim of the field mapping component is to identify and record the nature and location of glacial geomorphology not detectable at the resolution of the remotely sensed datasets and locate landforms suitable for cosmogenic surface exposure dating (see Section 3.2, below). This is achieved by:

- traversing the study locations by foot, recording observations on breaks of slope, sedimentary composition, landform configuration (such as cross-cutting relationships, degree of preservation) and morphostratigraphy;

- compiling detailed sedimentary logs/descriptions of exposed sections in key landforms to aid genetic interpretation;

- using a handheld global positioning system (GPS) unit to locate all observations and field photographs.

The principle of equifinality is one potential complication to geomorphological interpretation. In this instance, equifinality refers to the formation of landforms with the same morphological and/or sedimentological characteristics by two or more different processes (Chorley, 1962). There are several recent examples of such debates (e.g. Hewitt, 1999; McColl and Davies, 2011), perhaps stemming from '... an over reliance on the role of glaciation to interpret constructional ridges and mounds...' in upland environments (Knight et al., 2011).

(McArthur and Shepherd, 1990) acknowledge that moraine-like landforms on active volcanoes may be created by volcanic processes, although they do not provide any further detail into these processes. From a morphological perspective, volcanic landforms such as lava flow levees and debris avalanche (from sector collapse) mounds can resemble moraine ridges/hummocks. In such cases, the lithological and sedimentological architecture (e.g. Palmer and Neall, 1989) are sufficiently different from moraines that field investigations can resolve the formative processes. However, other volcanic processes can construct moraine-like landforms, which are less readily differentiated from glacial processes using only morphological and sedimentological enquiry. Volcanic mass movement events (debris flows, hyperconcentrated streamflows) can produce levees comprised of poorly sorted, weakly stratified/unstratified, angular to sub-rounded sediment, possbly exhibiting striae (Atkins, 2003). These are all common characteristics of glacial till. Potential incorporation of glacial sediments within such volcanic mass 
Table 3.1: Geomorphological mapping workflow for this study (based on Knight et al., 2011).

Pre-mapping

1. Identify and obtain relevant remote sensing data (topographic maps, aerial photography, digital elevation models)

2. Design and create a GIS database using digital and digitised remote sensing imagery

3. Map large landforms using remotely sensed data, where data resolution permits

4. Identify sites of interest for field investigation

5. Create 1:10000-scale paper base maps

6. Obtain permission for access to mapping regions

7. Conduct hazard/risk assessment for the planned mapping activities

\section{Syn-mapping}

9. Conduct mapping using the stated protocol

10. Consider landform genesis within a multiple working hypothesis framework

11. Use hand-held GPS to record important tracks/waypoints

12. Write notes and take photos positioned using the GPS

13. Adhere to health and safety issues / risk assessment

\section{Post-mapping}

13. Download and integrate GPS data with the existing GIS database

14. Compare field and remote sensing mapping data in order to validate remotely sensed observations

15. Write up notes, integrate notes and photos with GPS points in GIS database

16. Digitise field mapping data

17. Draw final geomorphological map, using analogue or digital cartographic symbols

18. Write/present explanatory notes accompanying the map

19. Apply geomorphological map output to the interpretation of past glacial activity 
movement deposits further complicates glacial vs. volcanic interpretations.

For these reasons, it is necessary to consider the individual landform genesis within the context of the wider landform assemblage, i.e. a landsystems approach. A number of glacial landsystems have been described, covering a range of different glaciological settings (Evans, 2003). I consider the temperate 'glaciated valley' and 'mountain ice field' landsystems (e.g.Benn et al., 2003; Golledge, 2007; Benn and Evans, 2010) most appropriate for this research. These landsystems are characterised by assemblages of erosional (due to basal sliding) and depositional landforms, where geomorphic directional ice flow indicators are generally concordant with contemporary surface slopes (Benn et al., 2003; Golledge, 2007). I consider these landsystem models are appropriate for this research based on: (i) the results of previous geomorphological research in TgVC (Mathews, 1967; Topping, 1974; McArthur and Shepherd, 1990), (ii) the more extensive body of contemporary and palaeoglaciological investigations of glacial sediment-landform assemblages (e.g. Kirkbride and Matthews, 1997; Hambrey and Ehrmann, 2004; Mager and Fitzsimons, 2007; Barrell et al., 2011; Barrell, 2014; Evans et al., 2013) in the Southern Alps, and (iii) existing constraints on the magnitude of past climate changes over the late Quaternary (e.g. Vandergoes et al., 2008; Golledge et al., 2012; Newnham et al., 2012, 2013; Doughty et al., 2013).

In summary, I consider the formation of linear, constructional landforms in TgVC within a multiple working hypothesis framework (i.e. glacial vs volcanic). I initially classify such landforms as moraine ridges using the diagnostic (but not deterministic) criteria of McArthur and Shepherd (1990): (1) landform is composed of diamicts characterised predominantly by sub-angular to sub-rounded, faceted and/or striated clasts of mixed lithology; (2) landform may display overflow channels on ridges, possibly caused by glacio-fluvial incision; (3) landform exhibits steep valley-proximal slopes possibly caused by presence of former ice mass; (4) glaciolacustrine deposits may be interbedded with diamicton. This initial interpretation is then evaluated in the context of the catchment-scale landform assemblage, using existing process-form and landsystem models from similar glacierised or glaciated landscapes.

\subsection{Surface exposure dating using terrestrial cosmogenic nuclides}

Exposure age dating of geological surfaces using in situ terrestrial cosmogenic nuclides, first proposed by Davis and Schaeffer (1955), is now a commonly applied geochrono- 
logical method used to date geomorphic events that have created distinct terrestrial landforms composed of previously unexposed geological material (Gosse and Phillips, 2001). In situ terrestrial cosmogenic nuclides (henceforth cosmogenic nuclides) are rare isotopes (e.g. ${ }^{10} \mathrm{Be},{ }^{36} \mathrm{Cl},{ }^{3} \mathrm{He},{ }^{26} \mathrm{Al}$ ) of elements common on Earth, which are produced in rock-forming minerals at the Earth's surface via nuclear reactions with a secondary cascade of high-energy particles (neutrons and muons), originating from primary galactic cosmic radiation (Gosse and Phillips, 2001). Measurements of the concentration of a stable cosmogenic nuclide (e.g. ${ }^{3} \mathrm{He},{ }^{21} \mathrm{Ne}$ ) in a mineral sample $(N)$ therefore represent a proxy for surface residence time, which can be converted into an exposure age $\left(T_{\text {exp }}\right)$ :

$$
T_{\exp }=\frac{N}{P}
$$

where $P$ is the production rate of the measured nuclide scaled to the sample site (see below). This equation assumes no post-depositional erosion (i.e. loss of nuclides) and no inheritance of nuclides from prior exposure. For radionuclides (i.e. ${ }^{10} \mathrm{Be},{ }^{26} \mathrm{Al},{ }^{36} \mathrm{Cl}$ ) age calculations must account for radioactive decay using the relevant decay constant (Gosse and Phillips, 2001).

\subsubsection{Cosmic radiation and nuclide production}

Primary galactic cosmic radiation at the top of the atmosphere consists primarily of protons (c. $83 \%$ ) and alpha-particles (c. $13 \%$ ) and predominantly originates within the Milky Way (Gosse and Phillips, 2001). The primary ray flux is modulated by Earth's magnetic field and, to a lesser extent, solar activity. Primary ray particles are deflected by the geomagnetic field and only penetrate when momentum exceeds the cutoff rigidity, which is a product of the incident angle and position relative to the geomagnetic field (Gosse and Phillips, 2001). Thus, primary ray production is spatially heterogeneous. For example, incoming particles require greater energies to overcome the geomagnetic field at lower latitudes compared to high latitudes, as geomagnetic field lines near the equator are orientated approximately perpendicular to the average incident angles of incoming primary rays. Particles that overcome this barrier collide with atomic nuclei in the atmosphere to initiate a cascade of secondary radiation. Successive reactions in this cascade reduce the number and energies of secondary rays that reach Earth's surface. The neutron flux at the Earth's surface decreases exponentially with increasing rock/soil depth, such that at depths of c. $2.5-3 \mathrm{~m}$ the flux is reduced to $<1 \%$ of that at the surface (Dunai, 2010). Attenuation of the neutron flux with depth is dependent on the density of the overlying material and the energy of the incoming neutron. Production of cosmogenic nuclei in a host rock predominantly (c. 98\%) occurs via spallation, where fast and high energy neutrons and muons strike and disintegrate 
target nuclei (Dunai, 2010). A separate mechanism for cosmogenic nuclide production is thermal neutron capture. This occurs when incoming neutrons are slowed down to thermal energies (c. $<0.5 \mathrm{eV}$ ) and become absorbed by target nuclei (Gosse and Phillips, 2001). Cosmogenic nuclide production via this mechanism varies between nuclides, depending on the abundance and cross sections of target nuclei (Dunai, 2010).

Accurate and precise determination of an exposure age from a given cosmogenic nuclide concentration requires accurate and precise knowledge of the rate of cosmogenic nuclide production ( $P$ : Eq. 3.1$)$ at the specific sample site. As outlined above, $P$ at earth's surface varies in time and space predominantly due to variances of the geomagnetic field and surface elevation. Several, commonly applied, physically-based numerical descriptions of these processes exist to predict $P$ at a given atmospheric depth and position relative to the geomagnetic field (Lal, 1991; Stone, 2000; Dunai, 2001; Lifton et al., 2005; Desilets et al., 2006; Balco et al., 2008). Minor differences in the treatment of magnetic field variability, atmospheric depth and solar variability between these models, results in different estimates of $P$ for the same sample position (Balco et al., 2008). Typically cosmogenic surface exposure ages are reported using all of these scaling schemes, however a single scaling scheme may be preferred where production rates have been derived using an independent geochronometer (e.g. radiocarbon), thereby allowing comparison between scaling methods. For example, in the Southern Alps, ${ }^{10}$ Be exposure ages calculated using the modified, time-dependent Lal (1991)/Stone (2000) scheme (commonly referred to as ' $\mathrm{Lm}^{\prime}$ ' after Balco et al., 2008) produced the best match to associated, independent radiocarbon chronologies (Putnam et al., 2010b).

The established scaling schemes require a reference value for $P$, which refers to production of the given nuclide at sea-level and high latitude (SLHL). These reference values are derived from empirical calibration studies, where the concentration of the cosmogenic nuclide of interest is measured in a surface of known age (e.g. Putnam et al., 2010b; Goehring et al., 2010). Local production rates derived using such an approach are normalised to SLHL $\left(P_{S L H L}\right)$ using each of the scaling schemes, for subsequent applications. Where available, locally calibrated production rates minimise the uncertainties that arise from production rate scaling. To aid this process and to help ensure internal consistency between applications, publicly-available cosmogenic exposure age calculators have been produced for individual nuclides (e.g. Balco et al., 2008 for ${ }^{10} \mathrm{Be}$ and ${ }^{26} \mathrm{Al}$; Goehring et al., 2010 for ${ }^{3} \mathrm{He}$ ). These tools allow users to generate exposure age datasets for measurements of the given nuclides, according to the scaling schemes listed above. Furthermore, site-specific influences on $P$ derived from field observations, such as erosion rates, local shielding by surrounding topography and sample thickness, 
can also be included in the exposure age calculation.

\subsubsection{Application to palaeoglaciology}

Cosmogenic surface exposure dating is now firmly established as the primary geochronological tool for constraining pre-historic glacier fluctuations (see review by Balco, 2011) as it is one of the few techniques that dates the deposition of clasts directly by ice. Glacial erosion and deposition, particularly within temperate glaciers, creates two main situations that can be exploited using cosmogenic nuclides to constrain the timing of past ice fluctuations. First, glaciers quarry and entrain material, which is transported and deposited at ice margins forming moraines. Once deposited, moraine boulders are exposed to the cosmic ray flux. Thus, cosmogenic nuclide concentrations of boulders on the crest of moraines that are now unoccupied by glaciers are assumed to represent the length of time since ice withdrew from that location. Second, temperate glaciers erode their bed through abrasion and quarrying, removing cosmogenic nuclide inventories that may have accumulated during prior periods of exposure to the cosmic ray flux. When the shielding ice mass retreats, abraded bedrock begins to accumulate cosmogenic nuclides. Thus, samples from such situations can also be used to infer the time since ice retreat. Since the 1980s, improvements in mass spectrometry, chemical preparation methods and understanding of cosmogenic nuclide production rates and scaling have revolutionised the ability to constrain the timing of past glacier and ice sheet variations (Balco, 2011). For example, the timing of glacier readvance in New Zealand during the late-glacial (c. 15-11 ka BP) represents a prominent case in point of how methodological improvements in cosmogenic surface exposure dating have helped to address key questions in palaeoclimatology (Denton and Hendy, 1994; Ivy Ochs et al., 1999; Kaplan et al., 2010; Putnam et al., 2010b,a, see Chapter 2).

Application of cosmogenic surface exposure dating to moraine boulders, with the goal of dating past glacier fluctuations, involves two main assumptions. First, that the sampled surface has remained exposed to the cosmic ray flux in its current position and has not undergone surface erosion since deposition (i.e. glacier retreat). If this assumption is violated, the measured concentration of cosmogenic nuclides will return a surface exposure age for the boulder that is younger than the age of the parent moraine. Second, it is assumed that the sampled moraine boulder surface contained no measurable quantity of cosmogenic nuclides immediately prior to deposition. If this assumption is violated, the measured cosmogenic nuclide concentration will overestimate the time since glacier retreat. 
The fact that these assumptions do not always hold true was illustrated in the first application of this technique to date moraines. Phillips et al. (1990) found that scatter in nuclide concentrations, outside of the measurement uncertainty, increased with the stratigraphic age of the parent moraine landforms. Furthermore, Phillips et al. (1990) found an age reversal, whereby boulders from the stratigraphically oldest moraine returned exposure ages younger than those from a stratigraphically younger, crosscutting landform. Hallet and Putkonen (1994) developed a topographic diffusion model that simulates moraine cross profile evolution over time, based on the rate of sediment transference from the moraine crest to the moraine slopes. This model also included a boulder weathering component that simulated the shrinkage and eventual loss of moraine boulders due to sub-aerial and sub-surface weathering. Applying this model to the study site of Phillips et al. (1990), Hallet and Putkonen (1994) found that a combination of moraine diffusion and boulder surface erosion could explain the observed distribution of cosmogenic surface exposure ages.

Subsequent analyses of large datesets of cosmogenic surface exposure ages from moraine boulders and geomorphic process model experiments have shown that postdepositional disturbance (i.e. moraine and boulder erosion) is the most common source of scatter in cosmogenic moraine chronologies (Putkonen and Swanson, 2003; Putkonen and O'Neal, 2006; Applegate et al., 2008; Heyman et al., 2011; Applegate et al., 2012). This is because moraines are unlithified and steep-sided at the time of ice withdrawal, and frequently form in environments where gravitational and climatic processes maintain an active land surface. In contrast, moraine boulders displaying evidence for inheritance of cosmogenic nuclides due to prior exposure are relatively rare in temperate glacial environments and often readily identifiable as outliers given a sufficient sample size (Putkonen and Swanson, 2003; Heyman et al., 2011; Balco, 2011).

It is important to note that moraine exposure age datasets exhibit scatter to varying degrees. The degree of scatter is a product of sample choices and the integrated effects of the aforementioned geological processes, with respect to time. Important parameters in moraine degradation models include boulder erosion rates and the proportionality constant, topographic diffusivity. The latter represents the sediment transfer rate normalised by the surface slope. Thus the value of this parameter reflects propensity of the substrate to erode and propensity of local climate to cause erosion (e.g. precipitation, freeze-thaw cycles). The role of precipitation in eroding boulder surfaces and moraines is perhaps illustrated by the the excellent internal consistency of recent datasets derived from low precipitation (c. $<1 \mathrm{~m} \mathrm{yr}^{-1}$ ) sites in the Southern Alps (e.g. Schaefer et al., 2006; Putnam et al., 2013b; Kelley et al., 2014; Schaefer et al., 2015). Understanding the range of potetial error sources in cosmogenic moraine chronology datasets is of vital 
importance when designing a sampling campaign and interpreting results that display scatter outside of the analytical uncertainty.

\subsubsection{Approach used in this thesis}

In this thesis I use the cosmogenic nuclide ${ }^{3} \mathrm{He}$ to constrain the timing of glacier fluctutaions on Tongariro and Ruapehu volcanoes. The primary reason for using this nuclide is the lithology of the moraine boulders at these sites. Cosmogenic ${ }^{3} \mathrm{He}$ is produced and quantitively retained in pyroxene, which is a relatively abundant phenocryst in the local andesitic lavas (Price et al., 2012). Quartz occurs infrequently as isolated xenoliths, but not in sufficient quantities to use ${ }^{10} \mathrm{Be}$. Cosmogenic ${ }^{36} \mathrm{Cl}$ represents an alternative nuclide that could be used in central North Island. However, the relatively complex production pathways and discrepancies surrounding element-specific production rates (Stone et al., 1996; Swanson and Caffee, 2001) limits the precision of ${ }^{36} \mathrm{Cl}$ exposure ages although recent advances are beginning to resolve these issues (Schimmelpfennig et al., 2009).

Below I provide a brief introduction to cosmogenic ${ }^{3} \mathrm{He}$, before outlining the sampling protocol and the laboratory procedures used.

\subsubsection{Cosmogenic 3-Helium $\left({ }^{3} \mathrm{He}\right)$}

${ }^{3} \mathrm{He}$ is a stable helium isotope that is extremely rare on Earth. Cosmogenic production of ${ }^{3} \mathrm{He}$ was first suggested by Bauer (1947), who recognised an inverse relationship between meteorite size and ${ }^{3} \mathrm{He}$ content. Bauer postulated that the lower velocities of smaller meteorites resulted in less removal of surface material (and therefore of cosmogenic ${ }^{3} \mathrm{He}$ ) relative to larger meteorites with higher velocities. In measuring the ${ }^{3} \mathrm{He} /{ }^{4} \mathrm{He}$ ratios of meteorites, Paneth et al. (1952) recognised the chronological potential of this nuclide production. They stated, "If the absolute amount of helium 3 produced by cosmic rays were known exactly we could calculate the time the meteorite -or at least a particular part of it - had been exposed to their influence; this would give us a second way for calculating its minimum age." Despite this early recognition of cosmogenic ${ }^{3} \mathrm{He}$ production in extraterrestrial bodies, the first studies to identify excessive ${ }^{3} \mathrm{He} /{ }^{4} \mathrm{He}$ ratios in terrestrial material advocated a primordial origin (Tolstikhin et al., 1974). Craig et al. (1979) first postulated a cosmic source as an explanation for elevated terrestrial ${ }^{3} \mathrm{He}$ content, however this was not supported until the mid-1980s, following the development of gas mass spectrometry. Repeated measurements of a surficial sample from a Hawaiian lava flow yielded ${ }^{3} \mathrm{He} /{ }^{4} \mathrm{He}$ ratios of up to 418 times meteoric values, whereas drill core samples from c. $160 \mathrm{~m}$ depth yielded atmospheric ratios ( Craig and Poreda, 
1986; Kurz, 1986a,b). These depth profiles were interpreted to represent cosmogenic ${ }^{3} \mathrm{He}$ production at the surface, which rapidly attenuates with depth.

Cosmogenic ${ }^{3}$ He nuclei can be produced in spallation reactions from all elements except hydrogen (Niedermann, 2002). At the Earth's surface, cosmogenic ${ }^{3} \mathrm{He}$ production is almost entirely from spallation reactions, with little to no muonic contribution (Lal, 1987; Farley et al., 2006; Dunai, 2010). Another potential production pathway for cosmogenic ${ }^{3} \mathrm{He}$ is via thermal neutron capture on ${ }^{6} \mathrm{Li}$, although this is only significant in rocks with elevated lithium concentrations (Niedermann, 2002). Thermal neutrons are also produced non-cosmogenically, as the product of alpha-neutron reactions initiated by $\mathrm{U}$ and Th decay in the host rock (Niedermann, 2002), therefore nucleogenic ${ }^{3} \mathrm{He}$ production via thermal neutron capture can be significant in rocks with old crystallisation ages (Gosse and Phillips, 2001). Helium can also be incorporated in melt and fluid inclusions during mineral crystallisation. The contribution of ${ }^{3} \mathrm{He}$ from this magmatic source can be determined and corrected for by crushing an aliquot of the sample in vacuo and measuring the ${ }^{3} \mathrm{He} /{ }^{4} \mathrm{He}$ ratio of the gas released from the mineral inclusions (Kurz, 1986a). Although produced in all minerals, cosmogenic ${ }^{3} \mathrm{He}$ readily diffuses from many minerals at environmental temperatures and therefore is only useful as a geochronometer in phases with structures suited to its retention (Dunai, 2010). Olivine and pyroxene are the most commonly utilised minerals, although biotite and hornblende (Amidon and Farley, 2012), and apatite and zircon (Amidon and Farley, 2011) also quantitatively retain helium.

Cosmogenic ${ }^{3} \mathrm{He}$ has a number of distinct advantages over other nuclides for surface exposure dating applications. First, it is radiometrically stable, therefore can be applied to date very old surfaces (e.g. Schäfer et al., 1999). Second, it has relatively high, and well-studied, production rate (e.g. c. 120 atoms $\mathrm{g}^{-1} \mathrm{yr}^{-1}$ at SLHL (Goehring et al., 2010 compared to $c .4$ atoms $\mathrm{g}^{-1} \mathrm{yr}^{-1}$ for ${ }^{10} \mathrm{Be}$ (Putnam et al., 2010b) and low detection limits, therefore can also be applied to very young surfaces (e.g. Fenton and Niedermann, 2014). Third, it is readily retained in common rock-forming minerals such as olivine and pyroxene (Goehring et al., 2010), therefore it can be applied in quartz-deficient lithologies that preclude application of the most frequently used cosmogenic ${ }^{10} \mathrm{Be}$. Fourth, the sample preparation procedures (see below) for ${ }^{3} \mathrm{He}$ measurement are inexpensive in comparison other nuclides (e.g. ${ }^{36} \mathrm{Cl},{ }^{10} \mathrm{Be},{ }^{26} \mathrm{Al}$ ). 


\subsubsection{Sampling protocol}

Moraine boulder samples were collected using a portable, $16 \mathrm{~V}$ rock saw fitted with a segmented, diamond-tipped blade (methodology adapted from Suganuma et al., 2012). In the field, each sample was measured and described (e.g. geometry, depositional context, degree of weathering) and photographed from multiple angles. Sample locations and elevations were recorded using a Trimble GeoXH global positioning system, relative to the WGS84 datum. These data were differentially corrected using continuous measurements from GeoNet 'Chateau Observatory' ('VGOB') base station (39 $11^{\prime}$ 59" S, $175^{\circ} 32^{\prime} 32^{\prime \prime} \mathrm{E} ; 1161 \mathrm{~m}$ asl), located within $15 \mathrm{~km}$ of all sample locations. Horizontal and vertical post-processed uncertainties for individual sample locations are $<1 \mathrm{~m}$. Where possible, samples were collected from several boulders per moraine, in order to assess the presence of geological scatter. I developed a set of criteria for selecting samples for cosmogenic surface exposure dating, with the aim of minimising the potential for scatter due to geological processes (as outlined in Section 3.2.2).

Boulder surface integrity Physical and chemical weathering of moraine boulders, which have been exposed for $10^{2}-10^{5}$ years, facilitates erosion of boulder surfaces. This process can reduce nuclide concentrations, resulting in exposure age calculations that underestimate the time since boulder exposure began. In this thesis, the integrity of boulder surfaces was assessed using the criteria outlined by Putnam et al. (2013b), who rejected potential samples that displayed one of more of the following: (i) a structure that exhibits significant internal jointing/fracturing; (ii) a significantly pitted surface, which is indicative of chemical weathering via pooled water; and (iii) boulders that display evidence of significant spallation/disintegration. The degree to which the latter has occurred is commonly quantified through measurement of the protrusion height of resistant mineral (typically quartz) veins on the boulder surface. The premise here being that mineral veins are commonly more resistant than the surrounding groundmass, therefore the difference in height represents the minimum amount of post-depositional boulder surface lowering that has occurred via weathering processes. This data can then be integrated into age calculations to correct for nuclide loss. This technique was not possible in this study, due to the absence of mineral veins in the local igneous rocks. To reduce the potential for errors occurring in this manner, preference was given to boulders with a glassy matrix, which are more resistant to weathering processes.

Shielding (burial / topographic) Boulders that have experienced post-depositional shielding from the cosmic ray flux will have cosmogenic nuclide concentrations that underestimate the age of the parent landform, as penetration of incoming secondary cosmic ray neutrons into the earth surface is exponentially attenuated with depth. 


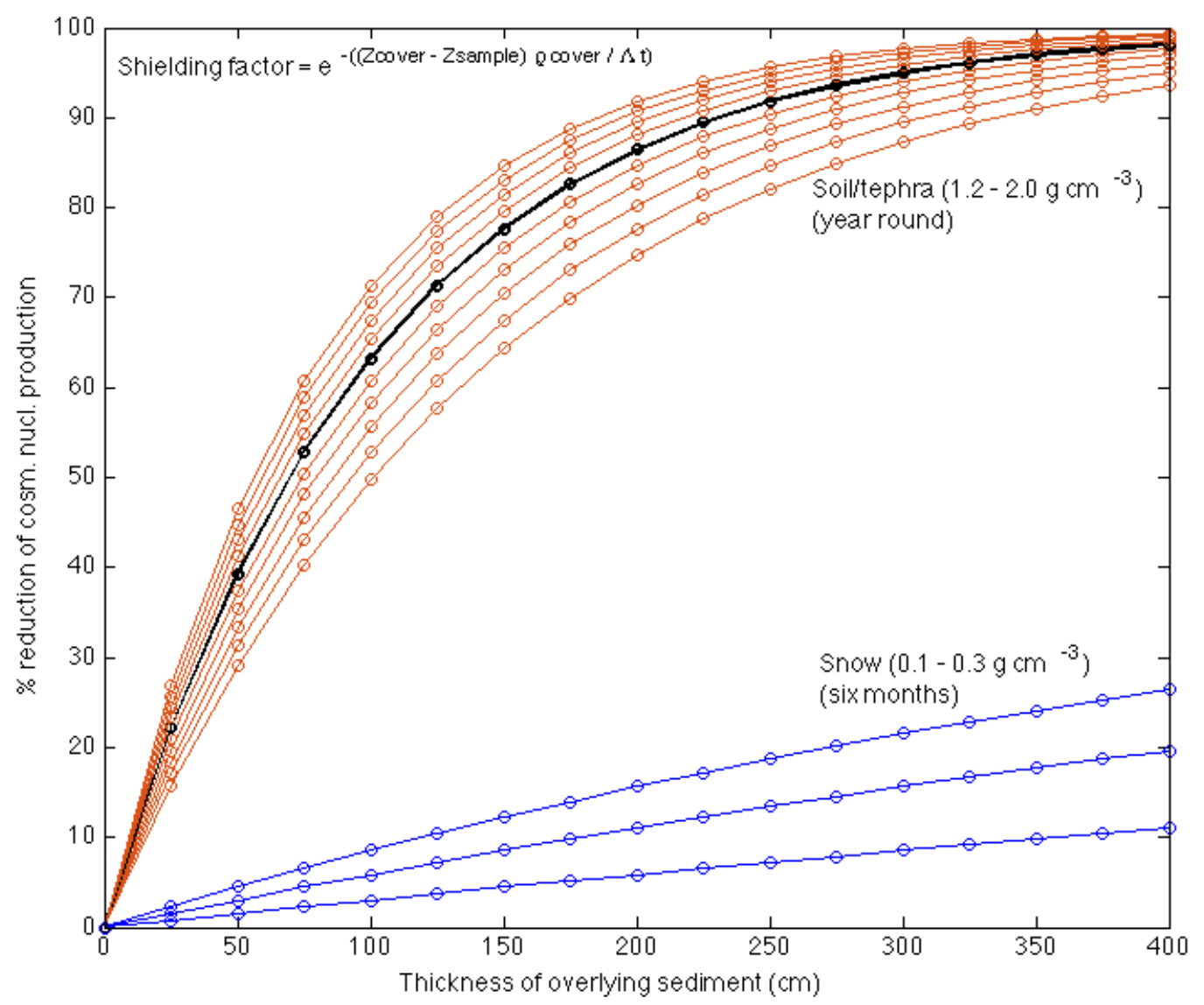

Figure 3.1: Attenuation of cosmogenic nuclide production due to shielding beneath year round soil cover ( $\rho$ cover $\left.=1.2-2.0 \mathrm{~g} \mathrm{~cm}^{-3}\right)$ and half a year of snow $\left(\rho\right.$ cover $\left.=0.1-0.3 \mathrm{~g} \mathrm{~cm}^{-3}\right)$ cover of thicknesses $0 \mathrm{~cm}-400 \mathrm{~cm}$. Calculated using equations from Gosse and Phillips (2001) - their section 3.7 .3

The deviation of boulder exposure age from moraine age resulting from shielding is proportional to the density of the overlying material, burial depth and burial time. For example, if a moraine boulder was covered by $1 \mathrm{~m}$ of snow (typical density of c. 0.1 - $0.3 \mathrm{~g} \mathrm{~cm}^{-3}$ ) for 6 months of the year, this would decrease the cosmogenic nuclide production at the boulder surface by 3 - $8 \%$ (Figure 3.1). By comparison, year-round burial beneath $1 \mathrm{~m}$ of soil with a density of c. $1.6 \mathrm{~g} \mathrm{~cm}^{-3}$ reduces production by c. 65 $\%$ (Figure 3.1). Shielding of boulder surfaces can occur beneath a variety of different media with varying thicknesses and densities. For example, a boulder at the surface today, may have been exhumed from the moraine subsurface via denudation of the surrounding moraine matrix (e.g. Hallet and Putkonen, 1994). Alternatively, a boulder at the moraine surface may have experienced post-depositional burial, for example beneath accumulating loess, volcanic ash, soil or snow.

The altitude (e.g. $>1000 \mathrm{~m}$ asl) and close proximity (e.g. $<2 \mathrm{~km}$ ) to active volcanic 
vents of the sample sites in this thesis raises the possibility that cosmogenic nuclide production in the geologic past may have been reduced by snowfall and volcanic ashfall, respectively. For example, it is notable that the only previous age constraints for past glacial activity in $\mathrm{TgVC}$ are provided by volcanic ash beds that stratigraphically overlie moraines (e.g. (Topping and Kohn, 1973; Topping, 1974)).

In this thesis, a number of methods were thus employed to minimise the potential for sampling boulders that had experienced burial and subsequent exhumation. First, boulders surfaces that stood $>50 \mathrm{~cm}$ ( $>1 \mathrm{~m}$ where sampling at elevations $<1400 \mathrm{~m}$ asl, where tephra/soil cover is greater) above the moraine surface were preferentially selected. Salient boulder surfaces have greater exposure to wind, which reduces the potential for settling of snow or fine-grained sediment. Furthermore, taller boulders are likely to have buried last/exhumed first if burial/exhumation has occurred, therefore exposure ages from taller boulders are more likely to approach the true depositional age. Second, all samples were removed from the highest point of the boulder above the moraine surface, for similar reasons to the previous point. Third, boulders in hollows or surrounded by erosional scarps were avoided, as these characteristics could be indicative of exhumation. Fourth, low-angle (generally $<10^{\circ} \mathrm{dip}$ ) boulder surfaces were preferred, in order to minimise self-shielding effects. Azimuthal elevations were measured in the field using a standard geological compass and clinometer to account for any topographic shielding by the surrounding land surface. These geometric shielding corrections were computed using the CRONUS-EARTH calculator (available at: http:/ / hess.ess.washington.edu/). All shielding corrections were $<1 \%$.

Estimation of snow cover on sampled boulders is difficult due to the paucity of information concerning snow depths in the pre-instrumental period. Contemporary annual snow cover varies greatly between the elevation range of sampled boulders. The peak winter snowline in the study region typically occurs at c. $1600 \mathrm{~m}$ asl although snowfall can occur down to $600 \mathrm{~m}$ asl, therefore most of the samples in this study are subject to periodic winter snowfall. However, observations of sampled sites in winter, as well as inspection of historical satellite imagery (e.g. USGS Landsat: http:/ /landsatlook.usgs.gov) shows that sample locations $<1800 \mathrm{~m}$ asl do not experience significant winter snow cover for significant periods (e.g. weeks-months). This is likely because wind transportation of snow favours erosion from topographic high points such as moraine ridge crests (prominent boulders in particular), and deposition in lee side depressions (which were avoided during sampling). In any case, Figure 3.1 shows that extreme scenarios for this location, such as $50 \mathrm{~cm}$ of snow for 6 months of the year, would impact the production rate by $<5 \%$, which is less than the present uncertainty in the cosmogenic ${ }^{3} \mathrm{He}$ production rate used to derive exposure ages (Goehring 
et al., 2010). Thus, the role of shielding by snow cover is not considered to be a major source of uncertainty in this study.

Boulder rotation The unstable, mobile nature of poorly consolidated moraine sediments can result in rotation of individual boulders, thereby altering the skyward-facing surface of the boulder and reducing the concentration of cosmogenic nuclides, relative to the moraine age. In this thesis, a number of methods were employed to avoid sampling boulders that may have moved since deposition: (i) preference was given to boulders that were visibly embedded in the surrounded moraine matrix, which therefore reduces their potential mobility; (ii) if this criterion could not be met, then preference was given to boulders with a vertical a-axis, as this orientation was deemed to be the least likely result of gravitational settling; (iii) all boulders sampled were on the the crest of the parent moraine, to minimise the potential for post-depositional transport.

Inheritance The erosional effects of glacial transport, particularly in temperate, mountain glaciers, are commonly assumed to remove nuclides from prior exposure. However, clasts transported short distances, or supraglacially, may not experience sufficient surface erosion to remove any existing nuclide inventory. To minimise the likelihood of sampling a boulder with inherited nuclides, boulders exhibiting evidence for wet-based glacial transport and erosion (i.e. faceted sides, striae) were preferred, although such features are not always preserved.

\subsubsection{Laboratory procedures for mineral separation and cosmogenic ${ }^{3} \mathrm{He}$ mea- surement}

Thin section analysis showed that the modal pyroxene grain size in samples was 250$500 \mu \mathrm{m}$. Samples were jaw-crushed, rinsed in de-ionised water and dry-sieved to isolate this size fraction. Density $\left(>3.1 \mathrm{~g} \mathrm{~cm}^{3}\right)$ and magnetic separation techniques were used to isolate 150-600 mg of pyroxene grains per sample. Following Bromley et al. (2014), separated pyroxenes were first leached in 5\% hydrofluoric ( $\mathrm{HF}) / 2 \%$ nitric $\left(\mathrm{HNO}_{3}\right)$ acid solution for 24 hours, followed by a separate $10 \%$ hydrochloric $(\mathrm{HCl})$ acid solution for 24 hours, to remove adhering groundmass particles. Leached pyroxene crystals were visually inspected for purity and wrapped in aluminium foil. Each sample was completely degassed by heating in a furnace to $>1300^{\circ} \mathrm{C}$ for 15 minutes, during which, released gases were exposed to a liquid-nitrogen chilled, charcoal trap. Extracted gases were exposed to an SAES getter before being collected on a cryogenic cold trap at $<15$ Kelvin. Helium was then isolated from other noble gases by heating the cold trap to $45 \mathrm{~K}$. Mass spectrometry was conducted using a MAP 215-50 noble gas mass spectrometer at 
Lamont-Doherty Earth Observatory, New York relative to the Yellowstone 'Murdering Mudpot' (MM) helium standard $\left({ }^{3} \mathrm{He} /{ }^{4} \mathrm{He}\right.$ ratio of $16.45 R_{a}$, where $R_{a}={ }^{3} \mathrm{He} /{ }^{4} \mathrm{He}_{\text {air }}=$ $\left.1.384 \times 10^{-6}\right)$, using the protocol of Winckler et al. (2005). Concentrations of Lithium (Li), Uranium (U) and Thorium (TH) were measured in multiple samples to check for possible errors resulting from helium production via nucleogenic and radiogenic pathways.

\subsection{Palaeoclimate reconstruction using glaciers}

Quantitative palaeoclimatic estimates from geomorphologically constrained glacier reconstructions are calculated using two main methods: (i) ELA reconstruction; and (ii) numerical modelling.

\subsubsection{Equilibrium line altitude (ELA) reconstruction}

The equilibrium line altitude (ELA) of a glacier is the spatially-averaged altitude at the glacier surface where the climatic mass balance is zero at a given moment, although most commonly at the end of the mass balance year (Cogley et al., 2011). Thus, the ELA represents the transition from net accumulation to net ablation and is strongly related to climate, in particular temperature and solid precipitation (e.g. Ohmura et al., 1992). Increases in air temperature and/or decreases in solid precipitation tend towards more negative glacier mass balance and increases in the ELA, and vice versa. Given this relationship, the ELA is a frequently used metric for tracking contemporary and palaeoclimatic changes in glacierised and glaciated regions, respectively.

ELA reconstruction from palaeoglaciers relies on accurate, manual delineations of former ice geometries (assumed to represent steady-state), which are constrained by interpretation of ice-marginal geomorphology (Porter, 1975; Benn et al., 2005). Whilst this is relatively straightforward at former glacier fronts, where lateral and terminal moraines delineate former ice margins, some uncertainty can arise in former accumulation areas where the geomorphological imprint of ice boundaries is less clear (e.g. Kaplan et al., 2010). A number of techniques, derived through empirical observation of modern glacier-climate relationships (e.g. Porter, 1975), can be applied to geomorphologically reconstructed glacier outlines, in order to estimate the former steady-state ELA. Typically, several of these methods are applied to any one glacier reconstruction and the results evaluated in light of the catchment-specific geomorphological and palaeo-glaciological characteristics (Benn and Lehmkuhl, 2000; Benn et al., 2005). Once a palaeo-ELA has been calculated, this can be related to climate using the ELA depression relative to that of local, contemporary glaciers and applying environ- 
mental air temperature lapse rates (e.g. (McCarthy et al., 2008; Putnam et al., 2012)). Although these methods involve several assumptions (Plummer and Phillips, 2003), recent glacier-climate modelling in the Southern Alps (Doughty et al., 2013) has shown results that are comparable with AAR estimations for glaciers with relatively simple geometries (e.g. cirque glaciers; Kaplan et al., 2010, 2013), which provides confidence in using such techniques for palaeoclimatic reconstruction.

In this thesis, I use geomorphological observations and cosmogenic surface exposure dating chronologies (see above) to reconstruct former glacier geometries in several catchments on Mt. Ruapehu and Tongariro massif, for several different time periods during the late Quaternary. Sites were chosen based on the preservation of moraine ridge crests, which depict the terminus and lower margins of the former glaciers, whilst erosional landforms such as glacial cirques and glacially-trimmed cliffs provide guidance on former, upper glacier limits.

\subsubsection{Accumulation area ratio (AAR)}

One of the most commonly used techniques is the Accumulation-Area Ratio (AAR), which utilises the observation that the accumulation area of a glacier represents a fixed proportion of the total glacier area. Accumulation areas of modern glaciers globally, typically occupy 50-80\% of the total glacier surface area (Meier and Post, 1962), whilst empirical studies show that New Zealand glaciers most commonly have an accumulation-ablation area ratio of 2:1 (AAR=0.67; Chinn et al., 2012). To calculate the former steady-state ELA from a reconstructed glacier outline, surface contours are interpolated across the reconstructed glacier surface, including a generalised account of the spatial variation in contour shape induced by extending and compressing glacial flow in the upper and lower glacier respectively. Planimetric areas between surface contours are calculated, with which the AAR-ELA is derived, using reference AAR values (e.g. Porter, 1975).

\subsubsection{Numerical glacier modelling}

ELA reconstruction provides a relatively quick and simple method of palaeoclimatic reconstruction from isolated cirque/valley glaciers, however uncertainties increase when dealing with ice caps / ice fields, where former glacier hypsometries in the accumulation zone are unconstrained by geological data (Plummer and Phillips, 2003). It is possible that small ice caps/fields, drained by valley outlet glaciers, existed on Tongariro massif and Mt. Ruapehu during the coldest periods of the last glacial cycle, when terrestrial air temperature in New Zealand was depressed by c. $5-8^{\circ} \mathrm{C}$ (Golledge 
et al., 2012; Putnam et al., 2013b; Newnham et al., 2013). Advances in the understanding of glacier-climate relationships (e.g. Oerlemans, 2001), as well as greater computing power and availability of digital datasets describing topoclimatic boundary conditions in glacierised and glaciated regions have resulted in widespread application of numerical glacier models to investigate past, present and future glacier-climate relationships (e.g. (Oerlemans, 1992; Oerlemans, 2005; Plummer and Phillips, 2003; Anderson et al., 2006; Kessler et al., 2006; Doughty et al., 2013). Given the variety of glacier model complexity now available, a model approach can be tailored to suit the research question. For example, glacier mass balance models based on surface energy balance concepts, provide a powerful method for investigating the relative contributions of individual energy fluxes to glacier mass balance, through sensitivity experiments (Plummer and Phillips, 2003; Anderson et al., 2010; Doughty et al., 2013).

In this thesis I employ a distributed mass-energy balance model to simulate the effects of changing climate on past glacier mass balance, which is coupled to a two-dimensional ice flow model that updates the glacial geometry based on the mass balance forcing. A full description is provided below, whilst abridged versions are given in the chapters that include model applications (Chapters 6,7). For dated moraines (see surface exposure dating section, above), climatic variables temperature and precipitation are experimentally varied, in order to find combinations of forcing that result in a modelled ice geometry that matches the geological record (e.g. Plummer and Phillips, 2003; Kessler et al., 2006; Doughty et al., 2013). This approach has a number of advantages. First, the physically-based energy balance model explicitly describes the relationship between climatic variables and the surface energy fluxes that contribute to glacier melt. Other melt models, such as temperature-index models, relate air temperature to melt rates using a proportionality factor, which implicitly includes the individual surface energy fluxes. Despite generally good performance (Hock, 2003), such models are less suitable for palaeotemperature constraint due to the over-dependence of melt on temperature. Furthermore, an energy balance model allows assessment of the uncertainty in the temperature estimates that could result from changes in other climatic variables (e.g. precipitation, wind, relative humidity), which are often not available for the past. Second, coupling the mass balance model to the ice-flow model accounts for topoclimatic (e.g. shading, temperature change with altitude) feedbacks that may result from a growing ice mass. Third, the two-dimensional model produces outputs of ice geometry that can be readily compared with moraine maps. Fourth, this style of modelling has previously been used in New Zealand (e.g. Doughty et al., 2013; Kaplan et al., 2013; Rowan et al., 2013), therefore results for the same time periods can be directly compared in order to reconstruct past climatic gradients and test hypotheses that seek to explain the mechanisms of past climate events (e.g. see Chapter 6). 


\subsubsection{Energy balance model}

To simulate ablation, the energy balance equation is solved (Equation 3.2) using a distributed energy balance model (EBM) as developed (Oerlemans, 1992; Anderson et al., 2010) and previously applied in contemporary (Anderson and Mackintosh, 2012) and palaeo-glaciological (Doughty et al., 2013) studies in New Zealand.

$$
Q_{M}=I(1-\alpha)+L \downarrow+L \uparrow+Q_{H}+Q_{E}+Q_{R}+Q_{S}+Q_{G}
$$

where $Q_{M}$ is the energy available for melt, $I$ is incoming shortwave radiation, $\alpha$ is the albedo of the glacier surface, $L \downarrow$ is incoming longwave radiation, $L \uparrow$ is outgoing longwave radiation, $Q_{H}$ and $Q_{E}$ are sensible and latent heat fluxes respectively, $Q_{R}$ is heat input from rain, $Q_{S}$ is the sub-surface heat flux and $Q_{G}$ is the geothermal heat flux. All terms are represented in $\mathrm{W} \mathrm{m}^{-2}$, where positive (negative) values indicate a gain (loss) of energy available for melt. The individual components of the energy balance equation are described below.

Input data Terrain elevation data comes from the New Zealand School of Surveying Digital Elevation Model (NZSoSDEM) (Columbus et al., 2011) and is resampled to 100 $\mathrm{m}$ resolution. An ice mask depicting the distribution of contemporary glaciers on Mt. Ruapehu is created using the 'snow/ice' data from the Land Information New Zealand NZMS260 map series. Ice thickness, based on the survey of Keys (1988), is subtracted from the DEM to create an ice-free surface. Climate data for the energy balance and snow accumulation models is from several different sources. Solar radiation and relative humidity are from the Virtual Climate Station Network (VCSN) gridded datasets, sourced from NIWA CliFlo Database (NIWA, 2014). These data were resampled to the model domain resolution using bilinear interpolation. Due to temporal artefacts in the VCSN grids (Anderson and Mackintosh, 2012) that result from discontinuous measurements, present-day wind speed data comes from the National Centers for Environmental Prediction (NCEP) 850 hPa level, reanalysis data (1981-2010; Kalnay et al., 1996). This dataset is scaled against observational data and applied uniformly over the model domain. Following Anderson and Mackintosh (2012) and Doughty et al. (2013), raw temperature and precipitation data is taken from individual climate stations distributed around and within the model domain in order to improve the temperature representation at higher elevations. Temperature grids are created using the method described in Anderson and Mackintosh (2012) and Doughty et al. (2013). First a sea-level reference surface $\left(T_{r}\right)$ is created in a horizontal plane (sensu Tait and Zheng, 2007) by normalising point-based station data $\left(T_{s t}\right)$ by station elevation $\left(z_{s t}\right)$, 
using a temperature lapse rate $\left(\frac{d T}{d z}\right)$ :

$$
T_{r}=T_{s t}-\frac{d T}{d z} z_{s t}
$$

We use the empirically-derived, seasonal, upland ( $>300 \mathrm{~m}$ asl) temperature lapse rate of Norton (1985) (Table 3.2). To obtain air temperature at the surface $\left(T_{a}\right) T_{r}$ at each grid cell $(z)$ is lapsed back to the elevation determined by the DEM, using the same temperature lapse rate:

$$
T_{a}=T_{r}+\frac{d T}{d z} z
$$

Monthly precipitation surfaces are created using individual station data (NIWA, 2014) and a mean annual precipitation surface (Tait et al., 2006), following Anderson and Mackintosh (2012). At each station the monthly proportion of total annual precipitation was interpolated across the model grid and then multiplied by the mean annual precipitation surface.

Table 3.2: Empirically derived, seasonal air temperature lapse rates for upland ( 300 $\mathrm{m}$ asl) New Zealand (Norton, 1985).

\begin{tabular}{ll}
\hline Season (months) & Lapse rate $\left({ }^{\circ} \mathrm{C} \mathrm{m}^{-1}\right)$ \\
\hline Spring (SON) & -0.0053 \\
Summer (DJF) & -0.0057 \\
Autumn (MAM) & -0.0049 \\
Winter (JJA) & -0.0048 \\
\hline
\end{tabular}

Shortwave radiation ( $I$ ) Incoming shortwave radiation $(I)$ is energy derived from the sun at wavelengths $0.2-4 \mu \mathrm{m}$. At a given point and time on the Earth's surface, I comprises diffuse $\left(I_{\text {dif }}\right)$ and direct $\left(I_{\text {dir }}\right)$ components. The former represents received radiation that has been subject to atmospheric scattering by aerosols (e.g. clouds, pollutants, volcanic ash) or topographic reflection, whilst the former describes unscattered incoming solar radiation. I reaching a given point on the surface of the Earth is further limited by aspect, slope, altitude and latitude. Under clear skies, $I$ is primarily limited by the zenith angle, whilst atmospheric transmissivity dominates attenuation in overcast conditions (Cuffey and Paterson, 2010). In maritime, mid-latitude environments, such as New Zealand, the importance of shortwave radiation for glacier melt is reduced by the high frequency of cloud cover (Conway et al., 2014). 
Both direct and diffuse radiation are dependent on the insolation receipt at the top of the atmosphere $S$, which varies temporally, according to changing orbital geometry. This is taken from the calculations of Huybers and Eisenman (2006) for the specific time window being studied (e.g. 13 ka for late-glacial simulations - Chapter 6; and 22 ka for LGM simulations - Chapter 7). Direct radiation $\left(I_{d i r}\right)$ is calculated following Oerlemans (1992):

$$
\begin{gathered}
I_{d i r}=[0.2+0.65(1-n)] S \cos \theta \\
\cos \theta=\cos (\beta) \cos Z+\sin (\beta) \sin Z \cos \left(\varphi_{\text {sun }}-\varphi_{\text {slope }}\right)
\end{gathered}
$$

where $n$ is cloudiness calculated according to Anderson et al. (2010), $\theta$ is the angle of incidence between the topographic slope angle $(\beta), Z$ is the solar zenith angle, $\varphi_{\text {sun }}$ is the the solar azimuth angle and $\varphi_{\text {slope }}$ is the slope zenith angle (aspect).

For diffuse radiation $\left(I_{d i f}\right)$, contributions from topographic reflectance and aerosols other than water vapour (cloudiness) are neglected, following Oerlemans (1992):

$$
I_{d i f}=[0.8-0.65(1-n)] S \sin \left(\begin{array}{ll}
\frac{\pi}{2} & -Z
\end{array}\right)
$$

The proportional contributions from $I_{d i r}$ and $I_{d i f}$ are then adjusted:

$$
I=t_{a} t_{c}\left(I_{d i f}+I_{d i r}\right)
$$

where $t_{a}$ (Equation 3.9) and $t_{c}$ (Equation 3.10) are transmissivity of air and clouds respectively (Oerlemans, 1992):

$$
\begin{gathered}
t_{a}=(0.79+0.000024 z)\left\{1-0.08 \frac{\frac{\pi}{2}-\gamma}{\frac{\pi}{2}}\right\} \\
t_{c}=1-(0.41-0.000065 z) n-0.37 n^{2}
\end{gathered}
$$

where $z$ is surface elevation, and $\gamma$ is solar elevation.

The contribution of $I$ to the total surface energy, is determined by the albedo $(\alpha)$, or reflectivity, of the ground surface. This can vary significantly in space and time, according to the land surface type (e.g. water, snow, vegetation, bare rock). For snow and 
ice, albedo depends on factors such as crystal structure, impurity content and water content, all of which change with time (Oerlemans, 1992). Across a glacier $\alpha$ can be as high as 0.98 (i.e. $98 \%$ reflectance) for fresh snow, or as low as 0.06 for debris-laden ice (Cuffey and Paterson, 2010).

Many parameterisation schemes exist for modelling spatial and temporal changes in $\alpha$ (Brock et al., 2000). I parameterise $\alpha$ using the 'ELA-dependent' method of Oerlemans (1992). First, a 'background albedo' $\left(\alpha_{b}\right)$ is determined:

$$
\alpha_{b}=0.43+\frac{0.18}{\pi} \arctan \left(\frac{z-z E L A+300}{200}\right)
$$

where $z E L A$ is the equilibrium line altitude. $\alpha$ is then calculated:

$$
\alpha=\alpha_{\text {snow }}-\left(\alpha_{\text {snow }}-\alpha_{b}\right) e^{-5 d}
$$

where $\alpha_{\text {snow }}$ represents the albedo of snow (0.72) and $d$ is equal to snow depth. For areas of glacier cover without snow, the albedo is set to 0.34 , a typical value for ice (Cuffey and Paterson, 2010).

Longwave radiation $(L)$ Longwave radiation $(L)$ is emitted by any physical object with a temperature above absolute zero (Cuffey and Paterson, 2010). $L$ is supplied to glacier surfaces $(L \downarrow)$ through radiative emission at infrared wavelengths (c. 4 - 120 $\mu \mathrm{m})$ from the atmosphere and surrounding terrain, and is lost through emission from the glacier itself $(L \uparrow)$. Snow absorbs all radiation at infrared wavelengths (Cuffey and Paterson, 2010), thus longwave radiation flux can be described by the Stefan-Boltzmann law for blackbodies:

$$
L=\epsilon \sigma T^{4}
$$

where $\epsilon$ is the emissivity of the emitting object (i.e. 1 for blackbodies), $\sigma$ is the StefanBoltzmann constant $\left(5.67 \times 10^{-8} \mathrm{~W} \mathrm{~m}^{-2} \mathrm{~K}^{-4}\right)$ and $T$ is the absolute temperature of the emitting object.

$L \uparrow$ is calculated assuming the glacier surface is at melting point and that snow is a perfect radiator $(\epsilon=1)$. Thus, $L \uparrow$ is assumed constant, at $317 \mathrm{~W} \mathrm{~m}^{-2}$.

Atmospheric water vapour absorbs and re-radiates energy as longwave radiation, and this process can supply a significant amount of energy for glacier melt, particularly in humid conditions. In alpine settings, radiation from exposed rocks and sediment 
at glacier margins can also provide a significant source of energy (Benn and Evans, 2010). $L \downarrow$ thus comprises atmospheric and terrain components, which are not perfect radiators therefore they are related to Equation 3.13 by their respective emissivities $(\epsilon)$ :

$$
L \downarrow=\epsilon_{e f f} \sigma T_{a}^{4} v+\epsilon_{t} \sigma T_{t}^{4}(1-v)
$$

where $T_{a}$ and $T_{t}$ are the temperature of air and terrain, respectively. Where covered by snow, $T_{t}$ is assumed to be $273 \mathrm{~K}$ and where not covered $T_{t}$ is assumed equal to $T_{a} . v$ is the topographic viewfield, calculated from the DEM, using the algorithm of Corripio (2003). $\epsilon_{t}$ is the emissivity of terrain, which is set to 0.4 (Plummer and Phillips, 2003), and $\epsilon_{e f f}$ is the effective atmospheric emissivity, calculated according to Konzelmann et al. (1994):

$$
\epsilon_{e f f}=\epsilon_{c}\left(1-n^{p}\right)+\epsilon_{o c} n^{p}
$$

I follow Anderson et al. (2010) in using $p=1$, based on measurements at Brewster Glacier, New Zealand. Emissivity for overcast conditions $\left(\epsilon_{o c}\right)$ is set to 0.924. $\epsilon_{c}$ is clear sky emissivity, calculated as (Konzelmann et al., 1994):

$$
\epsilon_{c}=0.23+0.484\left(\frac{e_{a}}{T_{a}}\right)^{1 / 8}
$$

where $e_{a}$ is vapour pressure.

Turbulent fluxes $\left(Q_{H}, Q_{E}\right)$ Sensible $\left(Q_{H}\right)$ and latent $\left(Q_{E}\right)$ heat describe energy transfers between the atmospheric boundary layer and the glacier surface. Eddies in the atmospheric boundary layer, enhanced by greater wind speed and glacier surface roughness, promote greater turbulent flux exchange (Cuffey and Paterson, 2010; Equations 3.17 and 3.20).

$Q_{H}$ is the direct conduction of energy between the glacier surface and the overlying air, and the direction of heat transfer is dependent on the sign of the temperature gradient between these media (Equation 3.17).

$$
Q_{H}=\rho_{a i r} c_{p} k_{H} U\left(T_{a}-T_{\text {surf }}\right)
$$

where $\rho_{\text {air }}$ is the density of ambient air, $c_{p}$ is the specific heat capacity of ambient air, and $U$ is wind speed at height $z=2 \mathrm{~m}$. $T_{\text {surf }}$ is assumed to be $0^{\circ} \mathrm{C} . k_{H}$ is the exchange 
coefficient for sensible heat:

$$
k_{H}=\frac{k_{0}{ }^{2}}{\log \left(\frac{z}{z_{0}}\right) \log \left(\begin{array}{c}
\underline{z} \\
z_{0 H}
\end{array}\right)}\left(1-5.2 R_{b}\right)^{2}
$$

where $K_{0}=0.4$ is von Kármán's constant, $Z_{0}$ and $Z_{0 H}$ are the effective roughness length for wind and sensible heat, respectively (Anderson et al., 2010). $R_{b}$ is the Richardson stability criterion, which accounts for boundary layer stability resulting from temperature inversions and reduced turbulent heat exchange:

$$
R_{b}=\frac{g}{T_{a}} \frac{\left(T_{a}-T_{\text {surf }}\right)\left(z-z_{0}\right)}{U^{2}}
$$

where $g=9.8 \mathrm{~m} \mathrm{~s}^{-2}$, is acceleration due to gravity. $R_{b}$ is applied in Equation 3.18 when $\mathrm{R}>0$ and $U>1$.

Latent heat transfer results from phase changes during mass exchange between the atmosphere and the glacier surface. For example, melting snow or ice uses energy at a rate of $334 \mathrm{~J} \mathrm{~g}^{-1}$ ( $L_{f}$ - the specific latent heat of fusion of ice), whilst condensation on the surface supplies energy for melt at a rate of $2834 \mathrm{~J} \mathrm{~g}^{-1}\left(L_{v}\right.$ - the specific latent heat of vapourisation). Phases changes at the surface are dependent on the vapour pressure gradient between the glacier surface and overlying air:

$$
Q_{E}=0.622 \rho_{i c e} k_{E} U L_{v} \frac{\left(q-q_{s}\right)}{p}
$$

where $k_{E}$ is the exchange coefficient for latent heat (Equation 3.18), $q$ is the vapour pressure of ambient air, $q_{s}$ is the vapour pressure of air at the glacier surface, and $p$ is air pressure.

Heat from rainfall $\left(Q_{R}\right)$ Sensible heat transfer from rainfall comprises a minor proportion of glacial energy budgets (Cuffey and Paterson, 2010):

$$
Q_{R}=c_{w} P T_{a}
$$

where $c_{w}$ is the specific heat capacity of water (Table 3.3), $P$ is the rain rate. Rainfall temperature is assumed to equal $T_{a}$.

Sub-surface heat flux $\left(Q_{S}\right)$ The sub-surface heat flux, also commonly referred to as ground heat flux, describes energy exchanges between the glacier surface and the glacier interior. As I assume that the ice is temperate and that the glacier surface is constantly at the melting point (Oerlemans, 1992), there is no temperature gradient, therefore $\mathrm{Q}_{S}=0$. 
Geothermal heat flux $\left(Q_{G}\right)$ Geothermal heat describes the energy retained within the Earth, which can contribute to basal melt of glaciers. The contribution of geothermal heat to glacier mass balance is generally considered negligible in comparison to the surface fluxes (Cuffey and Paterson, 2010). In continental settings average geothermal heat fluxes are c. $50-80 \mathrm{~mW} / \mathrm{m}^{2}$, which will melt approximately $6 \mathrm{~mm}$ water equivalent of temperate ice annually (Figure 3.2). However, geothermal heat fluxes show large spatiotemporal variation, according to age and lithology of the bed, volcanism, crustal thickness and radioactive decay (Van der Veen et al., 2007).

In active volcanic regions, convection and advection of heat to the surface via mantle upwelling and redistribution can raise the heat flux by several orders of magnitude (Figure 3.2). In glacierised, active volcanic regions, geothermal heat fluxes on the order of $10^{0}-10^{5} \mathrm{~W} \mathrm{~m}^{-2}$ have been inferred from glacier calorimetry (Clarke et al., 1989; Cuffey and Paterson, 2010). If sustained, such heat fluxes can have a non-trivial impact on glacier mass balance, however these extreme cases are typically only sustained over the order of days to weeks (e.g. Gudmundsson et al., 2004).

$$
\text { Melt }=\frac{Q_{G}}{\rho L_{f}}
$$

Given the spatial and temporal transience of geothermal heating events and the absence of data constraining past volcanic activity in the central North Island, it is not possible to include such effects into the palaeo-glacier simulations. Whilst it is possible that past volcanic activity may have impacted past glacier mass balance and ice dynamics, empirical observations from other glacierised, volcanically active regions have demonstrated that these effects are often highly localised and temporally restricted (Gudmundsson et al., 1997; Gudmundsson et al., 2004). It is therefore reasonable to assume that climate is the dominant driver of glacier behaviour over the timescales considered in this thesis. I employ a nominal geothermal flux of $1 \mathrm{~W} \mathrm{~m}^{-2}$ ( = $10 \mathrm{~cm}$ w.e. annual melt; Figure 3.2) and discuss the possible implications of past volcanism for the palaeoclimatic interpretations derived from glacier model experiments.

\subsubsection{Accumulation Model}

All precipitation when $T_{a}<0.5^{\circ} \mathrm{C}$ is assumed to fall as snow (Table 3.3). Potential contributions from avalanching are considered to be negligible, due to the low probability of non-glaciated terrain situated above the former valley glaciers on the volcanoes. This is consistent with the present-day, where few peaks exist at elevations greater than the contemporary glaciers on Mt. Ruapehu. The effects of wind redistribution on snow accumulation are also not accounted for in the accumulation model. This represents a 


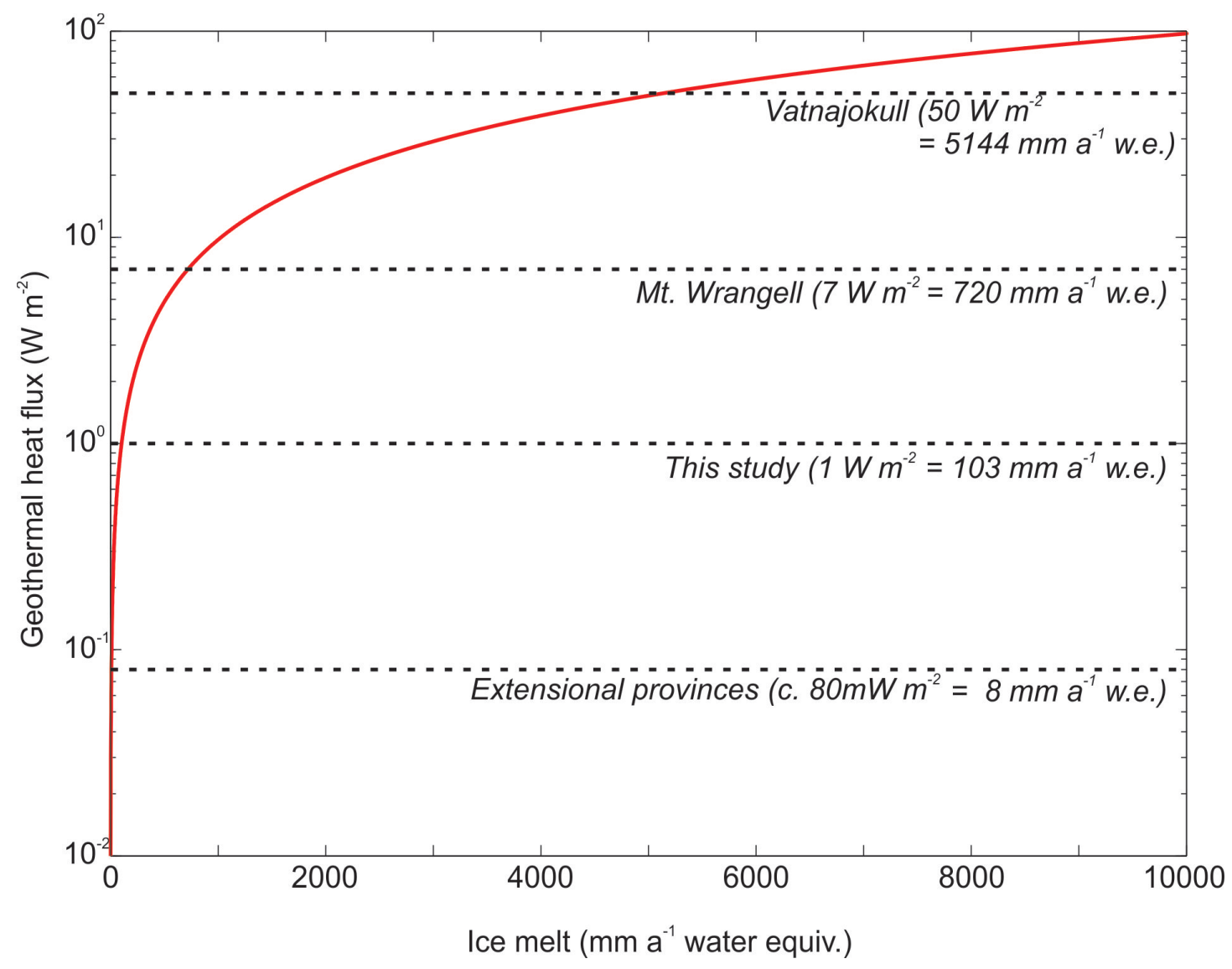

Figure 3.2: Annual melt total of temperate ice estimated for empirically derived geothermal heat fluxes from different geological settings (values taken from summary (p.418) of Cuffey and Paterson, 2010). Melt rates calculated using ice density of $917 \mathrm{~kg} \mathrm{~m}^{-3}$ and latent heat of fusion $=334 \mathrm{~kJ} \mathrm{~kg}^{-1}$ (Equation 3.22).

potential source of uncertainty, as previous mass balance investigations have noted the role of wind as a key control on the spatial variability in mass balance on Mt. Ruapehu (e.g. Krenek, 1959). Modelling of wind-driven snow accumulation is non-trivial (Dadic et al., 2010) and I discuss the potential role of this uncertainty for the palaeoclimatic interpretations made in Chapters 6 and 7.

\subsubsection{Ice flow model}

Glaciers transfer mass via a combination of internal deformation, basal sliding and bed deformation. These mechanisms form an important component of glacier response to climate change, therefore it is necessary to couple a numerical model describing ice flow to the mass balance model.

The material law describing the flow of glacier ice is that of an incompressible, viscous 
Table 3.3: Optimal energy balance and ice flow model parameter settings.

\begin{tabular}{|c|c|c|}
\hline Parameter & Value & Source \\
\hline \multicolumn{3}{|l|}{ Energy balance model: } \\
\hline Temperature lapse rate $\left(\frac{\delta T}{\delta z}\right)$ & $\begin{array}{l}\text { Seasonal (Table } \\
3.2 \text { ) }\end{array}$ & (Norton, 1985) \\
\hline Snow-rain threshold temperature $\left(T_{s}\right)$ & $0.5^{\circ} \mathrm{C}$ & $\begin{array}{l}\text { (Hendrikx and Hreinsson, } \\
\text { 2012) }\end{array}$ \\
\hline Snow albedo $\left(\alpha_{\text {snow }}\right)$ & 0.72 & (Oerlemans, 1992) \\
\hline Ice albedo $\left(\alpha_{i c e}\right)$ & 0.34 & $\begin{array}{l}\text { (Oerlemans and Knap, } \\
\text { 1998) }\end{array}$ \\
\hline Ice roughness $\left(z_{i c e}\right)$ & $0.004 \mathrm{~m}$ & $\begin{array}{l}\text { (Anderson and Mackin- } \\
\text { tosh, 2012) }\end{array}$ \\
\hline Snow roughness $\left(z_{\text {snow }}\right)$ & $0.001 \mathrm{~m}$ & (Brock et al., 2006) \\
\hline Modern snowline $(z E L A)$ & $2483 \mathrm{~m}$ asl & (Keys, 1988) \\
\hline \multicolumn{3}{|l|}{ Ice flow model: } \\
\hline Typical sliding velocity $\left(U_{c}\right)$ & $50 \mathrm{~m} \mathrm{yr}^{-1}$ & This study \\
\hline Glen's flow law coefficient $(A)$ & $\begin{array}{l}2.14 \times 10^{-16} \mathrm{~Pa}^{-3} \\
\mathrm{a}^{-1}\end{array}$ & (Paterson, 1994) \\
\hline Glen's flow law exponent $(n)$ & 3 & \\
\hline Characteristic driving stress $\left(\tau_{c}\right)$ & $100 \mathrm{kPa}$ & \\
\hline
\end{tabular}

fluid, and can be represented using the general Stokes flow equation for creeping motion:

$$
\mu \nabla^{2} u-\nabla p+f=0
$$

where $\mu$ is the dynamic viscosity of the fluid, $u$ is fluid velocity, $p$ is pressure and $f$ is an external force. Inertial terms that form part of the full Navier-Stokes equations are neglected due to the slow movement of glacial ice.

For ice, Equation 3.23 takes the form:

$$
\nabla \cdot \tau_{i j}^{\prime}-\nabla p+\rho_{i c e} g=0
$$

where the viscous force ( $\mu \nabla^{2} u$ in Equation 3.23) is represented by the deviatoric stress tensor $\left(\tau_{i j}^{\prime}\right)$ and the external force ( $f$ in Equation 3.23) is the weight of the ice.

Solving the full Stokes equation is computationally expensive (Leysinger Vieli and Gudmundsson, 2004), therefore many studies instead employ a simplified set of equations known as the 'Shallow Ice Approximation' (SIA; Hutter, 1983; Morland, 1984). The SIA equations were developed for efficient simulation of ice sheets and exploit the low aspect ratio $(H / W)$ of these ice masses, which mean that the driving stress can be 
assumed to be entirely balanced by vertical shearing at the bed (Pattyn, 2006). Thus, the effects of lateral shear and longitudinal extension/compression are neglected within the SIA and ice flow is simply related to changes in the surface slope and thickness of ice (Egholm et al., 2011). Whilst this assumption holds for large parts of the polar ice sheets, the SIA may not accurately represent the full stress fields of mountain glaciers, where bed topography can be complex and ice geometry aspect ratios can be high in comparison to ice sheets. However, comparison of full Stokes and SIA-based models shows that, in mountainous settings, the SIA produces comparable results to methods solving the full stress field (Leysinger Vieli and Gudmundsson, 2004; Le Meur et al., 2004). This method is therefore frequently applied in steady-state model simulations of past alpine glaciation (e.g. Plummer and Phillips, 2003; Doughty et al., 2013; Rowan et al., 2013), where uncertainty in the mass balance terms far outweighs that due to ice flow (Greuell, 1992; Leysinger Vieli and Gudmundsson, 2004).

In this thesis, I employ a vertically-integrated 2D ice flow model using the SIA (Kessler et al., 2006; Doughty et al., 2013). Ice flow velocity due to internal deformation $\left(U_{d}\right)$ is given as:

$$
\vec{U}_{d}=\frac{2}{5} A H \vec{\tau}_{b}^{n}
$$

where $\vec{U}_{d}$ is vertically-averaged ice velocity from internal deformation, $A$ is Glen's flow law coefficient, set to $A=2.14 \times 10^{-16} \mathrm{~Pa}^{-3} \mathrm{yr}^{-1}, \vec{\tau}_{b}$ is the gravitational driving stress $\left(\vec{\tau}_{b}=\rho g H \nabla z\right)$, and $n$ is Glen's flow law exponent, set to $n=3$ (Cuffey and Paterson, 2010).

Following Kessler et al. (2006), a sliding term is also included:

$$
U_{s}=U_{c} e^{1-\frac{\tau_{c}}{\bar{\tau}_{b}}}
$$

where $U_{c}$ is the characteristic sliding velocity, set to $U_{c}=50 \mathrm{~m} \mathrm{yr}^{-1}$, and $\tau_{c}$ is the gravitational driving stress that causes $U_{s}$, set to $\tau_{c}=100 \mathrm{kPa}$ (Cuffey and Paterson, 2010).

$$
\frac{d H}{d t}=M-\nabla \cdot \vec{q}
$$

where $H$ is ice thickness, $t$ is time, $\vec{q}$ is ice flux $\left(\vec{U}_{d}+\vec{U}_{s}\right)$ and $\mathrm{M}$ is mass balance.

Equation 3.27 evolves glacier geometry through time. Ice velocities are calculated on a grid offset from ice thickness and the flux gradients are used to update ice thickness using a forward explicit time-step (Hindmarsh and Le Meur, 2001). To account for 
boundary effects that may violate mass conservation in the finite difference formulation (e.g. Plummer and Phillips, 2003), the bed topography is smoothed using a 3x3 moving window to reduce high bed slopes in the upper catchment, and an ice flux correction is applied. For each cell, total ice divergence cannot exceed the total mass contained in the source cell. At each time step a check is carried out to make sure mass is conserved and if not, the excess ice is removed (sensu Plummer and Phillips, 2003).

\subsubsection{Model assessment}

As a test of model performance, Figure 3.3 compares modelled, steady state ice extent on Ruapehu, calculated using the energy balance model in combination with the ice flow model (model parameters in Table 3.3), against mapped ice extent and observed glacier ELAs (taken from Keys, 1988). Modelled ice is more extensive than observations in most catchments, particularly for Whangaehu and Whakapapa glaciers. In the Whangaehu catchment, the most likely reason for this mismatch is elevated geothermal heat flux around Crater Lake, which is not accounted for in the model. As Figure 3.3 shows, ice accumulates in the region currently occupied by Crater Lake (which fluctuates in temperature between $20-60{ }^{\circ} \mathrm{C}$ ), which is not the case in reality. The excess ice predicted by the model in this region feeds into several glacier catchments (largely the Whangaehu), causing the observed over prediction. It is notable that modelled ice extent in catchments that do not receive any/as much ice from Crater Lake (i.e. Mangaehuehu, Wahianoa) are better aligned with modern observations. The size of the modelled Whakapapa Glacier is also greater than observed, which is probably due to three reasons. First is the potential contribution from the excess ice in the Crater Lake region as discussed above. Second, the model resolution (100 m) smooths out the narrow rock lip that separates the Whakapapa catchment from Summit Plateau. Field observations show that this topographic constraint currently prevents ice leaving Summit Plateau, but this effect is not captured at the current model resolution. Third, this east facing glacier is exposed to prevailing westerly winds, which may may act to remove snow accumulation from the glacier. This process is not accounted for in the model. Despite the slight over-prediction of modelled ice extent, modelled ELAs of individual glaciers match closely with observed end of summer snowlines (Keys, 1988). The modelled ELAs of the Whangaehu, Mangatoetoenui, Mangaturuturu and Mangaehuehu glaciers all fall within or close to the observed ranges.

In summary, there is good agreement between the modelled and observed ice geometries on Mt. Ruapehu. Some important controls on present-day glacier distribution are not represented in the model, which cause some deviation between modelled and 
observed ice geometries. However, Crater Lake is believed to have formed in the Late Holocene (c. $3 \mathrm{ka}$; Donoghue et al., 1997), therefore post-dates the time periods of interest for glacier modelling applications in this thesis. Prior to $3 \mathrm{ka}$, the active vent location on Mt. Ruapehu is largely unknown and likely to have been transient, based on post-glacial lava distribution (e.g. Hackett and Houghton, 1989). Thus, although this currently represents an important energy source controlling snow accumulation patterns, it is not possible to constrain this for the past. Similarly, whilst small-scale topography not resolved by the model is also currently an important control on ice distribution, this is a smaller issue for previous periods when mountain glaciers were thicker and ice flow was less constrained by topographic undulations at short length scales (i.e. $<10^{2} \mathrm{~m}$ ). Thus, I conclude that the present day situation is well-represented by the input data and model formulation, which provides a good datum from which to simulate past ice geometries.
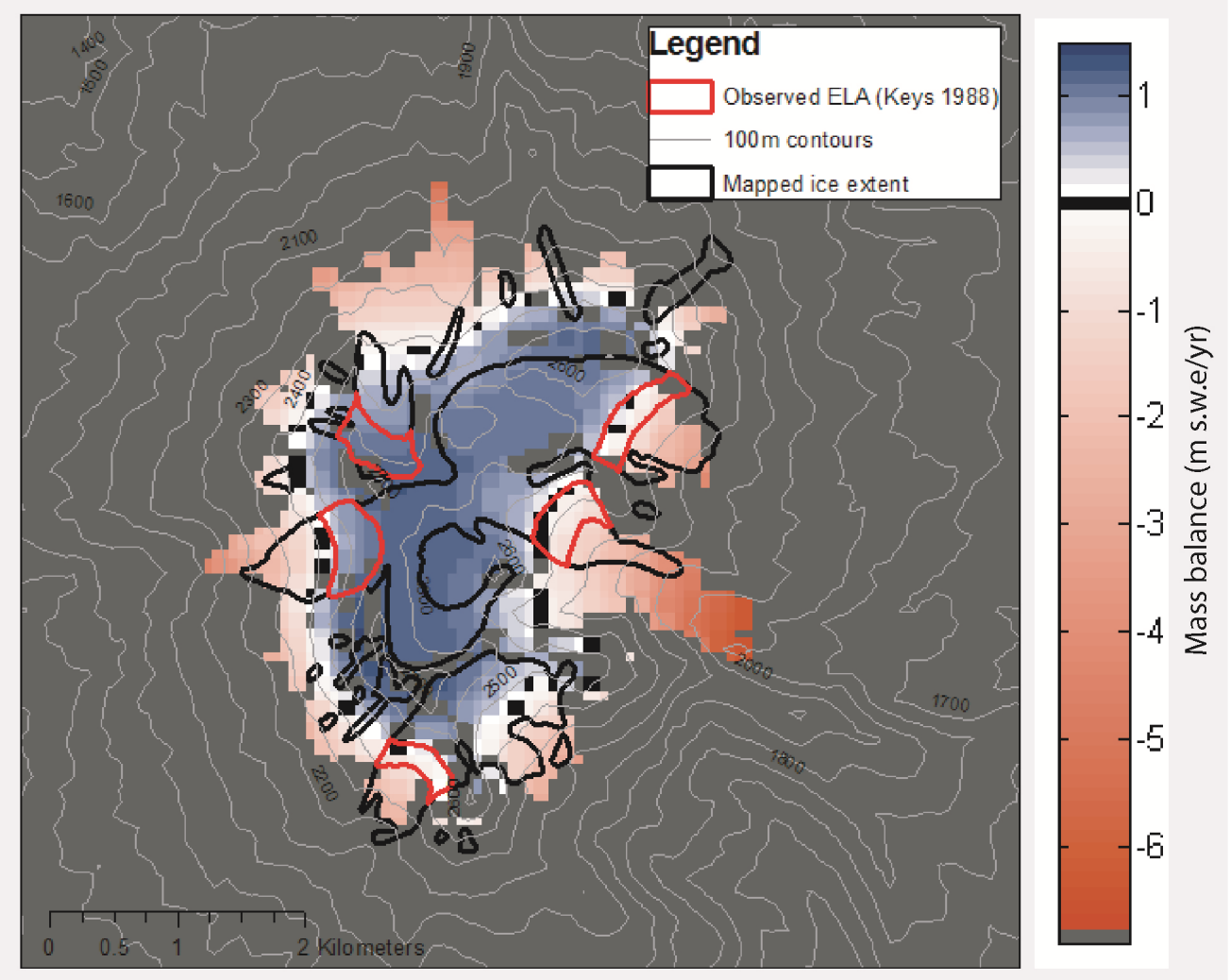

Figure 3.3: Steady state ice extent and mass balance on Mt. Ruapehu, compared to mapped ice extent and end of summer snowline ranges reported by (Keys, 1988). 


\subsubsection{Application of these methods in this thesis}

My goal is to constrain the timing and magnitude of past climate change in central North Island, using glaciers as a climate proxy. The four research chapters apply various combinations of the 3 methods described above to answer the research questions outlined in Chapter 2. I conducted field-based investigations of the glacial geology to increase the accuracy of existing mapping efforts, which have predominantly utilised remote-sensing products for landform interpretation (McArthur and Shepherd, 1990; Barrell, 2011). Coupled with cosmogenic surface exposure dating, this detailed mapping has shed new light on frequency and magnitude of past glacier fluctuations, as preserved in the local geomorphological record. For example, in Chapter 6 I target a moraine-set previously correlated to the LGCP by McArthur and Shepherd (1990). Field investigations showed that older moraines were present in vegetated regions down valley, which may instead pertain to the LGCP. Cosmogenic ${ }^{3} \mathrm{He}$ surface exposure dating supports this interpretation and places the formation of the inboard moraines in the late-glacial (c. 15-11 ka), which represents the northern most expression of glacial activity in New Zealand at this time. In Chapter 5, I use cosmogenic surface exposure dating to directly constrain the formation of moraines in Mangatepopo Valley, which occurred at c. 31-21 ka and c. $60 \mathrm{ka}$. Geomorphological and geomorphometric investigation of these landforms permitted extrapolation of these ages to glacial landforms across both volcanoes, which provided refined constraint of ice limits in the region during the LGCP.

Well defined and well dated former glacial geometries provide useful targets from which to extract quantitative palaeoclimatic information using glacier models. In Chapters 6 and 7, I constrain the range of climatic forcings associated with mapped and dated (or morphostratigraphically correlated) glacial extents, pertaining to the late-glacial (c. $13 \mathrm{ka}$ ) and the LGCP in New Zealand (c. 30-18 ka; Barrell et al., 2013). In these glacier simulations, present day temperatures are systematically reduced in order to find the degree of cooling, relative to present, that produces a steady-state glacier with a geometry that matches the geological constraints. Modern climate represents a useful datum from which to begin these simulations as it can be well constrained by observations. Each former glacier geometry can be reproduced by a range of combined temperature-precipitation changes. Due to uncertainty in past precipitation change, I present the range of palaeotemperature estimates that accompany precipitation changes of up to $\pm 50 \%$. In each of these studies, I draw on the existing palaeoclimatic literature (e.g. proxy reconstructions, climate model experiments) to inform whether precipitation was likely enhanced or reduced, relative to present. The addition of quantitative palaeoclimate reconstructions in central North Island increases the spatial resolution of palaeotemperature estimates, which are useful for tracing the drivers of past climatic 
change. For example, in Chapter 5 I compare my results to similar work from the central Southern Alps (Doughty et al., 2013; Kaplan et al., 2013) to test the theory that the magnitude of atmospheric cooling in North Island during the late-glacial climate reversal (c.13 ka; Barrell et al., 2013) was lower than that in South Island (Newnham et al., 2012).

A glacier modelling approach also allows exploration of unconstrained parameters, which improves understanding of both the uncertainty of the palaeoclimate estimates, and glacier-climate-topography relationships. For example, in all model applications I conduct sensitivity tests of energy balance and ice-flow parameters. In these tests, each parameter is varied in turn, in order to quantify the sensitivity of the palaeotemperature estimates to the parameter in question. Simpler glacier-climate reconstruction techniques, such as manual ELA reconstruction, have many inherent uncertainties that are often not quantifiable, therefore potential errors in the resultant palaeoclimate estimates are poorly constrained and often underestimated (Plummer and Phillips, 2003). In Chapter 6, I design model experiments that quantify the length sensitivity of glaciers on Mt. Ruapehu to climate changes that are unevenly distributed across the mass balance year (i.e. changing seasonality). This results in improved understanding of glacier-climate relationships, which is useful for interpreting the climatic significance of moraine records, particularly during abrupt climate events characterised by shifts in seasonality (Vandergoes et al., 2008; Sikes et al., 2013). In Chapter 7, I compare glacier model derived temperature estimates of the LGCP in central North Island using current topography and a geologically-based reconstruction of the land surface during the LGCP. These experiments permit assessment of whether post-glacial volcanism has altered the landscape to a degree that modern topography does not provide suitable boundary conditions for palaeoglacier modelling. 


\section{Chapter 4}

\section{A test of the cosmogenic ${ }^{3} \mathrm{He}$ production rate in the southwest Pacific $\left(39^{\circ} \mathrm{S}\right)$}

\subsection{Abstract}

Calculation of surface exposure ages, using in situ cosmogenic nuclides, requires knowledge of local production rates. Here, I report an attempt to calibrate cosmogenic ${ }^{3} \mathrm{He}$ production in the south west Pacific region. I present a new radiocarbon chronology that precisely constrains emplacement of the Murimotu Formation, a large debris avalanche deposit in central North Island, New Zealand (c. $830 \mathrm{~m}$ asl; 39 ${ }^{\circ}$ ), which occurred c. 10.4-10.6 cal. ka before present. Measurements of cosmogenic ${ }^{3} \mathrm{He}$ in large andesitic blocks deposited at the surface during this event yield a reference sealevel, high-latitude production rate of $120 \pm 12$ atoms gram ${ }^{-1} \mathrm{yr}^{-1}$, using the 'Lm' scaling scheme. This is consistent with a recent global compilation of production rates (Goehring et al., 2010), comprised predominantly of calibration sites located in the Northern Hemisphere. Thus, I conclude that the globally compiled cosmogenic ${ }^{3} \mathrm{He}$ production rate is appropriate for use in the south-west Pacific region. Using independent, proximal calibrations of cosmogenic isotopes ${ }^{10} \mathrm{Be}$ and ${ }^{14} \mathrm{C}$ from quartz in New Zealand, I derive cosmogenic ${ }^{3} \mathrm{He} /{ }^{10} \mathrm{Be}$ and ${ }^{3} \mathrm{He} /{ }^{14} \mathrm{C}$ production ratios of $32.2 \pm 3.2$ and $10.6 \pm 1.6$, respectively.

\subsection{Introduction}

Cosmogenic surface exposure dating is an important geochronological tool for constraining the timing of past climatic and geological events. Many cosmogenic nuclides exist (e.g. ${ }^{10} \mathrm{Be}, /{ }^{26} \mathrm{Al}, /{ }^{36} \mathrm{Cl}, /{ }^{3} \mathrm{He}, /{ }^{21} \mathrm{Ne}$ ), each with a unique set of properties that is 
useful in different applications and settings. Cosmogenic 3-Helium $\left({ }^{3} \mathrm{He}_{\text {cos }}\right)$ is a noble gas with a number of useful properties for Quaternary research. First, ${ }^{3} \mathrm{He}_{\cos }$ is stable, therefore can be applied to date very old surfaces (e.g. Schäfer et al., 1999). Second, it has a relatively high production rate (Goehring et al., 2010; Blard et al., 2013b) coupled with low detection limits, therefore has the potential to be applied to very young surfaces (e.g. Kurz and Brook, 1994; Fenton and Niedermann, 2014). Third, it is readily retained in common rock-forming minerals such as olivine (Kurz, 1986a) and pyroxene (Bruno et al., 1997; Schäfer et al., 1999), therefore it can be applied in quartz-deficient lithologies that preclude application of cosmogenic ${ }^{10} \mathrm{Be}$. Fourth, sample preparation procedures for ${ }^{3} \mathrm{He}_{\text {cos }}$ (e.g. (Bromley et al., 2014) are relatively inexpensive, both temporally and financially, in comparison other nuclides, whilst measurements are made on sector-field noble gas mass spectrometers, which are commercially available.

Accurate and precise knowledge of the rate at which cosmogenic nuclides are produced at the Earth's surface is a fundamental requirement for cosmogenic surface exposure dating applications. Geological calibrations of production rates provide increased accuracy for proximal applications as they integrate past changes in atmospheric pressure, geomagnetic and/or solar modulation effects, thus reducing the uncertainty inherent in existing scaling protocols (Balco et al., 2008). A relatively large number of production rate calibration studies exist for ${ }^{3} \mathrm{He}_{\text {cos }}$ (e.g. Kurz et al., 1990; Cerling and Craig, 1994; Licciardi et al., 1999, 2006; Dunai, 2001; Ackert et al., 2003; Blard et al., 2006, 2013b; Goehring et al., 2010; Amidon and Farley, 2011; Foeken et al., 2012; Fenton et al., 2013). However, these studies are largely restricted to the Northern Hemisphere (Figure 6.1). Recent compilations of these datasets (Goehring et al., 2010; Blard et al., 2013b) show ${ }^{3} \mathrm{He}_{\text {cos }}$ production is consistent over large spatial and temporal scales and suggest 119 \pm 9.9 atoms $\mathrm{g} \mathrm{yr}^{-1}$ (in pyroxene - Goehring et al., 2010, scaled with the 'Lm' protocol) as a widely applicable sea-level high-latitude (SLHL) production rate. However, this number and its consistency is challenged by Foeken et al. (2012), who report ${ }^{3} \mathrm{He}_{c o s}$ production rate estimates from a low latitude site in the Cape Verde islands $\left(15^{\circ} \mathrm{N}\right.$; Figure 6.1), which are up to $20 \%$ lower than Goehring et al. (2010). At the upper end, Ackert et al. (2003), consider past atmospheric pressure anomalies to explain relatively high (c. 130-139 atoms $\left.\mathrm{g} \mathrm{yr}^{-1}\right){ }^{3} \mathrm{He}_{\text {cos }}$ production rate estimates from Patagonia (47 $\left.\mathrm{S}\right)$.

Given the general paucity of Southern Hemisphere ${ }^{3} \mathrm{He}_{\cos }$ production rate sites (Figure 6.1) and the potential for regional anomalies in cosmogenic nuclide production (e.g. Foeken et al., 2012), I aim to test the ${ }^{3} \mathrm{He}_{\text {cos }}$ production rate of Goehring et al. (2010) in the south west Pacific region. To do this, I target a debris avalanche deposit on the lower northwestern flanks of Ruapehu (Topping, 1974; Palmer and Neall, 1989), a composite andesitic stratovolcano situated in the central North Island of New Zealand $\left(39^{\circ} 09^{\prime} \mathrm{S}\right.$, 


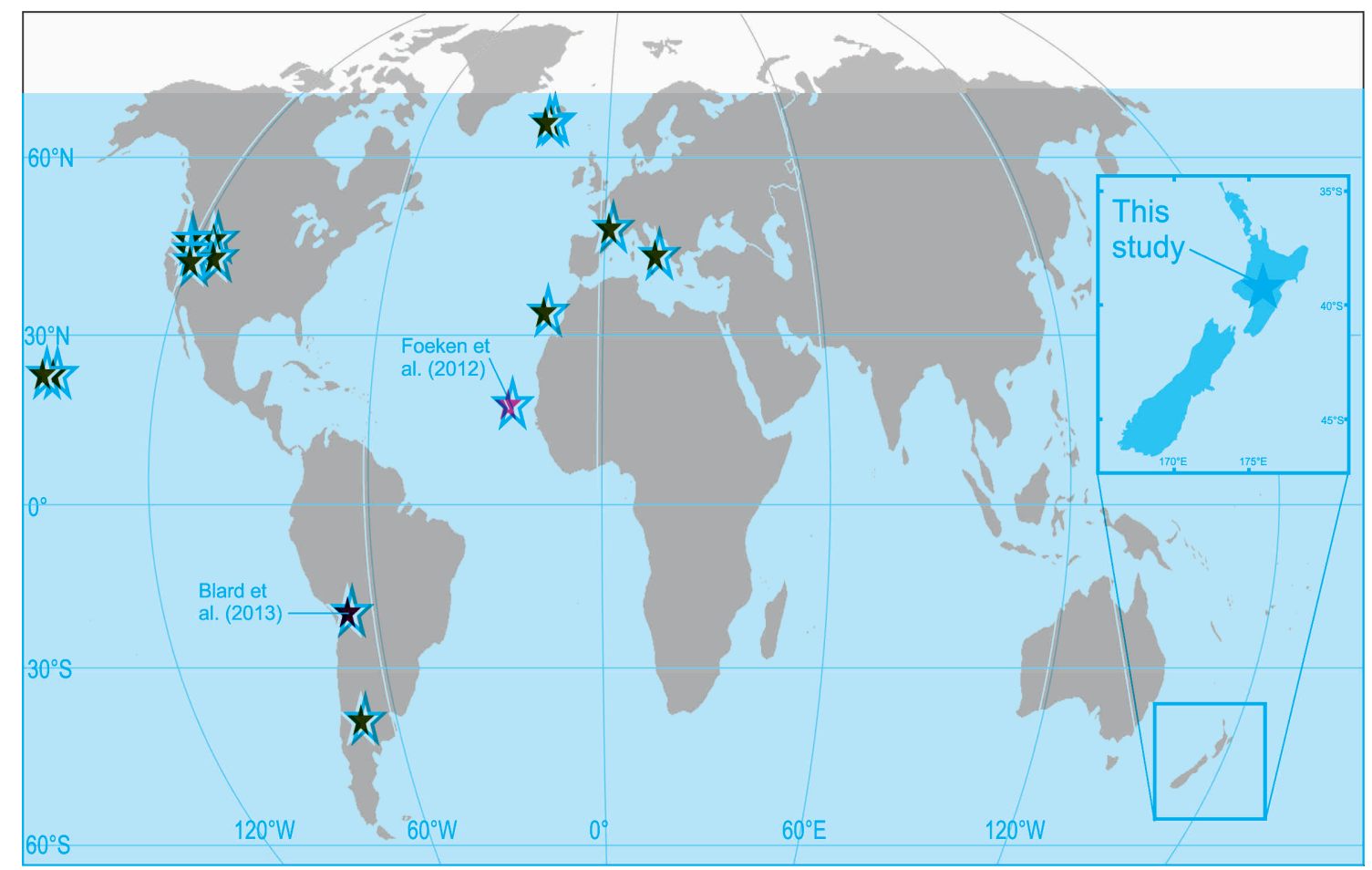

Figure 4.1: Distribution of individual calibration sites (red stars) that make up the existing global ${ }^{3} \mathrm{He}_{\text {cos }}$ production rate (from Goehring et al., 2010). Note the paucity of sites in the eastern and southern hemispheres. The location of this study is shown on the inset map.

$\left.175^{\circ} 29^{\prime} \mathrm{E}\right)$. This deposit includes buried organic horizons and prominently exposed andesitic boulders that protrude the present-day surface, thus providing an ideal situation to calibrate local ${ }^{3} \mathrm{He}_{\text {cos }}$ production. In this study, I first produce a refined, independent radiocarbon chronology for this event, before calibrating ${ }^{3} \mathrm{He}_{c o s}$ production using ${ }^{3} \mathrm{He}_{\text {cos }}$ concentrations measured in pyroxene separated from the associated andesitic boulders.

\subsection{Facies architecture and stratigraphy of the Murimotu Formation debris avalanche deposit}

The Murimotu Formation (MF) is a discrete debris avalanche deposit on the northwest slopes of Mount Ruapehu (Figure 4.2). The hummocky surface topography and occurrence of large volcanic clasts in this deposit has intrigued geologists for over 120 years (Hill, 1891; Park, 1926; Bossard, 1928; Topping, 1974; Hackett and Houghton, 1989; Townsend et al., 2008). Following observations of the May 18th 1980 syn-eruptive sector collapse of Mount St. Helens (Voight et al., 1981; Glicken, 1991), the MF was recognised as the product of a similar event sourced from the upper flanks of Mount Ruapehu (Hackett and Houghton, 1989; Palmer and Neall, 1989). Identification of similar deposits adjacent to Taranaki Volcano in western North Island (Neall, 1979; 
Ui et al., 1986; Neall and Alloway, 1986), led to the development of a sedimentary facies scheme applicable for topographically unconstrained debris avalanche deposits (Palmer et al., 1991).

The internal structure of debris-avalanche deposits can typically be subdivided into two major components: (1) fragmental rock clasts (FRCs), and (2) matrix. An FRC is defined as a fragmented or deformed piece of lava or layered volcaniclastic material commonly preserving stratification and/or intrusive contacts formed within the original volcanic edifice. The most commonly recognised FRC is andesitic lava that is commonly brecciated forming a diamicton of homogeneous composition. The scheme of Sundell and Fisher (1985) is used define the FRC size classes: boulder $(0.256-10 \mathrm{~m})$, megaboulder $(10-100 \mathrm{~m})$, block (100 - $1000 \mathrm{~m})$ and megablock $(1-10 \mathrm{~km})$. A gravel-sized class of FRCs $(0.002-0.256 \mathrm{~m})$ is also used.

The matrix is referred to as inter-clast matrix and is defined as all the material within the deposit surrounding the FRCs and $<0.002 \mathrm{~m}$ in diameter. It should not be confused with the matrix of an FRC, which is here termed intra-clast matrix. Inter-clast matrix includes all blended, unsorted, and unstratified parts of the deposit and consists of material ranging in size from clay to very coarse sand. Incorporated with the interclast matrix are rip-up clasts of plastically distorted soil, peat and tephra layers, clasts with variable rounding, and wood fragments derived from the terrain beneath. Inter-clast matrix is more abundant in inter-mound areas and is predominant in the distal and lateral margins of the deposit.

Three sediment facies are recognised within the MF (Palmer and Neall, 1989), subsequently referred to as axial $a$, axial b, and marginal facies (Palmer et al., 1991). Axial $a$ facies is defined as a mappable area where fragmental rock clasts (FRCs) dominate (2 - 36 m length), with $<30 \%$ inter-clast matrix, and where the surface topography is dominated by a concentrated area of steep sloping hills and mounds up to $30 \mathrm{~m}$ high with basal diameters as much as $300 \mathrm{~m}$. Axial b facies is defined as an area where the proportion of inter-clast matrix is subdominant to dominant (30-90\%) relative to FRCs and where the surface topography is dominated by sparsely distributed mounds and hills $<10 \mathrm{~m}$ high with basal diameters $<25 \mathrm{~m}$. This facies corresponds with the mixed block and matrix facies of (Glicken, 1986). Marginal facies is defined as an area where the proportion of inter-clast matrix is dominant (>90\%) relative to FRCs and where the surface is without mounds or hills. FRCs protruding at the surface in the areas mapped as the axial facies are the target of our cosmogenic surface exposure measurements. 
Existing age constraint for the MF debris avalanche event is scant. At some outcrops the MF is seen to underlie the time-transgressive Papakai tephra formation (c. 11.7 3.4 cal. ka BP; Topping, 1974; Donoghue et al., 1995), and overlie the Taurewa tephra formation (c. 13.8 - 11.2 cal. ka BP; Donoghue et al., 1999). Topping (1974) reports the only existing radiocarbon date from wood entrained within the MF, which places the event at $9.5 \pm 0.1{ }^{14} \mathrm{C}$ ka BP (c. 10.5-11.1 cal. ka BP OxCal v.4.2.3/SHCal13; Bronk Ramsey, 2009; Hogg et al., 2013).

To improve the age constraint for this event, I revisited several key sites from previous studies (Topping, 1974; Palmer and Neall, 1989). Stratigraphic descriptions were conducted to identify the context of radiocarbon samples within the MF facies framework (Figure 5.6). At both sampled sites, marginal facies predominates and can be subdivided into an upper oxidised portion (exhibiting strong post-depositional pedogenic weathering) and a lower anaerobic portion (exhibiting weak post-depositional pedogenic weathering). Fossil tree molds are commonly observed in the weathered upper portion, whilst wood and peaty material is preserved in the lower portion of the MF deposit. A road cutting to the north of Whakapapanui stream (39 $08^{\prime} \mathrm{S} ; 175^{\circ} 30^{\prime} \mathrm{E}$; Figure 4.2) presents east- and west-facing exposures on the northeastern margin of the deposit, which were previously sampled for radiocarbon dating by Topping (1974). At this same locality, I collected 5 further samples (Uoa-1, Uoa-2, Uo1, U6, U3a; Table 4.1) of bark and outer tree trunk wood entrained within the lower $1 \mathrm{~m}$ of the $\mathrm{MF}$, and a further 3 twig samples (U10, U12, U13; Table 4.1) were collected from a palaeosol immediately underlying the MF (Figure 5.6). Another wood sample (S2) was retrieved from one of the several flow-oriented tree trunks incorporated within marginal facies on the south-western margin of the MF ( $39^{\circ} 10^{\prime} \mathrm{S} ; 1^{\circ} 5^{\circ} 28^{\prime} \mathrm{E}$; Figure 4.2$)$. Wood samples were targeted to represent short-lived ( $<50$ years) growth material, including twigs, outer bark and growth rings from short-lived species identified primarily as Dracophyllum sp. (Table 4.1). 


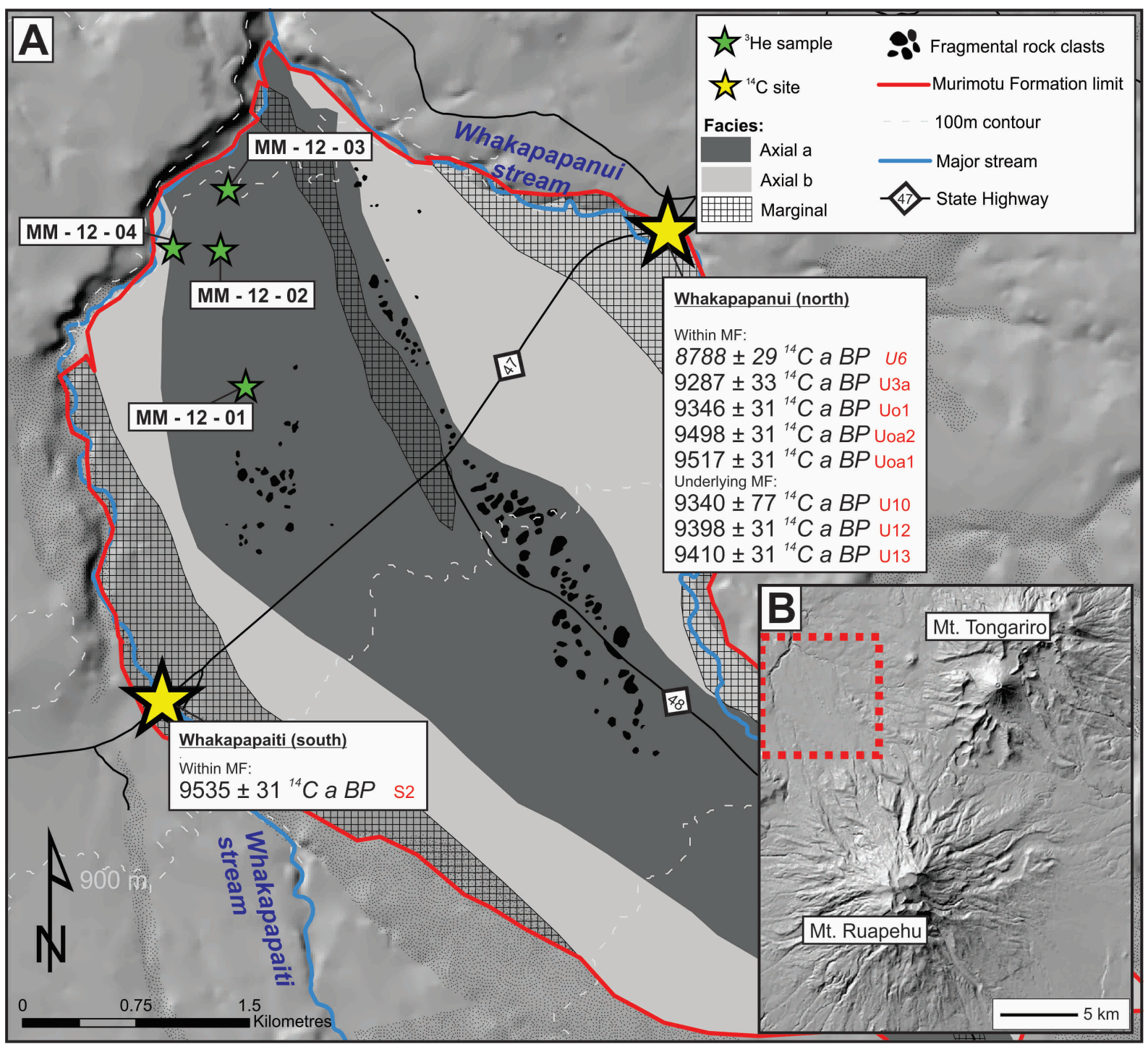

Figure 4.2: (A) The lower Murimotu Formation debris avalanche deposit with radiocarbon and ${ }^{3} \mathrm{He} e_{\text {cos }}$ sample locations. Sediment facies distribution taken from Palmer and Neall (1989); (B) Inset hillshade digital elevation model showing the location of $(A)$ (dashed red box) in the context of the local volcanic topography. 


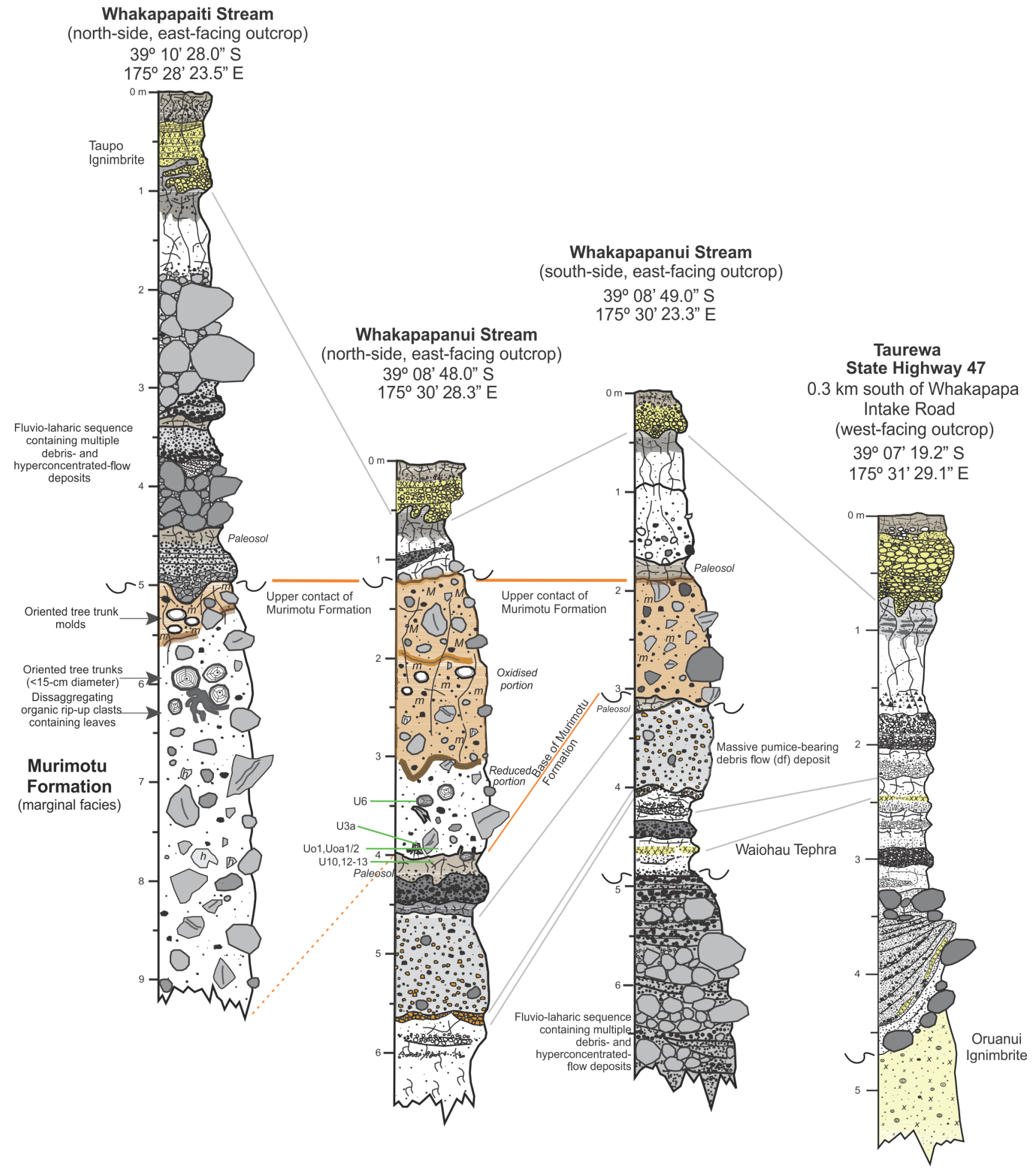

Figure 4.3: Volcaniclastic stratigraphy exposed at the Whakapapanui and Whakapapaiti sites showing the position of Murimotu Formation with respect to enveloping fluvio-laharic deposits, local-sourced basaltic-andesitic tephra and distal rhyolitic tephra from the Taupo and Okataina Volcanic Centres. The occurrence of the rhyolitic Taupo (232 AD), Waiohau (13.6 ka) and Kawakawa/Oruanui (25.4 ka) tephra beds within these sections (as indicated) provides supporting chronological control (Lowe et al., 2013; Vandergoes et al., 2013). The positions of radiocarbon samples associated with Murimotu Formation are also indicated. 


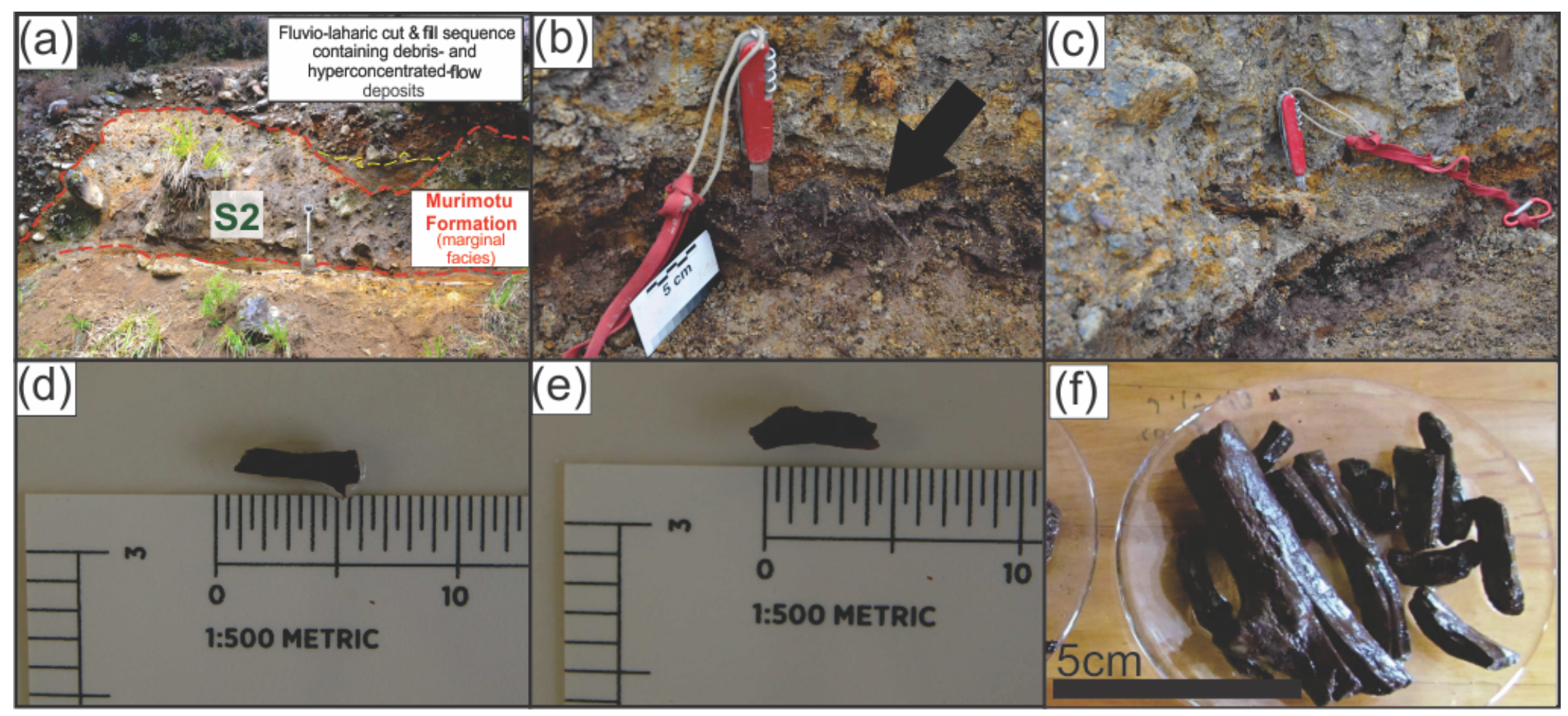

Figure 4.4: (a) Photograph of the sediment exposure at Whakapapaiti-south where marginal facies outcrops. Note the flow oriented tree trunk incorporated here. Sample'S2' was taken from this exposure and yielded an age of $9535 \pm 31{ }^{14} \mathrm{C}$ a BP. (b) Abundant small twigs (arrow - samples U10, U12, U13) within the well-developed palaeosol immediately beneath the Murimotu Formation at Whakapapanui-north. (c) Example of wood exposed within the Murimotu Formation at Whakapapanui-north. also note the organic horizon preserved beneath the marginal debris avalanche facies at this location. (d) Small twig (U10) from Whakapapanui-north, radiocarbon dated to $9341 \pm 77^{14} \mathrm{C}$ a BP. (e) Small twig (U12) from Whakapapanui-north, radiocarbon dated to $9398 \pm 31{ }^{14} \mathrm{C}$ a BP. (f) Various short-lived twig fragments found orented with debris avalanche flow direction at the basal contact with, and within, the Murimotu Formation. One twig (U3a) yielded a radiocarbon age of $9287 \pm 33{ }^{14} \mathrm{C}$ a BP. 


\subsection{Methods}

\subsubsection{Radiocarbon dating}

Radiocarbon samples were submitted to the Rafter Radiocarbon Laboratory of GNS Science, Lower Hutt, New Zealand (NZA samples) for analysis by accelerator mass spectrometry (AMS). Sample weights varied between 9-388 mg. Where observed, root hairs were manually removed from sample specimens using tweezers. Chemical pretreatment involved cellulose extraction and acid-alkali-acid exposure. Sample weights after pre-treatment were 2.1 - $33.7 \mathrm{mg}$. Carbon dioxide was generated using sealed tube combustion and yields varied between $0.7-1.9 \mathrm{mgC}$. Sample carbon dioxide was converted to graphite by reduction with hydrogen over an iron catalyst. Conventional ${ }^{14} \mathrm{C}$ ages are reported as defined by Stuiver and Polach (1977).

\subsection{2 ${ }^{3} \mathbf{H e}_{\cos }$ sample collection, preparation and measurement}

I sampled the surfaces of un-shattered, andesitic boulders embedded in the surface of the axial a facies of the MF (Figure 4.5). Post-depositional erosion and/or shielding of boulder surfaces would result in ${ }^{3} \mathrm{He}_{\cos }$ concentrations that under-represent the period of exposure since emplacement. I restricted sampling to clasts that are well-embedded in the MF and surfaces that remain free from soil or vegetation cover (Figure 4.5). Unfortunately, few such blocks exist, thus I was restricted to four boulder samples for the ${ }^{3} \mathrm{He}_{\cos }$ measurements. Samples were collected using a portable rock saw and by hammer and chisel. All samples were collected from the highest point of the parent boulder and boulders were up to $8 \mathrm{~m}$ tall, to minimise the potential for past burial, for example by volcanic ash. Boulder surfaces exhibited $<5^{\circ}$ dip relative to horizontal, thereby minimising self-shielding effects. Azimuthal elevations were measured in the field using a standard geological compass and clinometer. Sample locations and elevations were recorded using a Trimble GeoXH global positioning system, relative to the WGS84 datum. These data were differentially corrected using continuous measurements from GeoNet 'Chateau Observatory' ('VGOB') base station (39 ${ }^{\circ} 11^{\prime} 59^{\prime \prime}$ S, 175 32' 32'E; 1161 $\mathrm{m}$ asl), located c. $12 \mathrm{~km}$ to the south east. Post-processed horizontal and vertical uncertainties for individual sample locations are $<0.4 \mathrm{~m}$ and $<0.8 \mathrm{~m}$, respectively.

Thin section analysis showed pyroxene typically represents c. $10-15 \%$ of the total sample mass, with a modal grain size of c. 250-500 $\mu \mathrm{m}$. Whole rock samples were jaw-crushed, rinsed in de-ionised water and dry-sieved to isolate the desired size fraction. Density and magnetic separation techniques were used to separate c. 550-750 mg of pyroxene of (clino)enstatite pigeonite composition (Table 4.2). Following Bromley 
et al. (2014), mineral separates were twice leached in $5 \%$ hydrofluoric (HF) / 2 \% nitric $\left(\mathrm{HNO}_{3}\right)$ acid solution for 24 hours to remove adhering groundmass particles. This was followed by a separate $10 \%$ hydrochloric $(\mathrm{HCl})$ acid solution for 24 hours, to remove fluorite precipitates that resulted from exposure to HF. Leached mineral crystals were then visually inspected for purity and wrapped in aluminium foil. Each sample was completely degassed by heating in a furnace to $>1300{ }^{\circ} \mathrm{C}$ for 15 minutes, during which, gases were exposed to a liquid-nitrogen chilled, charcoal trap. Extracted gases were exposed to an SAES getter before being collected on a cryogenic cold trap at $<15$ Kelvin. Helium was then isolated from other noble gases by heating the cold trap to $45 \mathrm{~K}$. Mass spectrometry was conducted using a MAP 215-50 noble gas mass spectrometer at Lamont-Doherty Earth Observatory, New York relative to the Yellowstone 'Murdering Mudpot' (MM) helium standard ${ }^{3} \mathrm{He} /{ }^{4} \mathrm{He}$ ratio of $16.45 \mathrm{R}_{a}$, $\left(\right.$ where $\mathrm{R}_{a}={ }^{3} \mathrm{He} /{ }^{4} \mathrm{He}_{a i r}=$ $1.384 \times 10^{-6}$ ) using the protocol of Winckler et al. (2005).

\subsubsection{Production rate calculations}

All calculations are computed using the CRONUS-Earth exposure age calculator MATLAB code, as described by Balco et al. (2008), and modified for ${ }^{3} \mathrm{He}_{\cos }$ by Goehring et al. (2010) (version 1.1). Local surface pressure is calculated according to the standard atmosphere equation using mean sea level pressure and $1000 \mathrm{mb}$ air temperature values taken from NCEP-NCAR reanalysis (www . cdc. noaa.gov/ncep_reanalysis/). ${ }^{3} \mathrm{He}_{\text {cos }}$ concentrations are corrected for sample thickness using a uniform rock density of $2.7 \mathrm{~g} \mathrm{~cm}^{-3}$ and an effective neutron attenuation length of $160 \mathrm{~g} \mathrm{~cm}^{-2}$ (Dunne et al., 1999). Field measurements of azimuthal elevations are used to calculate topographic shielding for each sample site, which are negligible ( $<1 \%$; Table 4.3$)$. Sample thickness and topographic shielding corrections were computed using CRONUS-EARTH tools (available at: http://hess.ess.washington.edu/). Field investigations showed no obvious signs of erosion and observations from mid-winter showed that any snow accumulation at the sample elevation (c. $800-850 \mathrm{~m}$ asl) is short-lived and does not cover boulder surfaces. Similarly any volcanic ashfall from the proximal, active vents, is unlikely to persist on salient boulder tops. Thus, I do not consider surface erosion or past shielding to be a significant source of error at the sample sites and make no corrections for these effects. Regional uplift in the central North Island has been calculated as c. $0.6 \mathrm{~mm}$ yr- 1 for the past $500 \mathrm{ka}$ (Pulford, 2002), which has a negligible impact on helium concentration over the exposure time of our samples. Therefore, I do not include a correction for regional tectonic uplift. I present spallogenic ${ }^{3} \mathrm{He}_{\cos }$ production rates scaled to sea-level and high-latitude (SLHL) according to the five accepted scaling models and adopt the terminology implemented by Balco et al. (2008): St = Stone (2000) 


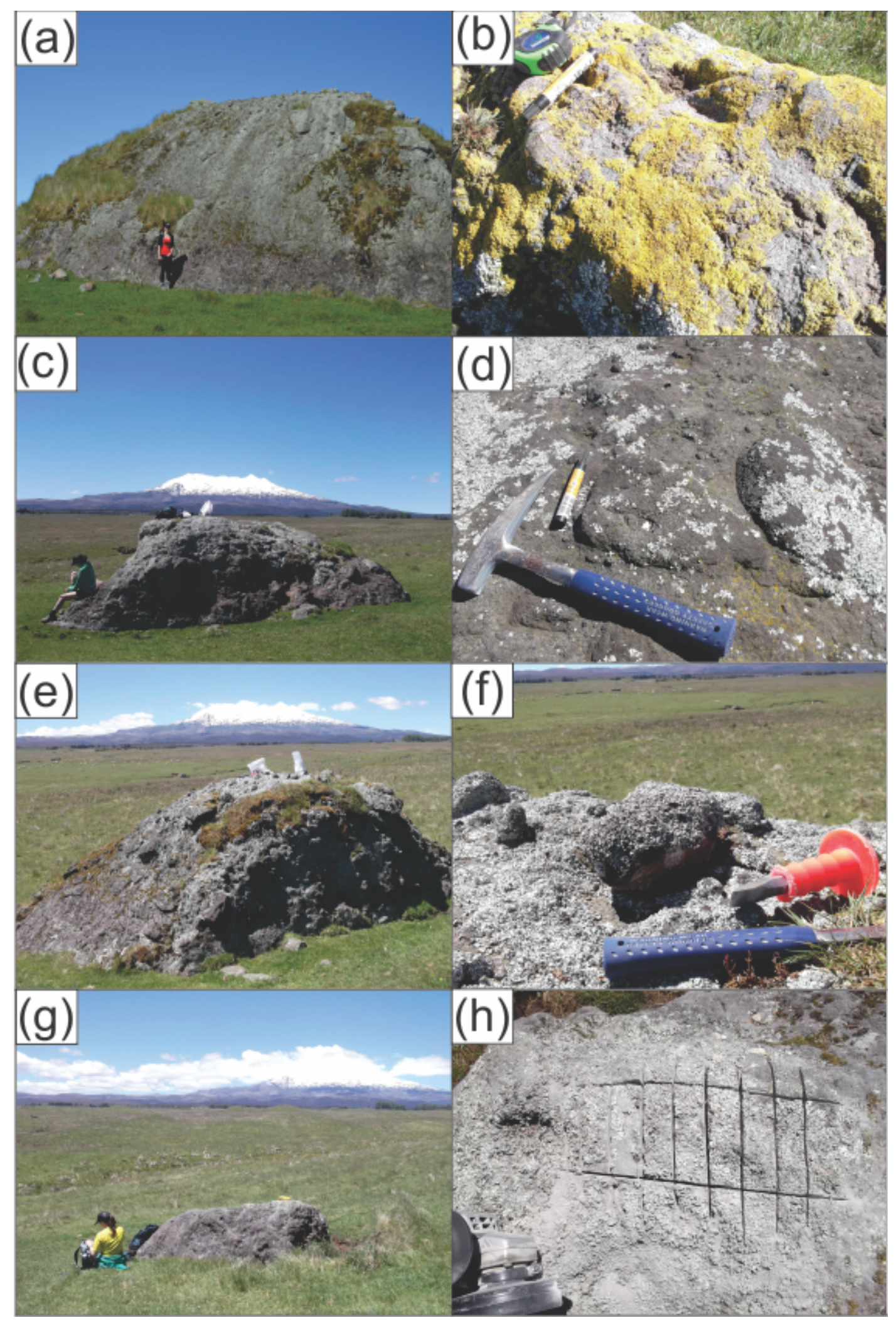

Figure 4.5: $(a, c, e, g)$ Parent boulders for samples MM-12-01, MM-12-02, MM-12-03 and MM-12-04, respectively; $(b, d, f, h)$ Sampled surfaces for each boulder, respectively. 
followingLal (1991); Du = Dunai (2001); De = Desilets et al. (2006); Li = Lifton et al. (2005); Lm = time-dependent adaptation of Lal (1991).

\subsection{Results and discussion}

\subsubsection{Radiocarbon dating of the Murimotu debris avalanche}

Eight out of the nine radiocarbon ages from wood fragments situated within and immediately beneath the MF, yield internally consistent ages that range from $9287 \pm 33$ to $9535 \pm 31{ }^{14} \mathrm{C}$ a BP (Figure 4.2; Table 4.1). These results also agree with the single previous determination of $9540 \pm 100{ }^{14} \mathrm{C}$ a BP (Topping, 1974). Sample 'U6' yielded an age of $8788 \pm 29{ }^{14} \mathrm{C}$ a BP, which is an outlier according to the Grubbs test $(p<0.05$; Grubbs, 1969). This anomalous result may arise from contamination by young carbon, such as infiltration of younger rootlets or humic acids, and I exclude this sample from further discussion of this dataset.

Table 4.1: Radiocarbon data from organic material entrained within ${ }^{a} / \mathbf{b u r i e d} \mathbf{b y}^{b}$ the Murimotu Formation debris avalanche. Sample U6, shown in italics, is an outlier $(p<0.05)$ according to the Grubbs test (Grubbs, 1969). Individual and combined age calibrations were calculated using OxCal v.4.2.3 (Bronk Ramsey, 2009) with the SHCal13 calibration curve (Hogg et al., 2013).

\begin{tabular}{|c|c|c|c|c|}
\hline Sample ID & Lab ID & Material & $\delta^{13} \mathrm{C}(\%)$ & $\begin{array}{l}{ }^{14} \mathrm{C} \text { age } \pm 2 \sigma \\
\left({ }^{14} \mathrm{C} \text { a } \mathrm{BP}\right)\end{array}$ \\
\hline \multicolumn{5}{|c|}{ Whakapapanui stream (north side; east-facing): } \\
\hline Uoa $^{a}$ & $40401 / 1$ & Bark & -26.09 & $9517 \pm 31$ \\
\hline $\mathrm{Uoa}^{a}$ & $40401 / 2$ & Bark & -26.17 & $9498 \pm 31$ \\
\hline $\mathrm{Uo}^{a}$ & $40401 / 3$ & Outer growth wood & -23.19 & $9346 \pm 31$ \\
\hline$U 6^{a}$ & $40401 / 6$ & Bark & -22.97 & $8788 \pm 29$ \\
\hline $\mathrm{U} 3 \mathrm{yr}^{a}$ & $40401 / 7$ & Outer growth wood & -28.67 & $9287 \pm 33$ \\
\hline $\mathrm{U} 13^{b}$ & $40401 / 9$ & Twig & -23.81 & $9410 \pm 31$ \\
\hline $\mathrm{U} 12^{b}$ & $40401 / 10$ & Twig & -28.48 & $9398 \pm 31$ \\
\hline $\mathrm{U} 10^{b}$ & $40401 / 11$ & Twig & -37.31 & $9341 \pm 77$ \\
\hline \multicolumn{5}{|c|}{ Whakapapaiti stream (north side; east-facing): } \\
\hline $\mathrm{S}^{a}$ & $40401 / 8$ & Wood & -22.04 & $9535 \pm 31$ \\
\hline
\end{tabular}

The remaining 8 samples comprise two groups with different stratigraphic relationships with the MF. Group 1 samples (Uoa1, Uoa2, Uo1, U3a and S2) represent organic material (bark and outer growth wood) incorporated within the MF (Figure 3, Figure 4.4), which suggests that the sampled material was entrained by the debris avalanche event. These samples may have been alive or dead at the time of entrainment, therefore the group may contain a mixture of individual radiocarbon decay signatures that provide direct or maximum ages for the debris avalanche event. Group 2 samples (U10, U12 and 
U13) are from twigs suspended within a c. $3 \mathrm{~cm}$ thick, organic-rich horizon immediately underlying the MF at the northern Whakapapanui site (Figure 3). I interpret this horizon to represent a leaf-litter environment that was present at the ground surface when the MF marginal facies was emplaced. Whilst Group 2 ages stratigraphically represent a maximum age for the $\mathrm{MF}$, the dates are from small (1 - $2 \mathrm{~mm}$ diameter) twigs, which typically have a short residence time in the forest floor environment $\left(10^{0}\right.$ $10^{1}$ a; Prescott et al., 1989). Radiocarbon dates from these samples therefore are likely to overlap, within measurement uncertainty, with the true age of MF emplacement.

Using chi-squared $\left(\chi^{2}\right)$ to test for a single population, Group 1 samples fail at the $95 \%$ confidence limit $\left(\chi^{2}(d f .=4, n=5)=49.4, p<0.05\right)$, which indicates that the deviation between individual ages is caused by processes other than measurement uncertainty. The internal variation of Group 2 samples is not significant at the $95 \%$ confidence interval $\left(\chi^{2}(d f .=2, n=3)=0.7, p>0.05\right)$, which suggests that they form a single age population. The probability density functions of individual calibrated ages (Figure 4.6) show that two sub-populations exist within Group 1. Samples S2, Uoa1 and Uoa2 (Subgroup 1a) are offset in age by c. 400 calendar years from the remaining samples, Uo1 and U3a (Subgroup 1b; Figure 4.6). I also note that Subgroup 1a is offset from the Group 2 samples (Figure 4.6). This offset can be explained by Subgroup 1a samples having died prior to entrainment in the debris avalanche and I discount them from further consideration. Subgroup $1 \mathrm{~b}$ and Group 2 samples are statistically indistinguishable $\left(\chi^{2}(d f .=4, n=5)=9.2, p>0.05\right)$, which supports our interpretation that Group 2 samples closely constrain the age of the MF debris avalanche. Given these stratigraphic and statistical analyses, I consider that Subgroup $1 \mathrm{~b}$ and Group 2 samples directly date MF emplacement. I combine these samples using the R-combine function implemented within the OxCal program, version 4.2.4 (Bronk Ramsey, 2009). This yields a calendar age of 10644 - 10425 cal. a BP for the debris avalanche event (Figure 4.6). For the purpose of ${ }^{3} \mathrm{He}_{\text {cos }}$ production rate calibration, I use the median of this range (10535 $\pm 110 \mathrm{cal}$. a $\mathrm{BP})$, plus 62 years, to account for the offset between the calibrated radiocarbon age in calendar years before AD1950 and ${ }^{3} \mathrm{He}_{\text {cos }}$ measurements, which represent cosmogenic nuclide accumulation until samples were collected in AD2012 (sensu Schaefer et al., 2009). This yields an age of $10597 \pm 110$ a (before AD2012), for the MF debris avalanche event.

\subsection{2 ${ }^{3} \mathrm{He}_{\cos }$ measurements and production rate calibration}

Individual ${ }^{3} \mathrm{He}$ concentrations of samples MM-12-01 to MM-12-04 range from 2.63 to $1.94 \times 10^{6}$ at. $\mathrm{g}^{-1}$, with measurement uncertainties of 3-4\% (Table 4.3). Our samples ex- 


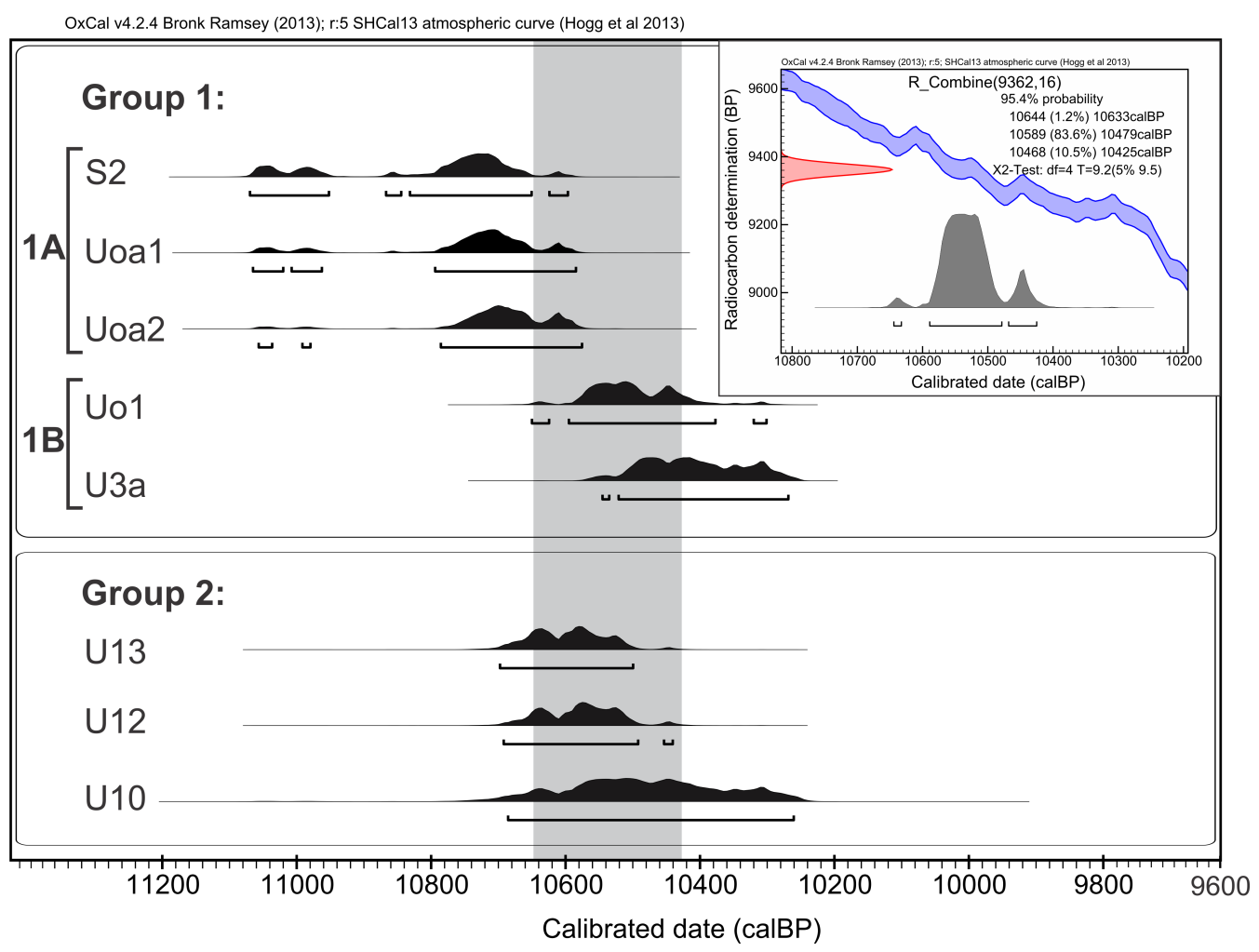

Figure 4.6: Probability density functions for individually calibrated radiocarbon ages, arranged by stratigraphic relationship with the Murimotu Formation. Brackets $1 A$ and $1 B$ denote sample subgroups (see text for discussion). Vertical grey bar and inset plot depict the calibrated age for emplacement of the Murimotu Formation (see text for details). Plots generated using functions implemented in the OxCal program (Bronk Ramsey, 2009), version 4.2.4 with SHCal13 (Hogg et al., 2013).

hibit high ${ }^{3} \mathrm{He} /{ }^{4} \mathrm{He}$ ratios (c.80-200R ; Table 4.3), together with low ${ }^{4} \mathrm{He}$ concentrations (Table 4.3). These characteristics reflect: (i) the youth of the parent material ( $<300 \mathrm{ka}$; Gamble et al., 2003), which restricts the time for radiogenic accumulation of ${ }^{4} \mathrm{He}$ (and ${ }^{3} \mathrm{He}$ ); (ii) sample preparation procedures (e.g. HF-leaching), which result in a higher purity pyroxene separates and absence or suppression of radiogenic ${ }^{4} \mathrm{He}$ (Bromley et al., 2014) and (iii) a negligible magmatic input. Following Dunai et al. (2007), I measured lithium concentrations in our samples to test for nucleogenic ${ }^{3} \mathrm{He}\left({ }^{3} \mathrm{He}_{n}\right)$ produced via thermal neutron reactions $\left({ }^{6} \mathrm{Li}(n, \alpha){ }^{3} \mathrm{H}{ }^{3} \mathrm{He}\right)$. Concentrations are higher than expected and vary between 9-44 ppm (Table 4.2). However, uranium and thorium concentrations are very low (c. 3-80 ppb; Table 4.2), which reduces the potential for thermal neutron production. Furthermore, our samples have young closure ages, individual crystals are large (c. 250-500 $\mu \mathrm{m}$ ) and they have undergone HF pre-treatment to remove the outer rims. The arguments above, combined with the fact that there is no correlation between the wide scatter in Li concentrations between samples and the internally consistent ${ }^{3} \mathrm{He}$ concentrations in the samples, lead me to conclude that thermal neutron produced ${ }^{3} \mathrm{He}$ is negligible in this study. Thus, I can robustly assume all ${ }^{3} \mathrm{He}$ to be of cosmogenic origin. 

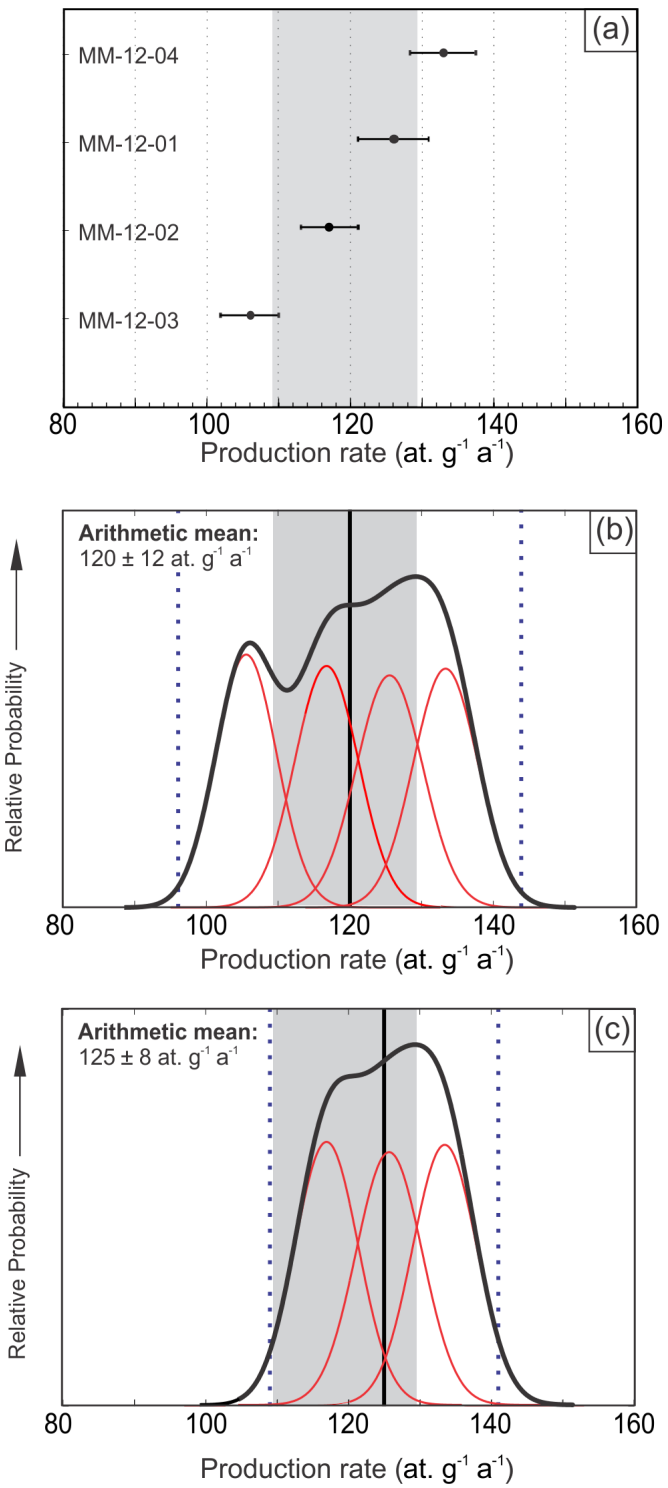

Figure 4.7: : (a) Sea-level, high-latitude (SLHL) production rates (1 sigma uncertainty) for individual ${ }^{3} \mathrm{He}_{\text {cos }}$ measurements, derived using the Lm scaling protocol. (b) Probability density function for the calibrated, SLHL (Lm scaling) ${ }^{3} \mathrm{He}$ cos production rate, derived using all samples $(\mathrm{n}=4)$. Vertical black bar denotes the arithmetic mean, with vertical dashed blue bars indicating the 2 sigma uncertainty range. (c) As for plot (b), but derived with sample MM-12-03 removed. Grey shading denotes globally compiled ${ }^{3} \mathrm{He}$ cos production rate in pyroxene, derived by Goehring et al. (2010). 
Table 4.2: Elemental composition of pyroxene samples (wt. \% unless stated) and pyroxene classification expressed as enstatite (En) ferrosilite (Fo) wollastonite (Wo). Major element analyses were undertaken using ICP-OES; U-Th-Li by ICP-MS.

\begin{tabular}{llllllllllllll}
\hline Sample & $\mathrm{Al}$ & $\mathrm{Ca}$ & $\mathrm{Fe}$ & $\mathrm{Mg}$ & $\mathrm{Mn}$ & $\mathrm{Na}$ & $\mathrm{Ti}$ & $\mathrm{U}(\mathrm{ppb})$ & $\mathrm{Li}(\mathrm{ppm})$ & $\mathrm{Th}(\mathrm{ppb})$ & $\mathrm{En}$ & $\mathrm{Fs}$ & Wo \\
\hline MM1201 & 0.72 & 1.24 & 16.40 & 14.08 & 0.36 & 0.03 & 0.20 & 18 & 44 & 80 & 64 & 33 & 3 \\
MM1202 & 1.02 & 1.28 & 14.37 & 15.88 & 0.19 & 0.03 & 0.08 & 4 & 15 & $<13^{a}$ & 69 & 27 & 3 \\
MM1203 & 0.77 & 1.89 & 16.05 & 13.93 & 0.35 & 0.04 & 0.10 & 3 & 9 & $<13^{a}$ & 63 & 32 & 5 \\
MM1204 & 0.72 & 1.47 & 16.93 & 14.56 & 0.36 & 0.04 & 0.22 & 19 & 38 & 60 & 63 & 33 & 4 \\
\hline
\end{tabular}

${ }^{a}$ Concentrations are below the detection limit

Table 4.3: ${ }^{3} \mathbf{H e}_{\cos }$ sample locations, geometrical corrections and noble gas mass spectrometry data

\begin{tabular}{|c|c|c|c|c|c|c|c|c|c|c|}
\hline Sample ID & $\begin{array}{l}\text { Latitude } \\
\left({ }^{\circ} S\right)\end{array}$ & $\begin{array}{l}\text { Longitud } \\
\left({ }^{\circ} \mathrm{E}\right)\end{array}$ & $\begin{array}{l}\text { eElevation } \\
(m \text { asl) }\end{array}$ & $\begin{array}{l}\text { Thickness } \\
\text { correction }\end{array}$ & $\begin{array}{l}\text { Shielding } \\
\text { correction }\end{array}$ & $\begin{array}{l}\text { Pyroxene } \\
\text { weight } \\
\text { (g) }\end{array}$ & $\begin{array}{l}{ }^{4} \mathrm{He} \pm 1 \sigma\left(10^{-10} \mathrm{cc}^{-}\right. \\
\left.S T P \mathrm{~g}^{-1}\right)\end{array}$ & $\begin{array}{l}{ }^{3} \mathrm{He} \pm 1 \sigma\left(10^{-14} \mathrm{cc}-\right. \\
\left.S T P g^{-1}\right)\end{array}$ & $\begin{array}{l}{ }^{3} \mathrm{He} \pm 1 \sigma\left(10^{6} \text { at. }\right. \\
\left.g^{-1}\right)\end{array}$ & $R / R_{a}$ \\
\hline MM-12-01 & 39.156 & 175.478 & 855 & 0.979 & 0.999 & 0.658 & $3.79 \pm 0.22$ & $9.48 \pm 0.33$ & $2.55 \pm 0.09$ & 181 \\
\hline MM-12-02 & 39.148 & 175.475 & 820 & 0.971 & 0.999 & 0.591 & $7.95 \pm 0.22$ & $8.50 \pm 0.31$ & $2.29 \pm 0.08$ & 77 \\
\hline MM-12-03 & 39.144 & 175.476 & 809 & 0.920 & 0.999 & 0.557 & $6.64 \pm 0.24$ & $7.22 \pm 0.30$ & $1.94 \pm 0.08$ & 79 \\
\hline MM-12-04 & 39.148 & 175.473 & 818 & 0.983 & 0.999 & 0.716 & $3.55 \pm 0.18$ & $9.81 \pm 0.29$ & $2.63 \pm 0.08$ & 199 \\
\hline
\end{tabular}


Table 4.4: Sea-level, high latitude ${ }^{3} \mathrm{He}_{\cos }$ production rates for individual and combined pyroxene samples from this study

\begin{tabular}{llllll}
\hline Sample(s) & $D e$ & $D u$ & $L i$ & $L m$ & $S t$ \\
\hline MM-12-01 & $132 \pm 5$ & $130 \pm 5$ & $143 \pm 5$ & $126 \pm 5$ & $129 \pm 5$ \\
MM-12-02 & $122 \pm 5$ & $121 \pm 5$ & $133 \pm 5$ & $117 \pm 4$ & $120 \pm 5$ \\
MM-12-03 & $111 \pm 5$ & $109 \pm 5$ & $120 \pm 5$ & $106 \pm 4$ & $108 \pm 5$ \\
MM-12-04 & $140 \pm 4$ & $138 \pm 4$ & $152 \pm 5$ & $133 \pm 4$ & $136 \pm 4$ \\
\hline Arithmetic mean $(\boldsymbol{n}=4)$ & $\mathbf{1 2 6} \pm \mathbf{1 3}$ & $\mathbf{1 2 4} \pm \mathbf{1 2}$ & $\mathbf{1 3 6} \pm \mathbf{1 4}$ & $\mathbf{1 2 0} \pm \mathbf{1 2}$ & $\mathbf{1 2 3} \pm \mathbf{1 2}$ \\
\hline Arithmetic mean $(n=3 ;$ MM-12-03 removed) & $132 \pm 9$ & $130 \pm 9$ & $143 \pm 10$ & $125 \pm 8$ & $128 \pm 8$ \\
\hline
\end{tabular}

Table 4.5: Ratios of New Zealand ${ }^{3} \mathbf{H e}_{\cos }$ production rate in pyroxene $\left({ }^{3} \mathbf{H e}_{\cos (N Z)}\right.$; this study) to the global compilation

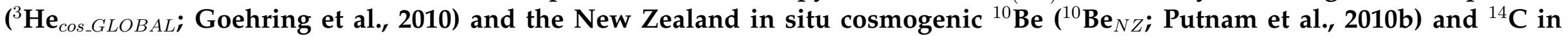
quartz $\left({ }^{14} \mathrm{C}_{(N Z)}\right.$; Schimmelpfennig et al., 2012) production rates.

\begin{tabular}{|c|c|c|c|c|c|}
\hline Samples & $D e$ & $D u$ & $\mathrm{Li}$ & $L m$ & St \\
\hline \multicolumn{6}{|l|}{ All $(n=4)$} \\
\hline${ }^{3} \mathrm{He}_{\text {cos }(N Z)} /{ }^{3} \mathrm{He}_{\text {COS_GLOBAL }}$ & $1.0 \pm 0.1$ & $1.0 \pm 0.1$ & $1.0 \pm 0.1$ & $1.0 \pm 0.1$ & $1.0 \pm 0.1$ \\
\hline${ }^{3} \mathrm{He}_{\text {cos }}(N Z) /{ }^{10} \mathrm{Be}_{(N Z)}$ & $32.6 \pm 3.3$ & $32.5 \pm 3.3$ & $33.0 \pm 3.4$ & $32.2 \pm 3.2$ & $32.1 \pm 3.2$ \\
\hline${ }^{3} \mathrm{He}_{c o s_{-}(N Z)} /{ }^{14} \mathrm{C}_{(N Z)}$ & $10.7 \pm 1.4$ & $10.5 \pm 1.3$ & $10.8 \pm 1.4$ & $10.6 \pm 1.3$ & $10.5 \pm 1.3$ \\
\hline \multicolumn{6}{|l|}{ MM-12-03 removed $(n=3)$} \\
\hline${ }^{3} \mathrm{He}_{\text {cos_ }(N Z)} /{ }^{3} \mathrm{He}_{\text {cos_GLOBAL }}$ & $1.0 \pm 0.1$ & $1.0 \pm 0.1$ & $1.0 \pm 0.1$ & $1.0 \pm 0.1$ & $1.0 \pm 0.1$ \\
\hline${ }^{3} \mathrm{He}_{\text {cos }(N Z)} /{ }^{10} \mathrm{Be}_{(N Z)}$ & $34.0 \pm 2.4$ & $33.8 \pm 2.4$ & $34.4 \pm 2.5$ & $33.5 \pm 2.2$ & $33.4 \pm 2.3$ \\
\hline${ }^{3} \mathrm{He}_{\text {cos- }(N Z)} /{ }^{14} \mathrm{C}_{(N Z)}$ & $11.1 \pm 1.1$ & $11.0 \pm 1.1$ & $11.2 \pm 1.2$ & $11.0 \pm 1.1$ & $11.0 \pm 1.1$ \\
\hline
\end{tabular}


When corrected for sample thickness and local shielding, I derive local ${ }^{3} \mathrm{He}_{\text {cos }}$ production rates of $199-253$ at. $\mathrm{g}^{-1} \mathrm{yr}^{-1}$, for the given sample locations and elevations (Table 4.3). When scaled to sea-level and high-latitude (SLHL) using the 5 standard scaling protocols, individual production rate estimates for each of the ${ }^{3} \mathrm{He}_{\cos }$ concentrations show good agreement with the compiled pyroxene production rates of Goehring et al. (2010) (e.g. Figure 4.7a). Taking the arithmetic mean ${ }^{3} \mathrm{He}_{\cos }$ concentration of our total sample population, scaled to SLHL $\left(1.28 \pm 0.13 \times 10^{6}\right.$ at. $\left.\mathrm{g}^{-1}\right)$, I derive a production rate of $120 \pm 12$ at. $\mathrm{g}^{-1} \mathrm{yr}^{-1}$ (Table 4.4). This rate is indistinguishable, within uncertainty, from that presented by Goehring et al. (2010) (119 \pm 9.9 at. $\mathrm{g}^{-1} \mathrm{yr}^{-1}$ for pyroxene; Figure 4.7a,b; Table 4.5). However, applying the reduced- $\chi^{2}\left(\chi_{\text {red }}^{2}\right)$ test for all samples gives $\chi_{\text {red }}^{2}=8.7$, which indicates a low probability that the dataset represents a single population. Figure $4.7 \mathrm{~b}$ shows that sample MM-12-03 forms a separate peak in the probability distribution for the total population, therefore may represent an outlier. This sample has a ${ }^{3} \mathrm{He}_{\text {cos }}$ concentration that is lower than the range of the other three samples, which could result from post-depositional erosion or previous shielding from ${ }^{3} \mathrm{He}_{\text {cos }}$ production. To test the influence of this possible outlier on our production rate, I re-calculate the production rates with sample MM-12-03 removed (Table 4.4). This yields a SLHL (Lm scaling) production rate of $125 \pm 8$ at. $\mathrm{g}^{-1} \mathrm{yr}^{-1}$ (Table 4.4), which remains within the range of Goehring et al. (2010) (Figure 4.7c; Table 4.5). Due to the low number of samples afforded by this study site, it is not possible to conclude with any certainty whether the ${ }^{3} \mathrm{He}_{\text {cos }}$ production rate in New Zealand falls in the centre (e.g. Figure $4.7 \mathrm{~b}$ ) or towards the upper end (e.g. Figure 4.7c) of that presented by Goehring et al. (2010). However, the close agreement between these rates does indicate that the globally-compiled ${ }^{3} \mathrm{He}_{\text {cos }}$ production rate is appropriate in the south west Pacific region, therefore it can be applied to exposure age and erosion rate applications with increased confidence.

Addition of $\mathrm{a}^{3} \mathrm{He}_{\text {cos }}$ calibration means that New Zealand now has independent calibrations of cosmogenic ${ }^{3} \mathrm{He}$ (this study), ${ }^{10} \mathrm{Be}$ (Putnam et al., 2010b) and ${ }^{14} \mathrm{C}$ (Schimmelpfennig et al., 2012) production rates. Ratios of production rates from co-existing minerals, or closely-spaced calibration sites provide insight to cosmogenic nuclide production (Schimmelpfennig et al., 2011). For example, co-existing measurements of cosmogenic ${ }^{3} \mathrm{He}$ and ${ }^{10} \mathrm{Be}$ have shown that, in some regions, the ratio of these nuclides changes with elevation (Gayer et al., 2004; Amidon et al., 2008), which suggests different elevation-dependence of production rates between nuclides. Previous ${ }^{3} \mathrm{He}_{p x} /{ }^{10} \mathrm{Be}_{q z}$ ratios have been reported from paired measurements in the Himalaya (32.3 \pm 0.9 Amidon et al., 2009, calculated by Blard et al., 2013a) and the high tropical Andes (33.3 \pm 0.9 at $4820 \mathrm{~m}$ asl; Blard et al., 2013a). Blard et al. (2013a) also derive a ${ }^{3} \mathrm{He}_{p x / o l} /{ }^{10} \mathrm{Be}_{q z}$ ratio of $31.7 \pm 4.1$ using globally-compiled, SLHL production rates for each nuclide. 
To compare these results with New Zealand, I take the arithmetic mean $(n=4)$ of our SLHL ${ }^{3} \mathrm{He}_{\cos }$ production rates in pyroxene and the weighted mean SLHL ${ }^{10} \mathrm{Be}$ production rates in quartz of Putnam et al. (2010b). This yields a ${ }^{3} \mathrm{He}_{p x} /{ }^{10} \mathrm{Be}_{q z}(\mathrm{NZ})$ production ratio of $32.2 \pm 3.2$ (Lm scaling; Table 4.5), which is indistinguishable from previously published ratios. Using the proximal in situ cosmogenic ${ }^{14} \mathrm{C}$ production rate of Schimmelpfennig et al. (2012), I derive a cosmogenic ${ }^{3} \mathrm{He}_{p x} /{ }^{14} \mathrm{C}_{q z}(\mathrm{NZ})$ ratio of 10.6 \pm 1.6 (Lm scaling; Table 4.5). These ratios provide a prediction for future tests of the production rates for each of these nuclides in New Zealand, in situations where quartz and pyroxene co-exist and have simple exposure histories. Such tests do not require independent age constraint.

\subsection{Conclusion}

I produced a precise radiocarbon chronology for the Murimotu Formation debris avalanche event on Mt. Ruapehu, which occurred 10.4-10.6 cal. ka BP. Using this independent age constraint, I present a ${ }^{3} \mathrm{He}_{\cos }$ calibration dataset for the south west Pacific region, which is consistent with the existing compilation production rate of Goehring et al. (2010). This rate can therefore be applied to exposure age and erosion rate applications in the south west Pacific region with increased confidence. Future work should aim to reduce the uncertainties of the existing ${ }^{3} \mathrm{He}_{\cos }$ production rate, through the addition of calibration sites with more robust sample sizes. This study, together with previous cosmogenic nuclide production rate calibrations from South Island $\left({ }^{10}\right.$ Be in quartz Putnam et al., 2010b; ${ }^{14} \mathrm{C}$ in quartz Schimmelpfennig et al. (2012)) means New Zealand now has independent constraints on each of the following production ratios: ${ }^{3} \mathrm{He}_{p x} /{ }^{10} \mathrm{Be}_{q z}(\mathrm{NZ})=32.3 \pm 3.2$ and ${ }^{3} \mathrm{He}_{p x} /{ }^{14} \mathrm{C}_{q z}(\mathrm{NZ})=10.6 \pm 1.6$. 


\section{Chapter 5}

\section{A cosmogenic ${ }^{3}$ He chronology of mountain glacier fluctuations in North Island, New Zealand $\left(39^{\circ} \mathrm{S}\right)$ during the last glacial cycle.}

\subsection{Abstract}

Establishing the timing and magnitude of southern mountain glacier fluctuations prior to, and through the Last Glacial Maximum, helps to identify the drivers and mechanisms of past climate change. In this study, I use cosmogenic ${ }^{3} \mathrm{He}$ surface exposure dating and tephrochronology to constrain the timing of past glaciation of Tongariro massif in central North Island, New Zealand ( $\left.39^{\circ} \mathrm{S}\right)$. Exposure ages from moraine boulders show that valley glaciation persisted between c. 31 - $21 \mathrm{ka}$. This followed an earlier period of glaciation, of similar magnitude to the LGM, that likely culminated late in Marine Isotope Stage 4 . The equilibrium line altitude of the reconstructed LGM glacier is c. $1400-1550 \mathrm{~m}$ asl, which is c. $930-1080 \mathrm{~m}$ lower than at present. This equates to a temperature depression of $5.6 \pm 1.1^{\circ} \mathrm{C}$, when uncertainties in the ELA reconstruction and temperature lapse rates are considered. Reinterpretation of moraine tephrostratigraphy, using major element geochemistry analysis, shows that ice retreat and climatic amelioration at the last glacial termination was well underway prior to $14 \mathrm{ka}$. Good agreement between the timing and magnitude of glacier fluctuations in central North Island and the Southern Alps indicate a response to a common climatic forcing during the last glacial cycle. 


\subsection{Introduction}

Explaining the drivers of Quaternary climate cycles in the Southern Hemisphere remains an outstanding goal of palaeoclimate research. New Zealand is one of the few locations in the Southern Hemisphere where terrestrial palaeoclimate can be reconstructed. Furthermore, it is ideally situated to record fluctuations of the southern westerly winds and the oceanic subtropical and subpolar fronts (Figure 6.1), which are considered to have played an important role in past climate dynamics (Denton et al., 2010). Regional tectonic uplift and localised effusive volcanism have resulted in high elevation and high relief topography in both the North and South Island of New Zealand, which support contemporary glaciers spanning latitudes from $39-46^{\circ} \mathrm{S}$. Empirical and model-based analyses show contemporary glacier mass balance in New Zealand is most sensitive to changes in atmospheric temperature (Oerlemans, 1997; Anderson and Mackintosh, 2006; Anderson et al., 2010; Brook et al., 2011). Steep mass balance gradients and relatively high ice velocities mean that mass balance changes are translated to the termini of mountain glaciers over timescales of $10^{1}-10^{2}$ yrs (Oerlemans, 1997; Purdie et al., 2014). Geological records of past glacier fluctuations in New Zealand therefore represent an important proxy for past climatic change in the southern mid-latitudes (e.g. Anderson and Mackintosh, 2006; Schaefer et al., 2006, 2009; Kaplan et al., 2010, 2013; Putnam et al., 2010a, 2012, 2013a,b; Golledge et al., 2012; Barrows et al., 2013; Doughty et al., 2013; Rother et al., 2014).

Existing reconstructions of late Quaternary glacier fluctuations in New Zealand have predominantly concentrated on large outlet glaciers that drained the central Southern Alps (e.g. Porter, 1975; Suggate and Almond, 2005; Schaefer et al., 2006; Barrows et al., 2013; Putnam et al., 2013b; Rother et al., 2014). Radiocarbon and luminescence dating of peat and loess units, interbedded with glacial till and glaciofluvial outwash, have provided the chronostratigraphic framework for this region (Suggate, 1990; Suggate and Almond, 2005). More recently, cosmogenic surface exposure dating of moraines has provided the means to directly constrain the timing and magnitude of past glacier fluctuations (Schaefer et al., 2006; Barrows et al., 2013; Putnam et al., 2013a,b; Rother et al., 2014). During the last glacial cycle, glacier length in the Southern Alps peaked relatively early (c. 32-26 ka; (Suggate and Almond, 2005; Putnam et al., 2013b; Barrows et al., 2013; Rother et al., 2014)), in comparison to global ice volume (Clark et al., 2009). At this time, local equilibrium line altitudes were depressed by c. $850 \mathrm{~m}$ and temperatures were c. $6-6.5^{\circ} \mathrm{C}$ colder, relative to present (Golledge et al., 2012). Subsequently, glaciers fluctuated about these positions until at least c. $18 \mathrm{ka}$ before rising temperatures resulted in widespread deglaciation (Schaefer et al., 2006; Putnam et al., 2013a,b; Rother et al., 2014). Recent work by Kelley et al. (2014) and Schaefer et al. (2015) have 
shown that the former Pukaki glacier in central Southern Alps exceeded its LGM extent multiple times during the last glacial cycle, in advances that culminated at c. $42 \pm 1 \mathrm{ka}$ and $65 \pm 3 \mathrm{ka}$. Previous work had suggested the occurrence of significant pre-LGM glacial advances, but the exact timing of these events was poorly resolved due to low chronological precision or small sample populations (Preusser et al., 2005; McCarthy et al., 2008; Sutherland et al., 2007).

Resolving the timing and magnitude of late Quaternary glacier fluctuations in locations outside of the central Southern Alps will provide insight to the synchroneity and climatic gradients of past climate change in this region. In this study, I use cosmogenic ${ }^{3} \mathrm{He}$ exposure dating, tephrochronology and equilibrium line altitude (ELA) reconstruction techniques, to constrain the timing and magnitude of glacier fluctuations on Tongariro massif, central North Island (39 $\mathrm{S})$.

\subsection{Setting}

\subsubsection{Regional climatic situation}

Situated between $34-47^{\circ} \mathrm{S}$ in the south-west sector of the Pacific Ocean, New Zealand spans subtropical and subpolar climes (Figure 6.1), therefore is highly sensitive to regional climatic fluctuations (Newnham et al., 1999). Westerly atmospheric circulation dominates between $30-60^{\circ} \mathrm{S}$ and is responsible for the eastward migrating troughs and anticyclones that define weather variability in New Zealand year-round (Sturman and Tapper, 1996). Meanwhile, interannual-decadal air temperature anomalies in New Zealand are strongly influenced by upwind sea surface temperatures (Sutton et al., 2005). The latitudinal range and high topographic relief of the New Zealand landmass result in meridional and zonal gradients in air temperature and precipitation respectively. Contemporary oceanic influences on North Island, New Zealand (34-41 ${ }^{\circ} \mathrm{S}$ ) are largely sub-tropical in nature, predominantly originating from an eastward flowing branch of the equatorial-sourced East Australian Current, known as the Tasman Front, which descends the northeast coast before continuing eastwards along the northern margin of the Chatham Rise (Figure 6.1). In contrast, South Island (40-47 ${ }^{\circ} \mathrm{S}$ ) intersects the sub-tropical front (STF), where sub-tropical gyres and sub-antarctic water masses converge, representing a temperature, salinity and nutrient boundary, which defines the northern margin of the Southern Ocean (Sikes et al., 2009). Consequently, steep, zonal and meridional sea surface temperature (SST) gradients exist across New Zealand. For example, in the far north annual SSTs average c. $20^{\circ} \mathrm{C}$ compared to c. $10{ }^{\circ} \mathrm{C}$ in the south (Uddstrom and Oien, 1999). 


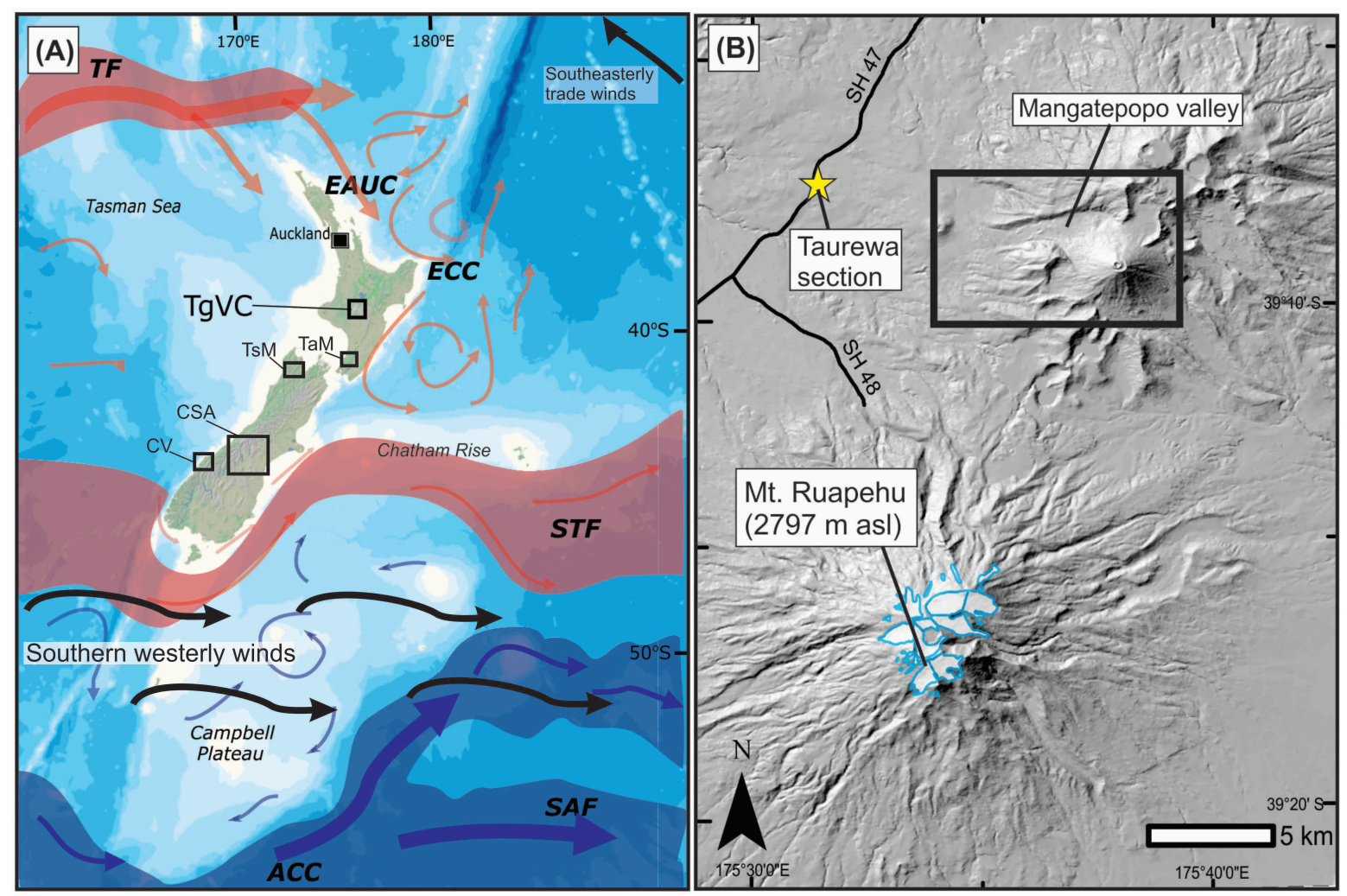

Figure 5.1: (A) Contemporary general atmospheric and oceanic circulation in New Zealand and locations of sites referred to in text (background image sourced from National Institute for Water and Atmospheric research (NIWA)). Sites: TgVC = Tongariro Volcanic Centre; TaM = Tararua Mts.; TsM = Tasman Mts.; CSA = Central Southern Alps; $C V=$ Cascade valley. Ocean currents: $E A U C=$ East Australian Current; $E C C=$ East Cape Current; STF $=$ Sub-tropical front; $S A F=S u b-$ Antarctic Front; $A C C=$ Antarctic Circumpolar Current; (B) Hill-shaded digital elevation model (Columbus et al., 2011) of the Tongariro massif and Mt. Ruapehu, with the main study region defined (black outline). The location of proximal tephra reference site at Taurewa and Mt. Ruapehu glacier outlines according to Keys (1988) are also shown.

\subsubsection{Study site and previous work}

For the glacial reconstruction, I target glacial landform assemblages on the western flanks of the Tongariro massif in central North Island $\left(39^{\circ} 08^{\prime} \mathrm{S}, 175^{\circ} 39^{\prime} \mathrm{E}\right)$. This volcano forms part of Tongariro Volcanic Centre ( $\mathrm{TgVC})$, an area of andesitic volcanism at the southwestern end of Taupo Volcanic Zone. Tongariro massif comprises 17 coalescing volcanic vents, with ages ranging from c. 270 ka to present (Hobden et al., 1996). The local climate, as recorded at Whakapapa village (1097 m asl) located $15 \mathrm{~km}$ SSW of Tongariro, is characterised by low seasonal precipitation variability, with winter precipitation averaging $762 \mathrm{~mm}$, compared to $624 \mathrm{~mm}$ in summer. Monthly mean 
temperatures range from c. $13{ }^{\circ} \mathrm{C}$ in February to c. $3{ }^{\circ} \mathrm{C}$ in July, with an annual average of $7.5^{\circ} \mathrm{C}$ (1981-2010; NIWA, 2014).

Geomorphological evidence for past glaciation on Tongariro massif has long been recognised (Mathews, 1967; Topping, 1974), however lack of chronological constraint has so far precluded any palaeoclimatic interpretation. Mathews (1967) describes conspicuous, lateral moraines in several valleys radiating from the volcano and suggests that they correlate with late Pleistocene moraines of the Southern Alps, based on their size and degree of preservation. Topping and Kohn (1973) identify two rhyolitic horizons in a soil section that overlies a large lateral moraine in the Mangatepopo valley. Using analyses of titano-magnetite assemblages, they correlate the lower horizon to the Rerewhakaaitu Tephra, which erupted from Okataina Volcanic Centre (OVC) c. $17.5 \pm$ $0.5 \mathrm{ka}$ BP (Lowe et al., 2013). This finding was then used to stratigraphically correlate the upper horizon to the Waiohau Tephra (cf. Donoghue et al., 1995), also sourced from the OVC, at $14.0 \pm 0.2 \mathrm{ka}$ (Lowe et al., 2013). On the eastern flanks of Tongariro, Cronin and Neall (1997) identified both the Waiohau and Rerewhakaaitu Tephras at the base of soils overlying lateral moraines. On nearby Mt. Ruapehu (2797 m asl), situated $15 \mathrm{~km}$ to the south west, McArthur and Shepherd (1990) identified geomorphological features representative of a former ice cap drained by several outlet glaciers that reached $c$. $1200 \mathrm{~m}$ asl. They suggest the former ice mass existed during the LGM, based on the presence of the Kawakawa/Oruanui Tephra (25.4 $\pm 0.2 \mathrm{ka}$ - Vandergoes et al., 2013) in moraine-bound glaciolacustrine deposits.

\subsubsection{Mangatepopo Valley}

The Mangatepopo valley is c. $6 \mathrm{~km}$ long and 1 - $2 \mathrm{~km}$ wide, with small, westwardflowing under-fit streams draining both the northern and southern valley margins, which converge at the valley mouth to form the Mangatepopo Stream (Figure 5.2). The Mangatepopo Stream flows northwards, before forming a tributary of the Whanganui River, which is a major drainage channel for the eastern-central North Island.

At the head of the Mangatepopo valley, South Crater is a large bedrock amphitheatre, which is $1 \mathrm{~km}$ across at its widest point and $250 \mathrm{~m}$ deep (Figure 5.2; Figure 5.3a). At $1967 \mathrm{~m}$ asl, Mt. Tongariro forms the highest point on the south-facing back wall of South Crater, whilst the Holocene-aged volcanic cone of Mt. Ngauruhoe (2287 m asl) is situated c. $3 \mathrm{~km}$ to the south. Following Mathews (1967), I interpret South Crater as a glacial cirque that served as the main accumulation centre for the former Mangatepopo glacier. The flat-bottomed, cirque floor is c. $1700 \mathrm{~m}$ asl, although this contemporary 
elevation represents infilling by an unknown thickness of post-glacial volcanic products. Bedrock spurs forming the mouth of the cirque have been partially overprinted by Mt. Ngauruhoe lavas, however these spurs clearly curve towards the southwest, which indicates the direction of former ice flow from this accumulation zone. To the southwest of Mt. Tongariro peak, the outer, western-facing flank of South Crater exhibits a stacked sequence of truncated lava flows in a steep, but shallow, concave amphitheatre, which is suggestive of headward erosion by a westward-flowing glacier. Field investigations show that bedrock exposures in this region exhibit smoothed surfaces, indicative of glacial abrasion by a temperate ice-mass (Hobden et al., 1996; Figure 5.2). Several radiometric $\left({ }^{40} \mathrm{~K} /{ }^{40} \mathrm{Ar}\right)$ ages from lavas show that cone-building in the South Crater region occurred c. 70 - $100 \mathrm{ka}$ (Figure 2.6). These dates provide a maximum bracketing age for the creation of the erosional glacial landforms.

The surface of the valley floor is convex, representing post-glacial infilling by lava flows and pyroclastics from the nearby volcanic vents. Both valley sides exhibit truncated lava cliffs, aligned parallel to the west-east trending valley axis, and are interpreted as having been glacially cut. On the northern edge of Pukekaikiore (Figure 5.2), two such vertical cliffs are stacked on top of one another, separated by a clear bench, perhaps indicative of multiple erosive periods, by ice masses of differing thickness. K/Ar dates from Pukekaikiore lavas range between c. 200-100 ka, suggesting emplacement prior to the peak of the last glacial cycle (Hobden et al., 1996).

Multiple lateral moraines exist on both valley sides and can be differentiated chronologically, based on morphostratigraphic criteria. This distinction is clearest on the lower portion of the northern valley side where two large lateral moraines have significantly different crest heights and widths (Figure 5.3b). Topographic profiles, aligned perpendicular to the moraine crest orientation illustrate the differing morphologies of these landforms (Figure 5.2B). The outer moraine (M3) is c. $20 \mathrm{~m}$ tall, with a highly rounded crest, whilst the inner moraine (M2) is sharp-crested and significantly taller. I interpret these geomorphic differences as representing a considerable time gap between the two moraine forming glacial episodes, with the outer, older moraine having undergone a greater amount of degradation.

Immediately north of the M3 moraine, a separate linear ridge, c. $500 \mathrm{~m}$ in length, is orientated NW-SE and appears to be overlain by M3 at its upstream end. I tentatively identify this landform as a moraine ridge, based on the similar appearance to M3, although the unbroken coverbeds on the surface make it difficult to establish the geological composition. If this landform is a moraine, then based on its orientation, it is unclear what the former ice geometery or source area would have been. Due to this 


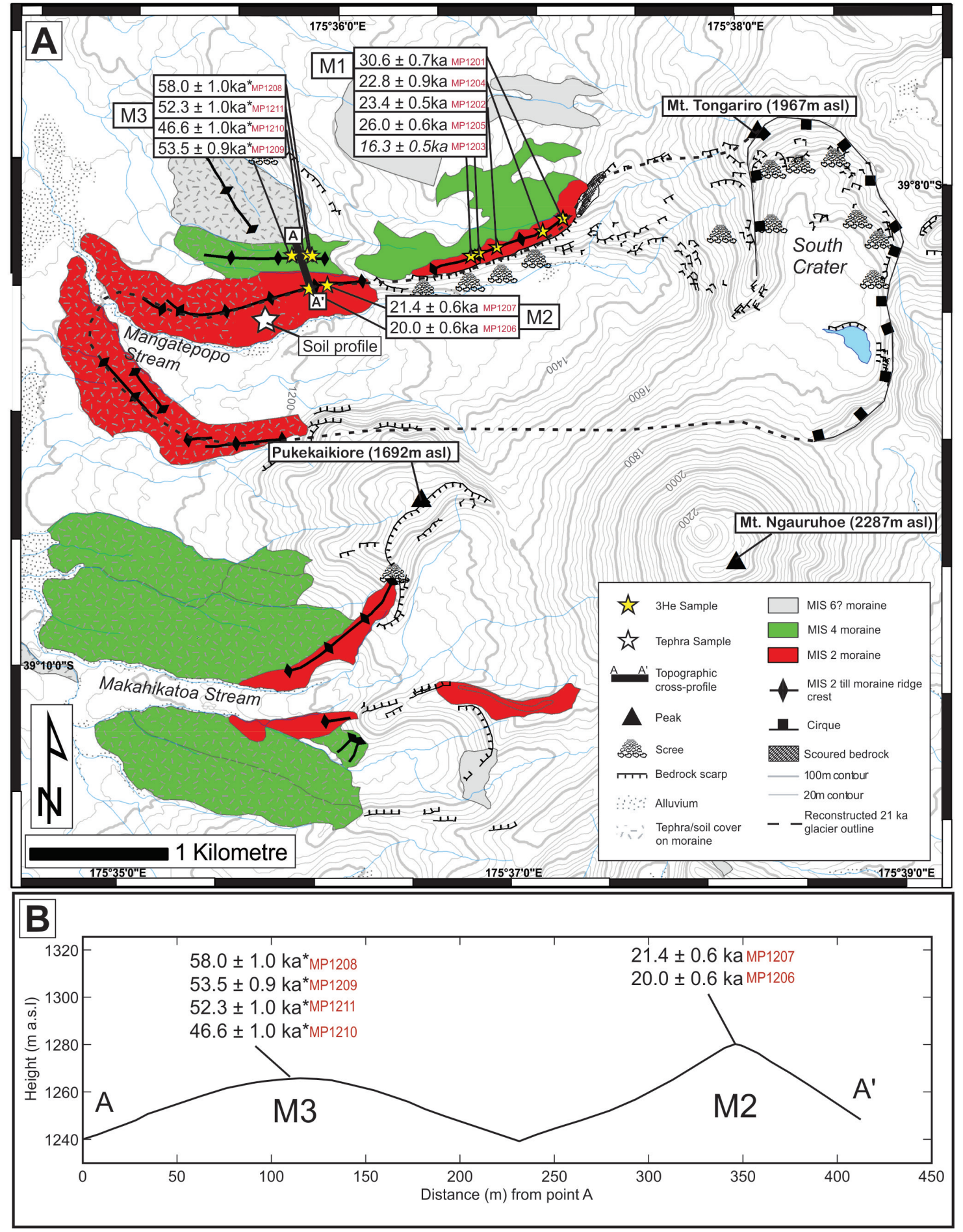

Figure 5.2: (A) Glacial geology and chronology of western Tongariro massif. Yellow stars represent the location of moraine boulder samples for cosmogenic ${ }^{3} \mathrm{He}$ exposure dating. Associated labels are the calculated exposure ages, using Lm scaling - see text for detailed description of age calculation methods. (B) Topographic profiles across moraines M2 and M3, with ${ }^{3} \mathrm{He}$ exposure ages and sample numbers. Note the greater roundness of the older, M3 crest. * Exposure ages for M3 are considered minimum ages for moraine formation - see text.

irregular relationship to the present day drainage and topography of Tongariro massif, I tentatively correlate this landform to the penultimate glacial cycle. As much of the 


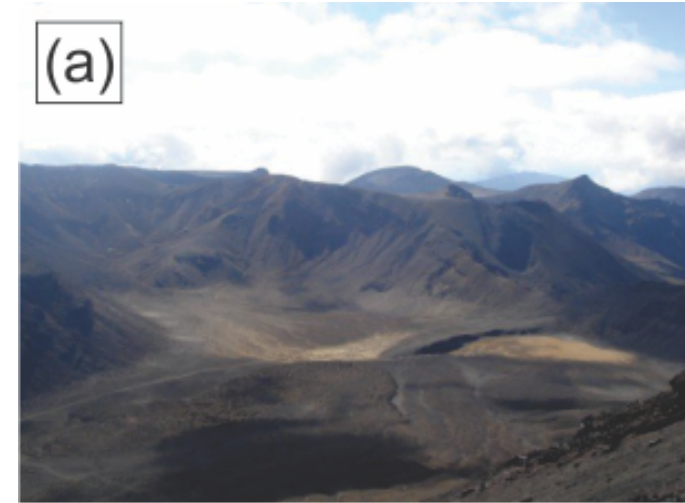

(c)
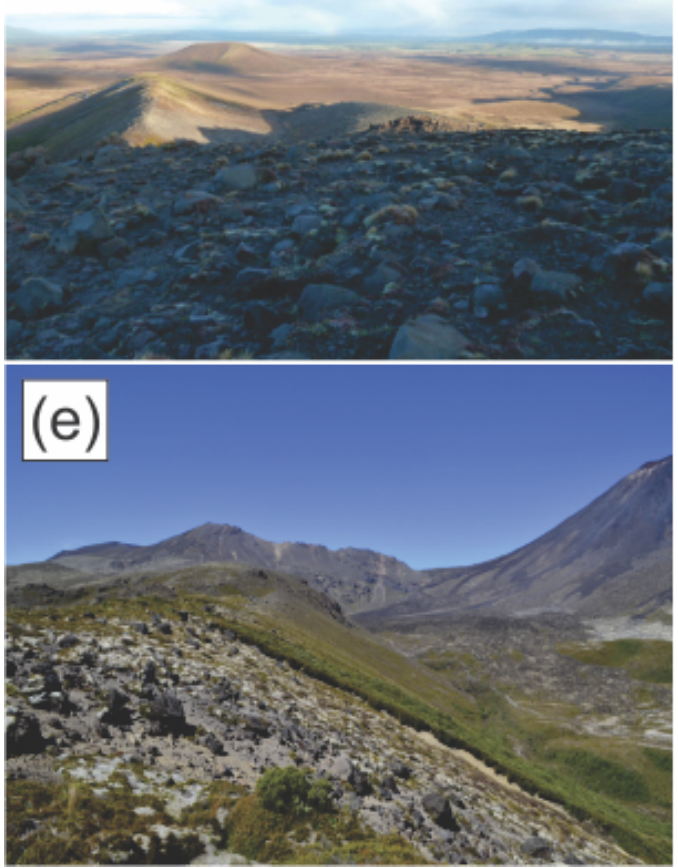

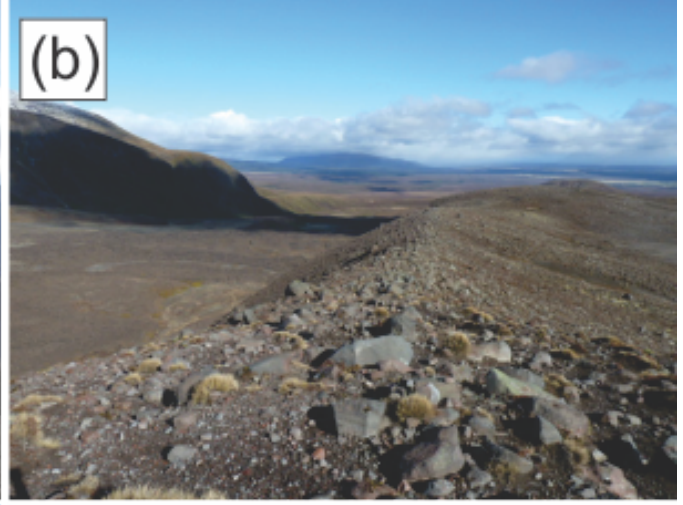

(d)
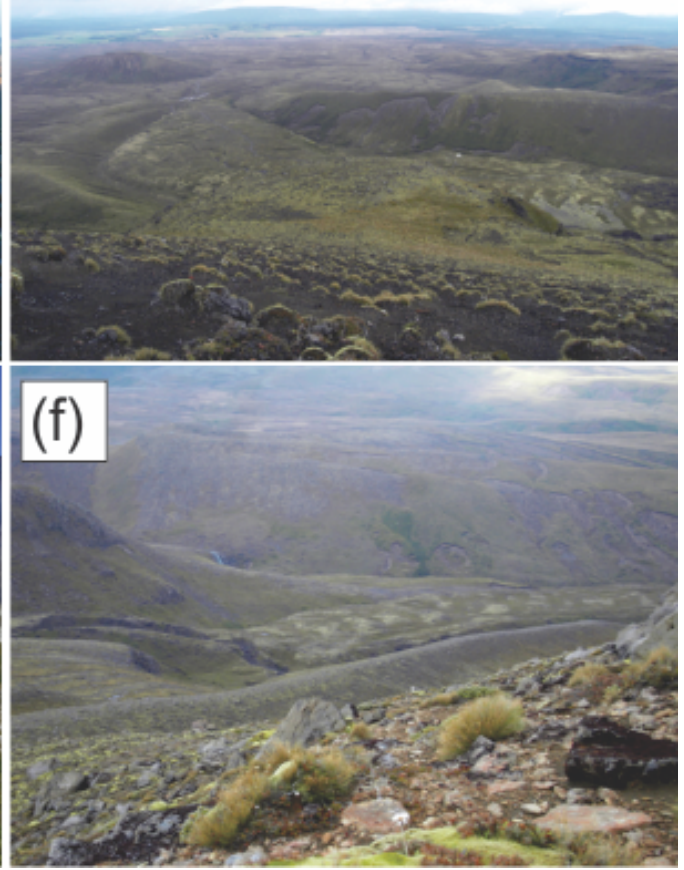

Figure 5.3: (a) South Crater cirque, viewed from the upper slopes of Mt. Ngauruhoe; (b) moraines M2 (middle ground, left) and M3 (middle ground, centre), note the difference in morphometry between the two landforms; (c) a view down valley from the upstream end of moraine M1 - note the glacially truncated side of Pukekaikiore in shadow on the far valley side; (d) the inner lateral moraines of Mangatepopo valley clearly depict the former glacier terminus (photo taken from the upper western slopes of Pukekaikiore); (e) coverbeds on the ice-proximal flank of M2 moraine thin towards the crest; (e) the sharp-crested right lateral moraine of the Makahikatoa valley runs diagonally from left to right across this image (photo taken from the upper northern slopes of Pukekaikiore).

underlying lava that forms the present Mangatepopo valley was emplaced 70-100 ka, it is possible that the geometry of any ice that existed prior to the last glacial cycle could have been significantly different from the most recent period of glaciation.

The lower portions ( $<1200 \mathrm{~m}$ asl) of both M2 and M3 moraines have continuous 
coverage by tephra, palaeosols and volcanic loess accumulation (Figure 5.2; Figure $5.3 \mathrm{~d}, \mathrm{e})$. Between 1200 - $1250 \mathrm{~m}$ asl, these coverbeds become discontinuous, with the transitions from bare moraine to the coverbeds marked by erosional scarps, which indicate former, more extensive coverage of the moraine surface at this elevation. The upstream end of moraine M2 (>1250 m asl) is characterised by continuous thin $(<1 \mathrm{~m})$ coverbeds on the lower moraine slope, which thins towards the bare, rocky moraine crest (Figure 5.3e). No erosional scarps exist on the upper portion of this moraine.

Directly upstream from moraine $\mathrm{M} 2$, moraine $\mathrm{M} 1$ is a single, continuous ridge (Figure $5.3 \mathrm{c}$ ), separated from M2 by a cliff, which represents the downstream limit of an underlying lava flow dated by Hobden et al. (1996) to $110 \pm 6 \mathrm{ka}$ (Figure 2.6). There is no tephra cover on M1 present today, nor are there any remnants to suggest that coverbeds have been more extensive in the past. It is likely that the greater elevation of M1 prevents the accumulation of fine-grained sediment due to wind exposure and lack of vegetation.

On the southern valley side, a single, sharp-crested lateral moraine extends westwards for c. $1 \mathrm{~km}$, from Pukekaikiore (Figure 5.2). The crest of this moraine is c. $40 \mathrm{~m}$ above the present day valley floor. Immediately down valley, two left latero-frontal moraines further constrain the former glacier margin. Soil and tephra cover on these moraines precludes sampling for surface exposure dating, although both landforms exhibit relatively sharp crests, which suggests that they correspond to the most recent period of glacier occupation (i.e. M2). The innermost moraines on both valley sides converge downstream at c. $1150 \mathrm{~m}$ asl, forming the valley mouth, thereby defining the maximum limit of the most recent period of valley glaciation (Figure 5.3d).

\subsubsection{Makahikatoa Stream}

To the south of Mangatepopo valley, the northern headwaters of the Makahikatoa stream drain southwestwards from a northeast-southwest orientated bedrock amphitheatre, interpreted as a glacially eroded cliffs cut into the south-east flank of Pukekaikiore (Figure 5.2). The eastern limits of this former glacial catchment are ill-defined owing to the Holocene lava flows of Mt. Nguaruhoe, which is situated immediately to the east.

A sharp-crested lateral moraine extends from the southern flank of Pukekaikiore, descending in a southwest direction for c. $500 \mathrm{~m}$, terminating at c. $1275 \mathrm{~m}$ asl (Figure 5.2; Figure 5.3e). This moraine is paired by a shorter moraine ridge, issuing from a steep bedrock spur that defines the southern margin of this former glacial catchment. The long, right lateral moraine cross-cuts a significantly wider, more rounded moraine 
ridge that can be traced down valley to c. $1200 \mathrm{~m}$ asl and represents a significantly older glacial limit. Based on the morphostratigraphic relationship of these moraines, I correlate them to the outer (M3) and inner (M1 / M2) moraine ridges situated on the northern flank of Mangatepopo Valley (Figure 5.2).

\subsection{Methods}

\subsubsection{Cosmogenic surface exposure dating}

Moraine boulder samples were collected using a portable rock saw fitted with a segmented, diamond-tipped blade. Samples were only taken from boulders on the moraine crest (Figure 5.4), and those close to known faults and beneath lava cliffs were avoided. Where possible, I sampled boulders that were partially embedded in the moraine matrix to minimise the likelihood that the boulder has undergone post-depositional rotation. All samples were collected from the highest point of the parent boulder, and all boulders were over $0.6 \mathrm{~m}$ tall, thus minimising the potential for past burial by snow and/or volcanic ash. Maximising boulder height was a key priority for sample selection on the lower moraines, which have abundant tephra coverbeds on their lower flanks. Thus, the majority of these samples come from boulders that stand $>1.5 \mathrm{~m}$ above the moraine surface (Table 5.1).

Sampled boulder surfaces exhibited $<12^{\circ}$ dip relative to horizontal, thereby minimising potential self-shielding effects. Azimuthal inclinations were measured in the field using a compass and clinometer and geometric shielding corrections were computed using the CRONUS-EARTH calculator (available at: http:/ / hess.ess.washington.edu). All shielding corrections were less than $1 \%$. Sample locations and elevations were recorded using a Trimble GeoXH global positioning system, relative to to the WGS84 datum. These data were differentially corrected using continuous measurements from GeoNet 'Chateau Observatory' ('VGOB') base station (39 11'59' S, 175 32' 32' E; $1161 \mathrm{~m}$ asl), located $8 \mathrm{~km}$ south west of Mangatepopo valley. Horizontal and vertical post-processed uncertainties for individual sample locations are $<1 \mathrm{~m}$.

Samples were jaw-crushed, rinsed in de-ionised water and dry-sieved to isolate the 250$500 \mu \mathrm{m}$ size fraction. Density $\left(>3.1 \mathrm{~g} \mathrm{~cm}^{-3}\right)$ and magnetic separation techniques were used to separate 150 - $600 \mathrm{mg}$ of pyroxene (clinoenstatite; $\mathrm{En}_{27-37}, \mathrm{Fo}_{17-31}, \mathrm{Wo}_{41-46}$ ). Crushing and mineral separation were undertaken using facilities at Victoria University of Wellington. Pyroxene separates were then prepared according to Bromley et al. (2014) at the Cosmogenic Nuclide Laboratory of Lamont-Doherty Earth Observatory (LDEO). 
Table 5.1: Location and geometry of cosmogenic ${ }^{3}$ He samples

\begin{tabular}{llllllll}
\hline $\begin{array}{l}\text { Sample } \\
\text { ID }\end{array}$ & Lat. & Long. & $\begin{array}{l}\text { Altitude } \\
\text { (m asl) }\end{array}$ & $\begin{array}{l}\text { Thickness } \\
\text { (cm) }\end{array}$ & $\begin{array}{l}\text { Surface } \\
\text { strike/dip }\end{array}$ & Shielding & $\begin{array}{l}\text { Boulder height } \\
(\mathbf{c m})\end{array}$ \\
\hline MP1201 & -39.1362 & 175.6194 & 1519 & 2.0 & 0 & 0.998 & 90 \\
MP1202 & -39.1387 & 175.6124 & 1429 & 2.0 & $210 / 10$ & 0.998 & 80 \\
MP1203 & -39.1389 & 175.6117 & 1429 & 2.0 & $004 / 4$ & 0.998 & 65 \\
MP1204 & -39.1371 & 175.6177 & 1481 & 1.5 & 0 & 0.997 & 70 \\
MP1205 & -39.1383 & 175.6139 & 1437 & 2.0 & $312 / 8$ & 0.997 & 60 \\
\hline MP1206 & -39.1413 & 175.5982 & 1302 & 2.5 & $098 / 10$ & 0.997 & 165 \\
MP1207 & -39.1411 & 175.5997 & 1308 & 2.5 & 0 & 0.998 & 155 \\
\hline MP1208 & -39.1392 & 175.5983 & 1286 & 2.5 & 0 & 0.998 & 60 \\
MP1209 & -39.1391 & 175.5980 & 1280 & 3.0 & $258 / 6$ & 0.998 & 165 \\
MP1210 & -39.1390 & 175.5979 & 1275 & 2.5 & $296 / 2$ & 0.998 & 150 \\
MP1211 & -39.1391 & 175.5969 & 1266 & 3.0 & $124 / 2$ & 0.998 & 120 \\
\hline
\end{tabular}

Mineral separates were first leached in 5\% hydrofluoric (HF) / 2\% nitric $\left(\mathrm{HNO}_{3}\right)$ acid solution for 24 hours, followed by a separate $10 \%$ hydrochloric $(\mathrm{HCl})$ acid solution for 24 hours, to remove adhering ground mass particles. Leached pyroxene crystals were visually inspected for purity and wrapped in aluminium foil. Each sample was completely degassed by heating in a furnace to $>1300^{\circ} \mathrm{C}$ for 15 minutes, during which, released gases were exposed to a liquid-nitrogen chilled, charcoal trap. Extracted gases were exposed to an SAES getter before being collected on a cryogenic cold trap at $<15 \mathrm{~K}$. Exclusively helium was then released by heating the cold trap to $45 \mathrm{~K}$. Mass spectrometry was conducted at the LDEO Noble Gas Mass Spectrometry Laboratory using a MAP 215-50 noble gas mass spectrometer. Measurements were made relative to the Yellowstone 'Murdering Mudpot' (MM) helium standard $\left({ }^{3} \mathrm{He} /{ }^{4} \mathrm{He}\right.$ ratio of $16.45 \mathrm{R}_{a}$, where $\left.\mathrm{R}_{a}={ }^{3} \mathrm{He} /{ }^{4} \mathrm{He}_{\text {air }}=1.384 \times 10^{-6}\right)$, using the protocol of Winckler et al. (2005).

The relatively young crystallisation ages of the samples ( $<273 \mathrm{ka}$; Hobden et al., 1996) explain the low ${ }^{4} \mathrm{He}$ content of the pyroxene crystals $\left(1-3 \times 10^{-9} \mathrm{~cm}^{3}(\mathrm{STP}) \mathrm{g}^{-1}\right)$ and the resultant high ${ }^{3} \mathrm{He} /{ }^{4} \mathrm{He}$ ratios, which range between 47 - 311 times $\mathrm{R}_{a}$ (Table 5.2). Following Dunai et al. (2007), I measured lithium, uranium and thorium concentrations in two samples to test for nucleogenic ${ }^{3} \mathrm{He}\left({ }^{3} \mathrm{He}_{n}\right)$ produced via thermal neutron reactions $\left({ }^{6} \mathrm{Li}(n, \alpha){ }^{3} \mathrm{H}^{3} \mathrm{He}\right)$. Concentrations for all three elements are low ( $\left.<1 \mathrm{ppm}\right)$, which indicates that ${ }^{3} \mathrm{He}_{n}$ content is negligible in the samples. Thus, I assume all ${ }^{3} \mathrm{He}$ to be of cosmogenic origin.

Attenuation of cosmogenic neutron flux with depth from the surface was corrected for using measured sample thickness, a standard rock density of $2.7 \mathrm{~g} \mathrm{~cm}^{-3}$ and an attenuation length of $160 \mathrm{~g} \mathrm{~cm}^{-2}$ (Dunne et al., 1999). Field observations from mid-winter (July) show that the sampled boulders are not subject to burial by seasonal snow. Snow cover is not quantifiable for the geological past, however the topographic prominence 


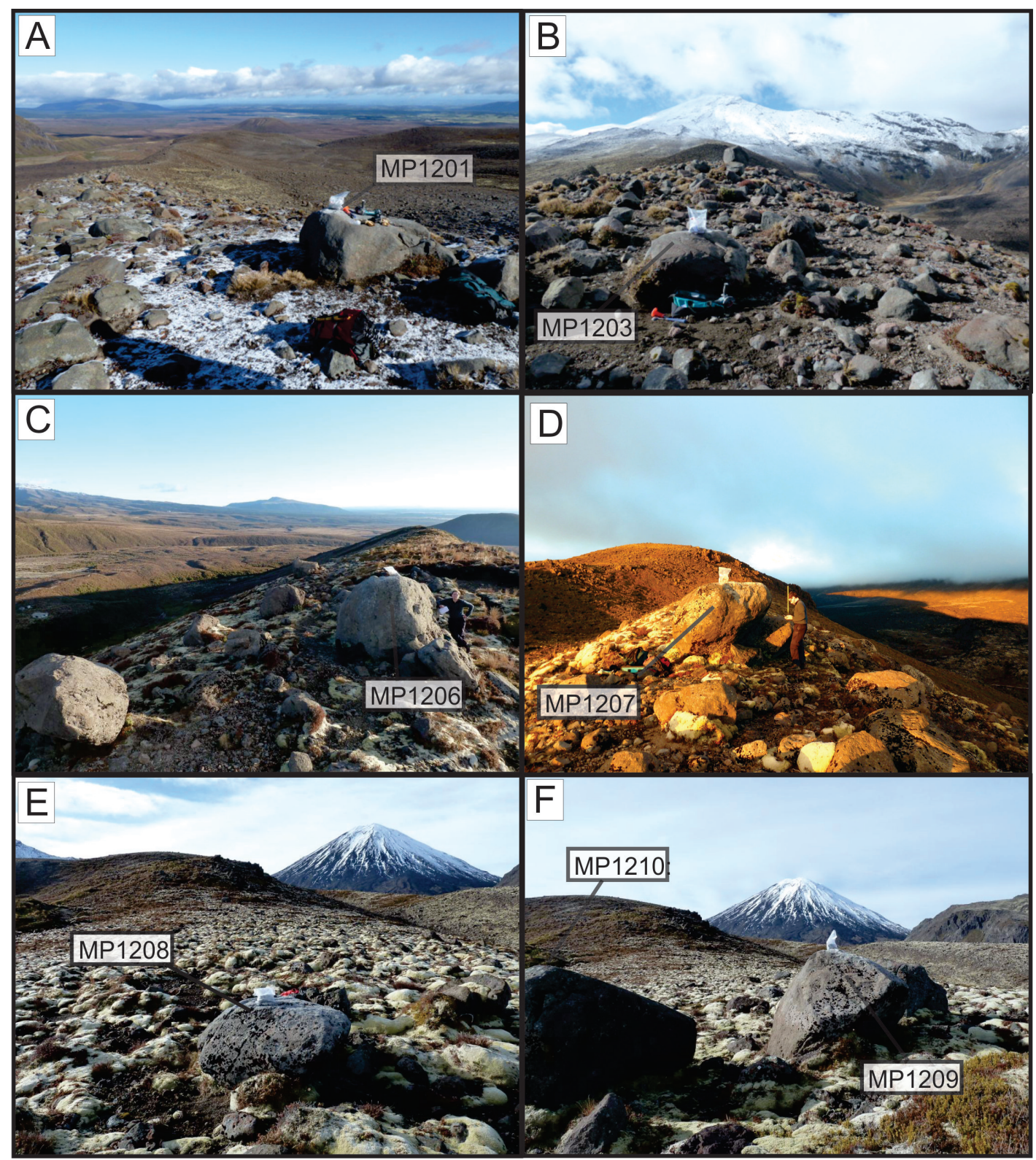

Figure 5.4: Examples of boulders sampled for cosmogenic ${ }^{3} \mathrm{He}$ surface exposure dating. Visible sample bags denote sample position on boulder surface. (A) Sample MP1201 at the eastern end of moraine M1. Photo facing westwards. (B) Sample MP1203 on moraine M1 in the foreground, with Mt. Tongariro (1963 m asl) in the background. Photo facing northeast. (C) MP1206 on moraine M2. Note prominent lateral moraines on opposite valley side. Photo facing southwest. (D) MP1207 on moraine M2. Photo facing east. (E) Sample MP1208 on moraine M3. Note the highly diffuse moraine crest, compared to moraine M1. Also, note the Holocene cone of Mt. Ngauruhoe (background right). Photo facing east. (F) Samples MP1209 and MP1210 on moraine M3. Photo facing east. 
of the boulders and moraine crests is not conducive to snow accumulation due to preferential erosion of snow by the wind. Thus, I do not apply any correction to the age calculation for burial by snow. The absence of resistant mineral veins in the local andesites precluded quantitative assessment of post-depositional erosion of boulder surfaces. Although sampled boulders did not exhibit glacial striae, some boulders retain faceted sides and care was also taken to avoid boulders that displayed clear evidence of erosion, such as discolouration, weathering scarps, onion-skin weathering, pitting/water pooling. I therefore choose to present the exposures ages without an erosion correction. Regional uplift in the central North Island has been estimated at c. 0.6 - $1.0 \mathrm{~mm} \mathrm{yr}^{-1}$ for the past $500 \mathrm{ka}$ (Pulford, 2002). Integrating this elevation change into the age calculations for boulders exposed during the LGM (c. 20-30 ka) does not alter the results outside the range of the ${ }^{3} \mathrm{He}$ measurement uncertainty. For the oldest samples of this study, integrating this uplift rate has the effect of increasing the exposure ages by 1-2 kyr. I present the age dataset without corrections for this effect, but discuss the implications for the glacial chronology in the text.

Exposure ages were computed using the cosmogenic ${ }^{3} \mathrm{He}$ exposure age calculator and globally-compiled, sea-level, high-latitude (SLHL) cosmogenic ${ }^{3} \mathrm{He}$ production rate of Goehring et al. (2010), which is applicable in New Zealand (Chapter 4). All calculations are computed using the CRONUS-Earth exposure age calculator MATLAB code, as described by Balco et al. (2008), and modified for cosmogenic ${ }^{3}$ He by Goehring et al. (2010). Elevation and latitude scaling of cosmogenic ${ }^{3} \mathrm{He}$ production to the sample locations was calculated using five standard scaling models described in Balco et al. (2008) (Table 5.3). Recently, Lifton et al. (2014) have shown that neutron monitor based scaling schemes ( $\mathrm{Li}, \mathrm{Du}, \mathrm{De})$ over-estimate scaling factors, and introduce an updated scaling scheme very similar to the Lm-scaling. Thus, I base the age-calculations and discussion on the Lm-scaling scheme.

\subsubsection{Tephrochronology}

The use of discrete, isochronous, pyroclastic (primarily ash and lapilli) marker horizons as chronological tie-points in sedimentary archives of paleoenvironmental change is well established in New Zealand (e.g. Lowe et al., 2008, 2013). In glaciated landscapes, well-dated tephra layers stratigraphically overlying depositional landforms such as moraines, provide minimum ages for moraine formation, whereas tephra preserved beneath deposits of glacial outwash or till, constrains the maximum age of deposition (e.g. Kirkbride and Dugmore, 2001). Since the work of Topping and Kohn (1973), significant progress has been made to constrain the precise age and geochemical signature of rhyolitic tephra marker horizons in New Zealand (e.g. Lowe et al., 2008, 2013). To test 
the interpretation of Topping and Kohn (1973), I revisited their moraine soil section in Mangatepopo valley to sample the lower two rhyolite horizons for electron microprobe (EMP) analysis of glass shard major element compositions. To aid identification, I compare the geochemistry of the Mangatepopo tephras to that of a discrete rhyolite horizon

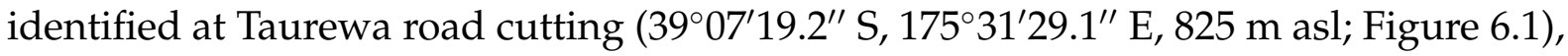
situated c. $5 \mathrm{~km}$ west from the study site. This tephra stratigraphically overlies the Kawakawa/Oruanui Tephra (KOT), which was recently dated at this section (c. 25.4 cal. ka; Vandergoes et al., 2013). All samples were wet-sieved to isolate the $>63 \mu \mathrm{m}$ fraction, before individual glass shards were handpicked $(n=>18$ per sample; Table 5.4 ) and loaded in an epoxy mount. All major element determinations were made on a JEOL Superprobe (JXA-8230) at Victoria University of Wellington, using the ZAF correction method. Analyses were performed using an accelerating voltage of $15 \mathrm{kV}$ under a static electron beam operating at $8 \mathrm{nA}$. The electron beam was focused to $10 \mu \mathrm{m}$.

\subsubsection{Equilibrium line altitude reconstruction}

Palaeoclimatic calculations from reconstructed glaciers rely on accurate delineations of former ice masses, which are constrained by interpretation of ice-marginal geomorphology (Porter, 1975; Benn et al., 2005). Moraine ridges and glacial till extent clearly depict the terminus and lower margins of the former Mangatepopo glacier, whilst erosional landforms such as glacial cirque and glacially-trimmed cliffs provide guidance on the upper glacier limits. I reconstruct the palaeo-equilibrium line altitude ( $p$ ELA) of the Mangatepopo glacier for the innermost glacier geometry (c. $21 \mathrm{ka}$ - see below) delineated by the preserved glacial landforms only, as the outboard ice limits are less well preserved. I consider the c. 21 ka glacier margin to be located slightly below M1 moraine on the northern valley side, based on the cosmogenic ${ }^{3} \mathrm{He}$ exposure ages and the topographic relationship of moraines M1 and M2 (Section 5.3.2.1). In the vicinity of Mt. Ngauruhoe, post-glacial volcanic activity has obscured evidence of the former glacial limits, therefore I estimate former ice limits in this region by interpolating between the cirque headwall and the glacially-truncated lava flows of Pukekaikiore (Figure 5.2), using analogous contemporary valley glacier geometries. To estimate the hypsometry of the former glacier, elevation contours are drawn from the intersection of the reconstructed ice margin and the modern topographic contours. Ice surface topography is reconstructed to represent flow vectors in contemporary glaciers, which are increasingly convergent with distance upstream from the ELA, and increasingly divergent downstream (Paterson, 1994). I define the upper margins of the LGM glacier using the head of South Crater cirque (sensu Kaplan et al., 2010), although, it is possible that additional ice was sourced from an ice field centred on Tongariro massif (Section 5.3.2.2). 
A number of methods exist to estimate the $p$ ELA for former glaciers. The Accumulation Area Ratio (AAR) method is applied most commonly, which is based on the assumption that the accumulation zone of a steady-state glacier represents a fixed proportion of the total glacier area. Accumulation areas of modern glaciers globally, typically occupy $50-80 \%$ of the total glacier surface area (Meier and Post, 1962), whilst empirical studies show that New Zealand glaciers most commonly have an accumulation-ablation area ratio of 2:1 (AAR=0.67; Chinn et al., 2012).

A shortcoming of the AAR method is the failure to account for glacier hypsometry (Furbish and Andrews, 1984). For former valley and cirque glaciers, reconstructed glacier hypsometry is usually well-constrained by topography, therefore AAR-based $p$ ELA estimates are subject to less uncertainty. However, the hypsometry of former valley glaciers sourced from ice caps or plateau ice fields is less certain due to the absence of geomorphic indicators that constrain ice thickness in the upper catchment. Underestimating the planimetric surface area at the glacier head leads to underestimation of the local ELA, as a larger ablation area is required to balance the expanded accumulation zone. Other techniques have been developed to overcome this shortcoming in the AAR method (Furbish and Andrews, 1984; Osmaston, 2005), however these are also reliant on accurate knowledge of the former ice geometry. The glacial geomorphology of the wider Tongariro massif suggests that the former Mangatepopo glacier may have been sourced from a central ice field, as several other moraine-lined glacial valleys radiate from the centre of the edifice (Mathews, 1967), thus implying a central source. If this were the case, the AAR method will underestimate the $p$ ELA, therefore I consider the AAR-based reconstructions as a maximum estimate of ELA depression from present.

Reconstructed $p$ ELAs provide a useful metric for comparing the magnitude of past climate change (Porter, 1975). This requires accurate knowledge of the present-day ELA. No glaciers currently exist on Tongariro massif, however small cirque glaciers persist on Mt. Ruapehu (2797 m asl), situated $15 \mathrm{~km}$ to the south. In the most recent survey of these glaciers, Keys (1988) reports contemporary ELAs of 2340 - 2650 m asl, based on end of summer snowline surveys. Topoclimatic factors such as wind-driven snow accumulation and topographic shading impart a strong influence on the mass balance of cirque glaciers (Kuhn, 1995), which can reduce the utility of the ELA as an index for atmospheric temperature change. However, Brook et al. (2011) analysed surface area changes of one glacier on Mt. Ruapehu between AD1988-2008 and found that variations closely follow ablation season temperature changes. This correlation supports the use of end of summer snowline observations on Mt. Ruapehu to relate local $p$ ELA reconstructions to past atmospheric temperature change. I take the arith- 
metic mean of the midpoints of Keys (1988) observations (2483 $\pm 55 \mathrm{~m}$ asl) to use as a modern (AD1988) ELA datum.

\subsection{Results}

\subsubsection{Cosmogenic ${ }^{3} \mathrm{He}$ results and moraine age interpretation}

\subsubsection{Upper moraine (M1)}

Exposure ages (with internal uncertainties) of the five boulders sampled from moraine M1 are $30.6 \pm 0.7 \mathrm{ka}, 26.0 \pm 0.6 \mathrm{ka}, 23.4 \pm 0.5 \mathrm{ka}, 22.8 \pm 0.9 \mathrm{ka}$ and $16.3 \pm 0.5 \mathrm{ka}$ (Table 5.3. I adjudge the youngest sample (MP1203) to be an outlier, based on the preservation of moraine M2 down valley, which dates to $21 \mathrm{ka}$ (see section 5.5.1.2 below). It is unlikely that M2 would be preserved today, if ice of sufficient thickness to be depositing boulder MP1203 at the elevation of M1 was present in Mangatepopo valley at c. $16 \mathrm{ka}$. Re-examination of field descriptions and photographs (e.g. Figure 5.4B) suggests that this boulder may have shed a portion of its surface since deposition, as evidence of fracturing is present, probably caused by preferential weathering along internal cooling joint planes. Post-depositional removal of the boulder surface through this process provides a possible explanation for the anomalous young age.

Following omission of this outlier, three possible depositional scenarios can explain the age distribution of the remaining four samples. First, the oldest age (c. $31 \mathrm{ka}-\mathrm{MP1201}$ ) may represent inheritance of cosmogenic ${ }^{3} \mathrm{He}$ from exposure prior to deposition at its current position on the moraine crest. In this scenario, the true age of M1 would be closer to the remaining three samples, between 26-23 ka. Second, the oldest age (c. $31 \mathrm{ka}-\mathrm{MP1201}$ ) may represent the true age of M1, with the remaining samples having been subject to post-depositional weathering or moraine degradation processes (e.g. Applegate et al., 2008), causing the surface exposure ages to post-date moraine formation. Third, M1 could represent a composite landform (e.g. Roethlisberger and Schneebeli, 1979) comprising deposits from several glacier fluctuations of similar magnitude between 31-23 ka.

Based on the existing dataset, it is not possible to unequivocally attribute either one of these scenarios to the M1 moraine, however some points can be made. Analyses of large datasets of moraine boulder surface exposure ages show that only a very small percentage of boulders deposited by non-polar, temperate glaciers exhibit evidence 
for prior exposure (inheritance) (Putkonen and Swanson, 2003; Heyman et al., 2011). This finding is supported locally, by recent dating campaigns in the Southern Alps that have generated several hundred, individual high-precision in situ cosmogenic ${ }^{10} \mathrm{Be}$ exposure ages for moraine boulders (Schaefer et al., 2009; Kaplan et al., 2010; Putnam et al., 2010a, 2013a,b; Kelley et al., 2014), which indicate that any inherited component is typically less than the measurement uncertainty (see Schaefer et al. (2009) for a detailed consideration). The maritime, mid-latitude location of the study site, together with geomorphic evidence for scouring of the glacier bed (Section 5.3.2.1) suggest that former glaciation at this site was warm-based. Thus, whilst it is feasible that the ${ }^{3} \mathrm{He}$ content of MP1201 could represent inheritance from prior exposure, I consider this scenario the least likely explanation for the age distribution. It is more difficult to decipher between the latter two scenarios, however both imply moraine aggradation at c. 31 $\mathrm{ka}$, with the younger ages either representing post-depositional disturbance (scenario 2 ), or further aggradation from glacial reoccupation at $26-23 \mathrm{ka}$ (scenario 3). Whilst scenario 2 is most commonly assumed in such situations, diachronous moraines have also previously been inferred from surface exposure age datasets displaying multiple populations (e.g. Licciardi et al., 2004; Briner, 2009). This is more likely in situations where a glacier is topographically constrained (Roethlisberger and Schneebeli, 1979), such as the Mangatepopo valley. Exposure ages from down-valley (Section 5.5.1.2) suggest valley glaciation endured until c. $21 \mathrm{ka}$, therefore I suggest the age distribution from M1 most likely represents time-transgressive aggradation through the period c. 31 - $23 \mathrm{ka}$. Moraine construction would have occurred when the ice surface elevation was sufficient to overcome the prominent lava flow that bounds the northern valley side.

\subsubsection{Lower moraine - inner (M2)}

Two boulders were deemed suitable for exposure dating (MP1206 and MP1207; Figure $5.4 \mathrm{C} \& \mathrm{D})$ and returned ages of $20.0 \pm 0.6 \mathrm{ka}$ and $21.4 \pm 0.6 \mathrm{ka}$, respectively. These ages are in close agreement and are stratigraphically coherent with the age of M1 and the tephrostratigraphy (Section 5.5.2). I consider that the arithmetic mean of these ages, 21 $\pm 1.0 \mathrm{ka}$ to represent the moraine formation age and onset of glacial retreat from this position.

This age is several thousand years younger than the age of M1 (above), which is situated directly up-valley, such that in plan view it appears that both M1 and M2 moraines may relate to a single period of moraine building. If M1 and M2 do in fact represent a single event, then the offset in surface exposure ages between the moraines 
must be caused by either, (i) inheritance in the M1 samples, or (ii) post-depositional erosion or shielding of the M2 samples. I consider the former unlikely, for the reasons outlined above in Section . Concerning the latter, there is no field evidence that either sample from M2 has undergone significant erosion of the boulder surface sufficient to raise the true exposure age by several $\mathrm{kyr}$ (c. $10-20 \mathrm{~mm} \mathrm{kyr}^{-1}$ ), therefore I consider this an unlikely source of this systematic offset. Concerning the latter, there is evidence to suggest that soil/tephra cover on M2 moraine has been more extensive in the past, as indicated by the present-day soil distribution and erosional scarps (Figure 5.3d,e). Thus, to assess the possibility that shielding from volcanic ash/soil development has reduced cosmogenic ${ }^{3} \mathrm{He}$ production in the geological past, I use the attenuation rate of cosmogenic nuclide production due to burial (Figure 3.1) to construct hypothetical burial scenarios beneath given thicknesses and burial durations of soil cover ( $\rho=1.6 \mathrm{~g}$ $\mathrm{cm}^{3}$ ). The nuclide concentration that would result from the hypothetical burial scenario, according to the attenutation rate of nuclide production depth (Figure 3.1), is subtracted from the measured nuclide concentration to leave the concentration aqcuired through simple exposure. The 'true' age is then calculated by adding to the simple exposure concentration, the nuclide concentration that would result from simple exposure for a duration equal to the hypothetical burial time. These calculations do not include possible changes in nuclide production with time due to changes in the geomagnetic field intensity.

Figure 5.5 shows that if the nuclide concentration in the M2 samples actually represents c. 31 kyr with intermittent burial, then the sample surfaces must have been buried by at least $250 \mathrm{~cm}$ of soil/tephra for a duration of c. $10 \mathrm{kyr}$ in order to produce the measured cosmogenic ${ }^{3} \mathrm{He}$ concentration. A true M2 moraine age of c. $24 \mathrm{ka}$ requires c. $8 \mathrm{kyr}$ beneath $50 \mathrm{~cm}$ of soil, or 2 - $3 \mathrm{kyr}$ beneath $>100 \mathrm{~cm}$. These thicknesses represent soil depth on the surface of the boulders, which stand $>150 \mathrm{~cm}$ above the moraine surface. Thus, even small burial thickness scenarios require at least c. $150 \mathrm{~cm}$ of sediment on the moraine surface before nuclide production in the boulder surfaces is reduced. This is inconsistent with the observed coverbed thinning from the base of the moraine slope to the crest (Figure 5.3e), which indicates that soil/tephra thickness on the moraine crest has not exceeded c. $1 \mathrm{~m}$. Furthermore, the time required for tephra and soil accumulation/development is substantial ( $5 \mathrm{~m}$ per $14 \mathrm{kyr}$ on the sheltered lower moraine slope - Figure 5.6), which further restricts the amount of time available to attenuate nuclide production in the samples.

In summary, it appears that the difference in age between the M2 and M1 exposure ages is real, as implausible erosion/shielding scenarios are required to raise the M2 ages by several thousand years to align with those for M1. The M1 moraine has a 

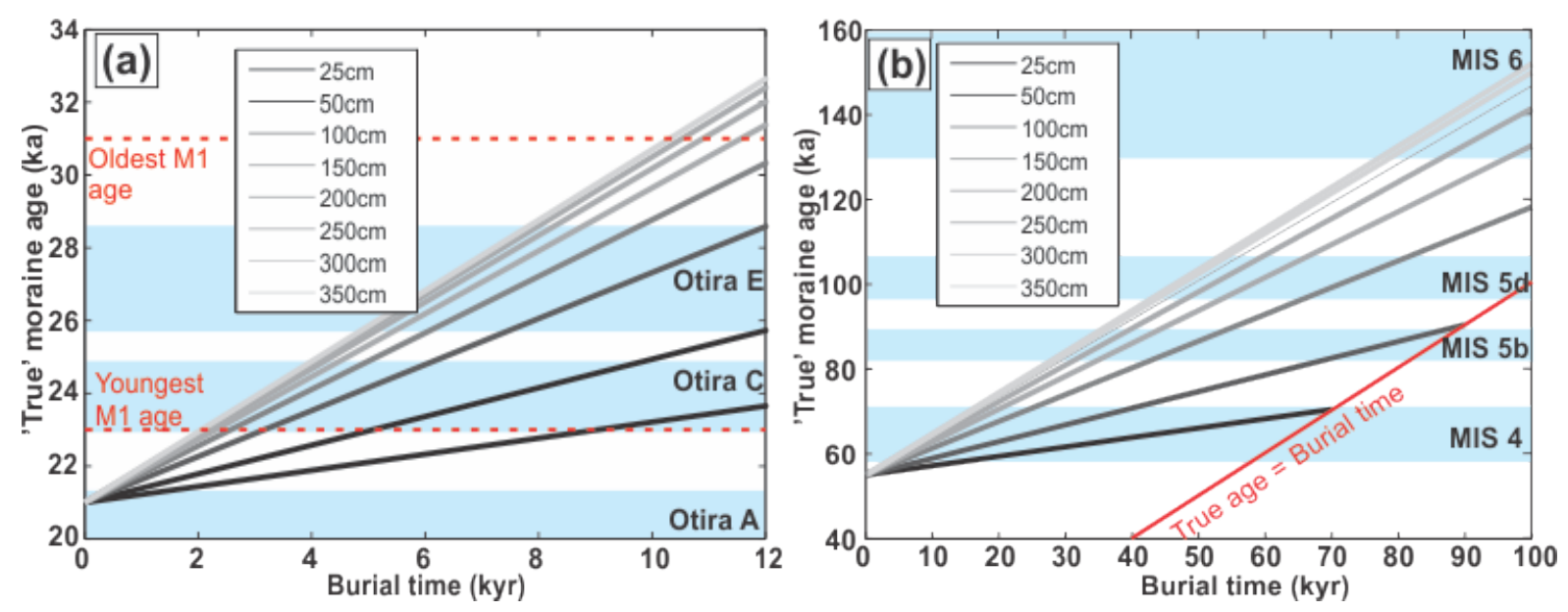

Figure 5.5: (a) The hypothetical 'true' ages of moraine M2 samples due to shielding of cosmogenic nuclide production beneath sediment $\left(\rho=1.6 \mathrm{~g} \mathrm{~cm}^{-3}\right)$ cover of given burial durations and thicknesses; (b) As (a), but using $55 \mathrm{ka}$ as the measured exposure age, thus representing an example from the M3 moraine samples. Soil thicknesses represent that overlying the sampled boulder surfaces, which typically sit $>1-1.5 \mathrm{~m}$ above the moraine surface (see Table 5.1).

smaller volume than M2 and is situated on top of a prominent lava flow that outcrops on the valley wall. Given the lack of an obvious M1 correlative moraine outboard of M2 it is likely that, during M1 time, the former Mangatepopo glacier terminated in a similar location to that depicted by the M2 moraine. This scenario could explain the large difference in volume between the two moraines, if M2 construction began in the period 31 - $23 \mathrm{ka}$, whilst M1 was only intermittently constructed during periods when the glacier thicknesses exceeded the topographic threshold presented by the prominent lava flow. This scenario requires an explanation for why the M1 moraine was not also buried during construction of M2 moraine at c. $21 \mathrm{ka}$, if the glacier geometry was largely the same. One possibility is that erosion of the glacier bed during between 31 23 ka could have resulted in a lower glacier surface by the time the M2 samples were emplaced, leaving the the M1 moraine stranded above the glacier margin. Another possibility is a change in the mass balance regime of the glacier between M1 and M2 construction. For example, higher precipitation during M1 time could have produced a thicker, steeper glacier (e.g. Golledge et al., 2012), whereas reduced precipitation during M2 construction may have produced a thinner glacier with a lower gradient longitudinal profile. This pattern of climatic forcing is observed in speleothem records, whereby the onset of the LGCP was characterised by higher precipitation and milder temperatures, whilst the culmination of the stadial was drier and colder (Whittaker et al., 2011). Regardless of the precise cause, the age data presented here indicates that the M2 samples were deposited after construction of the M1 moraine, thus they represent the last time that M2 was occupied by a glacier in the Mangatepopo valley. 


\subsubsection{Lower moraine - outer (M3)}

Samples were collected from four boulders, which returned ages ranging from 58.0 $\pm 1.0 \mathrm{ka}$ to $46.6 \pm 1.0 \mathrm{ka}$. I consider these ages to be minimum-limiting ages for this landform for the following reasons.

First, assuming that this landform was originally sharp-crested like the other, younger moraines in the valley, the rounded cross-section present today (Figure 5.2B) indicates substantial post-depositional landform degradation. Such degradation may have caused exhumation of boulders previously shielded from cosmic rays (Hallet and Putkonen, 1994; Applegate et al., 2012). This degradation probably occurred in vegetation-free, periglacial conditions during MIS 2, when renewed glacial conditions caused glacial re-advance and the deposition of moraines M1 and M2 in the Mangatepopo valley (see above). Previous workers have noted that many of the high-altitude coverbeds in the northern and western regions of TgVC represent post-glacial deposition (Topping, 1973; Donoghue et al., 1995), therefore it is likely that during glacial times the land surface was free of vegetation and soil, which facilitates hillslope diffusion.

Second, continual exposure of these andesitic boulders to the relatively high total annual precipitation at this location and elevation (c. $3 \mathrm{~m} \mathrm{yr}^{-1}$; NIWA, 2014), over several tens of millennia, is likely to have caused granular disintegration of the boulder surfaces. Such erosion would remove cosmogenic ${ }^{3} \mathrm{He}$ atoms, thus resulting in nuclide concentrations that underestimate the true exposure age of the boulder. For example, boulder surface erosion rates of $1.5-5.5 \mathrm{~mm} \mathrm{kyr}^{-1}$ would raise the exposure ages of the M3 samples to c. $63 \mathrm{ka}$, which corresponds with the culmination of a major glacier advance in the Southern Alps (Schaefer et al., 2015). Such rates of rock erosion agree well with the compilation of Portenga and Bierman (2011) which indicates typical long term erosion rates of c. 1 - $10 \mathrm{~mm} \mathrm{kyr}^{-1}$ for igneous lithologies in temperate climatic environments.

Third, the age calculations are uncorrected for potential tectonic uplift, which has been estimated at c. $0.6-1.0 \mathrm{~mm} \mathrm{yr}^{-1}$ (Pulford, 2002). Including c. $40-60 \mathrm{~m}$ of uplift into the exposure age calculation serves to lower the time-integrated local production rate, relative to that estimated for the present day sample elevation. Depending on the temporal pattern of uplift over the exposure period, this effect could cause underestimation of boulder ages by up to $2 \mathrm{kyr}$.

As with the M2 samples (above), the distribution of tephra and soil coverbeds and erosional scarps on M3 moraine, suggest that this cover was more extensive on the 
moraine surface in the geological past. Potential attenuation of cosmogenic nuclide production in the M3 samples can be assessed in two ways. First, Figure 5.5 shows the effect of different burial duration and thickness scenarios on the true age of a boulder that yields a hypothetical exposure age of $55 \mathrm{kyr}$. Given the height of the boulders (Table 5.1), realistic burial depths are likely $<100 \mathrm{~cm}$, thus Figure 5.5 shows that several tens of thousands of years of burial beneath such a soil thickness are required to push the true age of the M3 samples back beyond MIS 4. Second, all of the M3 samples are taken from a similar location on the M3 moraine, thus it is likely that all would have had a similar burial/exhumation history. Thus, the measured nuclide concentrations should correlate with boulder height, as taller boulders would likely be buried last by accumulating soil/ash, and uncovered first during subsequent exhumation. This is not the case, as the lowest boulder (MP1208; Table 5.1) on the M3 moraine returned the oldest exposure age, whilst taller boulders produced lower nuclide concentrations. In summary, it is unlikely that the samples on M3 have undergone any shielding due to more extensive soil/tephra cover, thus the most likely scenario is that this moraine was deposited during MIS 4 (c. 60-65 ka). 
Table 5.2: Helium isotope data of all samples from Mangatepopo valley.

\begin{tabular}{|c|c|c|c|c|c|c|c|c|}
\hline Sample ID & $\begin{array}{l}\text { Weight } \\
\text { (g) }\end{array}$ & $\begin{array}{l}{ }^{3} \mathrm{He} \\
\left(\text { atoms g }^{-1}\right)\end{array}$ & \pm & $\begin{array}{l}{ }^{4} \mathrm{He} \\
\left(\text { atoms g }^{-1}\right)\end{array}$ & \pm & ${ }^{3} \mathrm{He} /{ }^{4} \mathrm{He}$ & \pm & $\mathbf{R} / \mathbf{R}_{a}$ \\
\hline \multicolumn{9}{|c|}{ Upper moraine: } \\
\hline MP1201 & 0.3097 & $1.176 \times 10^{7}$ & $2.779 \times 10^{5}$ & $5.460 \times 10^{10}$ & $1.486 \times 10^{9}$ & $2.155 \times 10^{-4}$ & $7.766 \times 10^{-6}$ & 156 \\
\hline MP1202 & 0.5409 & $8.285 \times 10^{6}$ & $1.175 \times 10^{5}$ & $4.345 \times 10^{10}$ & $7.608 \times 10^{8}$ & $1.906 \times 10^{-4}$ & $5.171 \times 10^{-6}$ & 138 \\
\hline MP1203 & 0.3055 & $5.640 \times 10^{6}$ & $1.794 \times 10^{5}$ & $5.588 \times 10^{10}$ & $1.488 \times 10^{9}$ & $1.009 \times 10^{-4}$ & $4.187 \times 10^{-6}$ & 73 \\
\hline MP1204 & 0.1504 & $8.392 \times 10^{6}$ & $3.410 \times 10^{5}$ & $3.532 \times 10^{10}$ & $2.395 \times 10^{9}$ & $2.376 \times 10^{-4}$ & $1.878 \times 10^{-5}$ & 172 \\
\hline MP1205 & 0.4352 & $9.235 \times 10^{6}$ & $2.035 \times 10^{5}$ & $3.734 \times 10^{10}$ & $1.036 \times 10^{9}$ & $2.473 \times 10^{-4}$ & $8.758 \times 10^{-6}$ & 178 \\
\hline \multicolumn{9}{|c|}{ Lower moraine - inner: } \\
\hline MP1206 & 0.5174 & $6.337 \times 10^{6}$ & $1.739 \times 10^{5}$ & $9.793 \times 10^{10}$ & $6.315 \times 10^{8}$ & $6.471 \times 10^{-5}$ & $1.825 \times 10^{-6}$ & 47 \\
\hline MP1207 & 0.5846 & $6.861 \times 10^{6}$ & $1.921 \times 10^{5}$ & $6.185 \times 10^{10}$ & $6.107 \times 10^{8}$ & $1.111 \times 10^{-4}$ & $3.293 \times 10^{-6}$ & 80 \\
\hline \multicolumn{9}{|c|}{ Lower moraine -outer: } \\
\hline MP1208 & 0.5121 & $1.892 \times 10^{7}$ & $3.262 \times 10^{5}$ & $4.503 \times 10^{10}$ & $6.505 \times 10^{8}$ & $4.177 \times 10^{-4}$ & $9.399 \times 10^{-6}$ & 301 \\
\hline MP1209 & 0.4390 & $1.736 \times 10^{7}$ & $3.128 \times 10^{5}$ & $6.680 \times 10^{10}$ & $8.987 \times 10^{8}$ & $2.599 \times 10^{-4}$ & $5.844 \times 10^{-6}$ & 188 \\
\hline MP1210 & 0.3991 & $1.524 \times 10^{7}$ & $3.249 \times 10^{5}$ & $5.642 \times 10^{10}$ & $8.394 \times 10^{8}$ & $2.702 \times 10^{-4}$ & $7.023 \times 10^{-6}$ & 195 \\
\hline MP1211 & 0.4007 & $1.686 \times 10^{7}$ & $3.210 \times 10^{5}$ & $3.911 \times 10^{10}$ & $1.120 \times 10^{9}$ & $4.312 \times 10^{-4}$ & $1.482 \times 10^{-5}$ & 311 \\
\hline
\end{tabular}


Table 5.3: Exposure ages (ka) with internal (external) uncertainties. Calculated using the five scaling models of Stone (2000) ('St'), Desilets et al. (2006) ('De'), Dunai (2001) ('Du'), Lifton et al. (2005) ('Li') and Lal (1991) ('Lm'). Lm ages are presented in bold and are those discussed in text. ${ }^{a}$ Samples from Lower moraine - outer (M3) have been subject to 40-60 $\mathrm{m}$ uplift since deposition, therefore ages presented are a minimum estimate.

\begin{tabular}{|c|c|c|c|c|c|c|c|c|c|c|}
\hline Sample ID & St & \pm & De & \pm & Du & \pm & $\mathrm{Li}$ & \pm & Lm & \pm \\
\hline \multicolumn{11}{|c|}{ Upper moraine (M1): } \\
\hline MP1201 & 31.5 & $0.7(2.6)$ & 29.1 & $0.7(2.9)$ & 29.1 & $0.7(2.9)$ & 29.2 & $0.7(3.1)$ & 30.6 & $0.7(3.5)$ \\
\hline MP1202 & 23.7 & $0.5(1.9)$ & 22.3 & $0.5(2.2)$ & 22.3 & $0.5(2.2)$ & 22.5 & $0.5(2.4)$ & 23.4 & $0.5(2.7)$ \\
\hline MP1203 & 16.1 & $0.5(1.4)$ & 15.3 & $0.5(1.5)$ & 15.3 & $0.5(1.6)$ & 15.5 & $0.5(1.7)$ & 16.3 & $0.5(1.9)$ \\
\hline MP1204 & 23.0 & $0.9(2.0)$ & 21.6 & $0.9(2.2)$ & 21.6 & $0.9(2.3)$ & 22.0 & $0.9(2.4)$ & 22.8 & $0.9(2.7)$ \\
\hline MP1205 & 26.3 & $0.6(2.1)$ & 24.6 & $0.5(2.4)$ & 24.6 & $0.5(2.4)$ & 24.8 & $0.5(2.6)$ & 26.0 & $0.6(3.0)$ \\
\hline \multicolumn{11}{|c|}{ Lower moraine - inner (M2): } \\
\hline MP1206 & 20.0 & $0.6(1.7)$ & 19.1 & $0.5(1.9)$ & 19.1 & $0.5(1.9)$ & 19.3 & $0.5(2.1)$ & 20.0 & $0.6(2.3)$ \\
\hline MP1207 & 21.5 & $0.6(1.8)$ & 20.4 & $0.6(2.0)$ & 20.4 & $0.6(2.1)$ & 20.6 & $0.6(2.2)$ & 21.4 & $0.6(2.4)$ \\
\hline \multicolumn{11}{|c|}{ Lower moraine -outer (M3) ${ }^{a}$ : } \\
\hline MP1208 & 60.5 & $1.0(4.9)$ & 55.4 & $1.0(5.4)$ & 55.8 & $1.0(5.5)$ & 55.5 & $0.9(5.9)$ & 58.0 & $1.0(6.4)$ \\
\hline MP1209 & 56.0 & $1.0(4.5)$ & 50.9 & $0.9(4.9)$ & 51.4 & $0.9(5.1)$ & 50.9 & $0.9(5.4)$ & 53.5 & $0.9(6.0)$ \\
\hline MP1210 & 49.2 & $1.0(4.0)$ & 44.6 & $0.9(4.4)$ & 45.0 & $1.0(4.5)$ & 44.5 & $0.9(4.7)$ & 46.6 & $1.0(5.3)$ \\
\hline MP1211 & 55.0 & $1.0(4.4)$ & 50.0 & $0.9(4.9)$ & 50.4 & $1.0(5.0)$ & 50.0 & $0.9(5.3)$ & 52.3 & $1.0(5.9)$ \\
\hline
\end{tabular}

\subsubsection{Coverbed stratigraphy and tephra major element geochemistry}

Stratigraphic logging of soil sections overlying the ice-proximal flank of the M2 moraine (Figure 5.6A) permits correlation with the detailed descriptions of Topping and Kohn (1973) and Topping (1974). At c. $450 \mathrm{~cm}$ depth I identify a matrix-supported diamicton, predominantly consisting of boulders and cobbles in a silty matrix, which represents the surface of the underlying lateral moraine. A section containing approximately 90 $\mathrm{cm}$ of interbedded $\mathrm{cm}$ - to dm-thick andesitic ash and lapilli beds, with two yellowwhite rhyolitic tephra beds and weakly formed palaeosols, immediately overlies the moraine surface. The lowermost rhyolitic tephra (sample: 'MP833a') is $0.2-1 \mathrm{~cm}$ thick and situated c. $10-20 \mathrm{~cm}$ above the moraine surface, immediately overlying a $3 \mathrm{~cm}$ thick, coarse (med. sand), dark-grey andesitic tephra (Figure 5.6C). The lower rhyolitic tephra exhibits ductile fold structures (Figure 5.6B), which suggests post-depositional deformation, perhaps via frost-heave. Approximately $40 \mathrm{~cm}$ above MP833a, a discontinuous rhyolitic tephra (sample: 'MP833d') varies in thickness from 0-3 cm (Figure 5.6C). I identify a distinct cobble-to-fine gravel unit at $350 \mathrm{~cm}$ depth, which I correlate to the pebble unit identified by Topping and Kohn (1973) (described fully in Topping, 1974), therefore I am confident that these tephra samples correspond with those analysed by Topping and Kohn (1973). A sharp erosional contact separates this coarse unit from a massive, grey/brown silt-clay bed (300-50 cm depth), with abundant rhizomorphs and two, discrete, interbedded pumiceous horizons. The lower pumice bed (at c. $275 \mathrm{~cm}$ depth) is c. $10 \mathrm{~cm}$ thick and consists of yellow and dark brown coloured clasts, up to $2 \mathrm{~cm}$ in diameter. The upper pumice is c. $40-50 \mathrm{~cm}$ thick and immediately underlies the modern soil horizon. This pumice is correlated to the Taupo ignimbrite (AD232 \pm 


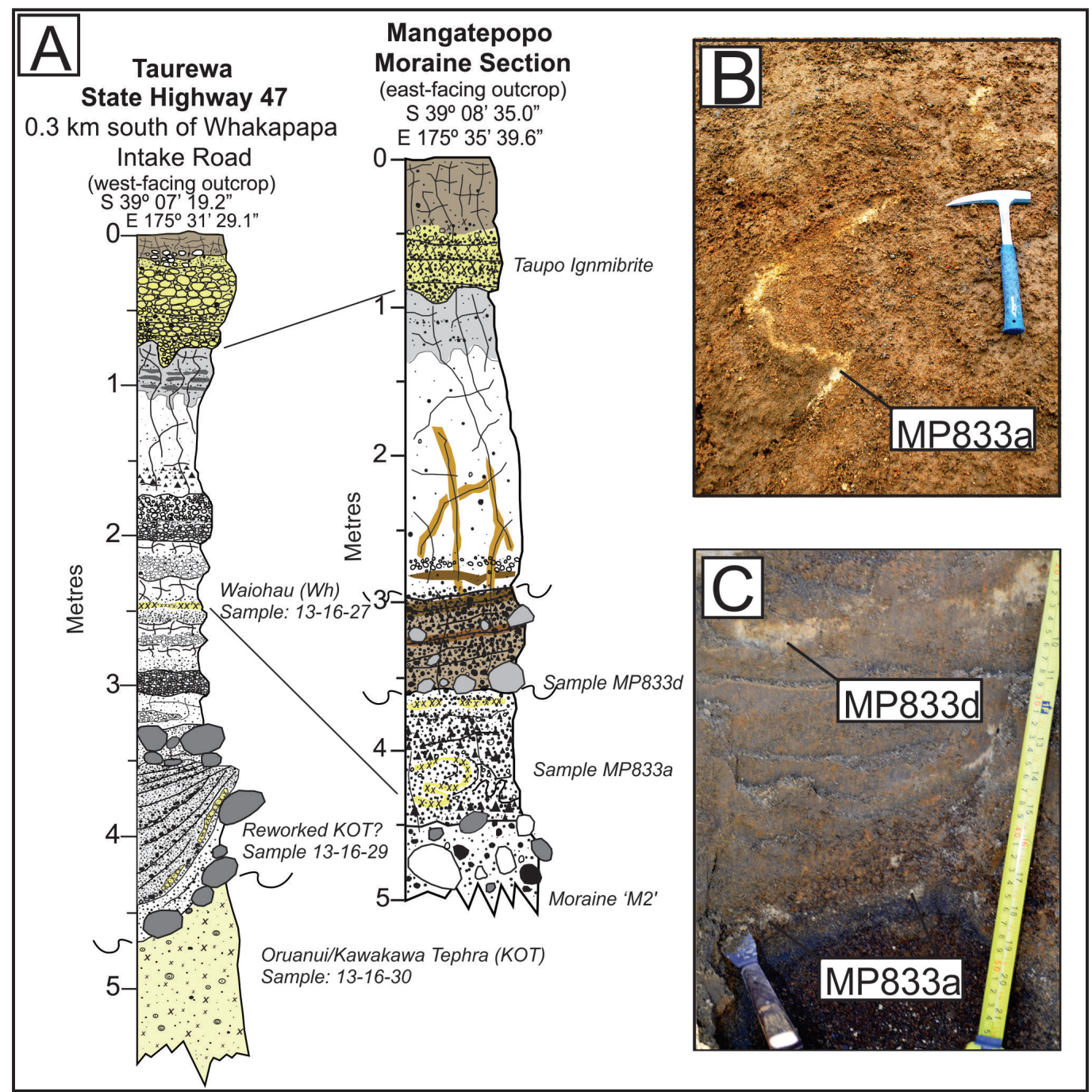

Figure 5.6: (A) Stratigraphic log of the Taurewa reference section and the Mangatepopo moraine section originally described by Topping and Kohn (1973), with the samples labelled; (B) The lowermost rhyolite horizon (sample MP833a) displaying evidence for post-depositional deformation; (C) Soil pit showing both rhyolite horizons at the Mangatepopo section.

10; Lowe et al., 2013), based on stratigraphic position, large pumice clasts (up to $10 \mathrm{~cm}$ diameter), and abundant charred twigs.

Shane (2000) summarised the major element chemistry of post-25 ka rhyolitic tephras in North Island and found that OVC tephras are characterised by higher $\mathrm{SiO}_{2}$ (c. 76-79 wt. \%) and lower FeO (c. 1 wt. \%), compared to those from the Taupo Volcanic Centre $\left(\mathrm{SiO}_{2}=\right.$ c. $71-77$ wt. \%; $\mathrm{FeO}=1.5-3.5 \mathrm{wt}$. \%). Using this information, I can assign samples MP833a and MP833d (Table 5.4 ; Figure 5.7) to the OVC with high confidence. This supports the original interpretation of Topping and Kohn (1973), who assigned both to horizons in the Mangatepopo section to OVC-sourced eruptions. However, the major element compositions of MP833a and MP833d are also indistinguishable from one another (Table 5.4; Figure 5.7), which suggests that the upper sample (MP833d) 
could represent a reworked remnant of MP833a below. This is further supported by the field observations of deformation structures within the lower horizon (MP833a), but contradicts the initial interpretation of Topping and Kohn (1973). The geochemical composition of the Taurewa rhyolitic tephra (Sample: 13-16-27; Figure 5.6) is indistinguishable from the Mangatepopo data, which suggests it represents the same volcanic event (Figure 5.7).

To further constrain deglaciation in the Mangatepopo valley, I seek to determine which OVC-sourced event is represented by the Mangatepopo tephra. To do this, I compare the glass shard major element measurements to proximal and distal OVC reference data from Honeycomb Trench (B.V. Alloway, unpub. data) and Waipaoa river basin (Bilderback, 2012; Marden et al., 2014), respectively. Using binary plots of $\mathrm{K}_{2} \mathrm{O}-\mathrm{FeO}$, the Rerewhakaaitu Tephra can be readily discriminated from the Waiohau Tephra in both the OVC-proximal Honeycomb dataset and distal Waipaoa dataset, based on the presence of high and low $\mathrm{K}_{2} \mathrm{O}$ populations (Figure 5.7B; Shane et al., 2008). The Mangatepopo and Taurewa data are sufficiently different from the Rotorua Tephra for us to rule this out as a possible correlative. Biotite has been noted as a diagnostic component of the ferromagnesian mineral assemblage of the Rerewhakaaitu Tephra (Froggatt and Lowe, 1990) and I do not identify any biotite flakes within the mineral assemblages of the samples. Isopach maps of tephra dispersal over North Island (Lowe et al., 2013) indicate a similar thickness $(0.5-1 \mathrm{~cm})$ for both the Rerewhakaaitu and Waiohau Tephras in the vicinity of the study site, therefore field observations of thickness are not useful in discriminating between the two.

In summary, field descriptions and EMP measurements of glass shard major elements suggest that the samples from two rhyolitic tephra horizons likely represent the same event, as opposed to the previous interpretation of two separate events (Topping and Kohn, 1973). Furthermore, the major element composition of this tephra can be correlated to the OVC with high confidence. The single $\mathrm{K}_{2} \mathrm{O}$ population and the absence of biotite is consistent with the known chemical and mineral composition of the Waiohau Tephra, rather than the Rerewhakaaitu Tephra. However, this interpretation is not consistent with the Fe-Ti analyses of Topping and Kohn (1973). Regardless of which specific event this tephra represents, the findings are stratigraphically consistent with surface exposure ages from the moraine crest (c. $21 \mathrm{ka}$; Section 5.5.1.2) and accord with moraine-tephrostratigraphy elsewhere on Tongariro massif (Cronin and Neall, 1997) that suggests moraine abandonment and soil aggradation in response to climatic amelioration prior to $14.0 \mathrm{ka}$. This represents a minimum age for ice-retreat, which likely occurred several thousands of years earlier, as indicated by the cosmogenic surface exposure ages on the moraine crest. 
Table 5.4: Glass shard major element compositions of rhyolitic tephras from the Taurewa and Mangatepopo sections, compared with potential correlatives from the Okataina Volcanic Centre (OVC). Oxide values are recalculated to $100 \%$ on a volatile-free basis. Total Fe expressed as FeOt. Mean and 1 standard deviation (italics), based on $n$ analyses. All samples normalised either against glass standard VG-568 or ATHO-G. EMP Analyst: B.V. Alloway, for all samples except 'MP833d' (S.R. Eaves).

\begin{tabular}{|c|c|c|c|c|c|c|c|c|c|c|c|c|}
\hline & $\mathrm{SiO}_{2}$ & $\mathrm{Al}_{2} \mathrm{O}_{3}$ & $\mathrm{TiO}_{2}$ & $\mathrm{FeO}$ & $\mathrm{MgO}$ & $\mathrm{MnO}$ & $\mathrm{CaO}$ & $\mathrm{Na}_{2} \mathrm{O}$ & $\mathrm{K}_{2} \mathrm{O}$ & $\mathrm{Cl}$ & Total & $n$ \\
\hline \multicolumn{13}{|c|}{ Mangatepopo moraine: } \\
\hline \multirow[t]{2}{*}{ MP833(i) } & 78.13 & 12.39 & 0.15 & 0.98 & 0.13 & 0.05 & 0.89 & 3.96 & 3.23 & 0.09 & 98.21 & 20 \\
\hline & 0.28 & 0.12 & 0.03 & 0.08 & 0.01 & 0.03 & 0.04 & 0.14 & 0.10 & 0.01 & 1.28 & \\
\hline \multirow[t]{2}{*}{ MP833a(ii) } & 78.21 & 12.38 & 0.14 & 1 & 0.12 & 0.05 & 0.88 & 3.84 & 3.28 & 0.09 & 98.2 & 20 \\
\hline & 0.29 & 0.1 & 0.03 & 0.14 & 0.03 & 0.03 & 0.04 & 0.14 & 0.31 & 0.02 & 1.58 & \\
\hline \multirow[t]{2}{*}{ MP833d } & 78.86 & 12.39 & 0.14 & 0.91 & 0.13 & 0.05 & 0.88 & 3.5 & 2.99 & 0.15 & 99.3 & 18 \\
\hline & 0.24 & 0.10 & 0.02 & 0.09 & 0.03 & 0.03 & 0.06 & 0.14 & 0.12 & 0.02 & 1.00 & \\
\hline \multicolumn{13}{|c|}{ Standard - VG-568: } \\
\hline \multirow{2}{*}{ Sept. 142012} & 75.6 & 12.2 & 0.23 & 3.27 & 0.1 & 0.1 & 1.72 & 3.75 & 2.61 & nd & 99.57 & 31 \\
\hline & 0.55 & 0.12 & 0.02 & 0.09 & 0.01 & 0.02 & 0.03 & 0.1 & 0.03 & & 0.65 & \\
\hline \multicolumn{13}{|c|}{ Standard - ATHO-G: } \\
\hline \multirow[t]{2}{*}{ Oct. 12013} & 75.57 & 12.2 & 0.26 & 3.27 & 0.09 & 0.1 & 1.7 & 3.73 & 2.64 & 0.02 & 99.58 & 48 \\
\hline & 0.60 & 0.09 & 0.03 & 0.10 & 0.01 & 0.03 & 0.03 & 0.13 & 0.05 & 0.01 & 0.75 & \\
\hline \multirow[t]{2}{*}{ Dec. 2013} & 75.62 & 12.2 & 0.24 & 3.27 & 0.09 & 0.11 & 1.7 & 3.73 & 2.64 & 0.08 & 99.68 & 20 \\
\hline & 0.36 & 0.07 & 0.02 & 0.09 & 0.01 & 0.04 & 0.02 & 0.11 & 0.06 & 0.06 & 0.41 & \\
\hline
\end{tabular}



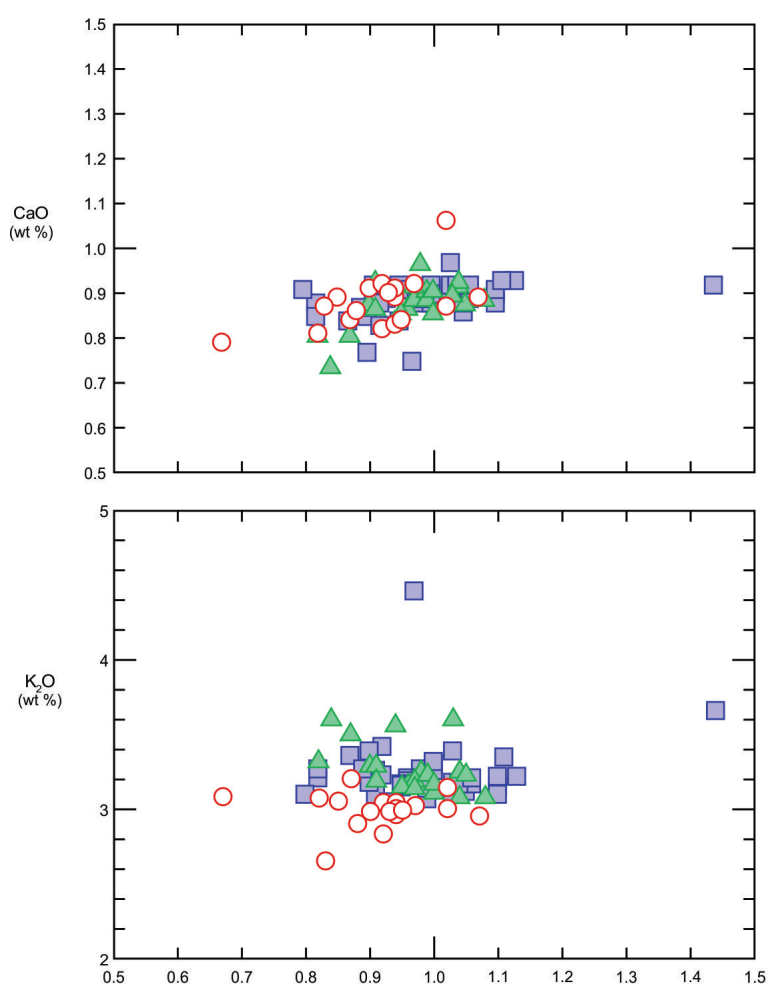

$\mathrm{FeO}(\mathrm{w}+\%)$

This study

Taurewa, SHW-47

$(13-16-27) n=21$

$\square \quad$ Mangatepopo (MP-833a; $n=40$ )

- Mangatepopo (MP-833d; $n=18$ )
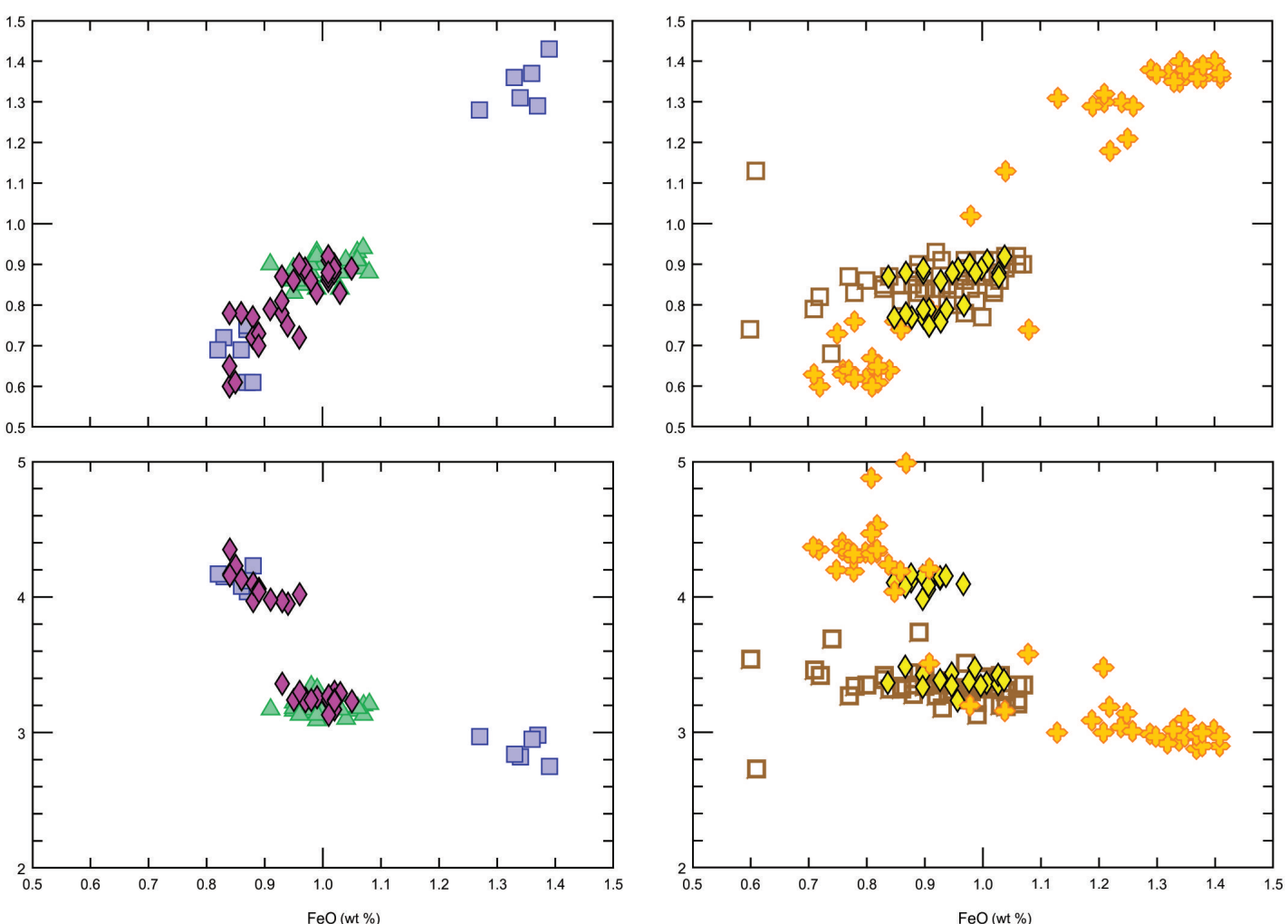

\section{Proximal Okataina VC tephra}

Bilderback (2012)

(acquired on VuW electron microprobe)

B.V. Alloway, unpublished data (acquired on VuW electron microprobe)

Waoihau Tephra, Honeycomb Trench $(n=58)$

Rotorua Tephra, Honeycomb Trench $(n=50)$

$\diamond \quad$ Rerewhakaaitu Tephra, Honeycomb Trench ( $\mathrm{n}=28$ )

Figure 5.7: $\mathrm{K}_{2} \mathrm{O}$ vs. $\mathrm{FeO}$ and $\mathrm{CaO}$ vs. $\mathrm{FeO}$ (wt. \%) plots for Mangatepopo samples and OVC-proximal reference data from Honeycomb Trench. 


\subsubsection{Equilibrium line altitude reconstruction}

I derive a $p$ ELA (AAR = 0.67; Chinn et al., 2012) for the LGM Mangatepopo glacier of $1410 \mathrm{~m}$ asl (Figure 5.8a). This is c. $120 \mathrm{~m}$ lower than the maximum elevation of lateral moraine (MELM; Andrews, 1975) M1, which can be used to approximate the $p$ ELA associated with the older (c. 31-23 ka), slightly thicker Mangatepopo glacier. The moraine stratigraphy suggests that the Mangatepopo glacier was broadly of similar extent during the period 31-21 ka, therefore the MELM method provides a useful independent test of the AAR-based ELA estimate, particularly as it is not subject to uncertainties in past glacier hypsometry or topographic change. The good agreement between the AAR and MELM methods provides confidence in this ELA reconstruction. The lower value predicted by the AAR supports the interpretation that the glacier sourced ice from a wider accumulation zone than currently appreciated, such as an ice field (Rea et al., 1999). It is therefore unlikely that the $21 \mathrm{ka}$ ELA was lower than 1400 $\mathrm{m}$ asl. I consider 1400 - $1550 \mathrm{~m}$ asl a most-likely estimate of the ELA in Mangatepopo valley during the period 31-21 ka. Using the modern ELA datum of Keys (1988) (2483 $\pm 55 \mathrm{~m}$ asl), this represents an ELA lowering of c. $930-1080 \mathrm{~m}$, relative to present.

The ELA on a given glacier is primarily controlled by summer air temperature and winter precipitation, although a range of other energy-balance (insolation, local wind speed, cloudiness, humidity) and topoclimatic (avalanching, snow drifting, topographic shading) factors also contribute (Oerlemans and Fortuin, 1992). Assuming no change in precipitation (see Discussion), it is possible to derive a first-order estimate of atmospheric temperature change associated with a $p$ ELA reconstruction, using a temperature lapse rate. Temperature lapse rates can vary significantly in space and time (Minder et al., 2010; Doughty et al., 2013), and ELA-based palaeotemperature reconstructions are sensitive to this value. For example, I calculate an LGM temperature lowering of c. 5.4 ${ }^{\circ} \mathrm{C}$ relative to present, when using the mean annual temperature lapse rate for upland (>300 m) New Zealand $\left(-5.1^{\circ} \mathrm{C} \mathrm{km}^{-1}\right.$; Norton, 1985). However, using the standard environmental lapse rate $\left(-6.5^{\circ} \mathrm{C} \mathrm{km}^{-1}\right)$ increases the temperature depression estimate to $7.0^{\circ} \mathrm{C}$. Figure $5.8 \mathrm{~b}$ shows the cumulative probability distribution of palaeotemperature estimates in Mangatepopo valley derived using the empirically constrained palaeo(1400-1550 m asl; AAR and MELM) and contemporary-ELAs (2483 $\pm 55 \mathrm{~m}$ asl; Keys, 1988) and a range of possible atmospheric temperature lapse rates, equally weighted between $4-7^{\circ} \mathrm{C} \mathrm{km}^{-1}$. This yields a normally distributed range of palaeotemperature estimates, centred on $5.6 \pm 1.1^{\circ} \mathrm{C}$ (Figure 5.8a), which I consider to be a best-estimate estimate of atmospheric cooling in central North Island between 31-21 ka. 

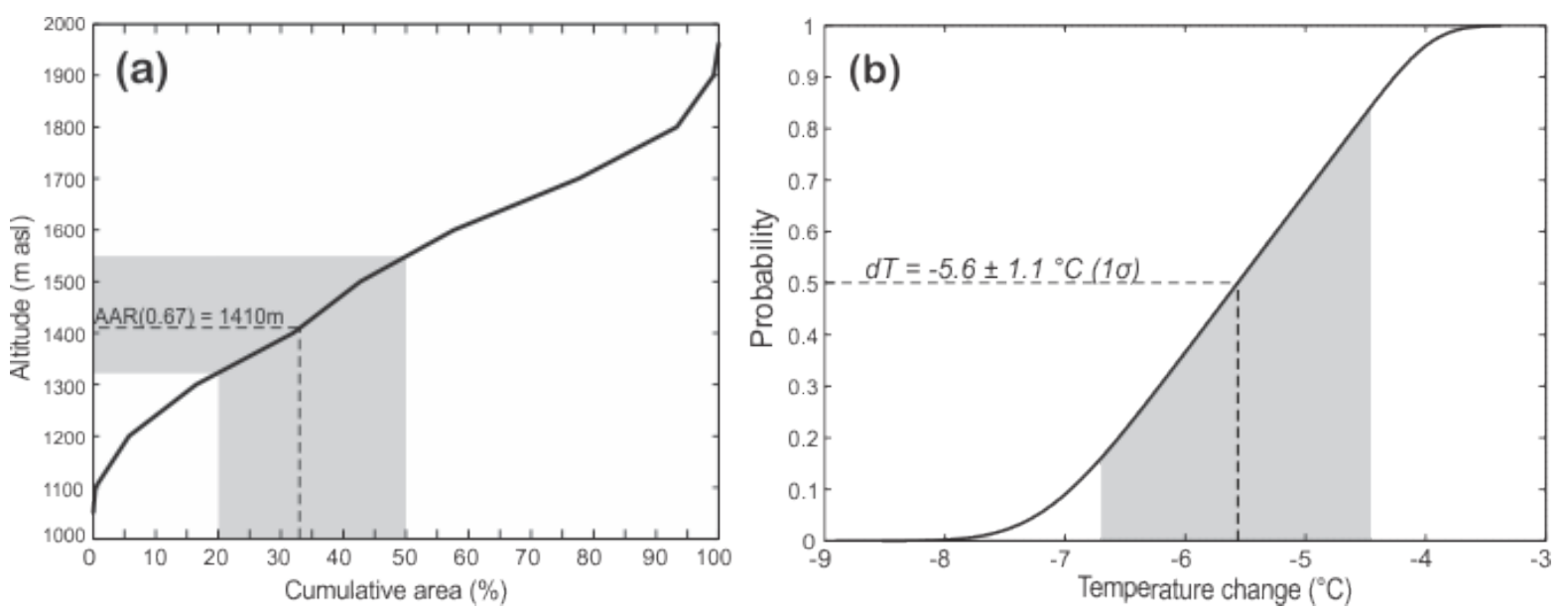

Figure 5.8: (a) Area-altitude curve for the reconstructed $21 \mathrm{ka}$ Mangatepopo glacier. Solid line depicts the associated ELA derived using an AAR of 0.67. Grey shading indicates range using the AAR values of 0.5 - 0.8 (Meier and Post, 1962). (b) Cumulative probability distribution function for $21 \mathrm{ka}$ palaeotemperature estimate in the Mangatepopo Valley derived using palaeo(1400-1550 $\mathrm{m}$ asl; AAR and MELM) and contemporary-ELAs (2483 $\pm 55 \mathrm{~m}$ asl; Keys, 1988) and a range of possible atmospheric temperature lapse rates, equally weighted between $4-7^{\circ} \mathrm{C}$ $\mathrm{km}^{-1}$. Shaded grey zone indicates $1 \sigma$ uncertainty interval.

\subsection{Discussion}

\subsubsection{The Last Glacial Cold Period in central North Island}

Using in situ cosmogenic ${ }^{3}$ He surface exposure dating of moraine boulders, I provide the first direct chronological constraint for extensive valley glaciation on Tongariro massif during MIS 3 - 2, which began as early as $31 \pm 3 \mathrm{ka}$ and persisted until at least c. $21 \pm 2 \mathrm{ka}$. This is well-aligned, within dating errors, with the Last Glacial Cold Period (LGCP; c. 29-18 ka) as identified in the New Zealand Climate Event Stratigraphy (Barrell et al., 2013). The local ELA depression associated with LGCP glaciation in Mangatepopo valley was c. 1400-1550 m asl. The timing and magnitude of these changes are in good agreement with previous palaeoenvironmental reconstructions from central North Island. On Mt. Ruapehu, situated c. $15 \mathrm{~km}$ to the south of Mangatepopo valley, McArthur and Shepherd (1990) identify geomorphological evidence for a former ice mass with an equilibrium line of 1500-1600 m asl, which agrees well with my $p$ ELA reconstruction. McArthur and Shepherd (1990) suggest deformed pro-glacial lake sediments interbedded with moraines on northeast Ruapehu record several glacier advances during the last glacial cycle. Topping (1974) identified the Kawakawa-Oruanui Tephra within these lake sediments, which places glacier advances either side of 25.4 $\mathrm{ka}$. The latter advance likely correlates to the final stand of the Mangatepopo glacier at $21 \pm 2 \mathrm{ka}$, however the lack of direct dating on Mt. Ruapehu means the timing of preceding glacier fluctuations is unconstrained. 
The glacial chronology presented here is in good agreement with the only other glaciological reconstruction in North Island, New Zealand. Brook et al. (2008) report cosmogenic ${ }^{10}$ Be moraine and bedrock exposure ages of c. $18 \mathrm{ka}$ in the Tararua ranges of southern North Island (c. $40^{\circ} \mathrm{S}$ ). Recalculating these ages using the local ${ }^{10} \mathrm{Be}$ production rate of Putnam et al. (2010b) yields revised ages of c. $21 \pm 2 \mathrm{ka}$, which is indistinguishable from the last pulse of glaciation recorded in the Mangatepopo valley. Brook (2009) also identifies the KOT within this moraine, which suggests it represents a composite feature first occupied prior to $25.4 \mathrm{ka}$ (Brook and Crow, 2008; Brook, 2009).

Recent, high-precision cosmogenic ${ }^{10}$ Be moraine chronologies from the central Southern Alps show a similar temporal pattern of glacier fluctuations. Local constraint of the ${ }^{10} \mathrm{Be}$ production rate (Putnam et al., 2010b), coupled with favourable topographic situations for moraine preservation and extensive exposure age datasets, have afforded detailed insight to late Quaternary glacier fluctuations in this region. For example, Putnam et al. (2013b) show that the former Ohau glacier deposited terminal moraines at c. $32 \mathrm{ka}$, c. $27 \mathrm{ka} \mathrm{c.} 23 \mathrm{ka}$ and c. $18 \mathrm{ka}$. On the west coast of South Island, Suggate and Almond (2005) suggest glacier advances culminated at c. 28 ka, $22 \mathrm{ka}$ and $19 \mathrm{ka}$, however recent cosmogenic ${ }^{10} \mathrm{Be}$ surface exposure dating of these moraine sequences has refined the age of these deposits to c. $25 \mathrm{ka}$, c. $21 \mathrm{ka}$ and c. $17 \mathrm{ka}$ (Barrows et al., 2013). On the eastern side of the Southern Alps, Rother et al. (2014) show that the former Rangitata glacier reached its maximum extent before c. $28 \mathrm{ka}$, followed by successive fluctuations of slightly lesser extent between 26-19 ka. Thus, the findings from central North Island add to a growing body of evidence that show glaciers across New Zealand attained their maximum extent in late MIS 3 and fluctuated about this position through the global LGM (26-19 ka; Clark et al., 2009).

At the last glacial termination, glacier retreat in central North Island may have begun as early as $21.0 \pm 2 \mathrm{ka}$, as indicated by the cosmogenic ${ }^{3} \mathrm{He}$ moraine chronology. Additional constraint from moraine tephrostratigraphy in the Mangatepopo valley, suggests significant climatic amelioration prior to deposition of the Waiohau Tephra (c. $14.0 \pm 0.2 \mathrm{ka}$; Lowe et al., 2013). Several catchments in the Southern Alps exhibit evidence for moraine formation at c. 20-22 ka (Schaefer et al., 2006; Putnam et al., 2013b; Kelley et al., 2014), however these high-precision chronologies also indicate that glaciers remained at, or close to, the $21 \mathrm{ka}$ limits until at least $18 \mathrm{ka}$. Given the current precision of the cosmogenic ${ }^{3} \mathrm{He}$ production rate (Chapter 4; Goehring et al., 2010) it is not possible to resolve any time lags in the onset of deglaciation that may exist between North Island and South Island. It is also possible that geomorphological evidence for a final, short-lived glacier advance may not be preserved or sampled in the study site. I 
note that multiple, sharp-crested moraines exist on the southern side of Mangatepopo Valley (Figure 5.2), which indicates there may be more structure to the LGM glacial signature in this valley than currently indicated by the chronology. However, thick overlying soil sequences at these lower altitudes preclude exposure dating of these moraines.

The palaeoglacier reconstruction for Mangatepopo valley indicates local atmospheric temperature was reduced by $5.6 \pm 1.1^{\circ} \mathrm{C}$ relative to present (Figure $5.8 \mathrm{~b}$ ) during the LGCP. This estimate assumes that precipitation remained similar to present. Currently there is a paucity of quantitative LGCP precipitation estimates in New Zealand, however proxy-, glacier model-, and climate model-based reconstructions are generally consistent in suggesting that precipitation was similar or slightly reduced, relative to present (Drost et al., 2007; Rojas et al., 2009; Whittaker et al., 2011; Golledge et al., 2012; Lorrey et al., 2012b; Stephens et al., 2012b). Reduced precipitation in central North Island during the LGCP would increase the magnitude of atmospheric cooling required to explain the reconstructed ELA. However, empirical and glacier model-based evidence suggests that past and present-day glacier mass balance in New Zealand is relatively insensitive to precipitation change, with precipitation increases of c. $30-80 \%$ required to balance $1^{\circ} \mathrm{C}$ of warming (Oerlemans, 1997; Anderson and Mackintosh, 2006, 2012; Anderson et al., 2010). Thus, the error in the palaeotemperature estimate arising from past precipitation change is relatively insignificant $\left(<1^{\circ} \mathrm{C}\right)$ in comparison to the uncertainty in the ELA reconstruction and temperature lapse rate.

The LGCP temperature estimate for central North Island exhibits good agreement with catchment- and regional-scale glacier model simulations of LGM glaciers in the Southern Alps, which indicate temperature depression of c. $6-7^{\circ} \mathrm{C}$ relative to present (Golledge et al., 2012; McKinnon et al., 2012; Putnam et al., 2013b; Rowan et al., 2013). The estimate also agrees with a recent pollen-based assessment, which indicates that average mean annual air temperature in New Zealand was reduced by $6.0 \pm 1.9^{\circ} \mathrm{C}$ during the LGM (Newnham et al., 2013). Offshore, local sea surface temperature estimates are spatially variable, but converge on a $4-7^{\circ} \mathrm{C}$ lowering between c. 30-18 ka (Pahnke and Sachs, 2006; Barrows et al., 2007a; Bostock et al., 2013).

\subsubsection{Pre-LGCP glaciation}

Cosmogenic ${ }^{3} \mathrm{He}$ surface exposure ages from moraine M3 in Mangatepopo valley indicate that the former Mangatepopo glacier attained its maximum extent of the last glacial cycle prior to the local LGCP (c. 28-18 ka; Barrell et al., 2013) and global LGM (26-19 
ka; Clark et al., 2009). Surface erosion (e.g. c. 1 - $6 \mathrm{~mm} \mathrm{kyr}^{-1}$ ) and tectonic uplift of these samples, which have been exposed since at least c. $58 \mathrm{ka}$, means that the exposure ages represent minimum ages for moraine formation and the true moraine age is likely several millennia older (e.g. c. 65-60 ka). Below, I consider this interpretation in the context of other geological records of glacial fluctuations during this time period.

Evidence for glacial activity prior to the LGCP is relatively scarce and, where present, the timing is often poorly constrained. However, a recent high-precision cosmogenic ${ }^{10}$ Be exposure age dataset from the Balmoral moraines in central Southern Alps shows that an advance of the former Pukaki and Tekapo glaciers culminated at $65 \pm 3 \mathrm{ka}$ ( $n=39$, plus three outliers; Schaefer et al., 2015). The Balmoral moraines associated with this advance (Barrell, 2014) are present outside of the well-dated, local LGCP limits (Schaefer et al., 2006; Kelley et al., 2014; Schaefer et al., 2015), thus indicating that the glaciers attained their maximum extent of the last glacial cycle prior to the LGCP. Sutherland et al. (2007) present cosmogenic ${ }^{10}$ Be surface exposure ages from a suite of moraines preserved on Cascade plateau $\left(44^{\circ} \mathrm{S}\right)$, on the west coast of South Island. The moraine belt immediately outboard of the LGCP limits at this location yielded boulder exposure ages of c. 60 - $68 \mathrm{ka}$ ( $n=2$, plus one outlier) when recalculated according to Putnam et al. (2010b). These revised ages provide further evidence for a significant glacial advance during Marine Isotope Stage (MIS) 4 (Williams et al., 2015).

Other glacial records from South Island also indicate glacier expansion around this time, however chronologies are less-precisely constrained, largely relying on bracketing luminescence ages from ice-marginal deposits. For example, McCarthy et al. (2008) present evidence from the Tasman Mountains in northern South Island $\left(41^{\circ} \mathrm{S}\right)$ that suggests two periods of glaciation, of similar magnitude, occurred during MIS 4 and the LGCP. The MIS 4 glaciation at this location is constrained with optically-stimulated luminescence ages of glacio-lacustrine deposits, which are present outboard of the LGCP limits, and date to $64 \pm 10 \mathrm{ka}$. On the central west coast of South Island, luminescence ages of sand/silt beds interbedded with glacial outwash gravels suggest glacier expansion at c. $85 \mathrm{ka}$ and c. $64 \mathrm{ka}$ (Preusser et al., 2005). However, moraines correlated with these outwash deposits have recently been shown to date to c. $25 \mathrm{ka}$ (Barrows et al., 2013). No moraines of MIS 4 age were recognised by Barrows et al. (2013), therefore they suggest that any such deposits were overrun during the LGCP when glaciers in this catchment attained their maximum extent of the last glacial cycle.

There is little evidence for glacier advance in New Zealand between 60 - $45 \mathrm{ka}$ (Williams et al., 2015), during which fall most of the exposure ages from M3 moraine, if taken at face value. Furthermore, continuous climate proxy data indicate that this time period 
was characterised by relatively mild, interstadial conditions (Shulmeister et al., 2001; Shane and Sandiford, 2003; Whittaker et al., 2011; Williams et al., 2015), which were probably unfavourable for significant glacier advance. Offshore, Barrows et al. (2007a) identify intervals of high clastic sediment input between 70 - $60 \mathrm{ka}$ in multiple cores, which are intepreted to represent higher terrestrial erosion rates due to expansion of nearby mountain glaciers. This is followed by a sharp reduction after $60 \mathrm{ka}$, which is consistent with the terrestrial evidence for climatic amelioration and glacial retreat. Thus, the majority of evidence from glacial records and other climate proxies support the interpretation of glacier advance in central North Island during late MIS 4 (c. 65 $60 \mathrm{ka})$, which was of similar extent to the LGCP.

\subsection{Conclusions}

1. Tongariro massif was last glaciated between 31-21 ka when a central ice field fed valley glaciers that extended down to c. $1200 \mathrm{~m}$ asl. The onset of glacial retreat occurred at c. $21 \pm 2 \mathrm{ka}$, which is in agreement with the only other moraine ages in North Island (Brook et al., 2008).

2. During the Last Glacial Cold Period (LGCP), the local equilibrium line altitude was c. $1400-1550 \mathrm{~m}$ asl, which is $930-1080 \mathrm{~m}$ lower than present. This equates to a best-estimate temperature depression of $5.6 \pm 1.1^{\circ} \mathrm{C}$, when uncertainties in the ELA reconstruction and temperature lapse rate are considered. The timing and magnitude of glaciation in central North Island is consistent with a growing body of evidence that shows mountain glaciers in Southern Alps attained their maximum LGCP position by 32-28 ka and persisted until the termination (Schaefer et al., 2006; Putnam et al., 2013b; Kelley et al., 2014; Rother et al., 2014).

3. Reinvestigation of the 21 ka moraine coverbed stratigraphy, using field observations and major element analysis, indicates that the rhyolitic tephra close to the moraine surface is the Waiohau Tephra. This horizon (c. 14 cal. ka BP; Lowe et al., 2013) provides a minimum limiting age for the onset of climatic amelioration and soil formation at this site. Previous work had suggested that this horizon corresponds to the Rerewhakaaitu Tephra Topping and Kohn (1973).

4. Cosmogenic ${ }^{3}$ He surface exposure ages from boulders on the crest of a degraded lateral moraine indicate that glaciers on Tongariro massif attained their greatest extent of the last glacial cycle prior to the Last Glacial Maximum. Geological processes such as boulder erosion, exhumation and tectonic uplift mean that these 
ages provide minimum limiting constraint of the moraine age and the true age is likely older by several millennia. This evidence, together with comparison to continuous climate proxy records from North Island and glacier records from Southern Alps, indicates that this event occurred late in Marine Isotope Stage 4. 


\section{Chapter 6}

\section{Uniform summertime cooling across New Zealand drove glacial readvance during the late-glacial (15-11 ka)}

\subsection{Abstract}

The mechanisms of atmospheric cooling in New Zealand during the last glacial interglacial transition remain uncertain. Improved understanding of the timing and magnitude of climatic variability during this period will help to identify the drivers of abrupt climate change. In this study, I report results from geological mapping and cosmogenic ${ }^{3} \mathrm{He}$ exposure dating, which show evidence for readvance of mountain glaciers on Mt Ruapehu in central North Island, New Zealand (39 ${ }^{\circ}$ ) during the late glacial chron (15-11 ka). Using a distributed energy balance model, coupled with a 2D ice flow model, I perform a range of experiments and sensitivity analyses to constrain estimates of past temperature associated with the mapped and dated former ice limits. Results show that glaciers in North Island readvanced early in the late glacial in response to a likely temperature cooling of $2.5-3.4{ }^{\circ} \mathrm{C}$ relative to present day, assuming precipitation remained within $\pm 20 \%$ of present. This magnitude of cooling is greater than that recorded in nearby pollen archives, which may reflect a seasonal bias between climate proxies. Strong agreement of the results presented here with other summer temperature proxy records (mountain glaciers, chironomids) from the Southern Alps, suggest New Zealand experienced uniform summertime cooling during the late-glacial climate reversal. 


\subsection{Introduction}

The last glacial termination (c. 18-11 ka BP; Denton et al., 2010) was characterised by millennial-scale climate oscillations that were antiphased between the poles (Blunier and Brook, 2001). In Antarctica, steady deglacial warming from c. 18 -14.7 ka was interrupted by a c. 2 kyr hiatus, which persisted until c. $12.6 \mathrm{ka}$, known as the 'Antarctic Cold Reversal' (ACR). In Greenland, this period is marked by an abrupt warming to near-interglacial temperature, followed by steady temperature decline. Resumption of warming in Antarctica at the end of the ACR, coincides with the onset of a c. $1000 \mathrm{yr}$ cold period in Greenland, known as the Younger Dryas (12.7-11.6 ka), during which time local temperature returned to near-glacial levels. A long standing goal of palaeoclimatology has been to document the precise timing and magnitude of these events outside of the polar regions (e.g. Thompson et al., 1995; Putnam et al., 2010a), in order to establish the key drivers and mechanisms of abrupt climate change.

In New Zealand, the timing, magnitude and spatial variability of climate events between 15-11 ka has proven controversial. Early work indicated that a millennial-scale cooling event occurred synchronously with the Younger Dryas (Denton and Hendy, 1994; Ivy Ochs et al., 1999), which implied the ACR was restricted to southern highlatitudes. However, improved dating precision (e.g. Schaefer et al., 2009; Putnam et al., 2010b; Lowe et al., 2013) from an increasing number of palaeoclimatic archives now places the 'late-glacial climate reversal' (LGR) in New Zealand at 13.5-11.6 ka (Alloway et al., 2007; Lowe et al., 2013), which largely overlaps the ACR.

Despite improved chronological constraint, the absolute magnitude of cooling and in particular the spatial pattern, remains uncertain. For example, in a latitudinal transect $\left(36-44^{\circ} \mathrm{S}\right)$ of terrestrial sediment cores, pollen-temperature reconstructions indicate northward attenuation of LGR cooling (Newnham et al., 2012), which suggests a steeper than present meridional temperature gradient existed across New Zealand at this time. However, other, multi-proxy, terrestrial records from southern New Zealand show differences in the magnitude of change recorded between proxies, which could represent differences in their seasonal sensitivity (Vandergoes et al., 2008; Sikes et al., 2013). Evidence for latitudinal control on terrestrial cooling across New Zealand is based solely on pollen records, therefore a critical test can be conducted by the addition of quantitative palaeoclimate reconstructions from other proxy archives. This is important, because constraining the spatial patterns of LGR cooling can inform the driving mechanisms. For example, as outlined by Carter et al. (2008), the existence of an enhanced temperature gradient points to a critical role for the sub-tropical front in modulating rapid, millennial scale climate events. 
In this study, I test this theory by reconstructing the timing and magnitude of glacier fluctuations in central North Island, New Zealand (39 $\left.{ }^{\circ} \mathrm{S}\right)$. I identify and date a moraine sequence in the central North Island that shows mountain glaciers readvanced in response to cooling during the LGR. Using numerical glacier modelling to constrain quantitative estimates of the cooling required to generate this advance, I test the following hypothesis:

$H_{\text {null }}$ : there is no significant difference in the magnitude of atmospheric cooling across New Zealand during the LGR, as indicated by numerical glacier modelling.

To reject $H_{\text {null }}$, evidence must exist for a significant difference between the cooling observed in central South Island records (e.g. Anderson and Mackintosh, 2006; Doughty et al., 2013; Kaplan et al., 2013) and the North Island site. If this is the case, then the alternative hypothesis $\left(H_{\text {alt }}\right)$ states:

$H_{\text {alt }}$ : there is a significant latitudinal difference in the magnitude of cooling during the lateglacial climate reversal, as indicated by numerical glacier modelling.

\subsection{Study site and previous work}

Situated in the southwest sector of the Pacific Ocean, New Zealand represents a rare opportunity to reconstruct terrestrial palaeoclimate in the ocean-dominated mid-latitudes of the Southern Hemisphere. The longitudinal extent $\left(34-47^{\circ} \mathrm{S}\right)$ and high topographic relief intercepts key components of global atmospheric and oceanic circulation, making this location highly sensitive to past climatic change (Alloway et al., 2007). The zonal, cyclone-bearing southern westerly winds are intercepted by the NNE-SSW trending axial ranges, which generate steep, $\mathrm{W}$-E precipitation gradients across central and southern portions of New Zealand. Meanwhile the sub-tropical front (STF), which defines the boundary between sub-Antarctic and sub-tropical water masses, augments the north-south temperature gradient that exists across the latitudinal length of New Zealand. For example, northernmost North Island lies within an oceanic domain characterised by subtropical water masses delivered from the central equatorial Pacific Ocean via the Tasman Front (Figure 2.7). Meanwhile, central and southernmost portions of New Zealand intercept the STF. South of this boundary, cooler sub-polar water masses bathe the western and southern coasts of South Island. Consequently, a sea surface temperature (SST) gradient exists across the latitudinal length of New Zealand, with average annual SSTs of c. $20^{\circ} \mathrm{C}$ in the far north, and c. $10^{\circ} \mathrm{C}$ in the south (Uddstrom 


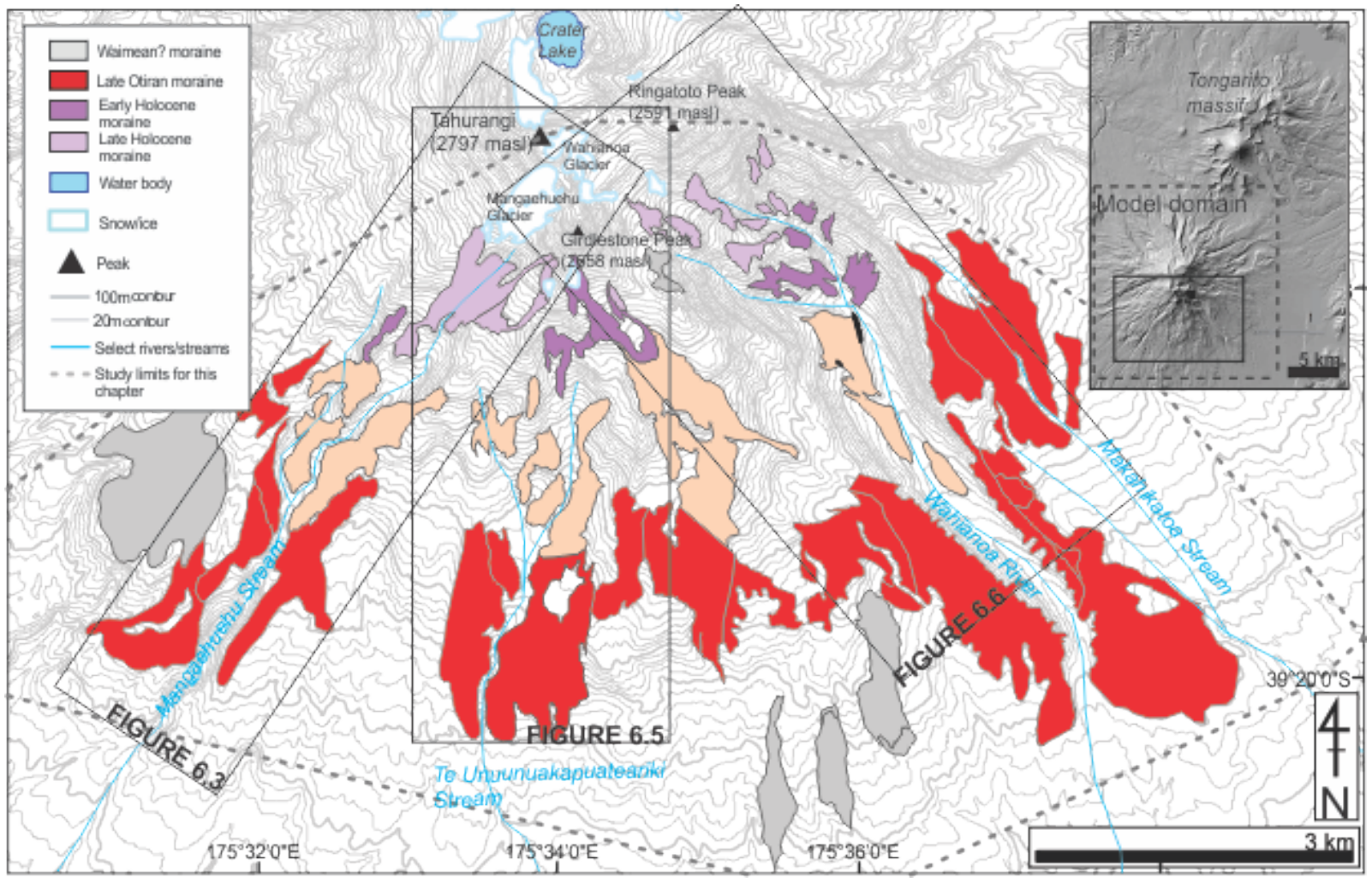

Figure 6.1: Overview map of the study region on southern Ruapehu for this chapter showing regional moraine distribution. Inset is the location of the main part of the figure (solid rectangle) and the glacier modelling domain (dashed rectangle).

and Oien, 1999).

Mount Ruapehu (2797 m asl; 39 $\left.2^{\circ} \mathrm{S}, 175^{\circ} 3^{\prime} \mathrm{E}\right)$ is a composite, andesite-dacite stratovolcano situated in the central North Island, at the southern end of the Taupo Volcanic Zone (TVZ). The TVZ is a c. $350 \mathrm{~km}$ long, NNE-SSW trending chain of volcanoes caused by subduction of the Pacific Plate beneath the Australian Plate (Cole, 1978). Radiometric (K/Ar) dating of andesitic lava flows constrain the onset of cone-building volcanism at Mt. Ruapehu to at least c. 250 ka (Gamble et al., 2003). Modern local climate, as recorded on the lower NW flank at Whakapapa village (1097 $\mathrm{m}$ asl), is characterised by relatively high total annual precipitation and low seasonal precipitation variability (Chapter 2). Monthly mean temperatures range from c. $13{ }^{\circ} \mathrm{C}$ in February, to c. $3{ }^{\circ} \mathrm{C}$ in July, with an annual average of $7.5^{\circ} \mathrm{C}$ (1981-2010; NIWA, 2014). Small glaciers and snow patches persist on the upper reaches of the mountain, generally above c. $2300-2400 \mathrm{~m}$ asl, in south-facing topographic hollows. Interannual fluctuations in the mass balance of these ice bodies, as recorded in annual surface area changes, correlates strongly with ablation season temperature and mean end of summer snowlines in the Southern Alps (Brook et al., 2011). 
Previous studies of past glaciation in central North Island have identified abundant geomorphological evidence for multiple periods of more extensive glaciation during the late Quaternary (McArthur and Shepherd, 1990; Chapter 5, Chapter 7). On Mt. Ruapehu, McArthur and Shepherd (1990) record large lateral moraines in several catchments, likely constructed by a former ice mass with outlet glaciers that reached c. 1200 $\mathrm{m}$ asl. McArthur and Shepherd (1990) suggest these deposits pertain to multiple fluctuations during the last glacial cycle, based on the presence of the Kawakawa-Oruanui Tephra (25.4 $\pm 0.2 \mathrm{ka}$ - Vandergoes et al., 2013) interbedded in deformed, morainebound glacio-lacustrine deposits. On nearby Tongariro massif, situated $15 \mathrm{~km}$ to the north-east, cosmogenic ${ }^{3} \mathrm{He}$ exposure dating of moraines supports this conclusion, indicating significant periods of glaciation during late MIS 4 (c. $58 \pm 6 \mathrm{ka}$ ) and the Last Glacial Cold Period (LGCP; c. 30-21 ka) when snowlines were depressed by c. 1000 $m$ relative to present (Chapter 5). On Tongariro massif, no evidence exists to suggest renewed glacial activity since the LGCP. This is most likely because the topography, prior to Holocene cone growth, was of insufficient relief to intercept the estimated snowlines during the LGR (c. 300-500 m relative to present - Porter, 1975; Kaplan et al., 2010, 2013; see also Chapter 7). However, at c. $2800 \mathrm{~m}$ asl and currently glacierised, Mt. Ruapehu is better positioned to record past cooling events of this magnitude.

In this study, I target three stream catchments on the southern flanks of Mt. Ruapehu: (i) the glacierised Mangaehuehu catchment, which drains in a south-west direction, originating between Tahurangi (2797 $\mathrm{m}$ asl) and Girdlestone (2658 m asl) peaks; (ii) Te Unuunuakapuateariki Stream, which rises at c. $2200 \mathrm{~m}$ asl below Girdlestone Peak and drains in a southward direction; and (iii) the deeply incised Wahianoa valley, which drains southeastwards from Girdlestone Peak (Figure 6.1). Recent geological mapping in these catchments has identified multiple former ice limits, depicted by discrete moraine ridges (Townsend et al., in prep.). Previous studies of the glacial geomorphology in the Mangaehuehu catchment have resulted in differing interpretations of former ice limits. For example, McArthur and Shepherd (1990) tentatively suggest a distinct moraine pair, which indicates a former ice mass that terminated at c. 1600 $\mathrm{m}$ asl, as the late Otiran (45 - $18 \mathrm{ka}$; Barrell et al., 2011) ice limits in this catchment and they do not recognise any glacial deposits down valley from this location. Conversely, Barrell (2011) suggests late Otiran ice extended further down valley and terminated at c. $1200 \mathrm{~m}$ asl. This latter interpretation therefore implies that the moraines identified by McArthur and Shepherd (1990) represent a glacier readvance/stillstand $<18 \mathrm{ka}$. In the Te Unuunuakapuateariki and Wahianoa catchments, moraines also exist at c. 1800 - 1500 $\mathrm{m}$ asl, which may have been deposited synchronously with those in the Mangaehuehu catchment. In this study, I refine the understanding of the glacial stratigraphy of this region using geological mapping, cosmogenic surface exposure dating and numerical 
glacier modelling.

\subsection{Methods}

\subsubsection{Geomorphological mapping}

Initial geomorphological mapping was conducted using aerial photographs, from which prominent landforms were delineated, such as large moraines, till cover, cirques, tephra coverbeds, lava cliffs and alluvial fans. Field mapping was then undertaken to ground-truth initial interpretations. Field data were recorded using a handheld global positioning system receiver and enlarged 1:50000 scale topographic base maps, then digitised using a Geographic Information System.

\subsubsection{Cosmogenic ${ }^{3} \mathrm{He}$ surface exposure dating}

Moraine boulder samples were collected using a portable, $16 \mathrm{~V}$ rock saw fitted with a segmented, diamond-tipped blade. Samples were taken only from boulders on the moraine crest (Figure 6.2). Where possible, boulders were partially embedded in the moraine matrix, to minimise the likelihood of post-depositional boulder rotation. All samples were collected from the highest point of the parent boulder, which were $>0.6$ $\mathrm{m}$ tall, thus minimising the potential for burial by snow and/or volcanic ash (Table 6.1). Azimuthal horizon elevations were measured in the field using a standard geological compass and clinometer, and geometric shielding corrections were computed using the CRONUS-EARTH calculator (available at: http://hess.ess.washington.edu/; Balco et al., 2008). All shielding corrections were $<1 \%$. Sample locations and elevations were recorded using a Trimble GeoXH global positioning system, relative to the WGS84 datum. These data were differentially corrected using continuous measurements from GeoNet 'Chateau Observatory' ('VGOB') base station (39 $11^{\prime} 59^{\prime \prime}$ S, $175^{\circ} 32^{\prime} 32^{\prime \prime}$; 1161 $\mathrm{m}$ asl), located $13 \mathrm{~km}$ north of the study site. Horizontal and vertical post-processed uncertainties for individual sample locations are $<1 \mathrm{~m}$.

Samples were jaw-crushed, rinsed in de-ionised water and dry-sieved to isolate the 250-500 $\mu \mathrm{m}$ size fraction. Density $\left(>3.1 \mathrm{~g} \mathrm{~cm}^{-3}\right)$ and magnetic separation techniques were used to isolate 150-600 mg of pyroxene grains. Following Bromley et al. (2014), separated pyroxenes were first leached in 5\% hydrofluoric (HF) / $2 \%$ nitric $\left(\mathrm{HNO}_{3}\right)$ 
Table 6.1: Moraine boulder cosmogenic ${ }^{3}$ He sample details.

\begin{tabular}{|c|c|c|c|c|c|c|c|}
\hline $\begin{array}{l}\text { Sample } \\
\text { ID }\end{array}$ & Latitude & Longitude & $\begin{array}{l}\text { Altitude } \\
\text { (m a.s.l) }\end{array}$ & $\begin{array}{l}\text { Thickness } \\
(\mathrm{cm})\end{array}$ & $\begin{array}{l}\text { Geometry } \\
(H \times L \times W(\mathrm{~cm}))\end{array}$ & $\begin{array}{l}\text { Surface } \\
\text { strike/dip }\end{array}$ & Shielding \\
\hline \multicolumn{8}{|c|}{ Upper moraine (LG2): } \\
\hline BH1210 & -39.311 & 175.5433 & 1779 & 1.5 & $75 \times 220 \times 140$ & $294 / 2$ & 0.998 \\
\hline BH1209 & -39.312 & 175.5424 & 1769 & 1.5 & $110 \times 180 \times 170$ & $102 / 8$ & 0.998 \\
\hline BH1211 & -39.312 & 175.5432 & 1780 & 2.0 & $60 \times 190 \times 100$ & $356 / 10$ & 0.998 \\
\hline BH1208 & -39.313 & 175.5424 & 1765 & 1.5 & $90 \times 140 \times 130$ & $048 / 8$ & 0.998 \\
\hline \multicolumn{8}{|c|}{ Lower moraine (LG1): } \\
\hline BH1204 & -39.318 & 175.537 & 1605 & 2.0 & $75 \times 150 \times 100$ & 072/9 & 0.998 \\
\hline BH1206 & -39.318 & 175.537 & 1605 & 2.5 & $80 \times 18 \times 120$ & $298 / 15$ & 0.996 \\
\hline BH1207 & -39.318 & 175.537 & 1606 & 1.5 & $90 \times 150 \times 140$ & $062 / 13$ & 0.997 \\
\hline BH1205 & -39.318 & 175.537 & 1602 & 2.5 & $75 \times 130 \times 100$ & $140 / 9$ & 0.998 \\
\hline BH1201 & -39.316 & 175.539 & 1621 & 1.5 & $85 \times 220 \times 200$ & $200 / 12$ & 0.996 \\
\hline BH1213 & -39.315 & 175.539 & 1632 & 2.0 & $80 \times 130 \times 110$ & $156 / 2$ & 0.998 \\
\hline BH1203 & -39.316 & 175.538 & 1630 & 2.5 & $140 \times 150 \times 100$ & $276 / 16$ & 0.995 \\
\hline \multicolumn{8}{|c|}{ Outboard moraine (LG3): } \\
\hline BH1212 & -39.312 & 175.539 & 1657 & 2.0 & $60 \times 100 \times 100$ & $154 / 13$ & 0.991 \\
\hline \multicolumn{8}{|c|}{ Outboard moraine (LG4): } \\
\hline BH1214 & -39.315 & 175.537 & 1612 & 1.5 & $150 \times 210 \times 140$ & $332 / 6$ & 0.995 \\
\hline BH1215 & -39.315 & 175.537 & 1605 & 1.5 & $100 \times 150 \times 130$ & $268 / 6$ & 0.995 \\
\hline \multicolumn{8}{|c|}{ TU1 moraine - left lateral: } \\
\hline ME1201 & -39.322 & 175.568 & 1673 & 1.5 & $125 \times 340 \times 160$ & $072 / 8$ & 0.996 \\
\hline ME1202 & -39.322 & 175.568 & 1684 & 1.5 & $80 \times 260 \times 130$ & 0 & 0.996 \\
\hline ME1203 & -39.322 & 175.568 & 1689 & 1.0 & $130 \times 220 \times 180$ & 0 & 0.996 \\
\hline \multicolumn{8}{|c|}{ TU2 moraine - right lateral: } \\
\hline ME1204 & -39.320 & 175.565 & 1691 & 2.0 & $75 \times 150 \times 120$ & $214 / 12$ & 0.994 \\
\hline
\end{tabular}

acid solution for 24 hours, followed by a separate $10 \%$ hydrochloric $(\mathrm{HCl})$ acid solution for 24 hours, to remove adhering groundmass particles. Leached pyroxene crystals were visually inspected for purity and wrapped in aluminium foil. Each sample was completely degassed by heating in a furnace to $>1300^{\circ} \mathrm{C}$ for 15 minutes, during which released gases were exposed to a liquid nitrogen chilled charcoal trap. Extracted gases were exposed to an SAES getter before being collected on a cryogenic cold trap at $<15$ $\mathrm{K}$. Helium was then isolated from other noble gases by heating the cold trap to $45 \mathrm{~K}$. Mass spectrometry was conducted using a MAP 215-50 noble gas mass spectrometer at Lamont-Doherty Earth Observatory, USA, relative to the Yellowstone 'Murdering Mudpot' (MM) helium standard $\left({ }^{3} \mathrm{He} /{ }^{4} \mathrm{He}\right.$ ratio of $16.45 R_{a}$, where $R_{a}={ }^{3} \mathrm{He} /{ }^{4} \mathrm{He}_{a i r}$ $\left.=1.384 \times 10^{-6}\right)$, using the protocol of Winckler et al. (2005). The relative youth of the parent lavas from which the samples are derived $(<300 \mathrm{ka})$ means that the samples have extremely low ${ }^{4} \mathrm{He}$ content and therefore high ${ }^{3} \mathrm{He} /{ }^{4} \mathrm{He}$ ratios, up to 547 times that for air (Table 6.2), meaning any corrections for magmatic ${ }^{3} \mathrm{He}$ would be $<1 \%$. I measured lithium (Li), uranium (U) and thorium (Th) concentrations in three samples (BH1206/07 and ME1204) to check for possible errors resulting from helium production via nucleogenic and radiogenic pathways. Concentrations of these three elements are negligible $(<1 \mathrm{ppm})$, therefore I assume all measured ${ }^{3} \mathrm{He}$ to be of cosmogenic origin. 
Exposure ages were calculated using the cosmogenic ${ }^{3} \mathrm{He}$ exposure age calculator and global, sea-level, high-latitude (SLHL) cosmogenic ${ }^{3} \mathrm{He}$ production rate of Goehring et al. (2010), which I have shown to be applicable in New Zealand (Chapter 4). Attenuation of cosmogenic neutron flux with depth from the surface was corrected for using measured sample thickness, a standard rock density of $2.7 \mathrm{~g} \mathrm{~cm}^{-3}$ and an attenuation length of $160 \mathrm{~g} \mathrm{~cm}^{-2}$ (Dunne et al., 1999). Field observations from mid-winter showed that the salient, ridge-top boulders are not subject to prolonged burial by seasonal snow, therefore no correction was applied to the age calculation. Although sampled boulders did not exhibit glacial striae, some boulders retain faceted sides. Care was taken to avoid boulders that displayed clear evidence of erosion, such as discolouration, weathering scarps, onion-skin weathering, or pitting/water pooling. Thus, I present the exposures ages without an erosion correction. Regional uplift in the central North Island has been estimated for the past $500 \mathrm{ka}$ at $<1 \mathrm{~mm} \mathrm{yr}^{-1}$ (Pulford, 2002). This does not alter exposure ages outside of the measurement uncertainty, therefore I do not include a correction for regional tectonic uplift. Elevation and latitudinal scaling of cosmogenic ${ }^{3} \mathrm{He}$ production is undertaken using the 'Lm' (Lal, 1991/Stone, 2000) model, which outperforms neutron-monitor based schemes (Lifton et al., 2014).

\subsubsection{Glacier modelling}

\subsubsection{Research design}

In order to test $H_{\text {null }}$, I use a distributed energy balance model, coupled with a 2D ice flow model to constrain quantitative estimates of past temperature in central North Island. This model has previously been used to constrain late-glacial temperatures in South Island (Doughty et al., 2013; Kaplan et al., 2013), therefore the results are directly comparable. The model domain is $24 \times 21 \mathrm{~km}$, centred on the peak of Mt. Ruapehu $\left(-39.28^{\circ} ; 175.57^{\circ}\right.$; Figure 6.1$)$, and has a grid cell resolution of $100 \mathrm{~m}$. I include the whole upper mountain in the simulations in order to capture any potential changes in glacier catchment boundaries that result from a growing ice mass. Modern climate (temperature, precipitation, solar radiation, wind speed and relative humidity) is derived from a combination of climate station and reanalysis data, which is summarised into monthly grids (see Section 7.3.2 and Chapter 3). Temperature $(\Delta T)$ and precipitation $(\Delta P)$ perturbations are imposed iteratively to find the necessary combination required to simulate the Mangaehuehu Glacier so that it reaches steady state and terminates within one grid cell $( \pm 100 \mathrm{~m})$ of the downstream end of moraine LG1 (Figure 6.3). $\Delta P$ is applied as a percentage change, relative to modern, and is varied between $-50 \%$ to $+50 \%$. All simulations begin from an ice-free domain and are run for 250-300 model years, which is sufficient for glaciers to reach equilibrium following an imposed cli- 

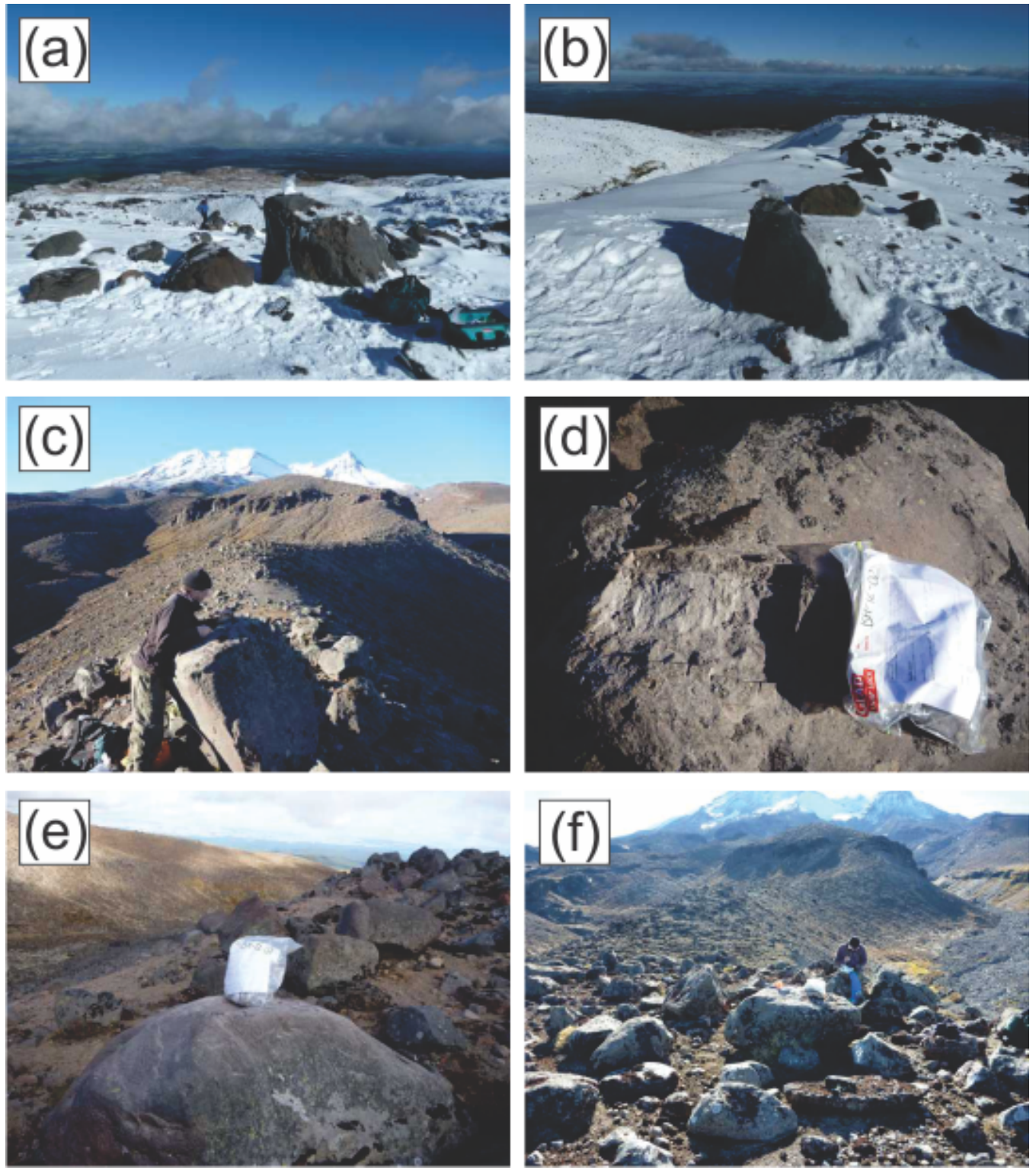

Figure 6.2: (a) Sample BH1209 (photo facing W); (b) Sample BH1211 (photo facing SW); (c) Sample BH1202 (photo facing N); (d) The sampled surface of BH1202; (e) Sample BH1207 (photo facing S); (e) Sample BH1204 (photo facing N). 
matic perturbation. To assess the impact of key parameter choices on the results, I perform sensitivity tests in which key parameters are systematically varied. Climate perturbations and parameter sensitivity changes are imposed uniformly across the model domain.

\subsubsection{Input data}

Terrain elevation data comes from the New Zealand School of Surveying Digital Elevation Model (NZSoSDEM) (Columbus et al., 2011) and is resampled to $100 \mathrm{~m}$ resolution. An ice mask is created using the 'snow/ice' data from the Land Information New Zealand NZMS260 map series. Ice thickness estimates, based on the survey of Keys (1988), are used to create an ice-free elevation model. Climate data for the energy balance and snow accumulation models is from several different sources. Solar radiation and relative humidity are from the Virtual Climate Station Network gridded datasets, sourced from NIWA CliFlo Database (NIWA, 2014). These datasets are resampled to the model domain resolution using bilinear interpolation. Present day wind speed data comes from the National Centers for Environmental Prediction (NCEP) 850 hPa level, reanalysis data (1981-2010; Kalnay et al., 1996). This dataset is scaled against observational data and applied uniformly over the model domain. Following Anderson and Mackintosh (2012) and Doughty et al. (2013), I use raw temperature and precipitation data from individual climate stations distributed around and within the model domain to generate climate grids using the methods detailed in Chapter 3.

\subsubsection{Mass-/energy-balance model}

Precipitation is partitioned in to rain and snow, using a temperature threshold $\left(T_{s}=\right.$ $0.5^{\circ} \mathrm{C}$ ). To simulate ablation, I use the energy balance equation (Equation 6.1) within a distributed energy balance model (EBM) as developed (Anderson et al., 2010) and previously applied in contemporary- (Anderson and Mackintosh, 2012) and palaeoglaciological (Doughty et al., 2013) studies in New Zealand (see Chapter 3 for full description).

$$
Q_{M}=I(1-\alpha)+L \downarrow+L \uparrow+Q_{H}+Q_{E}+Q_{R}+Q_{G}
$$

where $Q_{M}$ is the energy available for melt, $I$ is incoming shortwave radiation, $L \downarrow$ is incoming longwave radiation, $L \uparrow$ is outgoing longwave radiation, $Q_{H}$ and $Q_{E}$ are sensible and latent heat fluxes respectively, $Q_{G}$ is geothermal heat flux and $Q_{R}$ is heat input from rain. Sub-surface heat fluxes $\left(Q_{S}\right.$; Chapter 3$)$ are negated due to the assumption 
that ice is temperate and constantly at the melting point.

Incoming shortwave radiation $(I)$ comprises both direct and diffuse components (Oerlemans, 1992). The effect of changing orbital geometry is accounted for by using the insolation (13 ka) calculations of Huybers and Eisenman (2006). Albedo $(\alpha)$ is parameterised using the ELA-dependent scheme of Oerlemans (1992), whereby $\alpha$ increases with elevation and snow thickness, relative to the equilibrium line altitude. I use $\alpha_{\text {snow }}=0.72$ (Oerlemans, 1992; Doughty et al., 2013; Table 3.3) and test the influence of these parameterisation choices in sensitivity tests. Longwave fluxes ( $\downarrow \downarrow, \mathrm{L} \uparrow$ ) include the effects of surrounding topography, cloudiness and air temperature (Plummer and Phillips, 2003). Turbulent heat fluxes $\left(Q_{H}, Q_{E}\right)$ are calculated using the bulk method and include the roughness of snow and ice and the Richardson stability criterion (Oerlemans, 1992; Klok and Oerlemans, 2002; Anderson et al., 2010).

Geothermal heat flux $\left(Q_{G}\right)$ has the potential to contribute significantly to the energy balance of snow and ice situated on volcanically active terrain (see Chapter 3 for discussion). However, as $Q_{G}$ can vary greatly in space and time, and is unknown for the geological past, it is difficult to accurately parameterise in the model. I use a nominal value of $Q_{G}=1 \mathrm{~W} \mathrm{~m}^{-2}$ applied uniformly over the model domain.

I do not include debris cover in the simulations because it is unknown for the time of interest. Historically, debris cover on the glaciers situated on Mt. Ruapehu has varied greatly in space and time. During the most recent significant volcanic eruptions (AD 1995-96), all glaciers became buried by volcanic products. However, presently only ice bodies with a low surface slope and those situated close to the current volcanc vent, such as the summit plateau and the upper Whangaehu glacier, remain debris covered. Elsewhere on the mountain, steeper glaciers such as Mangatoetoenui and Mangaehuehu now have very little surface debris cover. Thus, evidence suggests debris cover emplaced via volcanic eruptions is transient in the maritime environment (e.g. Kirkbride and Dugmore, 2003) and the effects on energy balance are negligible over geological timescales. I acknowledge that this is a source of uncertainty in the simulations.

\subsubsection{Ice flow model}

Ice flow is described using a vertically-integrated, two-dimensional (2D) model based on the shallow ice approximation (SIA) (Plummer and Phillips, 2003; Kessler et al., 
2006). This formulation assumes ice flow is driven by vertical shear stresses, therefore compressional and tensional (longitudinal) stresses are neglected (Hutter, 1983). I consider that the role of longitudinal stresses on past glacial flow in the Mangaehuehu valley would be low, owing to the low bed slope and absence of steep, bounding valley sides in the lower catchment. Furthermore, several comparison studies between SIA and higher order ice flow models show little difference in ice geometry outputs (e.g. Le Meur et al., 2004; Leysinger Vieli and Gudmundsson, 2004), thus the SIA is commonly applied in mountain glacier environments (e.g. Plummer and Phillips, 2003; Kessler et al., 2006; Doughty et al., 2013).

Ice flow velocity due to internal deformation $\left(U_{d}\right)$ is given as:

$$
\vec{U}_{d}=\frac{2}{5} A H \vec{\tau}_{b}^{n}
$$

where $A$ is Glen's flow law coefficient, set to $2.14 \times 10^{-16} \mathrm{Pyr}^{-3} \mathrm{yr}^{-1}$ (Paterson, 1994), $\vec{\tau}_{b}$ is the gravitational driving stress $\left(\vec{\tau}_{b}=\rho g H \nabla z\right)$, and $n$ is Glen's flow law exponent, set to $n=3$.

Following Plummer and Phillips (2003) and Kessler et al. (2006), a sliding term is also included:

$$
U_{s}=U_{c} e^{1-\frac{\tau_{c}}{\bar{\tau}_{b}}}
$$

where $U_{c}$ and and $\tau_{c}$ are constants that represent average sliding velocity and driving stresses, which are set to $U_{c}=50 \mathrm{~m} \mathrm{yr}^{-1}$ and $\tau_{c}=100 \mathrm{kPa}$.

$$
\frac{d H}{d t}=M-\nabla \cdot \vec{q}
$$

where $H$ is ice thickness, $t$ is time, $\vec{q}$ is ice flux $\left(\vec{U}_{d}+\vec{U}_{s}\right)$ and $\mathrm{M}$ is mass balance.

Equation 6.4 evolves glacier geometry through time. Ice velocities are calculated on a grid offset from ice thickness and the flux gradients are used to update ice thickness using a forward explicit time-step (Hindmarsh and Le Meur, 2001). To account for boundary effects that may violate mass conservation in the finite difference formulation (e.g. Plummer and Phillips, 2003), the bed topography is smoothed using a $300 \times 300$ $\mathrm{m}$ moving window to reduce high bed slopes in the upper catchment, and an ice flux correction is applied. For each cell, total ice divergence cannot exceed the total mass contained in the source cell. At each timestep it was ensured that this criterion was met and if not, the excess ice was removed (Plummer and Phillips, 2003). 


\subsection{Results}

\subsubsection{Glacial geomorphology and chronology}

\subsubsection{Mangaehuehu catchment}

Multiple moraine ridges, often paired, are present between $0-5 \mathrm{~km}$ from the present Mangaehuehu Glacier terminus (c. $2300 \mathrm{~m}$ asl; Figure 6.3a). A pair of sharp-crested lateral moraines, which are c. $1 \mathrm{~km}$ long and are situated immediately down valley from present-day Mangaehuehu Glacier, represent the most recent episode of morainebuilding in this catchment. Between c. 1750 - $1500 \mathrm{~m}$ asl, a complex arrangement of moraine ridges indicates the position of a former ice margin. A thick (c. 20-30 m) lava flow dominates the centre of the Mangaehuehu valley at this location, which has recently been dated using ${ }^{40} \mathrm{Ar} /{ }^{39} \mathrm{Ar}$ to $20 \pm 2 \mathrm{ka}$ (C. Conway / G. Leonard, pers. comm. 2014). A single moraine ridge (LG2 - Figure 6.3a) overlies this lava, and extends down valley to c. $1720 \mathrm{~m}$ asl. Four cosmogenic ${ }^{3} \mathrm{He}$ surface exposure ages from boulders on this moraine are stratigraphically consistent with (younger than) the age of the underlying lava and three out of the four samples yield ages between 15-12 ka, with one anomalously young outlier at $7.1 \mathrm{ka}$ (Table 6.5.1.3). Immediately down-valley, an arcuate moraine ridge (LG1) builds from the downstream limit of the prominent lava flow front and terminates at c. $1550 \mathrm{~m}$ asl. Four of seven surface exposure ages from boulders on the crest of this moraine date to 14 - $11 \mathrm{ka}$, with the remaining three spread between 3-7 ka (Table 6.5.1.3). Immediately to the west, two smaller moraine ridges (LG3-4 - Figure 6.3a) represent deposition at a separate lobe of ice that flowed to the west of the prominent lava. Three exposure ages from boulders on these moraines range from $11.1-4.5 \mathrm{ka}$. On the eastern side of the valley a single, wide-crested composite moraine extends continuously from c. $1800 \mathrm{~m}$ asl to c. $1600 \mathrm{~m}$ asl and represents the eastern margin of the former valley glacier.

Further down valley, broad moraine ridges on both valley sides overlie thick (c. 10-20 $\mathrm{m}$ ) lava bluffs that outcrop in deeply incised gorges. The maximum downstream extent of these moraine deposits is unclear due to soil and forest cover, however interpretation of aerial photographs combined with the field investigations suggests ice reached at least c. $1200 \mathrm{~m}$ asl, which is consistent with the geomorphological interpretations of Barrell (2011).

Moraine LG1 is underlain by c. $5 \mathrm{~m}$ of finely laminated, well-sorted silts and sands 
(herein referred to as rhythmites) with occasional pebbles ( $<20 \mathrm{~cm}$ a-axis) and gravel lenses, as shown in a fluvially-eroded exposure at the base of the landform (Figure 6.3c; Figure 6.4a). Beds within the red-dark grey coloured rhythmites are of variable thickness $(<1 \mathrm{~mm}$ to $\mathrm{c} .2 \mathrm{~cm})$ and exhibit a range of ductile and brittle deformation structures. Evidence for ductile deformation is abundant, with acute folds that represent 2-3 m horizontal shortening (Figure 6.3c). Reverse faults with centimetreto decimetre-scale offsets are also prevalent. Sub-vertical clastic dykes crosscut the horizontally-bedded rhythmites and are c. 0.5 - $2 \mathrm{~cm}$ wide, several metres long and consist of highly-compacted, well-sorted clay-silt particles (Figure 6.4b,c). Internally, the particles filling the dykes commonly form sub-mm scale laminae, orientated parallel to the direction of dyke propagation (Figure 6.4b). The direction of dyke emplacement is uncertain due to incomplete exposure.

I interpret these sediments to represent deposition in a low-energy, relatively deep water (>20 m) lacustrine environment, where fine sediment was allowed to settle out of suspension and form centimetre to millimetre-scale laminae. The assemblage of polyphase deformation structures is consistent with that expected from post-depositional overriding by an advancing ice mass (Benn and Evans, 2010). The presence of isolated clasts and gravel lenses within the rhythmites, possibly represents deposition of ice-rafted debris, which may indicate that this lake was proglacial. Similar deformed sediments have been described interbedded with till deposits elsewhere on Mt. Ruapehu, which were also interpreted to represent deformation beneath an advancing glacier (McArthur and Shepherd, 1990). Clastic dykes are a common product of glaciotectonism (van der Meer et al., 2009), which, together with the overlying diamicton and moraine ridge, is also consistent with glacial readvance at this site.

\subsubsection{Te Unuunuakapuateariki catchment}

The Te Unuunuakapuateariki (TU) stream rises at c. $2100 \mathrm{~m}$ asl on the southern flank of Girdlestone peak (2658 m asl) and flows southwards (Figure 6.5a-d). No glacial ice exists at the head of this catchment, however small perennial snow patches are present in hollows at 2300-2400 m asl. Between 1900-1700 m asl, the TU stream drains a relatively narrow (c. $300 \mathrm{~m}$ wide) catchment. A prominent outcrop of polished bedrock rises above the modern stream channel at c. $1800 \mathrm{~m}$, indicating past glacial erosion beneath a temperate ice mass. At $1700-1600 \mathrm{~m}$ asl, the TU catchment opens into a c. $1 \mathrm{~km}$ wide basin. This transition is marked by a complex assemblage of lateral and latero-frontal moraine ridges that demarcate the terminus of a former glacier. Multiple individual moraine crests form a compound mass of glacial till on the eastern side of TU stream, which suggests the margin of the former ice mass oscillated around this 


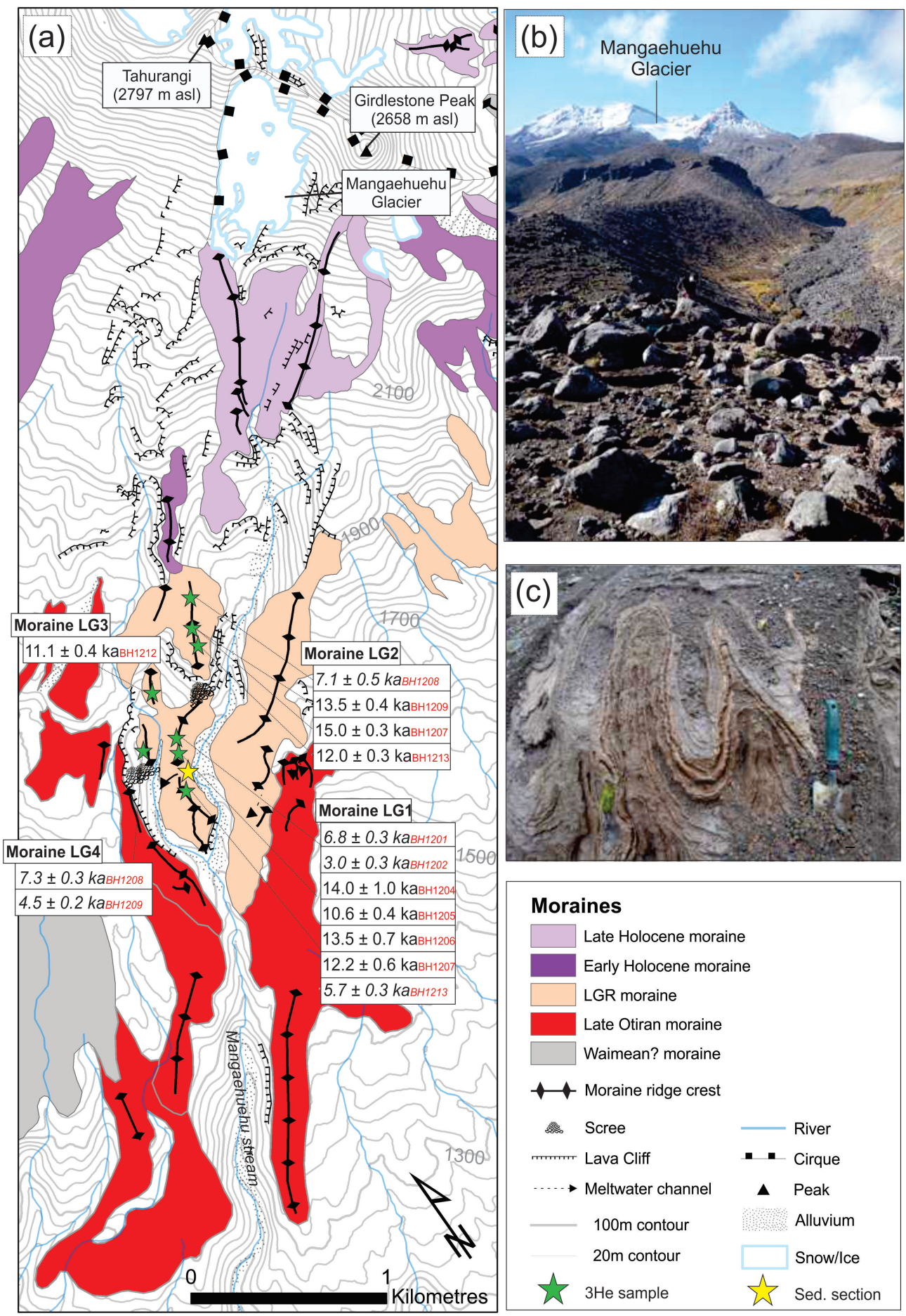

Figure 6.3: (a) Map of the glacial geology of the Mangaehuehu catchment on southern Ruapehu; (b) photograph showing the boulder-rich surface of moraine LG1 with person for scale. Note the prominent lava flow (see text) in the middle ground and the modern Mangaehuehu cirque glacier in the background; (c) Photograph of ductile deformation structures within rhythmite deposits beneath moraine LG1 - location depicted by yellow star in panel (a). 

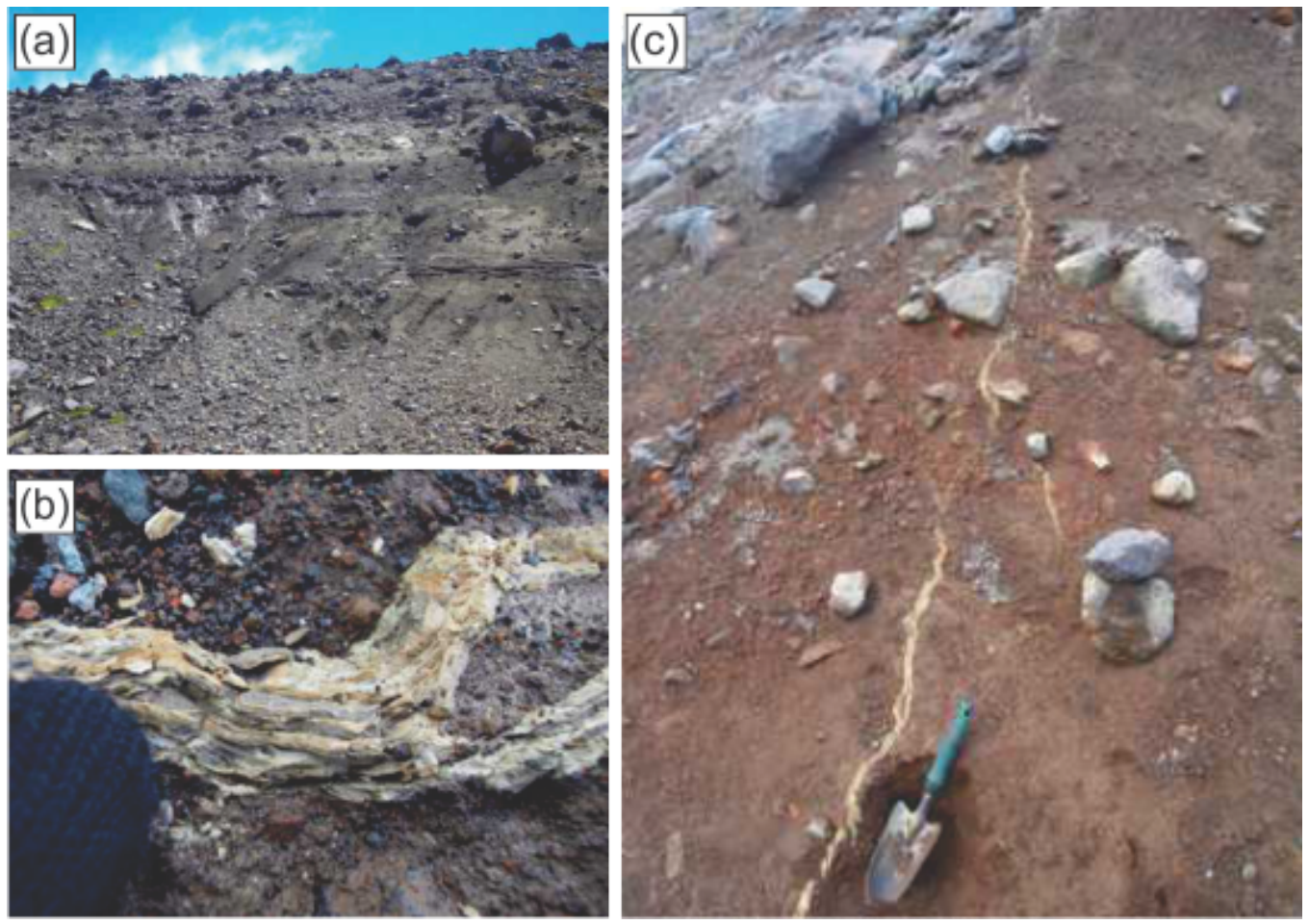

Figure 6.4: (a) Overview photo showing fine grained-sediment exposures beneath the unsorted moraine LG1 (photo facing NE); (b) Close up photograph of finely laminated, fine-grained clastic dyke within the fine-grained sediments; (c) photographic example of a sub-vertical clastic dyke within fine-grained sediments beneath moraine LG1.

position. Samples ME1201 to ME1203 (e.g. Figure 6.5b,c) were taken from boulders on a rounded moraine ridge crest (TU1 - Figure 6.5a) at the outer margin of this moraine complex. Two of these ages are indistinguishable within measurement uncertainty at c. $14.5 \mathrm{ka}$, with the other dating to $16.5 \mathrm{ka}$. On the western side of the stream, a prominent lateral moraine (TU2) has been undercut by the modern stream, which has produced a steep eastern flank of the moraine (Figure 6.5c).

\subsubsection{Wahianoa catchment}

Wahianoa valley is a deeply-incised valley with a parabolic cross-section, which drains towards the southeast from Tahurangi peak (2797 m asl; Figure 6.6). Boulder-rich lateral moraine crests line both flanks of the lower $3 \mathrm{~km}$ of the valley to c. $1200 \mathrm{~m}$ asl, recording glacier fluctuations during the most extensive period of glaciation preserved in this catchment (see Chapter 7). A pair of small (c. 5-10 $\mathrm{m}$ high) moraine ridges lies on the valley floor, approximately $2.5 \mathrm{~km}$ up-stream from the valley mouth, and are bisected by the modern Wahianoa River. The left lateral of this pair is a discrete, rounded ridge that has been partly incised by the Wahianoa River, exposing till sections close to the active river channel. Large boulders ( $>1 \mathrm{~m}$ high) are rare on the crest of this ridge and there is a thin mantle of pale-yellow pyroclastic material on the surface. 


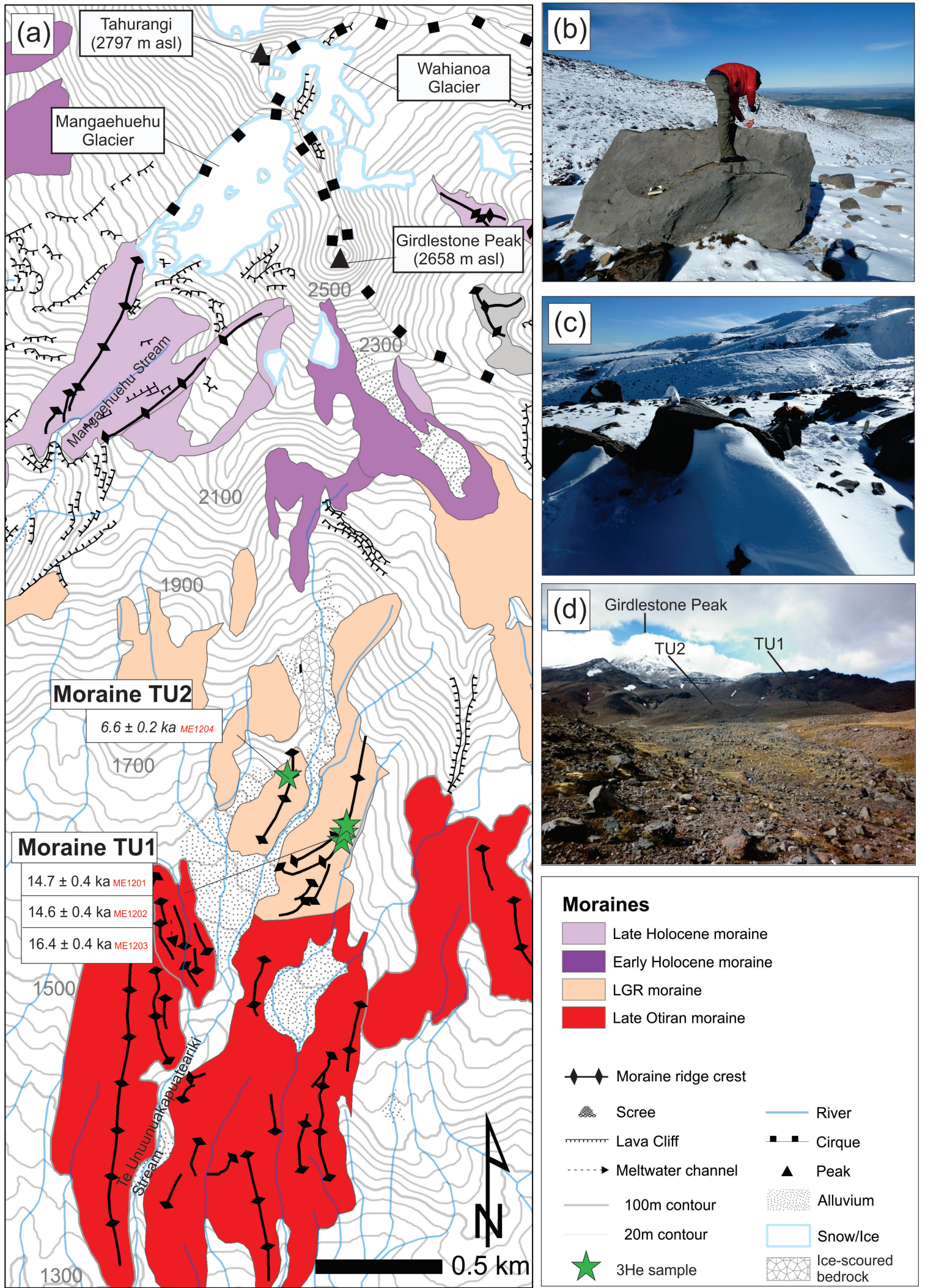

Figure 6.5: (a) Map of the glacial geology of the Te Unuunuakapuateariki catchment; (b) Sample ME-12-01 on moraine TU1 in the Te Unuunuakapuateariki catchment; (c) Sample ME-12-02 on moraine TU1 in the Te Unuunuakapuateariki catchment. Note the prominent crest of moraine TU2 in the background and the prominence of the boulder surfaces above the winter snow cover - photo facing north west; (d) Photograph of the Te Ununukapuateariki moraines complex, photo facing north. 


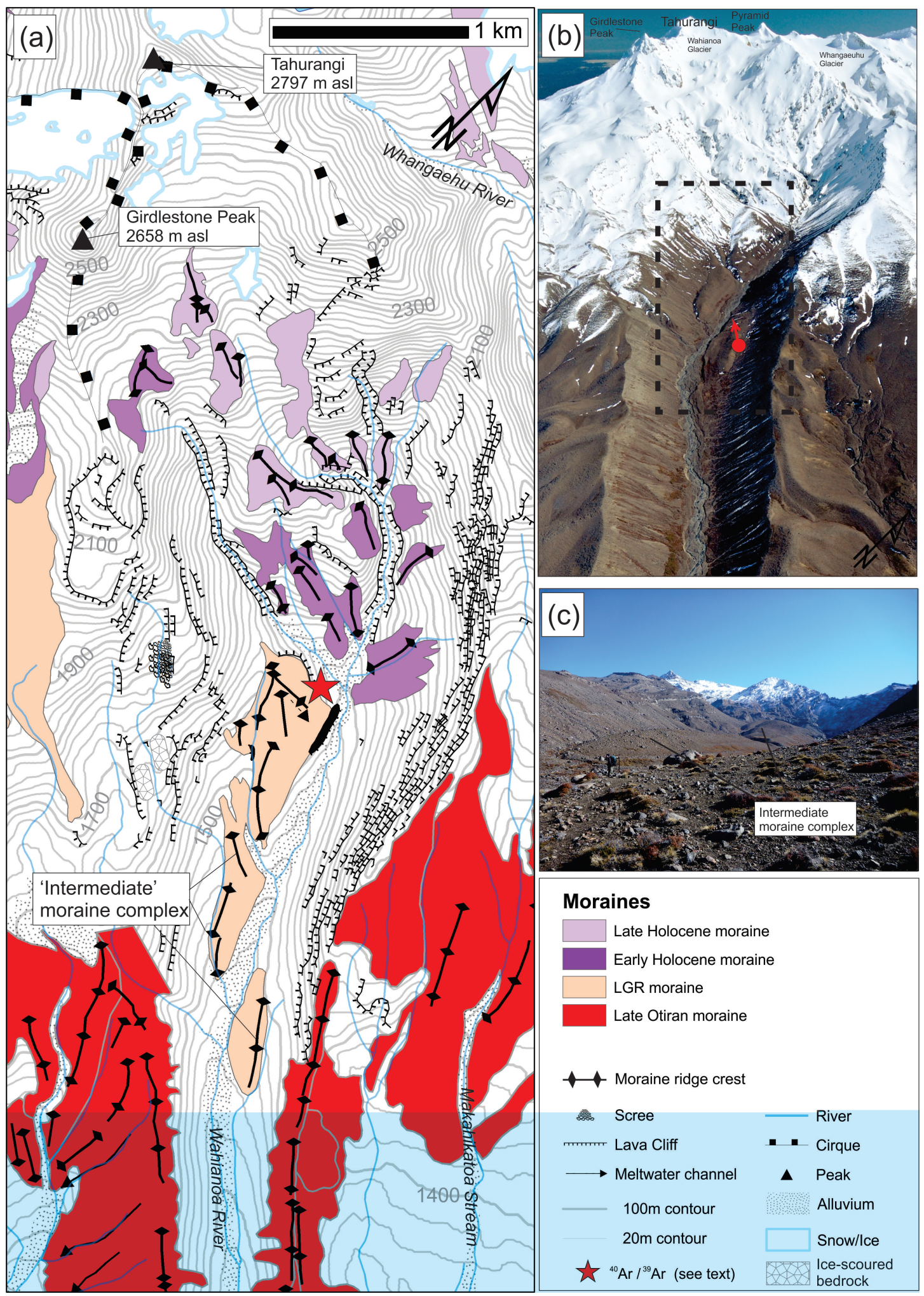

Figure 6.6: (a) Map of the glacial geology of the upper Wahianoa catchment.; (b) Oblique aerial photograph (source: D. Townsend) of the region shown in (a). Note the prominent moraine assemblage on the valley floor (dashed box). Red dot and arrow mark the location and orientation of photo in (c); (c) Photograph of the prominent true right moraines in the middle Wahianoa valley - photo facing north 
The right lateral of this pair can be distinguished as a linear landform, with a higher abundance of large ( $>1 \mathrm{~m}$ high) boulders, although does not have a discrete ridge crest. This morainic material continues for c. $1.5 \mathrm{~km}$ up valley, ending at a major fork in the modern Wahianoa River. Here, the moraine is underlain by a prominent lava flow, recently dated to $17 \pm 1 \mathrm{ka}$ (Conway et al., in prep), which provides a maximum bracketing age for the overlying moraine. The preservation and morphostratigraphic situation of this moraine assemblage indicate they were formed after the deposition of the more extensive moraines down-valley. This suggests a readvance or temporary cessation of glacier retreat of sufficient duration to deposit this volume of material.

The head of the Wahianoa valley, above $1700 \mathrm{~m}$ asl, is steep, remote terrain and, as such, mapping was restricted to visual inspection from high vantage points in the field and aerial photography. Small patches of glacial ice, which are relatively free of supraglacial debris, are present on the uppermost slopes. Immediate down-valley from the present-day Wahianoa Glacier, numerous linear, boulder-topped landforms are identified (Figure 6.6), which are interpreted as moraine ridges. These appear to track the recession of the Wahianoa Glacier terminus from c. $1800 \mathrm{~m}$ asl to its present elevation at c. $2400 \mathrm{~m}$ asl.

\subsubsection{Glacier modelling}

Figures 6.7a \& $\mathrm{b}$ show the range of combined temperature $(\Delta T)$ and precipitation $(\Delta P)$ perturbations that produce a steady state ice mass that fits the downstream limit of past glaciation in the Mangaehuehu catchment, as marked by moraine LG1. Using the optimal parameter set (Table 3.3), a cooling of $-2.9^{\circ} \mathrm{C}$ relative to present is necessary when $\Delta P=0$. In this scenario, the Mangaehuehu Glacier has a maximum thickness of c. $130 \mathrm{~m}$ (Figure 6.7c) and an equilibrium line altitude of c. $1950 \mathrm{~m}$ (Figure 6.7d). This is approximately $500 \mathrm{~m}$ lower than present, as observed in the last glacier survey (Keys, 1988).

Under the optimal model parameter settings the temperature forcing required to simulate the former Mangaehuehu Glacier depicted by moraine LG1 ranges between $\Delta T$ $=2.5-3.4^{\circ} \mathrm{C}$, when precipitation is varied by $\pm 20 \%$ from present day (Figure 6.7b). Systematic variation of model parameters causes maximum deviations in $\Delta T$ of $\pm 0.5^{\circ} \mathrm{C}$ from the optimal runs. Snow albedo is the most sensitive parameter, with variations in $\Delta T$ of $\pm 0.4^{\circ} \mathrm{C}$, when varying albedo by \pm 0.05 . Increases in the snow temperature threshold used to parameterise accumulation have relatively little impact on $\Delta T$ in low 
Table 6.2: Helium mass spectrometry results. (DL $=$ detection limit)

\begin{tabular}{|c|c|c|c|c|c|c|c|c|}
\hline SampleID & $\begin{array}{l}\text { Weight } \\
(g)\end{array}$ & $\begin{array}{l}{ }^{3} \mathrm{He} \\
\text { (atoms/g) }\end{array}$ & \pm & $\begin{array}{l}{ }^{4} \mathrm{He} \\
\text { (atoms/g) }\end{array}$ & \pm & ${ }^{3} \mathrm{He} /{ }^{4} \mathrm{He}$ & \pm & $R / R_{a}$ \\
\hline \multicolumn{9}{|c|}{ Mangaehuehu catchment: } \\
\hline \multicolumn{9}{|c|}{ Upper moraine (LG2): } \\
\hline BH1210 & 0.5385 & $6.80 \mathrm{E}+06$ & $1.48 \mathrm{E}+05$ & 8.98E+09 & 7.24E+08 & 7.57E-04 & 6.32E-05 & 547 \\
\hline BH1209 & 0.3358 & $6.03 \mathrm{E}+06$ & $1.80 \mathrm{E}+05$ & $2.85 \mathrm{E}+10$ & $1.23 \mathrm{E}+09$ & 2.12E-04 & 1.11E-05 & 153 \\
\hline BH1211 & 0.5494 & $5.37 \mathrm{E}+06$ & $1.26 \mathrm{E}+05$ & $1.42 \mathrm{E}+10$ & $7.20 \mathrm{E}+08$ & 3.79E-04 & 2.12E-05 & 274 \\
\hline BH1208 & 0.1471 & $3.20 \mathrm{E}+06$ & $2.15 \mathrm{E}+05$ & $3.20 \mathrm{E}+10$ & $3.18 \mathrm{E}+09$ & 9.98E-05 & 1.20E-05 & 72 \\
\hline \multicolumn{9}{|c|}{ Upper moraine (LG1): } \\
\hline BH1204 & 0.1523 & $5.54 \mathrm{E}+06$ & $4.01 \mathrm{E}+05$ & $3.11 \mathrm{E}+10$ & $3.11 \mathrm{E}+09$ & $1.78 \mathrm{E}-04$ & 2.20E-05 & 129 \\
\hline BH1206 & 0.1487 & $5.31 E+06$ & $2.59 \mathrm{E}+05$ & $0.00 \mathrm{E}+00$ & $3.32 E+09$ & DL & 2.92E-02 & - \\
\hline BH1207 & 0.1504 & $4.87 \mathrm{E}+06$ & $2.52 \mathrm{E}+05$ & $0.00 \mathrm{E}+00$ & $3.39 E+09$ & DL & 5.99E-04 & - \\
\hline BH1205 & 0.3423 & $4.18 \mathrm{E}+06$ & $1.40 \mathrm{E}+05$ & $5.60 \mathrm{E}+09$ & $1.04 \mathrm{E}+09$ & 7.46E-04 & 1.40E-04 & 539 \\
\hline BH1201 & 0.3155 & $2.76 \mathrm{E}+06$ & $1.19 \mathrm{E}+05$ & $1.24 \mathrm{E}+10$ & $1.19 E+09$ & 2.23E-04 & 2.34E-05 & 161 \\
\hline BH1213 & 0.2692 & $2.29 E+06$ & $1.21 \mathrm{E}+05$ & $1.13 \mathrm{E}+10$ & $1.44 \mathrm{E}+09$ & $2.04 \mathrm{E}-04$ & 2.82E-05 & 147 \\
\hline BH1202 & 0.3040 & $1.16 \mathrm{E}+06$ & $5.60 \mathrm{E}+04$ & $3.24 \mathrm{E}+10$ & $1.10 \mathrm{E}+09$ & 3.57E-04 & $1.24 \mathrm{E}-04$ & 258 \\
\hline \multicolumn{9}{|c|}{ Lower moraine (ii): } \\
\hline BH1212 & 0.3463 & $4.56 \mathrm{E}+06$ & $1.49 \mathrm{E}+05$ & $1.61 \mathrm{E}+10$ & $9.86 \mathrm{E}+08$ & 2.83E-04 & 1.96E-05 & 204 \\
\hline \multicolumn{9}{|c|}{ Outboard moraine (i): } \\
\hline BH1214 & 0.3197 & $2.94 \mathrm{E}+06$ & $1.31 \mathrm{E}+05$ & $1.34 \mathrm{E}+10$ & $1.19 \mathrm{E}+09$ & 2.19E-04 & 2.17E-05 & 158 \\
\hline BH1215 & 0.3268 & $1.75 \mathrm{E}+06$ & $9.49 \mathrm{E}+04$ & $3.24 \mathrm{E}+10$ & $1.37 \mathrm{E}+09$ & 5.38E-05 & 3.71E-06 & 39 \\
\hline \multicolumn{9}{|c|}{ TU catchment: } \\
\hline \multicolumn{9}{|c|}{ TU1 moraine - left lateral: } \\
\hline ME1201 & 0.5021 & $6.16 \mathrm{E}+06$ & $1.81 \mathrm{E}+05$ & $1.16 \mathrm{E}+10$ & $5.70 \mathrm{E}+08$ & 5.33E-04 & 3.05E-05 & 385 \\
\hline ME1202 & 0.4040 & $6.07 \mathrm{E}+06$ & $1.68 \mathrm{E}+05$ & $2.21 E+10$ & $1.05 \mathrm{E}+09$ & 2.75E-04 & $1.51 \mathrm{E}-05$ & 199 \\
\hline ME1203 & 0.5126 & $7.05 \mathrm{E}+06$ & $1.58 \mathrm{E}+05$ & $6.29 \mathrm{E}+09$ & $7.61 \mathrm{E}+08$ & 1.12E-03 & 1.38E-04 & 810 \\
\hline \multicolumn{9}{|c|}{ TU2 moraine - right lateral: } \\
\hline ME1204 & 0.4206 & $2.81 \mathrm{E}+06$ & $1.02 \mathrm{E}+05$ & $2.41 \mathrm{E}+10$ & $1.09 \mathrm{E}+09$ & 1.17E-04 & 6.79E-06 & 84 \\
\hline
\end{tabular}

precipitation experiments, but results in deviations of up to $0.5^{\circ} \mathrm{C}$ when precipitation is increased by $>10 \%$, relative to present.

Steady-state simulations of the former Mangaehuehu Glacier show excellent agreement between the modelled ice geometries and moraine records in the Te Unuunuakapuateariki and Wahianoa catchments (e.g. Figures 6.6 \& 6.5). The model experiments predict that climate forcings necessary to match the LG moraines in the Mangaehuehu catchment also produce glaciers that terminate close to the former glacier limits identified in these separate adjacent catchments (e.g. Figures 6.7c \& d).

To evaluate the sensitivity of Mangaehuehu Glacier length to seasonal climatic change, I ran steady state experiments where either temperature $\left(\Delta \mathrm{T}=-3^{\circ} \mathrm{C}\right)$ or precipitation $(\Delta \mathrm{P}=+20 \%)$ perturbations were applied to single months, and then 3-month windows, in turn (Figure 6.8). These experiments show that glacier length is most sensitive to temperature decreases during summer months (DJF), in particular December and January. The precipitation increases result in lower magnitude glacier advances, compared to temperature decreases, and are most important when applied to the months May-October. 
Table 6.3: Exposure ages (ka) for all samples using the 'St' (Stone, 2000) and 'Lm' scaling models, with internal ('Int.') and external ('Ext.') uncertainties after to Goehring et al. (2010).

\begin{tabular}{|c|c|c|c|c|c|c|}
\hline Sample & St & Int. & Ext. & $\mathrm{Lm}$ & Int. & Ext. \\
\hline \multirow{2}{*}{\multicolumn{7}{|c|}{$\begin{array}{l}\text { Mangaehuehu catchment: } \\
\text { Upper moraine (LG2): }\end{array}$}} \\
\hline & & & & & & \\
\hline BH1210 & 14.9 & 0.3 & 1.2 & 15.0 & 0.3 & 1.7 \\
\hline BH1209 & 13.4 & 0.4 & 1.1 & 13.5 & 0.4 & 1.6 \\
\hline BH1211 & 11.9 & 0.3 & 1.0 & 12.0 & 0.3 & 1.4 \\
\hline BH1208 & 7.1 & 0.5 & 0.7 & 7.1 & 0.5 & 0.9 \\
\hline \multicolumn{7}{|c|}{ Lower moraine (LG1): } \\
\hline BH1204 & 13.9 & 1.0 & 1.5 & 14.0 & 1.0 & 1.8 \\
\hline BH1206 & 13.4 & 0.7 & 1.2 & 13.5 & 0.7 & 1.6 \\
\hline BH1207 & 12.1 & 0.6 & 1.1 & 12.2 & 0.6 & 1.5 \\
\hline BH1205 & 10.5 & 0.4 & 0.9 & 10.6 & 0.4 & 1.2 \\
\hline BH1201 & 6.9 & 0.3 & 0.6 & 6.8 & 0.3 & 0.8 \\
\hline BH1213 & 5.7 & 0.3 & 0.5 & 5.7 & 0.3 & 0.7 \\
\hline BH1202 & 2.8 & 0.2 & 0.4 & 3.0 & 0.3 & 0.5 \\
\hline \multicolumn{7}{|c|}{ Outer moraine (LG3): } \\
\hline BH1212 & 11.1 & 0.4 & 0.9 & 11.1 & 0.4 & 1.3 \\
\hline \multicolumn{7}{|c|}{ Outer moraine (LG4): } \\
\hline BH1214 & 7.3 & 0.3 & 0.7 & 7.3 & 0.3 & 0.9 \\
\hline BH1215 & 4.4 & 0.4 & 0.4 & 4.5 & 0.2 & 0.6 \\
\hline \multicolumn{7}{|c|}{ Te Unuunuakapuateariki catchment: } \\
\hline \multicolumn{7}{|c|}{ Left lateral (TU1): } \\
\hline ME1201 & 14.6 & 0.4 & 1.2 & 14.7 & 0.4 & 1.7 \\
\hline ME1202 & 14.3 & 0.4 & 1.2 & 14.4 & 0.4 & 1.7 \\
\hline ME1203 & 16.4 & 0.4 & 1.3 & 16.5 & 0.4 & 1.9 \\
\hline \multicolumn{7}{|c|}{ Right lateral (TU2): } \\
\hline ME1204 & 6.6 & 0.2 & 0.6 & 6.7 & 0.2 & 0.8 \\
\hline
\end{tabular}





Figure 6.7: (a) Combined temperature $(\Delta T)$ and precipitation $(\Delta P)$ perturbations that result in steady state glacier in the Mangaehuehu catchment that terminates at moraine LG1, including a suite of parameter sensitivity tests. Flow model parameters $\left(A=1 \times 10^{-15}-1 \times 10^{-18} \mathrm{Pyr} r^{-3} \mathrm{yr}^{-1} ; U_{c}=\right.$ 20-80 $\mathrm{m} \mathrm{yr}^{-1}$ ) impart changes to $\Delta T$ of $<0.1^{\circ} \mathrm{C}$ and are not shown; (b) The range of $\Delta T$ forcings required to balance $\Delta P$ of $\pm 20 \%$; (c) Modelled ice thickness and (d) equilibrium mass balance for $\Delta T=-2.9^{\circ} \mathrm{C} ; \Delta P=0$ across the Mangaehuehu, Te Unuunuakapuateariki and Wahianoa catchments. Moraines LG1, LG2, TU1 and TU2 described in Section 6.5.1 are labelled. 


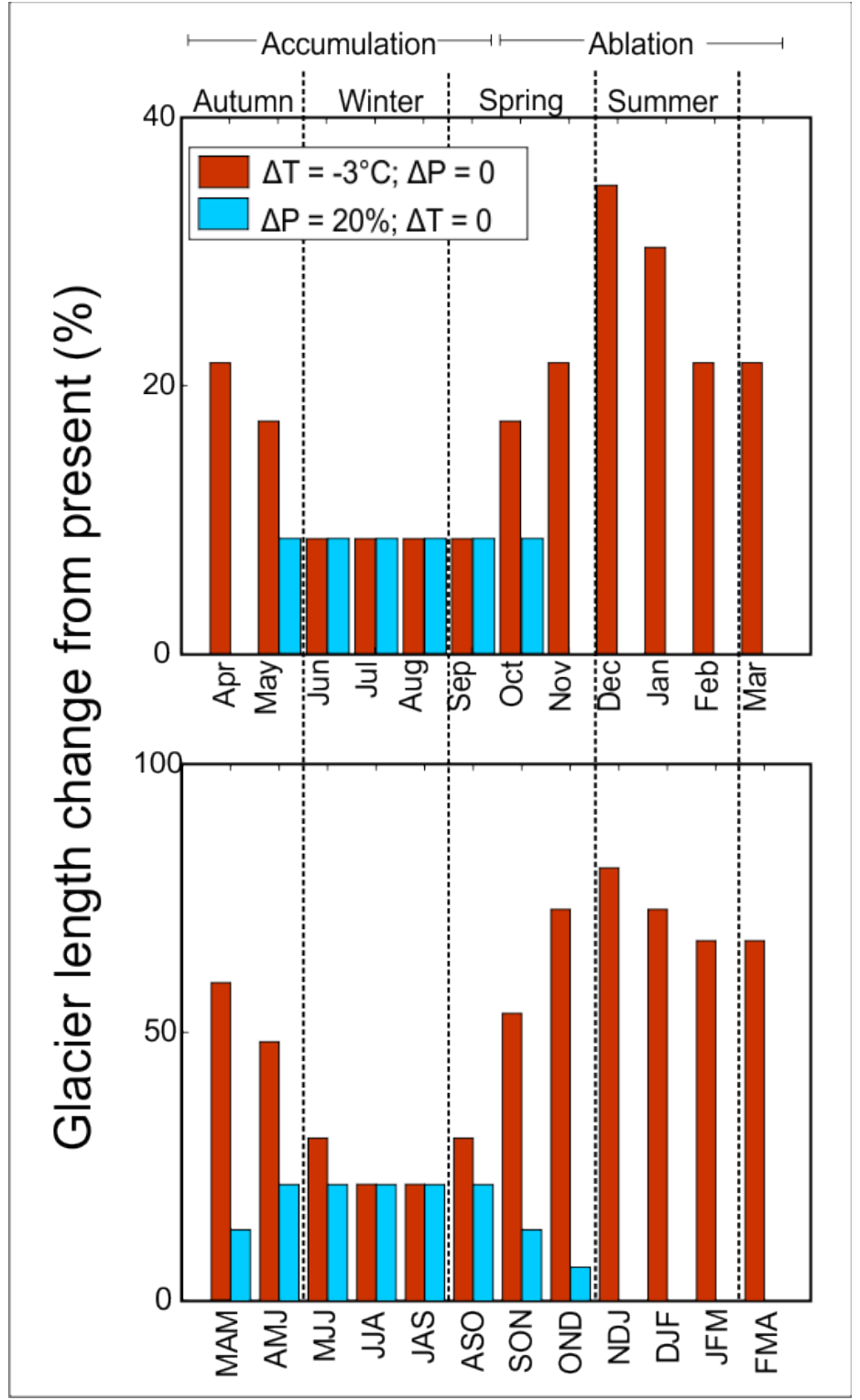

Figure 6.8: Top panel: Length increase of the Managehuehu glacier (\%) from present, resulting from temperature $\left(\Delta T=-3{ }^{\circ} \mathrm{C}\right)$ and precipitation $(\Delta P=+20 \%)$ applied separately to individual months. Bottom panel: the same forcing experiments but applied to 3-month moving windows across the mass balance year.

\subsection{Discussion}

\subsubsection{Glacial chronology}

\subsubsection{Cosmogenic ${ }^{3}$ He chronology}

Eighteen cosmogenic ${ }^{3} \mathrm{He}$ surface exposure ages of moraine boulders in the Mangaehuehu (Figure 6.10) and Te Unuunuakapuateariki catchments exhibit a high degree of internal scatter (Table 6.5.1.3). Field observations and previous studies (e.g. Putkonen 
and Swanson, 2003; Heyman et al., 2011; Applegate et al., 2012) lead me to conclude that processes causing incomplete exposure of moraine boulders are the most likely cause of the scatter observed in the dataset. For example, I find that the distributions of the Mangaehuehu dataset as a whole $(n=14)$ and for moraine LG1 alone $(n=7)$ are characterised by negative skewness (Figures 6.10a,b), which is a useful first-order indicator of incomplete exposure (Applegate et al., 2010). Also, multiple studies (Putkonen and Swanson, 2003; Heyman et al., 2011), utilising large empirical datasets (100s-1000s of ages) from a wide range of glaciological and climatic settings, have demonstrated that incomplete exposure is the most common cause of scatter in populations of moraine boulder cosmogenic exposure ages, especially in temperate glacial environments such as the study site. In these studies, the authors suggest that exposure ages should be interpreted as minimum limiting ages and the true moraine age lies closest to the oldest peak in the distribution (e.g. 15-11 ka; Figures 6.10a,b). Extension of these conclusions to the study site is further supported by the field observations of striated boulders and glacially-polished bedrock outcrops within the glacial catchment, which indicate that temperate conditions prevailed in the geological past, which decreases the likelihood of cosmogenic nuclide inheritance within moraine boulders. Also, steep valley sides that characterise most alpine glacier catchments and potentially contribute sediment with inherited cosmogenic nuclide components to the glacier surface, are absent from the field site. This further reduces the potential for inheritance of cosmogenic ${ }^{3} \mathrm{He}$, therefore the older ages are more likely to approximate the true age of the moraine.

In the Te Unuunuakapuateariki catchment, fewer ages are available to make a robust assessment of possible source of scatter. Extending the previous reasoning suggests the best-estimate age for the outermost moraine (TU1) is $16.4 \pm 1.3 \mathrm{ka}$ (Table 6.5.1.3), which is older than those in the Mangaehuehu catchment. However, the remaining two samples from TU1 are consistent with one another, within the measurement uncertainty, at c. $14.6 \pm 1.7 \mathrm{ka}$. If this is the true age of this outer moraine, then it closely agrees with the oldest ages from LG1 and LG2 moraines in the Mangaeheuehu catchment.

\subsubsection{Extreme exposure age scatter in Mangaehuehu: Possible causes}

Post-depositional processes that result in exposure ages to be younger than the true depositional age include, burial beneath sediment cover and erosion of the sampled surface. If samples are buried, then nuclide production is reduced by a factor related to the thickness and density of the overlying material (Figure 3.1). If samples have undergone erosion and this is not recognised and accounted for, then the loss of nuclides from the sample is the cause of exposure age underestimation. 
Using the known attenuation of cosmogenic nuclide production at depth, it is possible to investigate the possible 'true' age of the moraine for given burial scenarios (see also, Section 5.5.1.2). Figure 6.9 shows that samples that yield simple exposure ages of c. 13 ka, require between c. $5 \mathrm{kyr}$ and $12 \mathrm{kyr}$ of burial beneath soil/tephra of thicknesses 300 $\mathrm{cm}$ to $25 \mathrm{~cm}$ respectively, in order to explain the measured concentrations if the samples were actually deposited during the preceding cold period in New Zealand ('Otira A'; c. $18 \mathrm{ka}$; Barrell et al., 2013). Meanwhile, c. $10 \mathrm{kyr}$ of burial beneath soil/tephra at least $100 \mathrm{~cm}$ thick is required to explain the nuclide concentrations of LG1 samples that yield simple exposure ages of c. $6 \mathrm{ka}$, if they were deposited during the LGR and have solely been affected by shielding. Given the extreme paucity of evidence for substantial soil cover on the LG1 moraine in the geological past (e.g. remnant patches), it is unlikely that such shielding scenarios occurred to affect the samples measured in this study.

If, as suggested above (Section 6.6.1.1), moraine LG1 was deposited during the LGR at c. $13 \mathrm{ka}$, then boulder surface erosion rates of c. $10 \mathrm{~mm} \mathrm{kyr}^{-1}$ to $>100 \mathrm{~mm} \mathrm{kyr}^{-1}$ are required to explain the exposure ages from moraine LG1 that, simply interpreted, yield post LGR ages (Table 6.5.1.3). These rates exceed, by up to an order of magnitude, the compiled empirically-derived long-term erosion rates for igneous lithologies in temperate climatic environments ( $<10 \mathrm{~mm} \mathrm{kyr}^{-1}$; Portenga and Bierman, 2011). Thus, it is unlikely that surface erosion is the dominant cause of the extreme scatter shown in the Mangaehuehu dataset.

Recently, numerical models that describe the impact of moraine degradation and inheritance processes on cosmogenic nuclide production have been developed and applied to aid moraine age interpretation (Hallet and Putkonen, 1994; Putkonen and Swanson, 2003; Applegate et al., 2008; Applegate et al., 2010). These models simulate the distribution of cosmogenic ${ }^{10} \mathrm{Be}$ exposure ages found on a moraine surface under a prescribed geomorphic scenario and can be used to (i) test whether the observed exposure age distribution can be produced by hillslope diffusion; and (ii) better constrain moraine ages by fitting the modeled distributions to empirical datasets (e.g. Applegate et al., 2008, 2012).

I adapt the moraine degradation-cosmogenic nuclide production model developed by Applegate et al. (2010) to simulate the effects of moraine erosion on cosmogenic ${ }^{3} \mathrm{He}$ production (Equation 6.5). For example, ${ }^{3} \mathrm{He}$ is a stable isotope, therefore I remove the decay constant from the nuclide concentration calculation (Applegate et al., 2010, their equation 6/7). Furthermore, I neglect muonic contribution in the calculations (Applegate et al., 2010, their equation 5) and assume all production occurs via spallation 

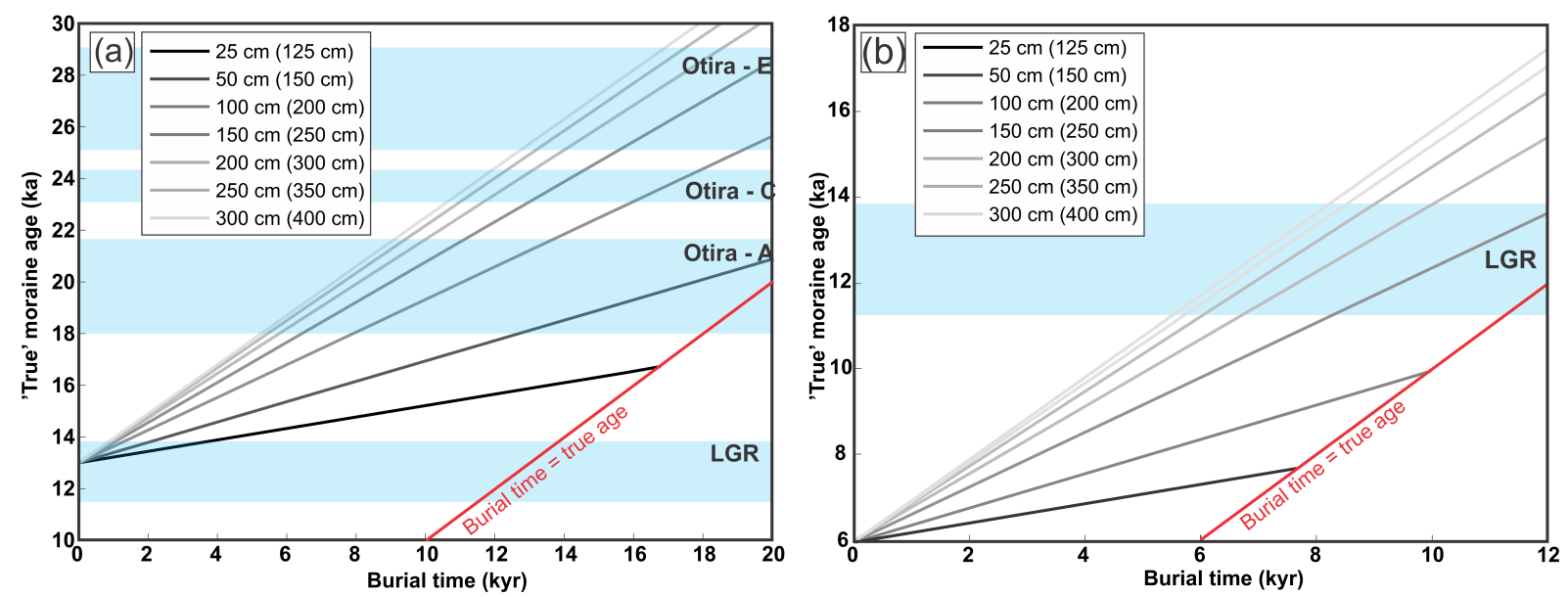

Figure 6.9: (a) Modelled 'true' ages of moraine LG1 samples due to hypothetical shielding of cosmogenic nuclide production beneath sediment $\left(\rho=1.6 \mathrm{~g} \mathrm{~cm}^{-3}\right)$ cover of given burial durations and thicknesses. Soil thicknesses represent that overlying the sampled boulder surfaces, which typically sit c. $1 \mathrm{~m}$ above the moraine surface (see Table 6.1). Calculated for samples that yield simple exposure ages of c. $13 \mathrm{ka}$. (b) As for (a), but calculated for samples that yield simple exposure ages of c. $6 \mathrm{ka}$.

(Equation 6.6), as production of cosmogenic ${ }^{3} \mathrm{He}$ via muons is not well constrained and not accounted for in cosmogenic ${ }^{3}$ He exposure age calculations (Goehring et al., 2010). Omitting muon production may cause underestimation of modelled ${ }^{3} \mathrm{He}$ concentrations within exhumed boulders, as production via high-energy muons becomes more important with increasing depth, due to higher effective attenuation lengths (Heisinger et al., 2002). However, Applegate et al. (2010) demonstrate that even when potential muonic contribution is considered, the majority of cosmogenic nuclide accumulation for deeply buried boulders is derived from spallation reactions after the boulder reaches the moraine surface. Furthermore, theoretical calculations indicate muons account for 2-3 \% of total cosmogenic ${ }^{3} \mathrm{He}$ surface production (Lal, 1987), therefore this is not a significant source of uncertainty in the calculations. All other model parameters match those for exposure age calculation (discussed above). The moraine diffusion model is unchanged from Applegate et al. (2010), who give a full description.

$$
C_{f}=\int_{0}^{t_{f}} P(d(t)) d t .
$$

where $C_{f}$ is the final ${ }^{3} \mathrm{He}$ concentration of surface boulders after simulation of moraine degradation over time $t$. Cosmogenic nuclide production at depth, $P(d)$, is described as:

$$
P(d)=P_{0} \exp \frac{-d}{\Lambda}
$$


where $P_{0}$ is the surface production rate scaled (using the ' $\mathrm{Lm}^{\prime}$ model) to the moraine surface using the calculator of Goehring et al. (2010), $-d$ is depth below the moraine surface, and $\Lambda$ is the effective attenuation length of cosmic rays $\left(160 \mathrm{~g} \mathrm{~cm}^{-2}\right.$; Dunne et al., 1999) divided by material density.

This model assumes that the distribution of nuclide concentrations of boulders at a moraine surface is a product of boulder exhumation and surface erosion, and that boulders are uniformly distributed throughout the parent till of the moraine (Applegate et al., 2010). These assumptions are therefore violated by compound, wide-crested moraine ridges where topographic diffusion is limited following glacier retreat, or for moraines that exhibit low boulder concentrations (Applegate et al., 2010). I apply the moraine degradation model to moraine LG1, which satisfies both criteria. It is relatively sharp-crested (Figure 6.10a) with relatively high (c. 20-25 $5^{\circ}$ slope angles on both the ice-proximal and ice-distal flanks, therefore there is high potential for down-slope sediment transfer. Furthermore, field observations show that the crest and parent till of the moraine is boulder-rich (Figure 6.3).

Apart from moraine age, important parameters in the degradation model are initial moraine height, initial moraine slope and topographic diffusivity, with the latter two imparting most influence on the derived exposure age distributions (Applegate et al., 2010). Each of these parameters are unknown for pre-historic moraines, therefore previous applications of this model have varied each parameter values between characteristic values derived from empirical datasets, to search for the parameter combination that best fits the empirical exposure age distribution (e.g. Applegate et al., 2012). Barrows et al. (2008) stress the importance of empirical observations to constrain the range of model parameter values, in order to best represent the study site. I use 14 topographic cross-profiles (Figure 6.10a), evenly-spaced along the length of moraine LG1, in order to measure the modern height and slope angles. Initial moraine height exerts little influence on modelled exposure age distributions (Applegate et al., 2010), therefore I keep this constant in the simulations at $60 \mathrm{~m}$. Initial moraine slope angles (i.e. immediately following glacier withdrawal) are uncertain for the past. Present-day slope angles for moraine LG1 are $21^{\circ}$ (Figure 6.10c), which I use as the lower bound in the simulations. The maximum upper bound for initial moraine slope is $61^{\circ}$, based on empirical measurements of recently vacated ( $<100 \mathrm{yr}$ old) moraines in the Swiss Alps (Curry et al., 2009). I iteratively run the model using all permutations $(n=6.8 \mathrm{x}$ $10^{3}$ ) of the parameter value ranges listed in Table 6.4. As implemented by Applegate et al. (2012), the Kolmonov-Smimov statistic (KS) is generated for each iteration, which provides a measure between 0 (good) and 1 (poor) of the fit between the modelled and 
empirical exposure age distributions.

I find modelled exposure age distributions best fit the empirical dataset when moraine age is prescribed as $13.6 \mathrm{ka}$ (Table 6.4; Figure 6.10c). This parameterisation also produces a final moraine cross-profile of similar geometry to the empirical measurements (Figure 6.10d). Figure 6.11 presents histograms of parameter values for the upper 5th percentile of $\mathrm{KS}$ results ( $\mathrm{KS}<0.2897 ; n=3386)$. This figure shows moraine ages of 12.4-16.8 ka can produce exposure age distributions that fit well with the empirical age dataset. All model runs where the prescribed moraine age is outside of this range yield KS results that fall outside of the 5th percentile, indicating low probability that the true moraine age is $<12.4 \mathrm{ka}$, or $>16.8 \mathrm{ka}$. The age dataset presented in Figure 6.11 exhibits a unimodal distribution about a mode of $13.8 \mathrm{ka}$. Topographic diffusivity of c. $0.03 \mathrm{~m}^{-2} \mathrm{yr}^{-1}$ produces the greatest number of modelled age distributions that fit well with the empirical dataset and this rate agrees well with observed diffusivities in alpine landscapes (Table 6.5). Moraine slopes and boulder erosion rates are uniformly distributed (Figure 6.11), which indicates that good-fit model results are insensitive to these parameters. Thus, although the best fit permutation includes a steep initial moraine slope $\left(61^{\circ}\right)$ and no boulder surface erosion, similar KS statistics result from when lower initial slope angles and higher boulder surface erosion rates are applied (Table 6.5).

As a further analysis, I examine the best-fit moraine ages produced when individual parameters are held constant at empirically observed values (Table 6.5). Again these parameterisations yield best-fit ages of 13.6-14.0 ka, with the slightly older best-fit age resulting from the inclusion of boulder surface erosion (c. $3 \mathrm{~mm} \mathrm{kyr}^{-1}$ ).

In summary, these results indicate that the cosmogenic ${ }^{3} \mathrm{He}$ surface exposure age distribution of samples from moraine LG1 can be closely reproduced by simulating the combined effects of boulder exhumation and surface erosion on cosmogenic nuclide concentrations. Simulations that prescribe a moraine age of 13.6-14.0 ka yield the closest fit to the empirical exposure age dataset and this result is robust across a range of observed parameter values. This is consistent with the age interpretation presented above, and further supports a late-glacial age for this moraine.

\subsubsection{Other chronologies of late glacial cooling in New Zealand}

The inference from cosmogenic ${ }^{3} \mathrm{He}$ dating, that the Mangaehuehu 'LG' moraines represent a glacial readvance in response to cooling at c. 14-12 ka is supported by several, well-dated terrestrial and marine climate proxy records from across New Zealand 
Table 6.4: Parameter space and best fit values for simulation of moraine degradation on cosmogenic exposure age distribution for moraine LG1.

\begin{tabular}{lcccc}
\hline Parameter & Upper bound & Lower bound & Step size & Best fit \\
\hline Moraine age $(\mathrm{ka})$ & 15 & 3 & 0.1 & $\mathbf{1 3 . 6}$ \\
Topographic diffusivity & 1 & -3 & 0.5 & $\mathbf{1 . 5}$ \\
$\quad\left(\log 10\left(\mathrm{~m}^{-2} \mathrm{yr}^{-1}\right)\right)$ & 61 & 21 & 5 & $\mathbf{6 1}$ \\
Initial moraine slope $\left(^{\circ}\right)$ & 10 & 0 & 1 & $\mathbf{0}$ \\
Boulder surface erosion $\left(\mathrm{mm} \mathrm{kyr}^{-1}\right)$ & & & & \\
\hline
\end{tabular}

Table 6.5: Best-fit moraine degradation model parameter combinations when individual variables are prescribed using literature-based values.

\begin{tabular}{|c|c|c|c|c|c|c|c|}
\hline Parameter & Value & Source & $\begin{array}{l}\text { Best- } \\
\text { fit age } \\
(\mathrm{ka})\end{array}$ & $\begin{array}{l}\text { Best-fit } \\
\text { slope }\left(^{\circ}\right)\end{array}$ & $\begin{array}{l}\text { Best-fit } \\
\text { diffusivity } \\
\left(m^{-2}\right. \\
\left.y r^{-1}\right)\end{array}$ & $\begin{array}{l}\text { Best-fit } \\
\text { erosion } \\
\text { rate (mm } \\
\left.k^{2} r^{-1}\right)\end{array}$ & KS \\
\hline Slope & $31-41^{\circ}$ & $\begin{array}{l}\text { Hallet and } \\
\text { Putkonen } \\
\text { (1994); } \\
\text { Putkonen } \\
\text { and Swan- } \\
\text { son (2003) }\end{array}$ & 13.6 & - & 0.1 & 0 & $0.2183-0.2293$ \\
\hline $\begin{array}{l}\text { Topographic } \\
\text { diffusvity }\end{array}$ & $0.1 \mathrm{~m}^{-2} \mathrm{yr}^{-1}$ & $\begin{array}{l}\text { Matsuoka } \\
\text { (1998) }\end{array}$ & 13.6 & 31 & - & 0 & 0.2183 \\
\hline Erosion rate & $3 \mathrm{~mm} \mathrm{kyr}^{-1}$ & $\begin{array}{l}\text { Barrows et al. } \\
\text { (2001) }\end{array}$ & 14.0 & 61 & 0.01 & - & 0.2217 \\
\hline
\end{tabular}

region. In North Island, the Waiohau Tephra (14.0 $\pm 0.2 \mathrm{ka}$; Lowe et al., 2013) is a critical chronological marker horizon for the late glacial stratigraphies. Previous latitudinal comparisons of continuous climate proxy records through the last glacial-interglacial transition have suggested there is a time-lag in cooling between the North and South Islands (Newnham et al., 2012), with northern cooling lagging the south. However, recent refinement of the Waiohau Tephra age, which forms the key chronological tiepoint in northern records, suggests late glacial cooling was likely synchronous across the latitudinal range of New Zealand (e.g. Table 6.6) and broadly concomitant with the Antarctic Cold Reversal (Lowe et al., 2013) evident in Antarctic ice core records (e.g. Blunier and Brook, 2001; EPICA Community Members, 2006).

The best constrained, continuous late-glacial climate proxy record comes from Kaipo Bog (Newnham and Lowe, 2000; Hajdas et al., 2006; Lowe et al., 2013), situated c. 150 $\mathrm{km}$ northeast of Mt. Ruapehu. This record forms the chronological type-locality for cold conditions during the lateglacial in the New Zealand Climate Event Stratigraphy (Barrell et al., 2013). At this location, a c. 1200 yr climatic reversal is evident, which began soon after deposition of the Waiohau Tephra, and is constrained to 13.8 - $12.6 \mathrm{ka}$ by Bayesian modelling of $20{ }^{14} \mathrm{C}$ dates (Lowe et al., 2013). Similarly, in pollen stratgraphy 
at Otamangakau Bog, c. $35 \mathrm{~km}$ north of Mt. Ruapehu, Turney et al. (2003) identify a moderate climatic reversal of c. 1000 yr duration, immediately following deposition of the Waiohau Tephra. Further north, in Auckland $\left(37^{\circ} \mathrm{S}\right)$, multi-proxy evidence from several maar records broadly agree that deglacial warming was interrupted by a climatic reversal that began at, or slightly before, the time of Waiohau Tephra deposition and lasted c. 700-1000 yrs (Augustinus et al., 2012; Stephens et al., 2012a,b; Sikes et al., 2013).

The distribution of the Waiohau Tephra does not extend to South Island, however several climate proxy records, dated using a variety of absolute techniques, constrain a cooling episode of similar timing and duration to those in North Island. In northern South Island $\left(41^{\circ} \mathrm{S}\right)$, pronounced negative $\delta^{18} \mathrm{O}$ excursions in multiple speleothem records imply cooling, which are constrained by uranium-series dating to 13.8-11.7 ka (Hellstrom et al., 1998) and 14.4-13.0 ka (Whittaker et al., 2011). In the central Southern Alps (43-44 ${ }^{\circ}$ ) multiple, well-dated climate proxy records constrain the timing of a lateglacial reversal. A continuous record of chironomid and pollen change from Boundary Stream tarn, in the Ben Ohau Range, shows cooling 14.2 - $13.2 \mathrm{ka}$, with the most intense cooling c. 13.7-13.2 ka (Vandergoes et al., 2008). Nearby, an increasing number of high-precision cosmogenic ${ }^{10} \mathrm{Be}$ (cf. Schaefer et al., 2009; Putnam et al., 2010b) exposure chronologies indicate a period of moraine building by mountain glaciers centred on c. 14-13 ka (Kaplan et al., 2010; Putnam et al., 2010a; Kaplan et al., 2013). On the central west coast, Franz Josef Glacier advanced over a prominent bedrock outcrop, Canavans Knob, depositing glacial till with wood fragments that date to c. $13.1 \mathrm{ka}$ (Denton and Hendy, 1994; Turney et al., 2007). Thus, multiple glacial records from the central Southern Alps suggest glaciers advanced at this time in response to cooling, or a hiatus in deglacial warming.

In summary, there is increasing evidence for broadly synchronous, and widespread atmospheric cooling in New Zealand between c. 14-12.5 ka in palaeoclimate proxy records. This is consistent with the geomorphological and geochronological evidence presented here from southern Mt. Ruapehu, which shows glacier readvance in multiple catchments at this time.

\subsubsection{Palaeoclimatic reconstruction}

\subsubsection{Late-glacial palaeoclimatic estimates derived from glacier modelling}

Glacier model-derived palaeotemperature estimates indicate that a cooling of 2.5 - 3.4 ${ }^{\circ} \mathrm{C}$ relative to present is necessary to simulate a steady state glacier that matches the 
former glacial limits represented by the LG moraines on southern Mt. Ruapehu (Figure 6.7). This temperature range reflects uncertainty in past precipitation change of \pm $20 \%$. Few precipitation proxy records exist to help further constrain the temperature estimate. Speleothem isotope records from western regions in New Zealand generally point towards increased moisture availability during the late-glacial reversal, which suggests increased precipitation (Hellstrom et al., 1998; Williams et al., 2005; Whittaker et al., 2011). At multiple sites on the west coast (43 S), Vandergoes and Fitzsimons (2003) conclude that changing pollen taxa assemblages during the period $14.4-11.4 \mathrm{ka}$ are also consistent with cooler, wetter conditions. However, multiple palaeoenvironmental proxy records from maar lakes in Auckland $\left(36^{\circ} \mathrm{S}\right)$ yield mixed signals concerning late-glacial precipitation change (Augustinus et al., 2012; Stephens et al., 2012b; Sikes et al., 2013). Pollen, cladocera and diatom assemblages lead Augustinus et al. (2012) and Stephens et al. (2012b) to conclude that the late-glacial climate reversal was a time of relatively dry conditions in northern New Zealand. Meanwhile, carbon isotopes suggest reduced aridity at this time, at least during spring and summer (Sikes et al., 2013). Thus, although most records suggest increased precipitation during the LGR, I consider the relative paucity of proxy records and the spatial and possible seasonal variability between existing records justifies the uncertainty range reported here.

I test the impact of the energy balance and ice flow parameter choices on the derived paleotemperatures, in a suite of systematic model sensitivity analyses (Figure 6.7). In model runs with increased precipitation relative to present, increases in the snow-rain temperature threshold $\left(T_{s}>0.5^{\circ} \mathrm{C}\right)$ impart a significant impact on palaeotemperature estimates (6.7a). This is because higher values for $T_{s}$ increase the ratio of snow to rain. When combined with greater annual precipitation, modelled accumulation increases significantly, thus requiring significantly less cooling to achieve the target palaeoglacier geometry (Figure 6.7). Altering snow albedo $\left(\alpha_{\text {snow }} \pm 0.05\right)$ consistently imparts the greatest deviation $\left( \pm 0.4^{\circ} \mathrm{C}\right)$ from palaeotemperatures derived using the optimal parameter settings. Increasing $a_{\text {snow }}$ requires less cooling to match the moraine limits, due to increased reflectance of incoming shortwave radiation, and vice versa (Figure 6.7a). In reality, $\alpha_{\text {snow }}$ is primarily determined by surface impurity concentrations, as well as snow crystal size (Cuffey and Paterson, 2010), however it is not possible to constrain pre-historic changes in these variables. The proximity of the Mangaehuehu Glacier to an active volcanic vent increases the likelihood of periodic delivery of sediment to the glacier surface, as was evident during historic eruptions. Depending on the thickness of the imposed debris cover, such events could lead to enhanced or retarded surface melt rates (Richardson and Brook, 2010). However, whilst such impacts may have a significant impact on the local energy balance in the short term (c. 1-10 yrs), long-term impacts in relatively steep, fast, temperate glaciers are generally low, due to mass loss 
at the terminus and erosion by surface meltwater (Kirkbride and Dugmore, 2003; Nield et al., 2013).

In prescribing modern topographic boundary conditions in the model application presented here, I assume that no significant change has occurred in the Mangaehuehu catchment in the last c. $15 \mathrm{ka}$. This assumption can be assessed in two ways: (i) by reviewing the known geologic events that have occurred over this time period, which may have impacted on the local geomorphology; and (ii) by comparing modelled glacier geometries in other catchments on Mt. Ruapehu to the local moraine distribution. Concerning the first point, the preservation of the LG moraines suggests little post-depositional geomorphic disturbance in the lower portion of the former glacial catchment. On the upper mountain, the major geomorphic events in the last $15 \mathrm{ka}$ include, the Murimotu debris avalanche flank collapse (10.4-10.6 cal. ka: Chapter 4; Topping, 1974; Palmer and Neall, 1989) and emplacement of the Whakapapa Formation lava flows (Hackett and Houghton, 1989; Gamble et al., 2003). The major geomorphic imprints of these events are concentrated on the northwest flank of Mt. Ruapehu, well away from the Mangaehuehu catchment. No known lavas of Holocene age exist in the Mangaehuehu catchment (C. Conway/G. Leonard/J. Gamble, pers. comm., 2014). Concerning the second point, 'intermediate' moraines (i.e. between inferred LGM and modern day ice) exist in several other catchments on southern Ruapehu (e.g. Figure 6.7c). Although some dating uncertainty exists, the excellent agreement between the model simulations and these geologically-inferred glacial limits supports the assumption of topographic stability over the last $15 \mathrm{ka}$. 

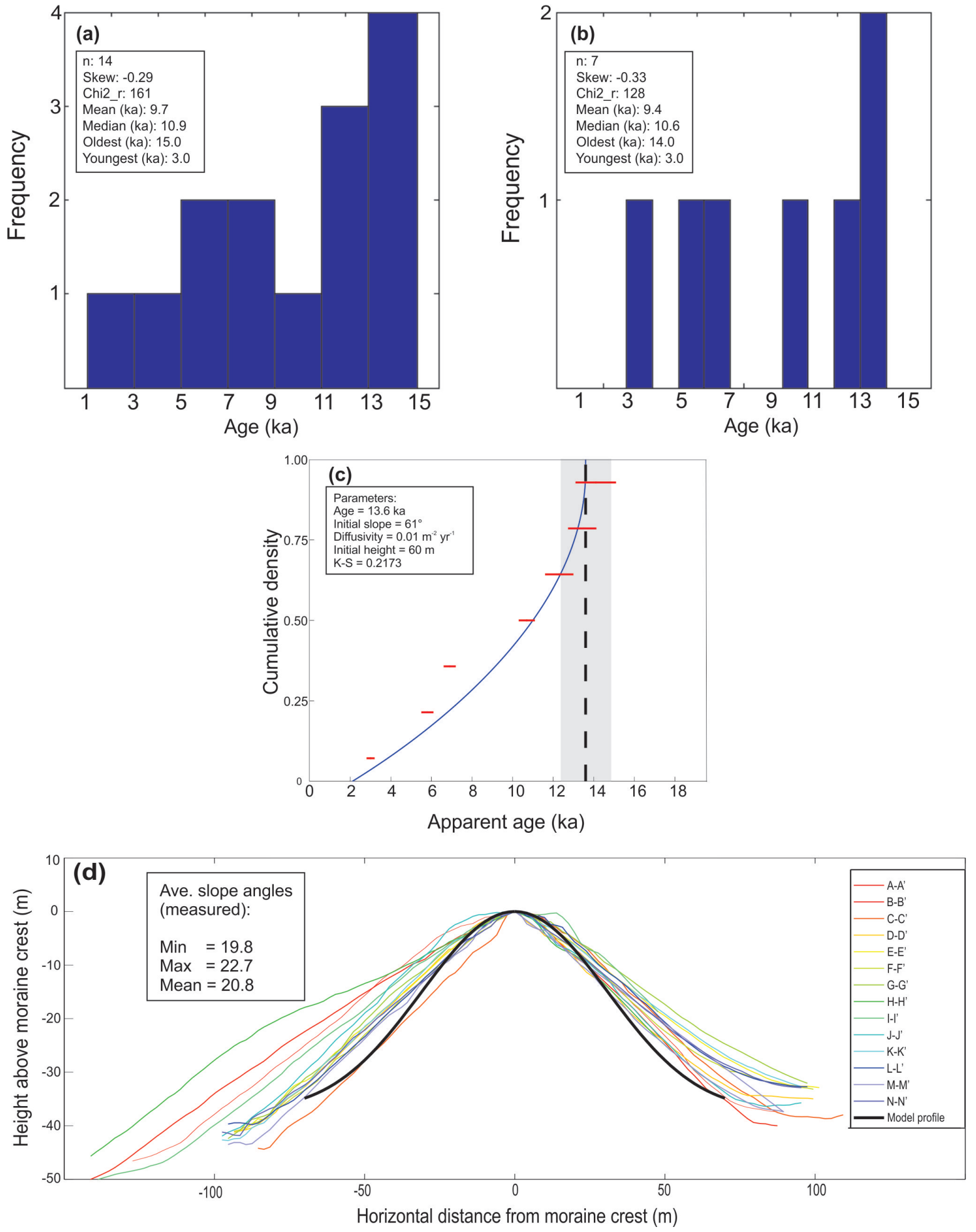

Figure 6.10: (a) Histogram and statistics describing the distribution of all moraine exposure ages from the Mangaehuehu catchment (LG moraines); (b) Histogram and statistics describing the distribution of moraine boulder exposure ages from moraine LG1 in the Mangaehuehu catchment; (c) Empirical (red) and modelled (blue) exposure age distribution for moraine LG1. Vertical dashed line depicts the best-fit moraine exposure age (grey shading represents $\pm 10 \%$ uncertainty), as indicated by moraine degradation modelling, according to Applegate et al. (2010); (d) Empirical and modelled topographic cross profiles of moraine LG1. 

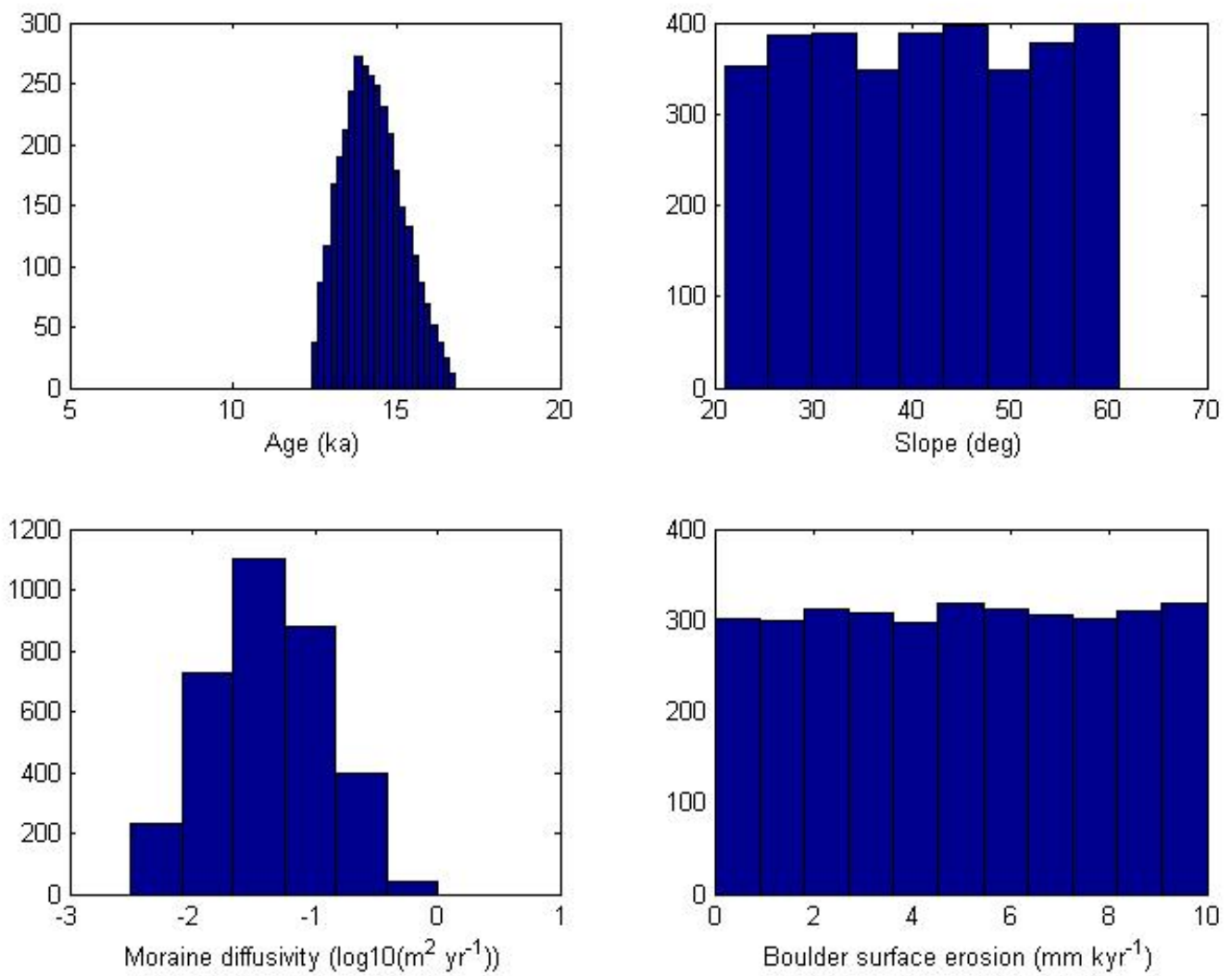

Figure 6.11: Histograms of moraine degradation model parameter values (moraine age, initial slope, topographic diffusivity and boulder erosion rate) for the upper 5th percentile of KS results $(K S<0.2897 ; n=3386)$ that result from comparison to the LG1 cosmogenic ${ }^{3} H e$ exposure age dataset. 
Table 6.6: A compilation of chronologies and quantitative palaeoclimate reconstructions for the late-glacial climate reversal in

New Zealand.

\begin{tabular}{|c|c|c|c|c|c|c|c|c|}
\hline Author & Site & Latitude $\left(^{\circ}\right)$ & $\begin{array}{l}\text { Onset } \\
(\mathrm{ka})\end{array}$ & $\begin{array}{l}\text { End } \\
(k a)\end{array}$ & $\Delta T\left({ }^{\circ} \mathrm{C}\right)$ & Dating method & $\Delta P$ & Proxy \\
\hline Stephens et al. (2012a) & Pupuke & -37 & $13.8^{a}$ & $12.8^{a}$ & - & tephra $/{ }^{14} \mathrm{C}$ & $\uparrow$ & $\begin{array}{l}\text { Sediment } \\
\text { flux/diatoms }\end{array}$ \\
\hline Sikes et al. (2013) & Onepoto & -37 & $14.5^{a}$ & $13^{a}$ & $\#$ & tephra $/{ }^{14} \mathrm{C}$ & $\downarrow$ & Pollen \\
\hline Newnham et al. (2012) & Pukaki & -37 & $12.8^{a}$ & - & \# & ${ }^{14} \mathrm{C}$ & & Pollen \\
\hline Augustinus et al. (2012) & Onepoto & -37 & $13.8^{a}$ & $12.4^{a}$ & - & tephra $/{ }^{14} \mathrm{C}$ & $\uparrow$ & $\begin{array}{l}\text { Pollen/sediment } \\
\text { influx }\end{array}$ \\
\hline Newnham et al. (2012) & Kaipo Bog & -38 & $13.6^{a}$ & $12.6^{a}$ & $-0.5--1 \pm 1.5$ & tephra $/{ }^{14} \mathrm{C}$ & & Pollen \\
\hline Lowe et al. (2013) & Kaipo Bog & -38 & 13.8 & 12.6 & - & $\begin{array}{l}\text { tephra } /{ }^{14} \mathrm{C} / \text { bayesian } \\
\text { model }\end{array}$ & - & - \\
\hline Williams et al. (2010) & Central-west North Island & -39 & 13.4 & 11.2 & - & $\mathrm{U} / \mathrm{Th}$ & $\uparrow$ & Speleothem \\
\hline Turney et al. (2003) & Durham Road & -39 & $14.7^{a}$ & $13.7^{a}$ & - & tephra $/{ }^{14} \mathrm{C}$ & & Pollen \\
\hline Turney et al. (2003) & Otamangakau bog & -39 & $14.7^{a}$ & $13.0^{a}$ & - & tephra $/{ }^{14} \mathrm{C}$ & & Pollen \\
\hline This study & Mt. Ruapehu & -39 & - & $\begin{array}{l}\text { c. } 14- \\
12\end{array}$ & $-2.5--3.4$ & ${ }^{3} \mathrm{He}$ & & Glacier model \\
\hline Williams et al. (2005) & NW South Island & -41 & 13.5 & 11.1 & - & $\mathrm{U} / \mathrm{Th}$ & $\uparrow$ & Speleothem \\
\hline Whittaker et al. (2011) & Hollywood Cave & -41 & 14.4 & 13 & - & $\mathrm{U} / \mathrm{Th}$ & $\uparrow$ & Speleothem \\
\hline Hellstrom et al. (1998) & Mt Arthur & -41 & 13.8 & 11.7 & - & $\mathrm{U} / \mathrm{Th}$ & $\uparrow$ & Speleothem \\
\hline Turney et al. (2003) & Lake Doubtful & -42 & $15.0^{a}$ & $12.9^{a}$ & - & tephra $/{ }^{14} \mathrm{C}$ & & Pollen \\
\hline Turney et al. (2003) & Kettlehole Bog & -43 & $15.0^{a}$ & $12.9^{a}$ & - & tephra $/{ }^{14} \mathrm{C}$ & & Pollen \\
\hline $\begin{array}{l}\text { Vandergoes and Fitzsimons } \\
\text { (2003) }\end{array}$ & South Westland & -43 & 14 & 12.7 & - & ${ }^{14} \mathrm{C}$ & $\uparrow$ & Pollen \\
\hline Putnam et al. (2010a) & Mid-Macauley & -43 & - & 13.0 & - & ${ }^{10} \mathrm{Be}$ & - & Glacier length \\
\hline Putnam et al. (2010a) & Birch Hill & -43 & - & 13.0 & - & ${ }^{10} \mathrm{Be}$ & & Glacier length \\
\hline Newnham et al. (2012) & Okarito & -43 & 15 & 13.4 & \# & ${ }^{14} \mathrm{C}$ & - & Pollen \\
\hline $\begin{array}{l}\text { Anderson and Mackintosh } \\
\text { (2006) }\end{array}$ & Franz Josef Glacier & -43 & - & - & $-3--4.7$ & - & - & Glacier model \\
\hline Vandergoes et al. (2008) & Boundary Stream & -44 & 14.2 & 13.2 & $-3--4 \pm 1.4$ & ${ }^{14} \mathrm{C}$ & - & $\begin{array}{l}\text { Chironomids (WA- } \\
\text { PLS) }\end{array}$ \\
\hline Vandergoes et al. (2008) & Boundary Stream & -44 & 14.2 & 13.2 & $-2--3 \pm 1.4$ & ${ }^{14} \mathrm{C}$ & - & Chironomids (PLS) \\
\hline Kaplan et al. (2010) & Irishman Stream & -44 & - & 13 & - & ${ }^{10} \mathrm{Be}$ & - & Glacier ELA \\
\hline Doughty et al. (2013) & Irishman Stream & -44 & - & - & $-2.3--3.2$ & ${ }^{10} \mathrm{Be}^{b}$ & - & Glacier model \\
\hline Kaplan et al. (2013) & Whale Stream & -44 & & 14 & $-1.8--2.6$ & ${ }^{10} \mathrm{Be}$ & - & Glacier model \\
\hline McGlone et al. (2010) & Homestead Scarp & -52 & 14.5 & 12.5 & $-2--2.5 \pm 1$ & ${ }^{14} \mathrm{C}$ & & Pollen \\
\hline McGlone et al. (2010) & Mt Honey & -52 & - & 12.5 & $-2--2.5 \pm 1$ & ${ }^{14} \mathrm{C}$ & - & Pollen \\
\hline
\end{tabular}


${ }^{a}$ Age model uses age for Waiohau Tephra that pre-dates the revision by Lowe et al. (2013)

${ }^{b}$ Dating by Kaplan et al. (2010) (c. 13 ka)

\# Palaeotemperature estimates are made relative to a pre-deforestation reference time - see text.

\subsubsection{Testing $H_{\text {null }}$ : Was there an enhanced latitudinal air temperature gradient across NZ during the late-glacial climate reversal?}

To test $H_{\text {null }}$, I compare the estimated late-glacial cooling of $2.5-3.4{ }^{\circ} \mathrm{C}$ to other welldated, quantitative palaeoclimate reconstructions (Table 6.6). Few quantitative reconstructions of LGR air temperatures exist for North Island. Those that do exist (e.g. Newnham et al., 2012; Sikes et al., 2013) are derived using a pollen-temperature transfer function that uses a database of pre-deforestation pollen taxa (Wilmshurst et al., 2007) in order to minimise the anthropogenic impacts that distort the present-day vegetationclimate relationship (Norton et al., 1986). Thus, the different reference times from which palaeotemperature estimates are made between proxies (e.g. glaciers - from present day, pollen - from c. AD1300) makes it difficult to compare absolute palaeotemperature estimates. However, this limitation does not prevent inter-proxy comparison of the spatial patterns of palaeotemperature reconstructions, which is the focus of the hypothesis test in this study.

The glacier model results for Mt. Ruapehu presented here are consistent with existing, quantitative glacier-palaeoclimate reconstructions from South Island (Table 6.6), most of which come from the central Southern Alps (c. 43-44 ${ }^{\circ} \mathrm{S}$ ). For example, at Franz Josef glacier, Anderson and Mackintosh (2006) use an empirically calibrated degree-day approach, with a 1D glacier flowline model to simulate the climatic forcing required for ice to override the well dated glacial till at Canavan's Knob (Denton and Hendy, 1994; Turney et al., 2007), c. $12 \mathrm{~km}$ down-valley from the present glacier terminus. They find that a cooling of c. $2.7-3.6^{\circ} \mathrm{C}$ is necessary to reach this site, when precipitation is varied by $\pm 20 \%$. Two key uncertainties surround this palaeotemperature estimate. First, the maximum down-valley position of the glacier terminus related to this advance remains uncertain (e.g. Barrows et al., 2007a; Applegate et al., 2008, 2012); further cooling is required to produce a glacier that terminates further down valley, e.g. at the Waiho Loop moraine. Conversely, the simulations conducted by Anderson and Mackintosh (2006) do not include potential ice contributions from the Callery tributary, which, if included, may lower the climatic forcing necessary to force Franz Josef Glacier out past Canavans Knob. Despite these uncertainties, the estimates of Anderson and Mackintosh (2006) are broadly consistent with the estimates of Doughty et al. (2013) and Kaplan et al. (2013), to derive palaeotemperature estimates of $2.3-3.2{ }^{\circ} \mathrm{C}$ and 1.8 $2.6^{\circ} \mathrm{C}$ for the well-dated (c. 14-12 ka) moraine records in Irishman (Kaplan et al., 2010) 
and Whale streams, respectively (Table 6.6). The strength of the latter two studies for the present hypothesis test is that the same glacier model approach is used for the South Island (Irishman \& Whale Streams) and North Island (this study). This consistent approach minimises the potential for methodologically-based differences in results and indicates uniform temperature change across New Zealand during the LGR.

The glacier model results presented here do not support the hypothesis of an enhanced latitudinal temperature gradient across New Zealand during the LGR, therefore I fail to reject $H_{\text {null }}$. This poses the question, what causes the discrepancy between the spatial pattern of cooling as indicated by pollen (e.g. Newnham et al., 2012) and glacier records during the LGR in New Zealand? I argue that such conflicts represent a difference between the seasonal sensitivity of the two proxies. Glacier mass balance in New Zealand is most sensitive to temperature (Figure 6.8; Anderson and Mackintosh, 2006; Anderson et al., 2010; Anderson and Mackintosh, 2012), due to its strong contribution to glacier melt and the close-proximity of winter temperatures to the snow-rain threshold. Seasonal sensitivity experiments conducted in this study show that glacier length sensitivity is most sensitive to temperature changes during the ablation season, as opposed to other periods of the mass balance year (Figure 6.8). This accords with similar work by Oerlemans and Reichert (2000), who demonstrate that mass balance sensitivity to temperature is greatest in months where average air temperatures exceed, or approach $0{ }^{\circ} \mathrm{C}$. In temperate, maritime locations such as New Zealand, mass balance sensitivity to temperature is therefore greatest in summer, but changes in the shoulder seasons (autumn/spring) can also be important (Oerlemans and Reichert, 2000). In contrast, the distribution of vegetation taxa in New Zealand is considered to be predominantly controlled by the duration and/or intensity of the cold season, or mean annual temperature, due to low resistence to freezing (Wilmshurst et al., 2007; Vandergoes et al., 2008). Thus, it seems glaciers and vegetation in New Zealand may be sensitive to different thresholds in the annual temperature cycle. Used in combination, these proxies may inform past changes in seasonality. Using a similar approach, Vandergoes et al. (2008) compare synchronous assemblage changes of chironomids and pollen through the LGR. They find a muted pollen signal during the LGR, in comparison to that from chironomids (c. $\Delta \mathrm{T}=-2--4{ }^{\circ} \mathrm{C}$; Table 6.6), which are most sensitive to changes in summer temperatures (Dieffenbacher Krall et al., 2007). This mirrors the relationship observed between glaciers and pollen in the central North Island, and supports the hypothesis that the LGR in New Zealand was a time of reduced seasonality, with greater cooling during summer than winter. Furthermore, it appears that summertime temperatures exhibited a similar latitudinal gradient to present-day across New Zealand during the LGR. The pollen-based LGR palaeotemperature gradient observed by Newnham et al. (2012) may therefore represent a steeper winter temperature gradient during the LGR. 


\subsection{Conclusion}

Mountain glaciers on Mt. Ruapehu in central North Island, New Zealand, readvanced during the late-glacial climate reversal (Barrell et al., 2013), which is largely coeval with the Antarctic Cold Reversal. Numerical glacier model experiments suggest local glaciers responded to a climate that was $2.5-3.4{ }^{\circ} \mathrm{C}$ cooler and assuming that precipitation remained in the range $\pm 20 \%$, from present-day. This magnitude of cooling differs from nearby pollen-based reconstructions, therefore I fail to reject a null hypothesis of uniform temperature change across New Zealand during the late-glacial climate reversal. I suggest that differences between the seasonal sensitivity of glacier mass balance and vegetation are the cause of these conflicting quantitative palaeoclimatic estimates. These findings suggest that uniform summer cooling occurred across New Zealand during the LGR, and that perhaps an enhanced north-south winter temperature gradient prevailed at this time. I therefore support the existing hypothesis that the late-glacial climate reversal was a time of reduced seasonality (e.g. Vandergoes et al., 2008). 


\section{Chapter 7}

\section{Temperature change during the Last Glacial Cold Period in central North Island, New Zealand $\left(39^{\circ} \mathrm{S}\right)$, inferred from 2D glacier modelling}

\subsection{Abstract}

Quantitative climate reconstructions provide important data for tracing the drivers and mechanisms of past, natural climate variability and for constraining possible future responses of the climate system. Geological evidence of former mountain glacier geometries affords the opportunity to reconstruct palaeoclimate, due to the strong relationship between ice extent and local climate. In this study, I present results from geological mapping, cosmogenic ${ }^{3} \mathrm{He}$ surface exposure dating and numerical glacier modelling, which constrains glacial extent and palaeoclimate in nine catchments on the central North Island volcanoes of New Zealand, during the Last Glacial Cold Period (c. 30-18 ka). Moraine distribution indicates that valley glaciers extended down to c. $1200 \mathrm{~m}$ asl, from individual ice fields centred over Tongariro massif and Mt. Ruapehu volcanoes. Simulations using a 2D coupled energy-balance/ice-flow model show that the mapped ice limits can be reproduced when present day temperatures are reduced by $4-7^{\circ} \mathrm{C}$. Glacier model experiments using topographic reconstructions that account for the effects of effusive post-glacial volcanism, generally increased the magnitude of cooling required to simulate the former ice limits by up to $0.5^{\circ} \mathrm{C}$. The palaeotemperature estimates presented here are consistent with independent, proximal temperature reconstructions from fossil pollen assemblages, as well as similar glacier modelling reconstructions from central Southern Alps. This agreement, together with the relatively small impact of topographic change, provide increased confidence in the use of 
moraine records from volcanically-active domains for palaeoclimatic reconstruction over millennial to orbital timescales.

\subsection{Introduction}

Constraining the magnitude of warming across glacial-interglacial transitions provides fundamental information about the global climate system (e.g. CLIMAP, 1976; Waelbroeck et al., 2009; Bartlein et al., 2011). Such data permit: (i) critical tests of hypotheses that seek to explain the drivers and mechanisms of past natural climate change (Shakun et al., 2012); (ii) constraint of climate sensitivity to radiative forcing (Schmittner et al., 2011; Hargreaves et al., 2012); and (iii) critical assessment of general circulation models that are used to predict future climatic change (Braconnot et al., 2012; Schmidt et al., 2013). Many environmental proxies now exist for palaeoclimatic reconstructions (e.g. Alloway et al., 2007). Mountain glacier length fluctuations primarily reflect mass changes resulting from the perturbation of snow accumulation and snow/ice ablation (Oerlemans, 2001). These perturbations are due primarily to changes in air temperature and solid precipitation, and records of past glacial extent provide useful insight to past climatic change. Moraines are landforms comprising unconsolidated sediment that has been transported via glacial flow and deposited at the ice margins (Benn and Evans, 2010). Preservation of such features in the modern landscape delineates past ice geometries which, when coupled with geochronological techniques such as cosmogenic surface exposure dating, provide the opportunity to constrain both the magnitude and timing of palaeoclimatic change (e.g. Chapter 5; Schaefer et al., 2006, 2009; Kaplan et al., 2010; Putnam et al., 2010a).

Traditionally, past glacial geometries have been related to palaeoclimate through manual reconstruction of former equilibrium line altitude (ELA; e.g. Porter, 1975; Meierding, 1982); however, these methods are subject to several unquantifiable sources of error (Plummer and Phillips, 2003). Increased understanding of glacier climate relationships (Oerlemans, 2001; Cuffey and Paterson, 2010), coupled with increasing computing power and availability of digital climate datasets now facilitates application of physically-based numerical models to simulate past former glaciers (Plummer and Phillips, 2003; Doughty et al., 2013). Models that describe glacier mass balance and ice-flow provide a glacier-climate transfer function, which allows quantitative palaeoclimatic information to be extracted from geological records of glacier length change (Oerlemans, 2005). This approach affords the opportunity to constrain palaeoclimatic estimates in an objective and consistent manner, at multiple locations where evidence for past glaciation exists, whilst uncertainty bounds can be quantified through model 
sensitivity analyses (e.g. Rowan et al., 2014). Comparison of palaeoclimatic estimates from such studies permits robust assessment of former climatic gradients, over a range of spatial scales, which can help to identify drivers of past climate change.

The Last Glacial Maximum ('LGM') describes the global sea level low-stand achieved between 26-19 ka, when Northern Hemisphere ice sheets reached their maximum extent of the last glacial cycle (Clark et al., 2009). During this interval, global mountain glacier extent also peaked (Schaefer et al., 2006; Clark et al., 2009), in response to ELA lowering of c. 900-1000 m, relative to present (Broecker and Denton, 1990). In New Zealand, local nomenclature such as 'extended LGM' (Newnham et al., 2007) or 'Last Glacial Cold Period' ('LGCP'; Alloway et al., 2007; Barrell et al., 2013) has been introduced to describe the prevailing glacial climatic conditions between c. 30 - 18 ka (e.g. Chapter 5; Vandergoes et al., 2005; Putnam et al., 2013b). Continuous and well-dated climate proxy records have greatly improved understanding of the timing and relative magnitudes of climatic changes in New Zealand through this period (e.g. Barrell et al., 2013). However, quantitative estimates of terrestrial palaeoclimatic variables (namely air temperature and precipitation) are rare. Where available, independent estimates of LGCP climate have shown good agreement across relatively short spatial scales (e.g. central Southern Alps - Golledge et al., 2012; Putnam et al., 2013a,b; Rowan et al., 2013). However, quantitative palaeoclimate reconstructions from elsewhere in New Zealand can differ greatly. For example, McKinnon et al. (2012; their Table 3) summarise all previously published, terrestrial, LGCP temperature estimates for New Zealand, which range from $+0.5^{\circ} \mathrm{C}$ to $-9^{\circ} \mathrm{C}$, relative to present. Such differences may arise from methodological/chronological uncertainties, or could represent meaningful spatial relationships that represent key climatic processes (e.g. Lorrey et al., 2012b) with the potential to inform the drivers of observed changes. Increasing the number and spatial coverage of quantitative palaeoclimate reconstructions will help to resolve these issues.

In Chapter 5, I present geological and geochronological evidence for valley glaciation on Tongariro massif, in central North Island, during the LGCP. Reconstruction of the palaeo-ELA associated with this former glacier indicates a lowering of c. $1000 \mathrm{~m}$ relative to present, which equates to a temperature depression of c. $5-7^{\circ} \mathrm{C}$ from modern. However, this estimate remains uncertain for two main reasons. First, former valley glaciers on the central North Island volcanoes were likely fed by central ice fields. The absence of geomorphic evidence to constrain past ice thickness in the accumulation zones means that the hypsometry of former glacier surfaces is uncertain, which can lead to errors in manual ELA reconstruction (Rea et al., 1999). Second, part of the catchment studied in Chapter 5 has undergone considerable post-glacial topographic change, due to effusive volcanism during the Holocene (Moebis et al., 2011). Growth of 
volcanic cones and emplacement of lava flows has potentially altered drainage patterns and adds further uncertainty to the reconstruction of former flow divides and glacier surfaces. In this chapter I aim to: (i) provide refined constraint of LGCP glacial limits in central North Island, through direct dating and morphostratigraphic correlation of the chronological results from Chapter 5 to glacial landform assemblages across a wider study domain that encompasses catchments on both Tongariro massif and Mt. Ruapehu volcanoes; (ii) constrain the magnitude of cooling associated with the identified glacial limits, using a 2D numerical glacier energy-balance/ice-flow model; and (iii) investigate the sensitivity of glacier model derived palaeoclimate estimates to post-glacial topographic change, using an expert-defined reconstruction of the topographic boundary conditions during the LGCP.

\subsubsection{Setting}

Tongariro Volcanic Centre (TgVC) represents the southernmost expression of the Taupo Volcanic Zone, which is a c. $300 \mathrm{~km}$ long, northeast trending belt of subduction zone volcanism at the Australian-Pacific plate margin (Cole, 1978). Located in central North Island, New Zealand (39 ${ }^{\circ} \mathrm{S} 174^{\circ} \mathrm{E}$; Figure 7.1), TgVC is dominated by the andesitedacite stratovolcanic centres of Tongariro massif (including Mt. Tongariro - $1963 \mathrm{~m}$ asl and the Holocene cone of Mt. Ngauruhoe - $2291 \mathrm{~m}$ asl) and Mt. Ruapehu (2797 m asl). Cone-building volcanism in the region began before c. $275 \mathrm{ka}$ (Stipp, 1968) and both have exhibited effusive activity in historical times (Houghton et al., 1987). The local climate, as recorded at Whakapapa village (1097 $\mathrm{m}$ a.s.l.) on the northwest flank of Mt. Ruapehu, is characterised by low seasonal precipitation variability, with winter (JJA) precipitation averaging $762 \mathrm{~mm}$, compared to $624 \mathrm{~mm}$ in summer. Monthly mean temperatures range from c. $13{ }^{\circ} \mathrm{C}$ in February to c. $3{ }^{\circ} \mathrm{C}$ in July, with an annual average of $7.5{ }^{\circ} \mathrm{C}$ (2000-2010; NIWA, 2014). At $2797 \mathrm{~m}$ asl, Mt. Ruapehu is the highest peak in North Island and the only to intercept the modern snowline and several small $\left(<1 \mathrm{~km}^{2}\right)$ cirque glaciers currently exist on the upper mountain slopes. The average equilibrium line altitude for the five main cirque glaciers on Mt. Ruapehu is c. 2500 m (Keys, 1988). Brook et al. (2011) show that interannual fluctuations in glacial extent on Mt. Ruapehu are influenced by El Niño Southern Oscillation (ENSO) and the Interdecadal Pacific Oscillation (IPO). This mirrors the pattern of glacier length changes observed in the Southern Alps, where enhanced southwesterly airflow during El Niño years results in lower air temperatures and enhanced precipitation, and thus positive glacier mass balance (Hooker and Fitzharris, 1999). 


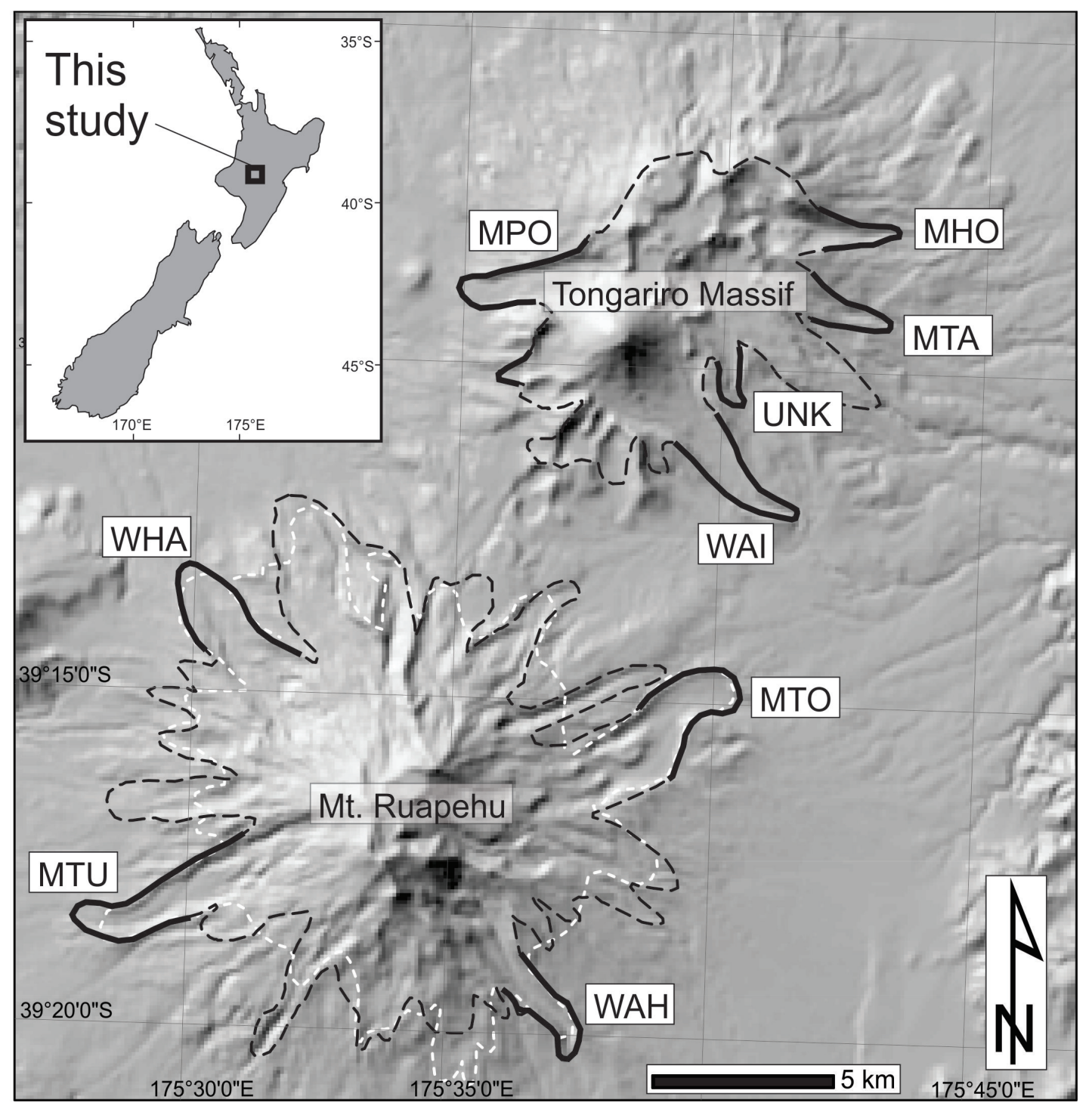

Figure 7.1: Hillshade digital elevation model depicting the study domain of this research. White dashed lines indicate the LGCP ice mass delineated by McArthur and Shepherd (1990), dashed black line indicate the inferred LGCP ice limits of Barrell (2011) and the solid black lines delineate the mapped ice limits constrained by the field investigations and morphostratigraphically correlated to the LGCP in this study. Three-letter catchment labels refer to catchments described in text: 'MPO' = Mangatepopo valley; 'MHO' = Mangahouhounui valley; 'MTA' = Mangatawai valley; 'UNK' = unnamed valley; 'WAI' = Waihohonu valley; 'MTO' = Mangatoetoenui valley; 'WAH' = Wahianoa valley; 'MTU' = Mangaturuturu valley'; 'WHA' = Whakapapanui valley. Inset map shows location of study domain in central North Island, New Zealand. 
Geomorphic evidence for past glaciation on the central North Island volcanoes has long been recognised (Taylor, 1927; Mathews, 1967; Topping, 1974; McArthur and Shepherd, 1990). On Tongariro massif, Mathews (1967) identified large (> $30 \mathrm{~m} \mathrm{high),}$ lateral moraines in several valleys radiating out from a central former ice source and suggested a correlation with late Pleistocene moraines of the Southern Alps, based on moraine size and the degree of preservation. In Chapter 5, I use cosmogenic ${ }^{3} \mathrm{He}$ exposure dating of moraine boulders in Mangatepopo valley on western Tongariro massif to constrain two main periods of glaciation at $>60 \mathrm{ka}$ and c. 31-21 ka, when the local equilibrium line altitude was depressed by c. $1000 \mathrm{~m}$ relative to present. The latter of these periods directly coincides with the Last Glacial Cold Period in New Zealand (Barrell et al., 2013). Identification of well-dated volcanic ash layers stratigraphically overlying moraines around the Tongariro massif indicates widespread glacial retreat and soil accumulation occurred in response to warming between c. 17.5 - 14 ka (Topping and Kohn, 1973; Cronin and Neall, 1997; Chapter 5). On Mt. Ruapehu, situated $15 \mathrm{~km}$ to the south west, McArthur and Shepherd (1990) identify geomorphological evidence for a former ice cap drained by several outlet glaciers that reached c. $1200 \mathrm{~m}$ asl. They suggest the former ice mass existed during the LGCP, based on the presence of the Kawakawa-Oruanui tephra (25.4 $\pm 0.2 \mathrm{ka}$; Vandergoes et al., 2013) in morainebound glacio-lacustrine deposits on the northeast flank of the volcano. In this chapter, I document the glacial geomorphology of the major catchments on Mt. Ruapehu and Tongariro massif, through detailed field and desk-based investigations.

\subsection{Methodology}

\subsubsection{Cosmogenic ${ }^{3} \mathrm{He}$ surface exposure dating}

Moraine boulders in the WAH catchment were sampled using a portable rock saw fitted with a segmented, diamond-tipped blade. All samples were collected from the highest point of the parent boulder, and all boulders were over $1 \mathrm{~m}$ tall, to minimise the potential for past burial by snow and/or volcanic ash. Azimuthal inclinations were measured in the field using a compass and clinometer and geometric shielding corrections were computed using the CRONUS-EARTH calculator (available at: http:/ / hess.ess.washington.edu). All shielding corrections were less than $1 \%$ (Table 7.1). Sample locations and elevations were recorded using a Trimble GeoXH global positioning system, relative to the WGS84 datum. These data were differentially corrected using continuous measurements from GeoNet 'Chateau Observatory' ('VGOB') base station ( $39^{\circ} 11^{\prime} 59^{\prime \prime} \mathrm{S}, 175^{\circ} 32^{\prime} 32^{\prime \prime} \mathrm{E} ; 1161 \mathrm{~m}$ asl), located $10 \mathrm{~km}$ to the north of the sample site. Horizontal and vertical post-processed uncertainties for individual sample 
locations are $<1 \mathrm{~m}$. Pyroxene crystals (pigeonite; $\mathrm{En}_{60-62}$ ) were separated at Victoria University of Wellington according to the protocols outlined in Chapter 3 and prepared for mass spectrometry according to Bromley et al. (2014). Helium measurements were conducted at the LDEO Noble Gas Mass Spectrometry Laboratory using a MAP 215-50 noble gas mass spectrometer. Measurements were made relative to the Yellowstone 'Murdering Mudpot' (MM) helium standard ( ${ }^{3} \mathrm{He} /{ }^{4} \mathrm{He}$ ratio of $16.45 \mathrm{R}_{a}$, where $\mathrm{R}_{a}=$ $\left.{ }^{3} \mathrm{He} /{ }^{4} \mathrm{He}_{\text {air }}=1.384 \times 10^{-6}\right)$, using the protocol of Winckler et al. (2005).

The relatively young crystallisation ages ( $<300 \mathrm{ka}$; Gamble et al., 2003) explains the high ${ }^{3} \mathrm{He} /{ }^{4} \mathrm{He}$ ratios $(R)$ of the samples, which range between 76 - 131 times that of $\mathrm{R}_{a}$. I therefore assume all ${ }^{3} \mathrm{He}$ to be of cosmogenic origin (sensu Bromley et al., 2011). Attenuation of cosmogenic neutron flux with depth from the surface was corrected for using measured sample thickness, a standard rock density of $2.7 \mathrm{~g} \mathrm{~cm}^{-3}$ and an attenuation length of $160 \mathrm{~g} \mathrm{~cm}^{-2}$ (Dunne et al., 1999). Field observations from peak winter (July / August) show that the sampled boulders are not subject to burial by seasonal snow (e.g. Figure 7.9b). Although this is not quantifiable for the geological past, the topographic prominence of the boulders and moraine crests is not conducive to snow accumulation due to wind exposure in the alpine environment, therefore no correction was applied to the age calculation. The absence of resistant mineral veins in the local andesites precluded quantitative assessment of post-depositional erosion of boulder surfaces. Care was taken to avoid boulders that displayed clear evidence of erosion, such as discolouration, weathering scarps, onion-skin weathering, pitting/water pooling, therefore I present exposures ages without an erosion correction. Regional uplift in the central North Island has been estimated at c. $0.6 \mathrm{~mm} \mathrm{yr}^{-1}$ for the past $500 \mathrm{ka}$ (Pulford, 2002). Integrating this elevation change into the age calculations does not alter the results outside the range of the ${ }^{3} \mathrm{He}$ measurement uncertainty, therefore I present the age dataset without corrections for this effect. Exposure ages were computed using the cosmogenic ${ }^{3} \mathrm{He}$ exposure age calculator and globally-compiled, sea-level, high-latitude (SLHL) cosmogenic ${ }^{3} \mathrm{He}$ production rate of Goehring et al. (2010), which I confirm for New Zealand in Chapter 4. All calculations are computed using the CRONUSEarth exposure age calculator MATLAB code, as described by Balco et al. (2008), and modified for cosmogenic ${ }^{3} \mathrm{He}$ by Goehring et al. (2010). Elevation and latitude scaling of cosmogenic ${ }^{3} \mathrm{He}$ production to the sample locations was calculated using the time dependent model of Lal (1991)/Stone (2000) (Lm), which has been shown to outperform the neutron-monitor based scaling schemes (Lifton et al., 2014). 


\subsubsection{Model input data}

Terrain elevation data comes from the New Zealand School of Surveying Digital Elevation Model (NZSoSDEM) (Columbus et al., 2011) and is resampled to $100 \mathrm{~m}$ resolution. An ice mask is created using the 'snow/ice' data from the Land Information New Zealand NZMS260 map series. This mask is assigned ice thickness values based on the survey of Keys (1988) and is used to subtract contemporary ice masses from the DEM. Climate data for the energy balance and snow accumulation models comes from several different sources. Solar radiation and relative humidity are from the Virtual Climate Station Network gridded datasets, sourced from NIWA CliFlo Database (NIWA, 2014). These datasets are resampled to $100 \mathrm{~m}$ resolution using bilinear interpolation. Due to temporal bias and spatial artefacts in the VCSN wind dataset (Anderson and Mackintosh, 2012), present day wind speed data comes from the National Centers for Environmental Prediction (NCEP) 850 hPa level, reanalysis data (1981-2010; Kalnay et al., 1996). This dataset is scaled against observational data and applied uniformly over the model domain. Following Anderson and Mackintosh (2012) and Doughty et al. (2013), I use temperature and precipitation data from individual climate stations distributed around and within the model domain (NIWA, 2014). Monthly temperature grids are created according to Anderson and Mackintosh (2012) and Doughty et al. (2013) using the method described in Chapter 3. A sea-level reference surface $\left(\mathrm{T}_{r}\right)$ is created in a horizontal plane (sensu Tait and Zheng, 2007) by normalising point-based station data $\left(\mathrm{T}_{s t}\right)$ by station elevation $\left(\mathrm{z}_{s t}\right)$, using the empirically-derived, seasonal, upland (> $300 \mathrm{~m}$ asl) temperature lapse rate $\left(\frac{d T}{d z}\right)$ of Norton (1985) (Table 3.2). To obtain temperature $(T)$ at the elevation of each grid cell at each grid cell $(z), T_{r}$ is lapsed back to the elevation determined by the DEM, using the same temperature lapse rate (see Chapter 3).

Daily variability is introduced to the monthly temperature data via random selection of a normally distributed perturbation value with mean zero and a standard deviation of $2.5^{\circ} \mathrm{C}$ (sensu Golledge et al., 2012). Monthly precipitation surfaces are created using individual station data (NIWA, 2014) and a mean annual precipitation surface (Tait et al., 2006), following Anderson and Mackintosh (2012). At each station the monthly proportion of total annual precipitation was interpolated across the model grid and then multiplied by the mean annual precipitation surface. 


\subsubsection{Model description}

\subsubsection{Mass-/energy-balance model}

Precipitation is partitioned into rain and snow, using a temperature threshold $\left(T_{s}\right)$. Snow accumulation occurs in grid cells when temperature falls below this threshold, set to $T_{s}=0.5^{\circ} \mathrm{C}$. To simulate ablation, the energy balance equation (Equation 7.1) is solved within a distributed energy balance model (EBM) as developed (Anderson et al., 2010) and previously applied in contemporary- (Anderson and Mackintosh, 2012) and palaeo-glaciological (Doughty et al., 2013) studies in New Zealand.

$$
Q_{M}=I(1-\alpha)+L \downarrow+L \uparrow+Q_{H}+Q_{E}+Q_{G}+Q_{R}
$$

where $Q_{M}$ is the energy available for melt, $I$ is incoming shortwave radiation, $L \downarrow$ is incoming longwave radiation, $L \uparrow$ is outgoing longwave radiation, $Q_{H}$ and $Q_{E}$ are sensible and latent heat fluxes respectively, $Q_{G}$ is geothermal heat flux and $Q_{R}$ is heat input from rain. Subsurface heat exchanges are negated (see Chapter 3).

Incoming shortwave radiation $(I)$ comprises both direct and diffuse components (Oerlemans, 1992). The effect of changing orbital geometry is accounted for using the insolation calculations of Huybers and Eisenman (2006). Albedo $(\alpha)$ is parameterised according to the ELA-dependent scheme of Oerlemans (1992), whereby $\alpha$ increases with elevation and snow thickness, relative to the equilibrium line altitude $(z E L A=$ $2483 \pm 50 \mathrm{~m}$ asl; Keys, 1988). Following Doughty et al. (2013), I use $\alpha_{\text {snow }}=0.72$ and explore the impact of this parameterisation in sensitivity tests. Longwave fluxes (L $\downarrow$ , $\mathrm{L} \uparrow)$ include the effects of surrounding topography, cloudiness and air temperature (Plummer and Phillips, 2003). Turbulent heat fluxes $\left(Q_{H}, Q_{E}\right)$ are calculated using the bulk method and include the roughness of snow and ice and the Richardson stability criterion (Table 3.3; Oerlemans, 1992; Klok and Oerlemans, 2002; Anderson et al., 2010).

Raised geothermal heat fluxes $\left(Q_{G}\right)$ due to active volcanism, have the potential to contribute significantly to the ablation of snow and ice in the study site, both today and during the LGCP. However, as such fluxes can vary greatly over relatively short temporal and spatial scales, and are unknown for the geological past, it is difficult to accurately parameterise in the model. I use a nominal value of $Q_{G}=1 \mathrm{~W} \mathrm{~m}^{-2}$ applied uniformly over the model domain (see Chapter 3 for further discussion of geothermal heat fluxes). I do not include surface debris cover in the simulations, also because it is unknown for the LGCP. Historically, debris cover on the glaciers situated on Mt. Ruapehu has varied in space and time. During the most recent volcanic eruptions (AD 
1995-96), all glaciers became buried by volcanic products. However, this is quickly incorporated and presently only ice bodies with a low surface slope and those situated close to the current volcanic vent, such as the Summit Plateau and the upper Whangaehu Glacier, remain partially debris-covered. Elsewhere on the mountain, steeper glaciers such as Mangatoetoenui and Mangaehuehu now have greatly reduced surface debris cover, relative to the immediate aftermath of the eruptions. This evidence accords with studies in Iceland, which suggest that fine-grained debris cover emplaced via volcanic eruptions in maritime regions is highly transient (Kirkbride and Dugmore, 2001). I acknowledge the potential for past geothermal heat cover and debris cover as sources of uncertainty in the simulations and provide further consideration of the specific impacts that these phenomena may have on the palaeoclimatic reconstructions in the Discussion section (below).

\subsubsection{Ice flow model}

Ice flow is described using a vertically-integrated, two-dimensional (2D) model based on the shallow ice approximation (SIA) (Plummer and Phillips, 2003; Kessler et al., 2006). This formulation assumes ice flow is driven by vertical shear stresses, therefore compressional and tensional (longitudinal) stresses are neglected (Hutter, 1983). I consider that the role of longitudinal stresses on past glacial flow in the glacial troughs studied here would be low, owing to the low-angle bed slopes and absence of steep, bounding valley sides that characterise typical alpine glacier environments. Furthermore, several comparison studies between SIA and higher order ice flow models show little difference in steady-state ice geometries (e.g. Le Meur et al., 2004; Leysinger Vieli and Gudmundsson, 2004). Thus, the SIA is commonly applied in mountain glacier environments for palaeoclimatic reconstructions, where mass balance imparts greatest uncertainty (e.g. Plummer and Phillips, 2003; Kessler et al., 2006; Doughty et al., 2013).

Ice flow velocity due to internal deformation $\left(U_{d}\right)$ is given as:

$$
\vec{U}_{d}=\frac{2}{5} A H \vec{\tau}_{b}^{n}
$$

where $\vec{U}_{d}$ is vertically-averaged ice velocity from internal deformation, $A$ is Glen's flow law coefficient, set to $A=2.14 \times 10^{-16} \mathrm{~Pa}^{-3} \mathrm{yr}^{-1}, \vec{\tau}_{b}$ is the gravitational driving stress $\left(\vec{\tau}_{b}=\rho g H \nabla z\right)$, and $n$ is Glen's flow law exponent, set to $n=3$ (Cuffey and Paterson, 2010).

Following Plummer and Phillips (2003) and Kessler et al. (2006), a sliding term is 
also included:

$$
U_{s}=U_{c} e^{1-\frac{\tau_{c}}{\bar{\tau}_{b}}}
$$

where $U_{c}$ is the characteristic sliding velocity, set to $U_{c}=50 \mathrm{~m} \mathrm{yr}^{-1}$, and $\tau_{c}$ is the gravitational driving stress, set to $\tau_{c}=100 \mathrm{kPa}$.

$$
\frac{d H}{d t}=M-\nabla \cdot \vec{q}
$$

where $H$ is ice thickness, $t$ is time, $\vec{q}$ is ice flux $\left(\vec{U}_{d}+\vec{U}_{s}\right)$ and $\mathrm{M}$ is mass balance.

Equation 7.4 evolves glacier geometry through time. Ice velocities are calculated on a grid offset from ice thickness and the flux gradients are used to update ice thickness using a forward explicit time-step (Hindmarsh and Le Meur, 2001). To account for boundary effects that may violate mass conservation in the finite difference formulation (e.g. Plummer and Phillips, 2003), the bed topography is smoothed using a $300 \times 300 \mathrm{~m}$ moving window to reduce high bed slopes in minor portions of the upper catchment, and an ice flux correction is applied. For each cell, total ice divergence cannot exceed the total mass contained in the source cell. At each timestep it was ensured that this criterion was met and if not the excess ice was removed (Plummer and Phillips, 2003).

\subsubsection{Sensitivity tests}

To test the sensitivity of the palaeotemperature estimates to model parameter choices, I quantify the deviation of $\Delta T$ from the optimal set up, in response to systematic variations applied to several key parameters. Model-based assessments of contemporary glacier mass balance in New Zealand have shown that turbulent fluxes contribute a significant proportion of the total energy available for melt (Anderson et al., 2010). In the optimal parameterisation, ice roughness length $\left(z_{i c e}\right)$ is derived from tuning experiments over a domain in the central Southern Alps (Anderson and Mackintosh, 2012), thus I include this parameter in the sensitivity tests. Furthermore, glacier mass balance in this maritime setting is highly sensitive to temperature, due to its control on precipitation phase and strong relationship with several components of the surface energy balance (e.g. longwave and turbulent fluxes). Thus, I test the impact of temperature-related parameters such as the lapse rate $\left(\frac{d T}{d z}\right)$ and snow / rain threshold $\left(T_{s}\right.$ $\left.=0-1.5^{\circ} \mathrm{C}\right)$. I also constrain palaeotemperature sensitivity to albedo $\left(\alpha_{\text {snow }}=0.67-0.77\right)$, which limits shortwave radiation. In the flow model, I assess the sensitivity of the characteristic sliding velocity $\left(U_{c}=20-80 \mathrm{~m} \mathrm{yr}^{-1}\right)$ and Glen's flow law coefficient $(A=$ 
$1 \times 10^{-15}-1 \times 10^{-18} \mathrm{~Pa}^{-3} \mathrm{yr}^{-1}$ ), which principally control ice thickness and can affect the fit to the geologically inferred former ice limits.

\subsubsection{Approach}

The aim of this work is provide a quantitative estimate of temperature change, relative to present day, for the LGCP in central North Island. To do this, I use the glacier model described above to constrain the climatic forcing required to simulate the geologicallyconstrained (Section 7.2.1) former glacial geometries in the catchments on Mt. Ruapehu (WHA, WAH, MTO and MTU) and Tongariro massif (MPO, MHO, MTA and WAI). This approach overcomes some of the uncertainties in manual ELA reconstruction (e.g. Chapter 5), as ice thickness and distribution is simulated based on the physical principles and interrelation of glacier mass balance and ice flow and does not require assumptions of past accumulation area ratios. Thus, this approach removes the uncertainty associated with manual interpolation of ice surfaces in area with few geomorphic constraints. Applying this objective methodology across several catchments permits critical assessment of the possible drivers (e.g. topographic, climatic) of variability in the palaeoclimatic reconstructions. Furthermore, uncertainty related to parameter choice can be quantified in sensitivity tests.

Chronological constraint comes from the cosmogenic surface exposure dating of moraines in the MPO (Chapter 5) and WAH catchments, which have been extrapolated to the current study domain using a morphostratigraphic approach. For example, in the MPO catchment the moraines of LGCP age stand higher above the valley floor and exhibit steeper slopes and more pronounced ridge crests, in comparison to older (c. $60 \mathrm{ka}$ ) moraines. Furthermore, in Chapter 5, I present chronological evidence for post-LGCP moraine formation on Mt. Ruapehu, of restricted extent in comparison to the LGCP limits. Recognition of this late-glacial glacier still-stand has also guided the relative correlation of glacial landforms. The good agreement between multiple, independent mapping of LGCP ice limits in this study domain (e.g. McArthur and Shepherd, 1990; Barrell, 2011, this study) also suggests that the interpretations made here are robust. However, it is possible the mapped former glacier limits are not contemporaneous. For example, multiple continuous climate proxy reconstructions show the prevailing stadial conditions were interrupted by prominent interstadials at $25.4-24.5 \mathrm{ka}$ and 22.6 - $21.7 \mathrm{ka}$ (Barrell et al., 2013). It is probable that the glaciers on the central North Island volcanoes would have fluctuated in response to these stadial-interstadial transitions therefore the targeted moraines could pertain to separate stadial events during the LGCP. For example, several catchments (e.g. WHA, WAH, MTU, MPO) exhibit 
multiple moraines that depict glacier fluctuations of very similar extent, which I have correlated to the LGCP. In these instances, I simulate the glacier geometry depicted by the outermost LGCP moraine, thereby targeting the peak magnitude of cooling during the LGCP (sensu Golledge et al., 2012). In the following section, I outline the 3 glacier modelling experiments undertaken in this study.

\subsubsection{Experiment 1}

First, I carry out an assessment of the patterns of ice growth that result from incremental reductions in temperature over a $30 \times 30 \mathrm{~km}$ domain (100 m resolution) that includes both Mt. Ruapehu and Tongariro massif. Step-coolings from present $(\Delta T)$ of -2 to $-7^{\circ} \mathrm{C}$, at intervals of $1{ }^{\circ} \mathrm{C}$, are applied uniformly across the domain and the resultant ice masses are allowed to evolve to steady-state. Equilibrium is achieved when ice volume change $(\mathrm{d} V / \mathrm{d} t)$ becomes zero, which takes 200-350 model years depending on the magnitude of $\Delta T$. These experiments permit an initial assessment of the patterns of ice growth across both volcanoes and the results will guide the catchment specific simulations carried out in Experiments 2 and 3 (described below).

\subsubsection{Experiment 2}

Second, I run steady-state simulations to constrain the combinations of $\Delta T$ and $\Delta P$, that produce ice extents that best fit the geological evidence in each individual catchment. Temperature forcing results are presented for three precipitation scenarios, whereby modern precipitation is varied by $+25 \%,-25 \%$ and $0 \%$ and I discuss the implications for these scenarios below. For efficiency, these simulations are run over a smaller domain than for Experiment 1, with a resolution of $100 \mathrm{~m}$. The domains cover the entirety of each individual volcano, in order to capture the potential effects of changing ice-divides that may result from a growing ice mass. Resultant steady-state ice extents were manually compared to the geomorphic constraints (e.g. Figure 7.4 and Figure 7.5). A satisfactory result was considered to have been obtained when the modelled glacier terminus reached within 1 grid cell $(100 \mathrm{~m})$ of the downstream limit of the LGCP ice mass, as inferred from geomorphology mapping (above). In some simulations ice spills over the lateral moraines before the glacier terminus reaches the inferred former limit. I discuss the implications and possible reasons for this, below (Section 7.6.2).

\subsubsection{Experiment 3}

Third, I repeat Experiment 2, but use modified topographic boundary conditions, in order to assess the sensitivity of $\Delta T$ to post-glacial topographic change. These simulations are run over altered digital elevation models considered representative of LGCP 
topography on both volcanoes (Figure 7.2). These surfaces have been reconstructed using the results of a 5-year project to constrain the spatial and temporal geomorphic evolution of this region. For example, compilation of existing mapping (e.g. Gamble et al., 2003; Townsend et al., 2008; Price et al., 2012), together with extensive primary field mapping has been used to produce 1:60000 scale maps of the volcanic geology, which delineate individual lava flows. Furthermore, a suite of new, high-precision Ar-Ar ages (Conway et al. in prep), together with existing chronological data (e.g. Gamble et al., 2003) and geochemical correlation using extensive documentation of major elements, has broadly constrained the timing of lava emplacement across the domain. To generate palaeo-topographies for these simulations, modern DEMs are manually altered to subtract the convex relief created by post-glacial ( $<15 \mathrm{ka})$, effusive volcanic activity (Figure 7.2). Manual alteration of contour lines was undertaken by experts working at GNS Science who have led the mapping project in this region (D.Townsend, pers. comm.). 

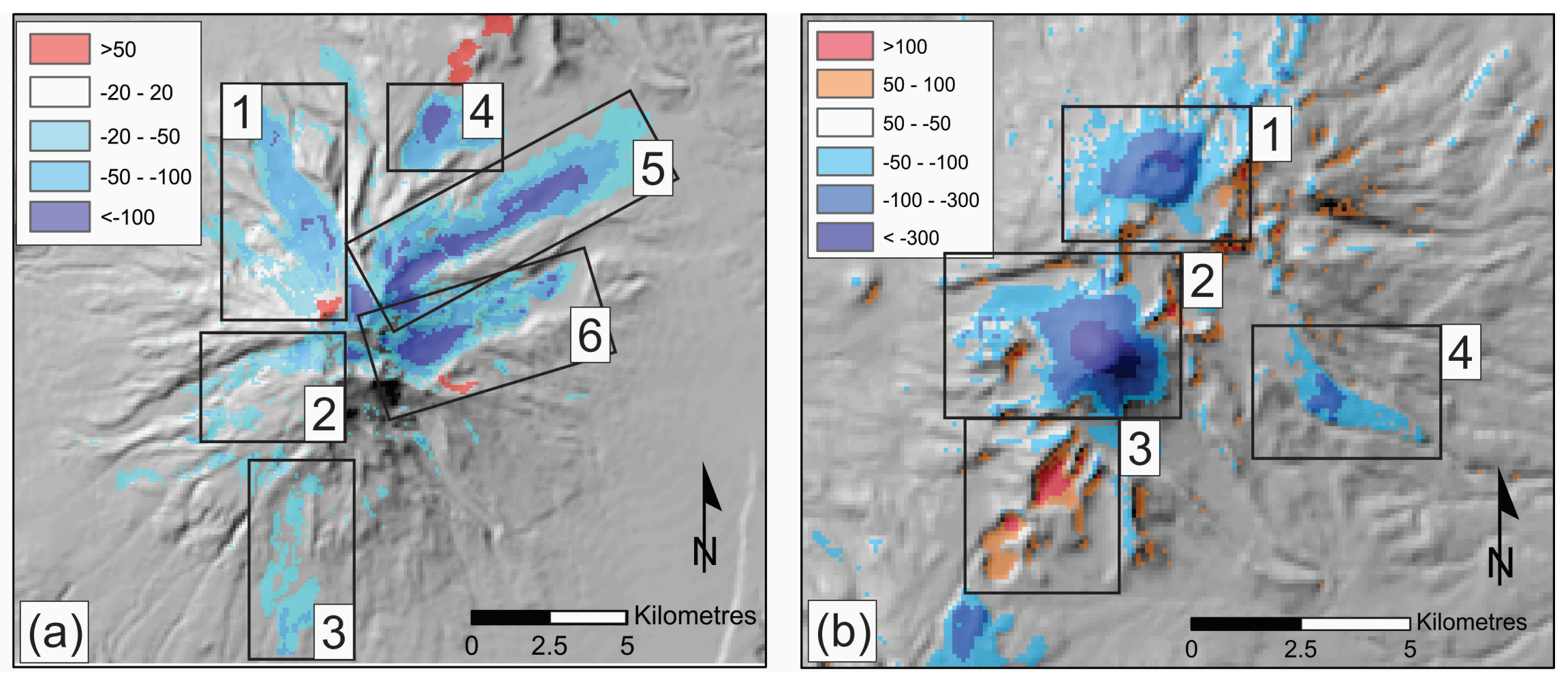

Figure 7.2: Geologically informed reconstruction of pre-15 ka topography, displayed as a difference (in metres) from modern topographic boundary conditions, for glacier model domains of (a) Mt. Ruapehu (1 = Whakapapa flows (Hackett and Houghton, 1989); $2=$ Holocene flows in upper Mangaturuturu; 3=Rangatauanui flow; 4 = Saddle Cone flow(s); 5-6 = LGCP-Holocene age flows in and adjacent to Mangatoetoenui), and (b) Tongariro massif ( 1 = North Crater; 2 = Mt. Ngauruhoe; 3 = Tama Lakes explosion craters; $4=$ Oturere flows). Blues = surface lowering (negative change); reds = elevation gain (positive change). 

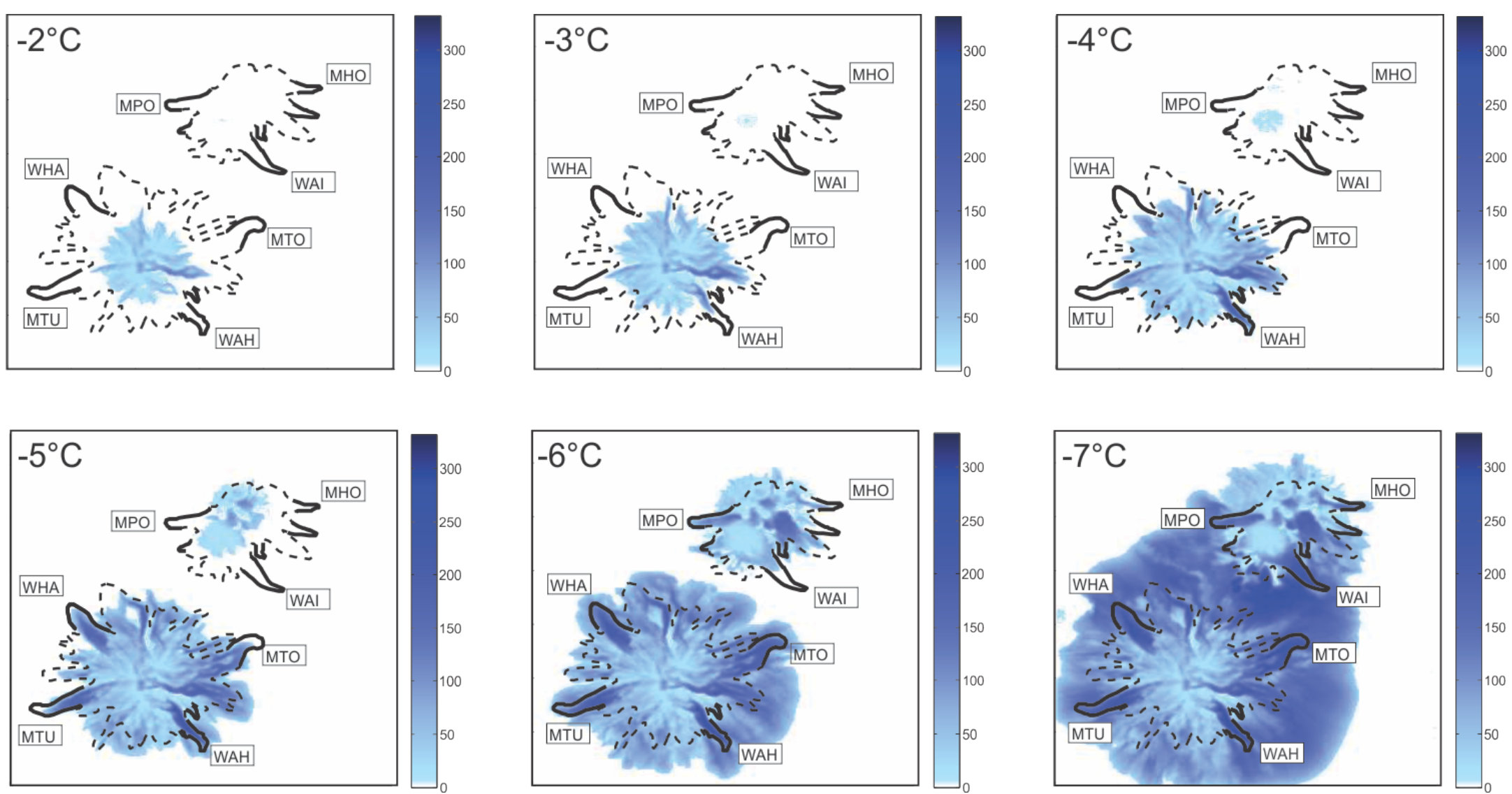

Figure 7.3: Eperiment 1: Modelled, steady-state ice thickness (in metres) and extent on Mt. Ruapehu and Tongariro massif resulting from step coolings of $-2^{\circ} \mathrm{C}$ to $-7^{\circ} \mathrm{C}$ from present, with precipitation unchanged. Solid and dashed lines represent geologically constrained LGCP ice limits of greater and lesser confidence, respectively (modified from Barrell, 2011). See text for catchment labels. 

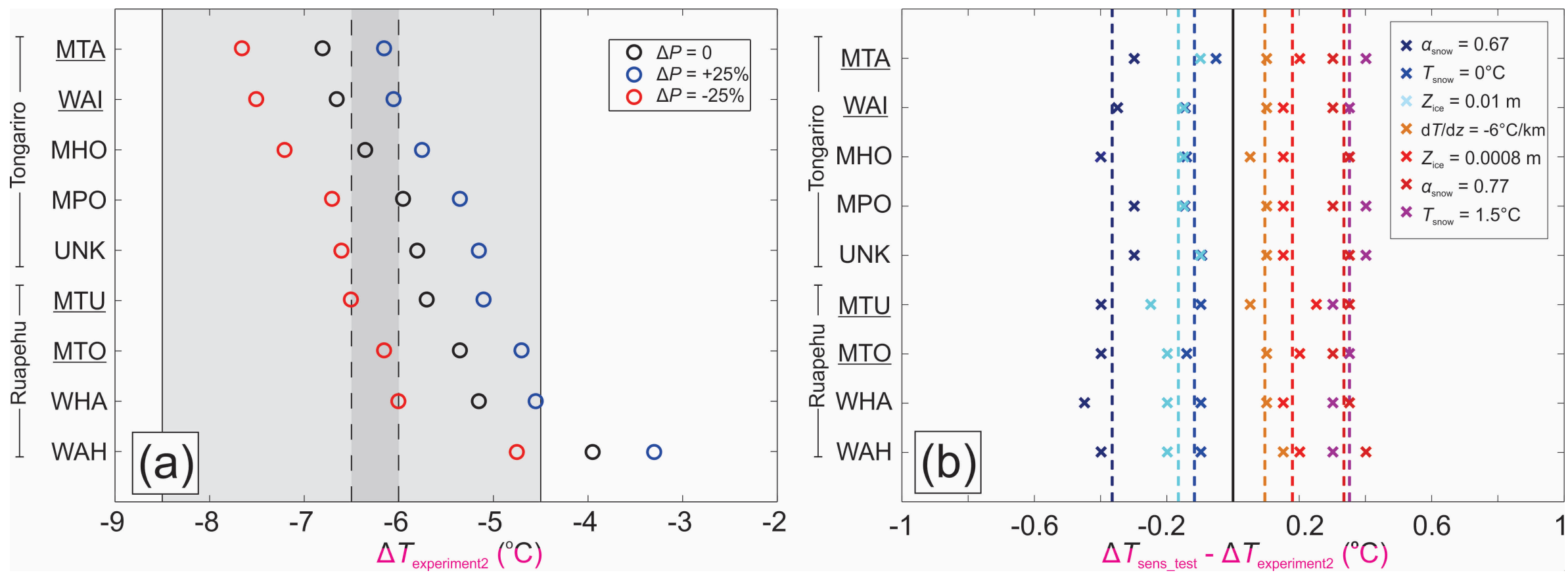

Figure 7.4: Experiment 2: (a) Temperature forcing, from present, necessary to simulate inferred LGCP ice geometries in catchments on Mt. Ruapehu and Tongariro massif. Results shown for three precipitation change $(\Delta P)$ scenarios: $0 \%$ (black); $+25 \%$ (blue); and $-25 \%$ (red) change from present. Underlined labels on the $y$-axis represent catchment where modelled ice thickness spills over ice-marginal landforms, before reaching the geologically inferred terminus (see text). Vertical black lines and light grey shading depict the pollen-based southern North Island LGCP temperature lowering estimate of Newnham et al. (2013) $\left(-6.5 \pm 2.0^{\circ} \mathrm{C}\right)$ - derived using the partial least squares method. Dashed black lines and dark grey shading depict the glacier model derived Southern Alps LGCP cooling estimate of Golledge et al. (2012) $\left(-6.0\right.$ to $-6.5{ }^{\circ} \mathrm{C}$, when precipitation is reduced by $25 \%$ ). (b) The sensitivity of palaeotemperature reconstructions for the following parameters: albedo of snow $\left(\alpha_{\text {snow }}\right)$, snow temperature threshold $\left(T_{\text {snow }}\right)$, air temperature lapse rate $(d \mathrm{~T} / d \mathrm{z})$ and ice surface roughness $\left(Z_{i c e}\right)$. Dashed lines indicate the mean impact of each sensitivity test. Flow parameters $U_{c}$ and $A$ (not shown) have negligible $\left(<0.1^{\circ} \mathrm{C}\right)$ impact on $\Delta \mathrm{T}$. 


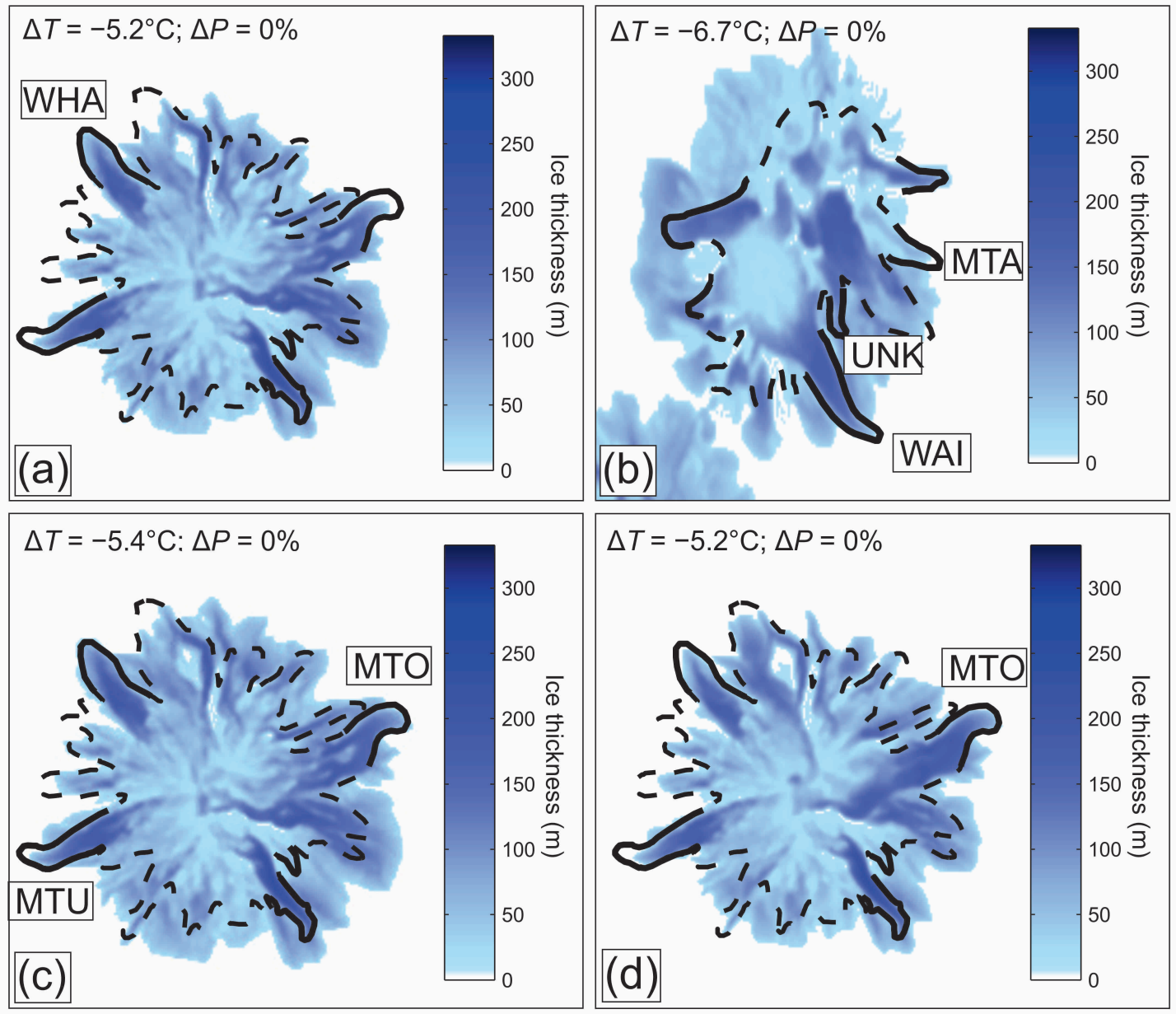

Figure 7.5: (a) Modelled, steady-state ice geometry on Mt. Ruapehu when $\Delta \mathrm{T}=-5.2{ }^{\circ} \mathrm{C}$ and $\Delta \mathrm{P}=0$ (Experiment 2). This represents the best-fit simulation for the WHA catchment; $(b)$ Steady state ice geometry on Tongariro massif when $\Delta \mathrm{T}=-6.7^{\circ} \mathrm{C}$ and $\Delta \mathrm{P}=0$ (Experiment 2). This is the best fit to the inferred LGCP terminus in the WAI catchment, however note the ice overspill at the lateral margins; (c) Steady state ice geometry on Mt. Ruapehu when $\Delta \mathrm{T}=-5.4$ ${ }^{\circ} \mathrm{C}$ and $\Delta \mathrm{P}=0$ (Experiment 2). Note the ice overspill in the MTO catchment, despite agreement between the inferred and modelled glacier terminus positions. (d) Steady state ice geometry on Mt. Ruapehu when $\Delta \mathrm{T}=-5.2^{\circ} \mathrm{C}$ and $\Delta \mathrm{P}=0$ (Experiment 3). Note the improved fit between the inferred and modelled glacier margins on the northern side of the MTO catchment, relative to panel (c). 

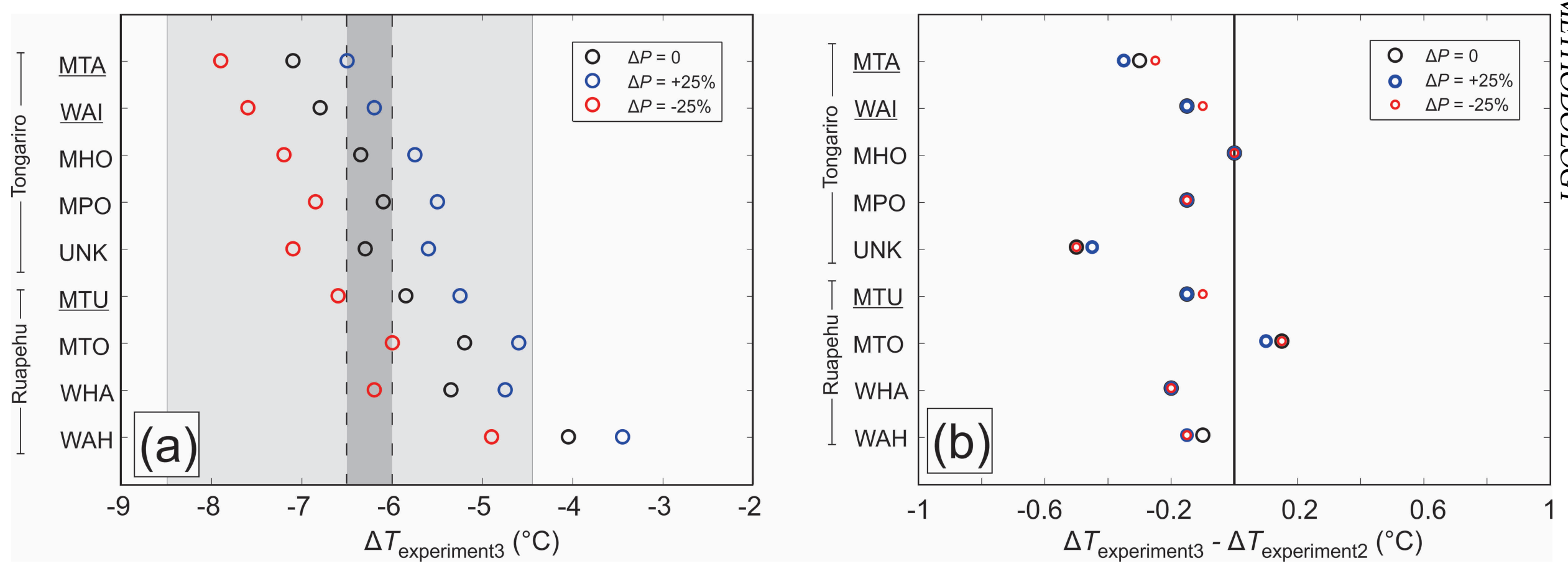

Figure 7.6: Experiment 3: (a) Temperature forcing, from present $\left(\Delta \mathrm{T}_{\text {experiment } 3}\right)$, necessary to simulate inferred LGM ice geometries in catchments on Mt. Ruapehu and Tongariro massif, using the modified, pre-15 ka topography. Results shown for three precipitation change ( $\Delta \mathrm{P})$ scenarios: $0 \%$ (black); $+25 \%$ (blue); and $-25 \%$ (red) change from present. Underlined labels on the $y$-axis represent catchment where modelled ice thickness spills over ice-marginal landforms, before reaching the geologically inferred terminus (see text). Vertical black lines and light grey shading depict pollen-based southern North Island LGCP temperature estimate of Newnham et al. (2013) $\left(6.5 \pm 2.0^{\circ} \mathrm{C}\right)$ - derived using the partial least squares method. Dashed black lines and dark grey shading depict the glacier model derived Southern Alps LGCP temperature estimate of Golledge et al. (2012) $\left(6.0-6.5^{\circ} \mathrm{C}\right.$, when precipitation is reduced by $\left.25 \%\right)$. (b) The difference in $\Delta \mathrm{T}$ between model simulations in Experiment $3\left(\Delta \mathrm{T}_{\text {experiment } 3}\right)$ and Experiment $2\left(\Delta \mathrm{T}_{\text {experiment } 2}\right)$. 


\subsection{Geomorphological characterisation}

\subsubsection{Whakapapaiti valley ('WHA')}

Whakapapaiti valley drains towards the northwest from Paretetaitonga peak $(2751 \mathrm{~m}$ asl) on Mt. Ruapehu (Figure 7.7). The lower valley is $2-3 \mathrm{~km}$ wide and is bound by large (c. $50 \mathrm{~m}$ high) lateral moraines on both flanks. On the northeastern valley side, a lateral moraine extends for $1.5 \mathrm{~km}$ from a prominent lava outcrop at c. $1550 \mathrm{~m}$ asl. Further down valley, at c. $1400 \mathrm{~m}$ asl, this moraine displays two clear crests, which indicates that this large feature possibly represents a compound landform formed during multiple periods of glacial occupation. Both crests are relatively sharp, which suggests they are of similar age and most likely formed during the last period of major glaciation on Mt. Ruapehu. This interpretation is further supported by the coverbed stratigraphy of the inboard lateral moraine on the true right of the valley (Figure 7.7c). At this location, the Waiohau Tephra (14.0 $\pm 0.2 \mathrm{ka}$; Lowe et al., 2013) is prominent c. $80 \mathrm{~cm}$ above the moraine surface. The soil profile shows strong similarity to that in the Mangaetepopo valley (Chapter 5), with interbedded, coarse andesitic tephras (4.5 - $3.0 \mathrm{~m}$ depth) overlain by a c. $1 \mathrm{~m}$ palaeosol and the Taupo pumice (Unit Y; AD $232 \pm 10$ a; Lowe et al., 2013) near the top of the sequence. Based on their similar morphology and coverbed stratigraphy, I suggest these moraines correlate to the M1 and M2 moraines in the Mangatepopo valley (Chapter 5), which formed between 31-21 $\mathrm{ka}$. On the southwestern side of Whakapapaiti valley, a prominent, but discontinuous lateral moraine marks the outermost limit of glaciation in this catchment. Based on the geometric and topographic similarity with the continuous moraine on the northeastern valley side, I suggest this landform delineates the outermost limit of glaciation during the LGCP. Low-relief, moraine crests on the southeastern valley side, mark minor stillstands during deglaciation (Figure 7.7). 

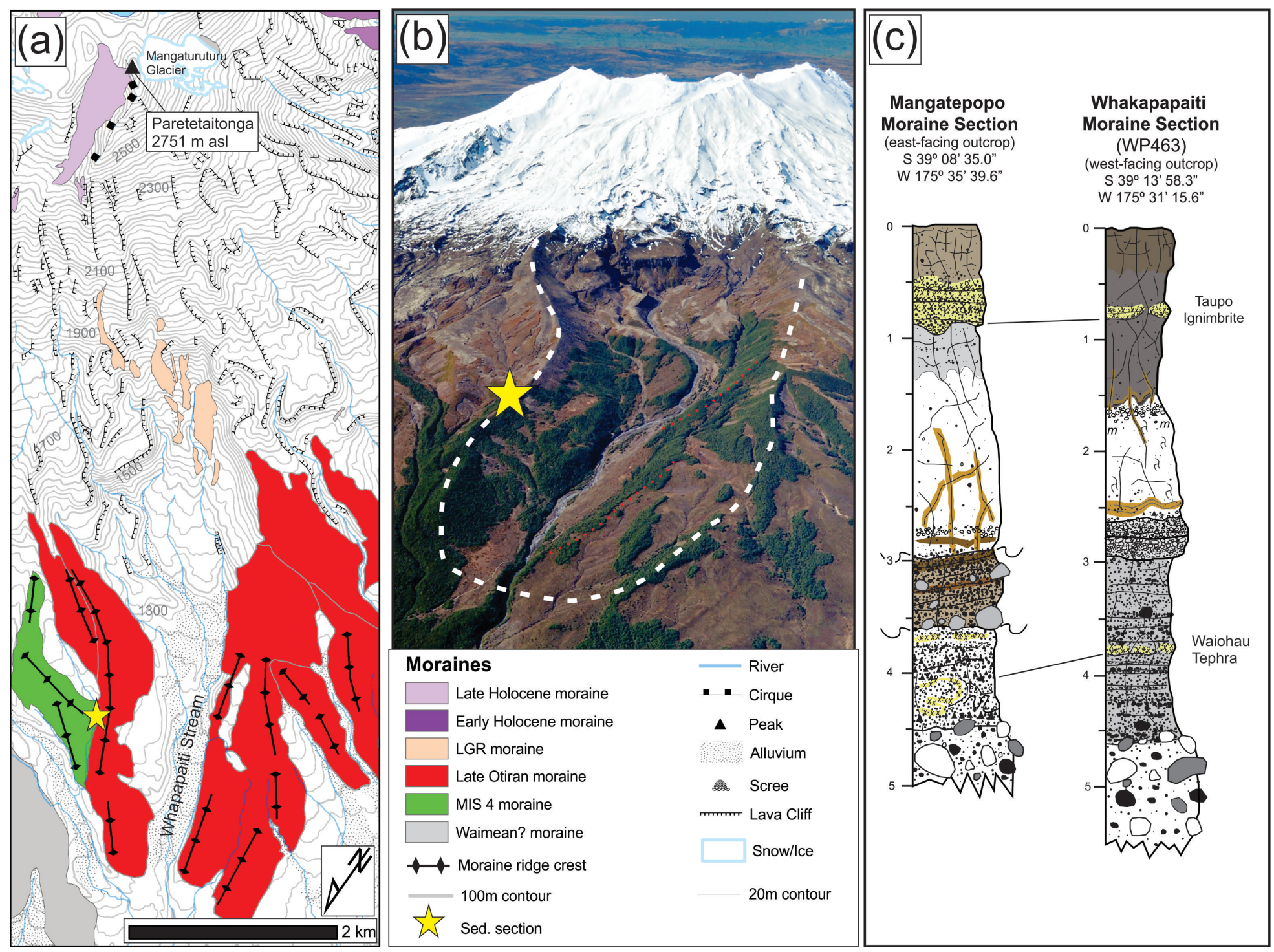

Figure 7.7: (a) A glacial geological map of the Whakapapaiti valley; (b) Oblique aerial photo of the Whakapapaiti valley (source: D. Townsend). White dashed line indicates the morphostratigraphically defined LGCP ice limit in the Whakapapaiti valley. Red dashed lines indicate small lateral moraine that mark short-lived glacier stillstands during deglaciation; (c) Stratigraphic logs of soil profiles from moraines in Mangatepopo and Whakapapiti (yellow star) valleys, correlated using rhyolitic tephras. 


\subsubsection{Mangaturuturu valley ('MTU')}

The head of this southwestward-draining catchment is occupied by the small $(<0.5$ $\mathrm{km}^{2}$ ) Mangaturuturu cirque glacier, which lies between Paretetaitonga and Tahurangi peaks on the western side of the summit of Mt. Ruapehu (Figure 7.8). At its head, the Mangaturuturu valley is c. $2 \mathrm{~km}$ wide and narrows as it descends in a southwest direction for c. $8 \mathrm{~km}$ to the inferred LGCP glacial limits. Due to the dense forest cover in the lower portion of this valley, the LGCP limits have been delineated predominantly using aerial imagery and digital elevation models. Glacial till cover is characterised by hummocky topography, often arranged in discontinuous linear ridges, orientated parallel, to sub-parallel with the valley axis. Relatively sharp-crested, but discontinuous lateral moraines are easily depicted in the remotely sensed datasets and provide good constraint on the former ice surface and lateral extent of the LGCP Mangaturuturu outlet glacier (Figure 7.8). Post-glacial fluvial erosion has removed any evidence of the former terminus location, however, projecting the lateral moraines downstream suggests that the most extensive former glaciation in this catchment did not descend below c. $1050 \mathrm{~m}$ asl. Downstream of c. $1100 \mathrm{~m}$ asl, the land surface texture becomes more smooth and grades linearly downslope to the west. This topography is characteristic of fluvial topography and likely comprises interbedded alluvium, volcaniclastic and glacial outwash.

The upper catchment is dominated by exposed bedrock outcrops, which commonly display glacially-polished surfaces, particularly above c. $1700 \mathrm{~m}$ asl. Post-glacial fluvial incision has created a deep (c. $50 \mathrm{~m}$ ) bedrock gorge on the northern valley side. Between 1300-1500 m asl, glacial till overlies thick (c. $10 \mathrm{~m}$ ) lava flows that outcrop to the north. These deposits, which are situated approximately mid-way between the inferred LGCP limits and and the present ice margin, likely represent a post-LGCP ice extent and have been correlated to the late glacial deposits of the nearby Mangaehuehu catchment (Chapter 6). However, the lack of discernable ridge crests within these deposits precludes precise delineation of the former ice mass at this location.

\subsubsection{Wahianoa valley ('WAH')}

Wahianoa valley is a deeply incised, c. $7 \mathrm{~km}$ long, glacial valley that drains towards the southeast from the highest peak of Mt. Ruapehu (Tahurangi peak, $2797 \mathrm{~m}$ asl). Today, small patches of glacial ice, which are relatively free of supraglacial debris, persist on the uppermost slopes at the valley head. Multiple, boulder-rich lateral moraine crests line both flanks of the lower $3 \mathrm{~km}$ of the valley to c. $1200 \mathrm{~m}$ asl, recording glacier fluctuations during the most extensive period of glaciation preserved in this catchment. 


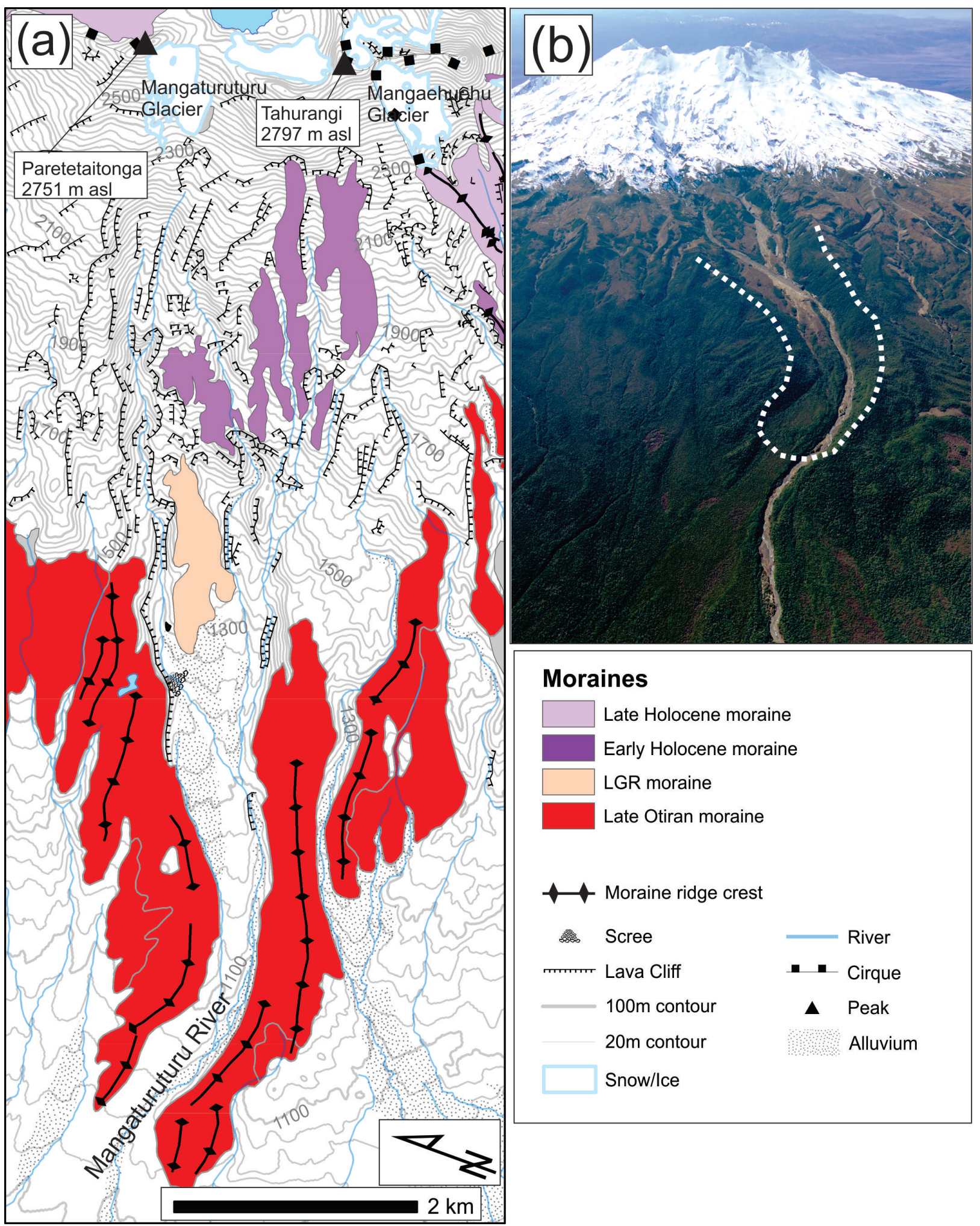

Figure 7.8: (a) A glacial geological map of the Mangaturuturu valley; (b) Oblique aerial photo of the Mangaturuturu Valley (source: D. Townsend). White dashed line indicates the morphostratigraphically defined LGCP ice limit in the Mangaturuturu valley. 
On the true-left valley side, the morphostratigraphic relationship of these individual ridges indicates at least two moraine-building events of similar extent. Figure 7.9 shows the outermost moraine on the true-left is bisected by a deep gully that has incised c. $20 \mathrm{~m}$ into the lateral moraine, which I interpret to represent glaciofluvial erosion from supraglacial meltwater runoff whilst the Wahianoa Glacier remained close to its maximum extent. Subsequent to this gully forming, a separate lateral moraine ridge was deposited, across the head of the outbreak gully. This inboard moraine was deposited by a slightly smaller glacier, which appears to have terminated c. $1 \mathrm{~km}$ up-valley from the valley mouth. This interpretation is based on the longitudinal angle of the moraine crest, which appears to dip more steeply than the outer moraines formed by a more extensive glacier. All of these moraines display sharp crests and steep lateral slopes, thus I interpret them to be of similar age, which record relatively minor glacier fluctuations during the LGCP.

On the lower true-right (south-western) valley side, a single, continuous lateral moraine extends from the valley mouth to approximately $3 \mathrm{~km}$ up-valley. The crest of this moraine stands $100-150 \mathrm{~m}$ above the valley floor and is punctuated by several southwarddraining gullies that have incised since moraine emplacement. In contrast to the true left flank of Wahianoa valley (described above), on the true right there is little discernable structure or stratigraphy to suggest multiple moraine building events. Given the clear evidence for fluctuating ice margins on the true left, the true right is interpreted to represent a compound morainic feature formed by multiple periods of occupation during, and possibly before, the LGCP. Ice-scoured bedrock exposures with parallel striae are preserved on the upper true right hand side of the valley (Figure 7.9; Figure 7.10), which indicates the former presence of a temperature glacier.

\subsubsection{Mangatoetoenui valley ('MTO')}

The Mangatoetoenui valley descends towards the northeast from between Te Heuheu (2732 $\mathrm{m}$ asl) and Tukino (2720 m asl) peaks on Mt. Ruapehu (Figure 7.11). At the head of this catchment, the Mangatoetoenui Glacier persists in a south-facing hollow and terminates at c. $2350 \mathrm{~m}$ asl. A series of sharp-crested, nested lateral moraines extend from the current elevation of the glacier terminus to c. $1900 \mathrm{~m}$ asl, which likely represent late Holocene - historical glacier positions.

Further down valley, several prominent lava flows are present on the valley floor between 1300 - $1900 \mathrm{~m}$ asl, in this catchment. It is likely that these were emplaced 


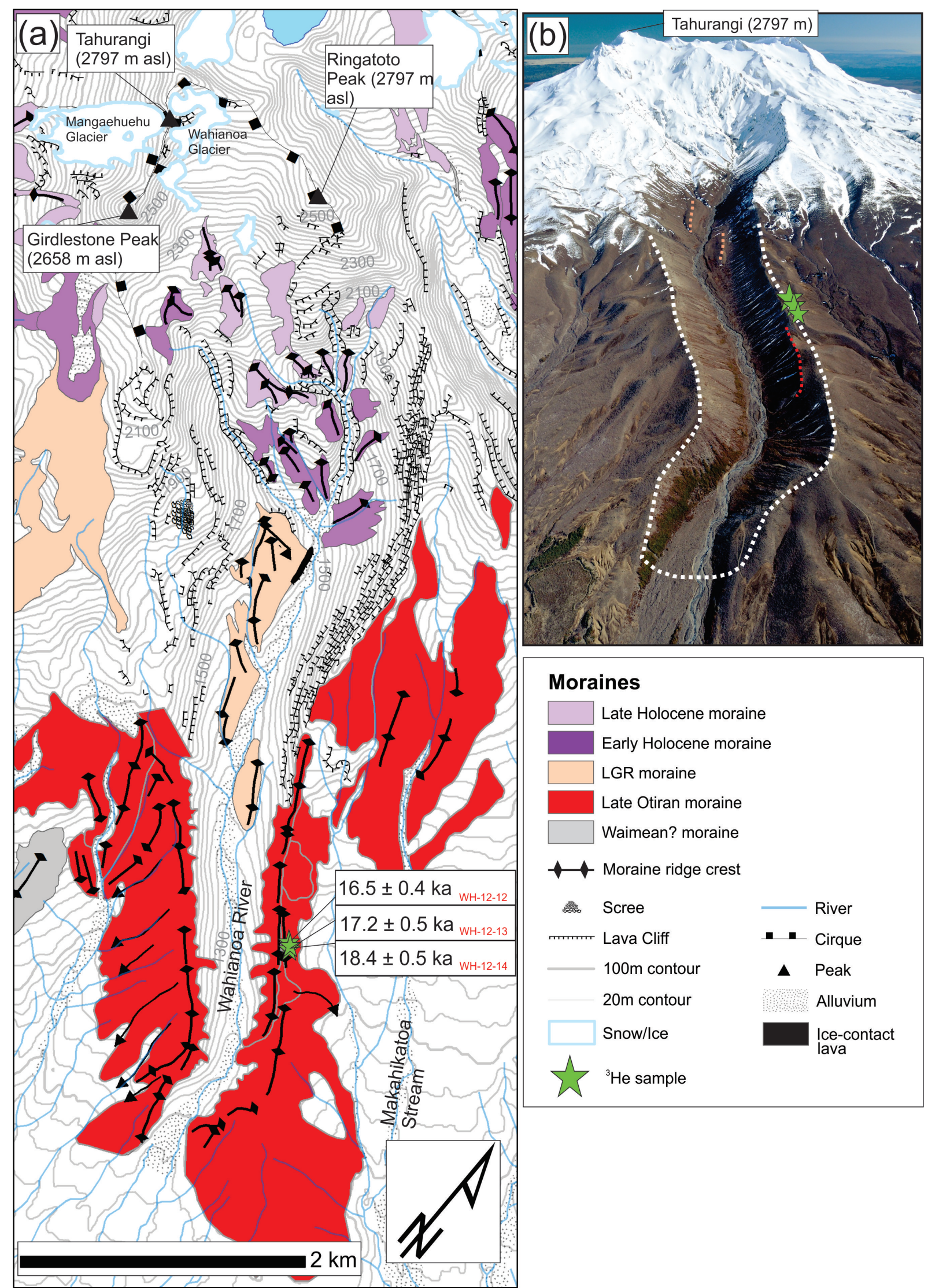

Figure 7.9: (a) A glacial geological map and cosmogenic ${ }^{3} \mathrm{He}$ surface exposure ages of the Wahianoa valley; (b) Oblique aerial photo of the Wahianoa Valley taken in August 2010 (Source: D. Townsend). White dashed line indicates the morphostratigraphically defined LGCP ice limit in the Wahianoa valley; red dashed line marks inboard LGCP moraine described in text; orange dashed lines mark the inferred late-glacial moraines (Chapter 6). 


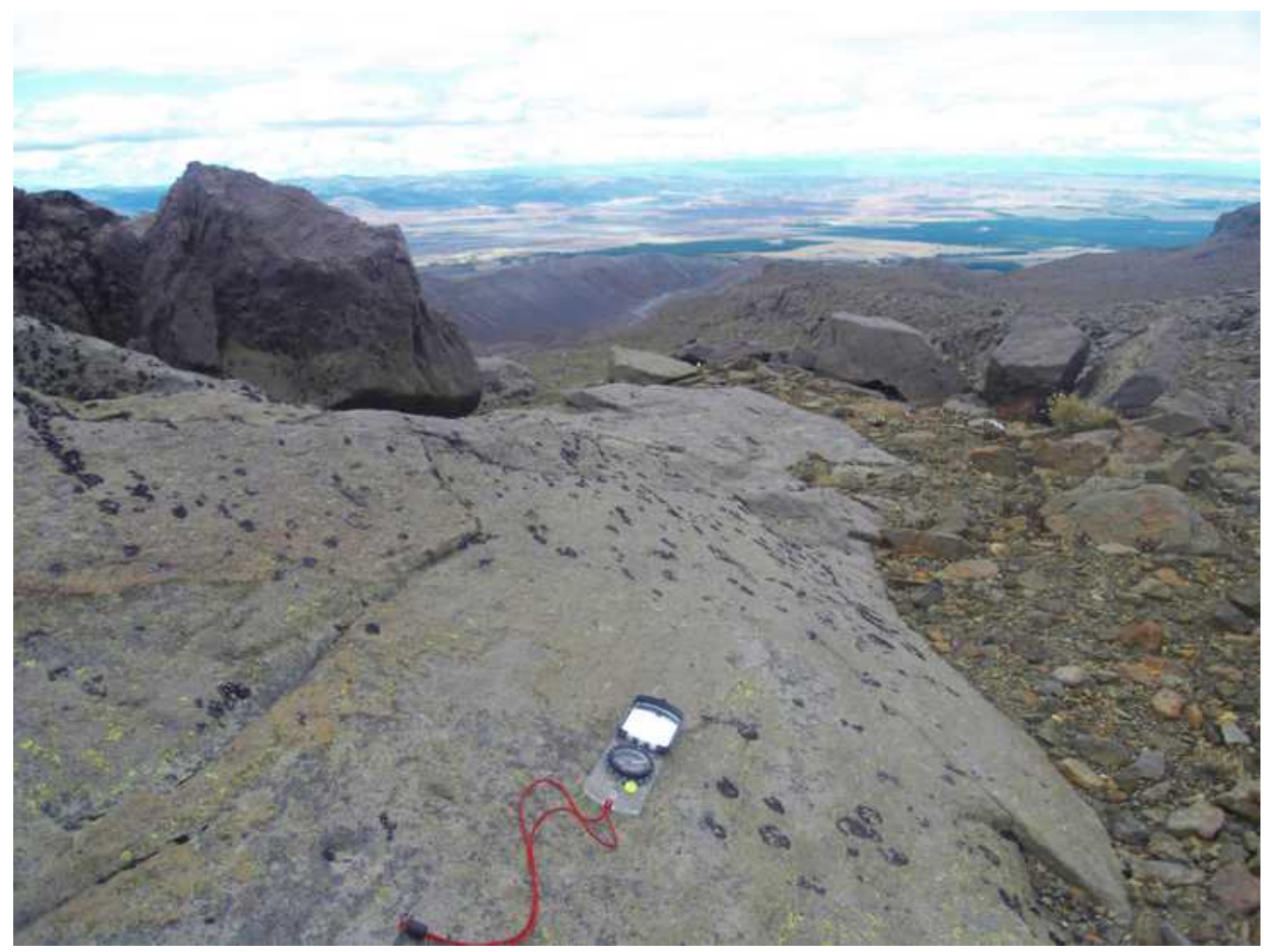

Figure 7.10: One of several exposures of ice-scoured, striated bedrock on the upper true-right hand side of Wahianoa valley. Compass is orientated parallel to striae, which point down-valley (Wahianoa valley in photo background, with prominent left lateral moraines) 

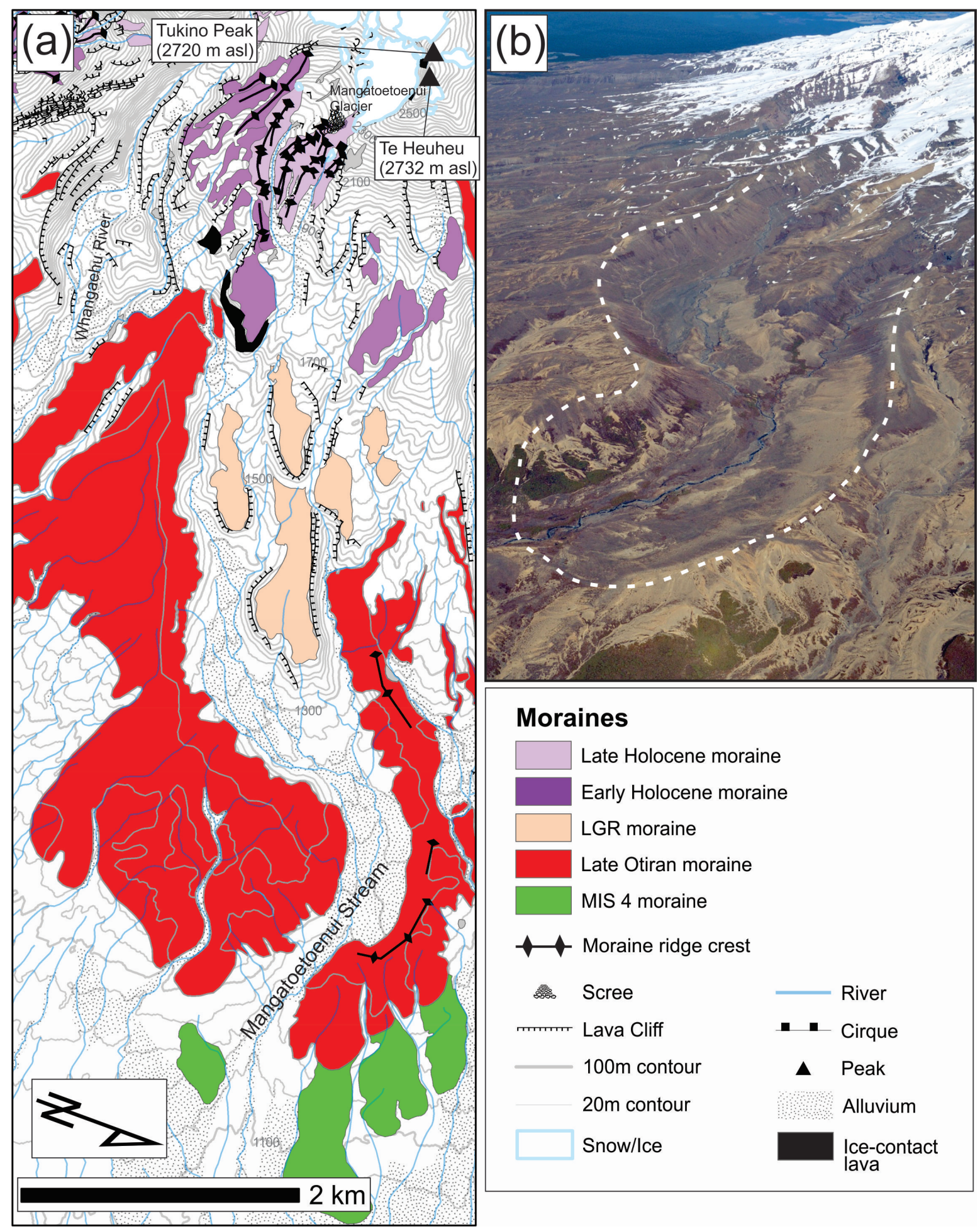

\section{Moraines}

Late Holocene moraine

Early Holocene moraine

LGR moraine

Late Otiran moraine

MIS 4 moraine

$\checkmark$ Moraine ridge crest

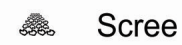

River

тागाला Lava Cliff

River

$100 \mathrm{~m}$ contour

- Cirque

$20 \mathrm{~m}$ contour

- Peak

Snow/lce

Alluvium lce-contact
lava

Figure 7.11: (a) The glacial geology of Mangatoetoenui valley (MTO) on northeastern side of Mt. Ruapehu; (b) An oblique aerial photograph of lower Mangatoetoenui valley (Source:D.Townsend). White dashed line indicates the morphostratigraphically defined LGCP ice limit. White star indicates the location of glaciolacustrine sediments decribed by McArthur and Shepherd (1990).

when ice filled the valley, which caused this overthickening (Conway et al., in prep). This interpretation is supported by radiometric dating (Gamble et al., 2003, C.Conway, 
pers. com.) and the presence of ice-contact textures, which have been described in lava outcrops in the upper Mangatoetoenui catchment (Spörli and Rowland, 2006). These thick flows are overlain by glacial till of uncertain age.

The maximum extent of former glaciation in the Mangatoetoenui catchment is wellapproximated by till distribution and valley shape. Discontinuous lateral moraines and till cover trace both valley sides down-valley to c. $1230 \mathrm{~m}$ asl. At this location the glacial limit is clearly defined by a well-preserved terminal moraine, which loops southwards from the northern valley side. Upstream, the lateral moraines are diffuse and provide approximate constraint of the former lateral margins of the Mangatoetoenui Glacier. For example, large, complex till accumulations, between 1400-1600 m asl on the southern valley side, possibly attest to former interaction between outlet glaciers of the Mangatoetoenui and Whangaehu catchments.

\subsubsection{Mangatepopo Valley ('MPO')}

Mangatepopo valley is a westward draining catchment on Tongariro massif, which is sourced from South Crater, a glacial cirque in the centre of the volcanic massif. A full description of the glacial geomorphology and chronology of this site is given in Chapter 5 , therefore I only provide a summary here. On the northern flank of the upper valley, a continuous moraine ridge was deposited early in the LGCP (c. 31 - 23 ka). Prominent, paired lateral moraines converge at the valley mouth (c. $1200 \mathrm{~m}$ asl), which record the final LGCP stand of glaciation in this valley at $21 \pm 2 \mathrm{ka}$. The former equilibrium line altitude of this glacier was likely between 1400-1550 m asl, which represents a lowering of c. 900-1100 m from present. Post-glacial volcanic activity, such as the development of present-day Mt. Ngauruhoe cone during the Holocene (Hobden et al., 2002; Moebis et al., 2011) may have significantly altered the drainage in the upper Mangatepopo catchment, as well as raising the elevation of valley floor through aggradation of lava and pyroclastic deposits.

\subsubsection{Eastern Tongariro massif}


Figure 7.12: The glacial geology of eastern Tongariro massif. 
Several east- to southeastward draining valleys on the eastern flanks on the Tongariro massif exhibit clear evidence for past glacial activity (Figure 7.12). To the north, the Mangahouhounui ('MHO') valley rises below Rotopaunga peak (1856 m asl) in an eastfacing glacial cirque. This c. $2 \mathrm{~km}$ wide, former accumulation area narrows down valley and lateral moraines on both valley sides converge at c. $1100 \mathrm{~m}$ asl. Possible till cover continues below this, however vegetation cover and the absence of clear topographic structure means that this remains unclear. The diffuse nature of these lowermost deposits means that they may correlate with the MIS 4 moraine in the Mangatepopo valley (Chapter 5). Immediately to the south of Mangahouhounui valley, is the southeastward draining Mangatawai Stream ('MTA'; Figure 7.12). Clearly defined, continuous lateral moraines line the sides of this underfit stream and converge at c. $1100 \mathrm{~m}$ asl. The absence of an obvious accumulation area for this former glacier suggests that it was either sourced from an ice field/cap over central Tongariro massif, or was an overflow outlet of a glacier in the adjacent Oturere valley ('OTU'; Figure 7.12) to the south. It is likely that the Oturere valley was occupied by a valley/outlet glacier during the LGCP, however, post-depositional infilling by lava has obscured the glacial geomorphology in this catchment. The lateral distribution of this valley-filling lava flow provides a clear indication of the planimetric geometry of the former glacial trough. The downstream limit of the flow coincides with the $1100 \mathrm{~m}$ contour. Downstream of this point the Oturere Stream is deeply incised. At the valley margins, glacial till is discontinuous and remnant lateral moraines are diffuse and ill-defined, thus the age of these landforms remains highly uncertain. Well-preserved lateral moraines are present in small unnamed ('UNK'; Figure 7.12) trough immediately to the south of Oturere. Similar to the Mangatawai Stream catchment, these sharp-crested moraines likely represent the former extent of a small lobe of ice that spilled over from the Oturere catchment. The moraines at this location clearly delineate the former glacier that existed here and terminated at c. $1350 \mathrm{~m}$ asl.

The Waihohonu valley ('WAI'; Figure 7.12) drains towards the southeast from the Holocene-age volcanic cone of Mt. Ngauruhoe. Large lateral moraines line both valley sides. These are cross-cut by several NE-SW trending faults, which have created vertical offsets in the moraines of up to several metres. A highly diffuse outboard moraine, present on the southwest side of the valley, may correlate to the c. 60 ka moraine of MPO catchment, thus I correlate the better preserved, prominant inboard moraine to the LGCP. This 1.5 - $2 \mathrm{~km}$ wide glacial trough has been partially infilled at the head by post-glacial lava and block-and-ash flows from Mt. Ngauruhoe, which may have removed evidence for less extensive ice stands. Similarly, creation of the modern cone of Mt. Ngauruhoe has obscured evidence that delineates the accumulation zone of the former Waihohonu Glacier. Although, the orientation and size of this glacial valley 
suggests that considerable relief or an ice field/cap must have persisted in that general region, in order to have supplied the former valley glacier.

\section{$7.5 \quad$ Results}

\subsubsection{Cosmogenic surface exposure dating}

Cosmogenic ${ }^{3} \mathrm{He}$ surface exposure ages from 3 boulders on the outermost moraine in WAH catchment range from 16.5 - $18.4 \mathrm{ka}$ (Table 7.1). This result places moraine formation late in the LGCP and supports the morphostratigraphic correlation of proximal moraines to this time period (Section 7.4.3). Formation of this outermost moraine late in the LGCP poses the question of whether the WAH glacier attained a similar or more extensive limit early in the LGCP, as seen in the MPO catchment (Chapter 5) and several Southern Alps moraine records (Putnam et al., 2013b; Rother et al., 2014). There is no geomorphic evidence outboard to suggest the WAH glacier was previously further extended. This outermost moraine may represent a composite feature formed over the LGCP, or the WAH glacier was inboard of this position earlier in the LGCP and any moraines pertaining to this time were subsequently overrun and eroded. I favour the former, due to the large size of this moraine and the widespread evidence for early-LGCP cooling of equal/greater magnitude than the late LGCP (e.g. Chapter 5; Barrell et al., 2013; Putnam et al., 2013b; Rother et al., 2014).

Table 7.1: Cosmogenic ${ }^{3}$ He surface exposure dating sample details, helium content and exposure ages for Wahianoa valley.

\begin{tabular}{|c|c|c|c|c|c|c|c|}
\hline ID & $\begin{array}{l}\text { Lat. } \\
\left({ }^{\circ} S\right)\end{array}$ & $\begin{array}{l}\text { Long. } \\
\left({ }^{\circ} \mathrm{E}\right)\end{array}$ & $\begin{array}{l}\text { Alt. } \\
\text { (m } \\
\text { asl) }\end{array}$ & $\begin{array}{l}\text { Thick. } \\
\text { (cm) }\end{array}$ & Shield. & $\begin{array}{l}{ }^{3} \mathrm{He} \mathbf{( 1 0}^{6} \text { at. } \\
\mathbf{g}^{-1} \mathbf{a}^{-1}\end{array}$ & $\begin{array}{l}\text { Exposure } \\
\text { age (ka; } L \\
\text { scaling) }^{a}\end{array}$ \\
\hline WH1212 & 39.32 & 175.62 & 1374 & 3 & 0.994 & $5.463 \pm 0.126$ & $16.5 \pm 0.4(1.9)$ \\
\hline WH1213 & 39.32 & 175.62 & 1437 & 1.5 & 0.995 & $6.093 \pm 0.167$ & $17.2 \pm 0.5(2.0)$ \\
\hline WH1214 & 39.32 & 175.62 & 1438 & 2 & 0.996 & $6.505 \pm 0.183$ & $18.4 \pm 0.5(2.1)$ \\
\hline
\end{tabular}

${ }^{a}$ External uncertainty shown in parentheses. 


\subsubsection{Glacier modelling}

\subsubsection{Experiment 1}

Figure 7.3 shows steady-state ice thickness results of Experiment 1, conducted over a domain covering both Mt. Ruapehu and Tongariro massif. Also shown are the inferred LGCP ice limits of greater and lesser confidence (Barrell, 2011, modified by this study). Figure 7.3 shows that modest coolings of $2-3{ }^{\circ} \mathrm{C}$ from present are sufficient to produce a small ice mass on Mt. Ruapehu (see also, Chapter 6), but this temperature change is insufficient to promote significant ice accumulation on Tongariro massif. A cooling of $4{ }^{\circ} \mathrm{C}$ is sufficient to meet the well-defined LGCP limits in the WAH catchment on southeast Ruapehu, however, the termini of other valley glaciers on this volcano remain well upstream of their mapped limits. Meanwhile in this scenario, ice accumulation on Tongariro is restricted to elevations > c. $1900 \mathrm{~m}$ asl, therefore remains well short of the mapped LGCP limits. Modelled ice extent approaches the LGCP limits in the remaining three catchments (MTO, WHA, MTU) on Mt. Ruapehu when $\Delta T=-5{ }^{\circ} \mathrm{C}$ and these limits are exceeded in all catchments at $\Delta T=-6^{\circ} \mathrm{C}$. On Tongariro massif, modelled ice extent is reaching the geological limits in several catchments (MPO, MHO, UNK) in response to a cooling of $6^{\circ} \mathrm{C}$. At $\Delta T=-7^{\circ} \mathrm{C}$, the individual ice masses have merged and extent of this single ice mass exceeds the LGCP limits in all catchments in the domain.

In summary, this experiment shows that all mapped LGCP limits can be attained in model simulations with temperature forcings that range between c. $-4{ }^{\circ} \mathrm{C}$ and -7 ${ }^{\circ} \mathrm{C}$, when precipitation remains unchanged from modern. However, the variability between individual catchments that suggest other factors (e.g. topographic change, climatic gradients, dating uncertainty) may be influencing this result.

\subsubsection{Experiment 2}

The precise $\Delta T$ required to simulate the LGCP ice geometries delineated by geological evidence in each catchment described above, range from -4.0 to $-6.8{ }^{\circ} \mathrm{C}$ when precipitation remains unchanged from present (Figure 7.4a). Steady state equilibrium line altitudes for these simulations range from c. 1380 - $1660 \mathrm{~m}$ asl, which represent depressions of c. 820 - $1100 \mathrm{~m}$ from present (Table 7.2). Imposing a $25 \%$ increase in modern precipitation reduces $\Delta T$ by c. $0.6^{\circ} \mathrm{C}$ for all catchments (Figure 7.4), meanwhile, decreasing modern precipitation by $25 \%$ requires increases in $\Delta T$ of c. $0.8^{\circ} \mathrm{C}$ (Figure $7.4 \mathrm{a}$ ).

Sensitivity tests of key energy balance parameters impact the palaeotemperature recon- 
structions by up to $\pm 0.5^{\circ} \mathrm{C}$ for the chosen ranges (Figure $7.4 \mathrm{~b}$ ). Altering the albedo of snow $\left(\alpha_{\text {snow }}=0.67-0.77\right)$ and snow-temperature threshold $\left(T_{\text {snow }}=0-1.5^{\circ} \mathrm{C}\right)$ have the greatest effects $\left(\mathrm{c} . \pm 0.1-0.5^{\circ} \mathrm{C}\right)$. Using a temperature lapse rate $(\mathrm{d} T / \mathrm{d} z)$ of -0.006 ${ }^{\circ} \mathrm{C} \mathrm{m}^{-1}$, uniformly applied across all months, decreases $\Delta T$ by $0.1-0.2{ }^{\circ} \mathrm{C}$. Changing the characteristic ice roughness length $\left(Z_{i c e}=0.0008-0.01 \mathrm{~m}\right)$ also causes deviations in $\Delta T$ of $\pm 0.1-0.2{ }^{\circ} \mathrm{C}$, relative to the optimal setting. Flow parameters $U_{c}$ and $A$ have negligible $\left(<0.1^{\circ} \mathrm{C}\right)$ impact on $\Delta T$.

Findings from Experiment 1 highlighted the variability in the LGCP palaeoclimate reconstructions that exists, both between volcanoes, and between individual catchments. Figure 7.4a shows that the Wahianoa (WAH) catchment on Mt. Ruapehu requires a conspicuously lower amount of cooling to match the identified LGCP ice limits $(\Delta T$ $=-4.0^{\circ} \mathrm{C}$, when $\Delta P=0$ ), compared to all other catchments studied (c. -5.2 to $-6.8{ }^{\circ} \mathrm{C}$, when $\Delta P=0$ ). Also, there is an offset in the temperature forcings necessary to simulate the mapped LGCP ice limits between the two volcanoes. Catchments on Tongariro massif range require a cooling of c. -6.0 to $-6.8^{\circ} \mathrm{C}$ (mean $\left.=-6.3{ }^{\circ} \mathrm{C}\right)$, when precipitation is unchanged, whilst catchments on Mt. Ruapehu require -4.0 to $-5.8{ }^{\circ} \mathrm{C}$ (mean $=5.0{ }^{\circ} \mathrm{C}$, or $5.4{ }^{\circ} \mathrm{C}$ when WAH is removed). Finally, the results presented in Figure 7.4 represent the climatic forcing, from present, required to meet the inferred downstream limits of LGCP glaciation. In several catchments, ice spills over ice-marginal indicators, such as lateral moraines, before the geologically-constrained termini are reached (Figure $7.5 \mathrm{~b}, \mathrm{c})$. The possible reasons for the discrepancies, and the potential implications for palaeoclimate estimates are discussed below (Section 7.6.2).

Table 7.2: Palaeo-equilibrium line altitudes (pELA) of the simulated LGCP glaciers and the difference from present using $\left(\operatorname{dELA}_{\text {mean }}(\mathrm{m})=\right.$ arithmetic mean of Keys $(1988)=2483 \mathrm{~m}$ asl; dELA = change from the mid-point of present day ELAs (in parentheses) of individual glaciers given by Keys (1988), where available.

\begin{tabular}{lllll} 
Glacier & $p E L A(m$ asl $)$ & $d E L A_{\text {mean }}(m)$ & $d E L A$ & Modelled $\Delta \mathrm{T}\left({ }^{\circ} \mathrm{C}\right)$ \\
\hline MTA & 1380 & -1103 & & -6.8 \\
WAI & 1390 & -1093 & -6.7 \\
MHO & 1460 & -1023 & -6.4 \\
MPO & 1510 & -973 & -933 & -6.0 \\
UNK & 1550 & $-953(2450-2600 \mathrm{~m}$ asl $)$ & -5.7 \\
MTU & 1530 & -953 & $-870(2400-2500 \mathrm{~m}$ asl $)$ & -5.3 \\
MTO & 1580 & -903 & $-1050(2550-2650$ masl $)$ & -5.2 \\
WHA & 1550 & -933 & & -4.0 \\
WAH & 1660 & -823 & & \\
\hline
\end{tabular}




\subsubsection{Experiment 3}

Figure 7.6a shows the change in temperature from present required to simulate the mapped LGCP geometries in the nine catchments, using topographic boundary conditions that approximate that of the LGCP (Figure 7.2). When precipitation remains unchanged from present, $\Delta T$ ranges from c. -4.1 to $-7.1^{\circ} \mathrm{C}$, which represent differences of +0.1 to $-0.5{ }^{\circ} \mathrm{C}$ from Experiment 2 (Figure 7.6b). In all catchments except one (MTO), more cooling was required, relative to Experiment 2 (Figure 7.6b). This is likely because the majority of the imposed topographic changes involved subtraction of depositional units (Figure 7.2), which increased local surface temperature. The greatest changes in $\Delta T$ between Experiment 2 and Experiment 3 occurs in the UNK catchment, where c. 0.5 ${ }^{\circ} \mathrm{C}$ of extra cooling is required to simulate the inferred glacial geometries (Figure 7.6b). This change is the result of reduced flux from the vicinity of Mt. Ngauruhoe, caused by the elevation reduction in the accumulation area, following removal of this Holocene cone (Figure 7.2). However, this topographic alteration has less of an impact in the WAI catchment, where $\Delta T$ is reduced by $0.2{ }^{\circ} \mathrm{C}$, relative to Experiment 2 . Whilst removal of Mt. Ngauruhoe may act to channel ice flow into the WAI catchment, the overall reduction in elevation reduces snow accumulation, therefore reducing the impact on $\Delta T$. The imposed topographic changes did not improve the poor fit between modelled ice geometry and the geological constraints, as ice still spills over lateral moraines in the WAI and MTA catchments before reaching the inferred LGCP termini.

On Mt. Ruapehu, the major changes to the topography were made in the MTO catchment, which is the only catchment where $\Delta T$ decreased by c. $0.1-0.2{ }^{\circ} \mathrm{C}$, relative to Experiment 2 (Figure 7.6b). In this instance, the removal of syn- and post-LGCP lava flows in the upper and middle parts of this catchments has resulted in increased ice flux to the lower valley, despite the overall reduction in elevation. It is also notable that the steady-state ice margins in the MTO catchment exhibit improved fit to the geologically inferred ice limits in Experiment 3 (Figure 7.5d). This is caused by a reduction in the ice flux leaving the catchment through overspill, which helps offset the effect of increased temperature caused by the reduction in bed elevation. In the other catchments on $\mathrm{Mt}$. Ruapehu, $\Delta T$ was reduced by $0.1-0.2^{\circ} \mathrm{C}$ relative to Experiment 2 . Thus accounting for post-glacial changes in bed topography cannot resolve the anomalous $\Delta T$ result in the WAH catchment. Finally, there remains a poor fit between the geologically-inferred lateral ice margins in the MTU catchment and those simulated in Experiment 3. 


\subsection{Discussion}

Using a numerical glacier model, I investigated the magnitude of temperature depression from present in central North Island during the LGCP and the sensitivity of these results to model parameterisation and changing topographic boundary conditions. The main findings are as follows: (1) the temperature depression required to simulate the LGCP glacial geometries of individual catchments varies between -4.0 and $-6.8{ }^{\circ} \mathrm{C}$; (2) there is a systematic offset of $>1^{\circ} \mathrm{C}$ in the model-derived palaeotemperatures associated with LGCP moraines between the two volcanoes; (3) using geologically-constrained reconstructions of LGCP topography has relatively little impact $\left(+0.2\right.$ to $\left.-0.5{ }^{\circ} \mathrm{C}\right)$ on the palaeotemperature reconstruction. Below, I first consider the possible sources of uncertainty, before placing the results in context of other, local terrestrial and marine palaeotemperature proxy reconstructions.

\subsubsection{Topographic uncertainty}

Improved constraint of the timing and extent of late Quaternary volcanism in central North Island has allowed a test of the impact that changing topographic boundary conditions have on palaeoclimate estimates for glacier modelling. Using expert-defined topographic reconstructions, informed by recent field mapping and radiometric dating, the temperature forcing required to simulate the inferred LGCP glaciers is altered by +0.2 to $-0.5{ }^{\circ} \mathrm{C}$. The majority of the imposed topographic changes serve to remove postglacial lava flows that have built volcanic cones (e.g. Mt. Ngauruhoe) or in filled glacial troughs (e.g. MTO, MPO; Figure 7.2). Subtraction of these features has lowered the glacier bed elevation, which raises the local surface air temperature and explains why most catchments require increased cooling to achieve the LGCP limits in Experiment 3, relative to Experiment 2. This mirrors the findings of McKinnon et al. (2012), who found that subtraction of post-glacial sedimentary fill from the Pukaki basin, in central Southern Alps, resulted in lower glacier model derived palaeotemperature estimates, relative to studies that used present day bed topography. Conversely, removal of the post-glacial lava flows in the vicinity of the MTO catchment reduced the temperature forcing required to simulate the LGCP ice geometry in that catchment by c. $0.2^{\circ} \mathrm{C}$, relative to Experiment 2.

Reduced overspill, as shown by the improved fit between the model output and the lateral moraines, indicates that the retention of ice within the MTO catchment was improved by the imposed topographic changes and this effect was sufficient to offset the decreased (increased) accumulation (ablation) induced by land surface lowering. How- 
ever, the imposed topographic changes did not improve the fit in all catchments where overspill occurs (e.g. MTA, WAI, MTU), thus it is probable that the LGCP palaeotemperature estimates presented in Figures 7.4 and 7.6 for these catchments overestimate the true magnitude of temperature lowering associated with the LGCP moraines in these catchments. This interpretation is supported by the fact that these catchments require the greatest magnitude of cooling, relative to present, of all catchments on the respective volcanoes. Discounting the reconstructions from these catchments leaves LGCP palaeotemperature estimate ranges of -4.1 to $-5.4{ }^{\circ} \mathrm{C}$ for $\mathrm{Mt}$. Ruapehu and -6.1 to $-6.3{ }^{\circ} \mathrm{C}$ for Tongariro massif ( $\Delta \mathrm{P}=0$; Experiment 3 ). Thus, accounting for ice overspill and known topographic changes is insufficient to resolve the apparent offset between LGCP palaeotempertaure estimates between these two volcanoes.

Identification and geometrical constraint of well-preserved post-glacial lava flows can be achieved with relative ease through detailed field investigations, however the recognition of post-glacial erosional events (e.g. sector collapse, fluvial incision) and subsequent topographic reconstruction is less straightforward. Some erosional events are identifiable in the modern landscape on Mt. Ruapehu (e.g. Murimotu Formation sector collapse at 10.4 - $10.6 \mathrm{cal}$. ka BP - Chapter 4), however the precise source locations and pre-event topographies remain highly uncertain (e.g. Hackett and Houghton, 1989; Palmer and Neall, 1989; McClelland and Erwin, 2003). Such erosional events act to decrease surface slopes, alter drainage pathways and alter the bed hypsometry, with potential implications for modelled ice distributions and palaeoclimatic reconstruction. For example, the offset in LGCP temperature reconstructions between the glacial catchments of Mt. Ruapehu and Tongariro massif, theoretically could be caused by post-glacial change in the relative altitudes of the two volcanoes. A post-glacial decrease in the summit altitude of Tongariro massif, relative to Mt. Ruapehu, could explain the need for greater cooling on Tongariro massif in the simulations presented here. However, there is little geological evidence to support the notion that Tongariro massif has experienced major post-glacial degradation, nor that Mt. Ruapehu has significantly increased in elevation since the LGCP. This absence of evidence, combined with the fact that known changes in topographic boundary conditions had relatively little impact on palaeotemperature reconstructions (Experiment 3), makes it unlikely that post-glacial topographic change is the primary source of this systematic offset. 


\subsubsection{Glacier model uncertainty}

Numerical glacier models represent simplified descriptions of glacier mass balance and ice flow, which often require assumptions about parameters due to lack of empirical constraint. The sensitivity tests presented in Figure 7.4b, provide a first-order assessment of the uncertainty imparted by parameters in the energy balance model. Varying key parameters within acceptable bounds causes deviations in reconstructed temperatures of up to $\pm 0.5^{\circ} \mathrm{C}$, which indicates that some of the variability in palaeotemperatures (e.g. WAH catchment) could be explained by spatial heterogeneities in model parameters, which are currently assumed uniform across the model domain.

Palaeotemperature estimates are most sensitive to albedo, which cannot be constrained for the past. Heterogeneous spatial distribution of surface albedo during the LGCP, for example differential surface debris thickness, provides a possible explanation for the offset in palaeotemperature reconstructions between the volcanoes, and/or the anomalous finding in the WAH catchment on Mt. Ruapehu. Debris cover can act to enhance or reduce surface melt on glaciers, depending on the debris thickness, which in turn is dictated by sediment availability. The potential for past inputs of volcanic ash to the glacier surface represents the most likely source of surface debris cover at this study site. Ice-contact structures in lava flows on Mt. Ruapehu (Spörli and Rowland, 2006) show evidence for such interaction, whilst ${ }^{40} \mathrm{Ar} /{ }^{39} \mathrm{Ar}$ dating shows that Mt. Ruapehu was active in the 30 - $18 \mathrm{ka}$ time window (Gamble et al., 2003). Richardson and Brook (2010) measured ice ablation rates on Mt. Ruapehu beneath tephra emplaced during the 2007 eruption and found that tephra cover up to $7 \mathrm{~cm}$ thick enhanced ablation rates of the underlying ice, relative to that of clean snow. This 'effective thickness' (at which maximum ablation occurs, relative to clean snow) is relatively high in comparison to other studies, which typically find that debris thicknesses of $0-1 \mathrm{~cm}$ are sufficient to retard ablation (Brock et al., 2007). Variability in the effective and critical (that at which ablation is reduced relative to clean snow/ice) thicknesses of surficial tephra cover is introduced by differences in tephra properties such as grain size, angularity and density (Nield et al., 2013), which can change with time due to different eruption styles. Kirkbride and Dugmore (2003) assessed the effects of historic volcanic fallout events on outlet glacier behaviour in Iceland. They found a long-term effect of enhanced surface ablation after a volcanic eruption, caused by re-distribution of tephra in the maritime setting. Enhanced ablation on Mt. Ruapehu by thin tephra cover, or retarded ablation on Tongariro massif by thicker tephra cover, provide possible scenarios that could explain some of the difference in glacier model derived LGCP palaeotemperature reconstructions on the two volcanoes. 
Volcanic activity has the potential to affect glacier mass balance and dynamics in several other ways, such as increased ablation by raised geothermal heat fluxes, catastrophic removal of ice through explosive eruptions and changing sub-glacial hydrology. Thermal energy released by volcanic eruptions also has the potential to ablate considerable volumes of snow and ice (Major and Newell, 1989), however such events are relatively short-lived, often persisting on timescales of days to months (e.g. Gudmundsson et al., 1997). Raised geothermal heat fluxes therefore can complicate the climatic interpretation of glacier fluctuations over annual- to decadal timescales (Rivera et al., 2012; Rivera and Bown, 2013), however climate is the most-likely driver of glacier fluctuations on active volcanoes over centennial to millennial timescales (e.g. Kirkbride and Dugmore, 2001; Mackintosh et al., 2002; Blard et al., 2007; Licciardi et al., 2007; Osborn et al., 2012). This interpretation is supported by the broad internal consistency of palaeotemperature reconstructions found in this study and the agreement of these estimates with independent reconstructions of LGCP climate in New Zealand (Golledge et al., 2012; Newnham et al., 2013).

In Chapter 3, I demonstrate the good agreement between contemporary ice distribution on Mt. Ruapehu and ice geometries simulated using the 30-year (AD 1981-2010) average climate datasets. This indicates that these datasets provide a useful starting point from which to assess the local LGCP climate anomaly in catchments on Mt. Ruapehu. No glaciers exist on Tongariro massif today, therefore it is more difficult to assess how representative the modern climate grids are for this volcano. The paucity of high-altitude precipitation data for the present day imparts considerable uncertainty in glacier model applications. Rowan et al. (2014) find that uncertainty in present day precipitation distribution imparts uncertainty of up to $25 \%$ in modelled LGCP glacier length in the central Southern Alps, which equates to about $0.5^{\circ} \mathrm{C}$ in the palaeotemperature estimate. The absence of continuous, high mountain ranges and the increased distance from the prevailing westerly storm track means that spatial precipitation gradients in central North Island are much lower than the central Southern Alps. However, it is likely that uncertainty in the present-day spatial precipitation distribution, as well as total precipitation amount, could explain part of the offset in LGCP palaeotemperature estimates between the two volcanoes.

Changes in the spatial gradients of precipitation across the model domain, between the LGCP and today, could impart similar uncertainty to the palaeotemperature estimates (Kessler et al., 2006). At present, precipitation-bearing cyclones in central North Island are predominantly advected from the west and orographic interaction of these weather systems with Mt. Ruapehu creates a west-east rain shadow effect on the volcano (Chapter 3). In a proxy-data driven assessment of palaeocirculation in New Zealand at $21 \mathrm{ka}$, 
(Lorrey et al., 2012b) conclude that winters were characterised by a greater frequency of blocking highs over South Island. This would result in more frequent north-easterlies in central/northern North Island, during the accumulation season, which may have increased precipitation on Tongariro massif at the expense of Mt. Ruapehu. Synoptic type frequency changes are not accounted for in the glacier model simulations and such an effect, at least in part, may explain the differences in palaeotemperature estimates between the volcanoes. The precipitation-temperature relationships presented in Figure $7.4 \mathrm{a}$ indicate that precipitation changes of $\pm 25 \%$ are balanced by temperature changes of \pm c. $0.6-0.8^{\circ} \mathrm{C}$, which is consistent with similar estimates for glaciers South Island (Oerlemans, 1997; Anderson and Mackintosh, 2012). Thus, precipitation on Tongariro would need to be increased by $>25 \%$, relative to Mt. Ruapehu, in order to account for the c. $1.0-1.3{ }^{\circ} \mathrm{C}$ temperature difference associated with the inferred LGCP glacial limits between the two volcanoes.

\subsubsection{LGCP climate in New Zealand}

The glacier modelling experiments presented here suggest that stadial conditions in central North Island were characterised by temperatures 4 to $7^{\circ} \mathrm{C}$ lower than present (Figure 7.4). Local precipitation change during the LGCP remains poorly constrained, although evidence from climate modelling (Drost et al., 2007; Rojas et al., 2009), previous glacier modelling (Golledge et al., 2012), carbon isotopes in speleothems (Whittaker et al., 2011) and diatoms in maar deposits (Stephens et al., 2012b) indicate that drier than present conditions prevailed across New Zealand at this time. Precipitation reductions of up to $25 \%$ from present require additional cooling of up to $0.8^{\circ} \mathrm{C}$ to achieve the LGCP glacial geometries in central North Island (Figure 7.4). Such a change in precipitation is likely a maximum estimate given that climate model simulations predict changes in total annual precipitation of $<10 \%$ (e.g. Drost et al., 2007).

Steady-state equilibrium line altitudes of the simulated LGCP glaciers fall between c. 1400 - $1650 \mathrm{~m}$ asl, which represent depressions of c. $800-1100 \mathrm{~m}$, relative to present. This estimate slightly exceeds that of McArthur and Shepherd (1990), who manually reconstructed the LGCP ELAs on Mt. Ruapehu to between 700-900 m below present. This difference likely reflects the addition of catchments on Tongariro massif, as well as the methodological differences between the two studies. In Chapter 5, I estimated the ELA of the LGCP glacier in the MPO catchment as c. 1400 - $1550 \mathrm{~m}$ asl, using the accumulation area ratio (AAR) and maximum elevation of lateral moraine (MELM) methods, which agrees well with the model simulation presented here (c. $1510 \mathrm{~m}$ asl; 
Table 7.2).

Lowering of the regional ELA to c. $1500 \mathrm{~m}$ at the LGCP is insufficient to promote widespread glaciation in the mountain ranges elsewhere in North Island, as few other peaks exceed this elevation. The only existing evidence for LGCP glaciation outside of the central North Island volcanoes comes from the Tararua Ranges in southern North Island, where the local pELA was c. $1100 \mathrm{~m}$ asl (Brook et al., 2005; Brook et al., 2008). This is considerably lower than the ELA depression in the present study and elsewhere in New Zealand (Porter, 1975; McCarthy et al., 2008; Golledge et al., 2012), which may represent topo-climatic controls on mass balance of this former cirque glacier, such as wind-driven snow accumulation. The absence of contemporary glaciers in the Tararuas precludes robust spatial comparison of ELA depressions to the results presented here. Several quantitative palaeotemperature estimates from North Island have been made using fossil pollen assemblages, which also indicate LGCP temperature depressions of 4-7 ${ }^{\circ} \mathrm{C}$ below present (McGlone and Topping, 1977; Newnham et al., 1989; Newnham et al., 2013; Sandiford et al., 2003; Wilmshurst et al., 2007), which is consistent with the glacier model results.

Several glacier-based assessments of LGCP temperature have previously been made for South Island, New Zealand, using a variety of different glacier models. Simulations of the entire Southern Alps icefield, using the Parallel Ice Sheet Model, indicate that the LGCP was characterised by temperatures $6-6.5^{\circ} \mathrm{C}$ colder than present, coupled with a reduction in precipitation of c. $25 \%$ (Golledge et al., 2012). It is notable that the best-estimate palaeotemperature scenarios did not achieve a good fit between modelled ice extent and the geological evidence in all catchments (Golledge et al., 2012, their Figure 10B). Using a different glacier model with higher grid resolution and a different representation of modern climate, Rowan et al. (2013) and Putnam et al. (2013a) achieve a good model fit in the regions where Golledge et al. (2012) did not (e.g. Rakaia), despite using a similar temperature forcing $\left(\Delta T=-6.25\right.$ to $\left.-6.5^{\circ} \mathrm{C}\right)$. Using the University of Main Ice Sheet Model, Putnam et al. (2013b) find that a cooling of $6.25 \pm 0.5{ }^{\circ} \mathrm{C}$ (with no precipitation change) is required to generate an ice extent that matches well-dated moraines in the Lake Ohau catchment. When precipitation is reduced by $30 \%$ the required cooling increases to $6.9^{\circ} \mathrm{C}$. Thus, these studies have shown that, despite differences in boundary conditions and formulations for glacier flow, glacier model experiments consistently suggest peak stadial air temperatures during the LGCP were 6-7 ${ }^{\circ} \mathrm{C}$ cooler than present across New Zealand. This magnitude of air temperature depression is also in broad agreement with sea surface temperature reconstructions from the New Zealand sector of the Southern Ocean (Barrows et al., 2007a; Bostock et al., 2013). 


\subsection{Conclusion}

In this chapter I have presented geomorphic mapping and 2D glacier modelling results, which constrain ice distribution and the climatic forcing associated with the Last Glacial Cold Period in central North Island, New Zealand. I have shown that:

1. During the Last Glacial Cold Period in New Zealand, valley glaciers extended to c. $1200 \mathrm{~m}$ asl from central ice fields that covered both Tongariro massif and Mt. Ruapehu in central North Island.

2. Temperatures $4-7^{\circ} \mathrm{C}$ lower than present are required to simulate geologically constrained glacier extents associated with these ice limits, when precipitation remains unchanged. A decrease in precipitation (as suggested by proxy evidence and climate models) of up to $25 \%$ from present, increases the required temperature change by up to c. $0.8^{\circ} \mathrm{C}$.

3. Steady-state ELAs were c. 800-1100 m lower than present in central North Island during the Last Glacial Cold Period, which agrees well with the manual reconstruction of the Mangatepopo valley presented in Chapter 5 (c. $1000 \mathrm{~m}$ ), as well as the previous determination (700-900 m) of McArthur and Shepherd (1990).

4. Accounting for volcanically-induced, post-glacial topographic change generally decreases the elevation of the glacier bed elevation, which increases the magnitude of cooling required to simulate the former ice limits. The imposed topographic changes do not significantly change past glacial drainage patterns, although the difficulty in reconstructing pre-erosional topographies makes it hard to fully assess this possibility. The impact of topographic change on the temperature reconstructions is variable between catchments, with changes on the order of 0.1 $0.5^{\circ} \mathrm{C}$, relative to the simulations with present day land surface.

5. The palaeoclimatic reconstructions here agree well with proximal, pollen-based estimates (Newnham et al., 2013), as well as several similar assessments from glacial records in central Southern Alps (Golledge et al., 2012; Putnam et al., 2013b; Rowan et al., 2013), which all indicate that temperatures were depressed by c. 6 
${ }^{\circ} \mathrm{C}$ during the Last Glacial Cold Period. 


\section{Chapter 8}

\section{Synthesis}

\subsection{Introduction}

The aim of this thesis is to constrain the magnitude, timing and associated climatic forcing of past mountain glacier fluctuations on New Zealand's central North Island volcanoes: Mt. Ruapehu and Tongariro massif. In this chapter, I will first outline the original scientific contributions made by the research presented here, before revisiting the research questions identified from the literature review in Chapter 2. Lastly, I discuss outstanding questions that I consider important for future research, in light of the progress made by this thesis.

\subsection{Original scientific contributions made by this research}

Well-constrained chronological and palaeoclimatic reconstructions of late Quaternary glacier fluctuations in New Zealand have largely been focused on the central Southern Alps (e.g. Suggate and Almond, 2005; Anderson and Mackintosh, 2006; Schaefer et al., 2006, 2009; Doughty et al., 2013; Putnam et al., 2013a,b), with very few other studies existing outside of this narrow latitudinal band (e.g. Shulmeister et al., 2005; McCarthy et al., 2008; Brook et al., 2008). Using a combination of geomorphological and geological mapping, cosmogenic surface exposure dating and numerical glacier modelling, I have provided new insights into the timing and magnitude of climatic change in central North Island $\left(39^{\circ} \mathrm{S}\right)$ during the Last Glacial Maximum and the late glacial.

In Chapter 4, I use a debris avalanche deposit on Mt. Ruapehu to constrain locally the production rate of cosmogenic ${ }^{3} \mathrm{He}$. In collaboration with VUW and GNS Science geologists, we constrained the timing of this event, using radiocarbon dating, to 10.4-10.6 cal. ka BP. I made measurements of cosmogenic ${ }^{3} \mathrm{He}$ concentrations in 
boulders deposited at the surface during this event, which show that a previous 'globally' (based primarily on Northern Hemisphere calibration sites) compiled estimate of cosmogenic ${ }^{3} \mathrm{He}$ production (Goehring et al., 2010) is applicable in New Zealand. This finding means that surface exposure dates and erosion rates, using cosmogenic ${ }^{3} \mathrm{He}$, can now be calculated with reduced uncertainties, in this region of the world. Although not a specific aim of this thesis, a separate, important result of this study is the improved age constraint of this major debris avalanche event. The new, robust radiocarbon age refines previous estimates based on a single radiocarbon date (Topping, 1974) and provides useful constraint of post-glacial topographic change on this volcano, which has important implications for palaeoglacier modelling (e.g. Chapter 7). This result is also of use for local geohazard assessment in this active volcanic setting.

Application of cosmogenic surface exposure dating to constrain past glacier fluctuations is presented in Chapters 5,6 and 7. In Chapter 5, I present evidence for two periods of extensive glaciation, when the local ELA was depressed by 930-1080 m relative to present, which occurred during MIS 4 (> $58 \mathrm{ka}$ ) and from late MIS 3 (c. $31 \mathrm{ka}$ ) through the LGCP. In Chapter 6, I constrain the timing of a glacial re-advance on Mt. Ruapehu during the late-glacial. I adapt a coupled model of cosmogenic nuclide production and moraine diffusion, previously applied to a moraine in South Island (Applegate et al., 2008), to investigate the scatter in this ${ }^{3} \mathrm{He}$ dataset. The results of this work, together with recent advances in local tephrochronology (Lowe et al., 2013), indicate that the North Island cooled in synchrony with South Island and Antarctica during the Antarctic Cold Reversal (c. $13 \mathrm{ka}$ ). In Chapter 7, I show that a valley glacier on the southeast side of Mt. Ruapehu was present until at least c. 17-18 ka. This finding provides constraint for glacier modelling experiments that seek to constrain temperature change in central North Island.

Improved age constraint of glacier fluctuations on the central North Island, provides useful targets for quantitative palaeoclimate estimates using glacier model experiments (e.g. Golledge et al., 2012; Doughty et al., 2013). In Chapters 6 and 7, I present the results of glacier model experiments with the aim of constraining the magnitude of air temperature depression, relative to present, associated with the glacial advances in central North Island during the late-glacial (Chapter 6) and LGCP (Chapter 7). Using a coupled, distributed energy balance and 2D ice flow model, I show that a cooling of c. $2.9^{\circ} \mathrm{C}$ from present is required to simulate the mapped and dated glacial geometry of a late-glacial re-advance on southern Mt. Ruapehu, when precipitation remains unchanged from modern (Chapter 6). Experiments with imposed precipitation changes of $\pm 20 \%$ from present, yield corresponding temperature estimates that range between 2.5 and $3.4^{\circ} \mathrm{C}$. These findings provide evidence to suggest that North Island cooling 
during the Antarctic Cold Reversal was of similar magnitude to that of South Island (e.g. Doughty et al., 2013) and the sub-Antarctic Islands (e.g. McGlone et al., 2010). I conduct seasonal sensitivity tests that show glacier length changes on Mt. Ruapehu are most sensitive to summer temperature change and that reduced seasonality may explain differences in the magnitude of cooling indicated by different proxies (e.g. glaciers, pollen).

In Chapter 7, I use the cosmogenic ${ }^{3} \mathrm{He}$ ages and extensive field-based geomorphological investigations to assign ages to undated moraines across the two volcanoes. These moraines are then used as targets in glacier modelling experiments, to constrain quantitative temperature estimates in central North Island for the LGCP. Of the 9 catchments studied, 8 yield LGCP air temperature estimates between $5.2-6.8^{\circ} \mathrm{C}$ lower than present, when precipitation remains unchanged. This range of cooling increases to 6.0 $-7.5{ }^{\circ} \mathrm{C}$, when precipitation is reduced by $25 \%$ from present. Experiments with $>15$ ka topographic reconstructions show that these estimates are insensitive to the known topographic changes (i.e. lava flow emplacement) that have occurred since deglaciation.

\subsection{Research Questions}

\subsubsection{Can cosmogenic isotopes be used to constrain past glacial activ- ity on the North Island volcanoes?}

\subsubsection{The suitability of cosmogenic ${ }^{3} \mathrm{He}$}

Yes. The work presented in this thesis has shown that, not only can ${ }^{3} \mathrm{He}$ be used for surface exposure dating on these volcanoes, but that it is very well suited to the local geology. A key determinant for use of ${ }^{3} \mathrm{He}$ in this study is the local lithology, as the andesitic moraine boulders contain abundant pyroxene phenocrysts (e.g. Price et al., 2012). Whilst cosmogenic ${ }^{3} \mathrm{He}$ is produced in all minerals, it diffuses out of most mineral phases at environmental temperatures (Niedermann, 2002). However, it has been demonstrated that cosmogenic ${ }^{3} \mathrm{He}$ is quantitatively retained in pyroxene crystals (e.g. Kurz, 1986a) and is routinely measured in this phase (e.g. Bruno et al., 1997; Schäfer et al., 1999; Bromley et al., 2009, 2011). The paucity of quartz in the andesite-dacite moraine boulders of the central North Island volcanoes precludes application of ${ }^{10} \mathrm{Be}$, until methods for extraction of these nuclides from other minerals (e.g. pyroxene) become established. ${ }^{36} \mathrm{Cl}$ is measured in whole rock samples of basaltic rocks, however the complex production pathways restricts the precision at which surface exposure ages can be calculated (Dunai, 2010). 
${ }^{3} \mathrm{He}$ can be cosmogenic, magmatic and nucleogenic in origin, therefore for surface exposure dating applications it is important to resolve the relative contributions from these potential sources. However samples measured in the course of this thesis display extremely high ${ }^{3} \mathrm{He} /{ }^{4} \mathrm{He}$ (up to several $100 x$ the atmospheric ratio), together with very low ${ }^{4} \mathrm{He}$ concentrations. These characteristics reflect: (i) the youth of the parent material (i.e. < $300 \mathrm{ka}$; Gamble et al., 2003), which restricts the time for radiogenic accumulation of ${ }^{3} \mathrm{He}$ and ${ }^{4} \mathrm{He}$; (ii) sample preparation procedures (e.g. HF-leaching), which result in a higher purity pyroxene separates and absence or supression of nucleogenic ${ }^{4} \mathrm{He}$ (Bromley et al., 2014); and (iii) a negligible magmatic input. Furthermore, contributions from nucleogenic ${ }^{3} \mathrm{He}$, which is produced via thermal neutron reactions on lithium-6 $\left({ }^{6} \mathrm{Li}(n, \alpha){ }^{3} \mathrm{H}^{3} \mathrm{He}\right.$; Dunai et al., 2007), are also negligible, due to the generally low lithium, uranium and thorium concentrations. Samples with elevated Li concentrations exhibit no clear correlation ${ }^{3} \mathrm{He}$ (Chapter 4 ), probably due to the acid leaching treatment (Bromley et al., 2014). Future applications should continue to assess the potential for non-cosmogenic contributions prior to exposure age / erosion rate calculations.

The results presented in Chapter 4 show that the time-integrated cosmogenic ${ }^{3} \mathrm{He}$ production rate in New Zealand since $11 \mathrm{ka}$ is well approximated by a globally compiled production rate sourced mainly from Northern Hemisphere calibration sites (Goehring et al., 2010). This constraint means that cosmogenic ${ }^{3} \mathrm{He}$ concentrations measured in New Zealand can be accurately converted to surface exposure ages.

\subsubsection{Processes causing scatter in surface exposure ages}

An interesting finding from the application of cosmogenic surface exposure dating to moraine boulders on Mt. Ruapehu and Tongariro massif is the common occurrence of scatter, outside of the measurement uncertainty, within sample populations derived from single moraine landforms. Whilst this is not an uncommon occurrence (e.g. Heyman et al., 2011), the degree of scatter in the datasets generated here is considerably greater than many other datasets generated in New Zealand (e.g. Schaefer et al., 2009; Kaplan et al., 2010, 2013; Putnam et al., 2010a, 2012, 2013a,b; Kelley et al., 2014), thus is worthy of discussion here.

Due to the number of samples available, the dataset presented in Chapter 6, from the Mangaehuehu catchment on Mt. Ruapehu, affords the best opportunity to analyse this problem. These samples exhibit a negatively skewed distribution, with a cluster of ages around 14-11 $\mathrm{ka}$ and a tail of younger ages. This type of age distribution is commonly observed and is attributed to 'geological processes' that act to suppress, or 
reduce cosmogenic nuclide concentrations, for example via shielding or erosion (Applegate et al., 2012). In Chapter 6, I use a coupled topographic diffusion / cosmogenic ${ }^{3} \mathrm{He}$ production model to show that the scatter observed in the Mangaehuehu dataset can be explained by the process of moraine diffusion, whereby exhumation of previously shielded boulders from within the moraine subsurface generates a population of surface boulders with a negatively skewed distribution of surface exposure ages. Topographic cross-profiles across moraines of MIS 4 and MIS 2 age in the Mangatepopo valley (Chapter 5) provide an opportunity to examine this possibility over longer timescales. The older landforms exhibit lower-angle slopes and wider ridge crests, compared to younger moraines, which is indicative of topographic diffusion.

Additional support for the moraine diffusion hypothesis comes from the ${ }^{3} \mathrm{He}$ measurements of debris avalanche material presented in Chapter 4 . These four relatively consistent measurements come from boulders well-embedded within a sediment body that has low surface slopes, therefore is not undergoing diffusion. The coherence of this small dataset, which have a similar exposure duration to the samples from Chapter 6, suggests that moraine diffusion may be the critical process leading to scatter. However, it is important to note that the elevation difference between these two sites is c. 800-900 $\mathrm{m}$, thus the higher elevation moraine samples are subject to greater annual precipitation totals and lower minimum temperatures, which may promote surface erosion of boulders, as well as moraine diffusion through physical weathering (e.g. freeze-thaw cycles).

I believe local climate is a major factor causing the observed scatter of moraine boulder surface exposure ages presented here. Support for this notion is provided by comparing the datasets presented in this thesis to cosmogenic moraine chronologies from the Southern Alps. Annual precipitation totals in the study sites of this thesis are c. 2000-3000 mm (Tait et al., 2006), which may contribute to chemical weathering of boulder surfaces and physical erosion and transport of moraine sediment. The altitude of sample sites (c. 1000-1800 m asl) means that freeze-thaw cycles contribute to physical erosion of moraines (Figure 8.1). Previous study sites in the Mackenzie Basin are lower in elevation and are situated within a rain shadow created by the central Southern Alps, which reduces local potential for boulder and moraine degradation. This interpretation is similar to that suggested by Applegate et al. (2008), who ascribe the scatter observed in the Waiho Loop exposure age dataset of Barrows et al. (2007b) to moraine diffusion processes in the hypermaritime setting.

Although I have provided evidence that moraine diffusion contributes towards the scatter in the exposure age datasets, it is difficult to resolve the relative contributions from all possible processes. Surface erosion of sampled boulders is also likely to have 


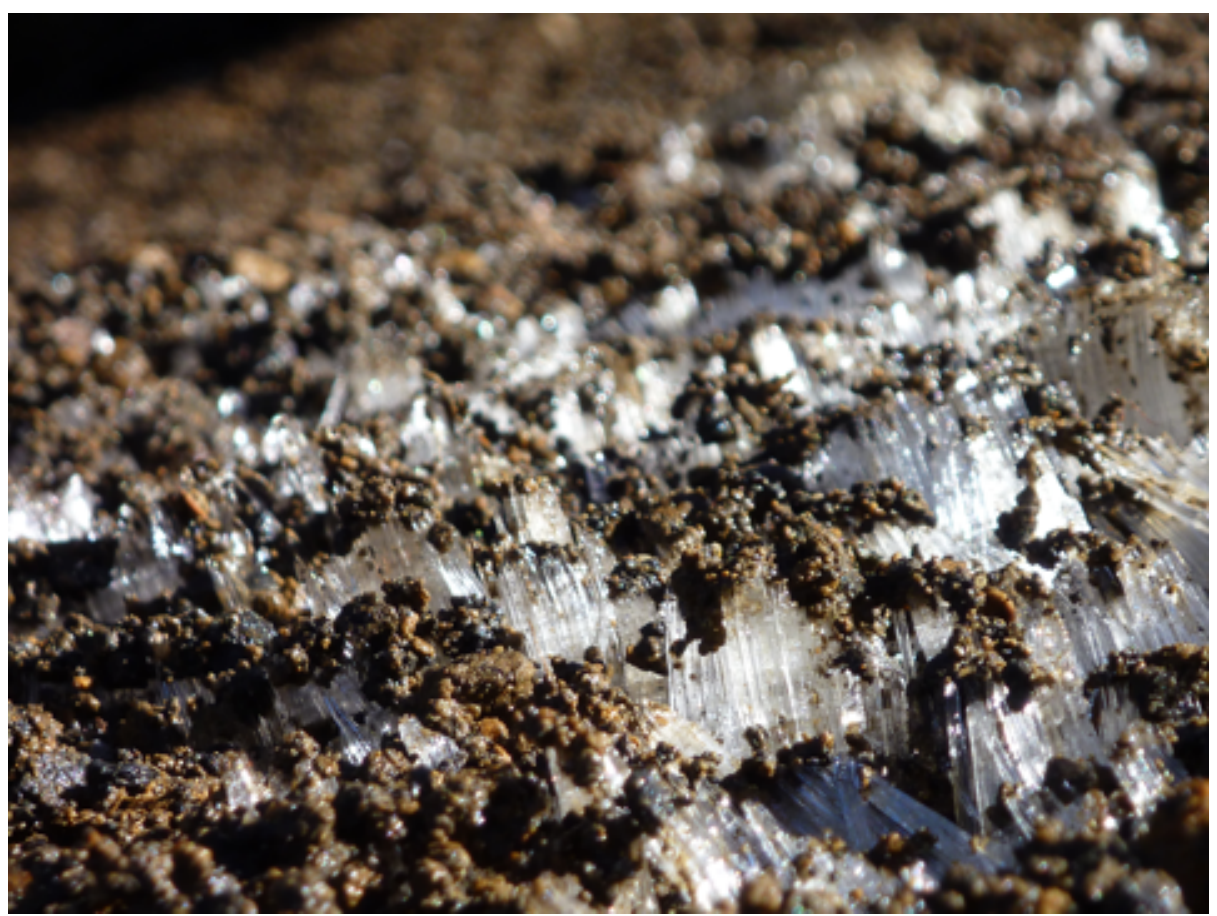

Figure 8.1: Ice needles (c. 2-4 cm) lifting silt - fine gravel particles on the LG1 moraine in the Mangaehuehu catchment. Field observations from several locations on both volcanoes show this process is capable of lifting large cobbles and small boulders. [7 May 2012]

occurred over the duration of boulder exposure, however the absence of resistant mineral veins in the local igneous rocks precludes quantitative constraint of this effect. Future work should integrate surface erosion effects into moraine diffusion model experiments. Volcanic processes (e.g. tephra fall) may also contribute some uncertainty to the observed exposure age distributions, although I have shown in Chapters 5 and 6 that shielding beneath ash fallout is is unlikely to change the main conclusions.

\subsubsection{When did glaciers in central North Island reach their maximum extent during the last glacial cycle?}

\subsubsection{Timing of glacier fluctuations}

Cosmogenic ${ }^{3} \mathrm{He}$ surface exposure ages from Mangatepopo valley show that glacier extent on Tongariro massif peaked prior to $58 \mathrm{ka}$, probably during MIS 4 (c. 65-60 ka). Renewed valley glaciation occurred by $31 \pm 3 \mathrm{ka}$ and remained extended until c. 21 $\pm 2 \mathrm{ka}$. The downstream limit of MIS 4 glaciation in Mangatepopo valley is relatively poorly resolved due to the paucity of geomorphic evidence. However, moraine M3 is $<100$ m outboard of the 21 ka moraine (M2), which suggests similar or slightly greater ice extent prior to the global LGM. 
Re-investigation of the moraine (M2) tephrostratigraphy in Mangatepopo valley, including addition of major element analyses of rhyolite horizons, has provided new insight into the timing of deglaciation. The findings presented in Chapter 5 suggest that the Waiohau Tephra is situated c. $20 \mathrm{~cm}$ above the moraine surface, whilst reworked pockets of this tephra are also present c. $30-40 \mathrm{~cm}$ higher in the soil sequence. In combination with the cosmogenic surface exposure ages from the moraine crest, this shows that the Mangatepopo glacier retreated from the moraine crest at c. $21 \mathrm{ka}$, and had undergone significant retreat prior to $14 \mathrm{ka}$. Deformation structures, possibly caused by frost creep processes, indicate probable cold conditions at some time after $14 \mathrm{ka}$.

The timing of glacier fluctuations on Mt. Ruapehu during the last glacial cycle is less well constrained by direct dating. However the close proximity of glaciated catchments to Tongariro massif and similar morphology of moraines permits correlation on morphostratigraphic grounds. This is supported by similar soil-tephra stratigraphy found overlying moraines in Whakapapaiti valley, which is used to correlate these features to the LGCP. Cosmogenic surface exposure ages from Wahianoa catchment on southeast Ruapehu indicate valley glaciation persisted until c. $18 \mathrm{ka}$.

\subsubsection{Implications for possible climate drivers}

The chronological results from Tongariro massif indicate that glaciers in central North Island fluctuated in phase with those in the Southern Alps during the last glacial cycle. This adds to a growing body of research that suggests an 'early' onset, or 'extended' period of peak glacial conditions in New Zealand c. 30-18 ka (Vandergoes et al., 2005; Alloway et al., 2007; Newnham et al., 2007; Barrell et al., 2013; Putnam et al., 2013b; Rother et al., 2014). Greatest ice extent and cooling appears to have occurred early in this window (c. 30-26 ka), during rising local summer insolation intensity and decreasing summer (and increasing winter) duration (Huybers and Denton, 2008). Furthermore, cold conditions prevailed until at least $18 \mathrm{ka}$, which coincides with a peak in local summer insolation intensity and a minimum in austral summer duration.

Vandergoes et al. (2005) argue that early southern cooling at the onset of the LGCP was driven by the minimum in austral summer insolation intensity at c.32 ka. This explanation accords with the timing of glaciation in central North Island (e.g. moraine M1 - Mangatepopo), however it does not satisfy geological evidence for the continuation of glacial conditions through the global LGM (c. 19-26 ka; Clark et al., 2009), when austral summer intensity was increasing (Mercer, 1984). It also does not explain 
recent evidence for extensive glaciation in the Southern Alps at c. $42 \mathrm{ka}$ (Kelley et al., 2014), which also coincides with a local insolation intensity maximum. Newnham et al. (2012) postulate that the extended LGM in New Zealand results from an early manifestation of the bipolar see-saw, whereby warming in Greenland during Greenland Interstadial 3 and 4 (c. 29 - $28 \mathrm{ka}$ ), was counterbalanced by increased export of heat from the Southern Ocean (Crowley, 1992; Broecker, 1998). These events fall within the production rate errors of the cosmogenic ${ }^{3} \mathrm{He}$ chronology from Mangatepopo valley, but can not explain the Lake Ohau glacial maximum at $32.5 \pm 1 \mathrm{ka}$ (Putnam et al., 2013b). Putnam et al. (2013b) present a hybrid hypothesis, whereby New Zealand glaciers respond to air temperature anomalies driven by stratification of the Southern Ocean in response to orbital forcing of winter duration (cf. Huybers and Denton, 2008), coupled with millennial-scale fluctuations of the sub-tropical front (e.g. De Deckker et al., 2012). Broecker (2013) hypothesises that glacier fluctuations are fundamentally driven by the radiative effects of changing atmospheric $\mathrm{CO}_{2}$. Further constraint of the timing and magnitude of past glacier fluctuations, particularly prior to MIS 2 (e.g. Kelley et al., 2014; Schaefer et al., 2015), will help to resolve the relative roles of these hypothesised climate drivers.

\subsubsection{How cold was was the Last Glacial Cold Period in central North Island?}

\subsubsection{Equilibrium line altitude reconstructions}

Manual reconstruction of the LGCP valley glacier in Mangatepopo valley indicates the local ELA was between 1400-1550 m asl (MELM; AAR =0.67). This is c. $930-1080 \mathrm{~m}$ lower than present $(2483 \pm 55 \mathrm{~m}$ asl), according to the glacier survey of Keys (1988). Iteratively applying air temperature lapse rates of -4 to $-7^{\circ} \mathrm{C} \mathrm{km}^{-1}$, I calculate a probability distribution of palaeotemperature estimates centred on $5.6 \pm 1.1^{\circ} \mathrm{C}(1 \sigma)$.

\subsubsection{Numerical glacier modelling}

Physically-based numerical glacier modelling of past ice geometries provides a more objective, robust means of constraining past climate variation (Plummer and Phillips, 2003; Doughty et al., 2013). This is especially the case where a paucity of geomorphic evidence can preclude accurate constraint of former ice margins in accumulation areas (Rea et al., 1999). 
Matching glacier model outputs to geologically constrained LGCP ice margins in 9 catchments across both volcanoes, I derive palaeotemperature estimates between -4 and $-7^{\circ} \mathrm{C}$, relative to present. Palaeo-equilibrium line altitudes ( $p$ ELAs) for the simulated glaciers range between c. $1400-1650 \mathrm{~m}$ asl, which represent depressions of 800-1100 m below present. In the Mangatepopo valley, the model-simulated glacier has a $p$ ELA of $1510 \mathrm{~m}$ asl (970 m below present) and best fits the LGCP moraines when temperature is reduced by $6{ }^{\circ} \mathrm{C}$ relative to present, and precipitation is held at present day levels. These results agree well with the manual $p$ ELA reconstructions presented in Chapter 5 (particularly the MELM estimate), despite the complex ice geometry.

Two results stand out from this work. First, the Wahianoa (WAH - Chapter 7) catchment on southeast Ruapehu requires an anomalously low temperature change (c. $-4{ }^{\circ} \mathrm{C}$ ) to simulate the LGCP glacier, in comparison with the rest of the catchments studied. Second, estimates of palaeotemperaure change from catchments on Mt. Ruapehu are systematically lower than those from Tongariro massif, by c. $1{ }^{\circ} \mathrm{C}$. Accounting for known topographic changes since the LGCP (see below) does not resolve these differences.

The result from the Wahianoa catchment is difficult to explain. Cosmogenic surface exposure ages provide reasonable age constraint and there is little geomorphic evidence for greater ice extent outboard of the moraines targeted in Chapter 7. It is possible that topographic change in the upper catchment may have changed the flow divides, but this is difficult to reconstruct and geomorphic evidence is absent.

The difference in palaeotemperature estimates between the volcanoes is also somewhat enigmatic and reflects uncertainty of several aspects of the experiment. A likely candidate for causing this difference is the uncertainty in present-day precipitation distribution and annual totals, which arises due to the paucity of high-altitude climate station measurements. I use empirical precipitation data from $>1000 \mathrm{~m}$ asl on Mt. Ruapehu to create the modern climate grids, however no such measurements are available from Tongariro massif. Thus, the palaeotemperature estimates may reflect an underestimation of precipitation on Tongariro. Similarly, changing precipitation patterns in the past may also contribute to this difference. Synoptic type frequency change at the LGCP (Lorrey et al., 2012b) may have changed the north-south precipitation gradient, meaning snow accumulation on Tongariro massif may be underestimated in the climate datasets. Finally, poor fit between the modeled ice mass and the moraines in two catchments on Tongariro massif causes overestimation of the temperature forcing. This poor fit may arise from model resolution, post-glacial infilling of valley floors by volcanic products, or uncertainty in flow parameters. 


\subsubsection{Topographic change}

The glacier simulations described above used models of the present day elevation as input for the glacier bed topography. This assumes that topography during the LGCP was similar to today. However, radiometric dating of lava flows (e.g. Hobden et al., 1996; Gamble et al., 2003) and stratigraphic investigations of tephra and debris avalanche deposits (e.g. Palmer and Neall, 1989; Moebis et al., 2011) suggest that this is not the case.

To assess the influence of possible changes in bed topography since the LGCP, I re-ran model simulations over a reconstructed $>15 \mathrm{ka}$ topography created by GNS Science geologists currently researching on the volcanic history of this region. This result generally increased the magnitude of cooling necessary to simulate the LGCP glaciers, by up to $0.5^{\circ} \mathrm{C}$. This reflects the the general lowering of the bed, caused by removal of post-glacial lava flows. The topographic reconstruction is probably biased towards such changes, which are more readily identifiable in the landscape. Furthermore, pre-historic topographies are difficult to constrain, particularly following destructional events. In these simulations, one catchment required lower magnitude cooling, which represents changes to the upper catchment boundaries that have reduced the ice flux into this valley, relative to the simulations using modern topography.

Accounting for known topographic changes did not improve the mis-matches in palaeotemperature estimates discussed above. This suggests that, either, (i) some topographic changes are unaccounted for; (ii) the mis-matches represent chronological uncertainties arising from the morphostratigraphic correlation; (iii) climatic gradients were significantly different between the LGCP and today; or (iv) some combination of the aforementioned possibilities. However, the relatively minor effects of topographic change on palaeotemperature estimates, as demonstrated here using glacier modelling, does provide increased confidence in the atmospheric cooling estimate of $4-7^{\circ} \mathrm{C}$ in central North Island, during the LGCP. 


\subsubsection{Did glaciers in central North Island respond to the late-glacial climate reversal in New Zealand?}

\subsubsection{Geomorphological and geochronological evidence}

In Chapter 6, I present geomorphological evidence from 3 adjacent valleys that contain moraines situated intermediate to the present day glacier termini and the ice limits of the LGCP. In the Mangaehuehu catchment, these moraines (termed 'LG' in Chapter 6) were previously correlated with the LGCP by McArthur and Shepherd (1990). My own field investigations support the interpretation of Barrell (2011) that the former Mangaehuehu glacier extended further down valley during the LGCP, which implies a younger age for the LG moraines. This interpretation is further supported by the glacier model simulations presented in Chapter 7, which predict that the glacier terminus in this catchment extended down valley of the LG moraines, when temperatures are reduced by $>4{ }^{\circ} \mathrm{C}$. The LG moraines overlie finely laminated glaciolacustrine sediments that display evidence for ductile and brittle deformation which suggests the Mangaehuehu glacier re-advanced to the location of the LG moraines, following an unknown amount of retreat.

Cosmogenic ${ }^{3} \mathrm{He}$ surface exposure ages of the LG moraines yield an arithmetic mean age of $13.4 \pm 1.3 \mathrm{ka}$, after removal of outliers (see above for discussion of scatter). This accords with the best-estimate derived from simulations using a topographic diffusion model (e.g. Applegate et al., 2010). A less robust exposure age dataset from the adjacent Te Unuunuakapuateariki catchment, affords slightly older ages, but these landforms may represent composite features that were occupied multiple times. The glaciers that deposited the dated and inferred late-glacial moraines identified in this study can be simulated by a numerical glacier model, using a common climatic forcing. This supports the interpretation of coeval deposition.

\subsubsection{Climatic significance}

Glacier model experiments presented in Chapter 6 show that a change in temperature of $-2.9^{\circ} \mathrm{C}$ (when precipitation remains unchanged), relative to present, is necessary to simulate a steady-state glacial geometry on southern Mt. Ruapehu that accords with the geomorphological and geochronological constraints. As precipitation for this time period is relatively poorly constrained, I show that the likely cooling for this event lies between $2.5-3.4{ }^{\circ} \mathrm{C}$, which represents the range of temperature change necessary to balance precipitation changes of $\pm 20 \%$ from present. This finding is indistinguishable 
from that of Doughty et al. (2013) for the ACR glacier in Irishman Stream $\left(44^{\circ} \mathrm{S}\right)$ and similar to that for nearby Whale Stream (Kaplan et al., 2013). The modelling experiments in the aforementioned study were conducted using the same model formulations for mass balance and ice flow and forced by climatic data from the same source, which facilitates robust comparison of palaeotemperature estimates. Thus, these findings indicate that glaciers between $39-44^{\circ} \mathrm{S}$ register a similar magnitude of cooling (c. 2-3 $\left.{ }^{\circ} \mathrm{C}\right)$ during the late-glacial climate reversal in New Zealand.

Recent pollen-based temperature reconstructions indicate a lower amplitude LGR temperature change in North Island, compared to South Island (Newnham et al., 2012). Previous research has suggested the late-glacial climate reversal was characterised by changing seasonality, as indicated by stronger response of summer-sensitive proxies such as chironomids, compared to winter-sensitive proxies such as vegetation (Vandergoes et al., 2008). Numerical model experiments suggest glacier lengths fluctuations on Mt. Ruapehu are most sensitive to summer temperature. This accords with previous, similar investigation of seasonal sensitivity of Franz Josef Glacier (Oerlemans and Reichert, 2000) and suggests moraine records may be biased towards summer temperature changes. Thus, changing seasonality during the late-glacial climate reversal, with greater summer cooling, represents a possible explanation for the discrepancy between glacier- and pollen-based palaeotemperature estimates.

Uniform terrestrial cooling (at least during summer) across New Zealand during the ACR does not accord with changes in the oceans at this time. Carter et al. (2008) find little to no response of sea surface temperature north of the sub-tropical front through this period. They implicate greater southward flux of sub-tropical water to the vicinity of New Zealand, which is consistent with increasing tropical foram abundances at the site. Air temperature anomalies in New Zealand are intimately connected to the oceans, however this connection is bridged by regional atmospheric circulation (Salinger, 1980b). Thus, I hypothesise that the differential oceanic and atmospheric temperature response observed for North Island during the ACR may be reconciled by a synoptic type frequency change, whereby enhanced southerly- and suppressed northerly airflow, particularly during summer, lowers air temperatures across New Zealand. Analogous conditions occur today during El Niño events (Jiang et al., 2013). Given the increasing number of well-resolved palaeoclimate reconstructions for this period, future research should aim to test this hypothesis using a regional climate regime classification approach (e.g. Lorrey et al., 2012b, 2014; see below). 


\subsection{Further research}

\subsubsection{Refined estimates of local cosmogenic ${ }^{3} \mathrm{He}$ production}

In Chapter 4, I show that the time-integrated (11- $0 \mathrm{ka}$ ) production rate of cosmogenic ${ }^{3} \mathrm{He}$ in New Zealand is well approximated by an existing compilation of calibration sites (Goehring et al., 2010). However, the paucity of suitable andesitic samples in the Murimotu Formation debris avalanche precludes refinement of the c. $10 \%$ uncertainty associated with the compiled production rate. It is desirable to reduce these uncertainties, through further addition of local calibration sites with robust sample sizes, in order to reduce the external uncertainties associated with surface exposure age calculation (e.g. Putnam et al., 2010b).

Throughout the developmental stages of my doctoral research, I considered many potential sites for local calibration of cosmogenic ${ }^{3} \mathrm{He}$ in New Zealand. The Murimotu Formation provided the best potential for development of a robust, independent chronology using radiocarbon, although other possible sites of late-glacial-Holocene age are worthy of future reconnaissance work. For example, Saddle Cone lava flow on the lower, northern flanks of Mt Ruapehu $\left(-39.22^{\circ}, 175.61^{\circ}\right)$, is a widespread deposit that flowed below the altitude of the modern day treeline (c. $1300 \mathrm{~m}$ asl), therefore may have buried organic material suitable for radiocarbon dating. On Tongariro massif, the post-glacial, valley-filling lava flow in the Oturere Valley $\left(-39.17^{\circ}, 175.68^{\circ}\right)$ provides a similar depositional setting. Fluvial incision at the margins of both of these lava bodies affords the opportunity for natural exposure of buried organic horizons. Furthermore, both flows display well-preserved flow structures at the surface, such as pressure ridges, which indicate minimal surface erosion - ideal for cosmogenic surface exposure sampling of the in situ lava.

I believe there is little scope for cosmogenic ${ }^{3} \mathrm{He}$ production rate calibration on the central North Island volcanoes over timescales >c. $15 \mathrm{ka}$. Lava flows and debris avalanche deposits in this age range have either been subject to previous burial by glacial advance, or exist at sufficiently low elevations to have been buried by soil/tephra.

On Mt. Taranaki in eastern North Island, debris avalanche deposits of similar appearance to the Murimotu Formation provide another potential site for production rate calibration. Of the the three main debris avalanche formations mapped by Neall (1979), the Pungaraehu and Opua formations probably afford the best opportunity for such work, due to their relative youth $(<23 \mathrm{ka})$, which means they remain well preserved at the land surface and are potentially dateable within the radiocarbon time frame. 


\subsubsection{Development of other cosmogenic nuclides for use in the south west Pacific}

Cosmogenic chlorine-36 $\left({ }^{36} \mathrm{Cl}\right)$ was the first in situ cosmogenic nuclide detected in terrestrial material (Davis and Schaeffer, 1955) and remains an important tool for earth science research, particularly in carbonate and basalt domains. In the south west Pacific, ${ }^{36} \mathrm{Cl}$ has been used in surface exposure dating applications to constrain the timing of mountain glacier fluctuations (Barrows et al., 2002, 2007a, 2013; Mackintosh et al., 2006), but has also been widely applied elsewhere in the world to constrain rates of palaeoseismicity (e.g. Schlagenhauf et al., 2010). The half-life of ${ }^{36} \mathrm{Cl}$ (c. $300 \mathrm{ka}$ ) also provides an opportunity to investigate complex exposure histories, when paired with other nuclides (e.g. ${ }^{10} \mathrm{Be},{ }^{3} \mathrm{He}$ ).

The accuracy of ${ }^{36} \mathrm{Cl}$ surface exposure dates is currently hampered by uncertainty in the production rates. Production of ${ }^{36} \mathrm{Cl}$ occurs via several pathways: spallation on potassium $(\mathrm{K})$ and calcium $(\mathrm{Ca})$, and to a lesser extent, iron (Fe) and titanium (Ti); negative muon capture by $\mathrm{K}$ and $\mathrm{Ca}$; and thermal neutron capture by ${ }^{35} \mathrm{Cl}$ (Dunai, 2010). The high abundance of ${ }^{35} \mathrm{Cl}$ in nature and the complex controls on thermal neutron flux are likely to be the main reasons for the existing uncertainty in ${ }^{36} \mathrm{Cl}$ production rates (Schimmelpfennig et al., 2009). Schimmelpfennig et al. (2009) show that ${ }^{36} \mathrm{Cl}$ surface measurements in bulk rock basalt samples are systematically higher than those derived from separated, pre-treated K-feldspar phases in the same sample. They conclude that preferential hosting of ${ }^{35} \mathrm{Cl}$ in the groundmass has been unaccounted for in previous spallation production rate calibration studies and that mineral separates with low $\mathrm{Cl}$ content should be used instead of bulk rock samples.

These findings, combined with developments presented in Chapter 4, present an opportunity to further develop cosmogenic ${ }^{36} \mathrm{Cl}$ extraction and constrain production rates for the New Zealand region. Samples from the andesitic megaclasts deposited during the Murimotu Formation debris avalanche contain abundant pyroxene and K-feldspar, which can be easily separated from bulk rock samples using magnetic and density techniques (Chapter 4). Furthermore, the depositional setting and new, robust, independent radiocarbon age constraint of this event, provide an ideal setting for cosmogenic nuclide production rate calibration (Chapter 4). I propose that this site should be utilised, with the following aims: (i) to establish a Cl-decontamination scheme for measurement of ${ }^{36} \mathrm{Cl}$ in pyroxene; and (ii) calibration of local $\mathrm{K}$ and $\mathrm{Ca}$ spallation production rates of in situ cosmogenic ${ }^{36} \mathrm{Cl}$. All of the capabilities required to achieve this work (mineral separation, major element analysis, dissolution experiments), except for accelerator mass spectrometry, are available at Victoria University of 
Wellington. The results would increase the utility of ${ }^{36} \mathrm{Cl}$ for geoscientific applications in the south west Pacific, particularly in older (several Myr) igneous domains such as Banks Peninsula and the sub-Antarctic Islands, where high uncertainties in cosmogenic ${ }^{3} \mathrm{He}$ may be incurred due to potential magmatic/nucleogenic sources.

\subsubsection{What caused the Antarctic Cold Reversal?}

The results presented in Chapter 6 and the recent findings of several other climate reconstruction studies indicate that air temperatures from the sub-Antarctics to northern New Zealand declined by $2-3^{\circ} \mathrm{C}$ during the Antarctic Cold Reversal (c.14.6 - $12.7 \mathrm{ka}$ ). The ultimate cause of this cooling remains unknown. It is commonly accepted that this southern cooling event represents a bipolar seesaw effect, whereby resumption of overturning in the North Atlantic (AMOC) leads to net heat export from the Southern Ocean (Crowley, 1992). But what triggered this? One possibility is that AMOC recovery occurred in response to cessation of freshwater input to the North Atlantic at the end of Heinrich Stadial 1 (Liu et al., 2009). Another possibility is that AMOC was restarted by a meltwater pulse delivered to the Southern Ocean from Antarctica (Weaver et al., 2003). Comparing the effects of each of these hypotheses predicted by coupled atmospheric/oceanic circulation models (e.g. Weaver et al., 2003; Liu et al., 2009; He et al., 2013), to proxy data could provide an effective evaluation of these proposed triggers.

Quantitative palaeoclimate reconstructions from New Zealand are well situated to help resolve these outstanding questions and there is a growing number of well-dated, point-based proxy records. Glacier model applications such as that presented in Chapter 6 and Doughty et al. (2013), conducted at the growing number of sites with dated moraines that depict glacial geometries during the Antarctic Cold Reversal, would permit detailed analysis of the spatial pattern of cooling during this event. Integrating such results with other, well-dated quantitative and qualitative palaeoclimate reconstructions (e.g. Newnham et al., 2012; Stephens et al., 2012a), using an approach such as that of Lorrey et al. (2014), would provide a holistic assessment of temperature, precipitation and synoptic type frequency anomalies that characterised this cooling event. Comparison of these spatially distributed, proxy-driven reconstructions to climate model outputs (e.g. Liu et al., 2009; He et al., 2013) would help to test the existing hypotheses that seek to explain the climatic driver(s) at this time. 


\subsubsection{Holocene glacier fluctuations in the Southern Hemisphere}

Constraining the timing and magnitude of glacier fluctuations during the Holocene provides important context for current glacial retreat, as well as important insight to the controls on glacier extent under interglacial climatic conditions. Recent ${ }^{10} \mathrm{Be}$ chronologies from the Southern Alps have noted important differences from the well-established Northern Hemisphere based model of Holocene climate change. For example, whilst northern glaciers were similar to or smaller in extent than present during the early Holocene (e.g. Goehring et al., 2011), moraine chronologies from New Zealand show that glacier termini slowly retreated between their late-glacial and present positions from c. 13 ka until at least c. 6-7 ka (Schaefer et al., 2009; Putnam et al., 2012; Kaplan et al., 2013). Mueller Glacier achieved its pre-industrial extent by c. $3.5 \mathrm{ka}$, and fluctuated about this position until the mid-1900s (Schaefer et al., 2009). Meanwhile, glaciers in the Arrowsmith and Ben Ohau ranges also achieved their pre-industrial positions prior to the 'Little Ice Age' (LIA; c. 1450 - 1850 AD) (Putnam et al., 2012; Kaplan et al., 2013). This contrasts with a large body of evidence from glaciers in the Northern Hemisphere, which were generally more extensive during this historical cold spell than at any other time in the Holocene. Recent compilation of palaeoclimate proxy records for the New Zealand region suggest that the mean climate state for the LIA was characterised by lower temperatures (summer temperatures were depressed by $0.6 \pm$ $0.3^{\circ} \mathrm{C}$ ), increased precipitation and lower than present sea surface temperatures in the Tasman Sea (Lorrey et al., 2014). This study attributes these conditions to increased frequency of weak El Niño-Modoki and negative Southern Annular Mode.

The geomorphological records of glacier fluctuations on Mt. Ruapehu provide the opportunity to contribute to our understanding of LIA, and potentially pre-LIA, Holocene climate variability in New Zealand. Two catchments in particular contain suites of moraines that constrain Holocene ice geometries - based on historical photographic evidence, morphostratigraphic correlation and preliminary cosmogenic ${ }^{3} \mathrm{He}$ surface exposure dates. In the Mangaehuehu catchment, prominent lateral moraines extend c. $500 \mathrm{~m}$ down valley from the current glacier terminus. Historical photographic evidence shows that the surface of the Mangaehuehu glacier was close to these limits in the early 20th century. Older, more fragmentary moraine landforms also exist outboard of these former glacier limits, but upstream of the late-glacial moraines described in Chapter 6. I have a preliminary set of cosmogenic ${ }^{3} \mathrm{He}$ surface exposure dates that suggest the glacier was extended at c. 5-6 ka (outboard moraines) and 0.8-0.2 ka (inboard moraines). On the northwest of Mt. Ruapehu, an even greater number of Holocene moraines are preserved immediately down valley of the present-day Mangatoetoenui glacier. No sampling of boulders on these landforms has yet been undertaken for cosmogenic 
surface exposure dating. Constraining the age and ELA depressions/model-based temperature depressions associated with these former glacial geometries will increase the spatial and temporal coverage of quantitative Holocene temperature estimates in New Zealand. Results from such work would provide increased constraint on the amplitude of natural climate fluctuations during global interglacial conditions and help to test hypothesised drivers of Holocene climate change (e.g. Putnam et al., 2012). 


\section{Bibliography}

Ackert, R. P., Singer, B. S., Guillou, H., Kaplan, M. R., and Kurz, M. D. (2003). Long-term cosmogenic ${ }^{3} \mathrm{He}$ production rates from ${ }^{40} \mathrm{Ar} /{ }^{39} \mathrm{Ar}$ and $\mathrm{K}$-Ar dated Patagonian lava flows at $47^{\circ} \mathrm{S}$. Earth and Planetary Science Letters, 210(1-2):119-136.

Adhemar, J. (1842). Revolutions de la Mer: Déluges Périodiques. Carilian-Goeury et V. Dalmont, Paris, France.

Agassiz, L. (1840). Études sur les glaciers. Jent and Gassmann, Neuchâtel, France.

Ahn, J. and Brook, E. J. (2008). Atmospheric $\mathrm{CO}_{2}$ and climate on millennial time scales during the last glacial period. Science, 322(5898):83-85.

Alexander, D., Davies, T., and Shulmeister, J. (2014). Formation of the waiho loop terminal moraine, new zealand. Journal of Quaternary Science, 29(4):361-369.

Allen, C. S., Pike, J., and Pudsey, C. J. (2011). Last glacial-interglacial sea-ice cover in the SW Atlantic and its potential role in global deglaciation. Quaternary Science Reviews, 30(19-20):2446-2458.

Alloway, B. V., Lowe, D. J., Barrell, D. J. A., Newnham, R. M., Almond, P. C., Augustinus, P. C., Bertler, N. A. N., Carter, L., Litchfield, N. J., McGlone, M. S., Shulmeister, J., Vandergoes, M. J., Williams, P. W., et al. (2007). Towards a climate event stratigraphy for New Zealand over the past 30000 years (NZ-INTIMATE project). Journal of Quaternary Science, 22(1):9-35.

Almond, P., Moar, N., and Lian, O. (2001). Reinterpretation of the glacial chronology of South Westland, New Zealand. New Zealand Journal of Geology and Geophysics, 44(1):1-15.

Amidon, W. H. and Farley, K. A. (2011). Cosmogenic ${ }^{3}$ He production rates in apatite, zircon and pyroxene inferred from Bonneville flood erosional surfaces. Quaternary Geochronology, 6(1):10-21.

Amidon, W. H. and Farley, K. A. (2012). Cosmogenic ${ }^{3} \mathrm{He}$ and ${ }^{21} \mathrm{Ne}$ dating of biotite and hornblende. Earth and Planetary Science Letters, 313-314(1):86-94. 
Amidon, W. H., Farley, K. A., Burbank, D. W., and Pratt Sitaula, B. (2008). Anomalous cosmogenic ${ }^{3} \mathrm{He}$ production and elevation scaling in the high Himalaya. Earth and Planetary Science Letters, 265(1-2):287-301.

Amidon, W. H., Rood, D. H., and Farley, K. A. (2009). Cosmogenic ${ }^{3} \mathrm{He}$ and ${ }^{21} \mathrm{Ne}$ production rates calibrated against ${ }^{10} \mathrm{Be}$ in minerals from the Coso volcanic field. Earth and Planetary Science Letters, 280(1-4):194-204.

Anderson, B., Lawson, W., Owens, I., and Goodsell, B. (2006). Past and future mass balance of 'Ka Roimata o Hine Hukatere' Franz Josef Glacier, New Zealand. Journal of Glaciology, 52(179):597-607.

Anderson, B. and Mackintosh, A. (2006). Temperature change is the major driver of late-glacial and Holocene glacier fluctuations in New Zealand. Geology, 34(2):121-124.

Anderson, B. and Mackintosh, A. (2012). Controls on mass balance sensitivity of maritime glaciers in the Southern Alps, New Zealand: The role of debris cover. Journal of Geophysical Research: Earth Surface, 117(F1):F01003.

Anderson, B., Mackintosh, A., Stumm, D., George, L., Kerr, T., Winter Billington, A., and Fitzsimons, S. (2010). Climate sensitivity of a high-precipitation glacier in New Zealand. Journal of Glaciology, 56(195):114-128.

Anderson, R. F., Ali, S., Bradtmiller, L. I., Nielsen, S. H. H., Fleisher, M. Q., Anderson, B. E., and Burckle, L. H. (2009). Wind-driven upwelling in the southern ocean and the deglacial rise in atmospheric CO2. Science, 323(5920):1443-1448.

Andrews, J. (1975). Glacial Systems. An Approach to Glaciers and Their Environments. Duxbury Press, North Scituate, USA.

Applegate, P. J., Lowell, T. V., and Alley, R. B. (2008). Comment on "absence of cooling in New Zealand and the adjacent ocean during the Younger Dryas chronozone". Science, 320(5877).

Applegate, P. J., Urban, N. M., Keller, K., Lowell, T. V., Laabs, B. J. C., Kelly, M. A., and Alley, R. B. (2012). Improved moraine age interpretations through explicit matching of geomorphic process models to cosmogenic nuclide measurements from single landforms. Quaternary Research, 77(2):293-304.

Applegate, P. J., Urban, N. M., Laabs, B. J. C., Keller, K., and Alley, R. B. (2010). Modeling the statistical distributions of cosmogenic exposure dates from moraines. Geoscientific Model Development, 3:293-307. 
Arz, H. W., Pätzold, J., and Wefer, G. (1998). Correlated millennial-scale changes in surface hydrography and terrigenous sediment yield inferred from last-glacial marine deposits off northeastern Brazil. Quaternary Research, 50(2):157-166.

Atkins, C. B. (2003). Characteristics of striae and clast shape in glacial and non-glacial environments. Phd thesis, Victoria University of Wellington.

Aubry, M.-P., Van Couvering, J. A., Christie-Blick, N., Landing, E., Pratt, B. R., Owen, D. E., and Ferrusquia-Villafranca, I. (2009). Terminology of geological time: Establishment of a community standard. Stratigraphy, 6(2):100-105.

Augustinus, P., Cochran, U., Kattel, G., D'Costa, D., and Shane, P. (2012). Late Quaternary paleolimnology of Onepoto maar, Auckland, New Zealand: implications for the drivers of regional paleoclimate. Quaternary International, 26:389-401.

Balco, G. (2011). Contributions and unrealized potential contributions of cosmogenicnuclide exposure dating to glacier chronology, 1990-2010. Quaternary Science Reviews, 30(1):3-27.

Balco, G., Stone, J. O., Lifton, N. A., and Dunai, T. J. (2008). A complete and easily accessible means of calculating surface exposure ages or erosion rates from ${ }^{10} \mathrm{Be}$ and ${ }^{26} \mathrm{Al}$ measurements. Quaternary Geochronology, 4:93-107.

Barker, S., Diz, P., Vautravers, M. J., Pike, J., Knorr, G., Hall, I. R., and Broecker, W. S. (2009). Interhemispheric Atlantic seesaw response during the last deglaciation. Nature, 457(7233):1097-1102.

Barnola, J., Raynaud, D., Lorius, C., and Korotkevich, Y. (1987). Vostok ice core provides 160,000-year record of atmospheric $\mathrm{CO}_{2}$. Nature, 329:408-414.

Barrell, D. J. A. (2011). Quaternary glaciers of New Zealand. In Ehlers, J., Gibbard, P., and Hughes, P., editors, Developments in Quaternary Science, volume 15, pages 1047-1064. Elsevier, Amsterdam, The Netherlands.

Barrell, D. J. A. (2014). The Balmoral moraines near Lake Pukaki, Southern Alps: a new reference area for the early Otira Glaciation in New Zealand. New Zealand Journal of Geology and Geophysics, 57:442-452.

Barrell, D. J. A., Almond, P. C., Vandergoes, M. J., Lowe, D. J., and Newnham, R. M. (2013). A composite pollen-based stratotype for inter-regional evaluation of climatic events in New Zealand over the past 30,000 years (NZ-INTIMATE project). Quaternary Science Reviews, 74:4-20. 
Barrell, D. J. A., Andersen, B. G., and Denton, G. H. (2011). Glacial geomorphology of the central South Island, New Zealand. GNS Science monograph 27.81 p. + map (5 sheets) + legend (1 sheet).

Barrell, D. J. A. and Read, S. A. L. (2014). The deglaciation of Lake Pukaki, South Island, New Zealand-a review. New Zealand Journal of Geology and Geophysics, 57(1):86-101.

Barrows, T. T., Almond, P., Rose, R., Keith Fifield, L., Mills, S. C., and Tims, S. G. (2013). Late Pleistocene glacial stratigraphy of the Kumara-Moana region, West Coast of South Island, New Zealand. Quaternary Science Reviews, 74:139-159.

Barrows, T. T., Juggins, S., De Deckker, P., Calvo, E., and Pelejero, C. (2007a). Long-term sea surface temperature and climate change in the Australian-New Zealand region. Paleoceanography, 22(2):PA2215.

Barrows, T. T., Lehman, S. J., Fifield, L. K., and De Deckker, P. (2007b). Absence of cooling in New Zealand and the adjacent ocean during the Younger Dryas chronozone. Science, 318(5847):86-89.

Barrows, T. T., Lehman, S. J., Fifield, L. K., and De Deckker, P. (2008). Response to comment on "Absence of cooling in New Zealand and the adjacent ocean during the Younger Dryas chronozone". Science, 320(5877):746.

Barrows, T. T., Stone, J. O., Fifield, L. K., and Cresswell, R. G. (2001). Late Pleistocene glaciation of the Kosciouszko Massif, Snowy Mountains, Australia. Quaternary Research, 55(2):179-189.

Barrows, T. T., Stone, J. O., Fifield, L. K., and Cresswell, R. G. (2002). The timing of the Last Glacial Maximum in Australia. Quaternary Science Reviews, 21(1-3):159-173.

Bartlein, P., Harrison, S., Brewer, S., Connor, S., Davis, B., Gajewski, K., Guiot, J., Harrison Prentice, T., Henderson, A., Peyron, O., et al. (2011). Pollen-based continental climate reconstructions at 6 and $21 \mathrm{ka}$ : a global synthesis. Climate Dynamics, 37(3-4):775-802.

Basher, L. and McSaveney, M. (1989). An early Aranuian glacial advance at Cropp River, central Westland, New Zealand. Journal of the Royal Society of New Zealand, 19(3):263-268.

Bauer, C. A. (1947). Production of helium in meteorites by cosmic radiation. Physical review, $72(4): 354$.

Benn, D. I. and Evans, D. J. A. (2010). Glaciers and Glaciation. Hodder Education, London, UK. 
Benn, D. I., Kirkbride, M. P., Owen, L. A., and Brazier, V. (2003). Glaciated valley landsystems. In Evans, D. J. A., editor, Glacial Landsystems, pages 372-406. Hodder Arnold, London, UK.

Benn, D. I. and Lehmkuhl, F. (2000). Mass balance and equilibrium-line altitudes of glaciers in high-mountain environments. Quaternary International, 65:15-29.

Benn, D. I., Owen, L. A., Osmaston, H. A., Seltzer, G. O., Porter, S. C., and Mark, B. (2005). Reconstruction of equilibrium-line altitudes for tropical and sub-tropical glaciers. Quaternary International, 138-139:8-21.

Bilderback, E. L. (2012). Hillslope response to climate-modulated river incision and the role of deep-seated landslides in post-glacial sediment flux: Waipaoa Sedimentary System, New Zealand. Ph.D. Thesis, University of Canterbury, New Zealand.

Blard, P.-H., Braucher, R., Lav, J., and Bourlés, D. (2013a). Cosmogenic ${ }^{10}$ Be production rate calibrated against ${ }^{3} \mathrm{He}$ in the high Tropical Andes (3800-4900 m, 20-22 $\left.{ }^{\circ} \mathrm{S}\right)$. Earth and Planetary Science Letters, 382:140-149.

Blard, P.-H., Lavé, J., Pik, R., Wagnon, P., and Bourlès, D. (2007). Persistence of full glacial conditions in the central Pacific until 15,000 years ago. Nature, 449(7162):591594.

Blard, P.-H., Lavé, J., Sylvestre, F., Placzek, C. J., Claude, C., Galy, V., Condom, T., and Tibari, B. (2013b). Cosmogenic ${ }^{3}$ He production rate in the high tropical Andes (3800 $\left.\mathrm{m}, 20^{\circ} \mathrm{S}\right)$ : Implications for the local last glacial maximum. Earth and Planetary Science Letters, 377-378:260-275.

Blard, P.-H., Pik, R., Lav, J., Bourls, D., Burnard, P. G., Yokochi, R., Marty, B., and Trusdell, F. (2006). Cosmogenic ${ }^{3} \mathrm{He}$ production rates revisited from evidences of grain size dependent release of matrix-sited helium. Earth and Planetary Science Letters, 247(3-4):222-234.

Blunier, T. and Brook, E. J. (2001). Timing of millennial-scale climate change in Antarctica and Greenland during the last glacial period. Science, 291(5501):109-112.

Bossard, L. (1928). Origin of the conical hills in the neighbourhood of Mount Egmont. N.Z. Journal of Science and Technology, 10:119-124.

Bostock, H., Barrows, T., Carter, L., Chase, Z., Cortese, G., Dunbar, G., Ellwood, M., Hayward, B., Howard, W., Neil, H., Noble, T., Mackintosh, A., Moss, P., Moy, A., White, D., Williams, M., and Armand, L. (2013). A review of the AustralianNew Zealand sector of the Southern Ocean over the last $30 \mathrm{ka}$ (Aus-INTIMATE project). Quaternary Science Reviews, 74:35 - 57. 
Braconnot, P., Harrison, S. P., Kageyama, M., Bartlein, P. J., Masson Delmotte, V., Abe Ouchi, A., Otto Bliesner, B., and Zhao, Y. (2012). Evaluation of climate models using palaeoclimatic data. Nature Climate Change, 2(6):417-424.

Braconnot, P., Otto Bliesner, B., Harrison, S., Joussaume, S., Peterchmitt, J.-Y., Abe Ouchi, A., Crucifix, M., Driesschaert, E., Fichefet, T., Hewitt, C., et al. (2007). Results of PMIP2 coupled simulations of the Mid-Holocene and Last Glacial Maximum-Part 1: experiments and large-scale features. Climate of the Past, 3(2):261-277.

Bretz, J. H. (1969). The Lake Missoula floods and the channeled scabland. The Journal of Geology, 77:505-543.

Briner, J. P. (2009). Moraine pebbles and boulders yield indistinguishable ${ }^{10}$ Be ages: A case study from Colorado, USA. Quaternary Geochronology, 4(4):299 - 305.

Broccoli, A. and Manabe, S. (1987). The influence of continental ice, atmospheric $\mathrm{CO}_{2}$, and land albedo on the climate of the last glacial maximum. Climate Dynamics, 1(2):87-99.

Brock, B., Rivera, A., Casassa, G., Bown, F., and Acuñn, C. (2007). The surface energy balance of an active ice-covered volcano: Villarrica Volcano, southern Chile. Annals of Glaciology, 45(1):104-114.

Brock, B. W., Willis, I. C., and Sharp, M. J. (2000). Measurement and parameterization of albedo variations at Haut Glacier d'Arolla, Switzerland. Journal of Glaciology, 46(155):675-688.

Brock, B. W., Willis, I. C., and Sharp, M. J. (2006). Measurement and parameterization of aerodynamic roughness length variations at Haut Glacier d'Arolla, Switzerland. Journal of Glaciology, 52(177):281-297.

Broecker, W. S. (1966). Absolute dating and the astronomical theory of glaciation. Science, 151(3708):299-304.

Broecker, W. S. (1978). The cause of glacial to interglacial climatic change. In Evolution of Planetary Atmospheres and Climatology of the Earth, pages 165-190. Centre National d'Etudes Spatiales, Toulouse, France.

Broecker, W. S. (1982). Ocean chemistry during glacial time. Geochimica et Cosmochimica Acta, 46(10):1689-1705.

Broecker, W. S. (1998). Paleocean circulation during the last deglaciation: A bipolar seesaw? Paleoceanography, 13(2):119-121.

Broecker, W. S. (2013). What Drives Glacial Cycles? Eldigio Press, New York, USA. 
Broecker, W. S. and Denton, G. H. (1990). The role of ocean-atmosphere reorganizations in glacial cycles. Quaternary Science Reviews, 9(4):305-341.

Broecker, W. S. and Donk, J. (1970). Insolation changes, ice volumes, and the $\mathrm{O}^{18}$ record in deep-sea cores. Reviews of Geophysics, 8(1):169-198.

Broecker, W. S., Thurber, D. L., Goddard, J., Ku, T.-L., Matthews, R., and Mesolella, K. J. (1968). Milankovitch hypothesis supported by precise dating of coral reefs and deep-sea sediments. Science, 159(3812):297-300.

Bromley, G. R., Schaefer, J. M., Winckler, G., Hall, B. L., Todd, C. E., and Rademaker, K. M. (2009). Relative timing of last glacial maximum and late-glacial events in the central tropical Andes. Quaternary Science Reviews, 28(23):2514-2526.

Bromley, G. R., Winckler, G., Schaefer, J. M., Kaplan, M. R., Licht, K. J., and Hall, B. L. (2014). Pyroxene separation by HF leaching and its impact on helium surfaceexposure dating. Quaternary Geochronology, 23:1-8.

Bromley, G. R. M., Hall, B. L., Schaefer, J. M., Winckler, G., Todd, C. E., and Rademaker, K. M. (2011). Glacier fluctuations in the southern Peruvian Andes during the late-glacial period, constrained with cosmogenic ${ }^{3} \mathrm{He}$. Journal of Quaternary Science, 26(1):37-43.

Bronk Ramsey, C. (2009). Bayesian analysis of radiocarbon dates. Radiocarbon, 51(1).

Brook, M. S. (2009). Lateral moraine age in Park Valley, Tararua Range, New Zealand. Journal of the Royal Society of New Zealand, 39(2-3):63-69.

Brook, M. S. and Crow, T. V. H. (2008). A debris ridge in Park Valley, Tararua Range, New Zealand as evidence for Pleistocene glaciation. New Zealand Journal of Geology and Geophysics, 51(1):23-28.

Brook, M. S., Dean, J. F., and Keys, H. J. R. (2011). Response of a mid-latitude cirque glacier to climate over the last two decades: Mangaehuehu Glacier, Mt Ruapehu. Earth Surface Processes and Landforms, 36(14):1973-1980.

Brook, M. S., Purdie, H. L., and Crow, T. V. (2005). Valley cross-profile morphology and glaciation in Park Valley, Tararua Range, New Zealand. Journal of the Royal Society of New Zealand, 35(4):399-407.

Brook, M. S., Shulmeister, J., Crow, T. V. H., and Zondervan, A. (2008). First cosmogenic ${ }^{10}$ Be constraints on LGM glaciation on New Zealand's North Islands: Park Valley, Tararua Range. Journal of Quaternary Science, 23(8):707-712. 
Bruno, L. A., Baur, H., Graf, T., Signer, P., Wieler, R., et al. (1997). Dating of Sirius Group tillites in the Antarctic dry valleys with cosmogenic ${ }^{3} \mathrm{He}$ and ${ }^{21} \mathrm{Ne}$. Earth and Planetary Science Letters, 147(1):37-54.

Burrows, C. J. and Russell, J. B. (1975). Moraines of the upper Rakaia Valley. Journal of the Royal Society of New Zealand, 5(4):463-477.

Carlson, A. E. and Clark, P. U. (2012). Ice sheet sources of sea level rise and freshwater discharge during the last deglaciation. Reviews of Geophysics, 50(4).

Carter, L., Manighetti, B., Ganssen, G., and Northcote, L. (2008). Southwest Pacific modulation of abrupt climate change during the Antarctic Cold Reversal-Younger Dryas. Palaeogeography, Palaeoclimatology, Palaeoecology, 260(1):284-298.

Cerling, T. E. and Craig, H. (1994). Cosmogenic ${ }^{3} \mathrm{He}$ production rates from $39^{\circ} \mathrm{N}$ to $46^{\circ} \mathrm{N}$ latitude, western USA and France. Geochimica et Cosmochimica Acta, 58(1):249-255.

Chinn, T., Fitzharris, B. B., Willsman, A., and Salinger, M. J. (2012). Annual ice volume changes 1976-2008 for the New Zealand Southern Alps. Global and Planetary Change, 92-93:105-118.

Chinn, T., Winkler, S., Salinger, M. J., and Haakensen, N. (2005). Recent glacier advances in Norway and New Zealand: a comparison of their glaciological and meteorological causes. Geografiska Annaler: Series A, Physical Geography, 87(1):141-157.

Chinn, T. J. H. (1981). Use of rock weathering-rind thickness for Holocene absolute age-dating in New Zealand. Arctic and Alpine Research, 13:33-45.

Chorley, R. (1962). Geomorphology and general systems theory. US Government Printing Office, Washington DC, USA.

Clark, P. U., Dyke, A. S., Shakun, J. D., Carlson, A. E., Clark, J., Wohlfarth, B., Mitrovica, J. X., Hostetler, S. W., and McCabe, A. M. (2009). The Last Glacial Maximum. Science, 325(5941):710-714.

Clarke, G. K., Cross, G. M., and Benson, C. S. (1989). Radar imaging of glaciovolcanic stratigraphy, Mount Wrangell caldera, Alaska: interpretation model and results. Journal of Geophysical Research: Solid Earth, 94(B6):7237-7249.

CLIMAP, P. M. (1976). The surface of the ice-age earth. Science, 191(4232):1131.

Cogley, J., Hock, R., Rasmussen, L., Arendt, A., Bauder, A., Braithwaite, R., Jansson, P., Kaser, G., Moller, M., Nicholson, L., and Zemp, M. (2011). Glossary of Glacier Mass Balance and Related Terms. IHP-VII Technical Documents in Hydrology No. 86, IACS Contribution No. 2, UNESCO-IHP, Paris. 
Cohen, K., Finney, S., Gibbard PL, and Fan, J.-X. (2013). The ICS International Chronostratigraphic Chart. Episodes, 36:199-204.

Cole, J. W. (1978). Andesites of the Tongariro Volcanic Centre, North Island, New Zealand. Journal of Volcanology and Geothermal Research, 3:121-153.

Collins, L. G., Pike, J., Allen, C. S., and Hodgson, D. A. (2012). High-resolution reconstruction of southwest Atlantic sea-ice and its role in the carbon cycle during marine isotope stages 3 and 2. Paleoceanography, 27(3):PA3217.

Columbus, J., Sirguey, P., and Tenzer, R. (2011). A free, fully accessible 15-m DEM for New Zealand. Survey Quarterly, 66:16-19.

Conway, C., Townsend, D., Leonard, G., Wilson, C., Calvert, A., and Gamble, J. (2015). Lava-ice interaction on a large composite volcano: a case study from Ruapehu, New Zealand. Bulletin of Volcanology, 77(21).

Conway, J., Cullen, N., Spronken-Smith, R., and Fitzsimons, S. (2014). All-sky radiation over a glacier surface in the Southern Alps of New Zealand: characterizing cloud effects on incoming shortwave, longwave and net radiation. International Journal of Climatology.

Corripio, J. G. (2003). Vectorial algebra algorithms for calculating terrain parameters from DEMs and solar radiation modelling in mountainous terrain. International Journal of Geographical Information Science, 17(1):1-23.

Craig, H., Poreda, R., Lupton, J. E., Marti, K., and Regnier, S. (1979). Rare gases and hydrogen in josephinite. EOS Trans. Am. Geophys. Union, 60(46):970.

Craig, H. and Poreda, R. J. (1986). Cosmogenic ${ }^{3} \mathrm{He}$ in terrestrial rocks: The summit lavas of Maui. Proceedings of the National Academy of Sciences, 83(7):1970-1974.

Croll, J. (1864). XIII. On the physical cause of the change of climate during geological epochs. The London, Edinburgh, and Dublin Philosophical Magazine and Journal of Science, 28(187):121-137.

Cronin, S. J. and Neall, V. E. (1997). A late quaternary stratigraphic framework for the northeastern Ruapehu and eastern Tongariro ring plains, New Zealand. New Zealand Journal of Geology and Geophysics, 40(2):185-197.

Crowley, T. J. (1992). North Atlantic deep water cools the Southern Hemisphere. Paleoceanography, 7(4):489-497.

Cuffey, K. and Paterson, W. (2010). The physics of glaciers. ButterworthHeinemann/Elsevier, Burlington, USA. 
Curry, A. M., Sands, T. B., and Porter, P. R. (2009). Geotechnical controls on a steep lateral moraine undergoing paraglacial slope adjustment. 320:181-197.

Dadic, R., Mott, R., Lehning, M., and Burlando, P. (2010). Parameterization for windinduced preferential deposition of snow. Hydrological processes, 24(14):1994-2006.

Dansgaard, W., Clausen, H., Gundestrup, N., Hammer, C., Johnsen, S., Kristinsdottir, P., and Reeh, N. (1982). A new Greenland deep ice core. Science, 218(4579):1273-1277.

Dansgaard, W., Johnsen, S., Clausen, H., Dahl Jensen, D., Gundestrup, N., Hammer, C., Hvidberg, C., Steffensen, J., Sveinbjörnsdottir, A., Jouzel, J., et al. (1993). Evidence for general instability of past climate from a 250-kyr ice-core record. Nature, 364(6434):218-220.

Dansgaard, W., Johnsen, S., Clausen, H., Dahl Jensen, D., Gundestrup, N., Hammer, C., and Oeschger, H. (1984). North Atlantic climatic oscillations revealed by deep Greenland ice cores. In Hansen, J. E. and Takahashi, T., editors, Climate processes and climate sensitivity, pages 288-298. American Geophysical Union, Washington DC, USA.

Dansgaard, W., Johnsen, S. J., Møller, J., and Langway, C. C. (1969). One thousand centuries of climatic record from Camp Century on the Greenland ice sheet. Science, 166(3903):377-380.

Davis, R. and Schaeffer, O. A. (1955). Chlorine-36 in nature. Annals of the New York Academy of Sciences, 62(5):107-121.

De Deckker, P., Moros, M., Perner, K., and Jansen, E. (2012). Influence of the tropics and southern westerlies on glacial interhemispheric asymmetry. Nature Geoscience, 5(4):266-269.

Denton, G. and Hendy, C. (1994). Younger Dryas age advance of Franz Josef glacier in the southern Alps of New Zealand. Science, 264(5164):1434-1437.

Denton, G. H., Alley, R. B., Comer, G. C., and Broecker, W. S. (2005). The role of seasonality in abrupt climate change. Quaternary Science Reviews, 24(10):1159-1182.

Denton, G. H., Anderson, R. F., Toggweiler, J. R., Edwards, R. L., Schaefer, J. M., and Putnam, A. E. (2010). The last glacial termination. Science, 328(5986):1652-1656.

Denton, G. H., Lowell, T. V., Heusser, C. J., Schlüchter, C., Andersen, B. G., Heusser, L. E., Moreno, P. I., and Marchant, D. R. (1999). Geomorphology, stratigraphy, and radiocarbon chronology of Llanquihue drift in the area of the southern Lake District, Seno Reloncavi, and Isla Grande de Chiloe, Chile. Geografiska Annaler, Series A: Physical Geography, 81(2):167-229. 
Deschamps, P., Durand, N., Bard, E., Hamelin, B., Camoin, G., Thomas, A. L., Henderson, G. M., Okuno, J., and Yokoyama, Y. (2012). Ice-sheet collapse and sea-level rise at the Bolling warming 14,600 [thinsp] years ago. Nature, 483(7391):559-564.

Desilets, D., Zreda, M., and Prabu, T. (2006). Extended scaling factors for in situ cosmogenic nuclides: New measurements at low latitude. Earth and Planetary Science Letters, 246(3-4):265-276.

Dieffenbacher Krall, A., Vandergoes, M., and Denton, G. (2007). An inference model for mean summer air temperatures in the Southern Alps, New Zealand, using subfossil chironomids. Quaternary Science Reviews, 26(19-21):2487-2504.

Donoghue, S. and Neall, V. (1996). Tephrostratigraphic studies at Tongariro volcanic centre, New Zealand: an overview. Quaternary International, 34:13-20.

Donoghue, S., Neall, V., Palmer, A., and Stewart, R. (1997). The volcanic history of Ruapehu during the past 2 millennia based on the record of Tufa Trig tephras. Bulletin of Volcanology, 59(2):136-146.

Donoghue, S. L. and Neall, V. E. (2001). Late Quaternary constructional history of the southeastern Ruapehu ring plain, New Zealand. New Zealand Journal of Geology and Geophysics, 44(3):439-466.

Donoghue, S. L., Neall, V. E., and Palmer, A. S. (1995). Stratigraphy and chronology of late Quaternary andesitic tephra deposits, Tongariro volcanic Centre, New Zealand. Journal - Royal Society of New Zealand, 25(2):115-206.

Donoghue, S. L., Palmer, A. S., McClelland, E., Hobson, K., Stewart, R. B., and Neall, V. E. (1999). The Taurewa Eruptive Epsiode: evidence for climactic eruptions at Ruapehu volcano, New Zealand. Bulletin of Volcanology, 60:223-240.

Doughty, A. M., Anderson, B. M., Mackintosh, A. N., Kaplan, M. R., Vandergoes, M. J., Barrell, D. J. A., Denton, G. H., Schaefer, J. M., Chinn, T. J. H., and Putnam, A. E. (2013). Evaluation of Lateglacial temperatures in the Southern Alps of New Zealand based on glacier modelling at Irishman Stream, Ben Ohau Range. Quaternary Science Reviews, 74:160-169.

Drost, F., Renwick, J., Bhaskaran, B., Oliver, H., and McGregor, J. (2007). A simulation of New Zealand's climate during the Last Glacial Maximum. Quaternary Science Reviews, 26(19-21):2505-2525.

Dunai, T. J. (2001). Influence of secular variation of the geomagnetic field on production rates of in situ produced cosmogenic nuclides. Earth and Planetary Science Letters, 193(1-2):197-212. 
Dunai, T. J. (2010). Cosmogenic Nuclides: Principles, concepts and applications in the Earth surface sciences. Cambridge University Press, New York, USA.

Dunai, T. J., Stuart, F. M., Pik, R., Burnard, P., and Gayer, E. (2007). Production of ${ }^{3} \mathrm{He}$ in crustal rocks by cosmogenic thermal neutrons. Earth and Planetary Science Letters, 258(1):228-236.

Dunne, J., Elmore, D., and Muzikar, P. (1999). Scaling factors for the rates of production of cosmogenic nuclides for geometric shielding and attenuation at depth on sloped surfaces. Geomorphology, 27(1):3-11.

Egholm, D. L., Knudsen, M. F., Clark, C. D., and Lesemann, J. E. (2011). Modeling the flow of glaciers in steep terrains: The integrated second-order shallow ice approximation (iSOSIA). Journal of Geophysical Research: Earth Surface (2003-2012), 116(F2):F02012.

Ehlers, J., Ehlers, J., Gibbard, P. L., and Hughes, P. D. (2011). Quaternary glaciations-extent and chronology: a closer look. Elsevier, Amsterdam, The Netherlands.

Emiliani, C. (1955). Pleistocene temperatures. The Journal of Geology, 63:538-578.

EPICA-Community-Members., Augustin, L., Barbante, C., Barnes, P. R., Barnola, J. M., Bigler, M., Castellano, E., Cattani, O., Chappellaz, J., Dahl-Jensen, D., Delmonte, B., et al. (2004). Eight glacial cycles from an Antarctic ice core. Nature, 429(6992):623-628.

EPICA-Community-Members., Barbante, C., Barnola, J., Becagli, S., Beer, J., Bigler, M., Boutron, C., Blunier, T., Castellano, E., Cattani, O., Chappellaz, J., et al. (2006). Oneto-one coupling of glacial climate variability in Greenland and Antarctica. Nature, 444(7116):195-198.

Epstein, S., Sharp, R. P., and Gow, A. (1970). Antarctic ice sheet: stable isotope analyses of Byrd station cores and interhemispheric climatic implications. Science, 168(3939):1570-1572.

Evans, D. (2003). Glacial Landsystems. Hodder Arnold, London, UK.

Evans, D. J., Rother, H., Hyatt, O. M., and Shulmeister, J. (2013). The glacial sedimentology and geomorphological evolution of an outwash head/moraine-dammed lake, South Island, New Zealand. Sedimentary Geology, 284285:45 - 75.

Evans, E. (1887). The authorship of the glacial theory. The North American review, 145:94-97. 
Farley, K. A., Libarkin, J., Mukhopadhyay, S., and Amidon, W. (2006). Cosmogenic and nucleogenic ${ }^{3} \mathrm{He}$ in apatite, titanite, and zircon. Earth and Planetary Science Letters, 248(1-2):436-446.

Fenton, C. R., Mark, D. F., Barfod, D. N., Niedermann, S., Goethals, M. M., and Stuart, F. M. (2013). 40Ar/39Ar dating of the SP and Bar Ten lava flows AZ, USA: Laying the foundation for the SPICE cosmogenic nuclide production-rate calibration project. Quaternary Geochronology, 18:158-172.

Fenton, C. R. and Niedermann, S. (2014). Surface exposure dating of young basalts (1-200 ka) in the San Francisco volcanic field (Arizona, USA) using cosmogenic ${ }^{3} \mathrm{He}$ and ${ }^{21}$ Ne. Quaternary Geochronology, 19:87-105.

Fitzsimons, S. J. (1997). Late-glacial and early Holocene glacier activity in the Southern Alps, New Zealand. Quaternary International, 38:69-76.

Fleming, K., Johnston, P., Zwartz, D., Yokoyama, Y., Lambeck, K., and Chappell, J. (1998). Refining the eustatic sea-level curve since the Last Glacial Maximum using far-and intermediate-field sites. Earth and Planetary Science Letters, 163(1):327-342.

Foeken, J. P. T., Stuart, F. M., and Mark, D. F. (2012). Long-term low latitude cosmogenic ${ }^{3} \mathrm{He}$ production rate determined from a 126ka basalt from Fogo, Cape Verdes. Earth and Planetary Science Letters, 359-360:14-25.

Froggatt, P. C. and Lowe, D. J. (1990). A review of late Quaternary silicic and some other tephra formations from New Zealand: their stratigraphy, nomenclature, distribution, volume, and age. New Zealand Journal of Geology and Geophysics, 33(1):89-109.

Fudge, T., Steig, E. J., Markle, B. R., Schoenemann, S. W., Ding, Q., Taylor, K. C., McConnell, J. R., Brook, E. J., Sowers, T., White, J. W., et al. (2013). Onset of deglacial warming in West Antarctica driven by local orbital forcing. Nature, 500:440-444.

Furbish, D. J. and Andrews, J. T. (1984). The use of hypsometry to indicate longterm stability and response of valley glaciers to changes in mass transfer. Journal of Glaciology, 30(105):199-211.

Gage, M. (1985). Glaciation in New Zealandthe first century of research. Quaternary Science Reviews, 4(3):189-214.

Gage, M. and Suggate, R. P. (1958). Glacial chronology of the New Zealand Pleistocene. Geological Society of America Bulletin, 69(5):589-598.

Gamble, J. A., Price, R. C., Smith, I. E., McIntosh, W. C., and Dunbar, N. W. (2003). ${ }^{40} \mathrm{Ar} /{ }^{39} \mathrm{Ar}$ geochronology of magmatic activity, magma flux and hazards at Ruapehu 
volcano, Taupo Volcanic Zone, New Zealand. Journal of Volcanology and Geothermal Research, 120(34):271 - 287.

Gayer, E., Pik, R., Lavé, J., France-Lanord, C., Bourles, D., and Marty, B. (2004). Cosmogenic ${ }^{3}$ he in Himalayan garnets indicating an altitude dependence of the ${ }^{3}$ he ${ }^{10}$ be production ratio. Earth and Planetary Science Letters, 229(1):91-104.

Gildor, H. and Tziperman, E. (2001). Physical mechanisms behind biogeochemical glacial-interglacial $\mathrm{CO}_{2}$ variations. Geophysical Research Letters, 28(12):2421-2424.

Glicken, H. (1986). Mt. St. Helens volcano. Ph.D. Thesis, University of California, Santa Barbara, California.

Glicken, H. (1991). Sedimentary architecture of large volcanic-debris avalanches. In Fisher, R. V. and Smith, G. A., editors, Sedimentation in Volcanic Settings, volume 45, pages 99-106.

Goehring, B. M., Kurz, M. D., Balco, G., Schaefer, J. M., Licciardi, J., and Lifton, N. (2010). A reevaluation of in situ cosmogenic ${ }^{3} \mathrm{He}$ production rates. Quaternary Geochronology, 5(4):410-418.

Goehring, B. M., Schaefer, J. M., Schlüchter, C., Lifton, N. A., Finkel, R. C., Jull, A. T., Akçar, N., and Alley, R. B. (2011). The Rhone Glacier was smaller than today for most of the Holocene. Geology, 39(7):679-682.

Golledge, N., Menviel, L., Carter, L., Fogwill, C., England, M., Cortese, G., and Levy, R. (2014). Antarctic contribution to meltwater pulse 1A from reduced Southern Ocean overturning. Nature communications, 5 .

Golledge, N. R. (2007). An ice cap landsystem for palaeoglaciological reconstructions: characterizing the Younger Dryas in western Scotland. Quaternary Science Reviews, 26(1):213-229.

Golledge, N. R., Mackintosh, A. N., Anderson, B. M., Buckley, K. M., Doughty, A. M., Barrell, D. J. A., Denton, G. H., Vandergoes, M. J., Andersen, B. G., and Schaefer, J. M. (2012). Last Glacial Maximum climate in New Zealand inferred from a modelled Southern Alps icefield. Quaternary Science Reviews, 46:30-45.

Gosse, J. C. and Phillips, F. M. (2001). Terrestrial in situ cosmogenic nuclides: theory and application. Quaternary Science Reviews, 20(14):1475-1560.

Grange, L. and Williamson, J. (1930). Tongariro Subdivision. NZ Geological Survey 24th Annual Report, pages 10-13. 
Greuell, W. (1992). Hintereisferner, Austria: mass-balance reconstruction and numerical modelling of the historical length variations. Journal of Glaciology, 38(129):233-244.

Grubbs, F. (1969). Procedures for detecting outlying observations in samples. Technometrics, 11:1-21.

Gudmundsson, M. T., Sigmundsson, F., and Björnsson, H. (1997). Ice-volcano interaction of the 1996 Gjálp subglacial eruption, Vatnajökull, Iceland. Nature, 389(6654):954957.

Gudmundsson, M. T., Sigmundsson, F., Björnsson, H., and Högnadóttir, T. (2004). The 1996 eruption at Gjálp, Vatnajökull ice cap, Iceland: efficiency of heat transfer, ice deformation and subglacial water pressure. Bulletin of Volcanology, 66(1):46-65.

Hackett, W. R. and Houghton, B. F. (1989). A facies model for a quaternary andesitic composite volcano: Ruapehu, New Zealand. Bulletin of Volcanology, 51(1):51-68.

Hajdas, I., Lowe, D. J., Newnham, R. M., and Bonani, G. (2006). Timing of the late-glacial climate reversal in the Southern Hemisphere using high-resolution radiocarbon chronology for Kaipo bog, New Zealand. Quaternary Research, 65(2):340-345.

Hallet, B. and Putkonen, J. (1994). Surface dating of dynamic landforms: young boulders on aging moraines. Science, 265(5174):937-940.

Hambrey, M. J. and Ehrmann, W. (2004). Modification of sediment characteristics during glacial transport in high-alpine catchments: Mount Cook area, New Zealand. Boreas, 33(4):300-318.

Hargreaves, J. C., Annan, J. D., Yoshimori, M., and Abe Ouchi, A. (2012). Can the Last Glacial Maximum constrain climate sensitivity? Geophysical Research Letters, 39(24):L24702.

Hays, J. D., Imbrie, J., and Shackleton, N. J. (1976). Variations in the earth's orbit: Pacemaker of the ice ages. Science, 194(4270):1121-1132.

He, F., Shakun, J. D., Clark, P. U., Carlson, A. E., Liu, Z., Otto Bliesner, B. L., and Kutzbach, J. E. (2013). Northern Hemisphere forcing of Southern Hemisphere climate during the last deglaciation. Nature, 494(7435):81-85.

Heine, A. (1962). Glacier changes on Mount Ruapehu, New Zealand:1957-1961. In Variations in the regime of existing glaciers. Proceedings of the Symposium of Obergurgl, pages $10-18$.

Heine, A. J. (1963). Mount Ruapehu ice and snow photo survey. New Zealand Journal of Geology and Geophysics, 6(2):261-267. 
Heinrich, H. (1988). Origin and consequences of cyclic ice rafting in the northeast Atlantic Ocean during the past 130,000 years. Quaternary research, 29(2):142-152.

Heisinger, B., Lal, D., Jull, A. J. T., Kubik, P., Ivy Ochs, S., Neumaier, S., Knie, K., Lazarev, V., and Nolte, E. (2002). Production of selected cosmogenic radionuclides by muons 1. Fast muons. Earth and Planetary Science Letters, 200(3-4):345-355.

Hellstrom, J., McCulloch, M., and Stone, J. (1998). A detailed 31,000-year record of climate and vegetation change, from the isotope geochemistry of two New Zealand speleothems. Quaternary Research, 50:167-178.

Hemming, S. R. (2004). Heinrich events: Massive late Pleistocene detritus layers of the North Atlantic and their global climate imprint. Reviews of Geophysics, 42(1):RG1005 $1-43$.

Hendrikx, J. and Hreinsson, E. (2012). The potential impact of climate change on seasonal snow in New Zealand: part iiindustry vulnerability and future snowmaking potential. Theoretical and Applied Climatology, 110(4):619-630.

Hewitt, K. (1999). Quaternary moraines vs catastrophic rock avalanches in the Karakoram Himalaya, northern Pakistan. Quaternary Research, 51(3):220-237.

Heyman, J., Stroeven, A. P., Harbor, J. M., and Caffee, M. W. (2011). Too young or too old: Evaluating cosmogenic exposure dating based on an analysis of compiled boulder exposure ages. Earth and Planetary Science Letters, 302(1-2):71-80.

Hill, H. (1891). Tongariro, Ngauruhoe and Ruapehu as volcanic cones. Report of the third meeting of the Australasian Association for the Advancement of Science. p.162-172.

Hindmarsh, R. C. and Le Meur, E. (2001). Dynamical processes involved in the retreat of marine ice sheets. Journal of Glaciology, 47(157):271-282.

Hobden, B. J., Houghton, B. F., Davidson, J. P., and Weaver, S. D. (1999). Small and short-lived magma batches at composite volcanoes: Time windows at Tongariro volcano, New Zealand. Journal of the Geological Society, 156(5):865-868.

Hobden, B. J., Houghton, B. F., Lanphere, M. A., and Nairn, I. A. (1996). Growth of the Tongariro volcanic complex: New evidence from K-Ar age determinations. New Zealand Journal of Geology and Geophysics, 39(1):151-154.

Hobden, B. J., Houghton, B. F., and Nairn, I. A. (2002). Growth of a young, frequently active composite cone: Ngauruhoe volcano, New Zealand. Bulletin of Volcanology, 64(6):392-409. 
Hock, R. (1999). A distributed temperature-index ice-and snowmelt model including potential direct solar radiation. Journal of Glaciology, 45(149):101-111.

Hock, R. (2003). Temperature index melt modelling in mountain areas. Journal of Hydrology, 282(1):104-115.

Hogg, A., Hua, Q., Blackwell, P., Niu, M., Buck, C., Guilderson, T., Heaton, T., Palmer, J., Reimer, P., Reimer, R., Turney, C., and Zimmerman, S. (2013). SHCal13 Southern Hemisphere calibration, 0-50,000 years cal. BP. Radiocarbon, 55(4).

Hooker, B. and Fitzharris, B. (1999). The correlation between climatic parameters and the retreat and advance of Franz Josef Glacier, New Zealand. Global and Planetary Change, 22(1):39-48.

Houghton, B., Latter, J., and Hackett, W. (1987). Volcanic hazard assessment for Ruapehu composite volcano, Taupo volcanic zone, New Zealand. Bulletin of volcanology, 49(6):737-751.

Hubbard, B. and Glasser, N. (2005). Field techniques in glaciology and glacial geomorphology. John Wiley \& Sons, Chichester, UK.

Hutter, K. (1983). Theoretical glaciology: material science of ice and the mechanics of glaciers and ice sheets. Reidel.

Huybers, P. (2006). Early pleistocene glacial cycles and the integrated summer insolation forcing. Science, 313(5786):508-511.

Huybers, P. (2009). Antarctica's orbital beat. Science, 325(5944):1085-1086.

Huybers, P. and Denton, G. (2008). Antarctic temperature at orbital timescales controlled by local summer duration. Nature Geoscience, 1(11):787-792.

Huybers, P. and Eisenman, A. (2006). Integrated summer insolation calculations. NOAA/NCDC Paleoclimatology Program, Data Contribution Series no.2006-079.

Imbrie, J., Berger, A., Boyle, E., Clemens, S., Duffy, A., Howard, W., Kukla, G., Kutzbach, J., MartinsonN, D., McIntyre, A., et al. (1993). On the structure and origin of major glaciation cycles. II: The 100,000-year cycle. Paleoceanography, 8(6):699-735.

Imbrie, J., Boyle, E., Clemens, S., Duffy, A., Howard, W., Kukla, G., Kutzbach, J., Martinson, D., McIntyre, A., Mix, A., et al. (1992). On the structure and origin of major glaciation cycles 1 . Linear responses to Milankovitch forcing. Paleoceanography, 7(6):701-738. 
Imbrie, J. and Imbrie, K. P. (1986). Ice ages: solving the mystery. Harvard University Press, Massachusetts, USA.

Ivy Ochs, S., Schlüchter, C., Kubik, P. W., and Denton, G. H. (1999). Moraine exposure dates imply synchronous Younger Dryas glacier advances in the European Alps and in the Southern Alps of New Zealand. Geografiska Annaler: Series A, Physical Geography, 81(2):313-323.

Jiang, N., Griffiths, G., and Lorrey, A. (2013). Influence of large-scale climate modes on daily synoptic weather types over New Zealand. International Journal of Climatology, 33(2):499-519.

Jouzel, J., Genthon, C., Lorius, C., Petit, J., and Barkov, N. (1987). Vostok ice core-A continuous isotope temperature record over the last climatic cycle $(160,000$ years). Nature, 329:403-408.

Kalnay, E., Kanamitsu, M., Kistler, R., Collins, W., Deaven, D., Gandin, L., Iredell, M., Saha, S., White, G., Woollen, J., et al. (1996). The NCEP/NCAR 40-year reanalysis project. Bulletin of the American meteorological Society, 77(3):437-471.

Kaplan, M. R., Schaefer, J. M., Denton, G. H., Barrell, D. J. A., Chinn, T. J. H., Putnam, A. E., Andersen, B. G., Finkel, R. C., Schwartz, R., and Doughty, A. M. (2010). Glacier retreat in New Zealand during the Younger Dryas stadial. Nature, 467(7312):194-197.

Kaplan, M. R., Schaefer, J. M., Denton, G. H., Doughty, A. M., Barrell, D. J. A., Chinn, T. J. H., Putnam, A. E., Andersen, B. G., Mackintosh, A., Finkel, R. C., et al. (2013). The anatomy of long-term warming since $15 \mathrm{ka}$ in New Zealand based on net glacier snowline rise. Geology, 41(8):887-890.

Kawamura, K., Parrenin, F., Lisiecki, L., Uemura, R., Vimeux, F., Severinghaus, J. P., Hutterli, M. A., Nakazawa, T., Aoki, S., Jouzel, J., et al. (2007). Northern Hemisphere forcing of climatic cycles in Antarctica over the past 360,000 years. Nature, 448(7156):912-916.

Kelley, S. E., Kaplan, M. R., Schaefer, J. M., Andersen, B. G., Barrell, D. J., Putnam, A. E., Denton, G. H., Schwartz, R., Finkel, R. C., and Doughty, A. M. (2014). High-precision ${ }^{10}$ Be chronology of moraines in the Southern Alps indicates synchronous cooling in Antarctica and New Zealand 42,000 years ago. Earth and Planetary Science Letters, 405:194-206.

Kessler, M. A., Anderson, R. S., and Stock, G. M. (2006). Modeling topographic and climatic control of east-west asymmetry in Sierra Nevada glacier length during the Last Glacial Maximum. Journal of Geophysical Research: Earth Surface, 111(F2002). 
Keys, H. (1988). 1988 Survey of the glaciers on Mt. Ruapehu, Tongariro National Park - A baseline for detecting effects of climate change. Technical Report Science and Research Internal Report No.24, Department of Conservation, Wellington, NZ.

Kirkbride, M. (1995). Processes of glacial transportation. In Menzies, J., editor, Modern and past glacial environments, pages 147-169. Butterworth-Heinemann, Oxford, UK.

Kirkbride, M. and Matthews, D. (1997). The role of fluvial and glacial erosion in landscape evolution: the Ben Ohau Range, New Zealand. Earth Surface Processes and Landforms, 22(3):317-327.

Kirkbride, M. P. and Dugmore, A. J. (2001). Timing and significance of mid-Holocene glacier advances in Northern and Central Iceland. Journal of Quaternary Science, 16(2):145-153.

Kirkbride, M. P. and Dugmore, A. J. (2003). Glaciological response to distal tephra fallout from the 1947 eruption of Hekla, south Iceland. Journal of Glaciology, 49(166):420-428.

Klok, E. and Oerlemans, J. (2002). Model study of the spatial distribution of the energy and mass balance of Morteratschgletscher, Switzerland. Journal of Glaciology, 48(163):505-518.

Knight, J., Mitchell, W. A., and Rose, J. (2011). Geomorphological Field Mapping. In Smith, M. J., Paron, P., and Griffith, J. S., editors, Geomorphological mapping: methods and applications, pages 151-188. Elsevier, Oxford, UK.

Konzelmann, T., van de Wal, R. S., Greuell, W., Bintanja, R., Henneken, E. A., and Abe Ouchi, A. (1994). Parameterization of global and longwave incoming radiation for the Greenland Ice Sheet. Global and Planetary change, 9(1):143-164.

Köppen, W. P. and Wegener, A. (1924). Die klimate der geologischen vorzeit, volume 1. Gebrüder Borntraeger, Stuttgart, Germany.

Krenek, L. (1959). Changes in the glaciers of Mt Ruapehu in 1955. New Zealand Journal of Geology and Geophysics, 2(4):643-653.

Kuhn, M. (1995). The mass balance of very small glaciers. Zeitschrift für Gletscherkunde und Glazialgeologie, 31(1):171-179.

Kukla, J. (1970). Correlations between loesses and deep-sea sediments. Geologiska Föreningen i Stockholm Förhandlingar, 92(2):148-180.

Kurz, M. and Brook, E. (1994). Surface exposure dating with cosmogenic nuclides. In Beck, C., editor, Dating in exposed and surface contexts, pages 139-159. Univ. NM Press, Albuquerque, NM. 
Kurz, M. D. (1986a). Cosmogenic helium in a terrestrial igneous rock. Nature, 320(6061):435-439.

Kurz, M. D. (1986b). In situ production of terrestrial cosmogenic helium and some applications to geochronology. Geochimica et Cosmochimica Acta, 50(12):2855-2862.

Kurz, M. D., Colodner, D., Trull, T. W., Moore, R. B., and O’Brien, K. (1990). Cosmic ray exposure dating with in situ produced cosmogenic ${ }^{3} \mathrm{He}$ : results from young Hawaiian lava flows. Earth and Planetary Science Letters, 97(1-2):177-189.

Lal, D. (1987). Production of ${ }^{3} \mathrm{He}$ in terrestrial rocks. Chemical Geology: Isotope Geoscience section, 66(1):89-98.

Lal, D. (1991). Cosmic ray labeling of erosion surfaces: in situ nuclide production rates and erosion models. Earth and Planetary Science Letters, 104(2-4):424-439.

Lambeck, K., Rouby, H., Purcell, A., Sun, Y., and Sambridge, M. (2014). Sea level and global ice volumes from the Last Glacial Maximum to the Holocene. Proceedings of the National Academy of Sciences, 111(43):15296-15303.

Le Meur, E., Gagliardini, O., Zwinger, T., and Ruokolainen, J. (2004). Glacier flow modelling: a comparison of the Shallow Ice Approximation and the full-Stokes solution. Comptes Rendus Physique, 5(7):709-722.

Lee, J., Townsend, D., Bland, K., and Kamp, P. (2011). Geology map of the Hawkes Bay area area: scale 1:250,000. Three maps and notes (36 p.). Institute of Geological and Nuclear Sciences 1:250,000 geological map 8. 86p. + 1 folded map.

Leverrier, U.-J. (1843). Recherches sur l'orbite de Mercure et sur ses perturbations. Détermination de la masse de Vénus et du diamètre du Soleil. Journal de Mathématiques Pures et Appliquées, pages 273-359.

Leysinger Vieli, G. and Gudmundsson, G. (2004). On estimating length fluctuations of glaciers caused by changes in climatic forcing. Journal of Geophysical Research: Earth Surface, 109(F1):F01007.

Licciardi, J. M., Clark, P. U., Brook, E. J., Elmore, D., and Sharma, P. (2004). Variable responses of western U.S. glaciers during the last deglaciation. Geology, 32(1):81-84.

Licciardi, J. M., Kurz, M. D., Clark, P. U., and Brook, E. J. (1999). Calibration of cosmogenic ${ }^{3} \mathrm{He}$ production rates from Holocene lava flows in Oregon, USA, and effects of the Earth's magnetic field. Earth and Planetary Science Letters, 172(3-4):261271. 
Licciardi, J. M., Kurz, M. D., and Curtice, J. M. (2006). Cosmogenic ${ }^{3}$ He production rates from Holocene lava flows in Iceland. Earth and Planetary Science Letters, 246(34):251-264.

Licciardi, J. M., Kurz, M. D., and Curtice, J. M. (2007). Glacial and volcanic history of Icelandic table mountains from cosmogenic ${ }^{3} \mathrm{He}$ exposure ages. Quaternary Science Reviews, 26(11-12):1529-1546.

Lifton, N., Sato, T., and Dunai, T. J. (2014). Scaling in situ cosmogenic nuclide production rates using analytical approximations to atmospheric cosmic-ray fluxes. Earth and Planetary Science Letters, 386:149-160.

Lifton, N. A., Bieber, J. W., Clem, J. M., Duldig, M. L., Evenson, P., Humble, J. E., and Pyle, R. (2005). Addressing solar modulation and long-term uncertainties in scaling secondary cosmic rays for in situ cosmogenic nuclide applications. Earth and Planetary Science Letters, 239(1-2):140-161.

Liu, Z., Otto Bliesner, B., He, F., Brady, E., Tomas, R., Clark, P., Carlson, A., Lynch Stieglitz, J., Curry, W., Brook, E., et al. (2009). Transient simulation of last deglaciation with a new mechanism for Bølling-Allerød warming. Science, 325(5938):310-314.

Lorius, C., Jouzel, J., Raynaud, D., Hansen, J., and Le Treut, H. (1990). The ice-core record: climate sensitivity and future greenhouse warming. Nature, 347(6289):139_ 145.

Lorius, C., Ritz, C., Jouzel, J., Merlivat, L., and Barkov, N. (1985). A 150,000-year climatic record from Antarctic ice. Nature, 316:591-596.

Lorrey, A., Dalu, G., Renwick, J., Diamond, H., and Gaetani, M. (2012a). Reconstructing the South Pacific convergence zone position during the presatellite era: a La Niña case study. Monthly Weather Review, 140(11):3653-3668.

Lorrey, A., Fauchereau, N., Stanton, C., Chappell, P., Phipps, S., Mackintosh, A., Renwick, J., Goodwin, I., and Fowler, A. (2014). The Little Ice Age climate of New Zealand reconstructed from Southern Alps cirque glaciers: a synoptic type approach. Climate Dynamics, 42(11-12):3039-3060.

Lorrey, A. M., Vandergoes, M., Almond, P., Renwick, J., Stephens, T., Bostock, H., Mackintosh, A., Newnham, R. M., Williams, P. W., Ackerley, D., Neil, H., and Fowler, A. M. (2012b). Palaeocirculation across New Zealand during the last glacial maximum at $21 \mathrm{ka}$. Quaternary Science Reviews, 36:189-213. 
Lowe, D. J., Blaauw, M., Hogg, A. G., and Newnham, R. M. (2013). Ages of 24 widespread tephras erupted since 30,000 years ago in New Zealand, with reevaluation of the timing and palaeoclimatic implications of the Lateglacial cool episode recorded at Kaipo bog. Quaternary Science Reviews, 74:170-194.

Lowe, D. J., Shane, P. A. R., Alloway, B. V., and Newnham, R. M. (2008). Fingerprints and age models for widespread New Zealand tephra marker beds erupted since 30,000 years ago: a framework for NZ-INTIMATE. Quaternary Science Reviews, 27(12):95-126.

Lüthi, D., Le Floch, M., Bereiter, B., Blunier, T., Barnola, J.-M., Siegenthaler, U., Raynaud, D., Jouzel, J., Fischer, H., Kawamura, K., et al. (2008). High-resolution carbon dioxide concentration record 650,000-800,000 years before present. Nature, 453(7193):379-382.

Mackintosh, A., Barrows, T., Colhoun, E., and Fifield, L. (2006). Exposure dating and glacial reconstruction at Mt. Field, Tasmania, Australia, identifies MIS 3 and MIS 2 glacial advances and climatic variability. Journal of Quaternary Science, 21(4):363-376.

Mackintosh, A. N., Dugmore, A. J., and Hubbard, A. L. (2002). Holocene climatic changes in Iceland: evidence from modelling glacier length fluctuations at Sólheimajökull. Quaternary International, 91(1):39-52.

Mager, S. and Fitzsimons, S. (2007). Formation of glaciolacustrine late pleistocene end moraines in the Tasman Valley, New Zealand. Quaternary Science Reviews, 26(5):743758.

Major, J. and Newell, C. (1989). Snow and ice perturbation during historical volcanic eruptions and the formation of lahars and floods. Bulletin of Volcanology, 52:1-27.

Marden, M., Betts, H., Palmer, A., Taylor, R., Bilderback, E., and Litchfield, N. (2014). Post-last glacial maximum fluvial incision and sediment generation in the unglaciated Waipaoa catchment, North Island, New Zealand. Geomorphology, 214:283-306.

Martin, J. H. (1990). Glacial-interglacial $\mathrm{CO}_{2}$ change: The iron hypothesis. Paleoceanography, 5(1):1-13.

Masson Delmotte, V., Schulz, M., Abe Ouchi, A., Beer, J., Ganopolski, A., Gonzlez Rouco, J., Jansen, E., Lambeck, K., Luterbacher, J., Naish, T., Osborn, T., Otto Bliesner, B., Quinn, T., Ramesh, R., Rojas, M., Shao, X., and Timmermann, A. (2013). Historical Overview of Climate Change. In Stocker, T., Qin, D., Plattner, G.-K., Tignor, M., Allen, S., Boschung, J., Nauels, A., Xia, Y., Bex, V., and Midgley, P., editors, Climate Change 2013: The Physical Science Basis. Contribution of Working Group I to the Fifth Assessment Report of the Intergovernmental Panel on Climate Change. Cambridge University Press, Cambridge, United Kingdom and New York, NY, USA. 
Mathews, W. H. (1967). A contribution to the geology of the Mount Tongariro massif, North Island, New Zealand. New Zealand Journal of Geology and Geophysics, 10(4):10271038 .

Matsuoka, N. (1998). Modelling frost creep rates in an alpine environment. Permafrost and Periglacial Processes, 9(4):397-409.

McArthur, J. L. and Shepherd, M. J. (1990). Late Quaternary glaciation of Mt Ruapehu, North Island, New Zealand. Journal - Royal Society of New Zealand, 20(3):287-296.

McCalpin, J. P. (1992). Glacial geology of the upper Wairau valley, Marlborough, New Zealand. New Zealand Journal of Geology and Geophysics, 35(2):211-222.

McCarthy, A., Mackintosh, A., Rieser, U., and Fink, D. (2008). Mountain glacier chronology from Boulder Lake, New Zealand, indicates MIS 4 and MIS 2 ice advances of similar extent. Arctic, Antarctic, and Alpine Research, 40(4):695-708.

McClelland, E. and Erwin, P. S. (2003). Was a dacite dome implicated in the 9,500 BP collapse of Mt Ruapehu? A palaeomagnetic investigation. Bulletin of Volcanology, 65(4):294-305.

McColl, S. and Davies, T. (2011). Evidence for a rock-avalanche origin for 'The Hillocks' moraine, Otago, New Zealand. Geomorphology, 127(3):216-224.

McGlone, M. and Topping, W. . (1977). Aranuian (post-glacial) pollen diagrams from the Tongariro region, North Island, New Zealand. New Zealand Journal of Botany, 15(4):749-760.

McGlone, M. S., Turney, C. S. M., Wilmshurst, J. M., Renwick, J., and Pahnke, K. (2010). Divergent trends in land and ocean temperature in the Southern Ocean over the past 18,000 years. Nature Geoscience, 3:622-626.

McKinnon, K. A., Mackintosh, A. N., Anderson, B. M., and Barrell, D. J. A. (2012). The influence of sub-glacial bed evolution on ice extent: A model-based evaluation of the Last Glacial Maximum Pukaki glacier, New Zealand. Quaternary Science Reviews, 57:46-57.

McManus, J. F., Oppo, D. W., and Cullen, J. L. (1999). A 0.5-million-year record of millennial-scale climate variability in the North Atlantic. Science, 283(5404):971-975.

Meier, M. F. and Post, A. S. (1962). Recent variations in mass net budgets of glaciers in western North America. In International Association of Scientific Hydrology Publication 58 , pages $63-77$. 
Meierding, T. C. (1982). Late Pleistocene glacial equilibrium-line altitudes in the Colorado Front Range: a comparison of methods. Quaternary Research, 18(3):289-310.

Menviel, L., Timmermann, A., Timm, O. E., and Mouchet, A. (2011). Deconstructing the Last Glacial termination: the role of millennial and orbital-scale forcings. Quaternary Science Reviews, 30(9):1155-1172.

Mercer, J. (1988). The age of the Waiho Loop terminal moraine, Franz Josef Glacier, Westland. New Zealand Journal of Geology and Geophysics, 31(1):95-99.

Mercer, J. H. (1984). Simultaneous climatic change in both hemispheres and similar bipolar interglacial warming: Evidence and implications. Climate Processes and Climate Sensitivity, 29:307-313.

Milankovitch, M. (1920). Theorie mathematique des phenomenes thermiques produits par la radiation solaire. Gauthier-Villars, Paris, France.

Milankovitch, M. (1941). Kanon der Erdbestrahlung und seine Anwendung auf das Eiszeitenproblem. Royal Serbian Academy, Belgrade.

Minder, J. R., Mote, P. W., and Lundquist, J. D. (2010). Surface temperature lapse rates over complex terrain: Lessons from the Cascade Mountains. Journal of Geophysical Research D: Atmospheres, 115(14):D14122.

Moebis, A., Cronin, S. J., Neall, V. E., and Smith, I. E. (2011). Unravelling a complex volcanic history from fine-grained, intricate holocene ash sequences at the Tongariro Volcanic Centre, New Zealand. Quaternary International, 246(1):352-363.

Monnin, E., Indermhle, A., Dllenbach, A., Flckiger, J., Stauffer, B., Stocker, T. F., Raynaud, D., and Barnola, J. . (2001). Atmospheric CO2 concentrations over the last glacial termination. Science, 291(5501):112-114.

Moreno, P. I., Lowell, T. V., Jacobson Jr., G. L., and Denton, G. H. (1999). Abrupt vegetation and climate changes during the Last Glacial Maximum and last termination in the Chilean Lake District: A case study from Canal de la Puntilla (41 $\left.{ }^{\circ} \mathrm{S}\right)$. Geografiska Annaler, Series A: Physical Geography, 81(2):285-311.

Morland, L. (1984). Thermomechanical balances of ice sheet flows. Geophysical $\mathcal{E}$ Astrophysical Fluid Dynamics, 29(1-4):237-266.

Neall, V. (1979). Sheets P19, P20 and P21 - New Plymouth, Egmont and Manaia. 1st ed. Geological map of New Zealand 1:50 000. Three maps and notes (36 p.), New Zealand Department of Scientific and Industrial Research, Wellington. 
Neall, V. E. and Alloway, B. V. (1986). International Volcanological Congress, New Zealand. Tour Guide C3: Quaternary volcaniclastics and volcanic hazards of Taranaki. N. Z. Geological Survey record 12.

Newnham, R. M. and Lowe, D. J. (2000). Fine-resolution pollen record of late-glacial climate reversal from New Zealand. Geology, 28(8):759-762.

Newnham, R. M., Lowe, D. J., Giles, T., and Alloway, B. V. (2007). Vegetation and climate of Auckland, New Zealand, since ca. 32000 cal. yr ago: Support for an extended LGM. Journal of Quaternary Science, 22(5):517-534.

Newnham, R. M., Lowe, D. J., and Green, J. D. (1989). Palynology, vegetation and climate of the Waikato lowlands, North Island, New Zealand, since c. 18,000 years ago. Journal of the Royal Society of New Zealand, 19(2):127-150.

Newnham, R. M., Lowe, D. J., and Williams, P. W. (1999). Quaternary environmental change in New Zealand: A review. Progress in Physical Geography, 23(4):567-610.

Newnham, R. M., McGlone, M., Moar, N., Wilmshurst, J., and Vandergoes, M. (2013). The vegetation cover of New Zealand at the Last Glacial Maximum. Quaternary Science Reviews, 74:202-214.

Newnham, R. M., Vandergoes, M. J., Sikes, E., Carter, L., Wilmshurst, J. M., Lowe, D. J., McGlone, M. S., and Sandiford, A. (2012). Does the bipolar seesaw extend to the terrestrial southern mid-latitudes? Quaternary Science Reviews, 36:214-222.

Niedermann, S. (2002). Cosmic-ray-produced noble gases in terrestrial rocks: dating tools for surface processes. Reviews in Mineralogy and Geochemistry, 47(1):731-784.

Nield, J. M., Chiverrell, R. C., Darby, S. E., Leyland, J., Vircavs, L. H., and Jacobs, B. (2013). Complex spatial feedbacks of tephra redistribution, ice melt and surface roughness modulate ablation on tephra covered glaciers. Earth Surface Processes and Landforms, 38(1):95-102.

NIWA (2014). CliFlo: NIWA's National Climate Database on the Web. Website: http://cliflo.niwa.co.nz/. Retrieved 2011-2014.

Norton, D., McGlone, M., and Wigley, T. (1986). Quantitative analyses of modern pollen-climate relationships in New Zealand indigenous forests. New Zealand Journal of Botany, 24(2):331-342.

Norton, D. A. (1985). A multivariate technique for estimating New Zealand temperature normals. Weather and Climate, 5:64-74. 
Odell, N. (1955). Mount Ruapehu, New Zealand: Observations on its Crater Lake and Glaciers. Journal of Glaciology, 2(18):601-607.

Oerlemans, J. (1992). Climate sensitivity of glaciers in southern Norway: application of an energy-balance model to Nigardsbreen, Hellstugubreen and Alfotbreen. Journal of Glaciology, 38(129):223-232.

Oerlemans, J. (1997). Climate sensitivity of Franz Josef Glacier, New Zealand, as revealed by numerical modeling. Arctic and Alpine Research, 29(2):233-239.

Oerlemans, J. (2001). Glaciers and climate change. Balkema, Rotterdam, The Netherlands.

Oerlemans, J. (2005). Extracting a climate signal from 169 glacier records. Science, 308(5722):675-677.

Oerlemans, J. and Fortuin, J. P. F. (1992). Sensitivity of glaciers and small ice caps to greenhouse warming. Science, 258(5079):115-117.

Oerlemans, J. and Knap, W. (1998). A 1 year record of global radiation and albedo in the ablation zone of Morteratschgletscher, Switzerland. Journal of Glaciology, 44(147):231238.

Oerlemans, J. and Reichert, B. K. (2000). Relating glacier mass balance to meteorological data by using a seasonal sensitivity characteristic. Journal of Glaciology, 46(152):1-6.

Ohmura, A. (2001). Physical basis for the temperature-based melt-index method. Journal of Applied Meteorology, 40(4):753-761.

Ohmura, A., Kasser, P., and Funk, M. (1992). Climate at the equilibrium line of glaciers. Journal of Glaciology, 38(130):397-411.

Osborn, G., Menounos, B., Ryane, C., Riedel, J., Clague, J. J., Koch, J., Clark, D., Scott, K., and Davis, P. T. (2012). Latest pleistocene and holocene glacier fluctuations on Mount Baker, Washington. Quaternary Science Reviews, 49:33-51.

Osmaston, H. (2005). Estimates of glacier equilibrium line altitudes by the Area Altitude, the Area Altitude Balance Ratio and the Area Altitude Balance Index methods and their validation. Quaternary International, 138-139:22-31.

Otway, P., Holdsworth, R., Bell, D., and Robertson S. H (1985). Radio echo sounding survey of sub-glacial topography, Mt Ruapehu, 28 March 1985. Technical Report Immediate report, New Zealand Geological Survey, Wairakei, NZ.

Pahnke, K. and Sachs, J. P. (2006). Sea surface temperatures of southern midlatitudes 0-160 kyr BP. Paleoceanography, 21(2):PA2003. 
Palmer, B. and Neall, V. (1989). The Murimotu Formation - 9500 year old deposits of a debris avalanche and associated lahars, Mount Ruapehu, North Island, New Zealand. New Zealand Journal of Geology E Geophysics, 32(4):477-486.

Palmer, B. A., Alloway, B. V., and Neall, V. E. (1991). Volcanic-debris-avalanche deposits in New Zealand - lithofacies organization in unconfined, wet-avalanche flows. In Fisher, R. V. and Smith, G. A., editors, Sedimentation in Volcanic Settings, volume 45, pages $89-98$.

Paneth, F., Reasbeck, P., and Mayne, K. (1952). Helium 3 content and age of meteorites. Geochimica et Cosmochimica Acta, 2(5):300-303.

Park, J. (1926). Morainic mounds on the Waimarino Plain, near Ruapehu. Transactions of the N.Z. Institute, 56:382-383.

Paterson, W. S. B. (1994). The Physics of Glaciers. Elsevier, Oxford, New York and Tokyo.

Pattyn, F. (2006). GRANTISM: An Excel ${ }^{T M}$ model for Greenland and Antarctic ice-sheet response to climate changes. Computers $\mathcal{E}$ geosciences, 32(3):316-325.

Paulin, T. (2008). Glaciers and Climate Change, Mount Ruapehu, New Zealand. Master's thesis, Victoria University of Wellington, NZ.

Penck, A. and Brückner, E. (1909). Die alpen im Eiszeitalter, volume 3. Tauchnitz, Leipzig, Germany.

Petit, J. R., Jouzel, J., Raynaud, D., Barkov, N. I., Barnola, J. ., Basile, I., Bender, M., Chappellaz, J., Davis, M., Delaygue, G., Delmotte, M., Kotiyakov, V. M., Legrand, M., Lipenkov, V. Y., Lorius, C., Ppin, L., Ritz, C., Saltzman, E., and Stievenard, M. (1999). Climate and atmospheric history of the past 420,000 years from the Vostok ice core, Antarctica. Nature, 399(6735):429-436.

Phillips, F. M., Zreda, M. G., Smith, S. S., Elmore, D., Kubik, P. W., and Sharma, P. (1990). Cosmogenic chlorine-36 chronology for glacial deposits at Bloody Canyon, eastern Sierra Nevada. Science, 248(4962):1529-1532.

Pierrehumbert, R. T. (2010). Principles of planetary climate. Cambridge University Press, Massachusetts, USA.

Plummer, M. A. and Phillips, F. M. (2003). A 2-D numerical model of snow/ice energy balance and ice flow for paleoclimatic interpretation of glacial geomorphic features. Quaternary Science Reviews, 22(14):1389-1406.

Portenga, E. W. and Bierman, P. R. (2011). Understanding Earth's eroding surface with ${ }^{10}$ Be. GSA Today, 21(8):4-10. 
Porter, S. C. (1975). Equilibrium-line altitudes of late Quaternary glaciers in the Southern Alps, New Zealand. Quaternary Research, 5(1):27-47.

Prescott, C., Corbin, J., and Parkinson, D. (1989). Input, accumulation and residence times of carbon, nitrogen and phosphorous in four Rocky Mountain coniferous forests. Canadian Journal of Forest Research, 19:489-498.

Preusser, F., Andersen, B. G., Denton, G. H., and Schlüchter, C. (2005). Luminescence chronology of Late Pleistocene glacial deposits in North Westland, New Zealand. Quaternary Science Reviews, 24(20-21):2207-2227.

Price, R. C., Gamble, J. A., Smith, I. E., Maas, R., Waight, T., Stewart, R. B., and Woodhead, J. (2012). The anatomy of an Andesite volcano: a time-stratigraphic study of andesite petrogenesis and crustal evolution at Ruapehu Volcano, New Zealand. Journal of Petrology, 53:2139-2189.

Pulford, A. K. (2002). Crustal structure and lithospheric doming: Aspects of deformation along an obliquely convergent plate margin, New Zealand. Ph.D. Thesis, Victoria University of Wellington.

Purdie, H., Anderson, B., Chinn, T., Owens, I., Mackintosh, A., and Lawson, W. (2014). Franz Josef and Fox Glaciers, New Zealand: Historic length records. Global and Planetary Change, 121:41-52.

Putkonen, J. and O'Neal, M. (2006). Degradation of unconsolidated Quaternary landforms in the western North America. Geomorphology, 75(3):408-419.

Putkonen, J. and Swanson, T. (2003). Accuracy of cosmogenic ages for moraines. Quaternary Research, 59(2):255-261.

Putnam, A. E., Denton, G. H., Schaefer, J. M., Barrell, D. J. A., Andersen, B. G., Finkel, R. C., Schwartz, R., Doughty, A. M., Kaplan, M. R., and Schlüchter, C. (2010a). Glacier advance in southern middle-latitudes during the Antarctic Cold Reversal. Nature Geoscience, 3(10):700-704.

Putnam, A. E., Schaefer, J. M., Barrell, D. J. A., Vandergoes, M., Denton, G. H., Kaplan, M. R., Finkel, R. C., Schwartz, R., Goehring, B. M., and Kelley, S. E. (2010b). In situ cosmogenic ${ }^{10}$ Be production-rate calibration from the Southern Alps, New Zealand. Quaternary Geochronology, 5(4):392-409.

Putnam, A. E., Schaefer, J. M., Denton, G. H., Barrell, D. J. A., Andersen, B. G., Koffman, T. N. B., Rowan, A. V., Finkel, R. C., Rood, D. H., Schwartz, R., Vandergoes, M. J., Plummer, M. A., Brocklehurst, S. H., Kelley, S. E., and Ladig, K. L. (2013a). Warming 
and glacier recession in the Rakaia valley, Southern Alps of New Zealand, during Heinrich Stadial 1. Earth and Planetary Science Letters, 382:98-110.

Putnam, A. E., Schaefer, J. M., Denton, G. H., Barrell, D. J. A., Birkel, S. D., Andersen, B. G., Kaplan, M. R., Finkel, R. C., Schwartz, R., and Doughty, A. M. (2013b). The Last Glacial Maximum at $44^{\circ} \mathrm{S}$ documented by a ${ }^{10} \mathrm{Be}$ moraine chronology at Lake Ohau, Southern Alps of New Zealand. Quaternary Science Reviews, 62:114-141.

Putnam, A. E., Schaefer, J. M., Denton, G. H., Barrell, D. J. A., Finkel, R. C., Andersen, B. G., Schwartz, R., Chinn, T. J., and Doughty, A. M. (2012). Regional climate control of glaciers in New Zealand and Europe during the pre-industrial Holocene. Nature Geoscience, 5(9):627-630.

Rea, B. R., Whalley, W. B., Dixon, T. S., and Gordon, J. E. (1999). Plateau icefields as contributing areas to valley glaciers and the potential impact on reconstructed ELAs: a case study from the Lyngen Alps, North Norway. Annals of Glaciology, 28(1):97-102.

Renwick, J. and Thompson, D. (2006). The southern annular mode and New Zealand climate. Water \& Atmosphere, 14(2):24-25.

Richardson, J. M. and Brook, M. S. (2010). Ablation of debris-covered ice: some effects of the 25 September 2007 Mt Ruapehu eruption. Journal of the Royal Society of New Zealand, 40(2):45-55.

Rivera, A. and Bown, F. (2013). Recent glacier variations on active ice capped volcanoes in the Southern Volcanic Zone $\left(37^{\circ}-46^{\circ} \mathrm{S}\right)$, Chilean Andes. Journal of South American Earth Sciences, 45:345-356.

Rivera, A., Bown, F., Carrión, D., and Zenteno, P. (2012). Glacier responses to recent volcanic activity in Southern Chile. Environmental Research Letters, 7(1):014036.

Roethlisberger, F. and Schneebeli, W. (1979). Genesis of lateral moraine complexes, demonstrated by fossil soils and trunks; indicators of postglacial climatic fluctuations. In Schlüchter, C., editor, Moraines and varves: origin, genesis, classification, pages 387420. Balkema, Rotterdam, The Netherlands.

Rojas, M., Moreno, P., Kageyama, M., Crucifix, M., Hewitt, C., Abe Ouchi, A., Ohgaito, R., Brady, E. C., and Hope, P. (2009). The Southern Westerlies during the last glacial maximum in PMIP2 simulations. Climate Dynamics, 32(4):525-548.

Rother, H., Fink, D., Shulmeister, J., Mifsud, C., Evans, M., and Pugh, J. (2014). The early rise and late demise of New Zealands last glacial maximum. Proceedings of the National Academy of Sciences, 111(32):11630-11635. 
Rowan, A. V., Brocklehurst, S. H., Schultz, D. M., Plummer, M. A., Anderson, L. S., and Glasser, N. F. (2014). Late Quaternary glacier sensitivity to temperature and precipitation distribution in the Southern Alps of New Zealand. Journal of Geophysical Research: Earth Surface, 24:PA2201.

Rowan, A. V., Plummer, M. A., Brocklehurst, S. H., Jones, M. A., and Schultz, D. M. (2013). Drainage capture and discharge variations driven by glaciation in the Southern Alps, New Zealand. Geology, 41(2):199-202. Cited By (since 1996):1.

Rowan, A. V., Roberts, H. M., Jones, M. A., Duller, G. A., Covey Crump, S. J., and Brocklehurst, S. H. (2012). Optically stimulated luminescence dating of glaciofluvial sediments on the Canterbury Plains, South Island, New Zealand. Quaternary Geochronology, 8:10-22.

Salinger, M. and Mullan, A. (1999). New Zealand climate: temperature and precipitation variations and their links with atmospheric circulation 1930-1994. International Journal of Climatology, 19(10):1049-1071.

Salinger, M., Renwick, J., and Mullan, A. (2001). Interdecadal pacific oscillation and south pacific climate. International Journal of Climatology, 21(14):1705-1721.

Salinger, M. J. (1980a). New Zealand climate: I. Precipitation patterns. Monthly Weather Review, 108(11):1892-1904.

Salinger, M. J. (1980b). New Zealand climate: II. Temperature patterns. Monthly Weather Review, 108(11):1905-1912.

Sandiford, A., Newnham, R. M., Alloway, B. V., and Ogden, J. (2003). A 28 000-7600 cal yr BP pollen record of vegetation and climate change from Pukaki Crater, northern New Zealand. Palaeogeography, Palaeoclimatology, Palaeoecology, 201(3-4):235-247.

Schaefer, J. M., Denton, G. H., Barrell, D. J. A., Ivy Ochs, S., Kubik, P. W., Andersen, B. G., Phillips, F. M., Lowell, T. V., and Schlüchter, C. (2006). Near-synchronous interhemispheric termination of the Last Glacial Maximum in mid-latitudes. Science, 312(5779):1510-1513.

Schaefer, J. M., Denton, G. H., Kaplan, M., Putnam, A., Finkel, R. C., Barrell, D. J. A., Andersen, B. G., Schwartz, R., Mackintosh, A., Chinn, T., and Schlüchter, C. (2009). High-frequency Holocene glacier fluctuations in New Zealand differ from the northern signature. Science, 324(5927):622-625.

Schaefer, J. M., Putnam, A. E., Denton, G. H., Kaplan, M. R., Birkel, S., Doughty, A. M., Kelley, S., Barrell, D. J. A., Finkel, R. C., Winckler, G., Anderson, R. F., Ninneman, U. S., Barker, S., Schwartz, R., and Schlüchter, C. (2015). The Southern Glacial 
Maximum 65000 years ago and its Unfinished Termination. Manuscript submitted for publication.

Schäfer, J. M., Ivy Ochs, S., Wieler, R., Leya, I., Baur, H., Denton, G. H., and Schlüchter, C. (1999). Cosmogenic noble studies in the oldest landscape on earth: Surface exposure ages of the Dry Valleys, Antarctica. Earth and Planetary Science Letters, 167(3-4):215226.

Schimmelpfennig, I., Benedetti, L., Finkel, R., Pik, R., Blard, P.-H., Bourlès, D., Burnard, P., and Williams, A. (2009). Sources of in-situ ${ }^{36} \mathrm{Cl}$ in basaltic rocks. Implications for calibration of production rates. Quaternary Geochronology, 4(6):441-461.

Schimmelpfennig, I., Schaefer, J. M., Goehring, B. M., Lifton, N., Putnam, A. E., and Barrell, D. J. A. (2012). Calibration of the in situ cosmogenic ${ }^{14} \mathrm{C}$ production rate in New Zealand's Southern Alps. Journal of Quaternary Science, 27(7):671-674.

Schimmelpfennig, I., Williams, A., Pik, R., Burnard, P., Niedermann, S., Finkel, R., Schneider, B., and Benedetti, L. (2011). Inter-comparison of cosmogenic in-situ ${ }^{3} \mathrm{He}$, ${ }^{21} \mathrm{Ne}$ and ${ }^{36} \mathrm{Cl}$ at low latitude along an altitude transect on the SE slope of Kilimanjaro volcano (3S, Tanzania). Quaternary Geochronology, 6(5):425-436.

Schlagenhauf, A., Gaudemer, Y., Benedetti, L., Manighetti, I., Palumbo, L., Schimmelpfennig, I., Finkel, R., and Pou, K. (2010). Using in situ Chlorine-36 cosmonuclide to recover past earthquake histories on limestone normal fault scarps: a reappraisal of methodology and interpretations. Geophysical Journal International, 182(1):36-72.

Schmidt, G., Annan, J., Bartlein, P., Cook, B., Guilyardi, E., Hargreaves, J., Harrison, S., Kageyama, M., LeGrande, A., Konecky, B., et al. (2013). Using paleo-climate comparisons to constrain future projections in CMIP5. Climate of the Past Discussions, 9:775-835.

Schmittner, A., Urban, N. M., Shakun, J. D., Mahowald, N. M., Clark, P. U., Bartlein, P. J., Mix, A. C., and Rosell Melé, A. (2011). Climate sensitivity estimated from temperature reconstructions of the Last Glacial Maximum. Science, 334(6061):1385-1388.

Schneider von Deimling, T., Ganopolski, A., Held, H., and Rahmstorf, S. (2006). How cold was the last glacial maximum? Geophysical Research Letters, 33(14):L14709.

Shackleton, N. J. (1967). Oxygen isotope analyses and Pleistocene temperatures reassessed. Nature, 215(5096):15-17.

Shakun, J. D., Clark, P. U., He, F., Marcott, S. A., Mix, A. C., Liu, Z., Otto Bliesner, B., Schmittner, A., and Bard, E. (2012). Global warming preceded by increasing carbon dioxide concentrations during the last deglaciation. Nature, 484(7392):49-54. 
Shane, P. (2000). Tephrochronology: A New Zealand case study. Earth Science Reviews, 49(1-4):223-259.

Shane, P., Nairn, I. A., Martin, S. B., and Smith, V. C. (2008). Compositional heterogeneity in tephra deposits resulting from the eruption of multiple magma bodies: Implications for tephrochronology. Quaternary International, 178(1):44 - 53.

Shane, P. and Sandiford, A. (2003). Paleovegetation of marine isotope stages 4 and 3 in Northern New Zealand and the age of the widespread Rotoehu tephra. Quaternary Research, 59(3):420-429.

Shulmeister, J., Fink, D., and Augustinus, P. C. (2005). A cosmogenic nuclide chronology of the last glacial transition in North-West Nelson, New Zealandnew insights in Southern Hemisphere climate forcing during the last deglaciation. Earth and Planetary Science Letters, 233(3):455-466.

Shulmeister, J., Fink, D., Hyatt, O. M., Thackray, G. D., and Rother, H. (2010a). Cosmogenic ${ }^{10} \mathrm{Be}$ and ${ }^{26} \mathrm{Al}$ exposure ages of moraines in the Rakaia Valley, New Zealand and the nature of the last termination in New Zealand glacial systems. Earth and Planetary Science Letters, 297(3):558-566.

Shulmeister, J., Shane, P., Lian, O. B., Okuda, M., Carter, J. A., Harper, M., Dickinson, W., Augustinus, P., and Heijnis, H. (2001). A long late-Quaternary record from Lake Poukawa, Hawkes Bay, New Zealand. Palaeogeography, Palaeoclimatology, Palaeoecology, 176(1):81-107.

Shulmeister, J., Thackray, G., Rieser, U., Hyatt, O., Rother, H., Smart, C., and Evans, D. (2010b). The stratigraphy, timing and climatic implications of glaciolacustrine deposits in the middle Rakaia Valley, South Island, New Zealand. Quaternary Science Reviews, 29(17):2362-2381.

Siegenthaler, U., Stocker, T. F., Monnin, E., Lüthi, D., Schwander, J., Stauffer, B., Raynaud, D., Barnola, J.-M., Fischer, H., Masson Delmotte, V., et al. (2005). Stable carbon cycleclimate relationship during the late Pleistocene. Science, 310(5752):1313-1317.

Sigman, D. M. and Boyle, E. A. (2000). Glacial/interglacial variations in atmospheric carbon dioxide. Nature, 407(6806):859-869.

Sikes, E. L., Howard, W. R., Samson, C. R., Mahan, T. S., Robertson, L. G., and Volkman, J. K. (2009). Southern ocean seasonal temperature and subtropical front movement on the South Tasman Rise in the Late Quaternary. Paleoceanography, 24(2):PA2201. 
Sikes, E. L., Medeiros, P. M., Augustinus, P., Wilmshurst, J. M., and Freeman, K. R. (2013). Seasonal variations in aridity and temperature characterize changing climate during the last deglaciation in New Zealand. Quaternary Science Reviews, 74:245-256.

Spörli, K. and Rowland, J. (2006). 'Column on column' structures as indicators of lava/ice interaction, Ruapehu andesite volcano, New Zealand. Journal of Volcanology and Geothermal Research, 157(4):294-310.

Stephens, T., Atkin, D., Augustinus, P., Shane, P., Lorrey, A., Street Perrott, A., Nilsson, A., and Snowball, I. (2012a). A late glacial Antarctic climate teleconnection and variable Holocene seasonality at Lake Pupuke, Auckland, New Zealand. Journal of Paleolimnology, 48(4):785-800.

Stephens, T., Atkin, D., Cochran, U., Augustinus, P., Reid, M., Lorrey, A., Shane, P., and Street Perrott, A. (2012b). A diatom-inferred record of reduced effective precipitation during the Last Glacial Coldest Phase (28.8-18.0 cal kyr BP) and increasing Holocene seasonality at Lake Pupuke, Auckland, New Zealand. Journal of Paleolimnology, 48(4):801-817.

Stipp, J. J. (1968). The geochronology and petrogenesis of the Cenovoic volcanics of the North Island, New Zealand. Ph.D. Thesis, The Australian National University, Canberra.

Stocker, T. F. and Johnsen, S. J. (2003). A minimum thermodynamic model for the bipolar seesaw. Paleoceanography, 18(4):PA000920.

Stone, J., Evans, J., Fifield, K., Cresswell, R., and Allan, G. (1996). Cosmogenic chlorine36 production rates from calcium and potassium. Radiocarbon, 38(1):170-171.

Stone, J. O. (2000). Air pressure and cosmogenic isotope production. Journal of Geophysical Research B: Solid Earth, 105(B10):23753-23759.

Stuiver, M. and Polach, H. A. (1977). Discussion; reporting of c-14 data. Radiocarbon, 19(3):355-363.

Sturman, A. P. and Tapper, N. J. (1996). The weather and climate of Australia and New Zealand. Oxford University Press, Melbourne, Australia.

Suganuma, Y., Miura, H., and Okuno, J. (2012). A new sampling technique for surface exposure dating using a portable electric rock cutter. Antarctic Record, 56(2):85-90.

Sugden, D. (2014). James Croll (1821-1890): ice, ice ages and the Antarctic connection. Antarctic Science, 26:604-613.

Suggate, R. P. (1990). Late Pliocene and quaternary glaciations of New Zealand. Quaternary science reviews, 9(2):175-197. 
Suggate, R. P. and Almond, P. C. (2005). The Last Glacial Maximum (LGM) in western South Island, New Zealand: Implications for the global LGM and MIS 2. Quaternary Science Reviews, 24(16-17):1923-1940.

Suggate, R. P. and Moar, N. T. (1970). Revision of the chronology of the late Otira glacial. New Zealand Journal of Geology and Geophysics, 13(3):742-746.

Sundell, K. A. and Fisher, R. V. (1985). Very coarse grained fragmental rocks: A proposed size classification. Geology, 13(10):692-695.

Sutherland, R., Kim, K., Zondervan, A., and McSaveney, M. (2007). Orbital forcing of mid-latitude Southern Hemisphere glaciation since $100 \mathrm{ka}$ inferred from cosmogenic nuclide ages of moraine boulders from the Cascade Plateau, southwest New Zealand. Bulletin of the Geological Society of America, 119(3-4):443-451.

Sutton, P. J. H., Bowen, M., and Roemmich, D. (2005). Decadal temperature changes in the Tasman Sea. New Zealand Journal of Marine and Freshwater Research, 39(6):13211329.

Swanson, T. W. and Caffee, M. L. (2001). Determination of ${ }^{36} \mathrm{Cl}$ production rates derived from the well-dated deglaciation surfaces of Whidbey and Fidalgo islands, washington. Quaternary Research, 56(3):366-382.

Tait, A., Henderson, R., Turner, R., and Zheng, X. (2006). Thin plate smoothing spline interpolation of daily rainfall for New Zealand using a climatological rainfall surface. International Journal of Climatology, 26(14):2097-2115.

Tait, A. and Zheng, X. (2007). Analysis of the spatial interpolation error associated with maps of median annual climate variables. National Institute of Water and Atmospheric Research, Auckland, New Zealand.

Tarasov, L., Dyke, A. S., Neal, R. M., and Peltier, W. (2012). A data-calibrated distribution of deglacial chronologies for the North American ice complex from glaciological modeling. Earth and Planetary Science Letters, 315:30-40.

Taylor, G. (1927). Notes on the glaciation of Ruapehu. Transactions of the N.Z. Institute, 57:235-236.

Thackray, G. D., Shulmeister, J., and Fink, D. (2009). Evidence for expanded middle and late pleistocene glacier extent in northwest Nelson, New Zealand. Geografiska Annaler, Series A: Physical Geography, 91(4):291-311.

Thompson, L. G., Mosley Thompson, E., Davis, M. E., Lin, P.-N., Henderson, K. A., Cole Dai, J., Bolzan, J. F., and Liu, K.-B. (1995). Late glacial stage and Holocene tropical ice core records from Huascaran, Peru. Science, 269(5220):46-50. 
Thompson, R. D. and Kells, B. R. (1973). Mass balance studies on the Whakapapanui glacier, New Zealand. The role of snow and ice in hydrology, pages 383-393.

Timmermann, A., Timm, O., Stott, L., and Menviel, L. (2009). The Roles of $\mathrm{CO}_{2}$ and Orbital Forcing in Driving Southern Hemispheric Temperature Variations during the Last 21000 Yr. Journal of Climate, 22(7):1626-1640.

Toggweiler, J. R. (2009). Shifting westerlies. Science, 323(5920):1434-1435.

Tolstikhin, I., Mamyrin, B., Khabarin, L., and Erlikh, E. (1974). Isotope composition of helium in ultrabasic xenoliths from volcanic rocks of Kamchatka. Earth and Planetary Science Letters, 22(1):75-84.

Topping, W. (1973). Tephrostratigraphy and chronology of late Quaternary eruptives from the Tongariro Volcanic Centre, New Zealand. New Zealand Journal of Geology and Geophysics, 16(3):397-423.

Topping, W. W. (1974). Some aspects of Quaternary history of Tongariro Volcanic Centre. Ph.D. Thesis, Victoria University of Wellington.

Topping, W. W. and Kohn, B. P. (1973). Rhyolitic tephra marker beds in the Tongariro area, North Island, New Zealand. New Zealand Journal of Geology and Geophysics, 16(3):375-395.

Tovar, D. S., Shulmeister, J., and Davies, T. (2008). Evidence for a landslide origin of New Zealand's Waiho Loop moraine. Nature Geoscience, 1(8):524-526.

Townsend, D., Vonk, A., and Kamp, P. (2008). Geology map of the Taranaki area: scale 1:250,000. Three maps and notes (36 p.). Institute of Geological and Nuclear Sciences 1:250,000 geological map 7. 77p. + 1 folded map.

Turney, C., Roberts, R., De Jonge, N., Prior, C., Wilmshurst, J., McGlone, M., and Cooper, J. (2007). Redating the advance of the New Zealand Franz Josef Glacier during the Last Termination: evidence for asynchronous climate change. Quaternary Science Reviews, 26(25):3037-3042.

Turney, C. S. M., McGlone, M. S., and Wilmshurst, J. M. (2003). Asynchronous climate change between New Zealand and the North Atlantic during the last deglaciation. Geology, 31(3):223-226.

Uddstrom, M. J. and Oien, N. A. (1999). On the use of high-resolution satellite data to describe the spatial and temporal variability of sea surface temperatures in the New Zealand region. Journal of Geophysical Research C: Oceans, 104(C9):20729-20751. 
Ui, T., Kawachi, S., and Neall, V. E. (1986). Fragmentation of debris-avalanche material during flowageevidence from the Pungarehu Formation, Mount Egmont, New Zealand. Journal of Volcanology and Geothermal Research, 27:255264.

Vacco, D. A., Alley, R. B., and Pollard, D. (2010). Glacial advance and stagnation caused by rock avalanches. Earth and Planetary Science Letters, 294(1):123-130.

van der Meer, J. J. M., Kjr, K. H., Krger, J., Rabassa, J., and Kilfeather, A. A. (2009). Under pressure: clastic dykes in glacial settings. Quaternary Science Reviews, 28(7-8):708-720.

Van der Veen, C., Leftwich, T., von Frese, R., Csatho, B., and Li, J. (2007). Subglacial topography and geothermal heat flux: Potential interactions with drainage of the Greenland ice sheet. Geophysical research letters, 34(12):L12501.

Vandergoes, M. J., Dieffenbacher Krall, A. C., Newnham, R. M., Denton, G. H., and Blaauw, M. (2008). Cooling and changing seasonality in the southern Alps, New Zealand during the Antarctic cold reversal. Quaternary Science Reviews, 27(5):589-601.

Vandergoes, M. J. and Fitzsimons, S. J. (2003). The last glacial-interglacial transition (LGIT) in south Westland, New Zealand: Paleoecological insight into mid-latitude Southern Hemisphere climate change. Quaternary Science Reviews, 22:1461-1476.

Vandergoes, M. J., Hogg, A. G., Lowe, D. J., Newnham, R. M., Denton, G. H., Southon, J., Barrell, D. J. A., Wilson, C. J. N., McGlone, M. S., Allan, A. S. R., Almond, P. C., Petchey, F., Dabell, K., Dieffenbacher Krall, A. C., and Blaauw, M. (2013). A revised age for the Kawakawa/Oruanui tephra, a key marker for the Last Glacial Maximum in New Zealand. Quaternary Science Reviews, 74:195-201.

Vandergoes, M. J., Newnham, R. M., Preusser, F., Hendy, C. H., Lowell, T. V., Fitzsimons, S. J., Hogg, A. G., Kasper, H. U., and Schlüchter, C. (2005). Regional insolation forcing of Late Quaternary climate change in the Southern Hemisphere. Nature, 436(7048):242-245.

Voight, B., Glicken, H., Janda, R. J., and Douglass, M. (1981). Catastrophic rockslide avalanche of May 18 (Mount St. Helens). U.S.Geological Survey Professional Paper, 1250:347-377.

Von Humboldt, A. (1852). Cosmos: vol. 4 (Translated by Paul, BH, and others). George Bell \& Sons, London, UK.

Waelbroeck, C., Paul, A., Kucera, M., Rosell Melé, A., Weinelt, M., Schneider, R., Mix, A., Abelmann, A., Armand, L., Bard, E., et al. (2009). Constraints on the magnitude and patterns of ocean cooling at the Last Glacial Maximum. Nature Geoscience, 2(2):127-132. 
Wang, X., Auler, A. S., Edwards, R. L., Cheng, H., Cristalli, P. S., Smart, P. L., Richards, D. A., and Shen, C. . (2004). Wet periods in northeastern Brazil over the past $210 \mathrm{kyr}$ linked to distant climate anomalies. Nature, 432(7018):740-743.

Wang, Y.-J., Cheng, H., Edwards, R. L., An, Z., Wu, J., Shen, C.-C., and Dorale, J. A. (2001). A high-resolution absolute-dated late Pleistocene monsoon record from Hulu Cave, China. Science, 294(5550):2345-2348.

Wardle, P. (1978). Further radiocarbon dates from Westland National Park and the Omoeroa river mouth, New Zealand. New Zealand Journal of Botany, 16(1):147-152.

Wardle, P. (1991). Vegetation of New Zealand. Cambridge University Press, Cambridge, UK.

Weaver, A. J., Saenko, O. A., Clark, P. U., and Mitrovica, J. X. (2003). Meltwater pulse 1A from Antarctica as a trigger of the Bølling-Allerød warm interval. Science, 299(5613):1709-1713.

Weber, M., Clark, P., Kuhn, G., Timmermann, A., Sprenk, D., Gladstone, R., Zhang, X., Lohmann, G., Menviel, L., Chikamoto, M., et al. (2014). Millennial-scale variability in Antarctic ice-sheet discharge during the last deglaciation. Nature, 510:134-138.

Whittaker, T. E., Hendy, C. H., and Hellstrom, J. C. (2011). Abrupt millennial-scale changes in intensity of Southern Hemisphere westerly winds during marine isotope stages 2-4. Geology, 39(5):455-458.

Williams, A. J., Stuart, F. M., Day, S. J., and Phillips, W. M. (2005). Using pyroxene microphenocrysts to determine cosmogenic ${ }^{3} \mathrm{He}$ concentrations in old volcanic rocks: An example of landscape development in central Gran Canaria. Quaternary Science Reviews, 24(1-2):211-222.

Williams, P. W., McGlone, M., Neil, H., and Zhao, J.-X. (2015). A review of New Zealand palaeoclimate from the Last Interglacial to the global Last Glacial Maximum. Quaternary Science Reviews, 110:92-106.

Williams, P. W., Neil, H. L., and Zhao, J. X. (2010). Age frequency distribution and revised stable isotope curves for New Zealand speleothems: Palaeoclimatic implications. International Journal of Speleology, 39(2):99-112.

Wilmshurst, J. M., McGlone, M. S., Leathwick, J. R., and Newnham, R. M. (2007). A pre-deforestation pollen-climate calibration model for New Zealand and quantitative temperature reconstructions for the past 18000 years BP. Journal of Quaternary Science, 22(5):535-547. 
Winckler, G., Anderson, R. F., and Schlosser, P. (2005). Equatorial Pacific productivity and dust flux during the mid-Pleistocene climate transition. Paleoceanography, 20(4):PA4025.

Wolff, E., Fischer, H., and Röthlisberger, R. (2009). Glacial terminations as southern warmings without northern control. Nature Geoscience, 2(3):206-209. 